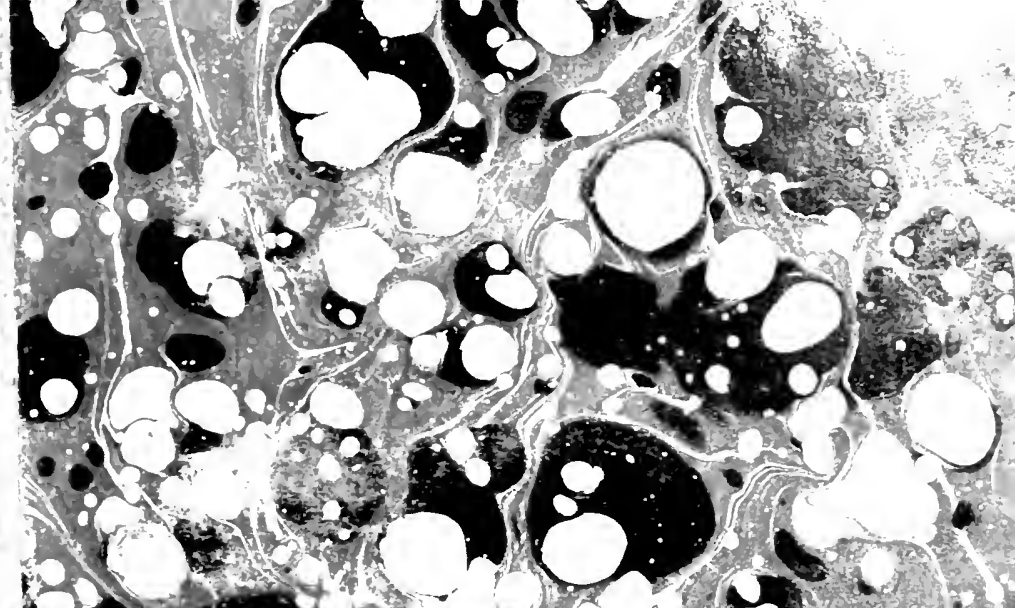

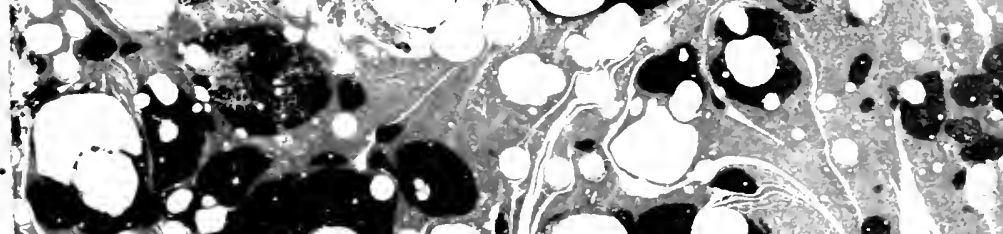
-aR QR ISOJ. - 4.20 .5

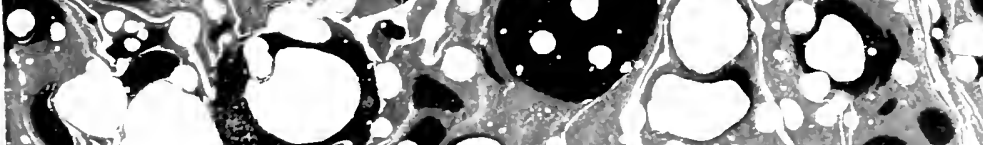
2 Lodo.

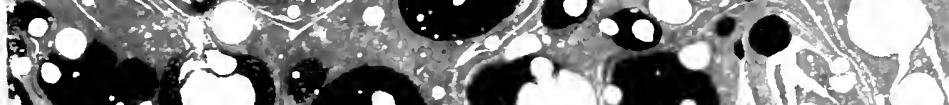
$x^{2}(2) \cdot 52.15$

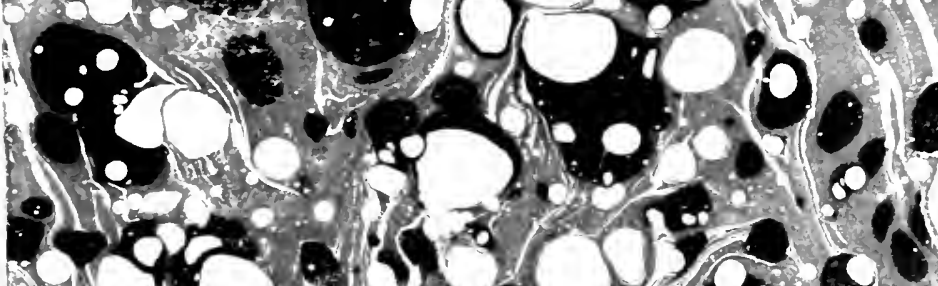
20.7 0. (a) 100. of 


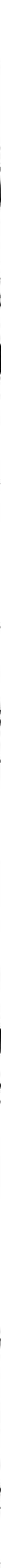




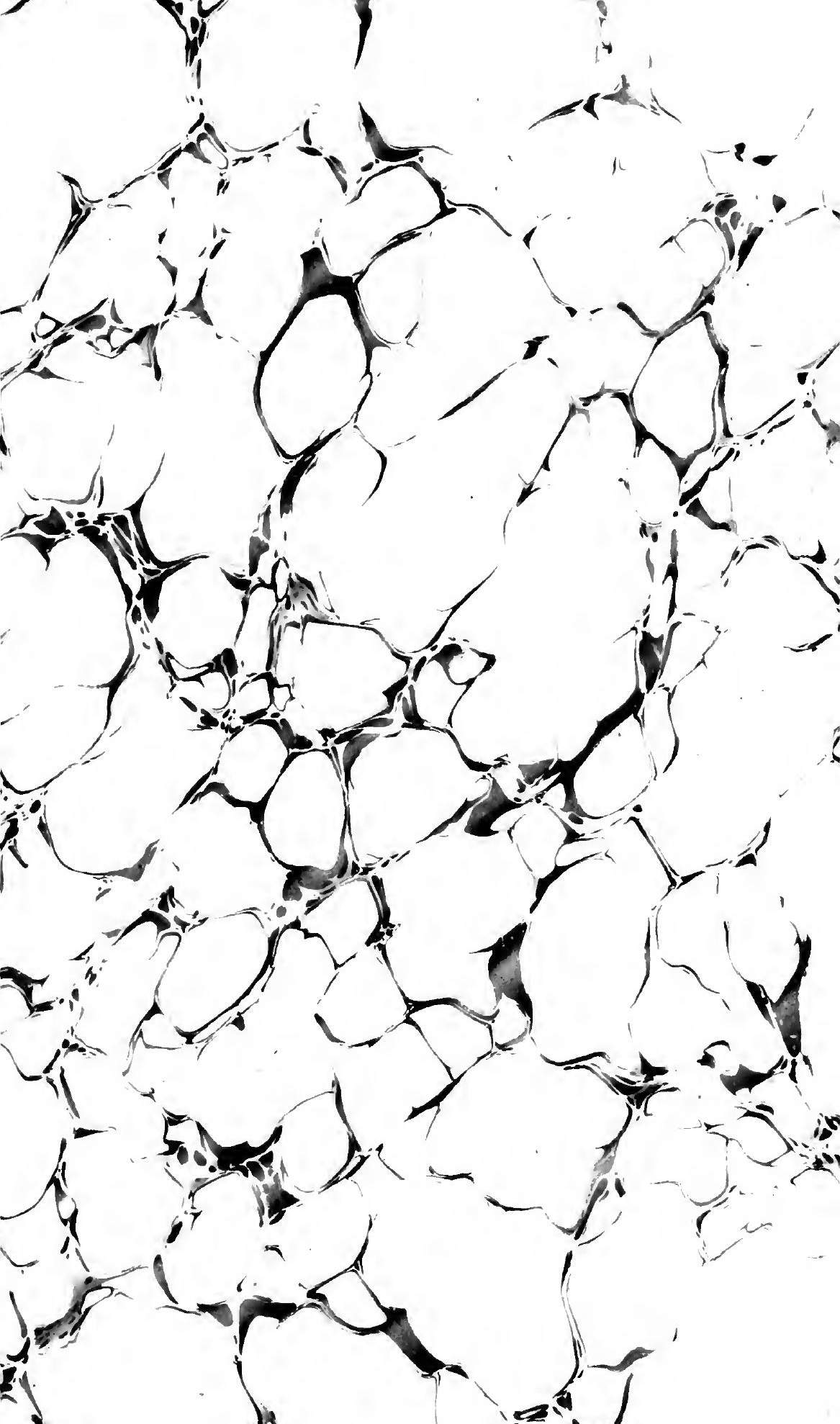









\section{L'IMPÔT}

DANS LES DIVERSES

GIVILISATIONS 


\section{OUTRAGES DU MEME AUTEUR}

Les Réformes nécessaires. - 1 vol. in-18. Paris, 1869.

Études économiques et financières. - 2 vol. in-18. Paris, 1883.

L'indépendance de l'Égypte et le régime international du Canal de Suez. - 1 vol. in-18. Paris, 1883.

La réforme de l'impôt. - Tome Ier, Les impóts et les théo-

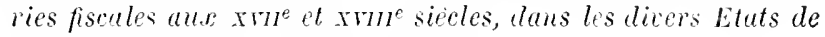
l'Europe. - 1 vol. in-8. Paris, 188 ö.

L'impôt sur le pain. - La réurtion protectionniste et les truites de commerce. -1 vol. in-8 $8^{\circ}$. Paris, $188 . .3$.

Traité de critique et de statistique comparée des institutions financières, systèmes d'impòts et réformes fiscales de divers Élats. - Tome Ier, Angleterre, Etats-Lnis, Austrulie, hussic, Allemugne, Italie. - 1 vol. in-8 ${ }^{\circ} .1589$.

La Statistique des Religions. - Paris, 1890.

Étude sur l'organisation comparée des Banques de circulation. - 1 brochure, 1891.

Pendant une mission en Russie - $1^{\text {re }}$ série, A trater's l'Allemugne. -2 vol. in-18. Paris, 1894.

Ces divers ourrages se trouvent chez MM. Gull laumin et $\mathrm{C}^{\mathrm{ic}}, 1$, , rue Richelieu, et à la librairie du Recueil des Lois et des Arrêts, 29, rue Souffiot, Paris.

\section{SOUS PRESSE :}

Le second volume de l'Impôt dans les diverses civilisations, paraitra dans le courant de mai 1897. Il contiendra les Alyendiees et l'index alphulétique des matieres. 


\section{L'IMPÔT}

D.MS LES IMERSAS

\section{CIVILISATIONS}

PAR

\section{E. FOURNIER DE FLAIX}

PREMIERE SERIE

I

1. ANCIENNES CIVILISATIONS D'ORIENT : CHALDEEE - ASSYRIE - BABYLONIE - FHÉNICIE - CARTHAGE - LES HËBREUX - ÉGYPTE - INDE - CHINE.

11. LA GRĖCE ANCIENNE : LA CRẺTE - LACĖdÉmONE ATHENES.

111. LES ROMAINS - LA RÉPUBLIQUE - L'EMPIRE.

IV. LE MOYEN AGE : L'ÉPOQUE FĖODALE EN FRANCE.

Et quesi rursores vitü limprade tradunt.

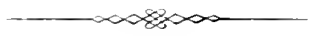

PARIS

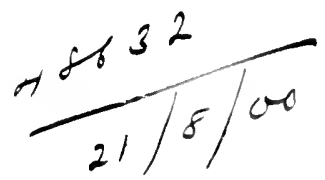

LIBR.IIRIE

delaStédu Recueil tral des Lois el des. Arrèts

L. LAROSE, Directeur

22, RUE SOUFFLOT, 22
GUILLAUMIN et Gie EDITELTis

du Journal des Économistes 1 i, RUE RLCHLEe, 1 í

LIBRAIRES-EDITEURS 



\section{INTRODUCTION.}

"Les societés humaines ne subsistent quà la con"dition de subvenir, dans la mesure necessaire, aux "besoins de la chose publique. Toutes ont à donner " aux youvernements, qui les régissent, les moyens de "remplir leur destination; toutes ont a pourroir aux " lépenses à effectuer dans lintérèt de la défense du " territoire national et du maintien de lordre inté"rieur, et, chez toutes, l"impùt existe sous des formes "appropriées à l'état, plus ou moins arance, de la ci"vilisation (1)."

Cette définition, théorique et philosophique, de l’origine et le la nature de l'imprit, empruntée à l'un des publicistes qui, dans ces derniers temps, ont traité de l’impòt avec le plus de compétence, suffit-elle pour donner une idée exacte, complète, de l'origine et de la nature de l'impùt? est-il vrai que, chez tous les peuples, sous les diverses formes de gouvernement, l“impùt ait été toujours approprié à l'état plus ou moins avancé de la civilisation, qu'il ait toujours eu pour but de pourvoir aux besoins collectif's et généraux des na-

(1) H. Passy, article Impôt, Dictionnuire l' Economie politique, $1^{\text {er }}$ vol., p. 398, edition $18 ; 3$ (Coquelin et Guillaumin). 
tions, d'assurer qu'elles seraient mises à mème de remplir leur destination?

Et mème, si des résultats contradictoires que fournirait l'étude de l'histoire de l'impìt, on passait à l'examen des systèmes d'impùt des litats contemporains, serait-il possible d'accepter, relativement à lorigine et à la nature de l'impìt, la formule de l'éminent Hippolyte Passy?

Cette formule, ne laisse-t-elle pas dans l'ombre une série de faits, une suite d'actes, d'une importance particulière, qui modifie les termes de la définition, car ces faits, ces actes attestent qu'elle ne contient pas tous les éléments de l'origine, ni de la nature complexe de l’impòt?

D'après les termes de la définition, ne semblerait-il pas que les sociétés humaines ont pu toujours statuer pour approprier limpòt à sa destination et à leur propre condition, que l'impùt a tonjours eu le caractère d'utilité générale de défendre le territoire comme de maintenir l'ordre, et qu'une sorte de justice tacite, mais supérieure, a présidé à son établissement?

L'histoire de l'impòt, son organisation présente chez les divers peuples, justifient-elles ces suppositions? le moindre regard sur les formes diverses que l'impòt a prises on revit encore, ne suffit-il pas pour les ébranler sinon pour les détruire?

L’impùt est-il un de ces faits économiques, politiques, sociaux, qui comportent, quand on veut en étudier la véritable nature et les divers aspects, une définition philosophiqne et, pour ainsi dire, abstraite? Ne laut-il pas, tout an moins, assortir la définition à J'histoire mème de ce fait, si important dans le mouvement des peuples? Pour définir l'impòt, analyser sa nature, étudier ses effets, il est nécessaire, par suite, et, au préalable, d'en connaitre le développement historique. L'impòt a non seulement une histoire, mais il est un élément essentiel de lihistoire de tous les peu- 
ples; il est un des facteurs de la civilisation. Son organisation, chez les divers peuples, ayant présenté de sensibles différences, ses aspects, ses effets n ont pas ité les mèmes. Ainsi, par exemple, avant de rechercher comment doivent se réfléchir ou se répercuter les divers impots, il y a lieu de vérifier comment ils se sont rélléchis jusqu’a présent ou comment ils se réfléchissent aujourd'hui. La vérification est d'autant plus nécessaire que, même dans leur état actuel, les peuples présentent les conditions les plus diverses, les plus variées, les plus opposées, et que ces diversités ne trourent leur explication que dans le passé.

Les peuples se sont transmis leurs systèmes fiscaux comme leurs religions, leurs langues, les élements de leurs sciences; ils les ont appropriés aux milieux dans lesquels ces systèmes devaient fonctionner. Aussi la matière de l'impòt appartient-elle à cette partie de la science économique qui est le plus près de la politique et de l'histoire. Storch ni Roscher ne l'ont comprise dans leurs Traités d'Économie politique. Rossi ne s’en est occupé qu’accessoirement à la fin de son cours.

L'examen et la critique des diverses définitions, successivement présentées, de l'impoit, vont montrer, plus énergiquement encorc, la puissance de la tradition fiscale.

Adam Smith n’a pas précisé de définition de limpùt. Il l'a compris parmi les sources du revenu de l'Etat. "Le peuple, avec une partie de ses propres revenus "particuliers, contribue à composer au souverain ou à " l'État ce qu'on nomme le revenu de l'État (1) ). Mais il ajoute, ce qui se rapproche de la formule de $\mathbf{~ I}$. H. Passy et ce qui est déjà contradictoire avec les réserves dont il accompagne ses observations sur les

(1) Richesse des nations, liv. v, chap. II. 
reflets des quatre règles célèbres qu'il ètablit : "Toutes " les nations ont fait de leur mieux pour chercher à " rendre leurs impóts aussi également répartis, aussi " commodes pour le contribuable, quant à l'époque et " au mode de paiement et aussi peu lourds pour le " peuple à proportion du revenu qu'ils rendaient au "prince, qu elles ont pu l"imaginer 1" ".

Ricardu est plus net. sans itre plus complet: "L’im"pit est cette partie du produit de la terre et de l"in"dustrie d'un pays qu'on met à la disposition du Gou"veruement $(2$ ).

Pour Rossi "l'impoit est la demande annuelle que " fait l'Etat d'une certaine portion de leur revenu à " tous ceux qui sont censés en aroir un... Limpôt tire "son origine du droit qu'a l'Etat de réclamer sa quote"part lans la distribution du produit général, dans la " distribution du revenu social (3)".

Evidemment, la définition de Rossi est déjà moins impartaite que celle d'Adam Smith et que celle de Ricarlo; elle est mème supérieure à la formule de M. H. Passy: elle contient, au point de vue scientifique, une idée plus générale. celle de la ruote-part revenant à l'Etat dans la distribution du produit général et l'indication. bien insuffisante, il est vrai, du mode par lequel l'Etat obtient cette quote-part, une demande annuelle.

J.-B. Say est plus explicite. "L Limpòt est cette por" tion des proluits d"une nation qui passe des mains " des particuliers aux mains du Gouvernement pour " subrenir aux consommations publiques. Quel que soit "le nom quion lui donne, cest une charge improsée aux "particuliers par le souverain, peuple ou prince, pour "foumir aux consommations qüil juge à propos de

(1) Richesse les nations, liv. r, chap. II.

(2) Principes le l'économie politique; de l'impôt, chap. viI.

(3) Cours l'économie politique, t. IV, p. 20 '. 
"faire à leur dépens (1) ". Il ajoute : "Il faut contri"buer de son bien pour assurer la conservation du " reste... et si les contributions étaient portées au delà " de ce qui est nécessaire pour protéger le public, il " serait difficile de ne pats envisager ce surplus comme " une spoliation, comme un sarrifice purement gratuit "exigé de force des particuliers... Je dis exigr" de "force, mime sous les gouvernements représenta" tifs(2) ». Ainsi le consentement ne caractériserait pas l'impôt et il contiendrait en lui-mème le prineipe d'un certain transfert de richesse par la violence, et pourrait devenir une spoliation.

C'est quelque peu différent de la demande annuelle de Rossi ou de l'optimisme d'Adam Smith.

Roscher, qui a tant contrilsué à éclairer, par l’histoire, la vérification des faits principaux sur lesquels repose l'économie politique, n’a eonsaeré que quelques notes, très précieuses, il est vrai, à la question de l'impoit. Dans ces notes, il indique comment l'incidence de l'impùt, soit dans l'Lntiquité, soit chez les peuples modernes, correspond à l'histoire des révolutions politiques et sociales, notamment à Rome. Il jette ainsi, quoique trop rapidement, une vive lumière sur l'origine et la nature de l'impòt.

Venu l'un des derniers, Stuart Mill a présenté une théorie qui s'éloigne de toutes les autres et qu'il donne comme un idéal. "L’impôt est la part dans laquelle " chacun contribue aux dépenses du Gouvernement; il " doit ètre réglé de façon que personne ne souffre plus "qu'un autre de l'obligation de contribuer; le sacrifice " doit être égal (3)".

Il serait facile de montrer que si cette théorie indique un idéal, elle explique en même temps, à beaucoup de

(1) Traité d'économie politique, liv. II, chap. Ix.

(2) Cours d'conomie politique, $4^{\mathrm{e}}$ partie, chap. xiv.

(3) Principes d'economie politique, liv. v, chap. $11, \S 2$. 
points de vue, les étapes du développement historique de limpôt. Mais si elle est l'avenir à réaliser, elle n'est point le départ. Elle confirme, par suite, indirectement les observations de J.-B. Say et de Roscher.

Proudhon a consacré quelques-unes des meilleures pages de sa Théoric de l'imprit à critiquer les diverses opinions sur l'origine et la nature de l'impôt. L’impôt ne serait ni un tribut, ni une rederance, ni un loyer, ni un honoraire, ni mne offrande, ni une assurance, l'impòt serait un échange (1). Dans cette discussion, Proudhon s'est placé au point de vue de la souveraineté populaire, rejetant toute tradition et toute influence de la tradition sur limpôt.

Dans son récent Traité théorique et pratique d'Économie politique, M. Paul Leroy-Beaulieu s'est rapproché de la formule de M. II. Passy, en acceptant la définition suivante: "l'impùt est la contribution de chacun "pour pourvoir aux obligations communes et aux frais " généraux collectifs de la nation ". A notre aris, cette définition, en ne tenant pas compte du caractère de nécessité rigonreuse de l'impòt, n'est pas assez complète. Elle n'est pas d'accord aree l'histoire de l'impôt (2).

L'honorable II. de Parieu éerivait, il y a plus de trente ans : "L̈institution de l'impüt est certainement "l'une de celles qui portent avec le plus d'évidence le " cachet de la nécessité. Il faut payer les taxes ou "mourir, dit avec énergie un proverbe anglais. La "nécessité est son principe, l'exigence son caractère, "la contrainte lui sert de sanction (3) ). M. de Parieu tient compte des faits : il respecte la tradition de l'histoire de l'impùt.

Néanmoins, cette tradition est encore plus rigoureuse que ne le laissent entendre les termes si précis de M.

(1) Théorie de limpôt, p. 36-41.

(2) $4^{\mathrm{a}}$ rol. 1895, p. 738.

(3) Traité des impóts, t. IV, p. 483. 
de Parieu. Quel a été, en effet, le fondement de cette nécessité, à quel genre d'obligation a-t-elle correspondu? Sur qui cette olligation a-t-elle porté? Qui a-telle atteint? E-t-ce mème sur une obligation générale ou sur une obligation spéciale, imposée à ceux-ci comme leur condition naturelle, inconnue de ceux-là comme un droit légitime, que repose cette nécessité? Combien son caractère changerait, combien saccentuerait la contrainte, combien les reflets de l'impôt seraient différents, combien les définitions devraient changer, si celte obligation naturelle de l'impól arait été dans le passé ou demeurait dans le présent, pourbonne partie, une exigence subie par les uns et dont les autres auraient non seulement eté exempts, mais profiteraient dirertement, et si, mème encore, le passé exerçait sur le présent, une influence prolondément inègale, arbitraire et parfois inique? ruue de difficultés, dès lors, pour donner de l’impôt une de ces définitions philosophiques qui complaisent à l'esprit, mais qui sont, jusqu'à un certain point, en opposilion non senlement avec l'histoire de l'impòt chez les principaux peuples, mais encore arec leurs systèmes fiscaux contemporains?

Ces réflexions nous donnent la clé d'une des remarques les plus sagaces de $\mathbf{M}$. Bastiat et de plusieurs de ses sophismes. L'impòt, enseignail-il, n’est dù qu’à l'État. C'est l'hypothèse même admise par toutes les définitions. Quesnay, par ses $23^{\circ}$ et $28^{\circ}$ maximes, avait déjà formulé les réserves de Bastiat, sans les préciser aussi clairement. L'impìt serait-il donc exigé, par d'autres que l'Etat? Mais il est in!tile d'insister sur la question. L'histoire de tous les peuples ne laisse à cet égard aucun doute. En réalité, l'impì! a étè exigé el est encore souvent exigé entre les diverses classes du corps social et mème entre les peuples, les États, les races. Dès iors il n'est plus seulement un prélèvement au profit de l'État, quelle que soit la forme de l'État, mais encore au profit d'autres forces. Sociétés, particuliers, Etats, nations, races. 
L'impòt revèt alors un autre caractère. Le sacrifice qu'il exige est plus rigoureux; il en augmente le poids; il accroit les inégalités naturelles; il modifie la distribution des richesses; il devient un véritable transfert de la richesse; il change, il aggrave les conditions de l'incidence; il est nécessairement une cause de perturbation dans la répercussion économique des systemes fiscaux des peuples et entre les peuples.

Si l'impôt a ce caractere arbitraire, s'il a été longtemps une violence, une spoliation, s'il est encore parfois une extorsion, si le libre consentement a cté bien souvent étranger à son octroi, s'il a profité et s'il profite à d’autres intérìts que les intérèts généraux, sil a été et sul demeure quelquefois un transfert de richesse de classe à classe, et de nation à nation, s’il a eu jusqu’à présent et s'il a encore très rarement pour principe cette égalité de sacrifice rêvée par Stuart IIill, cette pondération attestée par Adam Smith, cette modeste demande annuelle de Rnssi, cette destination supérieure de II. H. Passy, il faut bien reconnaitre l'insuffisance des définitions qu ils ont données. Elles sont incomplètes et au point de vue de la nature et au point de rue des origines de l'impòt. Elles substituent l'idéal à la réalité.

De ces diverses réflexions il faut conclure que l'impòt est un prélèrement sur leurs biens que les particuliers ont été ou sont contraints de subir, sous diverses formes et à diverses époques, fixes ou périodiques, soit au profit de l'État, soit au profit des autres forces ou des autres membres de la nation ou des autres peuples et États.

Cette définition permet de saisir, du premier vol, toute la portée des questions d'incidence. En effet, dans l'hypothèse que l’impòt n'est exigé que par l'État, on peut s'imaginer que les reflets de l'impòt se croiseront en divers sens et qu'une sorte de balance générale, dont il sera le centre, rétablira l'harmonie, sinon la justice. Celui qui aura avancé l'impôt pourra le rejeter sur son voisin, celui-ci sur un autre; celui qui est accablé 
pourra opprimer à son tour, et limpòt, en définitive, sera censé n’ètre supporté par personne.

Mais cette théorie raffinée, inconnue pendant de longs siecles, aux peuples ou aux classes assujettis it l’impòt, s'éranouit elle-mème, quand l’impit, au lieu d'être payé à l’État, est versé à d’autres forces sociales ou à de simples particuliers; l'espérance d'une compensation fiscale, si incertaine pour l'impit encaissé par l'État, derient une pure illusion quand il est encaissé par d'autres que lui, spécialement par d’autres États.

Limpoit na donc pas plus pour caractire que pour origine, d’après la tradition historique. d'itre une pure obligation naturelle, répartie également et équitablement sur tons les serviteurs de l'État.

C'est un idéal vers lequel il doit tendre - il y a mieux, c'est un ileal dont il se rapproche lentement arec les progres de la civilisation, mais dont il est encore bien éloigné, à raison de lïnfluence inéritable que la tradition historique, que le passé fiscal des peuples exercent sur leurs systèmes d’imput et sur les conséquences de ces systèmes.

La trailition historique n'est pas le senl ćlément des origines de l'impòt. D'antres facteurs interviennent, les uns permanents, comme le climat, le territoire. la race, la religion; d'autres temporaires, comme la forme de gourernement, les conditions civiles et sociales, le régime économique; ces facteurs ont aussi leur part dinfluence. Ils compliquent encore les reflets les systèmes fiscaux, car l'impòt n’a pas la mème forme et par suite la mème incidence, les mèmes reflets sur des territoires maritimes on continentaux, sons des climats opposés, avec des institutions dímocratiques ou aristocratiques, chez des peuples agricoles on commerçants, pour des nations indépendantes ou tributaires.

On le voit. la nature et l'origine de l’impôt présentent une très sérieuse complexité. 
Cette complexité est encore plus grande qu'elle n’apparait à première vue.

"Tant que les soriétés demeurèrent ignorantes et " paurres, limprit ne consista qu'en services person" nels.... Limpòt s'étendit graduellement des per" sonnes aux choses. Des dimes furent prélevées sur " les troupeaux, sur les récoltes, sur la plupart des " fruits du travail, et ce fut au moyen de ressources "réalisées en nature que s'effectua le solde d'une par" tie notable des répen-es collectives. Plus tard, l'usage " croissant des mélaux monnayés amena de noureaux " changements dans les modes de perception en pra"tique. Beancoup de contributions durent ètre payées " en numéraire ct le temps vint, où, gràce à la faci" lité d'en réaliser le montant sous une forme à la fois "plus commode et plus simple, les États, en roie de "prospérité, parvinrent à obtenir des revemus non seu"lenjent assez considérables pour couvrir les charges " annuelles, mais pour laisser des excédents thésau"risés en rue des éventualitésque l’a venir pourrait ame"ner. Ainsi se transformèrent, à mesure que la civilisa"tion étendit son cours, les systèmes de contributions "en usage aux époques antérieures; et du jour où les " tases purent ère ohtenues en numéraire, elles se mul" tiplierent arec une remarquable rapidité. Aux impùts " anciens en furent sans cesse ajoutés de noureaux, et "l'histoire atteste que les peuples, récemment sortis de "l'enfance, ne tardèrent pas à décourrir toutes les res"sources auxquelles il était possible de puiser dans l"in"térèt du fisc 1)."

Le mourement de transformation de l'impòt est carảctérisé, arec netleté, dans cette page tracée par M. H. Passy. Ce mourement a présente cependant plus d'ampleur; il a passé par des étapes moins régulières qu elle ne l'indique. La transformation de l'impot ne concerne

(1) Dictionnaire d'economir politique, Impot, ibidem, page 898. 
pas seulement le mode de perception. le moyen de l'acquitter, les formes variées qu il peut prendre, les ressources qüil peut procurer; ce n’est là que le mécanisme de l'impùt. Ce mécanisme lui-mème a dù ètre adapté à des circonstances plus rariables ou plus fixes. Mais à còté de l'instrument, il y arait ceux qui s'en servaient et ceux contre lesquels il fonctionnait. Le mécanisme mème pourait ètre et a été sourent modifié en rue des résultats qu ill devait produire.

Aussi ce mourement de transformation, en cela parallèle au cours de la civilisation, présente-t-il des alternatives, en sens divers, d'après les peuples, les époques et les territoires. D'un cöté, la Chine conservera limpòt en nature pendant 4000 ans; d’un autre còté, l'impót féodal remplacera en Europe, pendant plus de 10 siècles, la sarante organisation fiscale de l'Empire romain. Sparte gardera, pentant plusieurs siècles, le systeme fiscal le plus singulier. tandis qu'Athenes se livrera aux experiences les plus compliquées et les plus curieuses; la France atteindra au plus haut degré de perfection de l"impùt foncier, et l’impùt foncier sera à peine ébauché en Angleterre; il n'existera jas aux États-Unis.

Au milieu de pareilles diversités, de telles oppositions, comment reconnaitre les faits généraus des transformations de limput?

Nous retrouvons iei linfluence de la complexité signalée à propos de la nature et des origines de l’impòt. Limpòt est nécessairement arlapté aux morlifications qui ont lieu dans les sociétés; ces modifications sont extrèmement nombreuses. L'Egypte, soumise aux Musulmans, a ru changer son système fiscal en changeant de maitres. L'Empire romain n'a pas eu les mèmes impüts que la République, les dernier's siecles de l'Empire que les premiers. Les Anglais ont imposé l'income-tax à l'Inde entière. La révolution de 1789 a eu un caractère essentiellement fiscal. Pendant près de 
dix ans, en France, aucune classe n'a voulu payer d’impòt; à Florence l'impòt était modifié avec tout changement politique.

Lorsque Rome eut conquis la Macédoine, elle abolit l'impòt sur le capital en Italie. La Macédoine et la Grèce durent payer pour l'ltalie. L'un des motifs de la rési-tance implacable des Juifs à Rome a été le tribut. La scène de l'Érangile wi le Christ retourne le denier du tribut révele la risistance populaire. Le Juif a toujour's été rebelle à l'imprit. Il n’a pas voulu payer pour autrui.

Le mouvement de risistance des propriétaires romains i limpòt successoral est plus significatif encore. Organise par luguste(1), l'impoit successoral s'est effondre; on ignore comment il a disparu. Mème, en 1788 , apres une agitation intense, dangereuse, en prisence d'une situation extrime, les privilégiés, exempts en France des tailles, ont refusé de concourir à aucun cliangement.

Sans doute, les impöts se transforment, mais ces transformations sont varialles. parce que les conditions, dans lesquelles ils s'établissent et agissent, varient; ils ne formert point un simple mécanisme, mais une arme dont l'emploi change avec les influences politiques et sociales, les nations et les civilisations.

Dès que l’impòt est un prèlèvement obligatoire sur les biens, un amoindrissement considérable et permanent de richesse, il est devenu soit entre les classes diverses ${ }^{21}$ qui composent les nations, soit entre les na-

(1) Impơt sans répercussion possible; or les derniers temps de l'Empire romain sont caractérisés par ce fait, qui n'a pas peu contribué ì sa chute, que les classes supérieures rejettent les impôts sur les autres classes.

(2) C'est bien dans ce sens qu'a eu lieu la dernière proposition d'un impót sur le revenu en France; il devait ètre une arme de guerre sociale, un moyen de rendre aux petits ce que les autres étaient censés avoir en trop. 
tions elles-mèmes, une rause de dissentiment, de lutte et de guerre. Tantòt les classes aux mains desquelles le pouvoir politique et linfluence sociale etaient remis, ont organisé et modifié l'impùt de manière à ne pas le supporter ou à n'en supporter que la moindre part; tantót les nations ont prétendu, par la violence et la conquite, rejeter, sur d'autres nations, le poids de leurs dépenses. Et lorsque, par le lent progrés de lic civilisation, les classes prépondérantes ou les nations directrices nont plus été à mime de se soustraire à l'obligation directe de l'impüt. elles ont cherché, dans des combinaisons dilférentes, telles que leurs régimes douaniers, des moyens de se procurer des prélèrements l'une autre nature.

Il laut citer comme exemples décisil's lexploitation des peuples súdentaires par les peuples nomarles, l'exploitation par certaines religion, telles que le IIahométisme, et par les nations militaires, comme les Romains, des peuples paciliques. Les Mongrols, les Musulmans, les Romains ont porté cette exploitation à un tel point, qu'elle a éé l'une des causes de leur ruine ou de leur décadenre.

Par suite, les impoits sont soumis à un mourement incessant de transformation. Il faut ajouter yue ce mouvement a été souvent retardé, sourent accéléré par des faits généraux, qui tiennent à l'histoire mème de l'humanite, tels que l'occupation progesesive. lit mise en culture et lappropriation de noureaux territoires sur les divers contincnts du globe, le léreloppement des forces mécaniques de lindustrie, l'accroissement général de la richesse et du bien-itre, d'une part, et, d'autre part, les retaris, les reculs et mime les destructions resultant des migrations, des longues guerres et des révolutions.

Les évenements divers qui ont eu pour effet d'amoindrir la richesse et la prospérité des peuples ont naturellement tendu à rendre l'impùt plus rigoureux et 
mème plus inégal; au contraire, dans les époques où la richesse et le bien-ìtre général se sont accrus, quoique limpùt ait suivi cet accroissement. il n'en est pas moins derenu moins accablant et parfois plus égal, parce que les populations ont pu disposer d'excédents plus importants.

Ainsi la condition le !'Inde sous la domination anglaise, de l'Algerie et de la Tunisie, sous les Français, de la Bosnie et de l'Herzégorine sous l'Autriche, du Turkestan sons la Russie, et celle de la Roumanie, de la Bulgarie, de la Serbie, nème de l'Égspte. détachées de l'Empire ottoman. sest prodigieusement améliorée, malgré une augnentation d’impòts et des procédes plus efficaces de rendement.

Yous rerrons quà differentes époques, la mise en culture et lappropriation des nonveanx territoires. qui, à la fin du xix siècle, sont des faits économiques dune si grande portée, ont également exerce une influence sensible sur les systèmes d'impoit, en vue de modifier l’incidence de lömpit. Il en est de mème du déreloppement des forces nécaniques qui, à certains égards, peurent ètre rapprochees, par leurs effets sur la production, de lexploitation de nouveaux territoires.

Ce caractere complexe des transformations de l'impüt concorde necessairement arec tous les changements qui ont lien dans les sociétés, car ces changements modifient les résultats de l"incidence de limpôt. Telle branche de la production, telle classe sociale qui, dans des conditions donnees, pouvaient subir un prélivement proportionnel soit à leurs avantages, soit à leur impuissance de resistance, $n$ ont pu, les conditions étant changées, les supporter on oni refusé de les subir. D'autres sytènes dimpùts ont dù ètre expérimentés et il y eut mème des époques, comme à Lacédémone, à fiome. au Moven àge, pendant la période féodale, oì le caractère de l'impòt a été altéré, plus ou moins complitement. 
Dans les considérations qui précédent, l'impôt a été surtout enrisage au point de rue économique, tel qu’il se présente à l'observation d'un esprit judicieux, au milieu d'un peuple prospère et d'une société assise et calme, comme l'Angleterre au xvir siècle, ou la France sous l'ancienne monarchie, depuis Henri IV jusqu'en 1789. On comprend que, dans ces conditions, Adam Smith ait pu, par voie d'induction, formuler, d’après l'examen des faits par lui recueillis arec sa rare sagacité, les lois ou les rigles qui ont pris place dans la science et qui ont été depuis paracherées.

Mais il a été donné à peu de sociétús humaines de traverser de pareilles époques de prospérité et de quiétude; aussi pendant le xix siècle, qui a réalisé cependant de très grands progres sur le xrme siecle, il n’a cessé de régner, mème en Angleterre, au milieu d'un developpement économique sans exemple, une grande agitation fiscale, qui a été la mème dans la plupart des autres Etats; chez tous se sont accomplis ou se préparent des changements dont on n'aperecoit pas le terme (1).

Aussi l'histoire de l’impòt à travers les diverses époques et les diverses civilisations, sans èbranler l'autorité des règles d'Adam Smith, telles qu'elles ont éte depuis complétées, notamment par Stuart Mill, conduit-elle à la conviction que ces règles s'appliquent à une sorte d’arenir lointain dont, jusqu’à présent, les générations humaines se sont tenues à une bien grande distance. Il est très exact que le don volontaire, correspondant à la contribution de chacun dans les dé-

(1) H. Passy a aussi présenté des règles générales avec des formules techniques; mais la matière fiscale est trop changeante pour s’assouplir à ces formules. On aurait fort étonné l'honorable publiciste, en lui annonçant qu'un jour viendrait, où le monopole de l'alcool serait tenu comme assez productif, pour remplacer octrois, impòt foncier, prestations, impòt mobilier, portes et fenêtres, et amortir la dette publique! 
penses publiques, est l'une des formes les plus anciennes de limpùt, comme la plus respectable, forme que l'on retrouve, depuis les empires des civilisations primitives jusque chez les tribus nomades de toutes les races el mème au milieu de la fiscalité du régime féodal. Mais on est obligé de placer immédiatement après le don volontaire le tribut, le tribut que le vaincu, le faible, lopprimé est contraint de payer au plus fort, comme l'une des formes également les plus anciennes, les plus constantes, les plus universelles de lïmpòt. Il y a mème eu des peuples, des empires, comme les Romains, les Mongols, comme la plupart des peuples nomades, pour lesquels le tribut a été, ou toujours ou pendant quelque temps, la jrincipale, parfois la seule ressouree, de mème quil y a eu des peuples qui sont devenus perpituellement tributaires, comme l'Egyte. Ne royons-lous pas l'Angleterre faire la guerre, pour son propre compte, arec les impòts le l'Egypte? De mème, pentiant de longs sircles, les Slaves de toute origine, ont payé le tribut. Leur nom prorient probablement de leur qualite de tributaires a titre permanent. Bien mieux, une grande religion, qui continue de nos jours ses proglès, a établi comme l'un de ses dogmes, formuler au nom de bieu par son prophète Ilahomet, que tous ceux qui ne les accepteraient pas comme révélés, auraient à choisir entre le tribut ou le massacre. Mème de nos jours, si le tribut est mis en question ou en péril. te massacre commence. 11 suffit d'un coup de clairon. Les Musuhmans sont peut-itre plus exigeants que Sennachérib à cet égard. On sait combien les Romitins itaieul eux-mèmes peu endurants. Voilà une des faces de limpòt qui n’a peut-être pas èté suffisamment mise en relief jusqu'à présent. Et, dans ces lerniers temps, l'Europe entière n'a-t-elle pas laissé imposer à la France, habilement provoquée à une guerre dans des conditions d'inégalité désastreuses, une énorme indemnité de guerre, équivalant à un tri- 
but annuel de 300 millions? La plupart des publicistes allemands n'enseignent-ils pas que la guerre est un moyen de s'enrichir tout aussi légitime qu'un autre? ce qui implique la parfaite légitimité du tribut.

Sans rejeter entièrement l’idée de II. H. Passy que les formes de l'impòt s'approprient à l'état, plus ou moins avancé de la civilisation, il faut done reconnaitre qu'elles dépendent de circonstances variables dont la concordance avec l'état de la civilisation n'est que relative. Les Romains sont parvenus à un très haut degré de civilisation, tout en réduisant au minimum les impôts quils payaient et en rejetant la charge entière sur les peuples quils avaient vaincus. Pendant plusieurs siccles, ils se sont fait entretenir par leurs victimes. II en a été de mème pourles Musulmans, les Mongols et les grandes Confédérations de nomades. La guerre derait alimenter le budget. Les Turcs ottomans ont mème enchéri sur les uns et sur les autres. Leur oppression fiscale a été accablante partout.

Dans le présent volume, nous conduisons l'histoire de l'impòt jusqu'au xrr ${ }^{\mathrm{e}}$ siècle, c’est-à-dire à peu près au terme de I'époque qu'on est convenu d'appeler, quant à l'Europe du moins, Ie Moyen âge. Pour la plus grande partie de l'Asie, le Moyen ûge n'est caractérisé par aucune série de faits qui le distinguent des temps précédents; mais il n'en est pas de mème pour l'Europe qui a aujourd'hui en main la direction de l'humanité.

Durant cette longue suite de siècles, qui remonte fort loin dans les vallées de l'Euphrate, du Tigre, du Nil et du Hoang-Hò ou fleuve Jaune, et qui comprend la plus grande partie du développement historique de l'humanité, on peut résumer par les traits suirants les origines, la nature, les formes, les variations de l'impòt et son incidence, pour les diverses civilisations.

I. La civilisation a d'abord consisté dans l'établissement et la fixation sur des territoires déterminés, 
de tribus ou de Confédérations nomades, sous l'action de divers mobiles, notamment l'influence des hommes supérieurs dont elles acceptaient, subissaient ou recherchaient la direction, tels que Moïse, Zoroastre, Manou, Confucius, Lycurgue, Solon. Servius Tullius. Selon la remarque fondamentale de Thucydide, les points d'arrèt des tribus nomades en vue de se transformer en tribus sédentaires, transformation qui est la condition d'apparition et le fond de tout foyer civilisateur, ont eu lieu surtout dans les vallées, le long des fleuves, où les premières tribus humaines ont trouvé des moyens d'alimentation, de défense, de communication plus nombreux et plus faciles, en mème temps que des terres plus fertiles (1).

Il. C'est ainsi que se sont constitués les foyers primitifs des diverses civilisations, ayant probablement tous pour premier centre le Delta de l'Euphrate et du Tigre, d'où des colonies ont successivement émigré pour s'établir dans la vallée du Nil, dans celle du Hoang-Ho, dans celle de l'Oxus et dans celle de l'Indus. Ces tribus devaient posséder, de mème que celles si nombreuses et si redontables qui, plus tard, ont attaqué et prarfois détruit ou revivifié les foyers primitifs, une organisation fiscale. Les lois de Manou, les monuments chinois et celtiques, Strabon, César et Tacite en ont conservé la tradition. II était dù aux chefs des tribus un prélèvement annuel sur le bétail complété par des offrandes volontaires. Ce prélèvement obligatoire était réparti entre les clans ou familles de la tribu proportionnellement i leur importance. Le don volontaire et la capitation sur le bétail des peuples nomades doivent ètre, par suite, les formes primordiales de l'impòt. Ces formes subsistent encore chez les tribus ou Confédérations des tribus nomades.

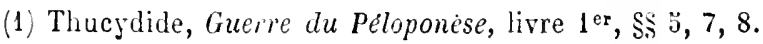


III. Chez les tribus sédentaires, dont les foyers sont devenus les centres de la civilisation, le don volontaire s'est maintenu, mais l'impoit sur le betail s'est transformé dans un impòt phus général sur la production agricole; cet impòt, c'est la dime. La dime sur les produits du sol et le don volontaire sont par suite les deux formes de limpoit primitives des peuples sédentaires ou civilisés. Ces impots, chez les peuples sédentaires n’étaient pas seulement dus au souverain, mais également, dans des proportions diverses, aux classes directrices, notamment aux sacerdoces, représentant les éléments actifs de la civilisation. 11 en a été ainsi dans l'Inde pour les Brahmanes, en Perse pour les Nages, en Egypte, en Judée, dans les Gaules pour les Druides. Ces sacerdoces ont eu, en effet, la première part dans l'œurre de la civilisation. Lne autre part a dù itre faite aux classes militaires, chargées de la défense du foyer. Tantùt ces attributions ont eu lieu au moyen de terres exemptes dimpòts, tantit au moyen diune participation mème dans lïmpòt. Ainsi se sont constituées des inegalités et des classes sociales, que rien ne pouvait prévenir, et qui correspondaient aux néressités de chaque nationalité et de la civilisation elle-meme. A ce sujet lhistoire de l'impòt et de la civilisation en Egypte contient un enseignement péremptoire.

IV. Dans ces conditions, qui ont été maintenues assez longtemps, les premiers foyers de la civilisation ont joui d'une incontestable prospérité fondée, sur la culture du sol et leur éloignement respectif; c'est ce qui est attesté par tous les monuments et tous les documents qui ont été conservés sur la civilisation de la Chaldée, de l'Assyrie, de la Babylonie, de l'Égypte ancienne et moyenne, de l'Arabie primitive, surtout de l'Inde, de la Chine et de l'ltalie arant Rome. Les légendes et les traditions sur une première époque de prospérité, sur l'àge d'or, se rattachent à ces temps. 
V. Cette prospérité a été troublée par l'intervention

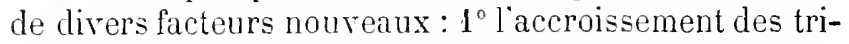
bus restées nomades, ayant préféré leur vie traditionnelle aux rudes labeurs des tribus sédentaires; $2^{\circ}$ la concurrence des foyers civilisateurs entre eus, concurrence provenant de la nature mème des choses, des différences de climat, de race. de religion, de conditions économiques; $3^{\circ}$ les modifications que la loi d’inégalité, ou le principe de differenciation, introduit necessairement dans toutes les sociétés humaines; $4^{\circ}$ le rapprochement des foyers civilisateurs entre eux sous l'influence des progris mèmes de la civilisation, de la population, de l'oceupation, de la mise en culture et de l'appropriation de noureaux territoires. L'action de ces divers facteurs a donné une extrème intensité à la loi de la guerre, réalisation brutale de la concurrence des peuples et des civilisations. De meme que les guerres tendent actuellement à devenir moins fréquentes, de mème elles ont dù ètre assez rares dans les premières civilisations; mais elles ont pris une terrible activité lorsque, d'une part, les foyers civilisateur's ont été plus nombreux, plus rapprochés, plus riches et que, d'autre part, les populations nomades ont pris julus d'importance. Elles ont en pour causes incessantes de provocation, les luttes entre les foyers civilisateurs et les nomades, les luttes entre les foyers cirilisateurs eux-mèmes. De ces luttes, deux résultats principaux, l'un et l'autre essentiellement fiscaux : le premier de rejeter l"impùt sur le vaincu, d'où le tribut, troisième forme primordiale de l’impòt; le second, sinon de faire apparaitre, du moins d'aggraver, dans d'énormes proportions, le plus grand élément d'inégalité entre les hommes, l'esclavage et, par l'esclavage, d'altérer profondément les moyens de production, les sources de la richesse, le caractère et la répartition de lümpòt.

11. Depuis l'époque des Empires de Chaldée et d'Assrrie et du second Empire d'Egypte jusqu'à Auguste, 
c'est-à-dire pendant au moins vingt siècles, on peut dire que la guerre, soit entre les foyers civilisateurs, soit entre ces foyers et les peuples nomades, ont été l'èlément principal de la vie des peuples méditerranéens et qu’elle résume à peu près les mouvements divers de leurs civilisations. Il y a sins doute certains foyers, tels que la Phénicie, Isrä̈l, l’Égypte, Athènes(1) où, à còté de la guerre, d'autres éléments se sont déreloppés, mais ils ont été toujours dominés par la guerre et, par suite, par l'esclarage, le pillage, le butin de gruerre, mème par la dépossession du sol, l'appropriation des impùts, à titre de conquète par les rainqueurs, car non seulement les vainqueurs imposaient le tribut au vaincu, quand ils ne le réduisaient pas en esclarage, mais sourent ils s'emparaient du sol et, süls lui en laissaient la jourssance, ils mettaient an moins la main sur tous les imprits ordinaires, pour en disposer comme d'une rente annuelle et perpétuelle. Dans les anciens empires d'Orient, les souverains traitaient, pour la perception du tribut, en quelque sorte a forfait, ce qui soulageait les populations; mais les Romains percevaient euxmêmes tribut et impòts et ils les employaient à leur fantaisie, notamment à nourrir la population famélique de Rome et de Constantinople.

VII. Pour résister à des perturbations pareilles, les populations sédentaires ont eu surtout recours à la coutume et à l'impòt en nature; ce sont ces deux moyens qui leur ont permis de sulssister, aussi bien en Asie Mineure qu'en Égypte, dans la Péloponèse et ailleurs. Tous les peuples conquérants ont dù s'y plier. L'oppression la plus affreuse que les Mongols ont fait sentir aux Russes a consisté à les contraindre de payer leur tribut en argent. Nul doute que cette oppression n’ait

(1) A Athènes mème, le butin de guerre entrait dans la constitution du budget. 
V. Cette prospérité a été troublée par l’intervention de divers facteurs noureaux : $1^{\circ}$ l'accroissement des tribus restées nomades, ayant préféré leur vie traditionnelle aux rudes labeurs des tribus sédentaires; $2^{\circ}$ la concurrence des foyers cirilisateurs entre eux. concurrence provenant de la nature même des choses, des différences de climat, de race. de religion. de conditions économiques; $3^{\circ}$ les modifications que la loi d’inégalite, ou le principe de diffërenciation. introduit nécessairement dans toutes les societes humaines: $4^{\circ}$ le rapprochement des foyers civilisateurs entre eux sous l"influence des progres mèmes de la cirilisation, de la population, de loccupation, de la mise en culture et de lappropriation de noureaux territoires. Laction de ces dirers facteurs a donné une extrème intensité à la loi de la guerre, réalisation brutale de la concurrence des peuples et des civilisations. De mème que les guerres tendent actuellement à devenir moins fréquentes, de mème elles ont dù être assez rares dans les premières civilisations: mais elles ont pris une terrible activité lorsque, d'une part, les foyers cirilisateurs ont été plus nombreux, plus rapproches, plus riches et que, d'autre part, les populations nomades ont pris plus d'importance. Elles ont eu pour causes incessantes de provocation, les luttes entre les foyers cirilisateurs et les nomades, les luttes entre les foyers civilisateurs eux-mèmes. De ces luttes, deux résultats principaux, l'un et lautre essentiellement fiscaux : le premier de rejeter l’impòt sur le vaincu, d’où le tribut, troisième forme primordiale de l'impòt; le second, sinon de faire apparaitre, du moins d'aggraver, dans d'énormes proportions, le plus grand élément d'inégalité entre les hommes, l'esclavage et, par lesclavage, d'altérer profondément les moyens de production, les sources de la richesse, le caractère et la répartition de limpòt.

11. Depuis l'époque des Empires de Chaldée et d'Assyrie et du second Empire d'Égypte jusquà Auguste, 
c'est-à-dire pendant au moins vingt siècles, on peut dire que la guerre, soit entre les foyers civilisateurs, soit entre ces foyers et les peuples nomades, ont été l’èlément principal de la vie des peuples méditerranéens et quelle résune à peu pris les mouvements divers de leurs civilisations. Il y a sans doute certains foyers. tels que la Phénicie, Isrä̈l, l’Égypte, Athènes(1) où, à cùté de la guerre, d’autres éléments se sont développés, mais ils ont été toujours dominés par la guerre et, par suite, par l'esclarage, le pillage, le butin de guerre, même par la dépossession du sol, l'appropriation des impùts, à titre de conquète par les vainqueurs, car non seulement les vainqueurs imposaient le tribut au vaincu, quand ils ne le réduisaient pas en esclavage, mais sourent ils s'emparaient du sol et, suils lui en laissaient la jonissance, ils mettaient au moins la main sur tous les impits ordinaires, pour en disposer comme d'une rente annuelle et perpétuelle. Dans les anciens empires dorient, les sourerains traitaient, pour la perception du tribut, en quelque sorte à forfait, ce qui soulageait les populations; mais les Romains perceraient euxmèmes tribut et impòts et ils les employaient à leur fantaisie, notamment à nourrir la population famélique de Rome et de Constantinople.

VII. Pour résister à des perturbations pareilles, les populations sédentaires ont eu surtout recours à la coultume et à l'impòt en nature; ce sont ces deux moyens qui leur ont permis de subsister, aussi bien en Asie Mlineure qu'en Égypte, dans la Péloponèse et ailleurs. Tous les peuples conquérants ont dù s'y plier. L'oppression la plus affreuse que les Mongols ont fait sentir aux Russes a consisté à les contraindre de payer leur tribut en argent. Nul doute que cette oppression n'ait

(1) A Athènes mème, le butin de guerre entrait dans la constitution du budget. 
XXij CONQLÉte ROMAINE. LE TRIBUt ET LA PROPRIÉtÉ DU SOL.

contribué à fortifier, au plus haut degré, la résistance des Russes et à leur donner l'énergie nécessaire pour la détruire.

VIII. Sans loute, dans certains foyers spéciaux, comme thènes et l'Égypte, sous l'inftuence de la civilisation supérieure de la frèce, les systèmes fiscaux ont pris un développement particulier extrèmement intéressant. Arec quelques différences, provenant de leurs conditions économiques, l"Egrpte et Athenes ont à peu près connu et pratiqué toutes les formes de l'impòt. Dautre part, Athènes a discuté la plupart des problèmes fiscaux que les démocraties contemporaines ont essayé de résoudre, impùt sur le capital, impòt sur le revenu, impòt progressif, impoits lirects et indirects, taxes de consommation, confiscations, pain gratuit, théàtre gratuit, vie gratuite; mais, au point de vue de Ïinfluence fiscale, Athènes a été un fort médiocre foyer, sans aucune action au dehors, promptement submergé par la conquète romaine.

IX. Cette conquète s'est faite au moyen des ressources de l'impôt sur le capital, le tributum ex censu, acquitté avec persévérance par une aristocratie supérieure, qu'on peut comparer aux grands sacerdoces de l'Égypte, de la Perse et de l'Inde et surtout à l'aristocratic anglaise. Cette aristocratie a eu, de bonne heure, la provision d'une haute mission à accomplir, exactement comme l'aristocratie anglaise, qui, depuis si longtemps, a jeté les éléments de l'Empire anglais. Le tributum excensu, en vue de la conquète de tous les peuples méditerranéens, est certainement un fait fiscal de premier ordre en opposition absolue arec les maximes pacifques d'Adam Smith. La conquite a été opérée, le $t r i$ butum excensu supprimé pendant plus d'un siècle et tous les peuples méditerrancens contraints : $1^{\circ}$ de payer le tribut territorial et personnel à Rome; $2^{\circ}$ de lui servir 
Jeurs impòts en argent ou en nature à titre de rente; $3^{\circ}$ de reconnaitre que Rome était devenue nue propriétaire de leur's territoires, que parfois, en cas de résistance absolue, comme les Juifs, elle réunissait au sien, après en avoir massacré ou vendu les habitants. Voilà les civilisateurs clont il est de tradition, malgré Montesquieu, d'admirer les bienfaits. Les Musulmans n'ont fait que se conformer à ces précédents, mais en les améliorant beaucoup, malgré leurs tendances à la férocité. Non seulement toute personne pouvait se convertir aux dogmes si simples de Mahomet, mais en payant le Djizyéh pour les personnes et le Kharadj pour les biens, on conservait et la vie et la fortune.

X. Lorsque le neveu de César, Auguste, après d'effroyables massacres, fut devenu le maitre de Rome et des peuples méditerranéens, il eut, s'il faut s'en rapporter à Dion Cassius, plusieurs conférences avec son ami intime et son conseiller, Mécène, l'un des esprits supérieurs des temps anciens. Mécène lui donna différents avis qui révèlent une très haute intelligence; mais ces avis étaient de beaucoup en avance sur les temps et sur les ressources de la civilisation romaine. Auguste fit faire un recensement général de l'Empire; puis il procécla à une refonte générale des impòts. Ces deux operations durent être un immense bienfait pour cette époque. L'impòt perdit quelque peu de son caractère tributaire, militaire, oppressif pour se rapprocher des axiômes d'Adam Smith ou des physiocrates du xvir ${ }^{\circ}$ siècle. La conquête cessa d'ètre le caractère dı Gouvernement; le massacre, l'esclavage, le tribut, le pillage ne furent plus nécessairement le sort des populations. Se propageaient en même temps, dans le soussol de la société, les idées nouvelles que le Christianisme apportait dans le monde et qui, comme un levain merveilleux, allaient changer lentement, mais irrévocablement, le cours de la civilisation. 
Trois siècles plus tard, Dioclétien, Constantin, après eux Théodose II et Justinien ont repris, renouvelé, parachevé l'œuvre d'Auguste, réalisé en partie les idées de Mécène, frayé les voies aux règles d'Adam Smith par une législation fiscale dont l'ensemble est de beaucoup supérieur à cette époque el qui est encore comme un modèle. Cette œuvre a été comme une réparation que Rome a accordée aux peuples qu'elle avait opprimés et le dernier legs de son génie politique. L'impòt a dù, dès lors, être envisagé comme un devoir à acquitter proportionnellement aux ressources. Ce n'est plus un don, ni une dime, ni un tribut, ni une extorsion, cest un devoir à remplir par le contribuable et un droil de l'État, exercé avec justice et humanité.

XI. Mais au moment où cette législation entrait en pratique, lédifice romain était battu en brèche de tous cùtés, par des difficultés politiques et sociales également insurmontables, car les éléments intérieurs des civilisations ne sont pas soumis à des changements moins importants que leurs éléments extérieurs; les conditions du travail, la vie économique de l'Empire romain se modifièrent en mème temps que sur les frontières se présentèrent des ennemis implacables.

XII. Le développement de la guerre, en multipliant les esclaves, avait exercé une influence désorganisatrice sur le travail; nulle part cette désorganisation n'a été plus grande et plus destructive qu'en Italie et qu'en Grèce. Le travail de l'esclave s'y substitua au travail de l'homme libre. L'esclave ne paie ni ne peut absorber l'impòt. Il le réfléchit sur son maitre. Le maitre s'y soumet lui-mème, sans bonne volonté. Les États esclavagistes ont, par suite, été toujours belliqueux; la guerre devait fournir des esclaves et payer le tribut. La pax romana avec Auguste mit un terme aux guerres, limita l'esclavage et le tribut. Le Christianisme accéléra ces 
changements. Il fallut se remettre au travail, comme Aristote l'avait prévu. Saint Paul faisait des tentes; les apùtres ont été la plupart des ouvriers; tous travaillaient. Puis, on clut reconnaitre que le travail de l'homme libre est plus productif que celui de l'esclare. Les affranchissements se multiplièrent; il fallut demander aux travailleurs leur part d’impoit; limpot revetit alors un certain caractère servile. simultanément les idées politiques, les bases et la forme du gouvernement romain changeaient, sous l’influence de l'Orient; de républicaines, elles derinrent monarchiques. Limpòt fut considéré comme appartenant à l'empereur, dans lequel l'État se personnifiait. Il devint la propriété de l'empereur, qui en disposa comme de sa chose, conformément aux traditions orientales; dès lors il put exempter de l'impòt, les personnes qui approchaient de lui : l'immunitas conduisit au don de limpòt, à la gratification fiscale, à lhonor. Paver l'impüt devint une marque d’infériorité politique et sociale. En outre, à cette époque si intéressante, le cours de la cirilisation prend une antre voie. Durbaine, elle devient rurale, à raison des progrès des défrichements, de la mise en culture de noureaux territoires et de la population. Les formes de la production se modifièrent en mème temps, surtout dans l'Europe occidentale. C'est donc aux propriétaires ou aux cultivateurs qüil fallut demander la part principale de limpòt.

XIII. C'est à ce moment décisif dans l'histoire économique de l'Empire romain, que s'aggravirent les attaques des peuples nomades qui l'entouraient sur toutes ses frontières, au nord, au levant. au midi. Ces peuples nomades n'étaient pas inconnus des peuples sédentaires du bassin de la Jéditerranée. Celtes, Scythes, Jassagètes avaient, à diverses reprises. menacé et franchi les frontières de la Perse. de la Nacedoine et de l'Italie. Leurs migrations et leurs inva- 
sions s'étaient calmées, lorsque, à la suite de conquêtes par les Chinois et de l'asséchement graduel du désert de Gobi et des deux Turkestans, il se produisit, dans toutes les tribus du nord de l'Asie, un ébranlement profond, à la suite duquel de nombreux peuples nomarles vinrent occuper les territoires situés entre la Vistule, le Volga et l'Oural. Dès avant César, les légions romaines se trouvèrent en présence de ces tribus, les Parthes sur l'Euphrate, les Cimbres et les Teutons en Gaules; puis les attaques se renouvelèrent, devinrent plus redoutables sur l'Euphrate, sur le Rhin, sur le Danube; c'est là que Rome dut concentrer ses légions, concentration qui mit le gouvernement impérial dans leurs mains. César, Trajan, Narc-Aurèle, Septime Sévìre, Constantin, Théodose étaient parvenus, aux prix des plus grands efforts, à les contenir. Mlais après Théodose, les barrières furent brisées, l'Empire partagé en deux moitiés, l'Empire d'Occident renversé; l'empire d'Orient put seul résister.

XIV. Toutefois l'empire d'Orient dut lui-mème abandonner la frontière du Danube et en Asie se limiter au Taurus. Les Arabes sédentaires et nomades, sous l'influence de la religion de Nahomet, s'emparèrent de toute la Syrie, de la Perse, de l'Afrique du Nord et de la plus grande partie de l'Espagne. lls conservèrent les anciens impòts romains, mais en restituant aux deux capitations le caractère tributaire. Ce fut un bien grand recul dans la nature de l'impòt, recul tel que les impòts directs ont conservé dans l’Empire ottoman le caractère tributaire jusqu'aux réformes qui ont suivi la guerre de Crimée et que, même depuis ces réformes, ce caractère persiste encore.

XV. En Occident la perturbation a été totale, le naufrage de la civilisation romaine complet; toutefois les désastres du naufrage furent relativement amoindris par les progrès du Christianisme et le développement 
de la culture du sol. Pour apprécier les résultats de ce naufrage au point de vue de l'impót, il faut liviser i'Europe romaine en deux zones: d'abord, la zone romplètement romanisée, comprenant l'l talie et l'Espagne. L'Italie finit par expulser ou absorber tous les éléments étrangers, Goths, Hérules, Lombards; elle conserve les traditions romaines, les lois romaines, les impòts romains et les approprie peu à peu aux temps noureaux; elle retrouve les divers éléments de civilisation que la conquite romaine avait comprimés. La situation de l'Espagne est plus difficile. Elle engage contre les Arabes une lutte de sept sières. Elle subit à la fois linfluence propre des . Irabes et l'inlluence de cette lutte mème. Ses institutions fiscales durent etre appropriées à cette lutte.

NT1. Wans la seconde zone, qui comprend les raules, la Cirande-Bretagne et l'Allemagne jusqu’a l'Elbe, la situation est differente. Les Gaules, alor's le territoire principal, n’ont pas été romanisées au mème rlegré que l'Italie et que l'Espagne; elles sont en partie occupées défnitivement par les tribus germaniques et scandinaves : il y eut une sorte de compromis, une véritable fusion entre ces divers éléments. En mème temps que le territoire des Gaules est défriché, assaini, mis en culture, les tribus celtiques, gernaniques, scandinaves, de demi-nomades tendent à devenir sèdentaires. Ciest de ces divers éléments qu'est sorti le régrime féodal en vue d'asseoir les populations, de mettre le sol en valeur, de développer la vie rurale, transition indispensable aux populations nomades, de défendre le territoire et de préparer les éléments de la nationalité.

XYII. Cette œurre complese s'est accomplie dans les grandes propriétés foncières, dans les seigneuries, qui ont remplacé le clan, démembrement de la tribu, ou plutôt qui ne sont que les payi, pays ou localités, où le clan s'est fixé, avec ses chefs et ses familles. La 
seigneurie s'est elle-même démembrée en fiefs et en tenures roturieres. de divers genres, le fief pour fournir le service militaire et garantir la défense de la seigneurie et du territoire, la tenure roturiere jour garantir la production. Comme l'a expliqué Sumner Maine, les impòts et les rederances des fiefs el des rotures sont provenus, en partie, des anciennes redevances, des clans et des fimilles dans la tribu. La société féodale et le régime féolal n’ont été que la cristallisation, l'agencement des stigneuries. La tribu est un État, le clan un autre État, avec ses chefs, son gourernement, ses agents. La seigneurie a donc été elle aussi un État, d'autant plus réel et sérieux qu'elle a en pour fondement la terre, le sol, tandis que la tribu, le clan n’avaient que la tradition, l'habitude et l'espace.

XYlII. Sous le régime féodal, l'impôt, loin de disparaitre ou de s'amoindrir, s'est multiplié, diversifié aver une ingéniosité dont tous les fiscs ont, depuis lors, profité. Il a survécu à la longue anarchie qui a duré du $\mathrm{rl}^{\theta}$ au $\mathrm{Xl}^{\mathrm{e}}$ siècle, mais il a été approprié, totalement dans les Gaules, partiellement en Angleterre, en Allemagne, en Espagne, en Italie. En Italie, cette appropriation s'est faite au profit des grands propriétaires et des villes. En Angleterre, en Allemagne, en Espagne au profit du pouvoir rogal ou impérial et des grands propriétaires. Dans les Gaules seules, elle a eu lieu exclusivement en faveur des principaux propriétaires, les Seigneurs, et des principaux fonctionnaires, les Comtes. Par suite, les Gaules ont été le foyer de la véritable féodalité, représentée par le seigneur foncier, et le seigneur justicier, celui-ci au nom de la tradition romaine, celui-là au nom de la tradition foncière. se reliant elle-mème à l'ancien clan et à l'ancienne tribu. Cette appropriation, l'un des faits les plus importants de l'histoire de l'impòt, a eu une durée d'au moins 400 ans par ses résultats immédiats, et par ses prolonge- 
ments elle a correspondu a l'époque féodale. epoque tris importante dans l'histoire de la civilisation.

XIX. L’époque, quant aux Gaules, où se milent, fusionnent et sasseoient pour toujours, les diverses coulches de population, les diverses races. sélentaires ou nomades, provenant soit de l'afflux des migrations du Nord, soit des colonies ou migrations latines, suit du rieux fond des Celtes, Ibères et Ligures: l'époque, encore ou le sol est définitivement conquis sur les forèts, les marais, ou les populations, devenues tout á fait sédentaires, se répandent de tous cùtés, fondent villes, bourgs. villages, bàtissent les sauvetés. les prieurés, les monasteres, les églises, les cathélrales, élèvent les ponts. préparent tous les matériaux de la civilisation agricole, qui caractérise au plus haut point la France. Limpùt suit naturellement la production dans ses diverses ramifications. Puis, il söntroduit simultanément dans l"impòt un autre élément, qui n'est ni le don volontaire, ni le tribut, ni la quote-part coopérative ou mutuelle dans la dépense, mais la rederauce, le cens, représentant pour le serf, ou le colon, le droit à la proprieté conditionnelle du sol. Il suftit de jeter un coup d'œil sur l'histoire de la propriété foncière et de limpòt pour reconnaitre, pour peu quion ait conservé une certaine liberté d'esprit, que le cens a été la forme d'un progrès inappréciable pour les classes rurales, puisque, moyennant le paiement du cens, elles devenaient propriétaires du sol. Il était, il est vrai, perpétuel et non rachetable, conclition qui a eu de graves inconvénients; mais il avait de bien plus précieux avantages, en assurant la stabilité à une société presque nomade. Les feudistes de la monarchie absolue, suivis au pied de la lettre par les publicistes de la Révolution, nont rien saisi de tout cela. Ils ont considéré les barons féodaux comme des usurpateurs des droits sacrés du Roi. Ce sont eux qui ont répandu, sur 


\section{INFÉRIORITÉ DES CONDITIONS DE L'EUROPE ORIEXTALE.}

l'époque féodale, des erreurs qui subsistent encore. En tout cas, cette époque a été le moment historique où la race française, que Louis XIV devait amollir, corrompre et dégrader dans les entre-sols et les salons de V'ersailles, sest élevé le plus haut, ou linfluence durable de la France a été portée le plus loin, où elle a proluit, avec Philippe-Auguste, saint Louis, Iuguesclin, Charles $\mathrm{V}$, Richemont et Jeanne ditre, ses trpes supérieurs.

XX. En Angleterre el en Allemagne, les déments sociaux et ethniques neetaient pas les mèmes: aussi le régime féodal y a-t-il èté diffẻrent, moins brillant, moins original, surtout moins fiscal; la fiscalité féodale étant de source romaine. Il y a, par suite, correspondu à un déreloppement moins complet de la cirilisation, parce que, d'une part. lélément romain, latin, y faisait défaut, et parce que, d'autre part. le moment n’ètait pas encore renu, en . Ingleterre et en Allemagne, pour une extension aussi importante de la culture du sol quen France. Les matériaux manquaient.

XYl. Les conditions de l'Europe centrale de l'Elbe à la Vistule et orientale ont éte. durant tout le IIoyen âge, bien plus défarorables encore. Llans toute l'Allemagne orientale et les provinces danuljiennes, les tribus nomades ont longtemps prévalu. Il a fallu beaucoup de temps pour quelles derinssent demi-sédentaires. Aussi pendant tout le Moyen ìge nont-elles pu fournir l’impùt qu'en nature et bien sourent qu à titre de tribut. Elles nont pas été à mème, comme dans l'Europe occidentale, desélever à la propriété fonciere conditionnelle au moyen du cens, parce que le servage soit direct, soit sous forme de travail à corvée. est demeuré indispensable à la culture du sol, mème a la protection de la rie et à la subsistance des générations. Le serf troure dans son maitre un défenseur contre les famines et contre les invasions, de mème cue le clan ou la 
tribu procurent une garantie à leurs membres; aussi lorsque, dans l'Europe orientale, les populations ont commencé à abandonner la vie nomade et que la tribu et le clan se sont désagrégés, ont-ils été remplacés par des communautés, à l'origine, souvent serviles ou demi-serviles, le Mir en Russie, la Zurluga, la Joupanie, dans les provinces danubiennes. Elles offraient plus de sécurité d’abord à ceux qui en faisaient partie, puis à l'État et aux propriétaires lonciers, au triple point de vue du service militaire, du paiement de l'impòt et de la culture du sol.

XXII. Pendant le $\mathrm{xi}^{\mathrm{e}}$ et le $\mathrm{x} \mathrm{I}^{\mathrm{o}}$ siècles, l'Europe orientale avait réalisé quelques progrès provisoires en Russie, en Ilongrie, en Bulgarie, lorsque se précipita sur elle la dernière et la plus terrible des vagues des migrations du Nord, les Mongols qui, partis des frontières de la Chine, parvinrent jusqu'au Danube sans pouvoir dépasser la Vistule, courrant cet immense espace de leurs troupeaux, de leurs chariots et de leurs hordes. Ils rétablirent partout le tribut en nature et en argent; ils provoquèrent dans la condition économique de l'Europe orientale un recul effrayant, un appaurrissement affreux. La Russie, qui en a tant souffert, leur doit cependant, en partie, son unité. Ce sont les Mongols qui ont fondu tout ce qui pouvait se fondre dans les éléments si variés des populations russes; ce fut aussi les Mongols qui les ont rompues au paiement de l'impòt, au moyen du tribut.

XXIII. L'Europe orientale se relevait à peine de ce cyclone humain, qui se dissipa avec bien moins de rapidité qu'il n'était apparu, lorsque les Tures ottomans, mélange de nomades et de sédentaires, se présentèrent à leur tour et parvinrent jusqu’au Danube, sans le franchir. L'occupation ottomane, a été plus funeste que l'invasion des Mongols, parce qu'elle dure 
depuis plus de quatre siècles; mais elle est le dernier effort des peuples nomades ou demi-nomades contre la civilisation des peuples sédentaires. Le $\mathrm{xx}^{\mathbf{e}}$ siècle verra l'affranchissement complet de l'Europe, des impòts et des tributs levés par les Turcs, comme le terme de leurs coups de clairon et de leurs massacres.

Avec l'expulsion, la disparition des Mongols, le Moyen àge est clos. La civilisation des peuples sédentaires a irrévocablement pris le dessus. Elle déborde de toutes parts. Le groupe des anciens foyers civilisés ne se reconstituera pas, tel que Rome l'arait construit; il se rétablira sur d'autres bases, arec d'autres conditions; ce qu il $y$ arait de violent, doppressif, de comminatoire dans le régime fiscal romain, ainsi que Dioclétien et Constantin l'araient établi, condamné par le temps, ne reparaitra pas; le tribut militaire ne sera plus que, par exception, une forme de limpòt. Néanmoins, dautres problemes, sur lesquels les institutions fiscales d'A thènes ont jeté un certain jour, seront a ppelésà surgir et à donner un intérêt noureau aux questions concernant l'origine, la nature et les formes de limpôt dans les diverses cirilisations. 


\title{
LIVRE PREMIER.
}

\author{
DE L'TMPÔT
}

DANS LES ANCIENTES CITILISATIONS DORIENT: 



\section{AVANT-PROPOS.}

Les anciens Etats d'Orient, qui ont exercé une si grande influence sur la marche de la cirilisation et qui sont les témoins de la tradition fiscale de l'humanité, doivent ètre partagés en trois catégories distinctes. Les uns ont comptètement risparu, nous laissant des documents, plus ou moins imparfaits, sur leurs institutions. Dans cette première catégorie se classent tous les Etats des vaflies de l'Euphrate et du Tigre, de l'Asie Nlineure ot Carthage. Ce sont des Etats la plupart d'origine proprement sémitique. D'autres subsistent encore et ont conservé leur autonomie : la Chine, le Japon, la Perse. Lun de ces Etats, la Chine, par un fait extraordinaire, est à la fois le plus ancien des Etats du globe et le plus considérahie par sa population. La troisième catégorie comprend les Etats qui, comme l'Egypte et l'Inde, ne jouissent que d'une autonomie incomplète. L'examen de leurs systèmes fiscaux présente beaucoup d'importance, parce qu'its offrent le tableau, dans tous leurs détails, des mourements de transformation de l'impuit.

Les Etats, compris dans la seconde et dans la troisième catécories, ont un caractère commun, l'absence de toute liberté politique, de tout contrôle sur leur gouvernement, quïl soit autonome comme dans celle-là, subordonné comme dans celle-ci. Or, dans l'histoire de limpüt, surtout de ses transformations, linfluence des institutions libres est un facteur de premier ordre. La Grèce ancienne est un exemple hors de pair de cette importance. Gir peut-on suivre les chancements, les retlets de limpoit, dans les anciennes cirilisations, si ce n'est à Ithènes qui, de tous les Etats lıelléniques, a joui des institutions les plus tibres? Il en est de mème pour Rome. Tant que Rome a 
possédé un gouvernement libre, l'histoire de l'impôt y a présenté le plus grand intérêt. Tout change peu à peu avec l'Empire pour aboutir à la situation si complexe du $1 I^{e}$ et du ${ }^{2} v^{e}$ siècles, puis à la désorganisation complète des siècles suivants.

En outre, les peuples libres sont les seuls qui se soient élevés à la notion de l'histoire, les seuls, la Chine exceptée, qui aient laissé des nuvres historiques où les faits économiques sont reconnus, analysés, appréciés. Pour tous les autres peuples, il faut demander à leurs livres religieux, aux papyrus, aux briques, aux inscriptions, des renseignements difficiles à comprendre et surtout à interpréter. Témoins muets du passé, ils mettent à notre disposition des textes, des usages, des chiffres, mais ils ne permettent que très-rarement de reconnaitre, comme dans les discours de Démosthènes ou certaines pages de TiteLive et de Tacite, les reflets de l'impót par l'opinion mème des contemporains.

On peut se faire une idée de cette situation par ce qui se passe actuellement dans l'Inde. Ce n'est pas en vain que les classes supérieures de l'Inde, parvenues d'elles-mêmes à un certain degré de culture, ont été mises, depuis plus d'un siècle, en rapport avec la civilisation européenne, représentée par l'Angleterre. Un changement, lent mais réel, s'est opéré dans les esprits. Les IIindous se sont habitués à lire des journaux, à ouvrir des cercles, à tenir des réunions, à discuter sur leurs intérêts. Ils ne possèdent pas de contrôle direct, mais ils ont en main les moyens d'exercer un contrüle indirect. Déjà des congrès ont été réunis dans les grandes villes de l'Inde et dans ces congrès toutes les questions politiques, économiques, fiscales ont dù être abordées. Le système fiscal y a été soumis à des critiques, qui nous serviront souvent de guide, en traitant des problèmes de l'impôt dans l'Inde. 


\section{CHAPITRE I.}

\section{DE L'iMPôt DANS LES ÉtATS DEs VALLÉEs DE L'EUPHRATE}

ET DU TIGRE : CHALDÉE, ASSYRIE, BABYLONe.

Plusieurs grrands empires se sont succédé dans les vallées de l'Euphrate et du Tigrre pendant au moins $\dot{x} 0$ siècles, peut-ètre davantage. Les travaux les plus autorisés de l'archéologie reportent à plus de 5,000 , peut-être même 6,000 ans l'époque où a tleuri la première civilisation dans le delta de l'Euphrate. Ce delta, par la prodigieuse fertilité dont il jouirait encore s il y régnait a même sécurité que du temps des maitres de Ninive et de Babylone, fertilité supérieure mème à celle de la vallée du Yil et surtout moins incertaine, explique cette longue persistance de la civilisation (1).

Ces divers empires ont laissé soit en Chaldée, soit à Ninive, soit à Babylone des quantités de détritus, - une véritable montagne à Babylone, - briques, cylindres en métal, bijoux, pierres de toute sorte, recouverts de traits, de dessins, de figures dont le déchiffrement est l'une des gloires de la science de notre siècle. Il faut $\mathrm{y}$ joindre des inscriptions gigantesques entaillées sur d'énormes rochers. On a utilisé ces documents pour compléter les renseignements transmis par les historiens grecs, notamment par Hérodote, sur l'orçanisation fiscale de ces empires qui, sous bien des rapports, ont eu le même caractère. On peut ramener cette organisation aux traits suivants :

10 Chacun de ces empires a été conquérant et militaire, comme l'empire perse ou l'empire ottoman. Il se composait d'un

(1) sclon Hérodote, le blé y rendait 200 pour 1. Les voyageur- modernes, Lorl Loftus, M. Riboire, le consul auéricain de Bassorah (1א94), estiment que la fertilité serait encore la mêne. - Maspero, Histoire ancienne de l'orient. 1). I38. 
peuple dominant qui, sans se les assimiler complètement, régissait par la force et une administration vigilante, les États ou peuples vaincus ou vassaux.

$2^{\circ}$ Les États vaincus ou vassaux devaient paver dabord le tribut en nature ou en argent - on n'en connait pas la quotité, - comme marque de leur subordination, ensuite la díme, comme concours au maintien de l'empire auquel ils appartenaient; morennant l'acquit de ces charges, ces peuples conservaient une assez grande autonomie (1).

$3^{\circ}$ Néanmoins, le paiement de ce tribut et de la dime se faisait arec difficultés; il était la cause de guerres incessantes, suivies de la dépossession et du déplacement des populations révoltées, rarement de leur servitude, plus rarement de leur massacre. Telle a été deux fois la condition d'Israil , une première fois arec l'empire de Babylone, une seconde aree Rome. Babylone se montra moins cruelle que Iiome.

C'est que le tribut, en nature ou en argent, quand il est élevé, est une charge redoutable pour les populations, mème sans tenir compte de l'infériorité dont il les marque. S'il est accompagné d'une dime, il devient plus accablant encore. Dans les deux cas il appaurrit irrémédiablement les payss tributaires, de la mème façon que l'absentéisme des propriétaires anglais a longtemps dévasté l'Irlande, que les charges de l'occupation romaine ont soulevé l'Egyte et que l'Angleterre humanitaire exploite l'Inde. Le tribut séculaire est l'une des causes de la désolation actuelle de l'Asie Mineure, surtout de la Mésopotamie. Les populations, condamnées, pendant de longrs siècles, à paver le tribut à des peuples étrangers, sont destinées à un appaurrissement fatal, car le tribut devient une exportation de richesse sans retour.

$\dot{4}^{\circ}$ La population dominante n’échappait pas elle-mème à l'impìt qui était essentiellement foncier dans des vallées où le sol rendait en moyeune 200 pour 1 . Cet impòt était perçu d'après un cadastre tenu, avec soin, au courant des mutations. Il servait

(1) " Laus ma 111e campagne. dit sennachérib dans une inscription, je marchai vers la syrie; j’instituai Ethbaal sur le tróne de la rosauté et je lui imposai le tribut et la dime de la suzeraineté ". - Lenormaut, Manuel d'histoire ancienne, 2* vol., 1669. 1. 99. 
de contrơle à l'état de possession des terres et de base à la répartition des impits (1).

$\breve{\partial}^{0}$ A limpùt foncier venait se joindre le don volontaire. Le don est la forme la plus antique de l'impìt. Il était à la fois l'hommage dù au souverain et le libre concours du sujet à ses dépenses et à celles de l'Etat. La tradition du don a persisté, comme coutume de bienséance et d'hommage, mème lorsqu'il eut été remplacé par d'autres impùts. Il existe encore de nombreux documents, dans les diverses civilisations de la Chine, l'Inde, l'Egypte où la scène de la remise du don volontaire, en dehors de toute obligation de tribut, est représentée. En Judée, les deux dimes nempèchaient pas le don. Le temple de Jérusalem et son célèbre trésor ont toujours été entretenus par les dons, qui étaient dus aux trois fètes principales, à titre religieux.

D’après Hérodote, Darius, fils d'Hysstaspés, aurait le premier, dans le raste empire des anciens Perses, transformé le don rolontaire en une capitation par tète, exigrible partie en nature et partie en argent, ce qui lıi donnait le caractère d'un tribut. Le don volontaire sest maintenu distinct de la capitation. Il compte encore parmi les ressources de tous les sourerains orientaux et de tous les rois africains $(2)$. On le rencontre mème dans la plupart des budgets européens et il ne serait pas difficile d'en trouver quelques vestiges dans les budgets de la France.

Telles ont été les premières formes de l'impùt : le don volontaire, devenu la capitation, l'imput foncier d'après un cadastre, ou la dime pour les sujets directs, le tribut et la dime pour les Etats vassaux. Avec le temps, le tribut se convertit égralement en une capitation.

Sur l'assiette et le taux de ces divers impòts les renseignements manquent. Après le don volontaire, converti en capitation, la dime a été le plus universellement pratiqué de ces impûts. En Egypte, la dime a mème été, du moins dans les temps

(1) Il a existé un eadastre daus l'ancienne chalde qui permettait d'établir l'impót sur une assiette solide et d'en ealculer le reudement (Ma-jero, Égypte et Chaldie, $1895, \mathrm{p}$. 761 ).

(2) A Madagascar, le don ou hasina, d'abord volontaire. puis obligatoire, est une des formes principales de l'impit. 
anciens, la forme de l'impòt foncier. Les Israélites ont dù l'emprunter à l'Egypte. La dime se rencontre dans l'Inde, dans toute l'A sie Mineure, en Italie, en Sicile. Elle existe encore en Turquie, en Angleterre, au Canada, en Chine. M. James Caird, le savant agronome anglais, a soutenu l'opinion que le rétablissement de la dime en nature serait un bienfait pour l'Inde. Pendant tout le xrmi siècle, sous l'influence de Vauban, il a existé en France un courant d'opinion en faveur de la dime en nature. Nous aurons occasion de revenir sur les discussions que ce courant a provoquées et qui se sont prolongres, mème après les réformes de l'Assemblée constituante.

Nous saisissons ici sur le vif la trame de la tradition de l'histoire et les raisons des transformations de l'impôt. Dans des temps prospères, comme l'époque de Darius, les peuples peuvent donner la préférence à un impôt foncier en argent, levé daprès un cadastre; au contraire, dans des temps calamiteux, comme les derniers siècles de l'empire romain, ils ont trouvé un grand soulagement dans la dime en nature sur le produit brut.

De grands bouleversements ont eu lieu dans la zone territoriale de l'Asie où ont récu ces grañds empires de Chaldée, d'Assyrie et de Babýlone. Rome a occupé longtemps la même zone; néanmoins l'organisation de l'impòt y est restée presque immuable. C'est mème Rome qui a emprunté à l'Asie Mineure les deux dernières formes de limpòt dans l'empire romain : la cupitatio terrena, qui correspondait à l'impòt foncier avec cadastre et la capitutio humana qui correspondait au tribut et à la capitation. L'une et l'autre ont été acceptées par les Arabes et appliquées de Bagdad à Cordoue, mais elles n'ont pu remplacer la dime qui a reparu et qui existe encore. La dime chrétienne n'a été qu'une importation des coutumes religieuses de la Judée et des traditions fiscales de toute l'Asie.

Biblographie. - Hérodote, traduction Rawlinson et les notes. Rawlinson, The fivegreat monarchies. - Maspero, Histoire ancienne de lorierit. - Lenormant, Manuel d'Histoire ancienne. - Sayce, Babylonia. - G. Smith, Assyria. - Maspero, Égypte et Chaldée, 1895, p. 761 . - Le livre principal à consulter est Rawlinson, The five great monarchies. 


\section{CHA PITRE II.}

DE L'IMPÓT CHEZ LES PHÉxICIENS ET A CARTHAgE.

L'histoire de la cirilisation des peuples méditerranéens a beaucoup perdu à la destruction complète de Tyr, de Carthage et de Jèrusalem. Les Juifs ont pu sauver la Bıble à srand'peine; mais tout a peri à $\mathrm{T} y r$ et a Carthage; or les Phéniciens et les Carthaginois ont été les trrands financiers de la civilisation orientale, en mème temps que ses meilleurs navigateurs et ses meilleurs agronomes. Héritiers directs des traditions de la Chaldée et de l'Assyrie, de Ninive et de Babylone, leur disparition a laissé un grand vide. Nul doute qu’il ne faille leur attribuer une notable partie des progrès que les Juifs et les Arabes ont fait faire aux sciences économiques.

On ne sait rien du système dimpòt de Tỹr, quoique les Phéniciens aient dominé tout le bassin de la Méditerranée pendant plus de dix siècles.

Aristote a écrit un chapitre fort curieux (1) sur les institutions de Carthage; mais il n’a donné aucun détail sur les impòts. On sait toutefois qu'elle exercait sur ses colonies une domination très-dure, de mème qu'Athènes; elle pratiquait le système mercantile de mème que Venise, l'Espagne, la Hollande et tous les peuples européens jusqu'au xix siècle. "Elle les condamnait à "fermer leurs ports aux marchandises étrangìres et à renir " chercher rlans ceux de Carthage les produits des contrées loin" taines $(\boldsymbol{2})$ ". Elle en exigeait rigoureusement des tributs trèslourds (3). Il résulte de l’ensemble des témoignages des historiens

(1) Politique, liv. 2. chap. 8.

(2) Lenormant, Hanuel "Histoire ancienne, 3e vol., 322.

(3) Les colons. con-iderés comme des fermiers de l'Etat, étaient tenus à des 
anciens qu'en dehors de ces tributs, dus également frar les alliés et les sujets, des droits de douane et de port, il ny arait pas d’impòts intérieurs à Carthage, surtout d’impit foncier.

$\mathrm{La}$ race sémitique, particulièrement le rameau chananéen, parait aroir été tout ¿̀ fait réfractaire à l'impit: au contraire, elle s'est toujours montrée, sauf Isräl, profondément esclavagiste. Elle a toujours pratiqué la traite et la piraterie sur la plus vaste échelle. Phéniciens, Carthaginois ont précédé les Barbaresques comme écumeurs de mer et comme corsaires. Ils exerçaient mème, comme les Grecs, comme les Sarrasins, la piraterie sur terre, enlerant toutes les personnes qui habitaient les cites pour les vendre sur tous les marchés.

Lagriculture carthaginoise se faisait par vastes domaines au moyen darmées desclares; certains domaines en comptaient jusqu’à 20.000 1). Dans les Etats eselavagistes, l’impöt se trouve sans répercussion possible sur le maitre; par suite, le maitre restreint l'impit au minimum. Il en a été à cet égard, à Rome, à Athènes, comme à Carthage. Plus s'est élendu l'esclarage, plus l'imprit est derenu onéreus, plus on a roulu le limiter.

Dans l'etude des preuples anciens, il importe de ne pas perdre de rue la composition de la société : l"esclarage modifiait tout. Il en était ainsi pour l"imput; de là, notamment, l’institution des repas en commun. Le repas en commun arait pour objet de maintenir une certaine égalité entre les maitres; souvent il était un mode de lever et de répartir limpìt, comme nous allons le montrer à propos des Doriens et de Lacédémone.

Bibliographit. - Les manuels de Maspero et de Lemormant. Aristote, Pulitinu, lir. 2, ch. 8. - Mürers, Phèrizische alterthum. - Rawlinson, Mistory of Phericia, 1889.

lederances en nature ifui jomvient representer la moitie lu prodnit brut. Les

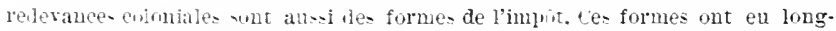
tempo la preference des penples eurnpens: elles ont ete la base de leur sytime

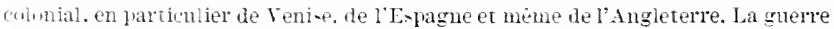

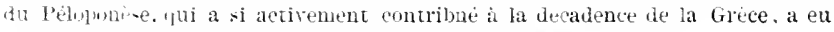

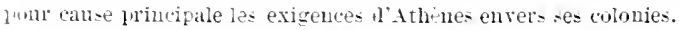

(1) Lommsen, Histore iomaine, 3 volume et clrapitre 1. 


\title{
CHAPITRE III.
}

\author{
DE L'IMPÓT CHEZ LES HÉBREUX ET EN JUDÉE.
}

Les institutions hébraïques présentent un caractère tellement particulier que des doutes sur leur application ont pu etre maintenus. It faut toutefois reconnaitre que les traraux récents sur les institutions de Sparte, mime sur celles d'Athènes, ont montré que les institutions des félureux n’étaient pas plus singulières que celles des Spartiates ( 1 et des Athiniens.

$1^{\circ}$ Les Hébreux riont pas eu de monnaie fruppée et les Juifs n'en ort connu et accepté que fort tard; 20 de Moïse à David lorganisation politique des llébreus a été toute républicaine et théocratique. Après son institution, le pouroir royal a toujours rencontré des barrières infranchissables; $3^{\circ}$ le gouvernement, puis les rois deraient trouver dans les terres du domaine des ressources suffisantes; pas d’impots, si ce n’est, plus tard, une prart des dimes; $4^{\circ}$ durant toute leur vie nationale, Hébreux et Juifs se sont montrés réfractaires à l'impùt. Les impoits etablis frar Salomon, aggrarés par Roboam ont été l'une des causes de la séparation des tribus et de la dispersion d'Israiel; $0^{\circ}$ jamais les Juifs nont consenti à accepter le tribut romain.

Ce qu’ils refusaient au grouvernement, surtout à l'étranger, Hébreux et Juifs l’accorlaient volontiers à la relizrion; 60 en outre des $\mathbf{4} 8$ villes, avec chacune un territoire, affecté à leur entretien, les Lérites ont droit à la dixième partie du produit brut des terres : c'est la véritable dime. Elle est d'origrine égyptienne, peutètre mésopotamienne. Elle a deux raisons, l'absence de métaux

(1) Les rigle- des E-céniens, qui ont en banconp d'inftuence sur le christia-

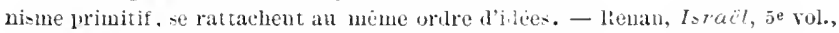
58. - Ce sont les debuts de la vie monacale en burnge. 
précieux, l'extrème fertilité des vallées du Nil et de l'Euphrate. Tous les trois ans, il est rù une seconde dime qui doit être partagée avec les pauvres. Après la captivité, les dimes furent levées par les prètres qui faisaient la part aux lévites; 7o à ces dimes, il faut ajouter les dons rolontaires. Chaque année, tout israélite majeur devait aux prètres du temple de Jérusalem le demi-sicle pour le prix du rachat devant l'Eternel. Le grand prètre mème acquittait cet impòt. Il était dù, en outre, des fournitures en nature assez importantes. Telle était l'organisation de limput. Cette organisation a suffi à procurer à Isrä̈l une influence réelle, puis une indépendance conditionnelle, c'est-àdire à charge du tribut, lorsqu'Isrä̈l fut nécessairement englobé dans les empires d'Assyrie, de Babylone et des Perses. Israël s'habitua difficilement à acquitter le tribut aux souverains d'Asie, plus difficilement aux Grecs, jamais aux Romains.

L’impòt direct, payé à l'étrantrer, surtout l'impôt romain qui atteignait tout, la personne, la femme, les enfants, les esclaves, les terres, les créances, bouleversait la constitution d'Israël. Isrä̈l arait strictement limité la part que le gouvernement pouvait prélever sur le revenu social. L“impopularité des demiers princes de la lamille Asmonéenne provint de leur avidité fiscale (1). Les Hérodes, les Antipas, comme tous les rois qui s'étaient accommodés à la domination romaine, avaient dù se réduire à la fonction de collecteurs dimpòts. Le moment rint où Fome ne voulut mème plus d'intermédiaires : changement préparé par Auguste, accompli par Tibère. La Judée devint une province romaine, gouvernée par un de ces procurators dont Cicéron nous a tracé le modèle (2). Les publicains s'emparèrent de la Judée. Selon l'Evangile, Ie Christ convertit le publicain saint Mathieu dans son bureau de perception.

Les deux dimes et les dons roluntaires, les 48 villes des lévites étaient de lourdes charges. Reynier en a évalué le mon-

(1) Heirode alla juscüit seconer les morts pour faire tomber l'or et l'argent quion purvait aroir eachés dans lemr linceul. - Renan . ibid., 251.

(2) Le proconsul Gabinius : haurire cotidie ex opulentissimis syrie gazis innumerabile ponlus auri, ut eorum veteres illibatas que divitias in profundissimum libidinuın suarum gurgitem profundat. - M. Renan, ibid., 191. 
tant au quart de la production brute. Toutefois, ils ne servaient pas seulement à l'entretien du culte dans lequel se perpétuait lidée de sa mission dont nul peuple n'a été aussi profondément pénétré qu'Isrä̈l; ils servaient également à l'éducation du peuple; car le lévite était à la fois le prètre, l'instituteur, le savant; le temple de Jérusalem, de mème que la grande mosquée du Caire, constituait le centre religieux et scientifique de la nation. Ces impôts, sauf, plus tard, la part royale, étaient attribués à des membres de la nation, exemptés de lout travail, et n'exerçant, sur le revenu social, aucun autre prélèvement. Ils n’amoinurissaient pas la richesse nationale; combien le tribut était différent! Fixé arbitrairement par un maitre étranger, fort loin, sans garantie et sans contrôle, levé par des étrangers qui en tiraient eux-mêmes un grand profit, il était tout entier exporté (1). Il n'en restait rien pour la nation, à la fois opprimée et appauvrie. Isrä̈l s'était bien lentement courbé devant cette nécessité, lorsque limpòt restait au moins en Asie. Juda se refusa absolument à s'appaurrir pour enrichir Rome. De là l'importance de la scène du denier dans l'Evangile. Jésus, avec tous les Juifs modérés et prévoyants, conseille aux Juifs de céder à la nécessité, de rendre à César ce qui est à César et dattendre de meilleurs jours. Il leur en apporte l'espérance. Les Juifs préférèrent résister. "Il y eut pour chaque personne, dit M. Ledrain, la " capitation (tributum copitis), mème pour les femmes et les " esclaves. L'impòt foncier (tributum agri) dut se payer en na" ture et le laboureur fut soumis à la charge de livrer une partie " de ses blés, de son huile (unnona)... Quand Quirinus donna "l'ordre que chacun indiquat ses terres, ses biens, les membres " de sa famille, Jehan le gaulonite et Zaddoq exhortèrent le " peuple à la résistance. L’Etat ne devait ètre qu une république " avec Dieu pour chef. Les Juifs poussèrent la haine de l'oppres"sion jusqu’à sa dernière limite, méprisant les tortures et la "mort $(2)$. "

(1) Plus de 10,000 talents furent payés en peu de temps. - Renan, Israël, $5^{*}$ vol., 155. - Le talent d'argent valant $5,500 \mathrm{r.,} \mathrm{cétaient} 55$ millions d'exportés. - Ledrain, Histoire disraël, 2 rol.. 353.

(2) L'iupót et le cens parurent aux Juifs des chose- insupiortables. - lienan, ibidem, 312 . 
Le peuple juif n'a eu en réalité qu'une notion imparfaite de l'impoit. Cette imperfection doit ètre attribuée partie à son caractère propre, partie aux révolutions quill a subies. Avant la captivité de Babylone. Isrä̈l formait une nation agricole, prospère et heureuse. On évalue que la population de la Palestine alors a pu s'élever à ä millions d'habitants. C'est l'époque où les deux dimes se levaient avec le plus de récularité; c'est aussi l'époque de l'année sabbatique et de lannée jubilaire, institutions si caractéristiques du vieil Isrä̈l. Pendant la septième année, qui stait l'année sabbatique, le travail était suspendu, la terre se reposait; les produits qu'elle donnait sans culture devaient être partagés entre les serviteurs et les étrangers. Lannée jubilaire, ou la septième année sabbatique, entrainait des changements d'un autre ordre. Les dettes étaient remises; les esclaves recouvraient la liherté; les vendeurs rentraient en possession des héritagres aliénés. Les deux années sabbatique et jubilaire avaient en rue une sorte de retour ì l'état supposé d'égalité primordiale. Elles correspondaient à d'autres tendances ou prescriptions de létat israélite; la gratuité du prèt entre Israélites (1), lassistance obligatoire du paurre, la mutualité attestée par les repas en commun, la limitation et le contrile re l'esclavage, l'interdiction de la serviturle de la femme, I’hospitalité envers l'étranger, la douceur pour les animaux. Ces institutions si curieuses n’ont pas empèché la Palestine de devenir un paýs riche, prospère, heureux, et de le rester longtemps, grìce au travail et aux vertus d'Israël, qui a réalisé l'idéal de ses prophètes. $E t$ folium ejus non lefuet, et omniu querumque faciet prosperatuntur. Et à certains égards, cette prospérité dure encore, ainsi que les vertus qui en sont le fondement $(\boldsymbol{2})$.

(1) 'ani habitabit in tabernaculo tuo' - Yerset 6: 'Qui pecuniam suam won dedit nd usurum et munera super innotentem non recepit; qui inIrelitur sine macula et operatur Justitium... le Procurateur Pontius lilatus répourla à Jésus : Qu'est-ce que la Justice? - Psaume 14, comparer le paume 1; ces deux psaumes onvraient des alercus entitrement diffirents des actesde Gahinius et de Verrít. Ilsfont partie des documents supérieurs de l'histoive de la civilisation.

(D) La charité la plus entiere itait prescrite envers les étrangers, contrairement 
Isrä̈l a, par suite, formé le foyer d'une très-haute civilisation ; c’est bien le précurseur du Christianisme. L'éducation, la cirilisation de l'humanité s'est faite cràce à des foyers, tels que le foger d'Isräl; leur destinée n'était pas de se perpétuer, mais de propager les forces qui s'y ritaient agglomérées. La captiviti de Babylone marque une première dispersion. D'asriculteurs, les Israélites deviennent commerçants, banquiers, changeurs, trafiquants. M. Munk soutient que, mème après la captivité, ils maintinrent leurs vieilles et si intéressantes institutions, mais leur notion de limpot s'oblitéra aussi plus profondément. Ils attachèrent moins dimportance à la culture de la terre; ils šéloignèrent des biens fonciers qui exposent rlavantagre l'homme aux exactions en étalant sa richesse; ils donnèrent la prélérence aux marchandises, aux capitaux mobiliers que l'impot atteint plus difficilement (1). En France, mème après 1789, l’impit a surtout frappé les biens immoliliers. Et avant 1789 , l'une des plus célèbres doctrines économiques n'enseirnait-elle pas que seule la terre devait l'impit?

La dispersion d'Isrä̈l ne doit pas ètre attribuée à une seule cause. Religieuse, nationale, politique, elle a encore son caractère économique, son caractère fiscal (2). Jérémie exprimait admirablement la plainte de Juda en disant : Princeps prorinciarum facta est sub tributo. Mais Isräl s’est révolté. II y a mieux : le peuple qui pratiquait l'année sabbatique, l'année jubilaire, les

aux mours de tous les penples antiques. L "Atranger avait part aux limes : ilavit le droit de glaner, "Voilia qui nous sejpare du vieux quirite, ruent letranger" L'ennemi , Hostis. y

(1) On a contesté, non pas la réalité légale de ces jrescriptions (les textes smt trop formels, Lévitique, ch. 25), mais le fonctionnement reld des in-titution- yui

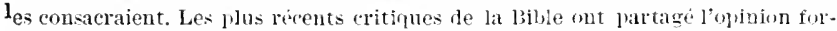

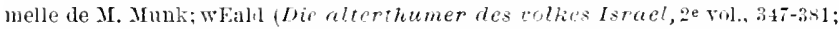
Eneyclopédie des sciences religieuses, t. 11, 3ts-69). Voici ce quen dit $M$. Renan (Israel, 5 wol., 35). "On olsservait tont sans distinctin, meme les utopies, les articles les moins rationnels, l'année sabbrtidue, l'année fubilaire qui, dans certaines cireonstances, causèent le grants embarras. " - If. de rauley (Sept siccles de lkistrire judä̈que, p. 2001), en cite un exenlle decisif bor-

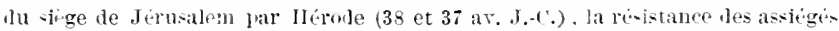
se prolongea malere ba famine dont ils sonffraient parce qu'un étuit dans une annce sabbatifue.

(2) Sur la dispersion on Dia-pora, - Renan, ibid., 5" vol, chap. It. 
repas en commun, le prêt gratuit et l'assistance, mème envers l'étranger, ce peuple est resté rebelle à l'impùt. Il l'est encore. Pas de contribuables moins faciles que les Juifs. Et si quelque chose a pu le consoler de perdre sa patrie, d'abandonner Jérusalem, de pleurer sur Sion, de se disperser de toutes parts sur le globe, ça été de ne pas acquitter le denier de César. Aussi les Romains ne se sont jamais mépris sur l'importance et la signification de la résistance des Juifs. Ils la réprimèrent sans pitié. lls détruisirent Jérusalem. Ils rendirent les Juifs dans les marchés. Vespasien fit frapper tout exprès une monnaie avec la légende Judea capta. Llais du foyer juif devaient naitre deux religions qui ont été les deux grands instruments de destruction, l'un au nord, l'autre au midi du monde romain. Juda traita avec l'Assyrie et les Perses, mème avec les Grecs. Les Grecs avaient aussi mis la main sur tous les impits. Ils traitèrent moyennant 300 talents par an $(1,630,000$ fr. $) .11$ n'y eut jamais de forfait avec les Romains. lls étaient inexorables, au surplus. Nos juristes et nos littérateurs nous ont façonné des Romains de mise en scène. Il faut s'en tenir encore, après tant de travaux, à ceux qui ont été mis sur toile par Hontesquieu (1).

Bibliogr.1Pine. - Les manzels Lenormant et Maspero. - Reynier. Economie politique des Juifs. - Renan, Histoire d'lsraël. - Munk, La Palestine dans la collection l'Lizire's. - Salrador, Histoire des institutions de Mö̈se. - Ledrain, Traduction de la Bible avec coinmentaires et II istoire d'Israël, 2 rol.

(1) Ils faisaient à leurs eunemis des maux inconcevables. Ils parlaient toujours en maitre. - Grandeur et décadence, chap. VI. 


\section{CHA PITRE IV.}

DE L'IMPÓT DANS L'EMPIRE DES PERSES.

L'empire des Perses a eu beaucoup plus d'étendue et d'importance que les empires Mésopotamiens de Chaldée, d'Assyrie et de Babylone. Comme il leur est très-postérieur, on possède, gràce surtout à Hérodote et à Strabon, plus de détails et des détails plus précis en ce qui concerne ses ressources et son organisation fiscale. Le fait qui caractérise cette organisation, c'est l'obligation, de plus en plus rigoureuse, de payer en métaux précieux, or ou argent, la eapitation qui est, peu à peu. exigée au lieu et place du don volontaire.

Déjà le tribut des peuples vassaux devait, en partie, ètre ainsi acquitté. Les métaux précieux étaient devenus plus abondants; le paiement en or ou en argent fut imposé à tous les sujets du Grand Roi, sauf les Perses mêmes quiétaient exempts d'impôt. à l'exception des prestations telles que le gite. Ce fait d'exemption est à retenir parce qu'il est de haute importance dans l'histoire de l'impôt. Il a joué un ròle de premier ordre à Rome, sous la République et sous l'Empire, pendant toute la période féodale, mème durant l'ère monarchique de l'Europe; nous le retrouverons dans les Etats musulmans et dans l'Inde. C'est un fait qui a un caractère universel. L'impöt n'est pas considéré comme un devoir, mais comme une sorte de sujétion. Le vainqueur l'impose au vaincu qui le paie à sa place. Longtemps l'homme supérieur, le prètre en sera exempté, puis le guerrier, puis le haut fonctionnaire; plus tard le seigneur, le grand propriétaire.

L'empire des Perses, comme ceux de Babylone et d'Assyrie, était partagé en grandes satrapies : il en comptait dix-neuf. Chaque satrapie avait un forfait financier avec le Grand Roi. Elle devait fournir, d’après les réformes de Darius, fils d'Hystaspès, 
une certaine quantité d'argent et une certaine quantité de produits en nature, représentant la dime, la capitation et l'impoit foncier, levé d'après un cadastre des biens et des personnes; peut-ètre mème faut-il y comprendre des droits à l'importation des marchandises, des taxes d'octroi et de circulation dans les villes; Grote a éralué à 100 millions de franes le montant du tribut en argent que deraient payer les satrapies, le don volontaire en nature restant à part. Ainsi les Perses taxèrent Babylone, qui était une province plutít qu'une ville, à $5,300,000 \mathrm{fr}$. par an en numéraire et à des fournitures en nature évaluées à 40 talents ou $220,000 \mathrm{fr}$. par jour, soit $80,300,000 \mathrm{fr} .,-$ total $85,800,000 \mathrm{fr}$. par an. Ces chiffres, acceptés par Movers, doirent ètre exagérés. Toutefois, les ressources de Babylone étaient considérables, puisque, sous les Perses, le gourerneur de Babylone en tirait pour lui seul, 2 millions de fr., par an.

II. Rawlinson estime que la population de l'empire des Perses s'élevait à 50 millions d’habitants et que les impots, foncier et dime, devaient représenter $3,500,000 \mathrm{t}$ en argent et $2,300,000 \mathrm{t}$ en nature, soit 150 millions fr., dont moitié payable en nature. Il évalue que ces 150 millions fr. pouvaient équiraloir à la dime de tous les revenus; prorata par tète $3 \mathrm{fr}$.; mais que représentait cette dime? Il pense qu'elle correspondait à une moyenne entre le dixième et le vingtième du revenu. D'après cela le revenu brut de l'Empire pourrait ètre porté à 2 milliards de fr., soit $40 \mathrm{fr}$. par tète, movenne de la dime, le quinzième du revenu (1).

Après ces taxes, renaient celles affectées aux dépenses des satrapies, sur lesquelles les renseignements manquent; on sait seulement par les historiens grecs que les satrapes ne valaient pas mieux que les pachas ottomans du siècle dernier et que certains de notre siècle. Ils ressemblaient la plupart à Pharnabaze et Tissapherne. L'auteur du livre de Daniel fait allusion à leurs excès et aux inspecteurs chargés de les surveiller $(\boldsymbol{2})$.

(1) Grote ne donne à l'empire des Perses que 40 millions d'habitants, mais il eleve le revenu du Grand foi a 250 millions fr. - History of Greece, toma $3^{*}$, 201 .

(2) La convocation des satrapes devant Xibuchodonosor, et leur comparution, 
Toutefois, la formation de l'empire des Parthes et du second empire des Perses, la résistance qu ïls ont opposée aux Romains, attestent limportance des ressources des prorinces, aujourd'ıui presque épuisées et malheureuses, qui, au deli de l'Asie Mineure, étaient les éléments essentiels de ces deux empires.

Sous les Sassanides, le système d'impùt de la Perse fut ré-

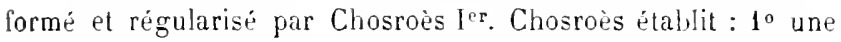
sorte de capitation srénérale sur les ressources du contribuable, payable en trois prarties et graduée, exactement comme la capitation de Louis XIV et la classenstever de Prusse ; $2^{\circ}$ un imput foncier exigible partie en nature, partie en artrent, selon l"importance de la récolte et la nature du sol, d'après un cadastre reviș de temps en temps. Ces impöts provenaient de ceux de l'Assyrie, de la Chaldée et de l'ancienne Perse. Ils existent encore dans la Perse actuelle, l'empire ottoman oì nous les retrourerons. Ils ont les plus intimes rapports avec les institutions fiscales de Dioclétien. La Perse est l'un des plus anciens États du globe. Elle a pu perdre et recourrer son autonomie. Nous aurons à nous occuper encore d'elle à propos des Etats orientaux contemporains. Mais elle est le type des freuples en complete décadence. L'organisation actuelle de la Chine a les plus grands rapports, en ce qui est des impùts, arec celle de l'empire r'es Perses.

Bublographie. Rawlinson, The fice great inonarchies, tome 4, chap. vil. - Hérodote, traduction Rawlinson. - Comparer les notes recueillies par Boulancer, Impots du peuple romain 1612, traduit par M. E. Renaudin, 18it, Paris, pare 6.

la colive du framl lioi et la nomination de Daniel comme contribletr général constituent une scrue le- llu-curieu-es de ce roman historique et religiens; - a-

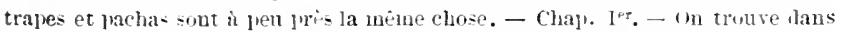
la cyrolédie, livre $\mathrm{Vm}$, chalp. vir, des détails intére-sants snr la décadence le la Perse même. 


\section{CHAPITRE V. \\ DE L'IMPÓT DANS L'ÉGYPTE ANCIENNE.}

L'Egypte appartient à la catégorie des peuples qui, sans conserver leur autonomie, ont néanmoins résisté à l'usure du temps. Elle doit cet avantage au Nil et aux quatités de sa population, de même que sa situation géographique est la, cause de ses épreuves. L'Egypte, en outre, présente un exemple des plus frappants de la transformation de l'impôt et de son adaptation aux diverses phases d'une longue civilisation. L'organisation fiscale de l'Egypte a exercé une très-notable influence sur celle de l'Empire romain et par suite sur les systèmes fiscaux des Etats de l'Europe moderne. Son histoire fiscale est du plus haut intérèt. Ce qui n'est pas moins remarquable, c'est la lutte acharnée de l'Egypte conire les Romains, la délivrance qu'elle invoque et qu'elle obtient des Arabes, sa chute presque irrémédiable arec les Turcs et son relèvement en ce siècle.

Après avoir opposé aux Romains une résistance insurmontable, fondée sur une exploitation sans merci, l'Egypte a joui d'une grande prospérité sous les Arabes. Son système d'impôt a dù s’approprier à la civilisation arabe. Au contraire, l'Egypte a beaucoup souffert sous la domination des Tures qui l'ont exploitée à l'instar des Romains et plus durement. Néanmoins, elle a pu résister à eette terrible crise. Elle n’a jamais été plus peuplée, peut-être plus prospère que dans la seconde partie du $\mathrm{xIx}^{\mathrm{e}}$ siècle, nouvelle adaptation de ses impùts à sa condition présente (1).

Bien qu'il soit devenu probable que la civilisation de l'Egypte

(I) Sur la force de résistance de la civilisation égyptienne, consulter un rapport de M. Mariette (Académie des inseriptions, Journal officiel, 1878, nos 282 et 290). 
doire ètre rattachée à un foỵer primordial plus ancien, dans le delta de l'Euphrate, d'où seraient éçalement parties les premières migrations qui ont mis en culture la riche vallée du Hoang-Hi, en Chine, cette cirilisation remonte néanmoins à $\because 0,600$ ans, peut-ètre 6.000 ans arant lëre chrétienne 1 . Ce vaste esprace de temps peut itre divisé en deus époques : la première correspond à l'ancien et au mosen empire, la seconde au nourel empire et aux conquètes des Perses, des IIacédoniens, des Romains jusqu'a l'invasion des Arabes. L'une et l'autre comprosent le cycle de l'Éggpte ancienne.

\section{S1. Premitres cirilisutions de lEyglpte.}

Ancien et Hoyen empire.

Cette première période, qui se prolonge pendant plus de :3,000, peut-ètre 4,000 ans, est caractérisée par une stabilité extraordinaire, plus crande que celle dont a joui la Cline depuis ses 40 siècles historiques. Les idies, les mours, les traditions demeurent immuables. Aucune autre cirilisation n'a eu une semblable puissance.

Cest la période que .11. Haspero comprend par les origines dans son beau livre. - Histoire ancienne des peuples de lorient clussiques 2, bien qu"il contienne des détails fort curieux et noureaux sur toute l'histoire de l'Esypte. Les ropulations primitives de l'Égrpte se sont établies dans le Delta et ont peu à peu remonté vers le Xord 3. Lour ceurre principale et almirable a éte l'utilisation du Nil, la création et l'entretien des canaux, a ungyen desquels des sables infertiles donnent jusqu'à trois récoltes. Ces populations se sont rouées, depuis des milliers de siècies, à ce labeur, condition d'existence de l'Égypte. Elles virent résignées et satisfaites. La corrée, ou travail périodique oblig̨atoire, a éte, elle est encore le seut moyen de maintenir liwure des siecles. Elles la subissent sans murmure. Dans cette uurre, elles ont ite

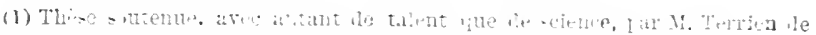

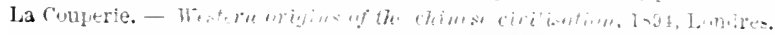

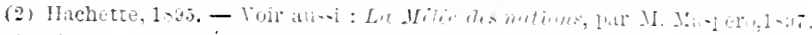

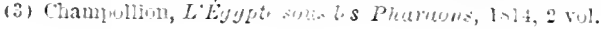


dirigées par des chefs dits Ropaitou, qui ont exercé la fonction des seigneurs féodaux en Europe; ce sont les pasteurs, les patriarches, les seigneurs; ils ont fait l'Egypte comme ils ont fait la France et l'Angleterre, mais la France surtout. Ce sont les princes des nòmes, ces grands domaines primitifs de l'Égypte, subdivisés depuis pour mille causes, comme les grandes seigneuries francaises, zomme le seront les immenses haciendas du Mexique et du Pérou. M. Maspero les appelle les premières principautés. Sur ces terres, les habitants sont à la fois cultivateurs et industriels. Ils moissonnent le blé, ils tissent les ètoffes, de mème qu'aujourd'hui; ils élèvent beaucoup de bétail; ils expérimentent les végétaux; ils pèsent les métaux, l'or et l'argent déjà les plus précieux. Les seigneurs reçoivent une part considérable en nature du produit des terres à titre de rente et d'impòt (I).

Ces nùmes se morcèlent et donnent lieu à des domaines beaucoup plus nombreux, ce sont des Hospou, parties des nùmes. M. Maspero cite des exemples de ces morcellements. C'est l'époque patriarcale mais sédentaire de l'igspte. Elle parait avoir été tris prospère $(\boldsymbol{2})$. On en retrouve des reflets dans la Bible.

Peu à peu (c'est exactement l'histoire des Capétiens), l'un des seigneurs, maitre d'un des centres agricoles (Memphis, Thèbes, Sais) devint plus puissant que les autres. L'époque rogyle commence arec la vie nationale de l'Égypte. L'époque royale se divise en phases diverses d'après l'importance et l'inthuence des villes rograles et des dýnasties qui les possèdent.

La tendance générale du mouvement de la civilisation en Éryte, par des causes naturelles et politiques, a été vers l'unité monarchique, ne serait-ce que par suite de la nécessité d'une forte administration pour entretenir les canaux et pour défendre le territoire. La Royauté devint l'élément national dominant et le Pharaon, qui la représentait, fut mème considéré, en principe, mais jamais en fait, comme le seul propriétaire du sol. A côté des

(1) C̈étaient de véritables seignemrs hérélitaires. ils rentaient la justice. prélebaient la taxe en nature sur lenrs suburdonnés, se réservaient la répartition des terres, menaient les hummes at combat, celebraient les sacrifices. Maslero, 71 .

(2) E. Petrie, Eisht foum carlist timse, 60, 192. 
Pharaons les seįzneurs, après eux les grands propriétaires ont conservé et ont encore en Egypte une situation considérable. La crande propriété a survécu aux Pharaons, aux Romains, aux Arabes. Elle a beaucoup contribué à la puissance des Mamelucks. Cest contre elle que Méhémet Ali a lutté par tous les movens sans la détruire.

Durant cette période le sol appartenait pour un tiers au Pharaon, pour un tiers aux prètres, pour un tiers aux guerriers. Les prètres formaient la classe sarante, lettrée; ils administraient le pays. Les prètres étaient taxés au quinzième et les guerriers au cinquieme du produit brut. Le produit brut était calculé, non pas dapres le territoire, mais d'apres la hauteur de l'inondation du Nil. Il : avait dans chaque village un scribe ou prètre pour controiler linondation. Le Pharaon avait le droit d'acheter les récoltes pour les vendre lui-mème. Les Romains ont impozé à l'Érpte une serritude analogue qui s'est prolongre pendant plus de six siécles. Le Pharaon recerait, en plus, des dons en nature que la tradition rendait obligatoires. Le Pharaon arait également un droit sur le produit des mines. L'extrème fertilité du sol, qui donnait habituellement trois récoltes, assurait à l'Etat de grandes ressources, puisquen dehors des contributions, le Pharaon possédait le tiers des terres. Il faut ajouter aux impigts ordinaires les corrées, immémoriales en Egypte; pour les travaux des mines, des carrières, des digues et des monuments. La corvée a joué un rùle notable dans le percement de listhme de Suez. Elle est à Madascrascar l'un des modes principaux de percevoir limpit.

Les travaux de l'archéologie moderne, la découverte et le déchiffrement des hiéroghyphes et des papyrus ont confirmé les opinions d'Hérodote et de Diodore de Sicile sur la longue prospérité de l'Egypte pendant cette période, ainsi que les récits de la Bible. La propriété foncière s'est constitué; elle se transmet librement par les actes de vente ou les contrats de mariage. Les éléments du droit civil égyptien sont arrètés (1). Ils exerceront

(1) C'es questions très-intéressante- du droit civil egytutien. intimement unies a l'état iconominue de l'Egypte, font l'objet du cours de :M. Rerillout au Lou- 
plus tard une notable influence sur le droit grec et sur le droit romain. La culture du sol avait lieu movennant un fermage qui, de mème que l'impoit, s'acquittait en nature. Il ne pouvait en être autrement pendant cette période; l'Egypte n'arait pas encore de monnaie. Le partağe en natıre était la règle, nous l'avons déjà trouvé en Mésopotamie. Yous en avons indiqué les avantages pour les temps où les métaux précieux circulent difficilement (1).

II. Lenormant présente ainsi le tableau de la condition fiscale de l'Egypte sous l'ancien et le moven empire. "L'administration était aux mains d'une bureaucratie puissante, la corporation des scribes (les prètres). Les services qui avaient le personnel le plus nombreux étaient ceux des travaux publics, de la guerre et des revenus publics. L’argent monnayé était inconnu; tous les impùts se percevaient en nature (2). Le sol était divisé en trois catégories suivant la nature des redevances qu'il fournissait à l'Etat. Les canaux payaient la dime en poissons, les terres arables en céréales et les marais en bétail; un cadastre, soigneusement établi, et tenu au courant des mutations, comprenait

we. Ces inestions comportent soment le nombrenx details fiscaux, Consulter, is cet égard, un article de M. Dareste (Journal des sacants, janrier 1895), dumnant fort bieu une idée de ces questions et de l'état arancé de la cirilisation égrptieune.

(1) Histoire ancienne de lOarient, t. 1, 1. 4 st.

(2) " L'ne ehambre de queliues pieds carrés et au besoin un coffre-fort con"tienlrait à l'aise le revenu total de l'un de nos empires molernes; la jlus dé"mesurée de nos halles n'aurait pas toujours suffi pour loger la masse d'objets " disparates dui représentait les richesses d"une seule province de l’Egypte. La "substance le l'impot prenant loutes les formes, il fallait pour la recevoir une " puantité inexprimable d'agents spéciaux et de locaux aprrolries, bouviers, " étables, boisseleurs, greniers, sommeliers, cellier- pour le vin, les bières, les "luiles. Vingt elasses d'ourriers collaboraient de len métier au service de la "trésorerie. Selon in'il s'agissait de boufs, ou de blés. on d'étoffes, on menait "limpit au jue, parfois it la boucherie, aux eorroyeurs; on le blutait; on le rédui"sait en farine. On en façounait du pain, de la pâtisserie. On le repassait, on le " pliait, on le debitait à l'habit ou la piece $\%$. Le momle jgnorait encore l'usage de la monnaie : l'or, l'argent, le cuivre constituaient de simples objets d'échauge. - Maspero. Ibiden, 1. 284. - Nous reprodnisons ce passage si curieux afin de donner également une idée de l'impôt en nature. Sous arons eu et nous aurons ncore occasion d'en parler ainsi que des charges frumentaires romaines. 
pour chaque district, le relevé de toutes les espèces de terres et les noms de ceux qui les possédaient. "

La dime et une capitation personnelle, étaient les principaux de ces impòts.

Il importe d'ajouter qu’à la suite de diverses révolutions, les terres du domaine roval furent, en grande partie, aliénées et celles des prètres soumises à la dime du dixième.

S. Seconde époque de la cixilisation éyyptienne. Fouvel empire. Conquetes des Perses, des Mucidoniens, des Romains.

Cette époque est marquée par une altération profonde des institutions de la vieille Egrpte, aussi bien sous l'action de ses Pharaons que sous celle des étrangers. On possède sur cette époque, grice aux monuments, aux papyrus, anx historiens grecs et romains, aux traraux dont ils ont été l'objet, surtout en ce siècle (1), une connaissance tout autrement précise des institutions fiscales de l'Egypte qui, bien que remaniées par les Ptolémées, conservèrent, sous l'influence du territoire, leurs éléments traditionnels fondamentaux, comme on va le roir.

$1^{\circ}$ Le principal revenu de l'Etat consiste dans les produits des domaines et des troupeaux royaux. Ce trait reporte bien loin dans le passé. Encore, dans l'Egypte contemporaine les domaines de l'Etat ont une grande importance. Ces domaines étaient, dès les plus anciens temps, affermés. L'usage, le tenups, les changements firent que les fermiers devinrent perpétuels et comme propriétaires, ils sous-affermèrent. Le domaine royal disparut ainsi et ne fut représenté que par la rente du sol.

20 Les achats mobiliers, achats immobiliers doivent une taxe particulière dabord du vingrtième, puis du dixième du prix. C'est le droit de mutation entre-rifs, e'est aussi le droit sur les achats dans les marchés, que les Arabes s’appoprieront plus tard. Les actes doivent ètre enregistrés 2 ?.

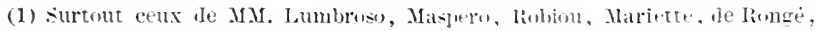

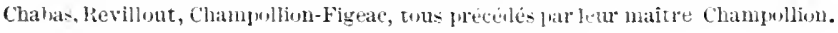

(2) La province d'Egyrte, lar M. Simaika, 1. 150. 
$3^{\circ}$ Les vins, les bières, acquittent une taxe de consommation.

$4^{0}$ Les biens transmis par succession sont frappés mème en ligne directe, d’une taxe très-élevée de 10 à 13 p. 0,0. On ignore lorigine de cette taxation qui a été inconnue aux Etats grecs. II. Lumbroso suppose que c'est à l'Egypte qu'Auguste a emprunté limpit sur les successions en ligne collatérale. Par suite, ce legs fiseal nous viendrait de l'Esypte; autre modification, cette taxe était affermée.

$\ddot{3}^{\circ}$ LEtat possède le monopole de certaines cultures et celui des mines - il est aussi propriétaire de nombreuses manufactures - fait qui s'est perpétué jusqu’à aujourd’hui.

$6^{\circ}$ LEtat recoit de la part de certaines villes des fournitures en nature, très-ancienne coutume de l'Orient, qui explique l'attribution qui élait faite en Egrpte, comme ailleurs, des revenus d'une ville à une personne donataire à vie ou temporaire.

7o Le Pharaon reçoit également des dons en nature aux grandes fètes religrieuses.

$8^{\circ}$ L'Etat a droit à la dime du produit brut de toutes les terres sans exception. C'est limpit foncier. Il est payable en nature ou en uryent. Cette option, que nous avons déjà signalée quant aux empires de la Mésopotamie, correspond à cle grands chansrements dans la condition de l'Eggpte et de l'humanité, à un notable progrès de la richesse, à un nouvel aftlux de métaux précieux et à l'usage de la monnaie.

Bien que la quotité de l'impoit soit le dixième du produit brut en général, elle peut ètre diminuée à raison de l’insuffisance de la crue du Nil. Sur les domaines royaux la dime était du cinquième du produit brut, parce qu’elle représente la rente et l’impòt; mème fait dans l'Inde moderne. Nous avons dit plus haut que, pendant la première époque, les quotités de liimput en nature variaient d'après la hauteur de linondation du vil (1).

(1) Le taux de plusieurs impôts. notamment la capitation et les fouruitures en nature variaient aur-i l'alures la hauteur le l'inondation. De là bien des difficultes. Les uns soutenaient ' lưil fallait 12 coulees d'eau, les autres 14, d'autres 16. 
$9^{\circ}$ Il existe pour toutes les terres un cadastre général et détaillé, étab!i d'après un arpentage qui parait remonter à Ramsès II. Ce cadastre est soumis à des vérifications périodiques. Il est lait par nòmes, toparchies et arroures par les topogrammates qui tiennent en ordre les livres fonciers et en délivrent des extraits; chaque domaine est divisé par parcelles: terres arables, vignes, terres à palmiers, terres vagues. Certaines terres étaient exemptes de limpòt foncier.

$10^{\circ}$ Les maisons, les industries, les personnes sont soumises à des taxes fixes, sorte de capitation qui est plus élevée pour les ouvriers $(1)$. M. Lumbroso attribue cette capitation à l'influence de la Grèce. Toutelois nous l'avons déjà rencontrée en Asie Mineure.

$11^{\circ}$ Les douanes sont organisées avec des droits d'entrée et de sortie, doubles droits en cas de fraude.

$12^{\circ}$ Les frais de justice sont très lourds; ils forment, comme en France, en .llemagrne d'aujourd'hui, un revenu budgétaire.

$13^{\circ}$ Les troupes et les fonctionnaires ont droit à des fournitures et au logement pendant un certain temps. Nous retrouverons cette charge dans l'organisation fiscale romaine qui l'a transmise à la plupart des Ėtats de l'Europe.

$14^{\circ}$ Les prêtres sont tenus à la fourniture des toiles de la marine, probablement à raison de leur part dans le mouvement industriel de l'Égıpte; ils acquittent également un droit de prètrise.

$10^{\circ} \mathrm{La}$ confiscation est devenue une des ressources principales de l'État. M. Lumbroso cite à ce sujet plusieurs exemples intéressants. Il en a été de mème à Rome, en Grèce, dans les empires des Perses, dAssyrie et de Chaldée. La confiscation s'est introduite tardivement dans les institutions hébraï ques : ce qui atteste leur supériorité. Était-elle, en Égrpte, d'importation étrangère ou provenait-elle des époques précédentes? Elle semble contraire aux institutions d'origrine égyptienne. on ne la trouve pas dans les monuments primitifs de l'Inde ni de la Chine.

(1) M. Simaika evalue de 4,30 fr. at 5,37 la taxe sur les personues. Cette capltation variait ausi avec la hatuteur du Nil. Renvol a lappendice. 
$16^{\circ}$ En sénéral les impits étaient affermés, ce qui les rendait plus accablants. Il en est de mème des tributs et des monopoles. Aussi pas de forme plus redoutable que le tribut affermé, mais la plus terrible est cependant le monopole affermé.

$17^{\circ}$ Pendant cette seconde époque de très grands changements ont eu lieu. Is ont coïncidé avec la décadence de l'Ĺgypte. Plus cette décadence s'est manifestée, plus le système fiscal s'est étendu. On peut dire qu ii est devenu complet sous les Lagides et que les Pharaons macédoniens ont laissé peu de chose à glaner dans le champ de la fiscalité. Majs ils n’étaient pas des Egyptieas; ils traitaient l'Egypte en province conquise. Cette nation, illustre entre toutes, qui a gravé ses idées religieuses sur tant de monuments admirables et transmis tant de preuves de son iufatigable labeur et de sa grandeur historique, s'est toujours enveloppée de mystère et de silence. Que pensait-elle de sa condition? Comment faisait-elle face à toutes ses charges? Elle ne l'a pas dit: on ne le saura jamais. On peut toutefois se rendre compte, dans une certaine mesure, de leurs effets. Les taxes de consommation, celles sur les achats, les frais de justice, les diverses capitations, les logements, les fournitures durent modifier la condition des classes agricoles et préparer les longrues souffrances qui les ont accablées depuis. Les droits de succession, le paiement en argent d'une partie de la dime, d'après un cadastre, les droits le mutation, ceux de douanes, et surtout les confiscations eurent sur les hautes classes de l'Égypte une intluence plus désastreuse encore. Ils les ruinèrent peu à peu et ainsi se constitua la société égyptienne de la décadence où lon ne rencontre guère plus que des fonctionnaires et des fellahs dans les campagnes, tandis que s'accumulent dans les villes des multitudes de toute race, de toute religion, de toute langue, sans tradition et sans patrie, qui révoltaient Tacite, mais qui ont eu une part décisive dans les deux puissants mourements 'du Christianisme et du Mahométisme.

M. Maspero trace un tableau, déjà lien sombre, de la situation les cultirateurs de l'ligypte à cette époque. "La condition des cullirateurs libres derait rappeler par plusieurs cótés celle du 
fellah moderne; certains ne possédaient d'autre bien qu'une cahute en boue faite assez large pour eux et pour leur femme. D'autres s'enhardissaient à louer les terres du seigneur ou d'un soldat voisin. Les plus heureux acquéraient des domaines dont ils n'étaient censés avoir que l'usufruit, la nue propriété restant toujours entre les mains du Pharaon, des feudataires laïques ou religieux. Ils pouvaient d'ailleurs la léguer, la donner, la vendre sans opposition. Ils payaient, outre la taxe personnelle, un impit foncier proportionné à l'étendue de leur fonds et à la nature des lerres qui le composaient ". M. Maspero donne des détails les plus complets sur les arpentements, nécessités par la crue du Nil, sur le cadastre et ses révisions, sur la surreillance de la crue du Nil par les agents du Pharaon el des seigneurs, sur les messagers chargés de renseigner les cultivateurs sur la crue c'est-à-dire sur limpoit, sur la rigueur des fiscalins qui rı'hésitaient pas a faire usage du baton la courbache est antique en Egrpte) pour démontrer le niveau moven de la crue, sur les corvées extraordinaires exigées parle seigrneur pour enlever les récoltes comme aux temps féodaux et naguère en Russie, sur les corvées ordinaires pour les canaux.

$10^{\circ}$ Cette décomposition, arrêtée pendant plusieurs siècles par a conquète des Arabes, a été la conséquence d'une longue lutte qui s'est engagée, d'une part, entre la royauté et les prètres, et d'autre part, les classes militaires égyptiennes. Le gouvernement royal, appuyé sur les scribes, les prètres, l'administration, n'a pu modifier le système fiscal de l'Egyple qu'en brisant la féodalité militaire qui en assurait l'indépendance. Il est douteux que ces classes militaires eussent pu protéger l'Egypte contre la Perses, les Grecs, les Romains ; mais elles auraient pu amoindrir l'inlluence politique et sociale de leurs invasions et, peut-ètre mème, permettre à la nationalité et à la race de survivre, de se reconstituer; quand les classes militaires d'un peuple sont détruites, tout est perdu.

19. L'administration fiscale et financière de l'Egypte ressemblait, dès cette époque, à ce qu'elle est aujourd'hui : elle a vait un caractère industriel, résultant des conditions physiques du

(1) Maspero, Ibidem, 1. 3i2. 
territoire (1). Le Trésor disposait de grandes ressources. Il faisait les arances aux propriétaires. Il possédait et il gérait de vastes domaines. II devint le banquier de l'Egrpte entière, qui, elle-mème, après la décadence de Tyr et de Babỵlone, vit affluer, surtout après la dissolution de l'empire d'Alexandre, tous les capitaux de l'Asie. C'est la première époque. probablement la plus belle, de la grandeur commerciale d'Alexandrie. Banquiers, riches marchands de Babylone, de la Phénicie, de la Judie. de la Perse se refugièrent en Errpte. Le centre de la richesse et rle la civilisation se déplaça; il quitta Babylone pour l'Egypte. C'est arec les capitaux de l'Egrpte que Carthage, la Macédoine. Antiochus le Grand, Jithridate mème, ont essaýé le lutter contre le peuple romain. Les Egsptiens navaient plus darmée; mais ıls avaient des capitaux. Ils ont joué contre Rome, mais dans de moins bonnes conditions, le meme jeu que liAnglelerre contre la France de Louis XIT et de Tapoléon. Leurs institutions fiscales sont la preuve d'une très-grande richesse, comme l'atteste l'impüt sur les successions qui n’a ité sérieusement implanté en Europe qua au $\mathrm{x}^{\mathrm{e}}{ }^{\mathrm{e}}$ siècle, particulièrement en France et en Antrleterre, les Etats les plus riches de l'Europe actuelle.

$20^{\circ}$ Les Romains furent émerveillés des ressources que l'Egypte mit a leur disposition 2 . Les trésors des Ptolẻmées produisirent à Rome une rérolution monétaire. Les Romains n'eurent qu'à maintenir les choses en état : imput foncier, carlastre, capitation, taxes sur les achats, taxes de consommation, droits dedouanes, droits de succession, ils conservèrent tout : seulement, tout dut ètre portè à Rome. Mieux encore: les blés d'Eggpte au lieu d'ètre rendus ou consommés en Egypte durent nourrir la plèbe romaine. En vertu de la loi frumentaria, les Romains s'atiribuerent aussi le droit, exercé déjà par les Pharaons, de s'approprier les blés,

(1) Le Tresor royal tenait a la fois de la ferme. de lentrepit et de lousine. - Masjero. p. 284.

(2) Le anteurs grees ont èté éblouis par la prusptrité matérielle de l'Egrpte. riokme de -icile almire l'Egypte sam restriction. Le tableau detaille qu'il fait de la ligislation egrtienne a quelquefois les allures dutolie comme la crrubenlie de Serophon. - Menarl, Anciens feuples dorient, 1. 219. 
non compris dans la dime, à un prix fixé par le lieutenant (legatus) impérial. Blés des dimes, blés réquisitionnés (emptum) dùrent ètre transportés à Rome, on construisit en Sicile des élévators ad hoc pour les emmagasiner. Pendant quatre mois chaque année, l'Egypte avait à livrer 20 millions de morlii de froment, charge que M. Narquardt a éralué à $1 \ddot{3}$ millions de deniers ou de francs. Cette charge a duré jusqu'au ${ }^{\prime}{ }^{\circ}$ siècle. Constantinople remplara ou plutít compléta Rome. Ce fut une exploitation de la mème nature, mais combien plus terrible! que celle sous laquelle l'Angleterre a courbé l'Inde et l'Irlande. Par une coincidence singulière, l'Egypte vient de retomber sous un jougr du mème genre, avec certaines garanties, il est vrai. Il fut interdit à l'Egypte de frapper de la monnaie d'or, tout comme les Anglais l'ont fait dans l'Inde, afin de se réserver les profits du change.

La condition de la population rgyptienne devint moins favorable. La séparation entre la population agricole, le véritable peuple égyptien établi sur le sol et le cultivant et la population urbaine, mélange fort différent, s’aggrava. Conservée sous les Perses et les Lagides, la vieille civilisation écyptienne s'affaissa, tomba peu à peu en poussière et disparut; les prêtres vendirent les dernières terres des temples et les abandonnèrent; les sables continuèrent à recouvrir les monuments des temps qui s'éloignaient de plus en plus. Il ne resta d'une civilisation, si ancienne et si remarquable, que les canaux et les réservoirs du Nil, entretenus avec soin par la population rurale dont ils assuraient l'existence; ils sauvegardaient l'avenir. Pendant les six siècles, d'occupation romaine, l'Egypte demeura étrangère aux mouvements des populations, migrations, gruerres de l'Empire romain, ça été son salut.

A tous les anciens impòts, maintenus et mème parfois augrmentés, les Romains en ajoutèrent d'extraordinaires, en vertu l'indictions qui paraissent aroir pris naissance en Ecrypte, à raison des variations des crues du Nil.

Mais le plus grand changement provint du zèle, de l'ardeur, de la rapacité du fisc romain qui a toujours traité l'Egypte comme terre conquise de prédilection; I'Erypte, en effet, était la province agricole la mieux cultivée, la plus productive, la plus riche 
de l'Empire, à peu près la France actuelle, le paradis de tous les fiscs; les impôts étaient fixés, levés, contrôlés, perçus, versés par une multitude de fonctionnaires, plus variés encore quaujourd'hui, d'autant plus que si, dans l'ensemble, l'Egypte relevait de l'Empereur, certains domaines dépendaient de la cassette particulière. Les fonctionnaires de l'illios Logos (procurator rei privata) surveillait la cassette, et le procurator Augusti contrôlait le Fiscus. De ces personnages, en dépendaient d'autres, tous fort onéreux, Basilicogrammates, Topogrammates, Comogrammates, Eclogistes, Logistères.

Les fermes d’impòts étaient mises en adjudications publiques et données au plus offrant et dernier enchérisseur sous la surveillance des Epimélètes.

Le produit de tous ces impits était versé dans les caisses du trésor-Fiscus, de la province et mis à la disposition du légat, préfet ou lieutenant impérial, qui avait pour mission principale, les dépenses provinciales acquittées, de les transmettre à l'Empereur directement.

Aussi l'Egypte a-t-elle dû, sauf l'exécution des lois frumentaires, plutòt gagner que perdre aux grandes réformes de Dioclétien et de Constantin. Ces réformes fiscales soumirent toutes les parties de l'Empire aux mèmes impòts. L'Egypte ne fut plus l'objet des préférences fiscales des Romains. Elle leur avait servi de modèle, comme le dit fort bien M. Abdalluh Simaika, d'après M. Mommsen, dans le mémoire auquel nous avons emprunté une partie des détails qui précèdent (1), non seulement pour les rélormes d'Auguste, mais pour celles de Dioclétien et de Constantin. "Ce fut dans la partie financière (assiette de l’impôt foncier, cadastre, droits de mutation et de succession) que l'annexion de la terre des Pharaons exerça le plus d'influence sur l'administration de l'Empire romain. ")

Bien qu'exploitée sans merci, l'Egypte conserva sous l'Empire romain une portion de sa richesse, par suite de ses avantages économiques : bonne culture du sol, avances de l'industrie, supériorité commerciale et maritime, afflux des capitaux orientaux.

(1) La province romaine d'Egyple, p. 168. 
En s'en tenant aux évaluations de Saint-Jéróme, acceptées par M. Marquardt (1), le budget moyen de l'Egypte sous les Lagides peut ètre fixé à $84,400,000$ fr. (2). Si l'on admet, avec MI. Lumbroso, que ce total représentait probablement le $1 / 13$ du revenu national, on troure que ce revenu sélevait à 1,260 millions. Réparti entre $7,000,000$ Egyptiens, le prorata donne $168 \mathrm{fr}$. Ce prorata était bien supérieur à celui du revenu des sujets du grand Roi et justifie la haute réputation de richesse de l'ancienne Egypte.

Néanmoins le trait essentiel de l'Egypte sous l'administration romane, c'est une résistance insurmontable au grouvernement étranger qui l'exploite. Elle devint le foyer le plus actif de l'opposition à Rome; Alexandrie, remplie de Juifs, surtout 3). Les Romains l'admiraient, la redoutaient, la ménageaient dans la mesure des nécessités de leur empire. Plusieurs empereurs la visitèrent et $y$ séjournèrent longtemps. Il n’y eut jamais d'assimilation: différence de race, différence de religion, différence de climat, différence de traditions. Toutefois la cause principale de lutie était économique, comme pour les Juifs. Sans doute, les Romains maintenaient l'ordre, la paix extérieure, mais cela coùtait trop cher. C'était d'abord chaque année, chaque mois qu'il fallait expédier au dehors, à Rome, plus tard à Constantinople les plus nettes ressources de l'Egyple. Les impòts étaient consommés par les frumentaires romains aux dépens des Egyptiens, en nature, sans compter les envois en argent, en or, en produits fabriqués. Telle est, sans doute, la condition des Etats qui servent actuellement des rentes aux capitalistes européens, lesquels les mangent joyeusement chez eux, à Nice, à Cannes, et partout; mais, au moins, une partie de ces rentes appartient

(1) Page 293. Savoir en especes 14,800 talents; en nature 1,500,000 artabes de ble

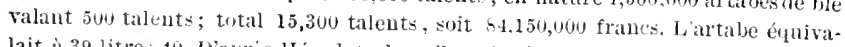
lait à 39 litres 40 . D'alres Hérodote le tribut de J'Egylte solls les l'eres netait en argent que de zoo talents de Babylone et le 700 talents en ble, lulus la preche du lac Meris.

(2) Friellander, cité par M. Marquardt, le lnite mene à $168,045,000 \mathrm{fr}$. mais sans deitails.

(3) Alexamirie fut la seernde latrie dens Juifs, Israül, 5* vol. 227-235. M. Mummsen évalue it 1 inillion le nombre des Juifs en Egylute sous les Flaviens. 
aux Etats quil les ont émises. En Egy pte, c'était l’̈mpìt lui-mème, surtout en nature. Pas de compensation, nul espoir de retour. Quand Ptolémée Epiphane mourut, les prètres égrptiens soumirent sa mémoire au jugement traditionnel. Larrèt qui sanctifiait la mémoire du Pharaon portait : "considérant qu"il a supprimé " tout à fait quelques-uns des impòts et tributs établis en Egrpte "et quili a diminué le poids des autres (1:."

L'opposition de l'Egypte a exercé une trés-grande influence sur l'histoire de l'humanité, à raison du concours qu'elle a prèté au Christianisme et au Mlahométisme, les deux forces qui ont préparé et achevé la destruction de l'Empire romain.

Bibliogr.phe. - Maspero, Les origine's, Egypte et Chalde', 1894; Lenormant, Histuive ancienne de lOrient, t. I; Ménard, Histoire des ancivin penples de lo,ient, p. 219 et s.; Maspero, Manuel Whistolive de l'O,int: Rawlinson, The fice great mondrelies: Reynier, Economie politique des Egyptiens: Robiou, Mémoires sur l'Egypte, 185: Lumbroso. Ferherehes su, leicoromie politique de l'Egypte, 1870; Revillout, Chestornathie egypticnne et noucelle ehresloinathir: Rerue arehiologique, 1880: Herodote, traduction de M. Rawlinson et les nutes; Diodore de Sicile: Mommsen, II ist. iromaine, Hist. de la inonaraie romaine, Hist. des provirees romaines (en allemand : Marquardt. Orgrenisation finaneiève des Romains, 228-329; Oueraye substentiel pourl s impots; Simaika, Lu Province romaine dÉEypte, 189?. Remarquable travail fait par un docteur grec au Caire, en français. Cest un ssmptome de temps noureaux.

(1) M. Mommsen evalue quaux lerniers tems les Lagiles, l'Egryte ne payait qu'un tribut the 6.0po talents soit 23 millions mares, Histoire des procines de l'Empire romain, 560 . 


\section{CHAPIT RE VI.}

DE L'IMPƠT DAXs L'INDE AxcIExxe.

Le tableau des systèmes de l'imprit dans les anciennes civilsations serait incomplet si une part n'y était réservíe à l'Inde et à la Chine. Ce n'est pas que les institutions fiscales de ces deux groupes, si considérables, aient exercé aucune influence directe sur la constitution et les transformations des imprits des peuples ou des Etats du bassin méditerranéen; bien au contraire : les sýstemes d'impüt de ces peuples ou de ces Etats se sont développés dans des conditions tout à fait indépendantes. Mais, à raison de cette séparation, mème de cette indépendance, il ne peut ètre que d'un haut intérèt de connaitre et de comparer les impòts de l'Inde et de la Chine, formant des milieux si éloignés, si différents et si importants. Les disersités doivent ètre mises en lumière; les analogies intéresseront peut-ètre davantage, car elles augmenteront la puissance des règles quón peut déduire des rapports entre les institutions fiscales des diver's peuples méditerranéens; elles démontreront que si les races, les climats, les territeires, les religions, les formes de gouvernement modifient les institutions, il existe d'autres causes qui tendent à leur imprimer la mème lorme et un caractère commun.

On possède des documents (1) d'une haute valeur sur les impơts dans l'Inde ancienne; quant à la Chine on est un peu moins farorisé; non que les doeuments manquent, mais la plupart n'ont pas été mis à la disposition du public lettré européen.

Ces documents, pour l'Inde comme pour la Chine, se rappor-

(1) James Mill. II istory of Inlia, t. 1, chap. IL, W, v. - Lenolmant, Manuel, t. 3, 5a8, et suriont les lois de Manou Ifsa oupanichud de yal-jour Vida) traduction par M. Panthier, Livres satre del orient ct Sacred Lurks. 
tent à des époques beaucoup plus récentes que pour l'Egypte ou les empires des vallées du Tigre et de l'Euphrate, aussi sontils postérieurs aux temps primordiaux de la civilisation en Chine ou dans l'Inde. Pour l'une comme pour l'autre, ils ne sont pas antérieurs au $\mathrm{x}^{\mathrm{e}}$ siècle avant l’ère chrétienne. Dejuis longtemps, l'Egrpte, la Challée, l'Assyrie, la Judée, la Plénicie étaient en possession d'une longue carrière historique et des documents s"y référant.

En ce qui est de l'Inde, la forme, l'étendue du territoire, les chaines de montagnes qui le limitent, le coupent ou le traversent, les grands fleuves qui l'arrosent et le partagent ont été moins favorables à la formation de peuples et d'Etats autonomes, tels que ceux restreints mais puissants du Nil, du Tigre et de l'Euphrate. D’autres causes encore aidant, il n'y a pas eu dans l'Inde une civilisation unitaire et brillante comne celle de l'Egrpte, militaire et conquérante comme les Assyriens et les Perses. Dans les temps anciens il ne s’est pas formé un grand empire dans l'Inde. Mème aujourd'hui, sous la domination de l'Angleterre, on ne saurait dire que l'Inde constitue un empire.

Tout autre a été le caractère de la civilisation dans l'Inde. A diverses époques (1), s'Y sont superposées plusieurs couches de population, de sang, dorigines, de traditions, de mceurs, de religions, de tendances différentes. A l'arrivée le chacune de ces couches a correspondu un mourement accusé dans la cirilisation de linde. Mais ces mourements ont comme prorluit des stratifications qui se sont superposées sans se confondre. Il y a eu juxtaposition, il n'y a pas eu assimilation. Les couches du mème mouvement, au lieu de recouvrir et d'absorber le tout, se sont à leur tour fractionnées. De là, d'abord, la formation de castes ( $\boldsymbol{(})$ qui coupent et partagent la population de l'Inde en plusieurs sections profondément accusées arec des oriçines, des incurs, des traditions, des cultes dissemblables; de là, ensuite, un manque grénéral d'unité et la formation d'une multitude d'Etats.

(1) Lenumant, wanuel, $3^{*}$ val. 410.

(2) sur les rapports des castes entre elles. sur leur valeur respeetive, le taux des lommages ou injures (wehrgeld) four elacune d'elles (Manou, live VII, $\$ 267$. 
Aussi on ne rencontre pas dans l'Inde cet ensemble qui fait une nation; c'est le morcellement féodal de l'Europe occidentale arant les Croisades.

A aucune époque de son existence historique, antérieure à l'invasion musulmane, l'Inde ne parait aroir été appeĺ́e à concevoir lidée d'une réunion de ses diverses parties, bien que, géographiquement, son territoire soit admirablement délimité par les IIimalayas et l'Océan indien; elle n'a pas formé une patrie, un Etat, mais tout un monde à part oì se sont successivement superposées, comme des strates géolorriques, des races différentes d'hommes; dans les temps anciens, les Aryas ont été la derniere; les Arỵas ont surtout occupé les deux grandes vallées de l'Indus et du Gange, s'étendant de toutes parts arec les siecles, mais sans jamais expulser, ni remplacer, ni détruire les races établies arant eux sur le mème territoire; leurs lois, leurs traditions, se sont cependant répanrlues à peu pris par toute l'Inde, mais ils ont dù eux-mèmes les adapter au milieu qu'ils ont modifié sans le faire. Les lois de Manou, tout en appartenant a leur influence correspondent à une ceuvre dassimilation.

Ces lois ne sont ni les lois de linde, ni celles dune partie de l'Inde, elles sont la règle, la loi des Rois, des principautés, des Aryas. Ces petits rovaumes ou principautés peuvent ètre comparés à peu près aux seigneuries importantes de la France ou de l'Europe féodale; un grand nombre subsiste encore.

Au-dessus de ces diversités, qui sont presque innombrables et comme irréductibles, il est sorti du dernier mouvement de population et de race - dans la période des anciennes civilisations, - celui des Aryas, une sorte de codification des traditions, des coutumes, des arrangements qui ont prévalu et qui sont devenus la règle rigoureuse pour tous les éléments de la population. Cette codification, conservée par les Brahmanes, élément directeur, consiste dans les lois de Manou. Ces Iois sont parrenues jusqu'à nous, elles ont été trarluites en anglais et en français. Elles donnent une description complete de la société hindoue à l'époque où elles ont été recueillies, à peu près 900 ans avant l'ère chrétienne. Elles sont partagées en 12 Jivres. Les 
second, troisième, quatrième et dixième tracent les règles de la vie de la famille, en soccupant principalement de la classe supérieure, les Brahmanes dont ils mettent en relief le rang exceptionnel, les devoirs, les droits; les cinuluième et sixième sont entièrement consacrés à la vie religieuse des Brahmanes.

Au contraire, le septieme intitule : conduite des Rois et de la classe militaire, traite des autres classes sociales et fixe les droits et devoirs des Rois (Radjas) et des guerriers Kichathrivas). Les huitième et neuvirme contiennent la législation civile et criminelle et les règles concernant les commerants Vaisyas) et les Coudras (classe inférieure et presque serrile). Le onzirme soccupe des relations des diverses classes ou castes les unes avec les autres. Le douzieme est exclusivement religieux ou philosophique. Dans les lois ciriles figurent les imprits, les successions et les droits de propriété et les diverses procédures judiciaires, matière principale des septieme et huitieme livres. Ce sont les plus importants des lois de Manou. Colebrooke les appelait le Digeste des lois de Manou. Il a essaré d'en distinguer et d'en classer en 18 titres les diverses parties d'après loordre indiqué aux sept premiers paragraphes du livre VIII. Plusieurs des règlements concernant les rapports du maitre et des serviteurs, les salaires, les prèts, les déprits, les associations, les ventes et achats présentent beaucoup d'intérèt. On ne possède une codification de mème ordre que pour la civilisation romaine (1)

Les dispositions qui se réferent au droit de propriété, à sa nature, ì son étendue, à ses diverses formes ont besoin d'ètre connues, car elles sont en rapport immédiat arec le système d'impòt et elles exercent, mème aujourd'hui avec loccupation anglaise, une grande influence sur la condition économique de l'Inde, sur les imputs qu'elle supporte comme sur leurs effets. Ces dispositions sont antérieures aux lécislations fiscales de la civilisation de la Grèce ancienne; mème à celles de la seconde période de la civilisation égyptienne. Elles peuvent ètre placées

(1) Manm. live VII. \$ 125, 126, - On tronve dans le lirre huitieme, \$134 i 154, des prescriptions fort interessantes sur les prits, les gages, le taux de l'intérét pour chapue carte, la monnaie. le Roi tixe toms les six mois la valeur des monuiles. Livre VIII. 403 , comlarez 135-13s. 
entre l’époque re la Chaldée primitire et celle du premier empire Assyrien.

$1^{\circ}$ La propriété s'acquiert par l'occupation et la mise en valeur, la culture du sol, le contrat, la donation et l'hérédité (1).

$2^{\circ}$ Cette acquisition est complite en ce qui concerne les objets mobiliers de toute nature, si elle a eu lieu sur des marchés en public. Dans certains cas, le gage lirré au créancier peut conduire à la propriété 2 .

$3^{\circ}$ Mais il n'en est pas de mème quant à la propriété du sol; cette propriété appartient au Roi (Radja), qui n'a jamais attribué aux cultivateurs que la possession à la charge de lui payer la rente du sol, représentant sa part dans les profits de la production agricole (3). Cette rente varie d’apris la fertilité du sol; dans des cas exceptionnels le Roi peut exiger une part plus grande (4).

$4^{\circ}$ Moyennant le paiement de cette rente le possesseur peut transmettre son droit de possession par vente, don, héritage, rage.

(3) Les lois de Manou donnent des détaiłs sur l'administration des Etats ou grandes principautés, formés de la réunion de grands et de petits villages. Les impoits se paient par village. Au dernier rang, un officier ou chef par chaque village; vient ensuite celui qui en a 10 ; puis celui qui en a 20 ; puis celui qui en a 100; enfin celui qui en a 1000. 1000 villages sont la plus haute unité, lïmpìt est payé partout en nature. Le chef de 1000 villages reçoit le revenu d'une ville (nagara, celui de 100 villagres le revenu d'un village (grama), celui de 20 villages, le produit de deux koulas de terre (le koula est l'étendue de terre qui peut ètre labourée en un jour par deux charrues attelées de 6 boufs) et celui de 10 villages une lioula ( $:$ i).

$6^{\circ}$ Ces dispositions concernent la répartition de limpòt, d’au-

(1) Mill, ibidem, p. 19x. - Manum, livre XI, s 115.

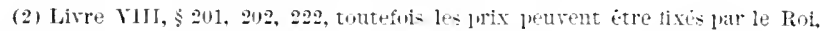
s 402,403 .

(3) Mill, ibidem, 265. - Nous disentons les opiniom- de M. Mill, yuil a exagt. rées dans le chapitre relatif in limpht dans I"Inde actuelle.

(4) Livre VII, \$13i).

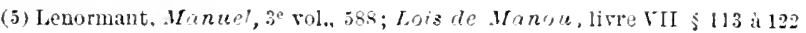


tres plus détaillées indiquent ensuite sa consistance. Il revient au Roi sur la production brute chaque année, de la terre (1).

I. Le $6^{\mathrm{e}}$, le $\mathrm{S}^{\mathrm{e}}$ ou le $12^{\mathrm{e}}$ des grains selon la fertilité du sol et le travail qu'il exige.

II. Le $6^{\text {e }}$ du croit annuel des arbres, des viandes, du miel, du beurre, des parfums, substances médicales, des liquides, des fleurs, des racines, des fruits, des feuilles ramassées, des herbes potatrères, des foins, des ustensiles en cuir et en corne, des pots de terre et de tous objets en pierre.

III. Le öo du bétail, des pierres précieuses, de l'or, de l'argent, ajoutés chaque année à ceux existant.

IV. De mème, le Roi ayant considéré le prix des rentes, des achats, des denrées, les distances qu'elles parcourent, les frais de leur port et de leur sùreté, aura le droit de lever une taxe permanente sur toutes les marchandises, il lèvera également une taxe annuelle sur les gens de commerce, sans les priver de leurs profits légitimes; ii livera aussi une taxe annuelle mais très-modique sur les gens du petit commerce, \$137; quant aux ourriers, aux artisans, aux personnes de condition servile, qui ne vivent que par leur travail, ils derront au Roi un jour de travail par mois.

V. En temps de guerre ou de grande détresse le Roi pourra exigrer le quart des récoltes dans ses Etats de la part des propriétaires (probablement la classe des guerriers), le huitième, le sixième et mème le quart des récoltes et profits de la classe des commeregants (vaisyas), sans que la taxe sur les marchandises et les gains en argent dépasse le vingtième. Les coudras (ouvriers de tout genre) paieront en travail, mais jamais en taxes $(\boldsymbol{2})$.

Le Brahmane ne doit jamais payer d'impùt mème lorsque le Roi meurt de besoin; au contraire le Roi ne doit jamais tolérer qu'un Brahmane souffre de la faim. - Livre III ${ }^{e}, \$ 133$.

Ces prescriptions se retrouvent en Judée et mème en Egypte. Elles sont la plus antique manifestation de l'exemption d'impôt

(1) Mill, Ibidem, 247; Lois de .1fanou, livre VII, $\$ 130,131$.

(2) Manou, lirre XI, \$118, 119, 120. 
pour la classe supérieure; exemption qui n'est pas inconnue aux lois fiscales d'Athènes et de Rome; dans tous les Etats Doriens la classe militaire était exempte d'imprit. La longue exemption de l'impòt direct du clergé et des nobles (militaire: dans l'Europe féodale et monarchique remonte loin.

En analysant ces divers imputs, I. James Mill les troure plus ou moins contraires aux principes de léconomie pulitique doctrinale de son temps; il les soumet au criterium des rècrles établies par Adam Smith 30 siècles plus tard; mais il neen restent pas moins pour nous des plus curieux, car ils attestent une condition économique et fiscale, supérieure à celle des autres anciennes civilisations. Les lois de IIanou, les usages, les traditions, qu'elles consacrent sont déjà une limite, une limite sacrée, qui a manqué à l'Egypte, ì la Mẻsopotamie et à la Judée, elle-mème devenue romaine. La grande intluence religieuse du Brahmanisme et des Brahmanes atteste à cet égard ses heureux bienfaits qui justifient l'autorité traditionnelle des classes supérieures dans l'Inde. Les Brahmanes ne sont pas autre chose que cette classe supérieure.

M. Mill a traité arec un soin particulier les questions relatives à la nature de la propriété foncière clans linde et aux rapports de limpùt foncier avec la condition de la propriété et de la rente du sol. Yous reprendrons ces questions, d'un si grand intérèt, en traitant do l'impit dans l'Inde actuelle.

Toutefois, nous crogons deroir reproduire ici la description si curieuse qu'il a faite du village hindou, parce que la constitution et le mode d'existence du village hindou n'ont pas changé. Ils remontent à l'Inde ancienne.

"Le rillage, géographiquement considéré, est une étendue de terre, comprenant quelipues centaines ou 'luelipues milliers d'acres de terre labourable ou en friche. Il a comme chefs le Potail, qui dirige les affaires du village, fait la police, apaise les disputes, recouvre les impits; le Burnum, qui s'occupe de la culture et qui enregistre tout ce qui s' $Y$ rapporte; le Boundenymean, ou l'arpenteur qui surveille les limites; le surintendant des eaux et réservoirs, charcé de la distribution des eaux; le Brahmane qui accomplit le culte public; l'instituteur qui apprend 
aux enfants à lire et à écrire sur le sable; l'astrologue ou météorologue chargé d'indiquer les moments propices ou contraires pour les semences ou les récoltes; ie charpentier et le forgreron chargés de construice les habitations et les instruments, outils des cultivateurs; viennent après le potier, le barbier, le vétérinaire, le blanchisseur, le médecin, le maitre de danse, le musicien et le poite. "

Ín employé supírieur de la compagnie des Indes qui a fourni ces détails en 1810, ajoutait : "Tel est le gourernement muni" cipal rle l'Inde depuis un temps immémorial. Les guerres, les "famines, les décés n’ont pas modifié les limites des terres ni "les familles. Les habitants n’ont aucun souci des affaires poli"tiques. Ils obéissent au Potail (chef local) et lui remettent la "rente lue. Tout le reste leur est indifférent. "

Dans un autre passage, M. Mill montre comment sont payés en nature tous ces petits fonctionnaires du village. Sur environ 110 hushels (1, cinq seer's pour le temple; autant pour les Brahmanes mendiants; un seer chacun pour l'astrologue et le Brahmane du village; deux seers cluacun pour le barbier, le potier, le blanchisseur, le charpentier, le forreron; sept seers pour l'arpenteur; huit seers pour le Potail; dix seers pour le comptable. Après quelques autres prélèvements pour les gardiens du village, il est accordé 10 p. 00 aux percepteurs du revenu. Le surplus est partagé entre le Roi et les cultivateurs $(\boldsymbol{2})$.

On doit concluce de ces divers détails que de mème que l'Egypte, 'du premier ef rlu second empire, que la Mésopotamie avant les empires d'Assyrie et de Perse, que la Grèce hérö̈que et que l'Italie, avant les Romains, l'Inde a traversé une trèsbelle époque agricole qui n’a été sérieusement troublée que par les invasions musulmanes. Limpòt en nature traditionnel, qui se consomme dans la contrée qui le fournit, est tout autre chose que l'imput en nature arraché à l'Egypte ou à la Mésopo-

(1) Le bushel inglais vaut 36 litres 31 , et le seer hindon rant $u n 40^{\circ}$ de $37 \mathrm{kil}$. $251 \mathrm{gr}$.

(2) Mill, ibidem, 266-264. La part du Roi serait devenue plus forte que celle fixée par le Code de Manou. 
tamie par leurs envahisseurs successifs, notamment par les Romains, les plus durs de tous.

Abritie en quelque sorte par les Himalayas et par l'HindouKousch, YInde est demeurée longtemps, comme la Chine, en dehors du mourement des races et des populations à la surface du globe. Les provinces comprises dans l'empire de Darius ne dépassaient pas le Pundjab; Alexandre n’a été pour l'Inde qu’un météore; pendant de longs siècles, avant et après l’ère chrétienne, elle a joui d'une prospérité réelle, agricole, féodale mème, quelle retrouve aujourd'hui, en partie seulement, sous la domination supérieure de la race anglo-saxonne.

Limpression que laisse encore, à plus de 30 siècles de distance, la lecture des monuments primitifs de l'Inde est favorable. Elle n'est pas sans beaucoup de rapports avec celle que l'on éprouve en étudiant tant de passages de la Bible. La notion du devoir social n’y est pas moindre, les obligations des Rois, des Brahmanes, des Kchathriyas y sont tracées avec autant de fermeté que dans les grands prophètes d’lsrä̈l. - $1^{\circ}$ que le Roi ne s'écarte jamais des règles par lesquelles il a déterminé ce qui est légal ou illégal; - 2o qu’il soit humble et modeste, livre VII, $\$ 13,29 ;-3^{\circ}$ qu'il protège le commerce et l'agriculture, $\$ 43 ;-4^{\circ}$ ru’il délibère avec les Brahmanes d'un haut savoir sur les choses du gouvernement, la paix, la guerre, sa force, ses revenus, $\$ 50 ;-5^{\circ}$ quil ne prenne à son service que des gens capables, expérimentés, actifs, $\leqslant 61 ;-6^{9}$ qu’il fasse percevoir ses revenus par des commis fidèles; qu'il observe les lois; qu'il se conduise comme un père enrers ses sujets, $\$ 80$; - $7^{\circ}$ qu'il établisse dans chaque partie de son royaume des inspecteurs, chargés d'examiner la conduite de ceux qui sont à son service, $\S 81 ; 8^{\circ}$ qu'il ne cause pas sa propre ruine en exigeant des tributs exorbitants; $\$ 12$ et $\$ 20$; $-9 \circ$ qu'il protège son peuple avec zèle et vigilance en remplissant les devoirs qui lui sont imposés, $\$ 143 ;-10^{\circ}$ qu il réfléchisse sur ses affaires, les revenus, les dépenses, la délense, etc., $\$ 10 \% ;-11^{\circ}$ que chaque jour, assis ou debout, modeste dans ses habits et ornements, il rende la justice. Lirre VIII, $s 2 ;-120$ le Roi qui ne protège pas les peuples et qui percoit cependant les rederances 
en nature, les impòts, les droits sur les marchandises, les dons journaliers, les amendes (1), va sur-le-champ en enfer après sa mort. Nanou, Livre huitième, $§ 30 \pi$.

Il est certain que sous linfluence de cette antique législation les populations aryennes ont eu des siècles prospères. Elles ont joui d'une sorte de calme séculaire, antérieur mème à l'époque d'Alexandre, calme qui s'est prolongé jusqu'aux invasions des Musulmans. L'Inde a retrouvé ce calme depuis plus d'un siècle griice à la direction d'un pe uple supérieur et à la sécurité qu'il lui procure au moyen d'un régrime approprié à une civilisation essentiellement agricole. Ces petits forers agricoles, si nombreux et si paisibles de l'Inde, n'ont pas joui de l'éclat de la civilisation du Tigre ou du Nil, mais leurs populations, arec leurs coutumes et leurs rederances inmémoriales ont été plus heureuses.

(1) Enumeration comple des anciennes formes de l'impot. 


\section{CHAPITRE VII.}

DE L'HPOOT DANS LA CHINE ANCIENAE.

Les plus anciens monuments écrits de la Chine, particulièrement le Chu-King, et les livres de Mencius (Meng-Tseu), donnent de la Chine une idée absolument différente de celle qu'on peut se faire de l'Inde d'après les lois de Manou:

$1^{\circ}$ Le territoire de la Chine constitue, d'après le Chu-King. composé bien avant Confucius, qui rivait au sixième siècle A. C., un vaste empire, soumis à un gouvernement complètement organisé, monarchique, ạ̧ant déjà apparienu à plusieurs $d y-$ nasties (1); c'est l'empire entre les '[uatre mers (2);

2 . Les Empereurs les plus illustres de ces dynasties y sont nommés, ainsi que les aurres principales auxquelles ils ont concouru; leur action personnelle dans l'administration de l'Empire est très-importante $(3)$;

$3^{\circ}$ Les sacrifices du culte officiel ont lieu dès l'époque de Chun, dans les conditions astronomiques et territoriales qui se sont perpétuées dans l'Emprire; le culte des ancètres, la véritable relicion actuelle de la Chine, est indiquée comme universellement pratiquée (4);

$4^{0}$ Le gouvernement impérial possède tous ses éléments séculaires qui paraissent fonctionner depuis un temps immémorial : 10 la cour impériale qui se transporte dans les divers centres de

(1) Chu-fing, partie IF, chap. xiv, p. 110, 112, chal. xx, 1\% 119. edition Pauthier du Panthéon litrécaire. Ce chapitle est le gramde importance dans l'histoire de la chine. Pour les dynasties, voir partie III, chap. x..

(2) Chu-King, lartie 1, chap. III.

(3) Ibid., marties 1 et 1 II.

(4) Ibid., lartie I, chal. II; partie III, chap. v. 
l'Empire (1); 2o les ministres au nombre de six ou sept 2 ; $3^{\circ}$ les grands fonctionnaires qui entourent l'Empereur $\left(3 ; 4^{\circ}\right.$ les membres de sa famille auprès de lui $+; 3^{\circ}$ les censeurs qui exercent encore aujourlhui leurs hautes fonctions $(\mathbf{3}) ; 6^{\circ}$ les grands rassaux, grands feudataires, princes héréditaires, qui araient alors une intluence tres-étendue $6 ; 7^{\circ}$ le corps entier des manlarins de tout ordre qui ont en mains toute l'administration de l’Empire; les mandarins apparaissent avec l'autorité qüils exercent toujours et arec la responsabilité qui leur incombe; plusieurs des allocutions des Empereurs mèmes, qui tiennent une très-grande place dans ce livre si curieux et si important, leur sont personnellement adressées, tantiot arec des élogses, tantùt arec des critiques (i).

;" Le fouvernement de l'Empereur est absolu, mais patriarcal, paternel, animé des meilleures intentions; un controle sévère est exercé sur tous ceux yui en font partie; le Chu-King contient dinnombrables textes de haute morale, d’appel à la raison, à la rertu, en vie de contenter le peuple, en vue à la fois d'abtenir son uleissance $(s)$ et de le diriger convenablement dans sa destinée. Toici un de ces textes, des plus intéressants, et notamment donnant une idée de l'ensemble du Chu-King.

"Le prince ne doit-il pas ètre aimé? Le peuple ne doit-il pas ètre craint? S̈il n' $y$ a pas te souverain, à qui les peuples auront-ils recours? Il faut aroir soin de conserver la vertu et de saméliorer soi-mème. Si les peuples situés entre les quatre mers sont maltraités et réduits à l'extrémité, rous perdrez pour toujours le bonheur que le ciel rous a procuré...: ašez de la tendresse pour le peuple; ne le méprisez pas: il est le fondement de l'Etat... Si rous faites en sorte que le peuple dise de

(1) Ibid, gatie III, chal. vi.

(2) Ibid., lartie $I V$, chal. II; protie IV. chay. xx. Les fonctions de chaqne ministre sont malitues.

(3) Ibid., partie IT, chap. xIx-svir.

(4) Ibid. partie IV. chap. xxvir.

(5) Ibid., partie II, chap. w et $\mathrm{xx}$.

(b) luid.. partie IV, chap. xx, xxur : partie I, chap. 1 .

(i) Ioid., fartie I. chap. III: partie IHI, chap. II ; partie II, chap. x, xx.

(b) Chu-Lino, partie I, chap. II. - Mencius, live I1, chap. $r$. 
l'Empereur que son ceur est droit, vous jouirez de la prospérité de votre aïeul et vous conserverez à jamais les liens et la vie du peuple . Dans de nombreux passages, recommandation est faite de s’adresser à la raison, cette droite raison qui réside dans le juste milieu de toutes choses (1). On croirait entendre Cicéron lui même. "Est quirdem iêru lax recta ratio, natura congruens, "diffusa in ommes, construns, sempiterna (2)."

$6^{\circ}$ Tout cel ensemble est indiqué comme remontant à la plus haute antiquité. "Les regrles, la doctrine, les exemples des grands de l'antiquité doivent ètre votre modèle n; il existe un grand historien de l'Empire (Tai-Sse). A diverses reprises, les Empereurs prenaient la parole pour retracer l'histoire de l'Empire, montrer comment il s'est formé, les nécessités auxquelles il a été pourvu, les changements dans les dynasties, les épreuves des propulations, la formation de l'administration, les occupations des peuples 3 ).

$\tau^{\circ}$ Quelques parties du Chu-King contiennent des détails sur la Chine elle-mème, ainsi que sur les grands travaux qui ont été nécessaires pour l'appropriation du territoire; ces travaux sont dus principalement aux Empereurs, à leurs ministres ou à leurs feudataires. Le premier chapitre du livre second du Chu-King forme une sorte de tableau de la Chine primitive; il porte mème le titre de tributs et redectances assignés par lu, mass s'il donne de nombreux renseignements sur les travaux de Yu, il n'en renferme sur les tributs et redevances que d'accessoires. Le labourage est représenté comme de neuvième ordre, de sixième ordre, de quatrième ordre, de troisième ordre dans des paragraphes différents de ce chapitre, et les imputs conme de neuvième or-

(1) Chu-King, part. 1, chap. II. - comparer chal. 15: jart. [1, cha] III, VI;

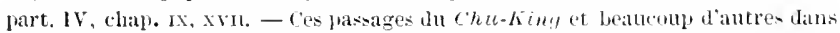
Mencius et dans les lives dits canoniques on claniques de la chine. revient

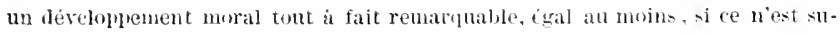
périeur, a celui des pasmmes, parfois de l'Evangile, et plus pris des bases de la eivlisation enroncenne actuelle pue la morale des philosphes grees on romains. A eet égard. la lecture du Chu-hing hisce une impresiom inefiagable, diatanl plus ine c'est le docmment de eet ordre le plus aneiun de l'humatuite.

(2) De republica, live III, chap. xx.

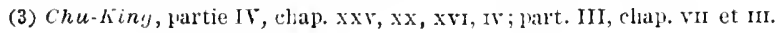


dre, de septieme ordre, de troisieme ordre et de second ordre. Ces distinctions se réfèrent probablement à limportance du labourage et des impòts dans direrses parties de l'Empire.

En outre, on trouve dans ce chapitre les détails les plus intéressants sur l'appropriation du territoire, le rèclement des eaux, la dirision des terres, la répartition des cultures et des revenus, qui sont divisés en trois classes et d’après lesquels on sut ce qu'on pouvait tirer de l'Empire, l'établissement des grands vassaux, la constitution du domaine impérial et des propriétés privées (1). On assiste ainsi aux origines mèmes de l'Empire et de la cirilisation chinoise. On roit comment elle s'est étendue peu à peu, les efforts qu'elle a exigés, la direction qu'elle a reçue des Empereurs, la place éminente qüils I ont occupée, car ils en ont été les inspirateurs, la rénération profonde que les populations en ont conçue pour eux, base inébranlable de leur autorite.

Les documents qui composent le Chu-King ont été réunis par Confucius au commencement du $\mathrm{r}^{\mathrm{c}}$ siècle avant lère chrétienne. 11. Pauthier pense qu'ils remontent à enciron 700 ans plus haut. Dans sa préface à la traduction lu Chu-Kiny, M. Max Muller dit: "Ces documents commencent aree le rème de Yao dans le $2 \dot{x}^{\mathrm{e}}$ siècle. A. C. et vont jusquà l'empereur Hsiang de la dynastie des Kaü $6 \ddot{1} 1-619$ A. C. Les premiers chapitres ne sont pas contemporains des événements qu'ils décrirent, mais les autres commencent à lètre dans le xxine siècle 2/."

Sous certains rapports, le second lirre canonique de la Chine ou le $Y$-King (livre des changrements; et les lirres classiques, le Ta-Hio ou la grande Etude de Confucius, le Tchoumg-young ou l'invariabilité dans le milieu recueilli par son pelit-fils, et le Lun-Yu, livre des entretiens philosophiques de Confucius, doivent ètre consultés après le Chu-King. Hais c'est surtout le lisre de Mencius ou Meng-Tseu, disciple de Confucius, qui en est le véritable complément.

(1) Sacred bouks of East. vol. 3. Le Chu-hing est traluit frar X. Legge. Le Chu-Kin! est le plus ancien Iocument classique de la Chine, dit M. Legge, il est relatif a la periole comprise entre 2357 et $627 \mathrm{~A}$. C.

(2) Combarer Jencius, livre II, chap. rI. 
L'ancienneté de l'occupation du territoire et de son appropriation, l'antiquité de la civilisation chinoise et de la forme du gouvernement, la succession des dynasties, la condition de la propriété privée, l'état de l'agriculture, l'ensemble des institutions, des mours, des traditions, tout cela est comme photographié, d'après le Chu-King, dans les entretiens de Mencius, dont le contrôle donne à cet antique document une valeur historique de premier ordre. Mencius ne montre pas, comme le fait le Chu-King, la constitution de tout l'empire : territoire, gouvernement, propriété, mais il explique comment tout a été ainsi constitué; c'est le commentaire du Chu-King.

Aussi est-il beaucoup plus complet pour la propriété (1), i'agriculture et les impòts. Il résulte des entretiens et réflexions de Mencius.

$1^{\circ}$ Que la propriété du territoire aurait à l'origine appartenu à l'Empereur, qui en aurait fait la répartition, dans direrses conditions aux grands feudataires, aux hauts fonctionnaires, aux ministres, aux mandarins, aux lettrés, aux populations agricoles (1); cette répartition successive est de la plus grande importance.

20 Que la terre servait en quelque sorte de monnaie - de moyen de paiement - les fonctionnaires qui araient des appointements recevaient l'équiralent de ce qu'ils auraient eu en cultivant la terre.

Tout cela n'a rien de fabuleux, ni mème d'extraordinaire, et, sauf l'influence des métaux précieux qui ont modifié les moyens de paiement ou d'attribution, tout cela se passe sous nos yeux en Amérique. Le sol des Etats-Unis est utilisé, réparti, distribué de la même manière; il est fait, au moyen de l'Homestead (2), des attributions analogues à celles qui avaient lieu dans l'ancienne Chine, d'après le Chu-hing, en faveur des particuliers, de mème qu'en faveur d'intérèts collectifs (3).

$3^{\circ}$ D'après les renseignements recueillis à Pékin, il y a en-

(1) Mencius, livre II, chap. 2 , p. 274. - Elition du Panthéon.

(2) Sur l'Homestead consulter le lirre de M. Levasseur l'Agricullure aus États-Unis, 1894, p. 458 et les ourrages de Mur. Vacher, Bureau, 1895.

(3) Mencius, tbid., p. 274. 
viron 40 ans (1), par une mission ecclésiastique russe, ces distributions auraient eu également en Chine un caractère collectif, soit celles aux grands vassaux, mentionnées si souvent dans le Chu-King et mème dans Mencius, soit celles à huit familles principales (qui devaient être les tribus primitives chinoises, celles fixées les premières dans la vallée du Hoang-Ho), soit celles à des groupes agricoles dits Gun-Jan (2).

$4^{0}$ Faut-il attribuer à la constitution collective de la propriété foncière rurale, les plaintes formulées par Mencius sur l'état de la propriété privée à son époque, état qui condamne les populations à la famine et à la misère (3)? Nous reviendrons sur cet important problème en examinant l'état actuel de la propriété foncière rurale en Chine, les rérolutions qu'elle a subies depuis l'ère chrétienne et les charges qu'elle supporte aujourd'hui.

$5^{\circ}$ On doit présumer d'après ces faits, et d'après la rareté actuelle des métaux précieux en Chine, que les impöts mentionnés au Chu-King devaient être acquittés en nature. A cet égard le lirre de Vlencius contient des textes formels. Dans l'un d'eux le premier ministre du royaume de Soung, déclare qu'il est obligé d'exiger pour tribut le dixième des produits et qu'il n’a pu abroger les droits d'entrée aux passages des frontières et des taxes des marchés ('́t). Tous ces impüts existent encore en Chine. La dime se payait en nature (ä).

Dans un autre texte, Nencius lui-mème fait observer que les barbares n'ont ni villes fortifiées, ni palais, ni maisons, ni temples consacrés aux ancètres, ni cérémonies des sacrifices, ni festins, ni pièces en soie pour les princes, ni une foule de magistrats, d'emplọés de toute sorte à rétribuer et c'est pourquoi, en fait de taxe et d'impòts, ils ne paient que le ringtième du produit.

(1) Artieles remarouales de la Revue germanique, t. 2, 1858.

(2) Létablissement des premières tribus chinoises sur le haut Hoang-Ho, leur provenance de la Tartarie chinoise sont favorables aux hypotheses de M. Terrien de la Conperie (Westem origins of early chinese civilisation), comparer l'article de I. Maspero (Journal des Debats), 16 novembre 1894.

(3) Mencius, livre I, chap. 1, p. 234.

(4) Mencius, lir. I, ch, vi, 1, 253. Sur la taxe des marchés, p, 248.

(5) Ibitem, 278. 
Et il conclut : "si nous voulions rendre l'imprit plus lérger qu'il " n'est d'après les principes de Yao et de Chun (qui exigeaient "le dixième du produit) nous deviendrions nous-mèmes barba" res (1). " Par où on voit que les grandes discussions d'impôts, de leurs reflets et de leur incidence ne sont pas nouvelles, puisque Mencius et ses interlocuteurs les ont entamées il y a près de 2't siècles.

Dès l'époque de Confucius et de Mencius s'agitaient déjà en Chine les problèmes économiques et sociaux qui ont éclaté en Europe au $x_{11}{ }^{e}$ siècle, au $x v^{e}$ et de nos jours. A beaucoup d'égards, la Chine serait autorisée à nous considérer de la manière dont les prètres d'Egypte, au dire d'Hérodote, parlaient des Grecs. La théorie très-moderne des arantages des gros budgets à raison de la réversibilité des impôts est contenue dans les observations de Mencius.

Mencius n’est pas moins exact quant à la nature des prix. "Si "rous donnez a toutes choses une valeur proportionnée d’après " seulement la quantité et la grandeur, rous jetez le trouble dans " l'Empire, linégale valeur des choses est dans la nature mème "des choses."

De mème Mencius n'a pas attendu l'apparition d'Adam Smith pour reconnaitre et signaler la loi supérieure, la loi fondamentale de la division du travail et de la séparation des fonctions contre laquelle devaient s'insurgoer le socialisme chinois au $x m^{\mathrm{e}}$ siècle et le socialisme contemporain, "une seule personne en cultivant " sa terre prépare (au moyen des échanges) les objets que tous "les artisans confectionnent. Si vous étiez obligés de les con"lectionner vous-mèmes pour vous en servir ensuite, ce serait "forcer tout le monde à ètre sans cesse sur les chemins. C'est "pourquoi il est dit les uns travaillent de leur intelligence, les " autres travallent de leurs bras. Ceux qui travaillent de leur "intelligence gouvernent les hommes, ceux qui travaillent de " leurs bras nuurrissent les hommes. C'est la loi universelle de

(1) Meneins, liv. II. ch. S'II, 1. 222. Comparer, liv. II, ch. Iv, P. 275, la série des appointements. 
"ce monde (1) ». Les interlocuteurs de Mencius ne le cèdent point à ceux de Platon ni de Joseph de Maistre.

On peut ainsi apprécier à quel degré de hauteur s'était éle vée la cirilisation de la Chine à l'époque de Confucius. Mais on sera peut-être encore mieux fixé par cette dernière réflexion, entièrement étrangère aux autres civilisations de l'Orient (sauf l'Inde) surtout à celles de la Grèce et de Rome. "Si l'on gou"verne les populations de manière a ce que leurs champs soient "bien cultirés; si on allège les impits (en n'exigreant que le " dixième du produit), le peuple pourra acquérir de l'aisance et "du bien-ètre (2). "

D'après des chiffres recueillis par Pauthier un dénombrement opéré en 780 , E. C., aurait évalué les revenus de l'Empire à $30,898,000$ taels ou $231,720 \%, 000 \mathrm{fr}$. plus 2, 7307,000 mesures de grains de 120 livres chacune. La population de la Chine se serait élerée à cette époque à $9,619,20 ̋ \dot{x}$ familles avec $322,883,000$ personnes $(3)$.

La Chine a tenu, a cette époque, le premier rang parmi les nations. Les documents qui s'y réfèrent, et qui sont parrenus jusqu'à nous, n'ont pas les mêmes caractères que la Bible, les Védas et les lois de Manou, les inscriptions ou pièces diverses relatives à l'Eg:pte et aux civilisations mésopotamiennes. Ils n'émanent pas de sacerdoces supérieurs, portés à tout ramener à des doctrines théologiques ou métaphysiques particulières. Ils indiquent une autre conception générale des choses. Ils contiennent sur les premiers temps de la civilisation historique, spécialement de la civilisation de la Chine, des faits plus en rapport avec la réalité historique, telle que nous la concevons nous-mèmes. Leur entière authenticité est attestée non seulement par des preures extrinsèques, mais par des preures intrinsèques, surtout par la similitude profonde des diverses époques de la civilisation de la Chine depuis $\check{0} 0$ siècles.

"Les principes du gouvernement, lisons-nous dans une bonne

(1) Mencius, hrre I, chap. v, 1. 247.

(2) Mrencius, livre II, chap. vi, p, 295.

(3) La Chine, p. 319 (Collection de l'Lniters). 
" histoire abrégée de la Chine (1), sont encore aujourd'hui ce "qüils étaient il y a $\mathbf{4 0 0 0}$ ans, lorsqu’ils présidaient à la vie "pastorale des tribus de la plaine du Chen-Si; car, de tous les "gouvernements dont l'histoire du monde nous a conservé le " souvenir, aucun n’a eu la mème stabilité que celui de la Chine. “ On a pu ajouter à la mème machine gourernementale quel" ques rouages nouveaux; elle a pu ètre arrètée ou endommagée "dans l'une ou l'autre de ses parties; mais elle a toujours été "ramenée dans la mème ornière, sans aucune modification " essentielle. Des insurrections, des révolutions, des invasions " ont sans doute quelquefois précipité du trùne $(\boldsymbol{2})$ des familles " anciennes et les ont remplacées par d'autres; mais ce n'étaient là " que des événements accidentels et qui ont cédé la place aux " usages antiques... Le peuple chinois est encore divisé offi"ciellement en quatre classes (comme dans le Chu-King): $1^{0}$ les "lettrés ou la noblesse; $2^{\circ}$ les agriculteurs; 3 " les industriels;

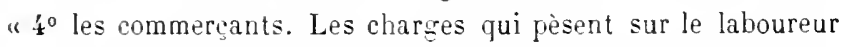
" sont plus légères que partout ailleurs et consistent seulement " en un dixième du produit de la terre (3). Le souverain étant " considéré comme le propriétaire unique de tout le territoire de "l'Empire, il ny a pas parmi ses sujets de propriétaires fon" ciers; cependant, quiconque est en possession d'une terre peut "être sùr de la conserver aussi longtemps qu'il remplira les "conditions auxquelles elle lui a été concédée ". En 1887, le missionnaire américain Wilson a risité le domaine sur lequel habite la famille illustre et toujours vénérée de Confucius depuis $2 \dot{4}$ siècles.

Il en a été de la Chine ancienne, comme de l'Inde ancienne; elle a traversé une époque de très-grande prospérité agricole.

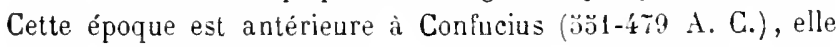
s'est prolongée longtemps après lui. A cette prospérité a corres-

(1) Paris, Desbarres, éditeurs, 1860. Histoire complite le l'empire de la Chino depuis ses origines jusqu'ì nos jours.

(2) Ibidem, 181, 178. Comparer Mencius, lirre II, chap. 1, Chu-King, partie IV, chap. xv.

(3) C'est pourquoi si quelqu'un se concilie l'affection du peuple de campagne il deviendra le fils du ciel, chap. vin, n. 1, livre II, 
pondu le développement d'une civilisation supérieure. Faisant allusion aux hommes remarquables de ces temps éloignés, Mencius dit : "Il faudrait cent générations pour arriver à l'époque " de ces grands hommes et encore cent générations après. Il n'est " personne qui, entendant parler de leurs vertus ne sente son " ûme émue et disposée à les imiter. Et combien doivent être "plus excités au bien ceux qui les ont approchés de près et " ont pu recueillir leurs paroles (1)."

Cette haute civilisation, supérieure en réalité à celle de l'Egypte, des Etats mésopotamiens, mème de la Grèce, et surtout à celle de Rome, s’est prolongée pendant des siècles avec la dime en nature et sans métaux précieux. Mème aujourd'hui cet immense empire n'a pour monnaie que la sapèque en cuivre, et il nourrit cependant plus de 400 millions d'hommes, après a voir accompli dans l'agriculture, l'industrie, le commerce, les arts, les sciences, les travaux publics, les plus grands progrès.

(1) Mencius, livre II, chap. vin, n, 13. 


\title{
LIVRE SECOND.
}

\author{
DE L'IMPÓT
}

DANS LES ÉTATS DE LA GRÈCE ANCIENNE. 



\section{CHAPITRE I.}

REMARQUES PRÉLIMIXAIRES.

La Grèce ancienne nffre, de mème que l'Egypte ancienne, l'exemple d'une nation, ou plutot d'une race (car la vieille Hellade n'a jamais pu réunir ses divers Etats en un seul fajsceau), qui est ressuscitée après de longs siècles de servitude et de mort. Cette résurrection est plus complète pour la Grèce que pour l'Egypte, du moins quant au moment actuel ; par contre, la Grèce est tombée bien plus bas et a plus souffert que l'Egypte, sa décadence a été plus rapide et plus profonde. Elle a possédé des institutions fiscales très-complexes et très-intéressantes à connaitre; mais ces institutions n'ont exercé aucune influence sur celles de l'Empire romain d'Occident, et, par suite, sur le développement fiscal des peuples, formés pendant ou après sa dissolution.

L'empire romain d'Orient, plus tard l'empire byzantin a fourni, il est vrai, une bien longue et très-illustre carrière, puisqu'il a survécu dix siècles à l'empire d'Occident, mais les institutions, l'esprit, les traditions de la Grèce héroïque, de celle des guerres médiques, de Périclès, d'Agésilas ou d'Alexandre n'ont eu aucune action sur la vie et le développement de l'empire byzantin qui n'avait conservé de la vieille Grèce que sa langue. Les institutions fiscales de Dioclétien et de Constantin se sont maintenues pendant toute la durée de l'empire byzantin et le christianisme a seul alimenté toute la vie morale, sociale, intellectuelle, religieuse de la société gréco-romaine, du monde byzantin.

Les divers Etats de la Grèce ancienne se divisaient en deux groupes : $1^{\circ}$ Le groupe des Etats démocratiques ayant Athènes à leur tête. $2^{\circ}$ Le groupe des Etats aristocratiques avec Lacédémone comme Etat directeur. Les institutions fiscales étaient à 
peu près les mèmes dans chaque groupe; mais elles différaient totalement entre les groupes. Athènes et les Etats démocratiques, avaient le commerce, l'esclavage, la piraterie, pour éléments économiques. Lacédémone et les Etats Doriens viraient du revenu de la propriété fonciere. Nalgré le ròle principal d'Athènes dans le développement de la civilisation hellénique, la prépondérance po. litique a appartenu au second groupe, établi dans le Péloponèse surtout et possédant une plus grande importance territoriale.

Le temps ne nous a transmis des documents et des renseignements nombreux, faciles à contröler que sur le sýstème fiscal athénien. C"est le moins disparate, à plusieurs égards, soit avec les impits des peuples contemporains de la Grèce ancienne, soit arec les impòts de l'Europe actuelle. Néanmoins, les institutions fiscales des autres peuples helléniques, Lacédémone, Corinthe, Arges, Thèbes, les Achéens ont eu une grande importance; Xénophon, Aristote, Plutarque nous ont conservé quant à Lacédémone, des faits du plus grand intérèt, à raison de l'originalité de l'organisation économique et fiscale des Lacédémoniens et de leur contraste, mème de leur opposition avec celle des États démocratiques de la Grèce; on est beaucoup moins fixé quant aux autres États de la Grèce.

Entre les législations fiscales et financières des deux groupes de la Grèce ancienne cette opposition est absolue; les différences des conditions économiques, provenant de la diversité des territoires, ne suffisent pas pour en expliquer toute la force et la persistance. On est obligé d'en demanter la raison à la présence en Grèce de deux races entièrement dissemblables par les origines, les mours, les tendances, la race dorienne, qui est la race militaire et aristocratique de la Grèce; la race ionienne, qui est la race commerçante, maritime, intelligente, savante.

Nulle entente entre ces deux races, mème aujourd'hui dans les centres occupés autrefois par la race dorienne, soit dans le Péloponèse, soit en Crète, on reconnait les descendants de la grande race militaire hellénique. Ce sont ces descendants qui ont lutté et qui luttent encore avec le plus de ténacité contre l'oppression des Ottomans, ce sont eux qui ont eu la principale part dans le réveil de la Grèce depuis deux siècles. 


\title{
CHAPITRE II.
}

\author{
LES DORIEYS.
}

Les Doriens appartiennent à la race illyrienne, dont les différentes tribus ont occupé, de tout temps, les territoires montagneux au sud du Danube. Ottfried Nuller, qui les a particulièrement étudiés dans un livre auquel se rattache le renouvellement des travaux de la Grèce antique (1), leur donne la Macédoine pour primitive patrie. Il les relie ainsi au groupe militaire qui a précédé les Romains. On retrouve aujourd'hui dans les Rouméliotes les antiques qualités des Doriens et des Mlacédoniens. Peu à peu, les tribus doriennes (Hỵlléens, Dymanes, Pamphyles) se seraient établies sur les pentes de l'Olympe; puis elles auraient garné la Thessalie, d’où elles se seraient dirigées vers le Péloponèse pour le conquérir et l'occuper. Leur invasion est restée une époque mémorable dans les fastes de la Grèce héroüque (2). C'était une invasion lente, mais complète, comme devaient ètre plus tard les invasions des Celtes et des Germains. Femmes, enfants, esclares, accompagnaient plus de vingt mille guerriers. C'était une première poussée des races du Nord vers le .Midi (3). Les Doriens apportaient un dialecte nouveau, des mœurs plus fortes, une éducation et des goùts militaires, une pratique persistante de l'esprit d'association, des habitudes plus fières et aristocratiques. A bien des égards, il en

(1) Ottfried Muller, Les Doriens, 1839. M. Cornewall Lewis a donné de ce livro célèbre une traduction en anglais excellente.

(2) Ibilem, introduction, livre I, 34-36. - Curtius, Histore grecque, I rol., p. 119,127 .

(3) Ibitem, 1) 37, 51. 
a été de mème des tribus germaniques aux $v^{\mathrm{e}}$ et $\mathrm{v}^{\mathrm{e}}$ siècles E. C. Les Doriens trouvèrent le Péloponèse formant plusieurs contrées séparées: Elide, Achaïe, Arcadie, Argolide, Laconie, Messénie (1), et correspondant à des zònes agricoles qui ont longtemps persisté. Ils en firent la conquète successive; celle de la Messénie fut la plus longue et la plus difficile. Puis ils se répandirent de tous côtés et fondèrent de nombreuses colonies dans le Péloponèse (Corinthe, Sicyone, Epidaure), puis dans l'Asie Mineure, en Crète, en Sicile, dans la grande Grèce (Halicarnasse, Rhodes, Cos, Syracuse). Avec le temps, les diverses contrées du Péloponèse furent réunies en une confédération dont Sparte était le centre et dont les Spartiates avaient la direction. Les colonies doriennes se rattachaient à cette confédération, dont la force s'est manifestée pendant la guerre du Péloponèse (2).

Il y eut ainsi, en Grèce, un milieu dorien, un monde dorien, un cosmos dorien, un ordre de choses dorien (3). L'aristocratie de race, la stabilité dans les institutions sociales et politiques, le maintien des traditions des ancètres ('́t), la préférence aux irlées conservatrices, justifiées par la dureee, l'égalité entre compagnons militaires, le mépris du travail, l'éducation militaire, la guerre ( 3 ), avec la lance pour symbole, la possession du sol, le respect personnel et le plus haut développement physique et moral de l'homme, formaient les éléments de cet ordre de choses, entièrement contraire à la mobilité, aux tendances égalitaires et démocratiques, aux habitudes commerciales et maritimes des autres populations grecques. Partout les Lacédémoniens

(1) O. Muller, 2e vol., p. 9 et 11.

(2) Histoire grecque, 1 vol., 1r. 33.

(3) Ott. Muller, tome 2, p. 2.

(4) Not to degenerate from his ancestors was the strongest exhortation which a

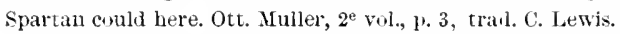

(5) Chant populaire spartiate :

$J^{\prime}$ ai jour richesse une grantle lance, une éje et le bouclier qui fait rempart à mil chair ;

C'est arec cela que je laboure, que je moissumne;

Arec cela que je fonle le donx jus le la vigne.

Curtius, 1 rol., I'. 207. 
renversaient soit les ty̧rannies, soit les démagogies, en opposition a vec leurs institutions et leurs meurs ( 1 .

Aussi .I. E. Curtius n'hésite-t-il pas à dire que "l'on peut voir dans les Doriens les rrais Hellènes (2) ". A cet égard, l'influence extraordinaire de la Renaissance et de l'enseignement classique explique seule les notions qui ont prévalu dans l'Europe méridionale et occidentale sur les éléments divers et opposés de la société hellénique et la préférence donnée à Athènes sur Lacédémone. On a ru surtout dans la Grèce ancienne des poëtes, des philosophes, des historiens, des artistes admirables que la race innienne a produits et qu'Athènes a réunis; mais la Grèce politique était tout autre chose que la Grèce artiste. II suffit dourrir les historiens Hérodote, Thucydide, Xénophon pour le reconnaitre. Le ròle militaire prépondérant a toujours appartenu à Lacédémone; et si la race Helléniı̧ue avait su vaincre ses insurmontables dirisions, l'hégémonie politique qui n’a réellement été exercée en Grèce que par Lacédémone, lui aurait été maintenue malgré et peut-ètre aussi grìce à ses institutions politiques, sociales et fiscales.

(1) Toulem, 73, 84, chap. $\mathrm{N}$.

(2) Tbidem, chap. 1x. 


\section{CHAPITRE III.}

LES ÉTATS DORIENS ET LA CRĖTE.

La caractéristique essentielle de la race dorienne est le partacre et la culture du sol en vue d'entretenir la classe militaire de façon à ce que celle-ci n’ait qu’à s'occuper de la gruerre et du gouvernement supérieur de l'Etat. Par suite, elle n'a pas à payer d'impit. Son entretien, assuré par le labeur d'autres classes, est déjà un mode de payer l’impót. Pendant leur passage en Thessalie, les Doriens ont autrefois réglé sur ces bases l'occupation, le partage, la culture du territoire. Ils apportèrent dans le Péloponèse les mimes institutions. Ils durent encore les fortifier pour contenir les populations qu'ils vainquirent (1).

Ils semblent aroir trouvé dans l’ìle de Crète un milieu spécialement approprié au développement de ces institutions. Aussi Aristote voyait-il dans les lois de l'ile de Crète le prototype de celles de Lacédémone (2). Elles étaient moins rigoureuses; elles navaient pas cet entrainement militaire absolu des Spartiates. Elles formaient un ensemble d’institutions fiscales qui avaient le double but de consilider le fait de la conquète sans oppression et de maintenir linégalité de condition entre les vainqueurs et les vaincus, d’un cité, et l'égalité entre les vainqueurs euxmèmes, d'un autre còté. A une éporue d'entraìnement égalitaire, socialiste, comme la fin du $x x^{e}$ siècle, il y a, par suite, un intérèt réel à connaitre, à étudier les institutions fiscales doriennes et à en examiner les résultats car, elles ont affecté un caractère

(1) Muller, Ibidem, t. 2. P. 64. A class of Perieci and also of helots was the basis of the Doric form of government, p. 64 .

(2) Politique, live II, chap. rn. 
socialiste accusé, en rue de conserver l'écalité entre les vainqueurs. Ces institutions ont eu deux foyers principaux. Lacédémone et l'ile de Crète. Lacédémone a joué dans la Cirèce ancienne le ròle politique dominant; quant à l'ile de Crète. elle a pu maintenir son indépendance jusqu à la conquète romaine 66 avant le Christ. Les Slakiotes, descendants des Doriens de Crète, ont opposé et opposent encore aux Jttomans une indomptable résistance. Ces institutions, à Lacédémone comme dans l'ille de Crète, araient pour fondements essentiels le droit supérieur de propriété de l'Etat sur toutes les terres, la restriction. aussi grande que possible, de la propriété mobilière, et le pajement de limpòt en nature; quant à ce troisième fait. nous l'arons déjà rencontré daus toutes les anciennes civilisations de l'orient. Il s'y est affaibli, sans jamais en disparaitre, puisque dans l'Empire ottoman la dime est encore parfe en nature, ansi que dans l*Inde et en Chine.

Les colonies doriennes avaient apporté dans l'ile de Crète les traditions et les muursqui ont produit l'organisation si curieuse et si puissante de Lacédémone. Les Doriens asserrirent les populations qui occupaient lîle de Crùte et les réduisirent à peu près à la condition de colons comme les Périéques de Lacédémone ou les Pénestes de Thessalie. Ces colons étaient les Clarotes. Les Clarotes cultiraient les terres des particuliers, probablement dans les mèmes conditions que les périèques, c'est-à-dire a la charge de remettre une certaine part en nature: à crité des Clarotes se trouraient dautres colons les IInoïtes qui cultivaient les domaines de l'Etat. L'Etat avait des revenus spéciaux.

Les colons deraient l"impòt en nature. "Sur les fruits qu'on " récolte et sur les troupeaux qu'on élère. qülls soient à l’Etat "ou qu"ils proviennent de rederances parées par les serfs, on "fait deux parts, l'une pour le cuite des dieux at pour l'admi"nistration, lautre pour les repas communs, ou sont ainsi " nourris, aux frais de l'Etat, hommes, femmes et enfants (1). "

II. Schömann a compiété le texte d’Aristote en lui donnant

(1) Aristote, Polirique, liwre II, chap. vit. st, traduction Bartheity SaintHilaire. 
une interprétation nouvelle. D'après lui (1), ce qui parait contraire à la tradition des Périèques, ce seraient les propriétaires, les maìres qui auraient dù l’impòt " dirisé en deux classes, " auxquelles étaient affectées deux caisses publiques, l’une " chargée de fournir aux frais du culte et de l'administration, "l'autre qui devait subvenir aux syssities (ou repas en com" mun) et plus généralement à la uourriture des citoyens et à "lentretien de leur maison. Seuls, en eflet, les hommes et les "enfants d'un àge déterminé prenaient part aux syssities, mais " la mème caisse était tenue d’alimenter, dans leur ménage, les "femmes, les filles, les garcons trop jeunes pour suirre leur "père et leur mère, et mème la domesticité, d'où l'usage de " payer par tète d'esclave un statère d’Egine. Si la dìme ac"quittée par les riches était considérable, ta part des pauvres "était loin de représenter l'équivalent des dépenses qu'ils im"posaient au Trésor et l'on pourait dire que tous les citoyens "etaient nourris aux frais du public. Les riches et les paurres " n’étant pas également répartis dans toutes les hétairies, il était "nécessaire que chacune d'elles versìt à la caisse générale les "cotisations qui devaient profiter à toutes. "

Au-dessous des Clarotes et des Mnoïtes venaient les esclaves des deux sexes affectés au service de la maison.

Quant aux étrangers, dont il faut toujours tenir compte, dans la Grèce ancienne, ils étaient admis aux syssities - ou repas en commun.

Ainsi la société, en Crète, se composait de trois classes : les Doriens-militaires, les colons-cultivateurs et les esclaves. Ces trois classes étaient entretenues exclusivement au moven de dimes en nature, par la seconde, qui exploitait le sol. Nous r etrouvons, dans leurs traits généraux, l'organisation sociale de la primitive Egypte, sauf les syssities, et de la Pálestine avant la captivité (2).

(1) Antiquités grecques, $1^{\text {er }}$ volume, 354 , traduction Galuski. Nous ne saurions trop recommander ce livre remarquable ví, à côté d'une connaissance approfondie des faits et des textes, on troure une admirable peiuture de la rieille société hellénique.

(2) Ottfried Muller a releré les raplorts généraux de ces institutions arec celles d'Israël. 
Dans ces sociétés limpoit n’est pas encore nettement dégagé soit de la rente du sol, soit de la part en nature revenant aux propriétaires.

Les repas en commun ont caractérisé la race dorienne, si remarquable par l'originalité de ses institutions qui doirent se rattacher à la communauté primordiale des intérêts, des muxurs de la tribu ou du clan. Les repas en commun étaient une forme de paiement de l’impòt. Ils avaient été institués pour maintenir l'égalité entre les compagnons militaires. Ils étaientalimentés au moyen de rederances en nature. Mlais ils cachaient une inégale répartition de l’impit qui, par suite, retombait plus sur le paure que sur le riche. Chaque convive devait livrer une redevance égale, lorsugue les charges domestiques et les revenus réels nëtaient pas égaux. Loin de faroriser l'égalité, les repas communs favorisaient l'inégalité. Le résultat a été ainsi contraire au but réel de l'institution qui était de maintenir l'égalité, mème aus dépens du paurre.

Les institutions d'Isrä̈l marquaient la mème tendance, entièrement inconnue à l'antique civilisation de l'Egypte, de la Chaldée et de l'Assyrie; elle s'est également produite, non seulement à Lacédémone, mais à Athènes, c'est-à-dire sous deux formes de gourernement et dans deux sociétés tout à fait opposées.

Dans une telle organisation sociale, l'incidence de l'jmpot, quelle que soit sa forme, quel que soit son nom, a-t-elle lieu en entier sur la classe qui cultive le sol, puisqu'elle ne dispose d'aucun mộen de répereussion ni sur les esclaves, ni sur les maitres, ni sur l'Etat?

La tradition du partage en nature, fondement de la dime, peut modifier cette incidence, à raison de la part que la coutume attribue à celui qui cultive le sol. Souvent cette coutume prenait, chez les peuples anciens, un caractère religieux, sacré. En tout cas, elle était presijue toujours immuable; cette immutabilité a marqué certaines cirilisations; elle explique, comme pour la Chine, l'Inde, l'Egypte, leur grande durée. Il n'en a pas été de mème pour l'aristocratie romaine, qui s'est montrée si dure, ni pour laristocratie anglaise, mais la persistance de la culture à 
moitié en France, en Italie et dans une partie de l'Europe appartient au mème ordre de faits.

Cette immutabilité suffit pour montrer comment, chez les Doriens, limpòt a fini par détruire leurs institutions. Dès que la part des classes cultivant le sol était fixe, immuable, les dépenses de la rie commune qui étaient un impòt, puisqu'elles avaient pour but de maintenir l'organisation sociale elle-mème, ont du ètre prélevées par les classes supérieures sur un revenu invariable et il n'en est resté qu'une part insuffisante pour l'entretien des familles les plus nombreuses, les plus coùteuses. En effet, les frais de familles, essentiellement variables et croissantes, ont dù se reprendre sur des ressources invariables (Aristote l'a nettement établi).

Delà, les précautions sérères prises dans les Etats grecs doriens contre l'accroissement du nombre des familles et l'augmentation de la fropulation; de là une réglementation de la vie et des rapports sexuels qui s’est propagée dans toute l'ancienne société hellénirgue, qui a modifié l'organisation de la famille, qui a singulièrement amoindri la place de la mère pour surélever le rang des Hétairres et qui a eu tant d'influence sur les mœurs grecques. Pour s'en faire une idée; il faut lire les tableaux qu'Athénée

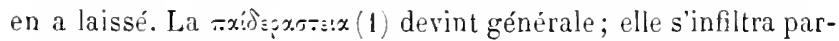
tout, elle fut acceptée par les hommes les plus remarıuables, jusqu'au moment où des obserrateurs sagaces, comme Polybe, purent en constater les résultats par la dépopulation, la dégradation, l'affaissement de la Grèce. Non seulement c'est le christianisme qui a combattu ces meurs et ces institutions, mais la guerre qu'il leur a faite a été l'une des grandes causes de son triomphe. Il a remis la société grecque, égarée, dans la voie tracée à la destinée humaine, roie que la Chine, l'Inde et l'Egypte n'ont jamais méconnue; aussi n'ont-elles pas traversé des temps aussi douloureux que la Grèce.

Les écoles socialistes contemporaines ne se font pas d'illusion

(1) La pédérastie greefue ne doit pas etre toutefois jugcée exelusivement d'après nos idées. Bien 'pue reconnue par les lois et les mueurs, si elle dégénérait en abus coupables, elle etait séveremeut punie. (1). Muller, livre II , chap. w. cicéron, cité 1ar M. O. Muller, a fait les mèmes observations. 
quant aux conséquences inévitables sur la population, la famille, les mours d'un nourel essai de leurs doctrines (1). Elles pensent, avec les théories pessimistes de tous les temps, spécialement du $\mathrm{xrx}^{\mathrm{e}}$ siècle, Schopenhauer et llartmann, certaines sectes russes que la diminution de la population, lamoindrissement, la restriction et l’interdiction de la génération, sont nécessaires pour modérer, réfréner, paralyser l'activité économique des sociétés contemporaines et combattre l'exploitation de l'homme par l'homme; elles voient dans cette activité la raison des excès du travail, du surmenarge, du sucuting system et de linézalité des condilions qu'elles déclarent plus grande que jamais. Elles ne reculent mème pas devant une limitation générale de la liberté humaine, limitation qui frappe dans les institutions doriennes; peut-ètre mème comme en Crète et comme à Sparte, car, en réalité, c’est la condition essentielle de toute expérimentation de leurs erreurs, se résignecont-elles, afin de faire vivre une communauté nouvelle des Egaux, entre une élite de maitres, à rétablir la servitude pour les humbles chargés de sa subsistance $(\boldsymbol{2})$.

(1) Le sociali-me peut amener un nouveau moyen âge, des barbares des Eglises, des éclipses de la liberté et de l'individualite, de la civilisation en mu mot. Renan, Isräl, 5́ vol., 420. Voir anki Rassegna, décembre 1893.

(2) Laeonupete dupain par le prince Kropokine, p. 76. - Lfs Foluntaires des denrées, comparer nus observations sur les lois frumentaires romaines, liv. III. 


\section{CHAPITRE IV.}

LaCédédione. - SEs institutions fiscales et sociales.

\section{\$ 1. Les Spartiutes.}

Engendrer le Spartiate, former, élever, entretenir le Spartiate; maintenir l'égalité entre tous les Spartiates; faire du Spartiate un ț̣pe d'homme, de guerrier supérieur qui assure à Lacédémone la suprématie, non pas par la quantité des hommes, mais par une sélection infatigable qui surhausse le niveau physique et moral de l'homme, voilà le fondement du système politique et social de Lacélémone (1). Les institutions fiscales lacédémoniennes y sont nécessairement adaptées. C'est l'esprit ¿nénéral des populations Doriennes. La similitude est donc frappante entre les lois de la Crète et les lois de Lacédémone; mais combien les institutions lacédémoniennes sontelles plus puissantes! elles ont été pratiquées pendant six siècles; si elles n'ont pas dominé le mouvement de la civilisation hellénique, elles ont une intluence décisive sur les destinées politiques de la Grèce; elles ont valu à Lacédémone la suprématie militaire parmi les nombreux Etats grecs; elles ont été considérées, par les classes instruites de la plupart des Etats de la Grèce, comme supérieures aux institutions démocratiques l'Athènes; elles ont obtenu la préférence des esprits les plus éminents de la Grèce, Thuç̃dide, Xénophon, Platon (2), Plutar-

(1) Toutes les fois qu'il s'agit de la classe milntaire supérieure, on doit employer le terme spartiates, mais le terme de Lacédémone est celui qui convient à l'Etat foudé et gouverné par les spartiates.

(2) La cité de Platon (Lois, lirre 5) arec 5,040 citoyens et 5,040 lots n'est qu'un abrégé de Lacédémone. - Dans le lirre 3, Platon montre par quels changements ou pulurait en faire un youternement parfait. - Iénophon, Lacéclémone, chap, rili. 
que; elles paraissent néanmoins en contradiction absolue avec les idées qui ont prévalu plus tard dans l'organisation de l'imprit.

En y regardant de plus près au surplus, en comparant les institutions de Lacédémone avec celles de Rome, mème avec celles d'Isräl, on retrouve des lignes communes, des rapprochements qui permettent de se rendre compte de la nature de l'organisation sociale des Lacédémoniens. Entre Lacédémone et Rome, notamment, la ressemblance est remarquable. L'une et l'autre sont des aristocraties, des aristocraties militaires; elles représentent l'un des deux grands mouvements politiques et sociaux qui se sont produits dans les Etats du bassin de la Méditerranée lors de l'amoindrissement, puis de la disparition de l'influence et de l'autorité des anciennes familles royales. Elles n'ont pas eu la mème destinée, parce que la situation géographique de Sparte ne comportait pas les ressources que Rome a rencontrées dans l'Italie centrale et que la Grèce n'offrant pas la mème unité que l'Italie, Sparte a eu à lutter contre un Etat plus important, mieux situé et appelé à lui résister. Cet Etat a été l'organe du second de ces deux courants, le courant démocratique. Malgré l'incomparable supériorité d'Athènes dans la marche de la civilisation hellénique, malgré la place brillante qu'Athènes a conservée pendant 3 à 6 siècles sous la domination romaine, Athènes n'a pas été pour la Grèce l'état modèle, l'état type, l'état directeur. Son influence est restée extérieure, coloniale, maritime, artistique, civilisatrice; dans la Grèce mème, elle n'a jamais obtenu la prépondérance (1). C'est que le courant aristocratique était plus puissant en Grèce que le courant démocratique. Les démocraties d'Athènes, de Corinthe et de quelques iles de l'Archipel ont été de brillantes exceptions, mais des exceptions; des foyers splendides, mais qui se sont éteints. En Grèce, comme en Italie, le courant aristocratique était le plus fort. Il a montré toute sa puissance avec l'aristocratie romaine; il a survécu à l'empire romain. C'est ce courant qui, à la chute de l'empire romain, a

(1) Schomann, Antiquités greeques, 1er vol., 220. "Les Spartiates restirent les maitres et par suite fut écrasée dans tous les Etats la démocratie qui avait eu le dessus durant l'hégémonie d'Athínes. » 
dù prendre et a conservé, pendant plus de dix siècles, la conduite de la civilisation en Europe. Comme rien ne reflète mieux les mouvements généraux des nations que l'histoire de l'impôt, il nous sera possible de reconnaitre, plus d'une fois, par l'histoire de l'impòt, les grandes lignes de la direction générale des peuples européens.

La singularité des institutions de Lacédémone, leur opposition arec celles des peuples actuels expliquent les critiques qu'elles ont provoquées et le scepticisme avec lequel on les a traitées. Les textes les plus clairs ont été torturés, détournés de leur véritable signification. Lourrage, si curieux, de Xénophon lui a été contesté. La rie de Lỵcurgue par Plutarque, rune de ses meilleures biographies, a été considérée comme légendaire. Lycurgue est devenu une sorte de personnage mythique comme Orphée ou Minos. Les progrès des études archéologiques, la comparaison des institutions primitives des races et des peuples ont détruit ces critiąues. Loin de perdre de leur importance, les plus vieilles traditions, les plus anciens textes que Plutarque nous a conservés en ont acquis une plus grande; le témoignagge de Xénophon, cet illustre et parfait représentant de la civilisation hellénique aux jours de son plus bel épanouissement, est aujourd'hui considéré comme l'une des sources les plus authentiques et les plus précieuses de l'histoire de la Grèce (1).

\section{\$2. Les conelitions du milieu.}

Quelques mots sur le territoire. La terre de Pélops forme un quadrilatère irrégulier de 22,201 kil. carrés, habité aujourd'hui par 800,000 habitants. Il ne devait pas être aussi peuplé à l'époque de la grandeur de Lacédémone. La Grèce renait, et cette renaissance, de mème que celle de l'Italie $\langle 2\rangle$, est un terrible argument contre la théorie de la dégénérescence et du remplacement des faibles races par les plus fortes. Le sol est toujours fertile :

(1) $1^{\circ}$ Gourernpment des Lacélémuniens : $2^{\circ}$ Agésilas.

(2) Ta population aetuelle de l'Italie est au moins 'pnatruple de ce qu'elle était après les gruer.e- puni gues, époque de sa plus grandeprospérité sous les Romains. 
la vigne, l'olivier, le mìrier, le froment, $y$ donnent les mêmes récoltes qu'aux jours de Lacédémone. Chaud le long des mers qui entourent le Péloponèse (1), le climat est rude sur les montagnes ou dans les vallées de l'intérieur. Les dentelures des còtes sont toujours farorables à la marine et à la piraterie, néanmoins le Péloponèse est encore un centre agricole comme du temps des guerres de Mlessénie. Les dénominations romaines, byzantines, turques du territoire ont disparu. Les vieilles provinces Helléniques, si chères à tous les Hellènes, Laconie, Messénie, Arcadie, Achaie, Elide, Argolide, Corinthe subsistent encore. Mélange de vieux Hellines, de quelques Romains, de Slaves, de Francs, de Turcs, la population est demeurée au fond grecque et, avec plus de sagesse politique, ce qui prouve que les Hellenes sont bien l'élément principal de la population, le Péloponèse pourrait redevenir une des plus heureuses récrions de l'Europe orientale.

Telle était la Lacédémonie.

Aristote était, sans doute, fondé quand il disait que les institutions de la Crète étaiert le prototype de celles les Lacédémoniens (2). Ce n'en est pas moins chez eux que ces institutions ont pris leur plein développement et qu'elles ont produit tous leurs fruits. Aussi la Crète n'a eu qu'un rôle secondaire à còté du ròle prépondérant qu'ils ont rempli dans l'histoire de la Grèce. A Lacédémone, comme en Crète, institutions politiques, institutions sociales, institutions fiscales forment un ensemble : on ne peut les séparer les unes des autres, on ne peut comprendre les unes sans les autres. Pour donner une idée claire et précise des institutions fiscales, il est, par suite, indispensable d'expliquer les conditions du milieu politique et social. Ce milieu n'a pas été créé par les lois de Lycurgue. Il leur est antérieur. C'est le résultat des traditions, des tendances, des efforts séculaires de la race dorienne elle-mème. Lỵcurgue (3)

(1) Beulé, Etude sur le Péloponese, 1855. Ce- etules contiennent une fraiche deseription du massif montagneux de l'Areatie, le l'Achaie, de l'Aluthe fet lle l'Elite, mais le ton est quelque peu bucolique.

(2) Politique, litre II. chaj. V. - ottf. Muller. 2" vol., 196.

(3) sur Lyeurgue, sa vie, son l rsomnage si curienx, son asure, l'école eriti-

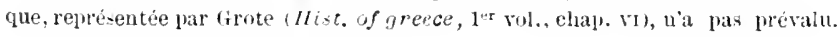


(vers $821 \mathrm{~A}$. C.) aurait prescrit, d'après les conseils formels de l'oracle de Deiphes, par des lois diverses, tout ce qui concernait le gouvernement, attribué aux seuls Spartiates; il aurait réglé le partage et la culture des terres, les rapports des divers éléments de la population entre eux, le maintien de l'égalité entre les Spartiates, la conservation des familles, l'éducation, le paiement de l'impit; mais tous ces rèclements avaient pour bases les institutions primitives des Doriens, leurs aptitudes militaires, leur gront pour l'association, leurs traditions aristocratiques (1). Lycurgue doit y avoir pris une grande part, toutefois les uns ont eu lieu avant lui, les autres après et successivement. Vainqueurs rles populations qui occupaient, avant eux, le Péloponèse, les Doriens eurent à approprier leurs institutions primitives de manière à dominer le Pèloponèse, sans l'asservir, car ils étaient tout à fait inférieurs en nombre; c'est cette appropriation qui a été principalement l'œuvre de Lycurgue. Il fallut assurer la suprématie militaire aux Doriens, plus tard les Spartiates, et obtenir le concours des populations vaincues, de manière à préparer l'hégémonie de Lacédémone ( $\mathbf{2}$ dans la Grèce entière. Comme le laisse entendre otfried Muller, ces arrangements doirent ètre antérieurs à Lỵcurscue (3). L'ưuvre de Lycurgue n'a dì consister qu'à donner sa forme et sa constitution définitives au gouvernement de Lacédémone et à établir les rapports des Spartiates entre eux.

Les populations péloponésiennes, dans ces arrangements, perdirent tout droit politique, mais elles durent fournir, de même que les Spartiates, le service militaire. Elles se composaient elles-mèmes de deux éléments distincts provenant de luttes an-

Consulter Curtius, 1er vol., 221. - Claulio Jannet. Instirutions de sparte, p. 29. - Fustel de Cohlanges, Cité antique, sl. - En sensopposé, G. Gilbert. traductiou auglaise, p. 11. - Les constitutions de sparte et d'Athenes, en allemand

(1) O. Muller, ibidem, p. 12, 16,64,281. - Curtins. 1er vol., 128. - Gilbert, ibidem, p. 7. -- Ces riglements formaient la grande Rhetra comme une charte, un pacte solennel.

(2) Domiuer le Péloponése sans l'asserrir. - Curtius, ibid., 1er vol.. 355.

(3) Sur le partage des terres, O. Muller, 2e rol., 195.197. - Claudio Jannet, $49 \cdot 54$, 
térieures. - Les Périèques et les Hilotes; les Périèques tenanciers à divers titres et les Hilotes cultivateurs desterres. Les uns et les autres ont constitué le fond de la population du Péloponèse jusqu’à la ruine de l'hégémonie des Spartiates. Les Périèques reçurent progressivement 30,000 lots de terres à titre de tenanciers hẻréditaires, moỵennant des rederances perpétuelles, mais fixes, envers l'Etat. Ils durent les cultiver eux-mèmes arec le concours de quelques esclares - mais il leur fut permis d'habiter les villes, de se livrer à l"iudustrie et de faire le commerce (1). En outre, ils furent tenus de faire le service personnel des Syssitics ou repas en commun des Spartiates. Quant aux Hilotes, ils devinrent des serfs, chargés de la culture de 9,000 lots de terres attribués aux Spartiates, dont ils a vaient à assurer l'entretien moyennant aussi des rederances déterminées. Certains Hilotes, inférieurs aux autres, cultivaient les terres de l'Etat.

Rien d'excessif dans ces arrangements 2 . Dans l'Inde, la condition des Croudras était pire que celle des Hilotes; la situation des Périèques était meilleure que celle des Fellahs de l'Ergpte romaine. Les Espagnols se sont montrés autrement inexorables envers les propriétaires et cultivateurs du Mexique et du Pérou. Grice à la fixité des rederances, Périèques et Hilotes ont pu grandement améliorer leur sort. Ils sont devenus les soldats d'Aratus et de Philopémcen. Avec le temps, leur droit de possession s’est changé en droit de propriété.

Les Périèques ne sont pas complets propriétaires ; ils ne peurent vendre leurs droits qui se transmettent dans leurs familles de màle en màle par les successions ou adoptions; s'ils sont adoptés par un Spartiate, ils entrent dans la classe supérieure, les Hilotes peuvent ètre affranchis. Ils prennent alors le nom de Hothaces ou de Néodamodes. S'ils sont adoptés après avoir été les serri-

(1) M. (). Muller cite plusieus de ces villes. Il en compte 24. Avec le temps les Périérues devinrent le principal elément de la prpulation urbaine des Lacedémonieus, 2e vol., chal'. 2. - schomann, ibidem, 236.

(2) 0 . Muller, $2^{*}$ vol., 1'. 31 . - Il serait facile d'ctablir des raplruchements entre les conditions diverses les Gallo-romains de elasse inférieure, les Périèues, les Hilotes. 
teurs des Spartiates, leur situation se rapproche de celle des Pèrièques (1).

Quant aux Doriens mèmes, aux spartiates, ils forment une caste militaire, soumise à un entrainement permanent. Les trois tribus doriennes primitives sont subdivisées chacune en dix abe; chaque obé compte 130 familles et chaque famille constitue une maison genea. L'existence des Spartiates n'a qu'un objet et qu'un but : la guerre. "Lacédémone, dit M. Curtius, était toujours sur le pied de guerre (2) n. Point de travail, point de trafic, point de monnaie circulante, point de propriété immobilière personnelle. Dans la répartition des terres, 9,000 lots, égaux quant au revenu quils pouvaient donner $(3$, ont été attribués, à titre perpétuel seulement, à chaque famille de Spartiate, avec sept familles dililotes par lot pour le cultiver. Nais ce fouds, à lorigine, ne se transmet que de mòle en màle dans la mème famille; la femme n'hérite pas; faute d'héritiers, l'Etat dispose du lot. Le lot ne peut ètre partagé. Il rerient ì l'ainé des héritiers, sauf par lui à assister les autres personnes de la famille. Partant ni partage, ni vente, ni achat, ni hypothèque. L'ohjet essentiel de l'Etat, en vue d'assurer sa durée et sa puissance, par le maintien de la supériorité de la race, est non seulement l'entrainement militaire des Spartiates, mais la conservation de l'égalité entre guerriers appelés aux mèmes devoirs, entre opoto: - entre éraux (ít). Les sociétés d'Eguux datent de loin; égalité de race, égalité de culte, égalité d'entrainement, égalité d'éducation, égalité de courage, égalité d'existence: de là, l'éducation en commun, la vie commune, les repas en commun, les jeux en commun, les liens et les aflections des compagnons militaires $(\ddot{3})$, de là encore la remise des dettes à l'avènement de chaque roi (6) : tout est disposé pour sauvegarder l'ègalitė phy-

(I) O. Muiler, ibidem, p. 62.

(2) Curtius, $1^{\mathrm{er}}$ rol.

(3) O. Muller, tome 2, chaj. x. 195-215. - Plutaruue, Lycurgue, chap. xi et xil.

(4) Sur l'́galite, les Egaux, - 0. Muller. 3'rol.. 1. 84. - Plutariue, chap. $\mathrm{x} 1$.

(5) Sotamment les Epeuuacte. les compagusu-de : Triaciles et des Enomoties.

(6) 0. Inuller, 3 rol.. 21 s. 
sique, matérielle, morale. De là enfin les règles sur le mariagre - l'homme ne peut se marier avant trente ans, la femme avant vingt-cinq; la génération mème sera réglée (1); les frères pourront avoir la mème femme; la polyandrie régnera au foyer lomestique et assurera la perpétuité de la maison.

Tel est le milieu : les institutions économiques et fiscales devaient y correspondre afin de le perpetuer.

\section{$\$ 3$. Institutions économiques el fiseales.}

$1^{\circ}$ En principe, le Spartiate ne doit pas et ne paie pas d'impòt, à moins de circonstances extraordinaires dans lesquelles il est obligé de fournir seulement certaines contributions en nature $(\boldsymbol{2})$.

$2^{\circ}$ Il est nourri dans les syssities (3) auxquelles il doit remettre par mois un médimne (environ 30 litres) de farine, 8 courges ou 23 litres de vin, 5 mines ou environ 2 kilog. de fromage et 1 kilog. de figues - plus en argent 10 oboles d'Egine (4.-Cesse d'être citoyen tout Spartiate qui n'assiste pas aux Syssities. Nul ne peut s'absenter sans congé. Est exclu tout Spartiate qui est déchu, notamment, par l'extrème pauvreté, qui n'est

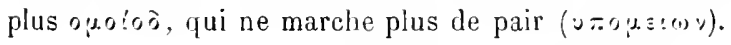

$3^{0}$ Les lemmes et les filles sont nourries à la maison; les jeunes garçons au-dessus de 12 ans mangent dans des réfectoires communs sous la surveillance de directeurs particuliers.

(1) O. Muller, ibirlcm, tome 2. 1. 201. - Ces idee. étaient courantes daus la siciété hellénique. - Platon (Lois, live 5), conseille a'interdire les générations trop abondantes tout en favorisant l'accoissement de la populatim. Il pense 'fu'on pent employer la femme a faire la guerre. - Xènophon, Lacédémone, chap. rir.

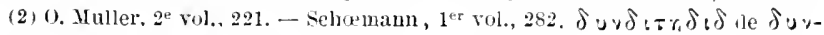
$\delta_{1} \div \varepsilon \omega$ : manger envemble.

(3) Plutarque, Lycurgue, xn it xr. - o. Vuller, tome 2, 212-281. - Curtius . 105, 206-234. - Fustel de Coulanges, ehap. vi. - les tables comptaient chacune 15 convives. Les repas en commun sont un des faits prineipatu de la eivilisation primordiale lu bassin de la Méditerranée. Ils avaient un caractire religieux, soeial, militaire. A Jérusalem, le sacrifice etait suivi de repas en commun ( Voir Re. nan, tome 5, 68, Israél). On les retrouve en Perse, it Ithines, is Rome. Nulle part ils u'ont en le mêtne caractire, la même imurtanee qu'u sirarte. lls n'ont pas été sans influenee sur le clrristlanisme. - Xéngluon. Cyropédie.

(4) Lobole valant $U, 15$. 
$4^{0}$ Les familles des Hilotes pourvoient, dans des conditions déterminées et fixes, à des redevances suffisantes pour l'entretien de l'usufruitier de chaque lot et de sa famille. Sur chaque lot se trouvent des greniers ou sont apportées et enserrées les diverses denrées formant cette part, qui ne dépassait pas, quant aux céréales, 40 hectolitres d'orge.

$\ddot{3}^{\circ} \mathrm{A}$ titre de propriétaire dominant des lots, l'Etat veille à ce que les familles sans enfants remplissent les vides en adoptant les " fils de familles alliées et que les orphelines riches épousent "des citorens paurres (1)."

$6^{\circ}$ Les ressources de l'Etat consistent dans les redevances des Périèjues, dans les revenus des domaines publics cultivés par les Hilotes et dans le butin de guerre sur lequel il prélerait la principale part. Les Rois étaient entretenus par les revenus des terres spéciales. Il n’y avait d'impòt en argent que dans les cas exceptionnels.

Ces dispositions concordent avec celles sirnnalées déjà chez la plupart des anciens peuples, notamment chez les Egyptiens du premier et du second empire, chez les Hébreux, dans l'Inde et mime en Chine. Seulement, les redevances correspondent à une part dans le revenu supérieure à l'impòt, notamment à la dime. Eiles comprennent à la fois l'impòt et la rente du sol. Les Hilotes n'étaient que des colons partiaires et les Périèques que des tenanciers censitaires.

Elles proviennent également de l'état de la civilisation, notamment de la rareté des métaux précieux. Elles démontrent que, malgré bien des différences, l'époque à laquelle elles appartiennent, a eu un caractère commun pour tous les peuples parvenus à une certaine civilisation.

7o La circulation de la monnaie d'argent et d'or est interdite ou restreinte entre particuliers, surtout entre Spartiates, d'abord en rue de les arracher à toutes préoccupations de richesse et de maintenir entre eux l'égalité, mais aussi à raison de la rareté; on n’a frappé des monnaies à Sparte qu’après Alexandre $(2)$.

(1) Schcemann, ibidem, 250 .

(2) Gilbert, ibidem, $78-\overline{-} 9$. 
Il existait cependant à Sparte un trẻsor, administré par les Ephores, qui contenait des sommes importantes en argent et en or; mais ces sommes ne servaient quaux besoins de l'Etat. Lusage courant des métaux précieux demeura interdit aux Spartiates pendant au moins quatre siècles 1 . Lors qu'd gis et Cléomène entreprirent leurs réformes 2,1 interdiction à nouveau de la monnaie dor et darent fut placée au premier plan. Cette interdiction avait pour but de limiter la richesse et de maintenir l'égalité sociale (3).

La seule monnaie en circulation était une monnaie de fer extrè. mement lourde. Par suite la transformation des redevances en nature, en impùt, en argent, transformation dont Athènes ra nous offrir le tableau, ne s'est accomplie que fort tard et incomplètement à Lacédémone.

$8^{\circ}$ Le nombre des Spartiates ne dépassait pas y,000 lors de la conquète : il s’élera à 6,000 , puis à 9,000, arant les guerres médiques. Ce qui permet de porter à ł0 ou on, 000 le nombre des Doriens; les Périèques et les esclares affranchis pouraient ètre 180,000 arec leurs familles et les Hilotes $17 \%, 000$ - lensemble de la population représentait $\{00$, mo imes. Tel quel, il ralait mieux que l'ensemble de la population athénienne, comme le résultat de la guerre du Péloponèse l'a prouré.

$9^{\circ}$ Lascendant complet à exercer et à maintenir par un dixièm de la population sur les neuf autres dixiemes, explique toutes les institutions de Lacédémone. Il explique surtout l'une des faces les plus curieuses et les moins connues de son histoire intérieure. On retrouve, en effet, ¿̀ Lacédémone, comme à Rome, la tentative persistante de conserver légalité sociale entre les citogens; c’est-à-dire les questions et les partages agraires.

Les sociétés hellénique et romaine ont été essentiellement aristocratiques. Elles se composaient d'une minorité d'élite entretenue par des masses soumises et silencieuses. Cette organisation

(1) Plutarque, Ly:uryue, s11. - Lysandre, s sy. - schemann, ibiden, 334. 316 .

(2) Schomann, ibidem. 229 .

(3) Xènophon, Lacédemone, chap. ra. - o on fait les perpuivitions d'or et d'argent, et quand cn en troure quelque part, le ditenteur ext mis is i a wende. 
n'était maintenue qu'au prix des plus grands efforts. L'intervention de l'Etat n'avait pas d'autre objet. L'Etat ne connaissait, ne représentait que cette minorité; gouverner la minorité, c’était gouverner l'Etat. De là les luttes politiques. Les luttes sociales avaient une autre cause : il ne s'agissait plus de gouverner I'Etat, mais de ne pas tomber par la paurreté - c'était le plus srand des malheurs, - des rangs de la minorité dans les basfonds dans la majorité, c'est-ì-dire dans la misère ou dans la servitude. Elles étaient par suite inexorables.

Ine aristocratie, surtout une oligarchie militaire a pour conllition l'égalité entre ses membres, quand elle ne peut renoureler ses forces dans d'autres milieux. Les Sissities avaient frour but le maintien de cette égalité; mais il arriva un moment où, au lieu de lui ètre favorables, elles lui furent contraires. La redevance en nature à porter chaque jour $\left(x_{\gamma}(\omega)\right.$ ri $)$ à la table commune devint une charge légère pour celui qui navait pas d'enfants, plus lourde pour celui qui en arait quelques-uns, accablante pour le Spartiate chargé de famille. Sur qui rejeter l'impòt? Et combien devait paraitre pénible cette cotisation quotidienne? Bientìt, il fut impossible à tous de subvenir aux mèmes charges. C'est la remarque faite par Aristote : "Les "plus paurres ne peurent prendre part à ces repas; et, pour"tant, de temps immémorial, le droit politique ne s'acquiert " qu'à cette condition, il est perdu pour celui qui est hors d'état "de supporter cette charge (1)."

Ainsi ce qui devait maintenir l'égalité, la détruisit. C'est un exemple très-catégorique de l'incidence de l'impòt et de la nécessité d’adapter l'jmpòt aux diverses inégalités sociales. "Le revenu de la terre, dit Schœmann, que les Spartiates fai" saient cultiver par les Hilotes, devait suppléer au travail per" sonnel qu'eussent exigé les besoins du propriétaire et lui per"mettre de vaquer à ses devoirs civiques; en outre, il fallait "que les domaines fussent de mème valeur, afin d'effacer autant

(1) Politique, livre II, chap. VI, 21. - Schomann, ibidem, 312. - Aristote ajoute : "Cest chose difficile que les pauves, en y apportant la part fixée par la loi, puisient en outre subvenir it tous les besoins de la famille ) (livre IV, chap. $1 x, \leqslant 6$. 
"que possible la différence entre les riches et les paures. Con"formément à ce principe, le sol avait été partaçé aussitut après "la conquète dorienne. Plus tard, lorsque le nombre croissant " des citosens eut troublé l'équilibre, on tenta de réparer l’iné"ralité des fortunes par une nouvelle et énerique application " de la loi agraire. Tout le pays, y compris les conquètes récentes, "fut divisé entre les citoyens dont le nombre était alors de ",, 300 ou de 6,000 . Enfin, quand, après la première guerre de "Messénie, le nombre des Spartiates s'accrut encore d'une ma" nière notable, et que l'éçalité fut de nouveau troublée, le roi "Polydaros profita de nouvelles annexıons pour opérer le dernier "partage général des terrés ( $\mathbf{t}$."

Ces partages ne pouraient suffire a paralyser les effets de l'inégalité qui est inhérente à la composition des familles. Il fallut peu à peu renoncer à la légrislation de Lỵcurorue et anx traditions sur lesquelles elle était fondée. Les sruerres perpétuelles d'un peuple, qui était toujours campé, venaient accroitre les causes d'inégralité. Les familles militaires sont sounises à une plus rapide extinction; elles finissent par n’ètre rejırésentées qup par des femmes $(2)$. Au temps d'Aristote les deux cinquièmes des terres étaient dans les mains des femmes (3). La charce des repas publics n'en devint que plus lourde et la mauvaise organisation de l’imprit à Lacédémone, sirnalée par Aristote, que plus funeste(4). L“inégalité s’accentua de plus en plus; elle s'acrgrava encore lors'que, sur la motion de l'Ephore Epitadeus $(\ddot{)})$, la liberté de disposer par donation et par testament fut reconnue aux Spartiates : c’était une révolution agraire, puisque les Spartiates n’avaient pas la propriété entière de leurs lots. La vente demeura interdite; mais la transmission pouvait avoir lieu sous forme de donation. Il se produisit alors comme à Rome, comme en Angleterre, un immense mouvement de concentration. Aristote put dire : "un autre défaut à sigraler dans la constitution de La-

(1) Antiquites grecques, $1^{\text {rr }}$ rol., 24 .

(2) c"est le ca- le la famille de Ilontajgne apris quatre generation:.

(3) Politique, livre 11 , cha]r. $\mathrm{I}$, s 11.

(4) Politique, livie ll . chap. vi, 24.

(5) L'éphorat d'Epitateus a eu lieu apris Lysandre et avant Aristote. 
"cédémone, c'est la disproportion des propriétés; les uns pos" sèdent des biens immenses, les autres n'ont presque rien; et "le sol est entre les mains de quelques individus (1)."

Cet état de choses s'est maintenu bien au delà de l'époque d'Aristote. Aristote ne comptait plus de son temps que 2,000 Spartiates; moins d'un siècle après. il n'Y en arait plus que 700 , sur lesquels un septième seulement était propriétaire de fonds. "Tout "le reste n'était qu'une multitude indigente qui, languissant à "Sparte dans l'opprobre et se défendant au dehors arec mollesse "contre les ennemis qu"elle arait ì combattre, épiait sans cesse "loccasion d'un changement qui la tirìt d'un état si mépri"sable :2. "Véanmoins les Srssities duraient encore, elles étaient devenues des sortes de bureaux de bienfaisance où les paurres viraient aux frais des riches. Cenx-ci enroyaient toujours les rederances sans en prendre leur part.

L'occasion recherchée par les paurres se présenta sous les rois Agris III et Cléomène qui proroquèrent un mouvement social et agraire du mème ordre que celui des Gracques. Agis III échoua, mais il n’en fut pas de mème de Cléomène. Il bannit quatre-ringt Spartiates les plus riches, sempara de leurs terres, procéda à une nouselle répartition, rencerza les Ephores, renouvela les Srssities et composa une armée arec laquelle il attaqua la ligue achẻenne. Epoque décisive dans l'histoire de la Grèce ancienne. Les Acheens n'étaient autres que les Périeques, les Iothuces, les Téodamigles, les Hilutes, coalisés contre les Spartiates, mortels ennemis d'un état de choses établi pour les condamner à une infériorité ou à une servitude perpétuelles en rue de garantir la dumination des Spartiates. Lacédémone avait été brisée en fait à Leuctres et à Mlantinée. La ligue achéenne en était sortie. La division inhérente à la race hellénique, n'en devint que plus grande. Elle prépara l'asserrissement et le dépérissement de la Grèce, dont la décadence datait de la guerre du Péloponèse.

D'autant plus que les Hilotes se séparèrent à leur tour des Pé-

(1) Llidem, s 11 .

(2) Plutarque, Agis, 6 . 
riéques et devinrent les principaux instruments des démagorgues, tels que Nabis, qui succéda à Cléomène. Cette renaissance de Sparte n’en a pas moins été remarquable. Après la défaite de Sellasie une transaction parait ètre intervenue au sujet res changements faits par Cléomène. Pausanias cite comme en fonction de son temps le cullège des Patronomes que Cléomène arait substitué aux Ephores.

A partir de Cléomène la décadence de Lacédémone se précipita; mais les institutions de Lycurgue résistèrent encore. Elles survécurent mème à la tyrannie de Nabis. "Il détruisait peu à " peu le dernier reste du nom Spartiate, jetant en exil tous les " citoyens illustres par leurs richesses et livrait les femmes et les "biers de ses victimes aux principaux de son parti et à ses mer"cenaires. C"était une troupe de voleurs et d'assassins de toute " sorte... Il ne se bornait pas à faire exiler les citoyens; sur la "terre étrangère il n'y avait pas pour eux de retraite assurée. "Il les faisait tuer sur les granrles routes. Il en rappelait d'au" tres à Lacédémone el les y égor reait. Pour comble d'horreur "dans la ville ou ils se retiraient, il achetait, sous le couvert "d'hommes non suspects, les maisons contigui's à celles que "ces infortunés occupaient, et enroyait des Crétuis qui, prati"quant des trous dans les murs mitoyens, les tuaient à coups "de flèches, soit couchés, soit debout (1) ". C'était la guerre sociale en permanence. L'obstination des vieux Spartiates fut plus forte que la eruauté de Nabis. Il était réservé, par un juste retour des choses humaines, à Philopumen seul, le chef de la ligue achéenne, de briser le moule des fortes institutions lle Lycurgue. Dès qu'il eut pris Sparte, il fit mettre à mort plus de quatre-ringt Spartiates, abattit les murailles, confisqua une grande partie des terres, transporta en Achaie toute la population à l'exception de 3,000 personnes qui, ayant refusé d'abandonner leur patrie, furent vendues à l'encan. "Philopumen, " ajoute Plutarque, renversa toutes les institutions de Lycurgue; " il força les enfants et les jeunes gens d'abandonner l'élucation "qu'ils recevaient à Sparte, persuadé que tant qu'ils obser-

(1) Eolybe, lime XII, chaw. v. 
"veraient les lois de Lycurgue, ils ne perdraient jamais leurs "sentiments généreux; accablés alors sous le poids de leurs "malheurs, et forcés de laisser Philopomen couper, pour ainsi " dire les nerfs de leur ville, ils vécurent dans la faiblesse et "dans la dépendance (1)."

II y a une certaine exagération dans ces affirmations de Plutarque; ni Nabis, ni Philopœmen ne parvinrent à détruire à fond l'ceurre de Lycurgue et l'acropole des Doriens.

Ainsi la législation sociale et agraire des Doriens, plus ou moins modifiée par Lỵcurque ou après lui, est caractérisée par la subordination d'une nation de $\mathbf{4 0 0 , 0 0 0}$ personnes à une aristocratie militaire, soumise à un énergrique entrainement, exemptée de toute contribution aux charges de l'Etat. Toutefois cette aristocratie se transforme lentement en une oligarchie, mème une timocratie sous linfluence des lois ou des coutumes destinées à la perpétuer. Les charges égales de la subsistance en commun et tous les moyens employés pour établir et maintenir une écralité parfaite aboutirent à l'inégalité la plus complète.

C'est l'exemple le plus péremptoire de la fonction sociale et économique de l'impoit.

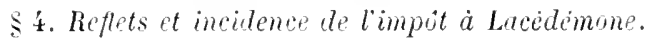

Quelle pouvait ìtre i'incidence des diverses rederances qui, à Lacédéinone, représentaient l'impôt? Ces rederances étaient : 10 celles des Périènues à l'Etat; 20 celles des Hilates aux Spartiates; $3^{\circ}$ celles des Spartiates aux Srssities. Toutes étaient fixes, daprès la coutume; toutes étaient acquittées en nature.

En ce qui est des rederances des Périèques, ceux-ci n’araient aucun moyen de s'en récupérer, puisque les Spartiates et les Hilotes étaient entretenus sur les revenus dautres lots de terres et que ces lots étaient les plus fertiles. Leur condition était néanmoins considérée comme bonne, car ils araient au moins la moitié des produits, sans compter les profits du commerce, de l'industrie; profits qui, longtemps médiocres, car les 
échanges avaient lieu en nature, ont dù s'accroitre beaucoup à l'éporjue où la monnaie d’or et d’argent est entrée en circulation. On peut admettre que les Périèques, surtout dans les années propices, pouvaient disposer d'un excédent de produits agricoles et en tirer un certain revenu. Aussi leur condition est-elle devenue meilleure que celle des spartiates.

Il en a été à peu près de mème des Hilotes. Tous les documents montrent que. jusquà leur afranchissement en masse après Leuctres, ils arajent déjà réalisé de notables progrès et que plusieurs d'entre eux étaient devenus riches. C'est que les redevances quils fournissaient étaient fixes et payables en nature. Ils ne devaient pas dimpoit.

En somme Périèques et Hilotes étaient à peu près des colons partiajres perpétuels, astreints spulement à des redevances fixes, en nature, ne devant en outre que le service militaire (1).

C'est la mime situation que celle des Clarotes. Les mèmes réllexions s’y appliquent. Dès que les rederances foncières des Périèques et des Hilotes étaient immuables d'après la coutume, leur condition devait s'améliorer puisqu'ils araient tous les profits du travail. Comme conséquence indirecte, leur part dans les charges publiques devenait moins lourde, puisque leurs ressources étaient croissantes.

La condition des Spartiates était plus défavorable : to Le travail leur était interdit; il était considéré pour eux comme une tìche; par suite ils étajent strictement réduits à leur part dans les revenus des terres. "Mème avant la loj d'Epitadeus, il y " avajt déja des Spartiates qui se trouvaient dans une situation "d’infériorité vis-à-vis des riches; mais c'est le cas de tous les " impòts qui, égraux en apparence, pìsent néanmoins très-iné"galement sur les riches et sur les paurres. Ils n'araient pas " pour cela lidée de s'en affranchir, sachant que cétait le seul " moyen de s’assurer l'jnappréciable jouissance du droit de cité " et d'obtenir la considération publique.... Tous ceux qui accom" plissaient ce devoir jouissaient de la plénitude du droit de "cité, qu'ils fussent riches ou paures; mais quiconque s'en

(1) schoemann, ilsiclem, 254. 
"affranchissait était réputé indigne d’ètre rangé plus longtemps "parmi les cucos. Il était frappé d'une sorte d’atinie, dégradé " de la noblesse et relégué dans une classe inférieure (1)". 2 La dépense de leur alimentation étant égale, constituait une réritable contribution qui portait plus sur le paure que sur le riche. Le paurre était sans moren de se récupérer; au contraire le service militaire aurgravait encore sa situation.

Telle était au xrrne siècle à peu près la condition de la noblesse militaire française. Elle n'arait pas de srssities; mais elle devait tenir un rang qui l'obliqueait à des dépenses supérieures it ses revenus. Elle a dù vendre ses biens et se fondre dans la Lourgenisie. Elle s'est amoindrie, comme les Spartiates, par la gruerre, et le tiers état, dispensé du service militaire, a grandi en nombre et, par le trarail, en richesse. C'est par la scuerre et le mépris du travail que la société féodale et seigneuriale, les puissants du ${ }^{\mathrm{e}}{ }^{\mathrm{e}}$ au $x \mathrm{r}^{\mathrm{e}}$ siècle, a peu à peu disparu. II ny arait en France en 1789 que 100,000 nobles avec 30,000 familles, sur une population de 29 millions. C'est exactement ce qui a eu lieu à Sparte.

Alors s'est formée la riche oligarchie qui a gouverné depuis Lysandre et Agresilas et que Vahis et Philopiemen ont accablée sans la détruire encore. Cette oligarehie possédait les terres sans paver d'impit. Lis rederances des Srssities pour 2,1000 , puis 700 Spartiates étaient peu le chose it crité de celles qui devaient en nourrir tous les jours 9,000. Ce n'est pas la seule aristocratie ou la seule oligarchie qui n’a pas consenti a parer dimpot. On peut lire daus Polybe (Lirre Xll, chap. ral), lhistoire d'une atroce invention de Yabis pour se procurer de l'arcent. C'était une statue de femme courerte de rètements magnifiques qui ressemblai it iépouse de Yabis. Guand Nahis ne pourait arracher d"un Spartiate l'argent dont il arait besoin, il le conduisait vers cette statue comme pour l'almirer, mais les bras de l'automate le saisissaient et l'étouffaient. Cette statue n'est peut-ètre qu'une lérgende. Elle donne assez bien limage du fisc auquel il fiaut faire sa part.

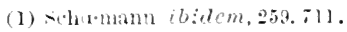


La fonction de l'impot est, en effet, sociale comme celle du gourernement, comme celle de l'Etat. Cette fonction de l'Etat se modifie nécessairement arec le temps, avec la marche des idées, avec les diverses transformations de la cirilisation. L'impit doit s'adapter à ces transformations diverses. Son organisation ne s'Y prètait pas arec assez d'élasticité chez les peuples Doriens. Quoique l'Etat fut propriétaire des terres, qu ill eut la haute main sur léducation et sur la famille, qu'il absorbàt la vie entière des citoyens, il n'était, en réalité, que l’organe des intérèts exclusifs d'une aristocratie militaire, c'est-à-dire d'ure minorité oppressive qui ne parait d"impưt qu’à elle-mème et qu’en vue du maintien de sa domination, aucune partie de l'impit n'était reversée sur les autres classes, sur les autres parties de la société; bien loin de là; c’étaient elles qui devaient procurer à l'Etat les ressources nécessaires pour faire face à tous ses besoins autres que l'entretien des Spartiates.

C'était le cas notamment pour la marine militaire et pour la cavalerie qui, bien que commandées toujours par des Spartiates, étaient à la charge des Périèques. Les rameurs des navires ne comprenaient que des Hilotes ou des étrangers (1).

De là la mauraise administration, ou plutit le manque de finances à Lacédémone; la condition de la monnaie, du commerce et de l'industrie $y$ ajoutait encore.

De là l'importance exclusive de la propriété foncière et les luttes terribles que soulera, à direrses époques, son accaparement; car elle était la seule ressource et cependant le Spartiate, usufruitier, ne devait pas d'impoit $(2)$.

De là encore la séparation des classes qui a ruiné Lacédémone après Leuctres; la plus grande partie des territoires et des villes habités par les Périèques fut séparée de Lacédémone et com-

(1) schnemann, Antiquités grecques, $1^{\text {tr }}$ vol. 329.

(2) Les luttes arraires ont caracterisé la plupart des Ftats grecs. Tantôt on voulait prévenir l'accal’arement, tantôt la division excessive. Dans les aristucı aties, on spoliait les petits propriétaires; dans les Etats demuclatipues, on exilait on on massacrait les riches. Dans celles-ci. on limitait les charges fiscales des propriétaires comme it sparte, lans celle-là, on le- aggravait. - schoemann, ibidem, $214-215$. 
pris dans la ligue achéenne. De là la lutte néfaste entre Sparte et la ligue, de là l'interrention des Romains, d'abord en faveur de la ligue, puis en fareur de Sparte, de là l'asservissement du Péloponèse, puis rle la Grèce tout entière:

"La Grèce était redoutable par sa situation, la force, la mul"titude de ses rilles, le nombre de ses soldats, sa police, ses "mreurs, ses lois; elle admirait la querre, elle en connaissait "l'art et elle aurait été invincible si elle arait été unie (1)."

\section{$\S$ כ. Derniers termps de sporte.}

Il y arait, entre Romains et Spartiates, trop de similitudes, d'affinités, de rapports dinstitutions, de tendances, de mœurs, de goùts militaires, de valeur personnelle, dentrainement physique et moral pour que, tit ou tard, un arrangement, nïntervint pas. Après aroir raincu Nabis et la Macédoine, Rome accabla la liggue achéenne, c'est-à-dire les représentants des a nciens Périèques. Sparte fut admise parmi les Ciritates fædemtx $\mathbf{2}$ ) : elle ne reçut pas de gourerneur; elle put conserver ses anciennes institutions; les patronomes remplacèrent les rois; les Ephores tombèrent au second rang; les Phylai et les Obai furent maintenues ainsi que les repas pullics; mêmes procédés d'éducation. Voulant témoigner de sa considération pour Lacédémone, qui avait été pour lui contre Brutus, tandis qu'Athènes arait soutenu Brutus, Auruste, de retour d'Actium, s'arrèta à Sparte et s’assit aux Sỵssities. Lne liste des maristrats de Sparte sous Hadrien nous est parrenue. Détruite par Alaric, elle fut reconstruite. Dans la description de l'empire byzantin au $x^{e}$ siècle E. C. par Constantin Porphyrogénète (3), on retroure la Lacédémonie et Sparte, thème de Mlorée. Le Péloponèse traversa alors une période prospère comme l'empire lui-mème; mais les Hellènes araient dù faire une place aux Slaves, accourus de toutes parts, et qui différaient des anciens Doriens moins par la race que par la religion.

Au $x 1^{\mathrm{e}}$ siècle. 1201-1262, quand la Horée devint un rovaume

(1) Montesquieu, Grandeur et décadence, chap. r.

(Q) Gibert. ibidem, $27-2 \pi$.

(3) Lambaud. L'Empire grec aux siecle, p. 330 . 
Sranc, divisé en 22 fiefs, la Lacédémonie tomba dans le lot de Venise qui le rétrocéda à l'évèque d'Amyclée. Mais Sparte avait disparu; on avait élevé, du côté opposé à celui qu'elle occupait sur l'Eurotas, et arec ses ruines, la ville de Mistra dont Viliehardouin s'empara à la tête de chevaliers francs, compagnons militaires qui, par leur entrainement, leur vie militaire, leur condition sociale olfrent aussi bien des ressemblances avec les Spartiates d'Hérodote et de Thuç̣dide, le casque en tète, la lance à la main et le manteau rouge au vent. Quand, en 1801, Chàteaubriand risita la Grèce dont il a tracé un incomparable tableau, c'est à peine s'il put s'asseoir sur quelques débris de Sparte, etiam periere ruinx, mais le poète a dit aussi : multu renascentur. La vallée de l'Eurotas est toujours fertile; les révolutions humaines ne détruisent pas la fécondité du sol. Sparte, relevée de ses cendres, est aujourd'hui une jolie préfecture de 11,000 itmes a vec station de chemin de fer; Sparte! Sparte!

\section{S 6. Compuruison des institutions de Lacédémone aver celles ituutres Etuts.}

Dans l'antiquité on ne peut, en dehors de la Crète et des colonies doriennes, rapprocher les institutions de Lacėdémone que de celles d'Isrä̈l et de Rome. En Isrä̈l, de mème qu'à Lacédémone, l'intervention directe, persistante de l'Etat a pour but et pour effet de régler et de modifier les rapports sociaux et économiques des familles et des particuliers. La distinction des classes, la limitation de la richesse, le développement de l'association, la préférence donnée à l'agriculture, la subordination du pouvoir royal, la remise des dettes, les repas en commun, l'absence prolongée de monnaie sont communs à Israël et à Lacédémone. Il y a bien des traits de ressemblance entre Moise et Lycurgue, toutefois le but diffère; Lacédémone veut le pouvoir; Israël poursuit la propagation de sa foi. Israël a choisi la meilleure part; tout autre sera sa destinée. Sous ces différences, se trouve à Lacédémone, comme en Israël, l'idée que la condition humaine ne doit pas être abandonnée aux chances d'une liberté absolue. La loi fera mieux que la volonté individuelle. 
Les points de repère n'ont pas moins d'importance avec le peuple romain, quoique sur un théitre autrement vaste. Point de chimère dans la conception romaine; l'égalité a été et est demeurée inconnue aux Romains, mème entre compagrnons militaires. Que de ressemblances en ce qui est de l'éducation militaire, de la formation d'un soldat ińbranlable dans la défaite comme dans la victoire, non point d'un mercenaire, mais d'un soldat citoyen actif, qui, rentré au foyer, rote et au besoin parle, à Rome du moins; en ce qui est aussi d'un gouvernement sérieux, énergique, en ce qui est de l'esprit de guerre, de con'quète, de butin. Le Spartiate se fera entretenir par les Hilotes, les Périèques paieront seuls l'impòt; viendront aussi les temps, qui dureront près de huit siècles, pendant lesquels le citoyen romain se fera également entretenir par les peuples vaincus. Les citoyens romains ne mangeaient pas en commun, mais ils consommaient néanmoins blés, huile, rin, lard d'Egypte, de Sicile, d'Afrique, de Gaule, de Grèce?

Au $\mathrm{xrl}^{\mathrm{C}}$ siècle, les Espagnols ont également eu leurs Périèques et leurs Hilotes au Mexique, et dans les diverses viceroyautés de l'Amérique du Sud. Si les rois d'Espagne recevaient, chaque année, les galions de Cadix, les propriétaires des Haciendas exploitaient le travail des Indiens, réduits à bien moins ¡ue ce qui restait aux Périèques et plus maltraités que les $\mathrm{Hi}$ lotes.

En Irlande, les landlords ont certainement traité les fermiers celtes plus mal que n'étaient les Périèıues, peut-ètre mème que les Hilotes; et mème en Angleterre, en Ecosse, jusqu'aux rrandes réformes de Pitt en 1798 et de Robert Peel en 1846, les lords anglais recevaient des rentes colossales sans payer à l'Etat aucun impùt en rapport avec leur part dans le revenu territorial.

Enfin, dans une partie de l'Inde, le gourernement anglais se montre certainement plus rigoureux que Sparte ne l'était envers les Périèques; car il peut augmenter les rentes comme maitre et seigneur supérieur, tandis que les rederances étaient immuables à Lacédémone.

Ce qui a le plus mal tourné à Lacédémone, c'est le système 
égalitaire, le but sorialiste et communiste, entre Spartiates seuls, qui enchantait Platon et Xénophon, peut-ètre mème Plutarque, mais qui, après avoir détruit la race, a détruit l'Etat.

Il serait injuste toutefois de méconnaitre la grandeur de Lyctirgue, de sparte et des Lacédémoniens. Cette grandeur a été saluée par toute la Grèce et par ses esprits les plus éminents, Thuç̧dide, Aristote, Platon, Aénophon, Plutarque; c'est un témoignage qui doit rendre circonspect. Tous ont mis leur rècle (Rhetra bien au-dessus des institutions ultra-démocratiques d'Athènes. Tous ont pensé, ont écrit que Lacédémone arait proposé à l'homme un idéal supérieur et formé des hommes plus complets. Platon dit quarec quelques changements on aurait pu faire du gouvernement de Lacédémone un gouvernement parfait. Platon ne l'aurait certainement pas perfectionné par les réformes qu'il a accumulées dans les cinquième et huitième lirres des Lois. Après avoir interdit la monnaie d'or et d'argent, les prèts, les emprunts, le trafic, les mines, les hoitelleries, les rentes, les achats si ce n'est en public, les douanes, il règle les raisins, les poires, les pommes, tout comme Fourier. Sur un point cependant, sur l'impòt, il se sépare des Lacédémoniens et donne raison aux theniens. Yous sommes ainsi conduits par Platon lui-mème à Athènes. 


\title{
CHAPITRE V.
}

\author{
ATHẼNES.
}

\section{$\$$ 1. Le territoire.}

Avant tout Athènes est un grand port. C'est un centre marıtime, du mème ordre que Tyr et que Carthage (1). "C'est le peu« ple qui fait la marine, dit Xénophon, et qui constitue la force "de la république. Les pilotes, les Céleustes, les Pentécon"tarques, les seconds, les constructeurs, voilà ceux qui ren" dent l'Etat florissant bien plus que les Hoplites, les nobles et "les riches $(\boldsymbol{2})$ ". Sur une population de 500,000 àmes que l'Etat comprend, plus de $\mathbf{2 0 0 , 0 0 0}$ habitent Athènes et ses ports.

Le territoire de l'Attique n'est pas étendu; il forme, selon la remarque pleine de sagacité de Xénophon, comme une ile (3). Il en était de mème de Tyr et de Carthage. Xénophon en a montré tous les avantages; mais il était montueux, rocailleux, ingrat; il produisait de lorge, peu de blé, du vin, de l'huile, les figues, un miel renommé; pas de gros bétail; des brebis et des chèvres; il était, par contre, très-riche en minerais d'arsent; les ciotes abondaient en poissons. Xénophon et Sophocle en ont néanmoins tracé des tableaux enchanteurs : "L'ex" trème douceur du climat est attestée par ses produits mèmes; "ce qui ne peut pas germer ailleurs vient ici à maturité. De "mème que la terre, la mer, qui entoure le pays, abonde en "produits de toute espèce. Tous les biens que Dieu accorde à

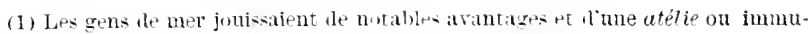
nite spéelale prour quel iues impôts. - B eckh, 1 rol., 147.

(2) Gowernomont des Atheniens, chat. 1.

(3) Gouvernement des athéniens, chai. 11. 
« chaque saison se montrent ici plus toit et disparaissent plus "tard. Et ce ne sont pas seulement les produits qu'une année " voit naitre et vieillir, qui donnent la supériorité à notre con" trée, mais elle possède encore d'éternelles richesses. Le sein " de la terre y est rempli de marbres...; il est des terrains qui " ensemencés ne donnent point de récolte, fouillés ils font "vivre plus de monde que s"ils rapportaient du blé. Comment "nier que son minerai dargent ne soit un bienfait du ciel... "Il n'y a non plus rien de déraisonnable dans l'opinion de " ceux qui placent cette ville-ci au centre de la Grèce et mème " de la terre habitée (1). "

Le contraste est complet arec Lacédémone, située au centre du Péloponèse, loin de la mer, dans un pays de riche culture, où les produits agricoles sont la seule ressource d'une population sédentaire.

\section{‥ La population.}

Le mourement des races qui descendent du Nord s'est dirigé vers le Pẻloponèse; trois couches humaines se sont superposées dans la Laconie. Une organisation politique et sociale particulière en est résultée. De temps immémorial, la population litre de l'Attique ne forme qu'un ensemble: point de maitres, point de vaincus $(2)$. La population ne comporte que

(1) Xemoluon, Des revenus, chap. 1. Traluetion Talbut.

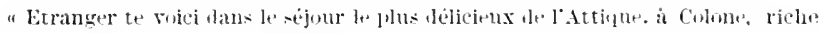

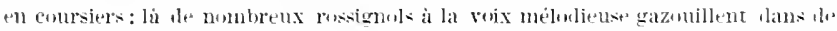

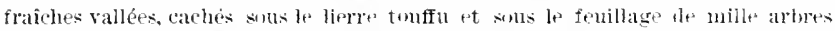
chargés de fruits..., la flemrit chaphe jour solus la rosete celeste le narciste an carlice gracienx et le safran dore; les taux lu Cephise qui ne sarretent jamais ser-

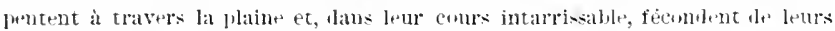

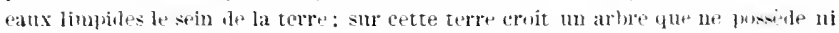
l'Ase, ni la gramle ile doriente de Pelops, arbo qui no fut jas plante par un

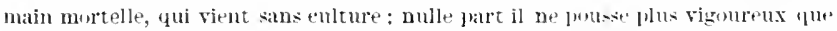

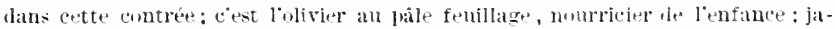
mais une main etrangire ne pourra lextirper lu sol... Eslipe a colonne. Traduction Artaul.

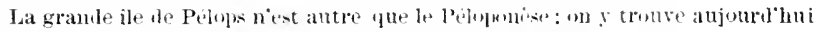

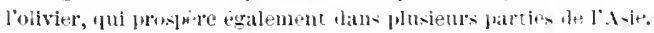

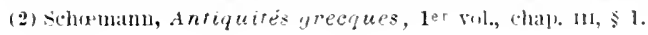


deux catégrories : les citoyens el les esclaves. Les étrangers (Métèques) sont très-nombreux, comme dans tous les ports. Ils y possèdent des garanties completes sous la protection de magistrats particuliers; on en compte 40,000 appartenant à tous les pays, parlant toutes les langues, donnant à Athẻnes la physionomie de Marseille d'aujourd'hui. Les citoyens, les vrais théniens ne dépassent pas 20,000, arec leurs familles 90,000 personnes, à l'époque de la plus grande splendeur de la puissance d'Athènes; 360,000 esclaves complètent la population. Athènes est un immense marché d'esclaves; cest après Rome le plus grand forer d'esclavage des anciennes civilisations (t).

\section{\$3. Letut sorial.}

Cette agglomération d'hommes libres, la plupart marins, commercants, pirates, arec un certain nombre de propriétaires, de cultirateurs et d'esclaves, très-nombreux, les uns agricoles, les autres urbains, s'est formée lentement, soit autour du rocher de l'Acropole, soit dans le port du Pirée. Comme tous les peuples primitifs sans aucune exception, mème les tribus primordiales chinoises du Iloang-lIo, ou les Aryens du Haut-Indus, elle a été constituée par la réunion de tribus antiques, qui n’étaient elles-mèmes que l'association de grandes familles. Quatre tribus : Geliontes, Hopletes, Eqicores, Argadiens, hommes brillants, chefs et prètres, guerriers, bergers, cultivateurs; chaque tribu comprend trois espèces d'hommes libres : les Eupatrides ou premiers propriétaires du sol, les gémores cultivateurs, les dimiurges artisans; mais tous, divers de condition, sont

(1) Sur l'esclavage is Athenes cousultel schremanu, Antiquités, 1er bol., 359, 39i. - M. Gilbert réduit le nombre des esclaves it plus de 100,000 et porte celui lles Athéniens libres le 40 a 47,000 , avec leurs familles 120 a 140,000 personnes, 1,us 10,000 absents, ourrage cité, I1. 181. Ceschiffres sont contraires à cenx de Backh et le sehcemann, it ceux transmis par Athénce te surtout anx célèbres hypotheses de Xénophon sur le noyen de faire face aux lépenses d'Athénes en constituant nue armee d"esclaves d'Etat; on leut comparer, il est vrai, ces hypotheses aux $\mathbf{1 . 4 0 0}$ millious bruts que le monofwle de lalconl proluirait en France. - Giraml, Propriété fonciere en Grèce (1893), montre les progres de leschavage en Grice, p. 72 et 123 . Voin a l'aprendice: De la population de la Grèce et dithènes. 
également libres et de mime rang (1). La plupart sont des colons venus de l'Asie-Mineure. Au fur et à mesure que la population libre s'est accrue, d'autres subdivisions se sont formées dans les tribus; d'abord les Dèmes ou quartiers de la trilun; II. Gilbert en compte tí; puis les Phratries, ou corporations, plutit mème confréries, car la Phratrie est une association essentiellement religieuse avec un dieu et un culte particulier. Le Dème est presłue un centre municijal; il émet des monnaies, il a ses marristrats, ses assemblées; il est relié à la tribu par une autre institution: la Trittye. On compte trois Trittyes par tribu. Enfin, la Phratrie relie entre elles les familles (yern) (2). Au-dessous de ces associations princijales, une mullitude d'autres genres de sociétes; sans ces groupements, les democraties ne peuvent dominer l'anarchie qui les a toujours menacées et dévorées. Les institutions fiseales, si complexes, d'Athènes, sont incompréhensibles si on n'en tient pas compte. Il en est de mème de ses institutions politiques 3 ).

Tribus, Dèmes, Trittyes, Phratries composent les divers éléments du sous-sol social, éléments relirieux, mutualistes, arec des repas communs aux fètes, des sacrifices de confréries, des sociétés de secours, mème parlois des communautés coopératives (i), le tout exclusivement pour les hommes libres. Athènes est la terre de l'esclavage et partant de la liberté. C'est un Saint-Domingue entre blanes. Aussi, à Athènes, la richesse compte bien moins que la liberté, la liberté de soi-mème, cela s'entend.

Grande est, à cet égrard, la différence avec Lacédémone; et, en réalité, la condition sociale de Lacédémone avec sa lıaute apistocratie militaire, ses tenanciers perpétuels, ses serfs de la grlèbe, invendables eux et les leurs comme les serfs questaux

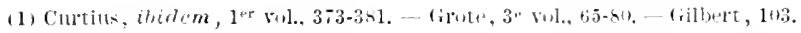

(2) Gilhut, ibidem, 192-214.

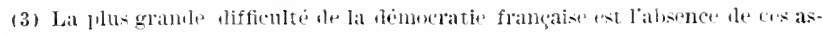

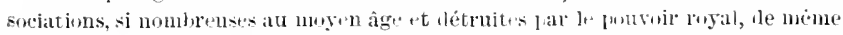
que les empereus rmain: ont détruit celles de: la rirece antiune. - Tindueville. Incien régime, livre II, chitp. 11r. - le clristianisme ne vit que lar l'assuciation.

(4) Voir notre etule sur les sucietes conderatives hans la Grect anci nne, article: conperation de la firmile Eneyclorielie. 
du $x_{1}{ }^{\mathrm{e}}$ siècle, était bien supérieure; car pas de dégrarlation pire que celle de l'esclavage, surtout l'esclavage du blanc. Il faut se figurer Horace esclave pour se faire une idée de l'esclavage athénien ou romain; c'est comme si Molière avait été esclave.

Autre élément, la mer : c'est-ì-dire la pèche, la navigation et la piraterie; qui dit Grec, dit pirate; mème aujourdhui le marin grec a la voile et la main lestes.

A l'origine, sur le sol de l'Attique restreint, pauvre, malgré les oliviers de Sophocle (1), les chefs des tribus, plus ou moins royaux, plus ou moins historiques, Cécrops, Thésée et Codrus, le dernier, exercent le pouvoir; puis il passe aux vieilles familles, aux grands propriétaires, avec archontat héréditaire, aux Eupatrides; larchontat héréditaire se transforme en archontat à vie, décennal, anuuel, dès 683 A.-C. Lintluence territoriale a eu son temps, mais l'exiguité, la sécheresse, l’infertilité du sol, ont dù laisser la première place à l'intluence de la marine, du commerce; le courant démocratique l'emporte à l'époque mème où le courant aristocratique domine dans le Péloponèse. C'est la diflérence des territoires.

\section{S. La democratie.}

Non seulement la société hellénique a été divisée en un assez grand nombre d'Etats, eu égard à son territoire et à sa population, non seulement il a été impossible de remédier aux inconvénients de cette division, mais deux grands partis politiques ont existé dans ces Etats, partis irréconciliables, de sorte qu'à la séparation nationale il faut ajouter la séparation sociale. Athènes a été le centre et le foyer, pendant longtemps de la démocratie $(\boldsymbol{2}\rangle$; néanmoins, elle a complitement échoué quand elle a essayé, comme dans la guerre de Péloponèse, d’assurer sa prépondérance sur les Etats démocratiques.

En ètudiant les institutions de Lacédémone nous avons eu à

(1) Sur l'époutue rurale de l'Attigue et ses transformations, Girad, ibidem, $\therefore$.

(2) Sur les causes et la foree de ce mourement démocratique, Girand, ibidem, p. $12.1,133,139$. 
signaler que, malgr é leur caractère particulariste, ces institutions présentaient de curieux rapports avec les institutions de toutes les aristocraties; cette concrurdance sera relevée plusieurs fois, au cours de cet ouvrage, notamment à propos de l'organisation de l'impòt dans la liome républicaine et en Angrleterre.

Réciproquement, les institutions d'Ithines, en particulier au point de vue de l’jmpót, se relient à celles des peuples démocratiques, accusent les teudances, les umes bonnes, les autres funestes des démocraties, dont la plus immédiate est de morlifier précisément, dans une large mesure, l’incidence de l’impôt, de manière à atteindre surtout les classes riches, tandis que, dans les aristocraties, domine la tendance de les exonérer.

Pendant de longs siccles, le mouvement de la cirilisation a eu, en Europe, un caractère aristocratique; les aristocraties ont prévalu. Les institutions d'Athines, aussi bien au point de vue politique social que fiscal, sont isolées: Athienes est un foyer resplendissant, mais solitaire. Mème au xrue siècle, daus le courant didées et de réformes qui aliait conduire it la Révolution française, Sparte conservait encore la prélérence sur Athènes.

Il n'en est plus de mème aujourd'hui. Le mouvement de la civilisation revèt un caractère démocratique. Par suite, l'étude des institutions d'Athines offre un intérèt plus actuel. Il est tout aussi intéressant de comparer ses institutions avec celles de la France, des Etats-Lnis, de la Suisse, des républiques de l'Amérique du Sud, dont plusieurs sont très-prosperes, "que de rapprocher l'organisation sociale et fiscale de Lacédémone, de celle de Rome ou de l'Angleterre contemporaine.

On peut discuter sur l'intensité, la durée et la destinée du courant démocratique contemporain en Europe; on peut prévoir pour ce courant de difficiles épreuves, il n'en est pas moins un courant puissant, mème fécond. Dès lors, il y a plus que de la curiosité scientifique, il y a un intérèt actuel, tangible a se rendre compte, notamment en ce qui concerne l’impôt - puisque l'impòt est la résultante des faits sociaux -- de ce qu'a été, en matière d'impôt, cette puissante démocratie athénieune qui occupe une si grande place dans l'histoire de la civilisation. 


\section{š. La production et la richesse.}

L'Attique, chantée par Sophocle, admirée par Xénophon, était très-paurre (1 . Sauf ses monuments, Athènes n'offrait qu'une agcrlomération de 10,000 maisons, basses, petites, malpropres. Les rues étaient mal tenues, presque infectes. Il y arait plus de luxe dans les habitations à Lacédẻmone qu’à Athènes. Telle était Marseille, le premier port de la Méditerranée, jusqu’au milieu de notse siècle.

Pour nourrir, dans l'Attique, 200,000 personnes, il fallait, par année, 3 millions de médimnes de blé. Litttique n’en produisait 2 millions que dans les bonnes années. En moỵenne, elle était obligée, comme l'Angleterre actuelle, d'importer la moitié du blé nécessaire, soit 1,300,000 médimnes (2). C'était beaucoup pour l'époque. En échange, Athènes exportait des vins, de l'huile et du miel, mais les exportations ne pouvaient courrir les importations, thenes y faisait face, comme en partie lingleterre, de nos jours, comme Venise, arant elle, par les profits du commerce maritime; le Piree et Ilunychie étaient tout.

"Les maladies des fruits, envorées par Jupiter, sont désas" treuses prour ceux qui dominent sur terre; mais, sur mer, elles "nont rien de crrave. Tous les pays ne sont pas maltraités en "mème temps; en sorte que des contrées productives arrivent "tout ce qu'il faut unx mutres de li mer. D'ailleurs, s'il faut "mentionner des détails moins importants, leur puissance "maritime a fait trouver aux Ithéniens, par le commerce, de "quoi fournir au luxe de leur table. Tout ce qu"il $₫$ a de déli" cieux en Sicile, en Italie, à Chypre, en Erypte, en Lydie, "dans le Pont, dans le Péloponèse et ailleurs, tout cela s'est "concentré sur un seul point, grice à l'empire de la mer (3). ".

(1). Achremann. Antiquités greeques, $1^{\text {or }}$ vol., 1\%. 599. Les plaines, dans la firéce europernne, ne sont que les ravin - lleutroits bassins creusés entre les montagnes: les comrs ileaux taris-ent leté. curtius. $1^{\text {er }}$ vol., 1r. 16.

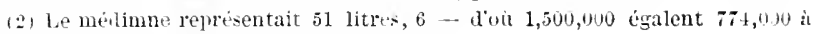
$8 \mathrm{fr}$. I'hectolitre en muyenne.

(3) Gouvernemont des Athiniens, chap. 2. 
Yénophon aurait décrit la situation actuelle de lingleterre qu'il n'aurait pas mieux dit. Athènes vivait done des profits du commerce maritime. Ils étaient alors restreints, car il fallait les partager avec Corinthe, Ty̧r, Carthage, Syracuse, Marseille, Byzance. Les fortunes se constituaient lentement; elles étaient rares; elles demeuraient précaires. Les moyennes variaient de 3 à $\ddot{z}$ talents. Ceux qui avaient $\$$ talents passaient pour riches; avec 12 talents on était classé dans les grandes fortunes. Le père de Démosthènes laissa 1 t talents sans les femmes esclares. Nicias, qui passe pour avoir eu une des grandes fortunes d'Athènes, était évalué à 100 talents (ä0,000fr.). On citait. encore le banquier Pasion 70 talents, Conon 40 , Isocrate 30, Diphile 160, la famille Callias dans laquelle entrèrent Périclès et Alcibiade; ces fortunes étaient exceptionnelles. La masse était pauvre. Cette paurreté fit de grands progrès après la guerre du Péloponèse. D'après Cicéron, dès le temps d'Alexandre, כ0 talents étaient considérés à Athènes comme une très-forte somme. Lorsqu'Antipater expulsa tous les citogens, qui avaient moins de 2,000 drachmes $(1,800 \mathrm{fr}$.), 12,000 personnes sur 20,000 furent frappées.

Au temps de Démosthènes avec un revenu de à mines la v'le était difficile (1); Socrate, qui navait pas darantage, vivait dans la gêne, n'avait qưun vètement et marchait nu-pieds. Bøekh évalue à $400 \mathrm{fr}$. par an la dépense d'une famille pauvre de quatre personnes. Sur cette dépense la nourriture, très-modeste, représentait près de 300 fr.

Les salaires étaient, en général, très-bas à cause de la concurrence du travail des esclaves. Ils ne dépassaient guère par jour 3 à 4 oboles pour le travail agricole; légèrement supérieurs dans la petite industrie, assez prospère, ils devenaient très-élevés pour les professions libérales: Médecins, sophistes, acteurs, musiciens, architectes (2).

(1) La mine valait $91 \mathrm{fr} .66$, la drachme 0 fr. 92, l'obole $0 \mathrm{fr} .15$, Brechl, 1 wol., chap. vil, xil, xir, xr.

(2) Buekh, 1er vil., liv. I, chap. xx-xxi, qui comptent parmi les meilleurs to cet ouvrage supérieur mème 80 ans apres sa publication. 
Le juge et l'ecclésiaste ne recevaient que 3 oboles.

Le soldat était rare, recherché, bien payé, il faisait fortune. Il devait fournir ses armes et son équipement. L'Hoplite recevait, selon les temps, pour lui et son valet de 4 oboles à 2 drachmes. - Le cavalier le double ou le quadruple. La condition militaire était considérée comme l'une des meilleures; Athènes entretenait beaucoup de mercenaires.

Il faut ajouter que les disettes étaient fréquentes, par suite les épidémies; que les prix des denrées variaient dans de grandes proportions. Ordinairement le médimne, qui ne valait que 2 drachmes en Sicile, coùtait le double à Athènes. L'Etat était obligé(1), comme à Ŕome, de veiller aux approvisionnements, d'avoir des magasins, de faire de nombreux achats, d'avoir recours à des distributions gratuites. Tantôt, il élevait, tantôt il abaissait le prix des blés. Il existait des lois contre les accapareurs et des magristrats ad hoc, tels que les agonaromes et les sitoplyylaques. La fabrication du pain était très-coùteuse et enchérissait le coùt de la vie. Aussi les exportations de blé étaient-elles défendues sous peine de mort, tandis que les importateurs de blé étaient exemptés du service militaire et que tout navire, chargeant au Pirée, devait rapporter des blés.

Les maisons rapportaient un bon revenu, de 8 à 10 p. 0,0 , à cause du nombre des Nétèques qui venaient faire le commerce à Athènes et qui ne pouraient y acruérir des immeubles. Ces Métèques, comme le dit Xúnophon, formaient de véritables colonies. Ils étaient l'une des plus réelles ressources d'Athènes. Ils trouvaient à Athènes la meilleure monnaie de l'époque(2), un bon système de poids et mesures, des consuls, des magistrats spéciaux, des banques où étaient déposés les capitaux des principaux oracles ou temples, une foule d'étrangers, de renseignements, des règlements maritimes équitables, l'habitude des affaires commerciales maritimes.

(1) Bøeckh, liv. I, chap. xr.

(2) Bœckh, liv. I, chap. I à vi. - Chapirres très-importants pour l'histoire de la monnaie. 
La propriété foncière était assez recherchée et morcelée en petits héritagres (1).

Les citoyens, à la plus belle époque d'Athènes, ne dépassaient pas le nombre de 20,000. Seuls ils avaient des droits politiques; seuls ils prenaient part au gouvernement.

Les esclaves n'avaient aucun droit; mais ils étaient, sauf ceux des mines, bien traités.

Ces divers renseignements sont indispensables pour saisir la nature, le mécanisme et l'incidence des imprits à Athènes.

\section{sั. Les depenses publiques.}

Avant d'indiquer les ressources de l'Etat, parmi lesquelles se trouvaient les impùts qui étaient très-variés, il convient de résumer les dépenses, parce que plusieurs dentre elles avaient un caractère politique et social qui rétroagissait sur l’organisation fiscale.

Quelques très-courtes observations, d'abord, sur le gouvernement et les institutions d'Athènes, qui sont le principal moteur des dépenses:

I. Le goucernement et les institutions. - Athènes est une démocratie absolue. Elle comprend seulement 20,000 citoyens. Ils sont tous égaux, sauf les effets de la richesse. lls gouvernent, ils administrent l'Etat directement. lls sont tous fonctionnaires publics; ils ont tous droit à un traitement. Ils sont aussi irresponsables que le Fxo:ise; de Suse. Le travail ne leur est pas interdit par les mours, ni par les lois; mais il n'est pas considéré. Dans tous les Etats grecs, le citoyen était, en principe, exempt dimpòt : cette exemption résultait de la condition libre (2). Elle attestait rindépendance, la noblesse du citoyen. On pouvait cependant lui demander certaines prestations, surtout à titre volontaire. En temps de guerre, le citoyen, représentant

(1) Sur les mouvements de la proprieté foncirre ì Athènes. Giraud, ibidén, liv. I, cliap. vili.

(2) Bockh, 2e vol., 1). 2 et lo. 
l'Etat, en formant partie intégrante, se devait tout entier, corps et biens. Il en était ainsi dans les démocraties comme dans les aristocraties; toutefois l'immunité fiscale appartient particulièrement aux aristocraties; cette immunité dont nous aurons à suivre la trace jusqu'en 1789 , et qui n’a pas encore tout à fait disparu, remonte bien loin dans les traditions de l'Europe (1).

Un second fait caractérisait les démocraties, fait qui se reproduit également dans les démocraties contemporaines, c'est que l'Etat devait entretenir, amuser (2), assister le citogen. A cet étrard, il importe de ne pas perdre de vue que les démocraties de l'antiquité étaient, au fond, des aristocraties avec tles institutions éçalitaires. De mème, on rencontrait, dans les aristocraties, des lois ou des mœurs démocratiques.

II. Dicision des dépenses. - Par suite, il y avait deux sortes de dépenses: celles afférentes aux besoins normaux de l'Etat, tels que nous les acceptons à peu près maintenant; celles afférentes à l'entretien, à l'amusement et à l'assistance des citoyens (3).

III. Dépenses normules. $-1^{\circ}$ La police des rues; 20 les emplois subalternes de la justice et de l'arlministration; $3^{\circ}$ les gardes de la cité, chaque garde recevait 3 oboles par jour; $4^{\circ}$ l'assemblée du peuple, chaque citoven recevait de 2 à 3 oboles par séance; 50 le Sénat, chaque membre recevait 1 drachı par réunion; $6^{\circ}$ les tribunaux, on comptait les tribunaux ordinaires au nombre de 10 avec 300 juges chacun, les petits tribunaux avec 200 à 400 juges et les grands tribunaux arec de 1,000 à 6,000 juges. En général, tout citoỹen passait son temps à en juger deux autres. Il recevait 3 oboles par jour, cétait le triobolon; $7^{\circ}$ les orateurs publics, les ambassadeurs, les professeurs et inspecteurs des écoles.

(1) Latélie (immunité fiscale) est très-ancienue à Athenes. Par atélie ou im. munité générale on comprenait l'exemption les droits de douane, des liturgies, du tribut res Météques. dans quelques eas de limpôt sur les propriétés et peutètre la dispense des saerifices. - Brechlı, 1 vol., 145. - L'immunité a une grande importance dans l'histoire de l'impüt.

(2) On la théatroeratie de Platon, Lois, livre III.

(3) Comparer Gilbert, ibidem, $342-348$. 
Bockh évalue la dépense du Théoricon (assistance aux théitres) de 2 ă à 30 talents par an, celle du Triobolon à 1 ŏ 0 , celle des oboles de l'assemblée de 30 à 30 talents, ensemble 203 à 210 talents; c'était une réritable liste civile d’environ 1,100 à $1,200,000 \mathrm{fr}$.

Enfin la marine et l’armée. Athènes n’était pas un camp comme Lacédémone; néanmoins la guerre y formait, comme dans tous les Etats de l'antiquité, la ressource principale (1). Tous les beaux monuments d'Athènes ont été payés au moyen de contributions de guerre. Tout le butin appartenait à l'Etat, sauf le dixième revenant à la Déesse. Le droit du vainqueur était absolu : prisonniers, femmes, enfants, parents, esclaves, biens tout leur appartenait. Très-rarement il y substituait une contribution. De là des institutions fiscales très-curieuses sur lesquelles nous allons revenir.

Les dépenses militaires et permanentes étaient celles des arsenaux, des vaisseaux et de la caralerie. Il n'y avait à Athènes, ni flottes, ni équipages, ni troupes d'infanterie organisés et entretenus en temps de paix.

Tout citoyen devait le service militaire, surtout à la mer.

En temps de guerre les dépenses étaient très-élerées; sur terre, il fallait payer assez cher un grand nombre de mercenaires comme à Carthage (2). Sur mer, il fallait fournir la solde et les vivres. Le peuple était belliqueux, parce que la guerre devait être profitable. Le goùt, l'habitude de la piraterie (3), invétérés chez les Grecs, étaient un ferment permanent de guerre : " semblables à des pirates, dit Bœckh, les Athéniens ròdaient " de tous còtés pour subvenir aux frais de la guerre ". Les héros grecs Ulysse Thémistocle, Alcibiade étaient de grands pirates: pirates sur mer, pirates sur terre. La guerre héroïque de l'Indépendance, en $182 \mathrm{t}$, qui devait attester la résurrection de la Grèce, a été une gruerre de pirates.

(1) Bopekh, liv. II, chap. xxi à xxir.

(2) sur les mercenaires cousulter Boekh, rol, 1, p. 438.

(3) sur la piraterie, Petit de Julleville, La Grice sous la domination ro. maine, chap. Ix, Breckh, Liv, III, chaj. X'r. 
IV. Dépenses particulières : $1^{\circ}$ l'assistance publique (1), spécialement aux blessés à la guerre, aux orphelins et mème aux infirmes. Le citoyen admis à l'assistance recevait de 1 à 2 oboles par jour. C'était relativement l'assistance faite aux riches. L'esclave, il est vrai, était à la charge du maitre; $2^{\circ}$ les médecins, les artistes, les musiciens, les gymnases publics; $3^{\circ}$ les sacrifices, très-lourde charge pour l'Etat; dans quelques-uns on immolait jusqu'à trois cents breufs; $4^{\circ}$ les repas publics qui avaient lieu par tribu et par mois; $\check{\partial}^{\circ}$ les fêtes religieuses trèsnombreuses et très-coùteuses, notamment les Diony̧siaques et les Panathénées; $6^{\circ}$ les représentations théitrales, si importantes et si célèbres à Athènes; $7^{\circ}$ les Théories et les prix des grands jeux nationaux de la Grèce qui ont survécu à son indépendance et qui caractérisent la civilisation hellénique.

En somme, l'assistance et le plaisir gratuits étajent les deux causes des dépenses particulières. L'une et l'autre se touchent de près. L'habitude des fètes a profondément pénétré dans la vie des Grecs. Toute une série de fonctionnaires dùt y pourroir; on désignait des ambassadeurs pour acheter au loin des taureaux et des chèvres. Bientòt il ne fut plus suffisant d'y assister. Périclès inventa le Théoricon des fètes ou le salaire donné aux citoyens pour venir aux fètes. Il était de 2 oboles. D’abord on le réserva pour le théâtre, chacun le recevait en entrant de même qu'il recevait le triobolon judiciaire en sortant. Puis on étendit la distribution du Théoricon aux repas publics (2); on finit par le donner pour toutes les fètes. Plus de 18,000 personnes le recevaient. La théatrocratie de Platon était bien réelle. Beaucoup d'Athéniens vivaient littéralement du Triobolon et du Théoricon. Ils étaient sobres. La mesure de blé de l'esclave et l'opson (3) (part quotidienne de légumes, poissons, viande, fruits pour un homme évaluée à 2 oboles) leur suffisaient.

(1) Xenoplun, Revenus, chal'. 11. et Schomann, Arriquités, 1 vol., 501. Platon at relevé avec raison l'importance le ce fait, l'assistance publique a lhènes. Lois, liv. $\mathrm{r}$.

(2) Aristote, Politique, chap. 1x, 4. Le repas public était à Athènes le débris d'un état social disparn, the mẻme que la dîme levée par certains temples comme rente funcière.

(3) Sur l'opson, Boekh, liv. I, chap. xrir. 


\section{\$ 6. Les ressources de l'Etat (1).}

Bœckh remarque qu'au fur et à mesure de l'extension du Triobolon et du Théoricon, les confiscations augmentèrent (2). Cela donne à réfléchir sur la démocratie athénienne. On confisquait les biens des riches pour amuser les paurres; de mème que les Pharaons, les rois d'Assyrie et de Perse. En quoi consistaient les ressources pour faire face à toutes les dépenses, normales et particulières?

Ces ressources se divisaient, comme les dépenses, en deux catégories distinctes : les revenus ordinaires et les revenus extraordinaires.

Les revenus ordinaires comprenaient: $1^{\circ}$ les produits des biens de l'Etat; $2^{\circ}$ les confiscations; $3 \circ$ les prestations ordinaires $; 4^{\circ}$ les taxes des étrangers; $\dddot{3}^{\circ}$ les frais de justice; $6^{\circ}$ les droits de douane et de port; $\tau^{0}$ les tributs.

Les revenus extraordinaires comprenaient $: 1^{\circ}$ les prestations extraordinaires; $2^{\circ}$ l'impüt sur le capital; $3^{\circ}$ le butin de guerre; $4^{0}$ les gains sur les monnaies; $3^{\circ}$ les contributions forcées.

Nous allons passer successirement en revue les diverses sources de revenus, en réservant les impòts, les prestations, les contributions forcées pour la fin, sauf les confiscations qui, chez la plupart des peuples anciens, devaient parfaire.

I. Les biens de l'Etat. - Athènes possédait un domaine considérable (3) que le peuple accroissait encore, de temps à autre, au moyen des confiscations. Ce domaine comprenait des propriétés rurales, des maisons, des esclaves; le tout était affermé à un fermier général qui sous-louait en détail. Les peaux des bètes des sacrifices et des repas formaient un revenu assez élevé.

A diverses reprises le peuple eut recours à des monopoles temporaires: importation du blé, commerce du plomb, même le change ('t).

(1) Gilbert, ibid., 350, 357 .

(2) Sur les confiscations, voir ci-apres, \$ 14.

(3) Bockh, Sur le domaine de l'Etat, liv. III, chap. II.

(4) Brekh, ler vol. 1, 87, 83, 89 . 
La plus précieuse ressource domaniale était les mines d'argent du Laurium, dont les scories sont encore riches et les mines d'or de Scapté-Hylé en Thrace (1). Ces mines étaient données à bail perpétuel, par portions, moyennant un prix fixe et un vingt-quatrième du produit. Chaque exploitation constituait une propriété qui était mise en société et se transmettait régulièrement. L'exploitation des mines était protégée par des lois sèvères. Thucydide devait sa grande fortune à des mines d'or. Les mines étaient exemptes d'impôt. Xénophon a consacré la plus grande partie de son traité des revenus d'Athènes à établir un plan d'exploitation à fond des mines du Laurium et de Sunium. Il proposait d'y affecter 10,000 esclaves qui auraient produit à l'Etat $550,000 \mathrm{fr}$. (100 talents). Rien de curieux comme de suivre dans ses détails cette spéculation imaginaire du disciple de Socrate, l'un des hommes qui ont le plus honoré la civilisation grecque. Combien était grande la misère de l'homme! L'esclave minier de Sunium était tout autrement accablé que le Fellah et surtout que l'Hilote. Tout pirate athénien pouvait enlever, à chaque instant, un citoyen d'un autre Etat pour le vendre au Sunium. "Si l'on adopte le plan que je "propose, dit sans hésiter le héros de la Cyropédie, le seul " changement qu'il y aura, c'est qu'à l'exemple des particu"liers, qui, en achetant des esclaves se font un revenu per"pétuel, l'Etat en achètera aussi à son compte jusqu’à ce que " chaque Athénien en ait trois... une chose réellement éton" nante, c'est que l'Etat voit une foule de particuliers s'enrichir " et qu'il ne fasse pas comme eux. (2)" Ainsi voilà l'auteur des Memoratilic, l'écrivain charmant qui a tracé le portrait histoque de Socrate, qui transforme l'Etat en un bouge d'esclaves. Ceux de Sunium étaient si malheureux, qu'ils se révoltèrent, mirent tout à feu et à sang, détruisirent les puits, répandirent

(1) Buckh, liv. III, chap. ri. - Xénopbon, Revenus, chap. rv.

(2) "Le probluit des esclaves augmentera les ressources de l'Etat; la ville elle" même verra sa population s'accroître prodigleusement; les terrains prendront "de lia valeur; la ville deviendra phus riche, plus docile, plus anie de lordre, plus "bellifueuse; on sera plus assidu aux exercices du grmmase ". - Des Revenus, cbap. $\pi$. 
partout une terreur telle que le travail des minerais dargent du Sunium a èté suspendu pendant plus de 20 siècles.

II. Le butin de guerre. - Le butin de gruerre était considéré comme une ressource domaniale normale (1). L'Etat en avait les $9 / 10$. On a indiqué plus haut combien le droit de gruerre était rigoureux, mème exercé par les citoyens de Sophocle et de Platon. On doit à Thucydide plusieurs pages admirables sur les excès du droit de la guerre de son temps $(2)$. Ces pages indiquent au moins que déjä bien des esprits, précurseurs d'autres temps, ne les acceptaient plus.

III. Les trituts. - C'était une des principales ressources d'Athènes $(3)$. Ils provenaient de deux sources : les tributs des Clérouques ou colons athéniens établis en dehors de l'Attique et les tributs des alliés. Ils étaient les mèrnes.

A l'origine, ces tributs araient été consentis librement, surtout après les guerres Nédiques, en vue de concourir à la défense de la Grèce. Ils n’étaient pạ̌és que par les peuples maritimes qui formaient la confédération de Délos. Ils s'élevaient à 460 talents qui, chaque année, étaient versés au Trésor de Délos, dans le temple d'Apollon. Ce Trésor était géré par les Hellénotames. La confédération de Délos marque l'apogée de la puissance d'Athènes. La tendance du gourernement athénien sous Aristide, Périclès et Alcibiade consista à transformer cette confédération volontaire en une hégémonie basée sur la force. Périclès éleva les tributs à 600 talents et réussit à transporter le Trésor à Athènes. Il s'en servit, comme Cẻsar devait faire du Trésor du temple de Saturne, pour embellir Athènes; cest l'une des causes de la guerre du Péloponèse; Alcibiade doubla les tributs. Les alliés se révoltèrent, abandonnèrent Athènes qui succomba. Rétablis en partie sous Thrasybule, ils disparurent après Chéronée. 1,200 talents représentaient 6,600,000 fr. On dirait une page de l'histoire de l'indépendance des Etats-Lnis. Cette perte exerça nécessairement une grande intluence sur les institutions fiscales d'Athènes.

(1) Bockh, liv. IV, chap. xvi.

(2) Défense des prisonniérs Platéens, liv. III, \$52.

(3) Bochh, livre III, chap. Xv à xvul. - Curtius, $3^{e}$ vol, 152. 


\section{$\S$ 7. Les impóts.}

L'Etat, fort dispendieux et fort dépensier, puisqu'il entretenait la plupart des Athéniens libres, avait sa principale ressource dans les impòts, aussi nombreux qu'en Egypte, quoique diffèrents en partie; la richesse étant principalement territoriale en Egypte et principalement commerciale et maritime à Athènes. A Lacédémone, l'impòt devait entretenir l'Etat et la classe militaire. Cet entretien était assuré par deux classes de cultivateurs spéciaux. A Athènes, il devait entretenir l'Etat et la plus grande partie des citogens libres. Il devait être plus lourd à Athènes qu'à Lacédémone et aussi plus varié parce que la production territoriale ne pourait, comme à Lacédémone, y suffire. Par suite, on trouve, dans les institutions fiscales d'Athènes, une diversité, une souplesse, une ingéniosité tout à fait comparables aux habiletés des fiscs modernes, mais elles révèlent aussi beaucoup d'énergie et de patriotisme, une pratique admirable de l'abnégation civique.

Les impòts étaient directs ou indirects.

10 Impöts indirects.

Les impuits indirects consistaient dans : A. les droits de douane; B. les droits de port; C. les taxes sur les ventes dans les marchés; D. les droits sur les ventes de biens-fonds; E. les frais de justice et les amendes (1).

A. Les marchandises, dans les ports ou aux frontières de terre, payaient, ì l'entrée et à la sortie, un droit du 50e de la valeur. Les blés n'en étaient pas exempts. Ce droit était affermé et produisait en moyenne, 'chaque année, de 30 à 36 talents, ce qui pourait correspondre à un mourement annuel de 1,500 à 2,000 talents environ. Pour diminuer les inconvénients des tributs dus par les alliés, on leur substitua plus tard un droit de

(1) Beckh, livre III, chap. Ir, V, VI, XI et xu. - Gilbert, ibid, 350-357. - Schœmann, jer vol.. 513 . 
douane du 20 levé par Athènes sur toutes les importations et exportations de ses alliés. Ce droit était également affermé. C'est ainsi que les Anglais levaient des droits de douane sur leurs colons américains.

B. Dans les ports, il était dû des droits spéciaux pour leur entretien, savoir; un droit du centième de la cargaison pour les frais mèmes du port et un supplément pour les frais des marchandises en douane. C'est arec les mèmes droits que se sont organisés les plus grands ports actuels tels que Londres, Hambourg, Anvers, New-York.

C. Les droits sur les rentes dans les marchés se percevaient aux portes d'Athènes. Ils équiralaient donc à de véritables droits d'octroi. Ils rariaient suivant la nature des marchandises. Il parait que le taux représentait plusieurs centièmes de la marchandise. A Bysance, il fut longtemps de 10 p. 00 . Le rendement était considérable. A Rhodes, ils produisaient $\mathrm{t} 66$ talents par an.

D. Le droit sur la rente des biens-fonds était seulement du centième denier, 1 p. 0/0. C'est le point de départ du droit de mutation entre-rifs - pas de droits sur les successions et donations. Les actes devaient ètre enregistrés. Il existait à cet effet des bureaux spéciaux; peut-ètre y. arait-il d'autres droits que ceux de mutation (1)?

E. Les frais de justice et amendes formaient un des grands revenus d'Athènes. Chaque partie les devait; ils étaient particulièrement appelés à payer à tout Athénien libre le Triobolon pour sa subsistance et le Theoricon pour son amusement. Le peuple, c'est-à-dire les citoyens libres, payant et dépensant lui-même, se montrait très-rigoureux afin de remplir la caisse publique; nul procès civil, criminel, politique, sans caution (Prỹtanée); on renouvelait les cautions en appel (Paracatabole), parfois avec complément (Epobélie). Les amendes étaient très-fortes. Socrate, bien que paurre, fut taxé à 10,000 drachmes; Miltiade, Callias, Démosthènes à 90 talents, Timothée à 100, qu'ils ne purent payer.

(1) Giraud, ibidem, 293. 


\section{Impôts directs.}

L'impòt direct, à Athènes, était temporaire. C'était son carac tère essentiel. En principe, le citoyen libre, tel que le noble dans l'Europe féodale, ne doit pas d'impòt. Il consistait : 10 en une taxe proportionnelle et progressive sur le capital (stfcecx), d'après un cens général et foncier; $2^{\circ}$ en des prestations ordinaires; $3^{\circ}$ en des prestations extraordinaires; $4^{\circ}$ en des taxes personnelles; $\breve{\jmath}^{\circ}$ en des dimes religieuses.

I. L'impöt sur le capital à Athènes. - Cet impòt, comme nous venons de le dire, portait le nom detofox. Bueckh a admis qu'un impit, d'après le cens de Solon dont nous allons parler,

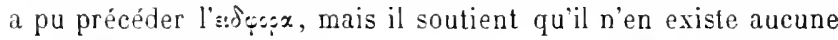
preuve. M. Gilbert n'en parle pas; landis que M. Giraud en fait un impüt foncier qui aurait été permanent, et qui aurait été aboli après les guerres médiques; Breckh y a vu une sorte de capitation. Selon M. Giraud, cet impôt prorenait d'une ancienne dime et représentait le douzième du produit brut. Il est certain que la dime a longtemps existé en Grèce, notamment dans le nord. Mais cet impòt foncier ayant disparu, il est sans intérèt de s'en occuper. Il ne reparaitra en Grèce que plus tard.

A. Cens et reformes saciules de Solon. - L'impòt sur le capital à Athènes est postérieur à Solon, mais il correspond à une réforme importante accomplie par Solon.

Avant Solon (1), la population libre de l'Attique, répartie dans Jes quatre tribus primitives et formant trois classes distinctes (propriétaires, cultivateurs et bergers, artisans) ne jouissait pas des mèmes droits. Les cultivateurs et les bergers payaient aux propriétaires à titre de redevance le sixième du produit des terres. Cette redevance s'acquittait en nature; c'était un reste de la dime qui a existé dans l'Attique comme dans toute la Grèce. Les temples, qui possédaient de grands biens, avaient conservé la dime en nature ou le dixième du revenu brut. Les maisons

(1) Schoemann, Antiquités, ler vol., $371,37 \pi$. Article $s ! \delta \varphi ̣ c s x$, Dictionnaire Daremberg, tome 11 . 
appartenant au temple de la Déesse à Athènes étaient affermées au dixième.

"Les habitants de la montarne, dit Plutarque, demandaient " un gouvernement populaire; ceux de la plaine préféraient un "état oligarchique et ceux de la còte, portés vers un gouverne"ment mixte, tenaient la balance entre les deux partis. Dans le "même temps, la division, que cause pres fue toujours entre les "paurres et les riches l’inégalité de fortune, était plus animée "que jamais dans la ville... Les paurres, accablés par les dettes "qưils avaient contractées envers les riches, étaient contraints "de leur céder le sixième du produit de leurs terres; ce qui "leur faisait donner le nom de sixenaires ou de mercenaires; "ou bien réduits à engager leurs propres personnes, ils se "lirraient au pouvoir de leurs créanciers qui les retenaient " comme esclaves ou les envogaient vendre en pays étranger. "Plusieurs mème étaient forcés de rendre leurs propres en"fants (1)."

Ces excès caractérisent les cirilisations anciennes de la Grèce et de Rome. Ils ont été inconnus à la Chine, moins grands dans l'Inde et dans les monarchies orientales; c'est dans la Grèce et à Rome que l'esclavagre a été le plus terrible. De mème l'esclavage des noirs aux $x^{\prime} H^{e}$ et $x$ rm ${ }^{e}$ siècles a eu un caractère plus dur chez les peuples chrétiens que l'esclarage dans les Etats musulmans. L'éclat extérieur de ces civilisations aristocratiques, Phidias et Euripide, Démosthènes et Aristote, Cicéron et Horace ne doirent jamais faire perdre de rue les violences et les souffrances intolérables des milieux dont ils ont été les reflets.

Solon a exercé sur les institutions et les destinées d'Athènes une intluence de la même nature, que celle de Lycurgrue à Lacédémone, ou que Servius Tullius à Rome. Les lois appropriées à une aristocratie militaire ne pouvaient convenir à un petit Etat où les intérèts du commerce et de la marine primaient tous les autres. 11 abolit le servage; il améliora la condition des trois dernières tribus; il supprima la contrainte par corps et par suite la vente de la personne du débiteur et de celle de ses enfants

(I) Plutarytt, l'ie de siolon, s li. 
pour dette; c'est une des plus grandes réformes dues à la civilisation d'Athènes; il réduisit les intérèts des dettes; il en facilita le paiement en élevant la valear de la mine de 73 à 100 drachmes (1). Cet ensemble a constitué la $\delta \notin \delta \% x \theta=t x$.

Ces premières réformes accomplies : "Il fit faire une situation " de chaque particulier. Il rangea dans la première classe les " citoyens qui araient 300 médimnes de revenu, tant en grains " qu'en liquides, et il les " appela Pentacosio médimnes (c'étaient "les Hoplites); la seconde classe comprit ceux qui avaient 300 "médimnes et qui pouvaient nourrir un cheral; ils furent " nommés les chevaliers. Ceux qui avaient 200 médimnes com"posèrent la troisième classe sous le nom de zeugites. Tous "les autres, dont le revenu était au-dessous de 200 médimnes, "furent appelés Thètes (2). "

Le cens avait-il un caractère et un but fiscal? Bceckh, après une discussion approfondie, se prononce dans le sens de la nétrative. Il établit que, bien que ce classement des citoyens d'après leur fortune ait pu servir à l'impòt foncier dont il a été cidessus question, on n'en trouve aucune trace; qu'il arait un but politique et non fiscal, mais que plus tard il a pu ètre utilisé dans un but fiscal (3).

Selon Thucydıde, la premiere sı siège de Mythilène ( $88^{\mathrm{e}}$ olýmpiade $\mathrm{I}_{j}$. C'était un impòt militaire que les généraux faisaient recouvrer dès que le peuple l'avait voté. Ils jugeaient mème toutes les contestations à son égard;

(1) solon, $\mathrm{xx}, \mathrm{xx} 1, \mathrm{xxin}$.

(2) Solon, xxirl. - Beckh, 2" rol., 304.

(3) Breckin, liv. Ir, chap. v. Dans toutes les civilisations esclavagistes le cens est une institution sociale de lesmier andre. Il sert it itablir la ligne de demarcation entre le cituren et leselave : car lans ces cirilisations la liberté vient au pre-

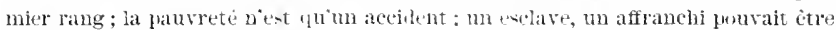

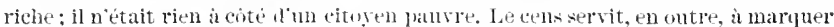

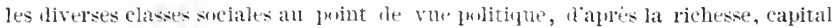
ou revenu, atin d"indinuter les obligations de chacun, notamment les obligations

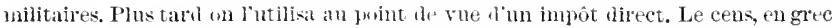
r.urux, êt alow une linble signification : $1^{\circ}$ ka signification anciemne, denombrement et classement de la phnlation: 2" le montant de limplôt direct étabii dapres

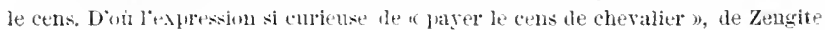
Dans l'Evangile le cens a cetfe lenble signification. Breckh, $2^{\circ}$ vol, $310,312,31$. 
nul, mème l'orphelin, n’en était exempt. Il était établi d’après le cens.

B. De lassiette et du tuux de l'imput. - De 228 à 378 l'imprit sur le capital parait avoir fonctionné à Athènes, toujours à titre temporaire, sur des bases fixes et régulières. Cest l'époque où il a dù ètre le plus nécessaire et le plus productif. C'était un impöt de répartition, chaque fois voté par l'assemblée du peuple.

Schœmann a contesté qü̈l constituàt un vẻritable impöt sur le capital; il pense qu'il était tout aussi bien un impüt sur le revenu. L'opinion de Schœmann ne semble pas acceptable. Elle provient d'une distinction fondamentale faite par Breckh quant à l'assiette de l'imput; mais cette distinction ne modifie pas le caractère réel de l'impit.

"Qui na pas raconté, dit Polybe. dans un passage célèbre, "que les Athéniens lorsquiils marclrèrent contre les Lacédémo"niens, de concert arec les Thébains, et qu"ils enrovèrent " 10,000 soldats et équipèrent $l(0)$ galères, ils résolurent de "subrenir a limpit de guerre arec le bien et que le pars, l'At" tique entière avec les maisons et tout l'aroir fut estimé. que "néanmoins l'estimation du bien n'atteignit pas 6,000 talents, "qüil en manqua $230(1)$. "

Quelle pourait étre cette estimation? Eridemment ce n'était pas le capital réel. Tout le bien des Athéniens dépassait de beaucoup 6,000 talents. Ce n'était pas non plus le rêrenu unnuel du capital réel. Il eùt été trop considérable. Ce derait ètre la portion considérée comme imposable du capital réel, portion qui avait un certain rapport arec le revenu annuel; c'est ce rapport qui a pu tromper Schumann. Maintenant quelle proportion exis-

(1) Buckh, 2 vul. 269. 310, 317, p. 324. schumann, Antiquites trecques, vil.

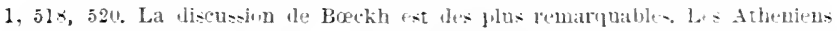

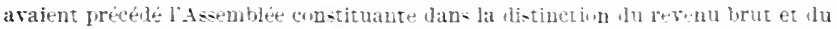
revenu net, lans la recherch" scientifique lu revenu impsable; cest ce derniter multiplie par le filteur donze yui donnat le capital imposable; ce fact ur a de Jimportance comme indicatif du taux de capitalistion. A legrlue de larchonte

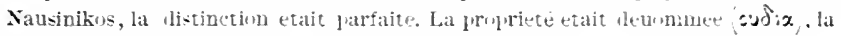

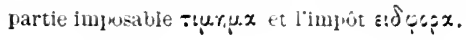


tait-il entre le capital réel et le revenu? Bæckh la fixe au douzième pour toutes les classes. Le capital réel était censé représenter douze fois le revenu. Quelle partie de ce capital était tenue comme imposable? Cette partie variait arec chaque classe. L'st $\delta$ Gra aurait ainsi eu un caractère progressif. La première classe prạait sur la totalité du capital. Le capital imposable était le capital réel. Pour les cheraliers, Bøeckh admet les $3 / 6^{\mathrm{es}}$, pour les zeugites les $\ddot{3} / 9^{e z}$. Les Thètes étaient exempts.

Bœclih a résumé ses intéressantes appréciations dans le tableau qui suit :

\begin{tabular}{|c|c|c|c|c|c|}
\hline CL.IS:E. & FEVENI. & CAPITAL. & $\begin{array}{l}\text { PAPPORT } \\
\text { avec } \\
\text { le capital } \\
\text { impusable }\end{array}$ & $\begin{array}{l}\text { C.APITAL } \\
\text { imposable. }\end{array}$ & $\begin{array}{c}\text { PRODLIT } \\
\text { de l'impot } \\
\text { du } 50^{\circ} \text { drach. } \\
2\end{array}$ \\
\hline Mnlle médımnes.... & $1,+410$ & 12.0100 & Totalité. & 12,000 & 240 \\
\hline Pentacusiumedimnes. & 750 & 9,000 & $1^{\circ}$ & 9,000 & 150 \\
\hline- & 500 & 6,01010 & $d^{\circ}$ & $6,0(40)$ & 120 \\
\hline - & $45 !$ & 5,4 in & $\mathrm{d}^{\mathrm{H}}$ & $4,5(1)$ & 90 \\
\hline Chevaliers ........ & 400 & $4, n+10$ & $5 / 6^{+6}$ & 4.000 & 80 \\
\hline$-\quad \ldots \ldots$ & $3 y 0$ & 3.600 & $d^{\circ}$ & $3 .(n+9)$ & 60 \\
\hline Zeugites......... & 250 & 3.000 & $5,9^{\circ}$ & 1.666 & 33 \\
\hline$-\quad \ldots \ldots \ldots$ & 200 & 2.400 & $11^{0}$ & 1,333 & 26 \\
\hline$-\quad \ldots \ldots \ldots$ & 150 & 1.3400 & $d^{\circ}$ & 1,000 & 20 \\
\hline
\end{tabular}

Les proportions discutées par Bneckh ne sont que des hypothèses : car on ne possède pas de chiffres authentiques; on sait seulement que l'impòt ne portait pas sur la dernière classe et qu'il était pour les autres décroissant, non pas d’après le taux qui était le mème, mais daprès la proportion pour déduire le capital imposable du capital réel. Le capital imposable était appelé $-: \mu x, u x$ (1) et le capital réel $x \xi: x$.

Yéanmoins, les hypothèses de Breclih reposent sur deux textes qui figurent parmi les plus curieux de l'histoire fiscale de l'antiquité. Le premier est une loi conservée par Démosthènes relative aux dots obligatoires. Ces dots sont fixées d'après le cens de Solon: $500,300,150$ drachmes. Le second est un texte

(1) le mot :y.ru, reçoit ici une troisieme signitication. 
de Pollux, discuté avec la plus grande sagacité par Buckh et qui établit le caractère de progression décroissante de la base ou de la matière de l'sidẹpx à Athènes. "Les Pentacosiomédimnes dépensaient 1 talent pour la chose publique, les chevaliers 30 mines, les Zeugites 10 et les Thètes ne donnaient rien ( $\mathbf{t}$ ).

Quant an taux de l'impit il variait avec les circonstances et les nécessités; it était le mème pour les diverses classes.

Les hypothèses de Bæckh ont été sérieusement contestées soit en France, soit en Allemagne, par des sarants d'une grande compétence. On a critiqué : $1^{\circ}$ les trois significations qu'il donne successivement au mot s!ru.x; $2^{\circ}$ l'interprétation qu'il a faite des textes de Démosthènes et de Pollux. On a nié le caractère de progressivité décroissante de l'stógç admise par Birckh, non pas d'après la diversité du tanx de l'impòt, mais d'après les différents modes d'évalner le capital sur lequel il était prélevé, sans proposer aucune explication aussi naturellement fiscale et économique que celle de Buckh. Le seul point accepté par tous les interprètes: c'est l'existence d'un impüt militaire, temporaire et de répartition à Athènes avec un taux variable $(2)$.

(1) Ces chiffres, comme Breckh le demontre (2 vol., 1', 306), ne correspondent qüa une appreiciation génèrale de Pollux sur la répartition froportionnelle decharges publinges pour les liverses classes a Athines.

(2) Bneckh, liv. IV, chap. VI. - M. Giraul, La propriété foncieve en Grèee.

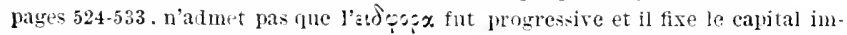
jusable reyrux au cinquieme du cens al'apres un texte de Demosthenes a mn timema de 3 talents suppose un capital de 15 talents m. Cette reiluction de la matière imposable, parait bien forte.-Comparer Gilbert, 366-Le carital assesser c'est-i-dire imposable aux Etats-[̌nis est bjen supérieur au cinquipme du capital veritable: ‘fuant a la diversite de methode pour caleuler la matiere imposable, d'apres la richesse du contribuable, elle se rencontre dans pas mal de legisation. tiscales actielles.

Un passage des Lois de Platon (Liv. XIl), indiplue que ces questions itaient, il son Epoque, étudites t bjen comprises. "A l'egard des contributions jour les besoins de l'Etat, il est nécessaire pour plusieurs raisons que l'on ait une tétimation just." des biens des citoyens et que dans chaque tribn on domne par cerit anx juspecteurs des camparnes un etat de la recolte annelle atin que, connue il y a 1 . -

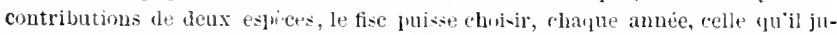
gera a propos, soit qu'il priffre faire prayer à proportion de l'stimation des bicn: des particuliers, on a popurtion du revenu de chanue annee. - "Voila bien les dcux impôts l'un sur le capital, l'autre sur le revenu. „

Dans un artiele techuique du Dietionnaire Daremberg (tome 11), M. Ch. Lécri- 
C. Du cens et du cadastre. - Le cens de Solon étaịt un classement politique et social. Il ne pourait suffire à la levée d'un impôt direct sur le capital. Un nouveau cens fut établi

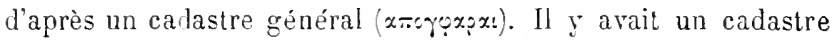
foncier et un cadastre de tous les biens mobiliers et immobiliers. Les biens de l'Etat n'y figuraient pas; mais on $y$ faisait entrer ceux des communautés, des temples et des bourgs. Le cadastre général comprenait les terres, les maisons, les esclaves, les capitaux, les produits bruts ou travaillés, le bétail, le mobilier, le tout évalué en numéraire; on y mentionnait aussi les dots des femmes. Chaqque citoyen faisait sa déclaration, sauf contröle. Elle était toujours au-dessous de la réalité. Les déclarations étaient renouvelées tous les ä ans. Les fortunes étaient rariables. Les Mlétèques, mème isotèles, avaient un cadastre particulier.

D. Du cens de Nausinique. - En 378, l'archonte Nausinikos modifia le cens et l'impöt sur le capital. Les proportions furent changées. Les distinctions faites par Solon avaient à peu près disparu. La proportion du capital imposable fut fixée pour les classes supérieures au cinquième du capital; on ne connait pas la proportion pour les autres. Toutes les propriétés mobilières et immobilières lurent taxées. Le minimum de capital atteint par l'impùt fut abaissé, le nombre des contribuables augmenté.

Bœckh a calculé que, pendant 10 ans, Démosthènes ne paya que la dixième partie de son capital imposable ou la cinquantième

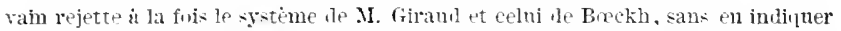
un antre. 11 ensillere les évaluations le Beckh comme trop élevés: il combat surtout l'hypothèse du capital imposable. Nous avons cru devir nous en tenir aux explieations. rectifiétes sur quelques 1 mints, he Boekh, et nous acejtons sou hypothese du eapital impuable comme rraisemblable: est l'assessed valuation des Etats Cuis lont on retrouve le principe lans le revenu net de lincome tax en Angleterre, ollosé aux gros rerenues (revenus bruts). Dailleurs, nutus narons pas la prétention de trancher des questioms de textes, mais d'indiquer les élements principaux des institutions fiscales en Grèce. Les critiques bien naturelles de l'onvrage de Boekh, paru en 1816, ne font que rehansser la valeur le cet ourrage exceptionnel. M. Lecrivain considere le milien financier et fiseal d'Athè comme rudi-

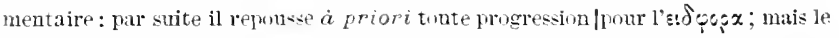
milieu d'Athenes etait-il flus rulimentaire que celni de Florence auxret an $\mathrm{x}^{\mathrm{e}}$ siecle? or dans le milien forentin, limpot progressif, naturel aux democraties, a été bien plus excessif ‘üà Athènes. Renvoi à lappendice : L'impót progressif a Athènes. 
partie de sa fortune - et la moitié seulement sous Nausinikos ou 1 p. $0 / 0$. - L’impoit aurait représenté 2 p. $0 / 0$ avant lui; mais en 378 Athènes était en décadence 1).

Pour apprécier cet impot, il faut compléter l'exposition des institutions fiscales d'Athènes.

E. Des Symmories. - Backh pense que l'impoit sur le capital à Athènes ne constituait pas une lourde charge (2). Son opinion est contraire aux faits. En effet, il se joirrnait à d'autres contributions qui vont ètre exposées et comme il les complètait, il pouvait ètre accablant, selon les circonstances.

Les Symmories l'attestent. Larchonte Nausinikos aràit hesoin de 300 talents. Pour en assurer la levée, il établit les Srmmories. La Symmorie était une association mutuelle pour lever et garantir l'impoit. 11 y avait 20 Symmories: elles étaient mème subdivisées. Elles comprenaient les 1.200 contribuables les plus riches qui repondaient de l'impoit. Les symmories pouvaient ètre, en outre, obligées, par décret du peuple, à l'arance de

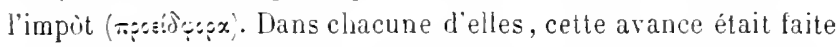
par les 300 plus riches contribuables qui rentraient plus ou moins dans ce qui leur était dù; à cet effet, on leur remettait lo Diagramme du rôle sur lequel étaient portées les cotes des contribuables. Tout membre d'une symmorie répondait de l'impoit sur sa propriété qui pouvait ètre saisie et confisquée. S'il se croyait

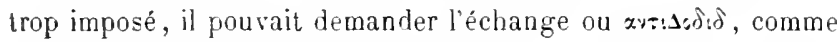
il va ètre ci-après expliqué. Par contre, la rocesç̣: était tenue comme une liturgie.

II. Des prestations ordinaires. - Les prestations s'appelaient des liturgies. Les liturgies ordinaires étaient les moins importantes. C'étaient la chorégie, la gymnasiarque, l'hestiase et l'archithéorie ( 3 .

(1) Bockh, liv. 1Y, chap. vir et vin.

(2) Breckh. liv. IT, chal. IX. M. Giraul arrive au taux de 2,086 1\%. 0/0 ce qui de-

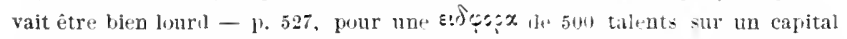
imposalje de 5.750 tahnt-. - En général le taux était de 1 1) o/0 du cajital

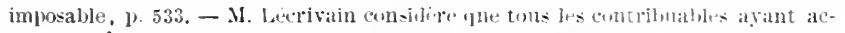

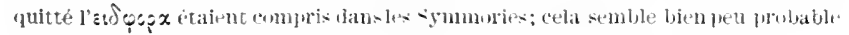

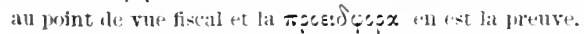

(3) Boekh, liv. IH, elap. Xxг. Xin, xxm. - Gibert, ibidem, 353. 
Les liturgies étaient un impit sur les riches: les citovens arant moins de 3 talents et les orphelins en étaient affranchis. Le peuple, à titre de récompense nationale, en exemptait quelques personnes. Elles étaient périodiques; elles revenaient tous les deux ans; elles étaient distinctes; nul n'était tenu d'en remplir deux à la fois. Léchange était admis : tout citoyen, désigné pour une liturgie, pouvait obliger un autre citoyen à la remplir, sauf à échanger leurs biens.

A. La chorégie. - Le chorège était chargé de veiller aux plaisirs du souverain. La chorégie formait une véritable administration des menus plaisirs; spectacles, fètes, poètes, artistes, chiens, musiciens, enfants, tout devait être préparé, organisé et påé par les chorèges. H y en avait chaque année dix, soit un par tribu. L'Etat concourait à la dépense; elle variait de

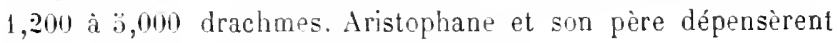
en cinq ans 3.000 drachmes en chorégies.

B. La gymnasiarque. - Autre charge sur les riches; elle consistait à fournir le nécessaire pour les courses publiques. Elle pourait coùter 1,200 drachmes.

C. L'Hestiase. - C'était la dépense des repas publics qui avaient lieu, par tribu, à certaines fêtes; coùt d'un repas, 700 drachmes.

III. Des prestations ertraordinaires. - A. La triérarchie. La triérarchie remontait aux àges héroïques d'Athènes 1$\}$. Elle était bien antérieure à Solon. C’était une liturgie extraordinaire et de beaucoup la plus lourde charge des classes riches; elle consistait dans l'obligation personnelle du service maritime et dans la participation aux dépenses. Elle correspondait assez exactement aux charges du service militaire pour les familles féodales jusquà la fin du $\mathrm{xr}^{\mathrm{e}}$ siècle; comme le service féodal, elle a revètu différentes formes.

En principe, le triérarque devait commander, équiper et eritretenir un navire de guerre. L'Etat fournissait le navire, la solde, les rivres, quelquefois les agrès. Plus tard, le trié-

(1) Beckh, liv. Ir. chap. xi à xr. - Sur lez origines de la tricrarchie, schoemann, 1 vol., 374. - Gilbert, 370. 
rarque fut admis à se faire remplacer. La triérarchie durait un an et ne pouvait ètre imposée à nouveau qu'au bout de un ou de deux ans. Elle cessait si l'Etat ne fouruissait pas la solde. Les archontes, les citoyens paurres, les orphelins, les infirmes, les clérouques, les femmes en étaient exempts. Quand le service devint plus pénible, il fut permis à denx ou trois personnes de fortune médiocre de s'associer pour la triérarchie. Vers la $3^{\mathrm{e}}$ année de la $10 \mathrm{a}^{\mathrm{e}}$ olympiade (1), elle cessa d'ètre obligatoire pour devenir volontaire. Démosthènes fut triérarque volontaire. Quelques années après, comme le nombre nécessaire de triérarques ne put ètre recruté, on organisa des symmories obligatoires ou syntélies de triérarques. Les 1,200 contribuables les plus riches, divisés en symmories de 60 personnes, furent chargés de la triérarchie. Il y eut done 20 sỵmories; une symmorie pouvait avoir à son compte 10 à 12 triérarchies; on les répartissait en syntélies d'un navire; chaque syntélie comprenait au moins 12 personnes. La charge peu à peu devint très-dure. Le concours de l'Etat s'amoindrit. Les 300 citoyens les plus riches eurent alors la haute main dans les armements. Le remplacement se développa. Le service cessa d'ètre personnel. L'argent devint l'élément principal des triérarchies et le triérarque fut appelé contribuable. Démosthènes fit abolir les symmories et les syntélies maritimes. Les nouveaux triérarques furent partagés en groupes qui devaient réunir 10 talents imposables d'après le cens; chaque groupe était chargé d'une galère. Tout contribuable, possédant 50 talents, comptait pour 1 galere. Diphile qui avait 160 talents dut ètre taxé à 3 galères et $t$ bateau. La triérarchie se transforma en un impòt sur le capital.

Eschine en fit voter la suppression.

Bøeckh établit que la charge de la triérarchie à l'époque de

(1) La triérarchie, qui était une lourile charge, a revetu quatre formes. Bockh a consacré un chapitre spécial llu livre if a chacune l'elles. La premiere forme

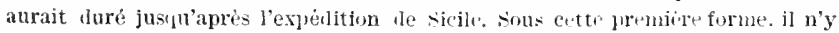
avait qu'un triéraruue par navire. Dans la seconcle forme on autorisa à mettre la triérarchie en association; e'est la meilleure preuve lle l'importance le l'obligation. A partir lie la $4^{*}$ année de la $103^{\mathrm{e}}$ olympiale, on constitua les symmories obligatoires, cest la $3^{e}$ forme; la $4^{\text {e et }}$ dernière fut celle établie d'apres le cens. 
Démosthènes pouvait représenter un impòt de 10 p. $0 / 0$ sur le capital des citoyens les plus riches, $62 / 3$ et $31 / 3$ pour les autres. Celui qui était porté au cens pour 20 talents dût en dépenser 2. Il trouve qu'une pareille taxe ne pouvait être oppressive (1). C'est une opinion qu'il est difficile de partager, car toute triérarchie représentait une dépense de ă,ö00 fr., soit 1 talent pour des contribuables en grénéral de rang modeste.

B. De l'echange. - L'avrsed:; ou faculté d'échange est le meilleur argument contre l'opinion de Backh sur la charge de la triérarchie, car l'échange s’appliquait particulièrement à la triérarchie. On pouvait linvoquer encore pour la chorégie et pour l'impoit sur le capital. Elle avait pour fondements l'excès des impoits et l'injustice de leur répartition. Les nombreuses réformes de la triérarchie sont une autre indication de son poids $(2$.

Socrate, qui était paurre, faisait partie d'une ș̣ntélie et contribuait en argent. Celui qui n'avait pas 3 talents était exempt de toute liturgie directe et personnelle; mais, plus tard, il dut contribuer pour sa part.

Toute personne, désignée pour une liturgie et spécialement pour une trierarchie, avait le droit de rejeter la charge sur un autre citoṣen qu'elle supposait plus en état d'y faire face. Si ce citoỵen refusait, elle le traduisait devant les généraux, juges des échanges en matière de triérarchie. Nème jrocédure quant à l'impòt sur le capital. La triérarchie et l'impòt sur le capital étaient des taxes extraordinaires et militaires.

Ce droit donnait, par suite, lieu à beaucoup de procès. L'un des plus curieux est celui de Démosthènes contre Thrasylochus. Démosthènes, désigné pour une liturgie, la rejeta sur Thrasylochus. L'échange comportait le transfert réciproque de tous les biens meubles et immeubles, sauf les mines. Mais Démosthènes arait a intenter une action contre ses tuteurs. Il voulut réserver

(1) Bneckh, 2e vol, 413. - Aussi il y arait un cens litnrgique; dans les derniers temps, on ne comptait que 1,200 liturges ou contribuables aux liturgies.

(2) Bochh, 2e vol., 412, 431, 432. - M. Giraul. ibidem, 1) 535. - Sur le ceût des diverses liturgies, un cllent de Lysias reconnait qu'en 9 ans les liturgies lui ont colté $62,000 \mathrm{fr}$. 
cette action; Thraş̧lochus s'y étant refusé, Démosthènes renonça à l'échange et fit sa triérarchie.

Dès que la demande était faite, les scellés étaient apposés sur les biens des deux parties. Le transfert devait ètre complet. II est clair que les droits ou charges érentuels compliquaient les situations.

L'échange est une des plus curieuses institutions fiscales d'Athènes et des peuples anciens. Il correspond directement à la question de la proportionnalité et de l'incidence de l'imput. Il suffit également pour constater quelle importante part l'impòt devait prélever sur les fortunes. On ne pouvait songer à échanger son patrimoine, à quitter son domicile, ses meubles, les objets auxquels on derait tenir, ses esclares, ses cheraux, que si la répartition était inique, si l'incidence était directe et définitive, si le poids était trop lourd.

IV. Taxes personnelles. - Il était dù des taxes personnelles, sorte de capitations fixes : $1^{\circ}$ par les llétèques; 20 par les affranchis; $3^{\circ}$ par tète d'esclare; $4^{\circ}$ par les charlatans, jongleurs et colporteurs; $\dddot{\jmath}^{\circ}$ par les courtisanes : ces deux dernières étaient proportionnelles aux recettes; les trois autres étatent fixes : 12 drachmes par chef de famille de Ilétèques, le fils moitié, la femme et la mère étaient exemptes; les affranchis deraient les mèmes taxes, plus le triobolon; le maitre avait à paver le triobolon par tète d'esclave.

Ces taxes étaient affermées.

\section{\$. De la confiscation.}

"Non père, écoute-moi d'un air un peu moins sévère. Fais "d'abord un calcul bien simple, sur tes doigts et non arec des "cailloux, de tous les tributs qui nous sont payés par les villes " alliées; compte, en outre, les impüts personnels, les centièmes, "les prytanées, le produit des mines, le droit des marchés et "des ports, les taxes, les produits des confiseations; la somme " de tous ces revenus monte à près de 2,000 talents (1)". Aris-

(1) Guèpes. 
tophane comptait les confiscations parmi les revenus. Elles constituaient, comme chez la plupart des peuples anciens, l'impòt complémentaire. Dans la première décade de chaque prỵtanée, on devait donner au peuple des renseignements sur l'état des confiscations. Des tables spéciales des biens confisqués étaient exposées en divers lieux, notamment à Eleusis (1).

La confiscation était directe ou indirecte : directe, quand elle résultait des condamnations au bannissement, à l'esclavage, à la mort. Les grandes fortunes paraissaient toujours suspectes. On confisqua la plus grande fortune d'Athènes, celle de Diphile estimée à 160 talents. Les dénonciateurs, les accusateurs recevaient tantôt les $3 / 4$, tantòt le $1 / 3$. Les fortunes des Métèques étaient particulièrement menacées, ainsi que celles des femmes. La moindre fraude en douane était punie de confiscation (2).

La confiscation indirecte se pratiquait au moven des taxations judiciaires, excessives dans leur quotité, exigrées sans merci. Le débiteur, qui ne payait pas avant le onzième jour ce qu'il devait à l'Etat, subissait la confiscation à moins de fournir le double. Le débiteur en retard était frappé d'atinie, par suite exclu des affaires publiques. Miltiade, Cimon, Platon, Démosthènes ont été frappés d’atinie. Libéral dans son mécanisme, le gouvernement était, en fait, oppressif, spoliateur. LAthènes des lettres et des arts a relégué dans la pénombre les Athéniens véritables, ceux qui ont banni tous leurs grands hommes, mème Aristote, après Thucydide, et que Thucýdide a peints d'après nature dans la scène célèbre de Mélos.

\section{\$9. Expélients dicers.}

Le grouvernement avait encore recours, dans les moments difficiles, à des expédients qui étaient des impôts déguisés.

(1) " Il existait une collection les regi-tres les confiscations. Elle est citée par Athénéet par Pollux. Elie lui a transmis la liste des biens confişués sur Alci. biade». - Breckh, ter vol., 324.

(2) sur les confiscations, il fant consulter principalement Aristote, Politique. liv. VII, chap. II, \$ 2 ; chap. III, \$ 4 ; liv. VIII, chap. IV, \$3. - Schomann, $1^{\text {er }}$ vol., 442. - Giraul, ibid., 204-208. - M. Girall fait remarquer avec raison, que le iroit le confiscation a subsisté bien longtemps. - En France, jusqu'en 1814. 
Ainsi, l'assemblée du peuple décrétait des contributions, volontaires en apparence, mais forcées en réalité. Ces contributions consistaient en argent, en armes, en vaisseaux (1).

Pour ces contributions, comme pour les confiscations, toute répercussion étant impossible, elles n’atteignaient que les classes riches et celles-ci ne pouvaient les rejeter sur les autres.

Il n’en était pas tout à fait de mème d’un autre expédient, laltération des monnaies. Athènes a èu, en général, de bonnes monnaies et le respect de sa monnaie (2). La drachme dargent, le statère d'or d'Athènes étaient très-recherchés sur tous les marchés. Comme la plupart des Etats grecs altéraient leurs monnaies sans scrupule, que quelques-uns avaient mème deux monnaies, l'une de bon aloi pour le commerce extérieur et l'autre de mauvais aloi pour les affaires intérieures, Athènes altérant pariois ses monnaies, notamment sa monnaie d'or $/ 3$.

Les pertes résultant de l'altération des monnaies constituent un véritable impôt; mais c'est l'un de ceux que les classes supérieures peurent le plus facilement rejeter sur les autres, surtout quand elles ont, en mains, comme à thènes le commerce, les banques et le mourement des capitaux. Elles sont mieux au courant des faits monétaires; elles suppléent à la monnaie de différentes façons. Le citogen actif d'Athènes, celui qui ne quittait ni les assemblées, ni les tribunaux, ni les théatres, n'avait aucun moven d'y suppléer, surtout si l'altération portait sur la monnaie d'argent.

\section{\$10. Reflets et incidence de l'impôt à Athenes.}

Lorganisation et le mécanisme de lïmpôt ne sont pas les seuls éléments qui en règlent l'incidence. Le milieu social et la nature des institutions exercent aussi une grande influence sur les reflets de l'impòt, cette sorte de mourement de ra-et-vient qui

(1) Bockh, liv, Ir, chap. xrif,

(2) Beckh, liv. I, chal'. Iv et v.

(3) sohremand, dntiquités. ler vol., P. 445. 
lui est propre et dont les oscillations se réfléchissent comme des rayons lumineux.

Nous en trouvons la preuve dans le système fiscal athénien. Ce sỵstème s'est évidemment constitué sous l'action des éléments particuliers à la société athénienne : les marins, les commerȩants, les petits propriétaires, les spéculateurs, les artistes et les institutions démocratiques appropriées à ces divers éléments.

La tendance de ces éléments et la fonction de ces institutions ont été parfaitement connues et signalées dans la Grèce ancienne. "La marche habituelle des rérolutions dans la démo"cratie, dit Aristote, est celle-ci : tantìt les démagogues rou"lant se rendre agréables au peuple, arrivent à soulever les " classes supérieures de l'Etat par les injustices qu'ils commet" tent envers elles, en demandant le partage des terres, en les "chargeant de toutes les dépenses publiques; tantôt ils se " contentent de la calomnie pour obtenir la confiscation des "grandes fortunes (1)."

Ces réflexions d'Aristote, qu'il a reproduites dans un'grand nombre de passages, s'appliquent particulièrement au système fiscal athénien qui arait été progressivement agencé de manière à mettre toutes les dépenses au compte des riches et qui arait compris la confiscation parmi les ressources règulières de l'Etat.

Tel a été l'effet des institutions.

L'effet du milieu social n'a pas été moins important. Deux forces contradictoires se rencontrent dans ce milieu : $1^{\circ}$ l'esclavage, dans des proportions qui ne se sont reproduites que dans la Rome de la décadence et dans les colonies à sucre de la France et de l'Espagne. On ne saurait trop se rappeler, quand on étudie la démocratie athénienne, que c'est une petite oligarchie, reposant sur l'esclarage et le commerce en grand des esclaves $(2) ; 2^{\circ}$ le travail libre cependant n'a pas péri et a persisté

(1) Politique, Iir. VIII, chap. Ir, $\$ 4$.

(2) Boekh, 1er vol., p. 73. -2 e vol, , p. 269. 
dans ce centre esclaragiste. Ce grand fait est dù à ce qu'Athènes était une rille de commerce maritime, ce qu'elle est encore. Nous avons sur ce point le témoignage si précieux d’Aristote. "Les riches, dit-il, ne veulent jamais quitter leurs affaires pour "plusieurs jours et ne consentent à les laisser que pour quel"ques instants 1 ". Il n'en était pas de mème à Lacédémone. Le Spartiate appartenait tout entier à l'Etat. Il ne s'occupait ni dagriculture, ni de commerce, ni dindustrie. Sa vie tout entière se passait dans les grmnases, les syssities ou dans les camps; l'Athénien. en général, était un homme daffaire. Il arait des intérèts multiples. Il donnait bien mieux l'idée d'un citoyen moderne que le Spartiate. Il devait sa richesse plutìt à la mer et au trarail quau sol national. Par suite, il etait un tout autre homme. Sans doute il emplorait beaucoup d'esclaves; c'était un esclaragiste; mais il traraillait sourent, ce à quoi le Spartiate n'aurait consenti à aucun prix. "Travailler. a écrit Aristote " dans un passage prophétique, témoignage de la perspicacité "profonde de son esprit, trarailler vaut mieux encore que gou"verner et commander. là où l'exercice du pouroir ne procure "pas de grands profits : car les hommes, en éénéral, préfèrent "l'argent aux honneurs $/ 2$. ."

Nous allons retrouver l'action de ces deux forces dans lincidence de l'imput à Athènes; l'une est destructire, l'autre est créatrice. Avec la décadence, le nombre des esclares a diminué, mais Athènes est restée un port maritime, une ville de marine et de commerce, où le travail personnel a été la condition de la richesse. Lacédémone ñétait plus qu’une cité rurale au milieu

(1) Politique, liv. VII. chap. Itt, 53.

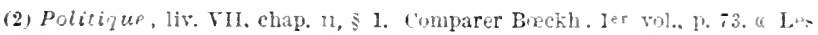
plus anciens homne: 1'Etat solon. Themistocle. Péricles favorisaient lo profesiuns industrielles dans la vue d'ameliorer le sort de la bant classe. d"enrichir l'Etat - un fabricant comme Clén, Hyporbolus et l'autre ont pu s'étever ju. qu“a s'emparer lu gouvernail le l’Etat. m

D'autre part Xénophon ajoute : Linposé de ce qui se roit chez les autro frecs se troute encore dans cette loi établie a sparte par Lycurgue. Ailleur=, tout le monde cherche a faire fortune comme il pert. A frarte, Lycurgur a interdit aux hommes libres toute espece le profesion en vue du profit n. - Lace. démoniens, chay. IIt. 
des domaines de quelques grands propriétaires, alors qu'Athènes conservait encore l'actirité, l'éclat et les ressources d'une ville de premier ordre.

I. Incidence des impóts indirects. - Parmi les impôts indirects sont comprises les taxes de consommation. Dans les Etats modernes ces taxes ont une très-grande importance à raison de leur incidence. Dans un Etat esclaragiste comme Athènes, cette incidence est moins générale, puisque l'immense majorité de la population est servile. L'effet de l'esclavage est de rejeter l'impôt sur les maitres, par la raison que l'intérèt du maitre est de conserver sa chose. Sans doute, l'esclave est réduit au strict nécessaire; mais le maitre lui procure ce nécessaire afin de ne pas laisser péricliter sa chose. La situation n'était pas la mème à Lacédémone, ni dans les autres Etats de la Grèce où la propriété rurale formait la principale ressource de l'Etat. Les esclaves y étaient peu nombreux; à còté d'eux viraient des colons à redevances fixes en nalure. Pour ces colons, certaines taxes de consommation, par exemple, les droits de douane ou les taxes d'octroi ou de marché, si elles frappent d'autres objets que ceux qu'ils produisent, peuvent porter sur eux sans répercussion possible, précisément à raison de la nature et de la fixité de leurs rederances. Leur servitude est limitée; ils ont une part de liberté et de responsabilité; par suite, il leur incombe une part d'impòt. D'où il faut conclure que les droits de douane, ceux de port, ceux d'octroi et du centième denier, ceux de justice, dans le milieu esclavagiste d'Athènes, restaient à la charge des citoyens et des Métèques, c'est-à-dire en ne tenant compte que des chefs de famille, de 30,000 personnes environ.

Quels étaient ou quels pouvaient être leurs reflets entre ces 30,000 personnes? Il faut distinguer entre les taxes de consommation et les frais de justice.

Dans une ville, et mème dans un petit Etat de commerce comme Athènes, où il fallait importer la moitié de la nourriture de la population, les taxes de consommation incombaient aux consommateurs; par suite, elles pesaient plutòt sur les pauvres que sur les riches; d'autant plus qu'à Athènes, à raison des institutions, c'est le riche qui travaille et qui gagne, 
selon la remarque d'Aristote; c'est le pauvre qui va à l'assemblée, dans les tribunaux et qui y passe sa journée moyennant le triobolon que sa fille, quand il rentre au logis, lui arrache des dents, selon l'expression si pittoresque et toujours exacte, d'Aristophane (1).

L'incidence du centième denier sur les biens-fonds n'était pas aussi rigoureuse; néanmoins les paures le supportaient en partie sur leurs maisons et sur leurs lopins de terre.

A qui incombaient les frais de justice et les amendes? Ils se répartissaient en partie sur toutes les classes, car la manie du procès était générale à Athènes, particulièrement chez les pauvres; malgré cela le lot le plus élevé devait ètre à la charge des riches, incessamment attaqués, accusés, enviés, visés et toujours sur le qui-vive. Le paurre, d'ailleurs, ne pouvait ! eaucoup contribuer à remplir la caisse des amendes.

II. Incidence des taxes personnelles. - Entre les citosens et les Métèques, il s'agit de rechercher, d'abord, si les Métèques pouvaient rétléchir sur les citoyens les taxes particulières auxquelles ils étaient soumis. Les Métèques nous donnent assez exactement l'idée des colonies des Européens à Alexanilrie, à Buenos-Ayres, à San-Francisco. Ils étaient nombreux à Athènes et considérés, ce qui était vrai, comme une grande ressource. Ils travaillaient et s'enrichissaient a lieu de gouverner. C'est ce que comprenait fort bien Xénophon et c'est ce qüil a dit dans son chapitre sur les Métèques à Athènes : "C'est là, selon " moi, un magnifique revenu, attendu que les Métèques en se " nourrissant eux-mèmes et en procurant aux villes de grands " avantages ne perçoivent rien et nous paient, au contraire, le "droit de domicile ( 2 ). Xénophon se trompait, quand il disait que les Métèques ne percevaient rien; ils réalisaient, au contraire, à Athènes des bénéfices qu'ils y venaient chercher et que les Athéniens, moins occupés de jugrer et de gouverner, auraient

(1) Dans les sucietés esclavagistes le pature nost pat le meme que dans les sociétés molernes. Cest ce qui expliquet les luttes suciales dans les civilisations grec-

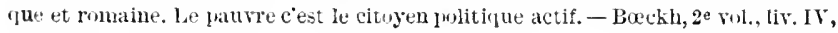
p. 270 .

(2) Revenus, chap. xi. 
encaissés; ce qui permettait aux Métèques de se rẻcupérer facilement de toutes les taxes spéciales qu'ils acquittaient. Xénophon proposait d'abolir ces taxes, d'autoriser les Métèques à servir comme Hoplites, de leur céder des terrains pour construire des maisous afin d'accroitre "le va-et-vient d'étrangers, le mou"vement d'importations et d'exportations, d'achats, de ventes, " de salaires, de tributs qui enrichissent Athènes (1)". Il avait raison, il devançait les temps; mais it aggravait, sans s'en apercevoir, la condition particulière du citosen athénien.

1II. De lincidence des prestations. - Suivons de près quel devait ètre le jeu des prestations ordinaires et extraordinaires. La

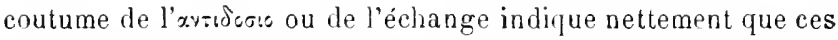
prestations étaient une taxation militaire, quant à la triérarchie, sur les classes riches. Le citoyen qui n'avait que 2 ou 3 talents en étant exempt (2); un moment vint où sur 20,000 citoyens, 1,200 seuls purent supporter les frais de la triérarchie. Les classes riches avaient-elles un moren quelconque de réfléchir sur les autres classes tout ou partie de ces charges? Elles ne gouvernaient pas; elles s'éloignaient de plus en plus des assemblées et des tribunaux; elles favorisaient le remplacement militaire; elles devaient, plus tard, prèter les mains à l'établissement de la domination étrangère, celle de la Macédoine, celle de Rome; elles recherchaient, avant tout, la sécurité que les institutions d'Athènes ne leur donnaient que très-incomplète, c'est qu'elles n'avaient aucun moren de se soustraire aux charges qui leur incombaient. L'exiguïté du sol, sa paurreté relative ne leur permettaient pas de trouver une compensation dans le haut prix des produits du sol. Le prix des céréales à Athenes dépendait, comme aujourd'hui à Londres, dẹs marchés étrangers; enfin linfluence des classes riches sur les salaires était très-limitée par l'esclavage et par les institutions politiques; ces institutions assuraient une sorte de salaire minimum au citoyen actif, sans parler des lois qui donnaient une retraite au citoyen invalide.

IV. De l'incidence de l'impót sur le capital. - Pour l'aidecpx, les

(1) Ibidem.

(2) Boekh, liv. III, chap. xI. 
citovens les plus paurres étaient seuls exempts. Règle générale, tout citoyen derait limpòt sur le capital que le cens lui avait attribué; seulement le taux de l'impót était gradué : il était moins élevé pour les paurres que pour les riches. Les pauvres, disposant à peu près du grouvernement, pouraient se récupérer, et ils l'ont fait souvent, par les frais de justice, les amendes et les confiscations. En outre, ils vivaient, en partie, aux frais de l'Etat. Les riches ne pouvaient se récupérer. Et dahord, aux dépens de qui l'auraient-ils essayé? dans un milieu limité par l'esclavage? et comment y seraient-ils parvenus ne disposant pas du pouvoir?

Ce n'est pas que, de sa nature mème, lïmpòt sur le capital ne puisse jamais ètre rélléchi sur autrui par celui qui le paie; ainsi les taxes sur les mutations de tonds immobiliers entrevifs sont souvent rejetées par l'acquéreur sur ie vendeur; ainsi les taxes sur les intérèts ou les capitaux des créances hỵpothécaires le sont également, 'quoique pas toujours, par les créanciers sur les débiteurs; mais les taxes successorales sur le capital ne peuvent ètre répercutées sur personne.

Cette difficulté de répercussion est d'autant plus réelle que la taxe est temporaire : ce qui était le cas de l's: $\delta$ ç $x$. Quand une taxe sur le capital est permanente, elle se convertit en un impôt sur le revenu (si du moins elle est annuelle) et peut ètre quelquefois réfléchie; si elle est simplement occasionnelle, elle reste en principe, au compte de celui qui la paie.

Elle pourrait toutefois ètre récupérée en partie, au moyen de la plus-value que la demande du capital produisait sur le marché des capitaux, l'élévation du taux de l'intérèt. Dans une place de commerce comme Athènes où les capitaux étaient demandés, où le cours de l'intérêt, celui du change variaient sans cesse, les riches armateurs, banquiers pouvaient se récupérer : il n’en était pas de mème des riches propriétaires. Ceux-ci ne trouvaient personne sur qui exercer les répercussions; ceux-là avaient à leur disposition le marché général des capitaux et des affaires.

La condition de l'incidence de l'sidyog, par suite, n’était pas tout à fait la mème que celle des prestations. 
Dans l'examen de l'incidence des impòts à Athènes, Bæckh a parfaitement indiqué la ressource que les riches avaient pu trourer dans le taux de l'intérèt des capitaux pour amoindrir leurs charges. Il a discuté l'hypothèse d'un citoren qui, pendant 9 ans, dont 7 de guerre, a payé 63,600 drachmes d’impôt avec une fortune de 12q,000 drachmes. Selon Buckih le taux de l'intérèt $(12$ p. 00 ) a permis à ce citoyen de se récupérer (1). L’hypothèse que l'entier capital était placé à 12 p. 000 est excessire. C'est par là que péche le raisonnement de Bæclih. Dans l'espace de $\mathbf{x}$ à à ans, Aristophane, qui était riche, dépensa, pour son père et lui, ə̆,000 drachmes en chorégie; il fut 3 fois triérarque; l'expédition de Sicile lui coùta 10,000 el celle de Chypre 30,000 drachmes. Il dut également paỵer l’sfys. Un comprend pourquoi il s’est montré si peu favorable aux Athéniens tels qu'il les a connus.

L'institution de l'Echange ne peut laisser aucun doute sur lincidence des impòts à Athènes. L'Echange ne s'exerçait qu'entre gens riches; sa pratique indique que les riches n'araient que de rares orcasions de se récupérer. L’Echange n’arait pour but que la réparcussion : èètait uniquement un moren d'égalisation entre gens conlamnés à porter le mème fardeau.

\section{s11. Décudence d'Athenes.}

Ainsi Athènes, depuis la fin des guerres médiques jusqu'à l'époque d’Alexandre, c'est-à-dire pendant deux siècles, offre l'exemple d'un Etat iulépendant, prospère, important où, sous l'influence du milieu social, des institutions politiques et des impòts, les charges publiques furent au compte des classes riches, tandis que les classes paurres riraient aux dépens de l'Etat.

C'est une situation différente et à peu près inverse de celle que nous arons constatée à Lacédémone. Lacédémone est un Etat aristocratique, guerrier; l'agriculture est la seule ressource de l'Etat et de la population; pas d'esclavage complet. Deux classes de colons, l'une servile, l'autre presque libre; l'une et l'autre

(1) Breckh, liv. III, chap. xxII. 
teunes à des redevances fixes en nature. Dans la classe supérieure, des efforts inouïs pour y maintenir une égalité factice. La fixité des redevances a amélioré la conlition de ceux qui les pavaient; ils se sont ou ont été affranchis. En cela Lacédémone est supérieure à Athènes - mais les efforts pour conserver l'éçalité militaire entre les Spartiates ont été inutiles; l'inégalité a détruit l'aristocratie; elle y a substitué une timocratie égoïste et perverse. La passion de l'égalité a suscité la haine sociale. L'organisation de l'impôt qui retombe sur le Spartiate paurre y a contribué.

Athènes est un peuple esclavagiste où l'Etat est soutenu par la marine, la guerre, le commerce; la marine et le commerce sont le fondement de ses institutions démocratiques, de mème que lagriculture est le fondement des institutions aristocratiques de Lacédémone. Athènes, policée, civilisée, brillante par les arts et les lettres, est un foyer d'esclares; mais c'est aussi un grand port. Le propriétaice d'esclaves, dans un Etat de commerce, ne peut rester inoccupé. Il est condamné au travail. LAthénien riche travaille. Il gagne de l'argent. Pasion est banquier, le père de Démosthènes industriel. C'est par là que les classes riches à Athènes ont résisté et survécu aux institutions démocratiques. Sparte a disparu : Athènes est restée importante jusqu'aux derniers temps de l'empire byzantin. Elle est aujourd'hui la capitale de la Grèce arec 100,000 ìmes de population libre.

A l'époque de Démosthènes l'Etat succombe sous le faix de la politirue fiscale ultra démocratique. La triérarchie est réduite; elle disparut nécessairement avec l'indépendance politique d'Athènes. C'était la plus lourde charge des classes riches. Tribunaux, assemblées politiques, perdirent de leur activité et de leur prix de revient. Dès la mort d'Alexandre, plus de la moitié des citoyens furent expulsés; ce furent les paurres. Les riches n'eurent plus ni à les nourrir ni a les amuser. Ce fait brutal d'Antipater coupa court à la ruine de l'Etat. Athènes perdit son indépendance politique, mais le capital n'y fut plus consommé, au fur et à mesure de sa formation, en oboles, en triobolons, en théoricons et en opsons au profit d'une démocratie qui avait le travail en arersion. 
Néanmoıns, les 20,000 citovens d'Athènes ne se changèrent pas en une timocratie de 100 propriétaires fonciers comme à Lacédémone. Athènes eut son port et ses affaires; elle conserva son autonomie municipale; elle demeura un centre de production et de richesse, un forer de civilisation', un centre littéraire et artistique. Il faut lui pardonner d'avoir cru à la régénération de la Grèce avec Antiochus et Mithridate. Elle opposa à Sylla une résistance hérö̈que mais imprudente; Sylla la traita avec rigueur sans la détruire.

Depuis cette époque, Athènes derint une ville de luxe, de plaisir et de science. Les Romains aimaient son climat et ses mours. Ils s y rendaient en allant en Orient. Saint Paul y vint en se rendant à Rome. Elle fut admise parmi les civitates froderatx. Elle fut astreinte peu à peu aux impòts romains et surtout à tempérer ses tendances démocratiques, contraires au gouvernement de Rome; ses institutions politiques ne furent plus que des simulacres, qui s'évanouirent eux-mêmes; mais elle conserva sa vie municipale, son port, sa marine et ses grandes traditions artistiques et littéraires (1). Les chorégies se maintinrent, Le Pirée sauva tout. Les taxes du port, des douanes, des esclaves, d'octroi furent une ressource permanente et municipale. Alors se réalisa, en partie, l'idéal qu'Aristote avait rèvé et qui ne pourait s'accomplir précisément que lorsque le fondement économique de la société grecque, d'après Aristote, se serait modifié ou effondré, la disparition de l'esclavage: "Une administra"tion honnète quand on peut l'établir est le seul moyen de "faire coexister dans l'Etat la démocratie et "aristocratie, c'est" à-dire d'accorder aux citoyens distingués et à la foule leurs "prétentions restrictives. En effet, le principe populaire, c’est "la faculté pour tous d'arriver aux emplois; le principe aristo"cratique, c'est de ne les confier qu'aux citoyens éminents. "Cette combinaison sera réalisée si les emplois ne peurent ètre "lucratifs. Les paurres alors, qui n'auraient rien à gagner, ne " voudront pas du pouroir et penseront de préférence à leurs " intérêts personnels; les riches pourront accepter le pouroir, 
"parce quils n'ont pas hesoin que la richesse publique vieune "ajouter à la leur (1)". Dans cette page si remarquable, Aristote fait allusion aux emplois résultant de la nature du gouvernement athénien, le peuple lécriférant, jugreant lui-mème, parfois administrant; par suite, recevant un salaire ad hoc. Il n'entend pas les emplois qui ne sont pas particuliers it la démocratie et qui sont nécessaires à tous les grouvernements. Le peuple gouvernait parce qu'il ne pouvait travailler. Or il ne pouvait travailler à cause de la concurrence des bras serviles et de la déchéance que la servitude implique au travail. De là sa formule (2) : "Tracailler vut encore micur que goucerner et communder". Aristote ajoutait, il est rai, faisant allusion aux institutions fiscales d'Athènes, "pourru qu'on puisse libre"ment vaquer aux soins de ses intérèts, sans redouter de spo"liations, on fait alors rapidement fortune, ou du moins l'on "échappe à la misère (3). "

Le travail devait se substituer, dans les sociétés, à la politique. Il fallait le génie d:Aristote pour entrevoir cette grande révolution qui, en abaissant les uns, élèverait les autres. Elle devait ètre lente, longue et douloureuse. Elle avait besoin pour aboutir du concours de nouveaux éléments. La conquète romaine, le christianisme, les progrès de la culture du sul, l'accroissement de la population allaient les lui procurer.

Les petits foyers, à forme républicaine, de la Grèce, ces foyers qui ont été l'un des éléments les plus précieux de la civilisation, étaient devenus insuffisants. Ils s'étaient corrompus, pervertis. "Ils portaient en eux-mèmes, dit Backh, le germe de la "destruction: l'arbre était grité : il devait ètre coupé (4)."

La grande transformation du travail, qui allait modifier l'impòt lui-même, exigeait pour l'accomplir de plus vastes sphères. L'esclavage n’aurait été que bien difficilement aboli à Athenes. Cette

(1) Politique, liv. Mil, chap. vin, $\$ 10$.

(2) Comparer it cette folmule d'Aristete les otservations le Xennflun sur lin-

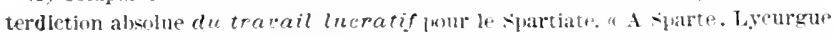

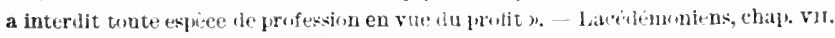

(3) Politique, lir. V1l. chay. It. \$2.

(4) Burckb, in . $\|_{\mu^{\prime}}, 2 \mathrm{e}$ w. 
132 DISPARITION DES PETITS FOYERS CIVILISATEURS.

abolition impliquait d'autres institutions. L'évolution républicaine, qui avait commencé avant Solon, était à son terme. La formation d'un vaste empire, renfermant de plus grandes masses, procurant plus de sécurité, brisant les barrières de tous les petits Etats, améliorant la condition des plus nombreux, préparant leur émancipation, était devenue nécessaire. Tel ful l'Empire romain. Telle sera bientül la condition de l'Europe actuelle. 


\section{CHAPITRE VI.}

DE L'impòt dans Les Autres États de la GRĖCE ANCIENye.

En dehors de Lacédémone, l'Athènes et de la Grète, les divers Etats de la Grèce se divisaient en leux catégories bien distinctes, ceux où dominait la race dorienne ou son influence; ceux oi prévalait, au contraire, l'intluence d'Athènes et, avec elle, de la race ionienne. Dans les premiers, les institutions politiques, sociales, fiscales des Doriens, particulièrement celles de Lacédémone l'emportaient complètement, sauf 'ertaines différences dont phusieurs avaient de limportance. En aucune autre partie le la Grèce, les Doriens n'avaient pu cependant installer leurs institutions dans les mèmes conditions quien Crète ou que dans le Péloponèse. Nulle part on ne rencontrait un élément militaire, entretenu de la mème manière que les Spartiates, aussi remarquable et aussi puissant. Comme dans tous les Etats doriens la production agricole étant la forme presque exclusive du travail et de la richesse; l'impot consistait surtout, notamment en Thessalie, en Sicile, dans la grande Grèce, en une dime, variable de taux, sur les produits bruts. La dìme a été générale dans la Grèce héroïque; elle a été remplacée à Athènes, à Lacédémone, à Crète par une organisation plus savante; mais elle y a été la première forme de l'impòt, forme que le Christianisme, d'origine orientale, y a ramenée. Ainsi on sait qu'il existait des Périèques en Thrace, en Thessalie, à Sinope, en Sicile, et qu'ils étaient astreints à des redevances fixes de mème qu'à Lacédémone (1).

Dans les Etats non doriens, la plupart des impüts, si variés d'Athènes, existaient également, mais on y levait aussi la dime qui n'avait été conservée à Athènes que comme contribution

(1) Guiratud, ibid., 537, 542. - Gillert. 
religieuse envers les temples; dans quelques Etats cette dime devait ètre payée en argent et prenait la forme d'un impòt foncier.

On y reneontrait notamment :

$1^{\circ}$ L'impìt sur le capital, ou s!feç $x$, parfois permanent, parfois temporaire, mais avec un caractère militaire. L'impòt sur le capital parait avoir été l'élément fiscal prépondérant pour les litrues d'Achaie, d'Etolie et de l'Asie-Mineure (1). .

2 Les douanes et les octrois intérieurs, qui ont beaucoup contribué à maintenir et à aggraver l'esprit de division des Hellènes.

3o Les droits de marché et mème de circulation sur les marchandises.

$4^{\circ}$ Les diverses liturgies, triérarchies, chorégies, avec leurs formes diverses, telles que l'hestiase (2).

La Sicile, qui appartenait en grande partie, à la colonisation hellénique, spécialement des Doriens, a été la partie la plus ravagée par les excès fiscaux, pour diverses causes; d'abord la grande prospérité dont elle a joui du ve siècle A.-C., au second siècle E.-C.; puis les difficultés intérieures, les tyrannies qui l'ont accablée, notamment Denys l'Ancien. Aristote prétend que Dengs l'Ancien leva pendant 3 ans un zis rog de 20 p. $0 / 0$ c'est à-dire la totalité du capital. C'est invraisemblable, mais cette affirmation doit se rélérer à de grands excès.

Limpòt principal de la Sicile, en rapport avec sa production célèbre de céréales, était la dime. Les Romains n'eurent garde de ne pas en profiter. Comme la conıpuète de la Sicile leur coùta fort cher, ils s'emparèrent des dimes afin de mettre la main sur les blés de Sicile. C'est en Sicile qu'ils ajoutèrent au frumentum decumanum, le frumentum imperatum et le frumentum emptum. Les Verrines donnent un tableau complet de la richesse de la Sicile, de ses ressources et des atroces exploitations qu'elle eut à subir. .I. Marquardt rappelle, d'après Cicéron, que la Sicile

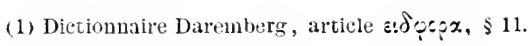

(2) fillitand ibidem, 540-544.

(3) Guiraul, 541. Marquardt, Oryanisation financière des Romains, 144. 
dut fournir, pendant une année, au préteur Verrès : $1^{\circ} 3,000,000$ modii, dime ordinaire, valeur, $2,750,000$ fr.; 20800,000 modii imperati, valeur, 700,000 fr.; $3^{\circ} 3,000,000$ modii, seconde dime, $2,750,000$ fr. (1).

La dime a des avantagres; mais elle a, entre autres inconvénients, celui de rendre les exactions plus faciles.

La dime a done joué un rơle fiscal considérable en Grèce, sauf à Athènes. A Lacédémone, les redevances des Périèques étaient une véritable dime.

(1) Sur tout ee qui concerne les blés que la sicile levait formir au peuple ro-

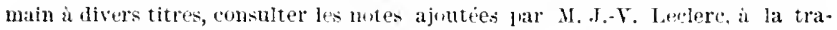
dnetion des Verrines, élition 1s24, letit format, tomes $\pi, 8,9$, notamment tome 8, $1.268,277,279,464$, t. 2, p. 21, et daus le Dictionnaire Dartmbers, larticle Frumentaric leges. 


\section{CHAPITRE VII.}

LES IMPÒTS EN GRẺCE sOUS LA DOMINATION ROMAME.

La décadence de la Grèce est bien antérieure aux guerres avec la Macédoine et avec les Romains. Thucrdide en a marqué le point de départ pendant la guerre du Péloponèse qui s'est prolongée, sauf un assez grand intervalle, pendant $2 \tau$ ans. Cette guerre a correspondu à la profonde division des races et des institutions en Grèce. La race dorienne, avec Lacédémone et ses alliés, eut la victoire; mais ses forces ne lui permirent pas de conserver l'hégémonie de la Grèce pendant plus d'un demisiècle. Après Leuctres et Mantinée (363), la Grèce n'eut plus de force directrice suffisante pour réunir ses divers tronçons. La Macédoine sans l'asservir, ne parrint pas à la réunir à elle-mème. Dès que la Macédnine eut succombé, sans recevoir aucun appui de la Grèce, les Hellènes furent fixés sur leur sort (1).

D’ailleurs Ies Romains rencontrèrent en Grèce des alliés fidèles; ètaient toutes les vieilles familles helléniques, accablées de vexations, de persécutions, de spoliations et d'impits par le parti démocratique grec. "Si tous les partis, dit M. Gui" raud, eurent recours à l'étranger, ce furent surtout les aris" tocrates qui montrèrent le plus de docilité envers lui; ce n'est "pas quils fussent moins patriotes que les gens du peuple, ni " moins vaillants; mais ils avaient beaucoup plus à perdre par " la résistance et beaucoup plus à gragner par la soumission; le " souci de leurs intérèts matériels les détournait de s'engager " bien à fond dans la lutte et leur òtait les armes des mains. Ils " cédaient d'autant plus volontiers que l'ennemi leur accordait "de grands avantages. Auparavant, ils étaient dans une foule " de cités, exclus du pouvoir, et, quand par hasard c'étaient

(1) Hertzberg, La Grèce sous la domination romaine, traduction BoucherLeclercq, ler vol., chap. I. 
" eux qui grouvernaient, ils araient à compter avec les exigences " d'une multitude avide et indisciplinée qui ne reculait derant " rien... Les rois de Macédoine eurent dabord une certaine " tendance à faire prédominer l'olirarchie... Les Romains adop" tèrent à leur tour cette politique et s"y montrèrent constamment "fidèles. Dès l'année 19't, Flamininus s'occupait en Thessalie " d'organiser les tribunaux et les conseils d’après des conditions " de cens et d'assurer le pouroir à ceux qui étaient le plus inté"ressés au maintien de la paix. Tous les proconsuls qui vinrent " après lui suivirent la mème politique, parce que le Sénat leur " donnait les mèmes instructions... Rome se montra aux Grecs " comme le gardien inflexible du droit de propriété et des pri"vilèges de l'aristocratie (1)..."

Les Romains ne rencontrèrent quelque résistance que de la part de la ligue achéenne, dont les anciens Périèques et les Hilotes composaient le fond. Périèques et llilotes étaient dins leurs röles. Ils furent soutenus par tous les démocrates et démagogues de Grèce, Corinthe, Athènes; ils succombèrent ensemble et non sans gloire $(\boldsymbol{2})$.

Devenus maitres de la Grèce, les Romains la traitèrent arec certains ménagements, plus apparents que réels. Cicéron luimème, le plus modéré de tous les Anciens, le plus morléré de tous les Romains trouva moven demporter 2 millions de sesterces de Cilicie $\langle 3$; quon juge par là de ce que les proconsuls, préteurs, propréteurs, autres que l'accusateur de Verrès et de Gabinius, exigrèrent des Grecs $(\mathbf{x})$. Cependant la Grèce n'arait jamais été riche; les guerres d'Alexandre, d'Antipater, d'Antiochus, de Mithridate aurgmentèrent sa gène, qui se changea en une grande misère, développée par la dépopulation et l'émigration des riches.

(1) Guirauel, ibidem, 627.

(2) Petit le Julleville. La frese sous la domination romaine, chap. II to vir. on tronve laus ce livre remarquable une histoire dramatique des derniers temps de la firce et lesexcis des Etatis lemocratiques.

(3) Petit le Jullerille, ibidem, 220-221.

(4) Voir le portrait ise Pison, phus atroce que Verres, par Cicéron. ibidem, 224-229. - Vuir Leclere, trabluction Ciceron, méme idition, t. s, pare 464. 
Les Romains firent deux parts de la Grèce, divisée, d'ailleurs en deux proconsulats. Les principales villes furent admises parmi le ciritates faderatæ(1). Par suite, elles conservèrent leurs propres lois et ne durent acquitter au fisc romain que les charges stipulées dans le traité d'admission, toujours plus modéré que l'acte de Deditio; mais lintluence supérieure passa de la démaśogie à laristocratie. Ce fut un fait général, conforme à la politique de Rome et conforme aussi à la marche supérieure de la cirilisation. L’époque des Républiques grecques était finie. Par suite, tout en conservant leurs lois et notamment leurs institu tions fiscales, leurs fètes, les cités durent tout approprier aux tendances romaines. Des changemeats eurent certainement lieu peu à peu dans les impits. La scène de la comparution de saint Paul ou de saint Deṇs, l'aréopagite, devant l'aréopage athénien donne une idée assez exacte de la vie intérieure des cités grecques.

Quant aux autres parties de la Grèce, elles furent soumises au tribut. Rome s'adjugea, comme partout, les dimes. "Tous les " ans, les magistrats municipaux dressaient la liste des exploi" tants et notaient la quantité de terres qui étaient mise en cul"ture; on éraluait approximatirement la récolte future, et, "d'après cette donnée, on déterminait le rendement probable de "l'imput, à raison de 10 p. $0 / 0$ du revenu brut; on adjugreait "ensuite au plus offrant le droit de recueillir le blé, l'orge, le "vin, l'huile, les légumes dus par les cultivateurs. Si la récolte " était supérieure aux prévisions, le fermier gardait pour lui "l'excédant de la dime; si elle était inférieure, il comblait à ses "frais. Ces règlements s'appliquaient à la Grèce tout en" tière (2). "

Dans le partage des provinces fait par Auguste, la Grèce fut attribuée au Sénat. Ce fut pour elle un nouveau malheur. Cela coùte à dire, mais entre le vieux Sénal de Caton et de Cicéron et l'Empereur, le pouvoir noureau, intelligent, modéré était celui de l'Empereur. Bien que les proconsuls sénatoriaux ne

(1) Gilbert, ibidem, p. 25-219.

(2) Guiraud, ibidem, 540 . 
pussent se mèler d'affaires financières, placées dans les mains d'agents spéciaux, nommés par l'Empereur parmi les chevaliers, ils se montrèrent partout plus durs que les légats de l'Empereur. Sous Tibère il fallut arracher l'Achaie et la Nacédoine au Sénat (1).

Jusqu'à la mort de Tibère, assez favorable à la Grèce de mème qu'Auguste $(-2)$, les choses demeurèrent en état, mais les crises qui assaillirent bientòt l'Empire aggravèrent la condition de la Grèce. Néron lui avait donné une dernière illusion d'indépendance en proclamant lui-mème solennellement aux jeux Isthmïques (3), son complet affranchissement; mais, quelques mois après, la dure voix de Vespasien la rappelait à la réalité. Il rendait à l'Achaïe son souverneur chargé de lui redemander le tribut ( $\mathbf{t}$ ). Seule Athènes conserva son ancienne situation.

Les Flaviens, les Antonins, se montrèrent plus bienveillants que Vespasien; Trajan accepta d'ètre archonte éponyme à Athènes (ั); Hadrien s'y rendit quatre fois; il encouragea ses fètes, il releva ses monuments, il prépara ainsi la nouvelle carrière que les écoles d'Athènes allaient parcourir; mais, au point de vue fiscal, les choses s'améliorèrent beaucoup moins. La tendance générale de l'empire était vers l'uniformité des charges. Avec chaque siècle, cette tendance s'accentua; peu à peu les impòts des villes revètirent un caractère tout municipal; et lorsqu'apparurent vers 282, les édits de Dioclétien, Athènes, Sparte, toutes les villes, tout le territoire de la Grèce y furent tout naturellement compris comme toutes les autres parties de l'Empire romain. La charge fut très-forte; mais elle eut des compensations. La vieille Grèce est morte. La Grèce chrétienne lui succède.

A ce moment, à la fin du II" siècle, la décadence de la Grèce,

(1) Petit de Julleville, page 247, Macédoniam et Achaiam onera deprecantes levari in prosens proconsuli imperio tradique Cusari placuit, Tacite, Annales, liv. I, 76.

(2) Petit de Julleville, il,idem, 245-247.

(3) Petit de Julleville, ibidem, 252, 262.

(4) Petit de Julleville, ibidem, 285. - Mahaffy, rhs greek world under roman suay, chap. xir.

(5) Petit de Julleville, ibirem, chap. xv. 
sa dépopulation, sa misère, sa solitude, son silence, déjà si grands au temps de Plutarque et de Pausanias, ont atteint leurs plus mauvais jours (1). Foyer de commerce maritime, d'échanges, la Grèce souffrit affreusement de la grande crise monétaire du

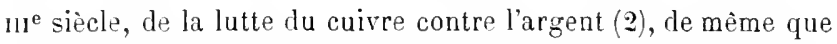
souffriront au $x s^{\mathrm{e}}$ siècle les Etats à argent qui lutteront contre l'or. Mais saint Paul n'arait pas comparu en vain devant l'aréopage; il apportait avec lui des idées nourelles, une direction nouvelle de l'humanité, une espérance (3). Les Hellènes s'y associèrent. Après Israël, la Grèce a été le principal agent du christianisme. Aussi son relèvement date de Constantin. Le transfert à Constantinople de l'Empire romain opéra pour elle le miracle de la résurrection. Le Gree sinstalla à Constantinople et peu à peu en chassa le Latin; une nouvelle période de prospérité s’ourrit pour les Grecs et la Grèce; cette période a duré plus de 800 ans; c'est bien quelque chose.

Enfin les grandes réformes fiscales et politiques de Dioclétien et de Constantin furent en réalité un immense bienfait pour tout l'empire, débarrassé à jamais des agents sénatoriaux et du Sénat lui-mème; mais "il n'y eut plus d'Athènes, de Lacédé" mone, de Doriens, d'Achéens ni d'Etoliens ('t)."

(1) Finlay History of yrecce, Jer vol., 42, 52, 58, 87.

(2) Finlay, ibidem, I03. 109.

(3) Petit de Julleville, ibidem, chap. xir. Saint Paal a A thenes.

(4) Finlay, ibidem, I09. 


\section{LIVRE TROISIENIE.}

DE L'IMPOOT CHEZ LES ROMAINS. 



\section{CHA PITRE I.}

\section{DE L'INFllexce DES INSTITUTIONS FISCALES ROMAINES}

SUR CELles des peUples de l'EURope MOdERNe.

\section{\$1. Carartere aristocratique et territorial de la} cicilistion romente.

Au point de rue de l'impit, la civilisation hellénique n’a ell aucune influence sur les institutions fiscales des divers peuples de l'Europe, de l'Asie et de l'Afrique, en rapport avec le bassin de la Méditerranée. Laction fiscale de la Grèce a été entièrement limitée à la Grèce seule et à quelques-unes de ses colonisations. Mème, l'étendue de l'action économi.jue de la Grèce ne saurait être comparéc au développement, chez elle et en dehors d'elle, des arts, des sciences, des lettres. Deux autres causes ont contribué à restreindre encore cette action, d'une part, lextension de la culture rurale, de la propriété foncière agricole en Europe, mème en Afrique, et, d'autre part, le changement imprimé par les Romains ì la direction politique de lintérieur des Etats en Europe. Partout les Romains, quoịue possédant des institutions républicaines, abattent, de mème que les Lacédémoniens, les démocraties pour y substituer les aristocraties qu'ils constituent ou prennent sous leur sauvegarde. La Grèce ne compte pour rien dans le développement de la propriété foncière en Europe et dans les changrements politiques qui en sont résultès.

Au contraire, l'influence des institutions fiscales de Rome a été directe, immédiate, prolongée, d'un côté, par l'étendue de son territoire et la masse de sa population; l'Italie de la grande époque républicaine, celle rles gruerres puniques, forme un tout autre milieu que le sol de la Grèce, consistant en monta- 
gnes peu fertiles et en quelques vallées froides à l'extrémité de l'Europe. Elle exerce donc une bien autre influence autour d'elle. A l'épolue de Polybe, la Grèce se dépeuple rapidement, l'Italie est encore très-prospère. Les populations qui entouraient le territoire romain, anciens Sabins, Osques, Equès, Herniques, Volsques, Etrusques, Samnites, n’ont pas encore été détruites. Le territoire est tout entier cultivé (1). La population et l'agriculture sont les deux fondements de la force du peuple romain, qui est composé de propriétaires fonciers. Dans un de ses plus beaux récits, Tite-Live met en scène le centurion Spurius Ligrustinus qui a fait toutes les grandes campagnes de l'époque de Paul Emile et qui est proprietaire. Sa famille vit sur son fonds $(2)$. Le Grec d'Athènes est surtout commercant, industriel, pirate. Le Lacédémonien est aussi, à certains points de vue, propriétaire; mais le territoire de Lacédémone est restreint et le nombre des Spartiates, très-limité. La Grèce ne pourait fournir les instruments de la transformation économique de l'Europe. Rome les a préparés.

Cette influence de la terre a été le foudement principal de de l'aristocratie romaine, aristocratie essentiellement territoriale. Elle subsiste mème encore aujourd'hui en Italie (3), elle y soutient tout, héritière directe de celle qui a contribué, avant tout, à donner à l'empire romain les institutions fiscales dont l'importance a èté si grande (千́t).

(1) Voir dans Tite-Live, le tallean de Rome après la batalle décisive du Métaure, en 208.

(2) son p’̀re lui a laissé un arpent. De son mariage, il a eu deux fils et six filles. Il compte 22 ans de service. Macedoine, Espagne, Italie. C'est le type des citogens romains. Tite Live, 1. 42 , ch. 34 .

(3) Lenormant, La yrande Grees, t. 2, 174-179. - E. Furnier tle Flaix, St". listique générale, t. $1^{\mathrm{er}}, 499-505$.

(4) Rome ne connnt jamais l'esprit démoeratique. Il n'y a pas une seule époque dans sa longue histoire ó elle n'ait en une noblesse. si on se transporte au dernier sirele de la Républiqne, on y tronve une aristocratie anssi fortement constituée que l'aneien patriciat; on doit encore faire cette remarque que dans tonte l'histoire Ie Kome, il n'y eut jamais atueun effort sérieux pour détruire cette hiérarehie. Vient ensuite l'Émpire, l'inégalité disparnt en politịne, mais elle subsista tont entiere dans les moeurs. - Fustel de Conlanges, Ancienne Franee, chapitre XI. M. Fustel de Coulanges aurait du dire dans les lois civiles et dans lia popriété. 


\section{S. La population et lagrieulture dans l'Italie ancienne.}

En Italie, Rome est un État récent, presque nouveau; c'est le dernier qui se constitue et qui suit une marche progressive. Athènes, Lacédémone, Thèbes, Arı́os ont subi bien des changements politiques; ils ont passé de la rovauté à l'aristocratie, avant que les fondations de la ville Eternelle aient été projetées. Lycurgue est antérieur de près de trois siècles a Servius Tullius. Lacédémone traverse sa plus belle époque quand saccomplit la Révolution qui prépare la grandeur de l'aristocratie romaine; Solon était archonte en 3̈9'. Le consulat n’a été établi qu'en ž10, vingt ans seulement arant la bataille de Jarathon.

Si les temps diffèrent, les éléments ne diffërent pas moins. La Grèce n’a jamais été très-peuplée. Pays de monlagnes et de vallées étroites, elle ne comportait pas un rapide dévelopjement de l'espèce lıumaine. Les mours déplorables des Grees avaient, en partie, pour cause le contrile de l'accroissement de la population. Aristote en a fait la remarque à plusieurs reprises; aussi quand le luxe, la guerre, la corruption des idées vinrent amoindrir encore le goùt et les habitudes des Grecs pour l'élevąre des hommes, qui est partout une rude et pénible tìche, la dépopulation se fit de toutes parts avec une rapidité désolante. Polybe en constatait les causes el les progrès dans le second siècle arant l'ère chrétienne (1); au lemps de Pausanias et de Plutarque la Grèce était devenue un désert.

Il n'en était pas de mème de l'Italie, surtout du Latium. Elle est demeurée très-peuplée jus qu’après la seconde guerre punique. Rome contenait au moins 1 million d'habitants à l'époque des victoires d'Annibal. Elle était elle-même entourée de toutes parts de peuples nombreux et puissants par leur population. Tous ces peuples vivaient de l'arriculture et du commerce des produits agricoles. La terre avait pour eux une très-grande valeur. Ils la morcelaient en petits domaines d'une contenance moyenne de

(1) Livre 37, \& 4 . 
1 hectare. Dans certaines parties de la vallée du Pò et en Toscane, l'Italie est encore le pays de la petite culture. Telle Sismondi a peint la condition des métayers de la Toscane, au commencement de notre siècle; telle était celle des Sabins, des Osques, des Hérniques, des Volsques, des Eques, des Etrusques, de tous ces campagnards qui ont opposé une si énergique résistance aux entreprises des Romains, avant de devenir l'un des principaux éléments de leur grandeur.

Ainsi la population et l'agriculture forment les deux fondements de ce peuple romain qui, malgré tant d'armirables travaux, depuis Bossuet, Montesquieu, Vico et Beaufort jusqu'à Michelet, Duruy, Savigny et Mommsen, Marquardt (1), Humbert, Cagnat, est encore un incomparable sujet d'étude et de méditation.

\section{\$ 3. La Procidence et le yénie romain.}

Nais ces deux fondements ne suffisent pas pour expliquer l'ceurre. "D'heureuses circonstances, l'énergique habileté de son " arisrocratie et les secrets desseins de la Providence, ajoute "M. Duruy, lui ont donné l'empire du monde. " C'est, en effet, la Providence qui a dù fäire sortir des éléments divers qu'elle avait réunis ce qu'il faut appeler le génie romain, cet ensemble de vertus et de forces qui a caractérisé, penlant plus de 800 ans, la race romaine et qui différe profondément du génie grec. Le génie grec est idéaliste, le génie romain est positif; mais la Grèce ne peut s'élever, si ce n'est dans le domaine de l'art et de la science, à aucune conception générale : au contraire, le génie romain est essentiellement assimilateur. C'est ce qui marque sa destination; c'est de cette puissance d'assimilation que procède la faculté juridique de Rome. Rome a beaucoup emprunté pour le droit, comme pour toutes choses, à la Grèce, à l'Egypte, en rapports directs elles-mèmes avec les grandes monarchies de l'Orient; mais tout en condensant le droit dans des formules plus précises, elle lui a donné un caractère universel.

(1) Histoire des Rumains, $1^{\mathrm{e}}$ vol, 117. 


\section{\$. Laristocrutie romaine et les anciennes aristociatips.}

A crité des différences entre des peuples, des races représentant des civilisations si opposées, quoique se donnant la main, il y a plus d'un rapport à signaler.

A Rome, comme en Grèce, le mourement national ne s'accuse, ne se précise quavec l'abolition de la rozauté, qu'avec la forme républicaine. Ces deux civilisations, auxquelles il faut ajouter celles de Carthage et de la Judée, ont été dominées, pendant plus de 500 ans par les idées républicaines: elles ont vu éclore et se développer des institutions libres qui, à plusieurs égrards, sont encore des modeles pour les nations christianisées contemporaines.

Pour les unes et les autres, ce grand fait a ses racines dans la constitution, l'influence et le crouvernement d'une aristocratie tantot territoriale comme à Lacédémone, tantit religieuse comme en Judée, tantit de commerce comme à Carthagre et à Athènes.

L'aristocratie romaine participe de ces trois caractères, exactement comme l'aristocratie anclaise : elle est religieuse; elle est territoriale; elle est commercante. C'est ce qui explique, comme pour l'aristocratie anglaise, non seulement son influence, son immense supériorité, mais son renourellement.

Nous arons vu l'épuisement de l'aristocratie des spartiates; celle de Carthage a péri parce qu'elle est devenue exclusivement commerciale, financière, et sous le terrible effort de l'aristocratie romaine. L'aristocratie athenienne s'est plus longtemps maintenue gràce précisément à l'appui de l’aristocratie romaine.

Néanmoins il y a lieu de signaler entre ces diverses aristocraties et l'aristocratie romaine une différence essentielle : l'aristocratie romaine a de bonne heure accepté l'écalité politique; elle n'a jamais accepté l'égralité sociale; c'est ce qui la sépare des aristocraties grecques et mème de celle de Carthage; c'est ce qui la rapproche encore de plus pres de l'aristocratie anglaise.

Enfin le grand élément d'action de cette aristocratie a été la guerre. Aussi de 1688 à 1810̆, l’aristocratie anglaise n’a cessé d'ètre le principal facteur de la guerre sur le globe; c'est l'époque 
14. L'aristuchatie ROMAINE ET LA PRUP'RIÉTÉ FONGIÉRE.

de sa plus grande prépondérance comme de la fondation de l'empire anylais.

Les aristocraties grecques étaient également, mème à Athènes, des aristocraties militaires. La Triérarchie, si lourde dans les derniers temps, était, à l'époque de Thémistocle, acceptée comme un honneur; mème à Carthage, une notable partie des familles arıstocratiques était militaire.

s.. Linistoratie pomaine et la propriete fonciere en Europe.

Ma'rré ces rapprochements, les différences demeurent tout autrement décisives. Certes, l'aristocratie romaine a fait, de mème que l'aristocratie anglaise, un terrible usage de la guerre; la guerre nest cependant pas son caractère définitif. Son ourre principale dans la civilisation européenne, à laquelle elle a eu une si crande part, cette curre c'est l'extension, le rayonnement de la propriété foncière par l'occupation, la conquète, la culture du sol et plus tard par le droit. Il en est de mème de l'aristocratie anglaise; elle poursuit de toutes parts, au mogen de ses puissantes colonisations, lieurre accomplie par l'aristocratie romaine en Europe et, temporairement, dans une partie de l'Afrique. C'est plle qui représente et qui répand sur le globe le droit de propriété et arec ce droit l'élément fondamental des progrès de la richesse et de la civilisation. Au septième lirre de cet ourrage une partie de l'exposé des institutions fiscales de divers Etats contemporains consistera dans le tableau des impoits de colonisations anglo-saxonnes; ces colonisations et le génie anglais seront, au siècle prochain, une force de résistance et d'activité aussi grande qu'ont été autrefois les colonisations et Je génie de Rome. Rome, c'est la propriété, c'est la terre, c'est le droit, c'est le cultirateur maitre de son terrain, l'agrandissant, le transformant en un domaine moven, plus vaste, immense, au fur et à mesure de l'occupation du sol en Europe. Dans la civilisation féodale, la terre a été tout. Pas de terre sans seigneur; mais l'époque féodale n'est autre que l'occupation, le défrichement, la mise en culture et l'appropriation de l'Europe occidentale. La part de la cirilisation romaine a été 
nécessairement supérieure, par l'occupation, par la culture, surtout par le droit sur des territoires bien plus étendus (1).

\section{\$ 6. La propriete fonciere sur le ylobe et les futures aristocuties.}

Il ne faudrait pas considérer comme un accilent cette inlluence de la propriété fonciere, d’abord pendant la République romaine, puis sous l'empire romain, sur la constitution de la société et les institutions politiques. II $\mathrm{y}$ a, au contraire, concordance nécessaire entre les conditions politiques et sociales des peuples et la fonction de la propriété foncière dans leur état politique, social, économique. On peut citer des preures bien décisives de cette concordance. Lorsque de Tocqueville, de retour de son voyage aux États-Unis, lançait, en 1833 , dans le public européen son livre : La démocrutie en Amérique, inspiré comme un prophète, il prédisait une sorte de naufrage général de la vieille civilisation. Il avait oublié de tenir compte de l'énormité du territoire, 920 millions d'hectares, dont un tiers seulement a pu ètre mis en culture après trois siècles de colonisation. Aujourd'hui, les observateurs sagaces du milieu américain, sont obligés de constater, la formation d'une véritable aristocratie territoriale et financière qui ramène tout à elle et qui domine tout : élections, tribunaux, journaux, chemins de fer. Quel fait plus curieux, entr'autres, que l'organisation des chemins de fer aux États-Cnis, représentant $ّ 0$ milliards et accaparés par quelques milliardaires d'une puissance bien autrement étendue que les sénateurs romains les plus riches ou que les plus hauts barons féodaux.

"La République des États-Lnis, écrivait il y a quelques an" nėes, l'un des publicistes francais qui les ont le plus longtemps " habités et le mieux connus, n’est point une démocratie dans " le sens que l'on donne ordinairement à ce mot, de ce cité le "l'Atlantique : les idées aristocratiques et les combinaisons d’é-

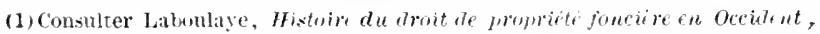
ouvrage déja ancieu, compus atrant les travaux réchts sur ce grant sujet qui est cncore à traiter, surtout atu point de vue éconminute que Labonlaye n'a las saisi. 
" quilibre de l'école anglaise se retrourent presque toutes dans " la constitution de l'union américaine : la liberté et l'égalité y " ont des contre-poids et des entraves considérables dont les "républiques d'Europe n’ont compris ni les rouages ni la por" tée (1)".

M. de Mandat Grancey, qui a récemment fait de longs royages aux États-Lnis, a développé les mèmes idées à propos du livre de .I. Paul Bourget : Outre-mer.

"Quand M. de Tocqueville est allé en Amérique, il y a trouvé " une société oủ étaieut en train de disparaitre les derniers élé"ments d'une aristocratie dont Washiurton était le tỵpe, et il "en a conclu que cette société marchait tout droit à la démo"cratie pure et simple. Sil ! virait de nos jours, et surtout s'il " yétait mèlé à la rie industrielle et politique, il serait proba"blement beaucoup moins alfirmatif en royant le röle qu'y jouent "les millionnaires. En somme, ce qui distingue un pays démo"cratique d'un pays aristocratique, c'est que dans le premier, il " ne peut y aroir d'autre autorité que celle exercée en vertu d'un " mandat donné à quelques-uns frar la masse des citoyens libre"ment consultés : tandis que si une classe de citoyens a le droit ou "le pouroir dimpuser sa volonté aux autres, cette classe cons"titue une aristocratie. Or, il est incontestable qu"il y a, actuel"lement aux États-Lnis, une foule de gens qui, grìce à leur "prodigieuse fortune, et surtout à la façon dont ils l'emploient, " se trouvent précisément dans cette situation privilégiée, vis-à"vis du reste de la population. Ainsi, il y a beaucoup d'États " dont tous les chemins de fer ou la plus grande partie des che"mins de fer sont la propriété exclusive et absolue d'un tout "petit groupe d'hommes, le plus souvent mème d'un seul homme, " qui peut donc imposer à la population de toute une région les "tarifs qui lui conviennent, sans avoir besoin de consulter qui "que ce soit. La population d'un pays où tous les moyens de "transport sont ainsi accaparés par un seul homme, se trouve

(1) F. Gaillardet, Loristocrotio mmitrine, Paris, 1883. U. F. Gaillardet a

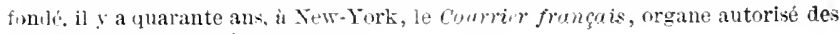
interets français aux États-Ľnis. 
vis-d-vis de lui absolument dans la situation où étaient les vas. "saux d'un seigneur féodal : car, sur les produits du travail des habitants, il peut, en fait, prélever pour son usage personnel telle part qu'il lui convient uniquement par le jeu des tarifs qu'il leur impose; de mème qu'un seigneur féodal pré* levait sur ses rassaux une part de leur travail quand il les forçait à renir cultirer ses terres, un ou deux jours par se"maine (1)."

De Tocquerille n'est pas sans aroir admis, à propos des progrès de l'industrie manufacturière, un certain retour vers 'ne aristocratie des plus dures et des plus restreintes; mais il n'a tenu aucun compte de linfluence du territoire qu'il ne connaissait qü̈mparfaitement et qu'il éraluait à six fois la France. Or, il equiraut à dix-sept fois la France '2).

On doit appliquer les mèmes rétlexions à l'empire anglais et à la Russie; car, pour chacun de ces gigantesques empires, la fonction du territoire est telle qu'il n'est laissé que de fort médivcres perspectires d'avenir aux hypothèses démagocriques de petits foyers de l'Europe occidentale. Il suffit de faire une simple equation entre les territoires et les populations qui les courrent pour connaitre leurs institutions, leur état social. Il en a été, dans les anciennes civilisations, comme il en est aujourd hui - comme il en sera au siècle prochain. La démocratie exige un territoire modique pour une population nombreuse; mais partout où un nombre relativement restreint de familles occupe un teritoire considérable, la forme aristocratique est nécessairement la règle. Le mouvement colonial de l'Angleterre n'aurait pas eu lieu arec un territoire morcelé en petites parcelles; aussi la formation des grandes terres seigneuriales britanniques est-elle de la mème époque que ce mourement même. C'est ainsi qu'on explique qu'en Russie un grand nombre de pařsans ont réjà aliéné tout ou partie des lots que l'émancipation leur a attribués, que la

(1) Article du Figor. 1\% juin 1 255 . M. le Manlat Graney a oublit de dire que les seigneurs feodaux ont ete les proprietaires militairs qui unt defriche, cultive, plantedakini, constitue et deienlu la France.

(2) La demoratie en A xérique. t. II, 2" part. (hap. XX, et t. I. chap. I. 
grande propriété et que le mïr, qui est aussi un mode de la grande propriété, aient conservé ou repris tant d'importance.

A létendue du territoire il faut ajouter les conditions de son exploitation. Les deux faits ont eu presque une part égale dans la constitution de l'aristocratie romaine. On a pu s"imaginer, à la suite de la Rérolution française, que la petite propriété allait envahir l'Europe. Sismondi a écrit des pages charmantes sur l'agriculture en Toscane. MI. H. Pasş a composé un traité technique sur les arantages et l'arenir de la petite propriété. Certains philanthropes anglais ont obtenu des lois d'allotment pour morceler les grandes terres et les revendre en parcelles; il en a été de mème en Prusse. Mlais, aujourd'hui, sous linfluence des conditions de concurrence de la culture, on a bien moins denthousiasme pour le morcellement de la terre, parce que ce morcellement enchérit la production au moment où la mise en culture de territoires gigantesques de tous còtés fait baisser le prix du froment de $16 \mathrm{fr}$. l'hectolitre à $I$ fr. Seule la grande propriété peut s'accommoder de pareils prix, comme seule elle convient à d"immenses territoires.

La concentration de la propriété foncière entraine arec elle la concentration de l'industrie. Elle s'accomplit de toutes rarts arec une très-grande rapidité, d'autant plus qu'elle est farorisée par d'autres causes. Rien d'étonnant, si ce double mourement de concentration, bien autrement vivace à la fin de notre siècle, que le mourement de dissémination, exerçait à son tour une action sur les conditions politiques de l'Europe actuelle et y provoquait, dans le cours du siècle prochain, un courant centralisateur, indispensable pour mettre l'Europe en état de résister à la concur. rence qui deviendra, chaque année, plus redoutable, des noureaux territoires mis en culture.

Sans doute la politique du Sénat, l'entrainement militaire des Romains, la décadence ou la faiblesse des peuples qui les entouraient ont eu une grande part dans la fondation de l'empire romain; mais dautres causes y ont concouru, en particulier l'extension de l'occupation du sol, celle de la propriété foncière, la concurrence, exactement comme aujourd'hui, de noureaux territoires mis en culture. Et la raison décisive de la chute de la 
République romaine, malgré une résstance qui a été terrible, conduite par des hommes de premier ordre, Sylla, Labienus, Petreius, Alranius, Caton, Brutus, Dolalsella, Pompée, Cicéron, c'est que la forme monarchique a été la condition de la réunion des territoires.

Quant aux agitations subversires des foyers, à rayons bien limités de l'Europe occidentale, elles restent impuissantes. Radicaux, socialistes, communistes, anarehistes - l'anarchie est leur véritable domaine comme leur seul nom - ne peuvent que laciliter le mouvement de concentration. C'est leur seule part d'action, leur unique avenir, leur lot. Leur idéal de détruire la grande propriété pour accroitre la petite, en attendant qu'ils la détruisent à son tour, est précisément en opposition avec l'ordre fatal des faits économiques. Il est donc chimérique.

\section{\$ 7. Epropues diverses de l'impót chez les Romains.}

Par suite, il est indispensable de connaitre le développement historique de l'impòt chez les Romains pour se rendre compte des phases diverses de l'impöt dans la plupart des nations de l'Europe, notamment la France, l'Espagne, l'Italie, les États Danubiens, la Hollande, la Belgrique, l'Nllemagne de l'Ouest et du Midi, l'Empire ottoman. Sans cette connaissance préalable, on s'expose à remplacer la tradition, qui est la base mème de tous les systèmes d'imprit sérieux, par des théories ou le hasard, comme certaines coneeptions de l'Assemblée constituante.

Il y a eu dans le développement des institutions fiscales romaines trois époques différentes. La première est essentieflement romaine; elle s'étend depuis les origines de Rome et les institutions royales jusqu'à la fin de la République. C'est l'époque républicaine; l'époque de la conquète des peuples et des territoires qui formeront l'Empire romain. Deux faits la earactérisent: 10 l'impôt sur le capital, le tributum exe censu ou cirium romanorum, le mème qui est l'une des bases des ressources fiscales des États-Unis de l'Amérique du Nord, impöt que la Prusse vient d'adapter en partie à son système financier, imprit que diverses écoles révolutionnaires contemporaines préconisent comme un 
instrument de boulerersements sociaux et de transfert violent de la richesse de certaines classes des peuples à certaines autres. Pour les Romains de cette première époque, l'impòt sur le capital a été un formidable instrument militaire de conquète; il a, de mème qu'aux Etats-Unis, correspondu aux progrès de la culture du territoire romain, puis de l'Italie elle-mème; $2^{\circ}$ le tribut étranger, en nature ou en argent, c'est-à-dire le remplacement des ressources fournies par limpòt sur le capital romain par les subrentions des peuples que cet impit a tant contribué à raincre. Vais le poids de ces subrentions est si accablant; elles proroquent tant de risistances, les conditions économiques et politiques de la République romaine deriennent si difficiles, qu'il faut rétablir le tributum ex censu, au moment où l'Italie n’est plus en état de le supporter: la Réprublique s'effondre.

La seconde époque correspond à la partie brillante de l'Empire romain, à celle pendant laquelle les traditions romaines dominent encore. Elle commence à Auguste et aux importantes réformos qu"il a accomplies dans le srstème d'impit de Rome en vue de lapproprier aux conditions, non seulement des changements politiques dans le gouvernement qui cesse peu à peu d'ètre républicain pour devenir monarchique, arec le fondement aristocratique immuable romain, mais surtout à la diversité des éléments dont se compose l'empire mème: territoires, races, religions, peuples, traditions, institutions de tout genre. Durant cette seconde époque, il sopère une lente et laborieuse assimilation entre les institutions fiscales romaiues et les institutions fiscales des diverses nations de l'empire : une fusion a lieu, et bientit se constitue un seul système fiscal, adapté non plus à Rome, ni à l'Italie, mais à l'empire romain tout entier. Dans ce travail de fusion, dans cette transtormation, les éléments romains sont ceux qui perdent le plus; ce sont les éléments des parties orientales de lempire qui ont la prépondérance. Quant aux éléments occidentaux (Gaules, Espagne, Germanie) ils n'exercent aucune action. Leur état de cirilisation ne le leur permet pas. Il en est de mème de la Grèce qui a perdu toute imporiance, toute fonction dans le mourement économique du 
monde romain. C'est la vieille Erypte, toujours riche, toujours très-peuplée et bien cultivée, c’est la Judée, c’est la Syrie, ce sont les divers états de l'Asie Mineure, fondés après la mort d’Alexandre, qui, possédant la richesse, les populations les plus denses, les territoires les mieux cultivés et les plus productifs, ont le plus d'activité économípue et, par suite, occupent dans cette transformation la place principale (1). Non seulement l'Orient lonne, depuis Vespasien, des empereurs à l'Empire, mais il introduit à Rome ses mœurs, ses traditions, ses religions et bientut il fera de Rome le grand centre de la révolution religieuse dans laquelle se personnifie la résistance implacable au vieux monde politique romain. Le Christianisme, en s'installant à Rome, ne peut mème arrèter ou modérer la puissance du courant qui dirige le monde romain d'Occident en Orient. Dioclétien ne séjourne pas à Rome. Il habite Nicomédie, en Asie Mineure; il se retire et meurt en Dalmatie; Constantin transporte sur le Bosphore le foyer, le cour de l'Empire. Linfluence de l'Orient prédomine entièrement.

Alors sourre la troisième époque, la plus considérable des trois dans l'histoire de limpôt romain, précisément par ce retour de la civilisation vers les foyers primordiaux où elle est née et doù elle est partie, les vallées du Tigre, de l'Euphrate et du Nil, cette Mésopotamie sur laquelle les plus antiques parties de la Bible contiennent des renseignements si précieux. C'est à cause de ce retour, dont nous allons montrer l'influence, que l'histoire de l'impoit des antiques empires d'Orient est une partie constitutive de l'histoire de l'impùt dans les derniers siècles de l'empire romain et pour tous les États qui ont été formés arec ses débris. Au surplus, le fait historique n'est ici que l'expression du fait économique. Le caractère principal des deux civilisations grecque et romaine a été d'être des civilisations urbaines. Le territoire propre de chacune d'elles, celui mème de

(1) L'lalie était, in l'origine, un pays pavre; la vie y eitait triste et austère. La vie grecque, simple et charmante, n'etait nullement une vie d'olulence. L'A. sie bien llus riche et plus smutueuse, morifia toutes ces conceptions. Renan, Isrä̈l, 5* vol., 203. 
l'Italie entière, ne sauraient, au point de vue de l'extension de la propriété foncière et de la culture agricole, entrer en comparaison avec les vallées du Tigre, de l'Euphrate, du Nil et de toute l'Asie Mineure. Nous arons vu se constituer et se dérelopper les systèmes fiscaux des grands empires d'Orient. Les Romains en admiraient la perfection et l'cuvre d'Auguste consista à les transporter à Rome et en Europe. Ils acquirent donc une grande influence, qui dut entièrement prévaloir lorsque le mouvement des faits politiques eut pour conséquence le transfert du centre de l'empire d'Occident en Orient. Le système d'impùt qui sortit de cette fusion se troura, par la suite mème des choses, bien mieux approprié aux changrements décisifs qui allaient aroir lieu dans la condition économique de l'Europe. D’urbaine, la cirilisation allait devenir rurale; l'ạriculture allait prendre le pas sur le commerce et l'industrie; le servage agricole allait remplacer l'esclavage urbain. Tout cela existait déjà en Orient. C'est ce qui explique comment les institutions fiscales de cette troisième époque ont eu tant dimportance. Elles unt correspondu aux nécessités de la mise en culture de la plus grande partie de l'Europe. C'est aussi pendant cette troisième époque que se prépare un changement extraordıaire, radical, presqu'inexpplicable dans le caractère de l'impoit, chancement accompli en partie en Orient. Bien que le Spartiate lùt exempt, à titre de service militaire, d'impìt, le Grec libre, de mème que le Romain libre, considérait comme un devoir d'acquitter l'impüt; par contre l'esclave était à l'abri de l'impüt. En Orient, les conquètes successives des territoires et des populations, soumis aux tributs, avaient altéré de bonne heure la notion du devoir de limpòt; mais en Gréce et à Rome cette notion demeura longtemps intacte. Dans cette troisième époque de lïmput romain, elle s'altéra aussi à fond, sous deux influences : $1^{\circ}$ la transformation du trarail, la transformation de l'esclavage en serrage; le serf fut assujetti à l'impùt, ce qui donna à l’impòt un caractère servile; $2^{\circ}$ la transformation du gouvernement qui, de républicain, devint monarchique et absolu : limpôt fut considéré comme la propriété du souv zrain, tradition bien vieille en Orient. A ces deux causes, s'en joignit plus tard une troisième, 
la résistance des Barbares et de tout individu militaire à l'impôt. Il en fut de mème pour le Musulman (1).

La portée de cette altération dans l'idée et le caractère de l'impit a été immense. On peut jurrer, d'après ces quelques réflexions, de tout l'intérèt qui s'attache à cette troisième époque de l'histoire des institutions fiscales romaines. Correspondant à un changement profond rlans les forces productires de l'Europe, dans l'expansion simultanée de la propriété foncière rurale, dans la mise en valeur du sol et dans les formes du travail, ces nouvelles institutions, comme il en avait été en Orient, prirent un caractère de durée tel qu'elles ont persisté, notamment en France, qui était la contrée de l'Europe qui avait fait le plus de progrès, jusqu'en 1789, malgré des transformations diverses. La tendance fut de mettre au premier rang l'impôt sur la terre, l'impót foncier et de le laire supporter non plus par le propriétaire, qui en devint exempt, mais par les cultivateurs. Mème, pendant de longs siècles, les propriétaires s'emparèrent de cet impoit et le confondirent avec leur part tans la production. D'abord, cette confusion dut cesser, mais l'exemption d'impit persista plus longtemps. Dans les parties les plus complètement romanisées de l'Europe, l'Italie, la France et quelques régions de l'Allemagne occidentale, les traditions et les répartitions fiscales romaines subsistent encore.

Nous avons montré quels rapports étroits existaient entre les institutions sociales et politiques de la Grèce et ses institutions fiscales, comment avait lieu l'incidence des impôts dans des milieux souvent dissemblables, malgré des rapprochements inévitables; les mèmes recherches ont été faites pour d'autres peuples, quoique plus difficilement, à raison de la pénurie des documents.

Les documents sont plus abondants, plus précis pour ce qui concerne les Romains. Ils ont été fouillés, étudiés, discutés par des maitres qui n'ont pas laissé beaucoup à relaire après eux. 11 est donc plus facile de présenter un état exact des impôts chez les Romains et d'éturlier leur incidence. Mais la facilité n'enlève rien a l'importanee du sujet paree qu'ilest plus varié et plus vaste.

(1) Allssi le tributum es o nsu caracterise-t-il le citoyen romain ; lui seul le paie, c'est l'impót les cieium romanorum. 


\section{CHAPITRE II.}

DES MMO'TS ROMAINS JUSQU'A L'ÉTABLISSEMENT DE L'EMPIRE.

\section{S. Premiers temps.}

Les travaux des historiens et des juristes de la seconde partie de notre siecle, en particulier ceux de Mommsen, de Marquardt, de Savigny, de Humbert, de Dureau de la Nalle, des savants rédacteurs du dictionnaire archéologique de Daremberg, ont remis à leur rang les éléments fondamentaux de la société romaine primitive. Les critiques de Beaufort, de Niebhur, de Michelet mème ont été délaissées. Ces éléments primitifs étaient la terre, la propriété foncière, les propriétaires ou quirites portant la lance comme le Spartiate, le roi et la guerre. La guerre pour s'emparer de la terre, comme font encore tous les peuples. Sur une petite échelle, Sparte a procédé comme Rome; quant ¿t Athènes, la nature de son territoire la réduisait à peu près au commerce. Elle n’a jamais été, malgré nos illusions classiques, le peuple prépondérant en Grèce. Son territoire ne lui donnait pas la prépondérance. Elle a tenu le sceptre des arts, des lettres, des sciences, mais l'État directeur de la politique des Hellènes, c'est Sparte, établie au centre du Péloponèse; c'est l'État grec militaire par excellence. Il ne faut pas seulement dire que les Romains ont eu en rue de faire un grand empire, mais, de mème que les Anglais, les Américains et les Russes, de mettre surtout la main sur la terre, d’étendre, autant qu'ils le pourraient, leurs propriétés territoriales. A côté des quirites portant la lance et combattant au premier rang dans la légion, tout comme les Spartiates, se trouvait une autre population qui ne pouvait ni acquérir, ni tester, ni adopter, ni porter la lance, ni combattre, et qui ne devait ni l'impòt, ni le service militaire, mais cette population n'était pas tenue de cultiver le sol et d'en- 
tretenir les quirites. D'oì la supériorité romaine sur les éléments de la société grecque $(1)$.

\section{S. Refomes de Sercius Tullius.}

Le temps rapprocha nécessairement les divers éléments du peuple romain. Licurre de Servius Tullius, l'une des plus curieuses physionomies des anciennes civilisations, a consisté à cimenter le rapprochement. Nul législateur n’a eu plus d’action sur les destinées dun peuple. M. Mommsen pense que cette curre s'est faite sous l'influence de la Grèce et des réformes de Solon à Athenes. Elle est ì la fois politique et fiscale $(\boldsymbol{2})$. Voici l'cuure politique: les habitants de Fome sont classés d'après leur fortune et non d’après leur origrine, par suite les riches plébéiens vont marcher de pair avec les quirites. La population est partagée en 193 centuries. La première classe comprend 98 centuries et lous les habitants possedant au moins 100,000 as, soit 8,000 fr. Laristocratie de richesse remplace celle du sang. C'est le principe de la grandeur de l'aristocratie romaine comme celui de l'aristocratie anglaise. Leurs auvres parlent pour elles; puis viennent trois autres classes avec un aroir différent, mais tenues au service militaire. Dans la sixième classe sont réunis tous ceux ayant moins de 11,000 as, pas de service militiire. Chaque classe a un armement différent. La première seule est tenue au plus complet. Cette réforme politique

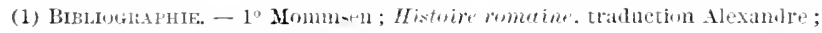

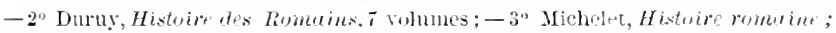

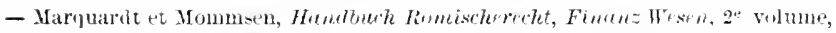

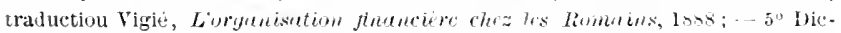

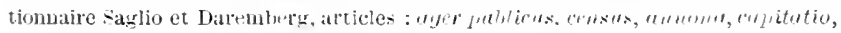

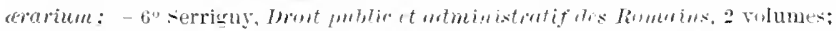

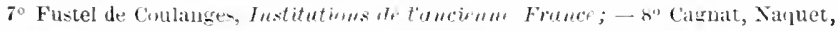

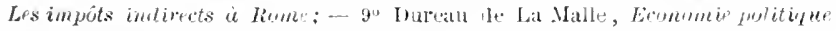

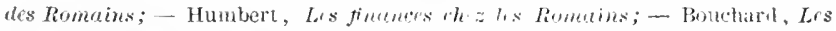

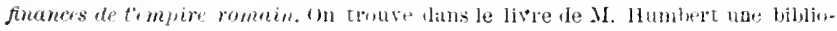
gatahie tris complete. Parmi ces divers ouvrages, aucum na lauturté complinte

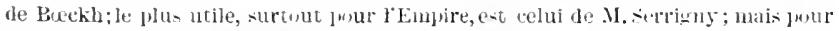
I'Empire roluatil an promile les textes officiels fort rales pour Athentes et la iriece.

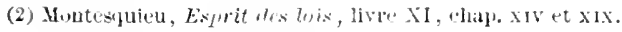


permit à Servius Tullius d’y joindre une grande réforme fiscale, fondement de la puissance de Rome. Avant lui, les ressources du gourernement consistaient dans : $1^{0}$ les revenus des terres affectées au service du roi, à peu près le tiers du territoire (ayer pullicus), 20 le prix d'affermage du second tiers formant le domaine public, $3^{\circ}$ le tributum, sorte de sapitation, acquitté par les quirites entre lesquels le troisième tiers des terres arait été réparti (1); $\dot{4}^{\circ}$ le butin de guerre et $\check{\partial}^{\circ}$ quelques autres taxes, notamment certains Portoria, le cinquième du produit des arbres, une taxe sur les marais en culture, la dime sur le produit des terres vaines et ragues $(2)$. Serrius Tullius étendit le tributum aux citoyens des cing premières classes; et le rendit proporticnnel mais temporaire. Le taux fut d'abord de 1 as par mille de capital. Le tributum était dù sur les fonds de terre, les maisons, le bétail, les esclares, les objets mobiliers et les créances certaines. Dès avant la réforme de Serrius Tullius, il y avait à Rome, selon l'expression de Mommsen, une sorte de terrier oủ chaque citoyen, quirite ou plébéien, inscrivait et évaluait les objets qu il possédait. Pour assurer la perception de l'impòt réformé, Serrius Tullius n'eut qu’à utiliser ce terrier, qui arait servi à la formation des centuries. D'où le tributum ex censu; le grand instrument fiscal de la conquète romaine. Les citoyens de la sixieme classe paraient une capitation au lieu du tributum. - Daprès Denys d'Halicarnasse Rome comptait alors 84,000 habitants dont 20,000 devaient le service militaire et acquittaient le tributum e.r. censu (3).

Lf tributum ex censu est exactement l'impit local principal aux Etats-Unis, produisant à peu près 1,800 millions de francs

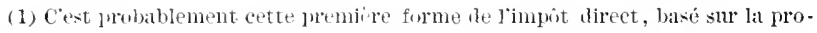
priete foncise, qui a porté Dureau de La Malle trommen (Histuire romaine, tome Vl, chap. xn) a ammettre "füil y avait et un impot foneier it Rome. Marunarit, pages $206-207$.

(2) Dureau de La Malle, Eronomie politiune des Romains, 1 er vol., 447.

(3) Dureau de La Malle soutient que les llébéiens senls supportaient, sous les Rois, le tributum e.c eensu (1er vol., 402) d'apres un texte de Tite-Live qu'il interprite à faux. "Les citoyens aixés supportaient à peu près seuls les frais de la "guerre. 》- IIumbert, Finanees des Romains, 1 $1^{\text {er }}$ vol., 20. - Cela est vrai pour toutes les anciennes cirilizations. 
par an et affecté, en grande partie, aux dépenses de l'enseignement primaire. Malgré la dinérence des temps, des territoires et des races, le fondement du tributum ex censu et de la Real and personal propexty tax est le mème, la propriété foncière rurale. Mème incidence sur les proprietaires du sol.

\section{s. Les impóts sous la Ripublipue romaine.}

La révolution qui remplaça le gouvernement monarchique par le gouvernement républicain ne morlifia pas les institutions fiscales du peuple romain $\mathbf{1}$ ). Le tributum erp rensu demeura l'impìt romain par excellence. Il en fut établi divers autres, mais ils neurent pas rimportance de l'impot sur le capital. Après lexpulsion des rois, le cens entra dans les attributions de censeurs auxquels il valut lrur titre si honoré à Rome. Le cens avait un caractère très-général. Il en est de mème actuellement aux États-Unis; č́tait une statistique complète des ressources de toutes les familles, la description de tous les biens et valeurs, les naissances, mariagres, décès, dots, dettes, revenus. Les citovens étaient tenus de justifier de leur situation par des actes de famille, actu. Ils en affirmaient l'exactitude. Les résultats du cens étaient constatés par les Tubulæcensuales, qui se conservaient dans les familles. Denys d'Halicarnasse en a consulté un grand nombre. A crité des Tubulx censuales, il y avait un cadastre foncier, particulier pour les domaines ruraux. Il servait de base pour l'impót sur les terres et le bétail. Il fut mème exécuté, sous la Républịue, un plan cadastral général, gravé sur cuivre et déposé au tubulariun (archives romaines) (2). Les plans et les estimations étaient confiès à des ingénieurs spéciaux agri mensores). Les terres publiques ('yer pullicus) étaient distinctes des terres privées (ager pricutus). Les ingénieurs marquaient mème les terres soumises a limpùt (uger vectigulis; et celles qui

(1) Dureau de La Malle pense que le tributum fut aboli, dapris une plurase de

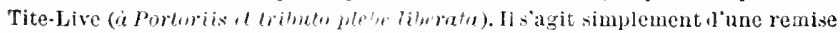
temporaire. - Consulter surtout llaryuarit, fage 228, oryanisalion financiere des Romuins.

(2) Dureau de la Valle, vol. 1 ch. le et 17. 
en étaient exemptes (ager immunis'. Les terres étaient classées d'après leur fertilité. Quelques ingénieurs, opérant au premier siècle de l'Empire, ont mentionné que les bornes limites, placées au temps des rois, subsistaient encore.

Après la chute des rois, le Sénat prit en mains l'administration des finances de l'Etat et des impeits. Il l'a conservée en partie sous l'Empire. Dès lors ce fut lui qui habituellement ordonna la levée et fixa le taux du tributum ex censu, qui fut porté plus tard jusquau double, mème au triple. Il y eut des circonstances où une imposition spéciale fut exigée, parfois avec une certaine progression.

Il importe, dailleurs, de ne pas exagérer le caractère temporaire du tributum cixium romanorum pour dellx raisons : d’abord, parce qu'à partir de l'établissement de la solde militaire en $406 \mathrm{~A}$. C., il fut indispensable et ensuite parce que peu à peu la guerre devint la politique permanente du peuple romain. Il y eut mème des guerres qui exigèrent que limpôt fùt doublé, triplé et accompagné de levées forcēes, considérées comme des emprunts. En ce cas, tout ou partie de l'impôt était remboursé (1).

Il fut ajouté ì cet impôt, sous la République, et quant aux citoyens romains : $1^{\circ}$ un droit de mutation entre-rifs sur les affranchissements d'esclaves. En 33't, le consul Curius Manlius, étant campè à Sutrium, conroqua les soldats par tribus et en vertu de son imperium, porta une loi établissant un impòt du vingtième ou o \% sur la valeur des esclaves affranchis; cet impôt a été maintenu pendant plusieurs siècles; $2^{\circ}$ diverses taxes de consommation dites portoriu, spécialement des droits de douane, des taxes de port et de cabotagre, des octrois à l'entrée des villes; abolis en 17 ils furent rétablis en 121 . Abolis de nouveau en 60 , par Métellus le prèteur, César les réinstalla.

(1) Pendant la seconde guerre punique, malgré le donblement du tribut dès la $4^{\text {e }}$ année, et l'établissement de l'impôt ou emprunt progressif, le Sénat dut en renir (216) à des mesnres exceptionnelles. Il dut abaisser le titre et le poids des monnaies. il fallut permettre anx censeurs de traiter à crédit avee les entrepreneurs de fournitures, puis ouvrir un emprunt et créer une banque de prêts pour le rachat des captifs, - IIumbert, ibilem, 1er vol., 25. 
Le tributum fr. censu lui-mème, sans ètre aboli, ne fut plus demandé à partir de 16\%, aprés la conquète de la Macédoine, jusquen $\mathbf{2}$.

\section{s. t. Le domaine romain (ager publicus).}

Dès les premiers temps, il a existé à Rome un domaine d'État dont les rerenus appartenaient à lixrarium. On rencontre le mème fait chez tous les peuples, Chine, Inde, Empires mésopotamiens, Egrpte, Grèce. Actuellement, plusieurs nations possèdent de très-importants domaines, en particulier la Prusse, la Russie, les États-Lnis et tous les peuples de l'Amérique du Sud, en quète de colons et d’acquéreurs de terre.

I. L’élément principal du domaine primitif romain consistait dans des paturages communs dont le prix daffermage (scriptura) formait le plus net revenu du domaine (vectigal). Lusagre habituel était d'affermer les terres pour 100 ans; les questeurs passaient les baux. Le rectigal était versé à l'xrarium.

Après la chute du pouvoir royal (:i10) le tiers des terres affecté à l'entretien du Roi et géré par le Fiscus royal, fut réuni au domaine dont limportance devint plus grande.

II. Faisaient également partie du domaine, les mines, les carrières, les salines dont il avait la propriété; celles qui ne lui appartenaient pas devaient le dixième du produit brut. Le sel constituait un monopole. Le prix de vente était modéré.

\section{sั. Les lois agraires.}

Dès l'année 486 , c'est-à-dire $2 \dot{t}$ ans après la Révolution républicaine, les terres de l'uger publicus donnaient lieu à des difficultés qui deraient s'aggraver avec le temps et bouleverser entièrement l'économie des institutions romaines.

A partir de ölo, le Sénat en̂t la direction de l'ærarium, exactement comme la Chambre des communes gère directement l'Échiquier et toutes les finances de l'Angleterre. Les fermiers emphy̧téotiques des terres domaniales étaient tous des patriciens ou des plébéiens riches. "Le Sénat, oubliant les inté- 
" rèts de l'État pour ceux de son ordre, négligea peu à peu de "faire rentrer les dimes. C'était le signe cependant qui distin"guait ces possessions précaires des propriétés quiritaires. Aussi, "le signe disjaraissant, les fermes se trourèrent changées en "propriétés, et l'État perdit doublement par la diminution des "rederances payées au Trésor et par l'amoindrissement du "domaine pullic, transformé en domaines prirés (1). "

Le mème fait s'est produit pendant tout le Moyen ìge et mime jusqu'en 1789, en France, aux lépens des propriétés communales et parfois domaniales pour lesquelles les baux, les simples occupations de fait étaient changés arec la connivence des seigneurs, des Parlements, du Roi, en propriétés privées. Il a eu lieu pendant toute la période rérolutionnaire de 1790 à $\mathrm{t} 800$; mais il a surtout pris un immense développement en Angleterre de 1688 à 18300 .

Ce fait touche ì un autre plus grave encore, l'accaparement du sol, de la terre, sur des proportions gigantesques, dans quelques Etats de l'Amérique du Nord, du Dominion et de l'Australie. Il hui est analogue el marque essentiellement les aristocraties territoriales qui se constituent nécessairement, comme aux ÉtatsUnis, en Australasie, dans l'Afrique du Sur, avec l'occupation et la mise en culture des grandes étendues de terres.

Cette tendance de l'aristocratie romaine à mettre la main sur les terres de l'uger publicus s'était déjà produite sous les Rois. Des lois agraires avaient été, à diverses reprises, introduites par eux, des distributions ou assignations faites aux Plébéiens. Elles n'eurent lieu qu'une seule fois après la Rérolution de ŏ10. Et, dès lors, se développa rapidement l'accaparement des terres. A trois reprises différentes, en $\$ 86$ Spurius Cassius, en 437 Spurius Melius, en 383 Marcus Manlius Capitolinus essayèrent, de faire accepter sans succès, diverses réformes agraires; mais en 366 les tribuns Licinius Stolon et L. Sextius firent voter une loi portant quaucun eitoyen ne pourrait posséder plus de 500 arpents en terres de l'ager pulilicus ni envoyer dans les pâtu-

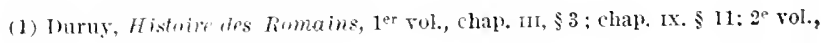
bages $47,53,55$. 
rages publics pius de 100 tètes de gros bétail et 300 de petit 1 ; que sur les terres restituées a l'itat, on distribuerait à chaque citoyen paure 7 arpents; que les détenteurs de terres de l'ager publicus paieraient à l'arurium le dixième duproduit de la terre, un cinquième du produit des oliviers et de la vigne et la redevance due pour chaque tète de britail; qu'it chaque lustre (tous les cinq ans) ces redevances seraient affermees au plus offrant par les censeurs et affectées à la solde militaire.

Ces lois célébres ne furent exricutées qu'en partie, et, pendant un assez court intervalle. En 3\%7, Licinius Stolon lui-mème fut condamné à une amende de 10,000 as comme possédant mille jugera (arpents de 23 ares, 28 a juyerum . Laristocratie romaine comprit cependant qu'elle ne pourrait pas toujours résister. La politique qu'elle adopta dans ces circonstances critiques est la preuve de sa haute clairvoyance :

$1^{\circ}$ Sous l'autorité de la dictature de Camille, elle fit avec les Plébéiens une transaction politique définitive; elle leur ouvrit ses rangs en les admettant au consulat, à la préture, à l'édilité curule, à la censure, c'est-i-dire aux cliarges qui leur assuraient d'entrer au Sénat; les plébiscites rendus dans les centuries devinrent obligatoires pour les patriciens. Ces concessions, confirmant la Fiécolution de 310 , renouvelèrent, accrurent les forces de l'aristocratie romaine. C'est l'époque de sa plus grande puissance.

$2^{\circ}$ Elle imprima plus d'activité au mouvement de colonisation qui avait déjà commencé.

$3^{\circ}$ Elle entreprit la conquète de l'Italie, afin de préparer celle du monde.

L'aristocratie anglaise n'a pas procédé différemment afin de conserver intacte la situation territoriale qui fait sa grandeur; elle détient la terre aussi bien en Écosse quen Anrleterre, aussi bien en Irlande qu'en F́cosse. Il existe en Écosse et en Irlande des Latifundia plus considérables que ceux dont parle Pline. Dans le mouvement électoral de 188\%, si intéressant et si mal connu, des propositions analogues à celles de Licinius Stolon et de Sex-

(1) Dureau re La Malle. ler swl, 254-354. 
tius ont été soutenues sur la plate-forme électorale, par des hommes d'État d'une grande notoriété; on a réclamé une part du sol national pour chaque anglais; on a prouvé que pendant plus de 150 ans le Parlement, à peu près comme le Sénat romain, avait autorisé l'enclòsure ou absorption des terres communales, ou domaniales par les propriétaires privés; on a demandé le droit d'exproprier (sauf indemnité) les Landlords afin de commercialiser la terre (1).

Comment ces faits se rattachent-ils à la question de limpòt?

Le but des guerres du peuple romain en Italie surtout, alors très-peuplée et trés-prospère, a toujours été l'acquisition de la terre. C'était la condition de son développement économique. Les peuples agricoles ne connaissent que la terre. Tels ont été les Lacédémoniens, tels les Égyptiens. Tout peuple vaincu devait donc se restreindre et céder une partie de ses terres; cétait alors la loi de la guerre. Ces terres faisaient partie du butin réel; elles entraient dans l'aner publicus (2).

Dans tous les États anciens et dans beaucoup d'États modernes, notamment en France, sous les Capétiens, dans la Prusse actuelle, aux États-Ĺnis, le domaine de l'État a été ou est encore une grande ressource. Plus abondante est cette ressource, moins il faut demander à l'impùt. Or, à Rome l'impòt était prélevé sur le capital; ce n'était point la dime en nature. Il fallait apporter, quelle qu'eùt été la récolte, le prorata fixé par le Sénat, prorata qui variait selon les besoins, comme a varié l'incometax en Ingleterre. Mais lincometax ne porte que sur le re-

(1) Stutistique comparte hes finaners ot hes impots, par M. E. Fournier de Flaix,

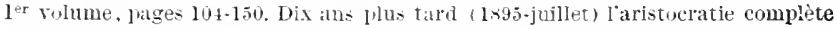
a encore montré sa solilité et sa popularité lar les élections genérales.

(2) Marpuardt, Ibidem, 3 I2, - Voici un exemple sur des milliers de cas. - La ville titait-elte détruite, la totalite des habitants extermine ou rendue comme esclaves, on disperse, il n'y avait jus qu’a exploiter le territure on le donner a une ville voisine. Tal fut le sort a'Haliarte domnée à Athines, le Corinthe donnée à sicyone. Quam L Rome exploitait, thle affermait anx publicains dont le manceps divisait le territoire en lots et sous affermait. Quelquefois, le general, dans l'acte de Deditio, consentait a laisser tout on partie de leurs terres aux habitants; ils devenalent de proprietaires simples fermiers. Telle était la con uete romaine. - Marquardt, 313. 
venu. Le revenu a-t-il manqué? Le fermier et le propriétaire sont exemptés. Le tributum exx censu n'avait pas le mème caractère. C'est le danger de l'impùt sur le capital. Il est plus destructil parce qu’au li. u de porter sur le produit annuel, il porte sur les réserves et qu'il est dì, récolte ou non.

C"est ainsi que la question agraire se reliait directement à la question fiscale; quant à l'incidence, il laut remarquer que si le grand propriétaire peut répercuter quelquefois limpôt au moyen de l'augmentation des prix des récoltes quil rend, le petit propriétaire, qui subsiste sur son bien, n'est pas dans le mème cas. Il subit l'impùt tout en entier; cétait précisément ce qui a vait lieu. M. Duruy ( 1 ) cite une cause fort curieuse d'aggravation; une portion notable de l'ager publicus était exploitée en prairies, d'où le mot pecunia pour exprimer le droit de pàturage; or, qu'arrivait-il? Les grands propriétaires, - les lois de Licinius Stolon en font foi - enrahissaient les prairies arec d'énormes troupeaux; le petit propriétaire n'osait y envoyer sa rache. Combien de fois le fait s'est-il présenté dans les communaux de la France et de l'Angleterre?

Enfin, il faut bien ajouter qu'il y a des limites aux avantages de lirnpòt proportionnel et que lorsque son taux est élevé, il est bien plus lourd pour le petit propriétaire que pour le grand.

De 366 à 133, c'est-à-dire pendant plus de 200 ans, les difficultés agraires se caiment. C'est l'époque de la conquète de l'ltalie et du monde méditerranéen. Les luttes sociales disparaissent. Tout est dominé par la grandeur, les résultats des conquètes. Le domaine romain s'étend de toutes parts. "Dans les provinces " qui, avant la conquète romaine, avaient fait partie du royaume, "les biens du roi passèrent au peuple romain. C'est ce qui eut " lieu en Sicile, en Bithrnnie, en Asie, en Macédoine, à Cỵrène; "de plus, dans toutes les provinces au cas où une cité avait "été conquise par la force des armes, ce n'était pas seulement " une partie du territoire qui lui était enlevée, comme pour l'I"talie, e'était la propriété du tout qu'elle perdait, c'est par "l'annexion de semblables domaines que se constitua l'ayer

(1) Histoire des Romains, 1"r rol., 170. 
"publicus en Sicile, en Achaie, en Lycie, en Pamphỵlie, en "Afrique. Il se divisait en catégories diverses, dont les trois "principales étaient les champs cultivés, les forèts serrant aux "patturages, les mines(1)."

Par suite, le domaine s'accrut successivement et rapidement avec la défaite et la ruine de tous les petits peuples qui entouraient Rome, puis avec celles des Samnites, des Campaniens, des Grecs, des Cisalpins. Les usurpations continuèrent et avec elles se développèrent les grandes terres sénatoriales. Les luttes et les lois agraires n'ont pas eu d'autre cause. Les usurpations de la terre par les grands propriétaires romains se sont rencuvelées à la fin de l'Empire romain et pendant toute l'époque féodale et, en Angleterre, au xwme siècle. Ces usurpations forment l'un des chapitres les plus curieux de lhistoire de Rome. Elles ont été l'une des causes des conquêtes du peuple romain, de mème qu'en Angleterre elles expliquent, en partie, les immenses colonisations de lingleterre. Les aristocraties rurales font les grandes races, les déınocraties rurales les réduisent en poussière (2).

Aussi les lois agraires n'enrayèrent pas le mouvement. La perpétuité de la guerre accablait les petits propriétaires romains; elle les contraignait à vendre leurs propriétes; ceux qui résistaient étaient lorcés de se retirer par la baisse du prix des céréales et la conversion des terres à blé de l'Italie en prairies. La baisse des céréales était provoquée par l'augmentation de la prorluction en Sicile, en Afrique, en Sardaigne et par l'apport sur les marchés des blés que les peuples vaincus devaient livrer gratuitement ou au-dessous du prix de revient, à titre de tribut. Les petits propriétaires, si nombreux en Italie, ne purent lutter longtemps. Ils devinrent des prolétaires, mais impuissants devant la force et l'extension de l'Empire. Alors commença la longue décardence de l'Italie, ruinée par le peuple romain; cette déca-

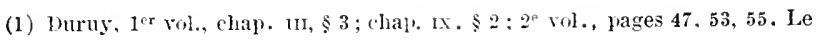
Sénat permit aux fermiers des biens donaniaux the ne pas payer les dimes et de convertir ainsi des terres publiques en terres jrivées.

(2) Sur le domaine et les lois agraires Humbert, 1 ${ }^{\text {er }}$ vol.. 28, 95, 204, 275. Article, Ager publicus, Dict. Daremberg, et Marquardt, 310. 
dence a duré douze siècles. Elle ne rendit que plus inéxorable laristocratie romaine pour conquérir le monde. L'aristocratie anglaise a montré la mòme persistance contre la France de Louis XIV, de la République et de Xapoléon. La conquète procura les tributs avec lesifuels l'aristocratie romaine put, pour un temps, faire face à la crise.

C'est un moment très-curieux et tres-imprtant dans l'histoire économique de l'Europe, offrant des points de comparaison frappants arec les temps actuels. La politique de laristocratie romaine, en annexant des noureaux territoires a Fome ou seulement en les placant sous son influence, provorpe un accroissement énorme de la production descéréales. Cet accroissement accable les prix en Italie.

De mème, les colonisations anglaises font ten ce moment et feront désormais une concurrence redoutable aux céréales de l'Europe et mème à tous ses produits.

\$ 6. De lie transformution de la eulture et de la propritete fonciere en Itulie.

La conquète de l'Italie arait été une ceurre longue, laborieuse, pénible. Les Sabins, les Latins, les Étrusques, les Samnites opposèrent une résistance désespérée. Il n’y a pas eu de guerres plus héroïques. L'Italie fut dérastée, depeuplée. Les guerres puniques, surtout celle d'Annibal, achevèrent la ruine de I'Italie; elle ne s'est relevée quaprès les invasions des Arabes 1 . Les colonies romaines enrayèrent cette décadence sans l'arrèter. Le Latium est devenu désert 2 , et malsain dès cette époque. La guerre a détruit la petite culture. Il faut lire dans Tite-Lire le discours du centurion Sp. Ligustinus; son père lui a laissé un arpent; de son mariagre sont nés six fils et deux filles. Il a servi trois ans en Macédoine, un an contre Antiochus et l'Étolie, deux ans en Espagne. Il est centurion après $\mathbf{2} \mathbf{2}$ ans de services.

(1) Tite-Livre. L. Xll1. chap. xxxiv.

(2) Sur les Arabes en Italie, consultr Leudimant, framte frice, t. 2 et 3. 
Combien n'ont eu ni ses vertus, ni sa chance et ont dù vendre leur arpent $(1)$ ?

La petite culture a disparu avec la population.

La guerre n’a pas été la seule cause de ce grand changement dont l'Italie porte encore et portera probablement toujours les traces; la conquète romaine eùt pour conséquence un trèsgrand développement de la culture des céréales - spécialement du froment en Sicile, en Afrique, en Sardaigne. Ces blés vin-rent faire une concurrence redoutable aux blés italiens à un double point de vue - d'abord sur le marché libre (2), ensuite comme prestations en nature des peuples vaincus. L'État eut des masses de blés à vendre; il les rendit au-dessous du prix de revient de la culture. Les intérèts de l'alimentation de la population de Rome primérent tous les autres.

Les grands propriélaires romains ne furent pas étrangers à cette extension de la culture des céréales aux alentours de l'Italie, de mème que ce sont les Landlords anglais quj, pour une bonne partie, exploitent sur une vaste échelle la culture du blé dans le Manitoba, dans le Minnesota, en Australie, et dans l’lnde. Téanmoins cette extension de la culture du blé eut alors, comme aujourdhui, un caractère plus grénéral. Elle se proluisit sous l'intluence de causes diverses; les événements agronomiques sont, à bien des égards, indépendants des événements politiques. Cette culture des céréales résulta à la fuis de l'esprit d'entreprise, des spéculations de l'aristocratie romaine et du développement normal de l'agriculture dans certaines parties du bassin de la Méditerranée.

Les exigences du service militaire, la baisse des prix des céréales, l'envahissement des communaux de l'ager publicus contraignirent les petits el les moyens propriétaires à abandonner leurs anciens héritages; quand ils persistaient à les

(1) Aut innumerabilem multitndinem liberorum sapitum in eis fuisse locis !tua nunc, via seminario exiguo militum relicto, servitia romana ab solitudine vindicat. - Tite-Live.

(2) M. Boissiere (Algśrie romaine, page 49) a clairement expliqué cette concurrence et ses effets. 
sarder, les grands propriétaires ne reculaient devant aucun moven de fraude, la violence, les poursuites en justice pour les en expulser. Ils étaient encouragés ì s'en défaire par l'attrait qu'exerçait sur eux la vie politique à Rome, la participation à cette existence agitée qui n'était pas sans rapport avec celle du eitoyen d'Athènes (1).

Si les citoyens romains étaient traités aussi durement, quel sort pouvait ètre réservé aux propriétaires étrusques, latins, samnites, pour la part qu'ils avaient conservée? Leur condition était telle qu'ils devaient vendre avec empressement ce qu'on ne leur avait pas pris, pour se réfugier soit dans les petites villes de l'Italie, soit à Rome, où seulement une sorte de sécurité était à espérer.

La conquète romaine a été un tléau terrible partout, mais spécialement pour l'Italie. La Gaule, l'Espagne, l’Afrique du Nord, les prorinces danubiennes ont pu, dans certaines limites, profiter de la conquête romaine; l'Italie n'a eu qu'à en souffrir: "Nous avons abandonné le soin de nos terres aux derniers de " nos esclaves, écrivait deux siècles plus tard Columelle; aussi "les traitent-ils en vrais bourreaux. Dans le Latium, il nous "faut, pour éviter la famine, tirer le blé de pays situés au delà "des mers." De Re Rustica, ( $111-3)$.

C'est ainsi que se sont constitué les Latifundia. Ils existent encore dans certaines parties de l'Italie. Lenormant en a visité et décrit plusieurs remontant probablement à l'époque romaine (2).

Un double changement se produisit alors dans la condition économique et dans la condition sociale de l'Italie. La prairie remplaça la culture des céréales et le travail servile remplaça le travail libre.

Ce mouvement fut d'autant plus rapide que les populations, vaincues ou alliées, avaient été privées d'une partie de leur territoire; que cette partie avait été annexée à l'ager publicus et

(1) En 185, selon Tite-Live, le sénat fit renvoyer dans leur pays jlus de 12,000 latins. Dix an-après, nuwvelles plaintes des magistrats du Latium, le pays est abandonné. - Dureau de La Malle, $2^{2}$ vol., 372.

(2) Lenormant, La Grande Gréce, t. 1, 174.179 et E. Fournier de Flaix, Réforme de l'impôt, $1^{\mathrm{er}}$ vol., 314. 
que l'aristocratie romaine disposait complètement de la gestion des terres de l'ayer publicus, si mème elle ne s'en attribuait pas la propriété. "Les citoyens riches, dit Appien, accaparèrent la " plus grande partie de ces terres incultes et, à la longue, ils s'en "resardèrent comme les propriétaires incommutabies. Ils acqui"rent, de gré ou de force, les propriétés des paurres qui les " avoisinaient. Les terres et les troupeaux furent remis à des " mains esclares. Les esclaves, n’étant pas appelés à porter les "armes. multipliaient à l'aise; des hommes libres étaient sou"vent éloiønés par le service militaire. Il résulta de toutes ces " circonstances que les grands devinrent très-riches et que la "population des esclares fit dans les campagnes beaucoup de "progres, tandis que celle des hommes libres allait diminuant "par suite du malaise, des impòts et du serrice militaire qui les " accablaient (1)."

De là d"immenses souffrances. Ces incomparables légionnaires, qui ont lirré le monde à l'aristocratie romaine, ne revenaient au foger domestique que pour y trouver la misère et la faim. Ils reprenaient du service : la gruerre entretenait la guerre. "Les bètes "saurarres qui sont répandues dans l"Italie ont leurs tannières " et leurs repaires oủ elles peurent se retirer, et ceux qui com"battent, qui versent leur sangr pour la défense de i’ltalie n’y "ont à eux que la lumière et l'air qu ils respirent; ils errent de " tous cités arec leurs femmes et leurs enfants. Les généraux "les trompent quand ils les exhortent à combattre pour leurs "tombeaux et pour leurs temples. En est-il un seul, dans un si "grand nombre, qui ait un autel domestique et un tombeau où " reposent ses ancètres; on les appelle les maitres du monde et "ils nont pas une motte de terre $(2, n$. Les Ergastula remplacèrent les petits propriétaires ruinés.

(1) Pasage trainit $1^{\circ}$ Michelet (Histoire romaine, $2^{\circ}$ rol.. 145). Pline parle clun esclare affranchi qui lostedait en Italie 3,0010 paires de brenfs, 150,000 têtes de petit betail et 4,416 esclaves; sauf les esclares, cest la conlition des Rauchos du Texas ou des montaqnes Rocheuses. Ainsi l'Italie était ramenée au point de départ de la culture. La Mésopotamie a éprouvè le mème sort: elle n'a pu encore se relever.

(2) Fragment d'un discours le Tiberius Gracchus, traduit yar Michelet, $2^{\mathrm{e}}$ vol., 163 . 
Tibérius et Caïus Gracchus essayèrent de faire face ì une situation aussi terrible. Ils ont échoué. Il y avait en présence trop d'éléments contradictoires. La dépopulation de l'Italie, la concurrence des blés étrangers, la culture par esclaves, la haine des Italiens contre Rome, leur risolution de prendre part a son gouvernement, étaient des faits d'ordre supérieur quill n'était possible à personne de maitriser.

Il en est de l'aristocratie romaine comme de l'aristocratie anglaise. Son aurre est sortie du génie même du peuple romain, de mème que la puissance du peuple anglais se manifeste surtout dans son aristocratie. Les grandes familles anglaises sont entourées dans tout l'Empire britannique d'un véritable respect et d'une sorte d'auréole de popularité (1). 1 l en était de mème ì Rome. Longtemps après que la forme du gouvernement, les institutions, les inlluences politiques et sociales eurent été changées, Jes vieilles familles romaines les Claudius, les Cornelius, les Lentulus, les Marcellus conserverent leur prestige. Saint Jéròme considérait comme un honneur de donner asile à sainte Marcelle et à sainte Paule 2 .

L'aristocratie anglaise s'est constituée 20 siècles après l'aristocratio romaine, dans un milieu supérieur, dans des temps plus favorables. Elle a doté l'Angleterre d'institutions plus durables, plus libérales; la pression qu'elle a exercée autour d'elle a étí moins dure, moins égoïste; elle s'est montrée plus sage dans ses jouissances, plus large dans ses vues; elle a assuré au peuple anglais un tout autre avenir que celui préparé au peuple romain par l'aristocratie romaine; elle a renoncé à l'esclavage dans les colonies; elle a donné la paix à l'Inde tout en l'exploitant (l'aristocratie romaine n'a jamais amélioré la condition d'aucun peuple); elle a farorisé, autant qu'elle l'a pu, le grand mouvement d'industrie, de commerce, de colonisation de l'Angleterre; elle I a retrempé ses forces. Tout en formant, conservant et resserrant son monopole foncier, elle a tout fait pour

(1) Dureau he La Malle, $2^{e}$ vol., 1 is $7,53,93,130,245,270-280$.

(2) Fustel de Coulanges. Le peuple a vait autant de respect prur les nobles que des nobles avaient d'orgueil vis-ù-vis du leuple, 235 , Institutions anciennes de la France. 
le rendre le moins oppressif qu'il lui a été possible. Ainsi, elle a cédé sur la question des céréales, après une lutte acharnée; mais elle a cédé sans retour; elle a renoncé, après avoir accaparé le sol, à continuer (ce qu'elle a fait pendant un siècle), d"imposer à la nation l'achat de ses produits à prix fixe; $c \in$ qui faisait double monopole. L'aristocratie romaine à supprimé la culture des céréales et exposé l'Italie à la famine. Les différences sont donc considérables.

Sous l'autres rapports, elles le sont moins, notamment en ce qui concerne l'impòt. Longtemps l'aristocratie anglaise a tout essayé pour soustraire son monopole à l'impôt, pour rejeter l'impôt sur les autres classes, tout en se réservant la plupart des fonctions rétribuées de l'État : fixité et modicité de la Landtax - son rachat - pas de taxes successorales, pas d'impòt de transmission entre-rif́s. Il en a été de mème de l'aristocratie romaine; après aroir accaparé les terres, elle a longtemps lutté pour les soustraire à l'imprit. Pendant 123 ans elle a maintenu la suppression du tributum ex censu en Italie. [Sous l'Empire, elle a concouru à l'accroissement des impôts de consommation, à l'établissement de liimpuit successoral - la transmission en ligne directe exceptée, - elle a réduit souvent les empereurs à la nécessité des confiscations; elle a peu à peu propagé la pratique de l'immunité et préparé le grand mouvement d'idées qui derait aboutir à ce singrulier et douloureux axiome, si admirablement mis en scène par Voltaire, que l'impôt est à la charge du pauvre et que le riche, par honneur mème, en est exempt (1).

Nous ne sommes pas encore arrivés, dans la longue évolution historique de l'impòt, à cette transformation si curieuse qui signale un déshonneur dans le paiement de l'impôt. Cette évolution remonte à l'aristocratie romaine et au temps de sa prépondérance.

(1) Théofie de l'impút, par M. E. Fournier de Flaix, 1er vol., page 225. 


\section{: . Les lois frumentaires.}

Ces lois sont dues à Tibérius et à Caïus Gracchus. Ce sont des lois absolument romaines, c'est la compensation donnée au légion naire ou au propriétaire ruinés. Le peuple romain était le véritable souverain. La souveraineté est le fondement des lois frumentaires. Au surplus, le Spartiate et le citoyen libre d'Athènes étaient entretenus aux frais de l'ítat. La loi frumentaire constitue une liste civile, la liste civile du peuple romain. Caius Grarchus fit décider que tout citoyen romain recerrait le modius (13 livres 1/2) de blé à raison de $3 / 6$ d'as, c’est-à-dire au-dessous du cours. L'allocation annuelle était de ä modii par mois. En ös, la loi Clodia supprima tout prix. La distribution devint gratuite. Sur tó0,000 citoyens romains du temps de César, 320,000 prenaient part aux distributions. Il les ramena à 1300,000 . Dès Auguste, il fallut les relever à 200,000. Les maitres pauvres en vinrent à affranchir leurs esclaves pour qu'ils pussent prendre part aux distributions. On remettait une plaque (tessera) à tout citoyen admis. Toutefois, les citogens dont le cens s'élevait à ‘00,000 sesterces (le sesterce valait 0,22 à la fin de la République) n’étaient pas inscrits. Ce fait suffit pour prouver que la loi frumentaire avait d'autres fondements que la paurreté. M. Marquardt a calculé qu'en 73 avant l’ère chrétienne, la dépense s'éleva à 10 millions de sesterces et à $\breve{7}, 600,000$ sesterces en 46 . II fallut créer une grande administration, celle de l'Annona; construire des magasins, des greniers, entretenir une flotte, de nombreux employés (1).

L'aristocratie anglaise a dù en faire autant au moyen des proor laus; mais c'était elle qui payait. A Rome, c'étaient les peuples vaincus, les tributaires. La plus grande partie des blés, et plus tard, les autres provisions nécessaires à l'annona venaient de l'Égypte, de l'Afrique, de la Sicile, de la Sardaigne contraintes de les fournir à titre de dime frumentum decuma-

(1) Articles Annona et Frumentaria leges. - De M. Humbert, Dictiomaire

Daremberg, Wartuarit, ibifom, 138 et Hureau de La Valle, livre 4, chap. 12. 
num), ou de réquisition (frumentum imperutum), ou d'achat (rmtum) et à prix réduit. En réalité l'annona représentait la part du peuple de Rome dans la conquète, dans la victoire; l'aristocratie arait pris les terres, au peuple les tributs et le pain. L'annona s'est maintenue jusqu'à la fin de l'Empire et a eté l'une des causes de sa chute; car il constituait une lourde charge pour les parties de l'Empire qui devaient $\mathrm{y}$ faire face.

L'effet le plus certain de ces charges, sous la République, fut de priver les peuples conquis des ressources nécessaires à leurs propres affaires. De là des résistances insurmontables. La Judée ne se soumit jamais; l'Éç̣te resta frémissante et devint un tel pays d'ardente opposition que le Christianisme et le Mahométisme y ont trouvé un concours efficace; la Grèce continua à se dépeupler el à sappaurrir. Pendant quelque temps, Rome parut senrichir et croitre, mais la décadence au contraire s'accentua en Italie; Rome ne jut bientât s'y soustraire. La maitresse du monde devint une ville entourée d'un octroi; par compensation tout citogen romain is Riome, puis dans tout l'Empire, nayant pas 400,000 sesterces, fut nourri gratuitement. Les leuples conquis entretipnnent le peuple romain du plus pur de leur moelle; ils paient, en outre, limpit direct; ils paient les droits de doune, les péares, les corvées, ou prestations; ils remplissent l'aruium Qu'avaient-ils à perdre à la ehute de la République romaine?

Les lois frumentaires du peuple romain ne sont pas assez connues. Elles méritent une très-sérieuse attention; car c'est vers des lois analogues, bien que pour des causes différentes, que semblent se mouroir les sociétés contemporaines. Entretenir certaines classes de la société, au moven de l'impòt, aux dépens des autres. Des lois exagérées sur l'assistance publique, sur les retraites obligatoires, sur la responsabilité des aceidents du travail, la suppression de la faute pour le travailleur, tout risque au compte du patron, la limitation factice du temps du travail, des coalitions syndicataires restrictives de la production, des garanties du taux des salaires, des corporations d'ouvriers d'État, des séries de prix ou tarifs constituant des privilèges, tout cela conduira fatalement à des lois frumentaires; tout cela 
est basé sur le principe le l'entretien llune fraction des citogens par les autres. A Paris, l'assistance publique est une vaste administration, déjà insuffisante, donnant une certaine idée de l'Annona (1).

\section{s. Desadence de l'Italie.}

La longue décadence de I’ltalie, à partir de la conquète de la Macédoine, de la Grèce et de la destruction de Carthage, époque de la grande splendeur de Fome et du plus grand déplosement du caractère romain, après la véritable conquite de l'Europe civilisèe du temps, et avant les terribles guerres sociales, est l'un des faits les plus curieux et les plus importants de l'histoire de la civilisation (2). Cette lécadence s'est prolongée pendant 1200 ans. Dès le temps de Charlemagne, malgré les invasions, Goths, Ostrogoths, Huns, Vandales, Lombards, Sarrasins, l'Italie se relève lentement pour arriver à la belle époque des Républiques du Moven ige et, peu à peu, s’élever à une population de 31 millions d'habitants arec une émigration considérable; c'està-dire à près de 6 fois sa population du temps de la Rípublique romaine. Le facteur principal de cette décadence a été la suprématie de Rome, la guerre implacable faite à tous les peuples de l'Italie, leur asservissement, leur spoliation, leur ruine, la confiscation de leurs terres, au protit du peuple romain c'est-à-dire des famiiles sénatoriales, la constitution de crandes terres dont

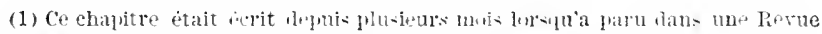

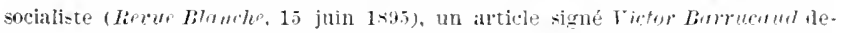

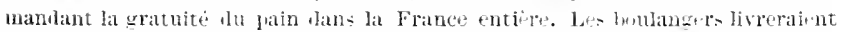

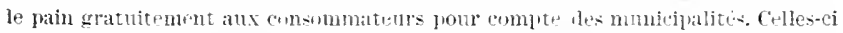

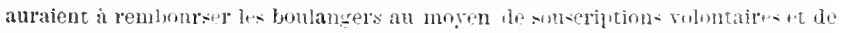

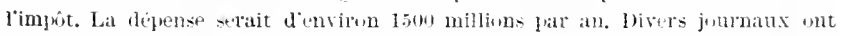

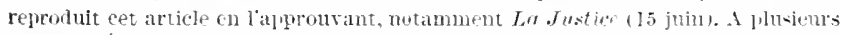

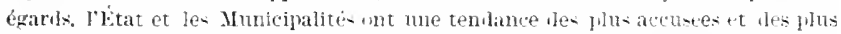
dangereuses a dévelophne la gratuite : enseign ment gratuit, a-mistance gratuite, baims gratuits, spectack gratuits. alimentatim destents gratuite. Plusieurs deputes suchaliotes ont fat savoj que la prowsition de la gratuite du pain serait

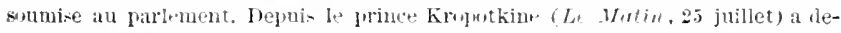
nambe le logement gratuit.

(2) Cette belle question vient lletre trateje par M. Vanlate. Lo dipupulation

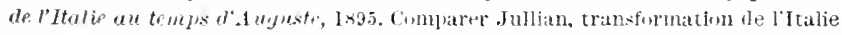

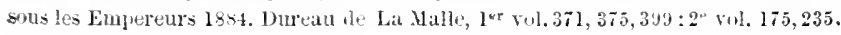


quelques-unes existent encore, les transformations de la culture, la substitution du travail servile au travail libre, les guerres sociales pour obtenir l'égalité civile, les guerres civiles qui se prolongent, jusque sous les Flaviens et qui achèvent la désolation de l'Italie. A ces diverses causes, il faut en ajouter une autre d'une nature différente et à laquelle l'Italie n'aurait pu échapper : la mise en culture de nouveaux territoires, en Europe et en Afrique correspondant à la mise en culture actuelle des ÉtatsUnis, des territoires du Brésil et de la Plata, de l'Afrique australe et de l'Australasie. L'Europe entière se trouve placée aujourd'hui dans les mèmes conditions que l'Italie il y a 22 siècles. Elle est également exposée à de grandes épreuves (1).

(1) Maryuarit, Orgunisation te VEmpire, 1 rol. Banker"s, Magasine de NewYork, anit 1s87. Dureau de La Malle, 2e vol. 175-235. 


\section{CHAPITRE III.}

DES INSTITUTIONS FISCALES DE L'EMPIRE ROMAIN DEPUIS AUGCSTE JUSQU'A DIOCLÉTIEN ET CONSTANTIN.

\section{s 1. Le gouvernement imperial et ses finances.}

La constitution de l'Empire et la paix générale avaient pour. condition essentielle une politique fiscale nourelle. Auguste a inauguré cette politique, mais elle n'a produit tous ses effets, elle ne s'est traduite dans des institutions fiscales spéciales que plus tard. Ces institutions tiennent une place de premier ordre dans l'bistoire de l'impòt.

Auguste eut aussi à pourroir à l'administration des finances, désorganisée pendant les guerres civiles. César s'était emparé par force de l'ararium; il en avait livré toutes les réserves à ses légions. L'or fut jeté de tous còtess, si bien qu une crise monétaire éclata. Le rapport de l'or à l'argent tomba de 11 à 8,93.

Pendant longtemps le gouvernement impérial a dù subir l'intluence des souvenirs, des idées, des lois de l'époque républicaine. Jusqu'aux derniers jours de l'empire, les consuls ont été renourelés chaque année; le Sénat a conservé une autorité d'abord considérable, puis restreinte à Rome mème. Le gouvernement impérial, d'Auguste à Dioclétien, a porté la marque de cette situation : il a été transactionnel. Auguste maintint au Sénat, sous le contròle et la surveillance de l'Empereur, l'administration des finances. Le Sénat l'a conservée à peu près jusqu'ì Dioclétien. C'est une des plus sages mesures d'Auguste. C'est au Sénat qu'étaient portées et discutées toutes les questions d'impòt. De nombreux textes de Tacite et des auteurs de l'histoire Augustale en font foi. L'ararium demeura au temple de Saturne; il fut encore administré par le Sénat; tous les impùts, les ressources diverses continuèrent à y ètre centralisés; néanmoins par la force même des choses, il devint peu à peu moins important. D'un autre còté, l'Empereur 
eut à organiser la gestion de la maison impériale : le Fiscus reparut. Il était destiné à remplacer l'xrurium. Auguste plaça à cité des quæstores xururii agents du Sénat, les prefecti impériaux. Quxstores et præfecti ne purent jamais s'entendre et au $1^{\circ}$ siècle les quxstores disparurent.

Arec Auguste s'ourre l'ère des grandes administrations permanentes que l'Empire romain a léguées aux sociétés de l'Europe moderne. Pendant la période républicaine le fonctionnaire avait été temporaire, de mème quaux États-Lnnis aujourd"hui. Si les institutions républicaines s"implantent en Europe, it rederiendra temporaire. Or, il est difficile de pratiquer un sı̌stème d'impôt, cumplexe et fixe, arec des fonctionnaires temporaires; sous la République, le procès de Verrès le prouve, la surveillance et le contrulerles fonctionnaires ne puraient s'exercer. Cela dut changer avec l'Empire.

\section{S. 2. Des réformes fiscales d'Auguste.}

Auguste eut à opter entre deux politiques fiscales. Mécène, son grand conseiller 1), l'aurait engąré, d'après Dion Cassius, à rendre toutes les terres du domaine public, à constituer arec le produit des rentes une banque puissante. un Crédit foncier romain, qui aurait arancé des capitaus aux proprietaires, en vue d'accroitre la production agricole et de tempérer la crise économique, résultat des guerres ciriles, et à soumettre tous les sujets libres de l'Empire au mème impòt, d'après des éraluations précises - une sorte de raste income-tax - en fractionnant le recourrement de l"impit en de nombreux termes. Il a fallu ringt siècies pour réaliser une partie des hautes rues de Mécène. Elles derançaient les temps. Auguste se contenta de réorşaniser et de compléter les anciens impüts.

\section{S 3. Du recensement générul sous Auguste.}

La première opération d'Aug̣uste fut un recensement géuéral des ressources de l'Empire 27 . C'est ce qu'aurait dú faire l'As-

(1) Dureau de La Malle, $1^{\text {er }}$ rol., 331. Voir à lappendice, le résumé des plans de Yrione.

1:) Iliditil, 195-199. 
semblée constituante en 1789 et l'Assemblée nationale en $18 \% 1$; cette seule mesure montre, mieux que tout, la puissance de l'Empire et la portée de lintelligence d'Auguste. Auguste composa lui-mème plus tard un abrégé de recensement. Il l'avait toujours sous la main: Breviurium totius imperii. Les Américains du Nord possèdent seuls un recensement analogue et ils le renouvellent tous les dix ans. Celui de 1890 leur coǹtera au moins כ̋0 millions de francs. Les famitles, les fortunes, les impôts, les armées, les recettes et les dépenses étaient spécifiés en détail. On ignore si le recensement a été simullané dans tout l'Empire ou successif par province. Il est fait, au recensement opéré en Syrie, une allusion formelle dans Josèphe et dans l'évangile de saint Luc. Tous les Juifs se rendent à leur domicile (Suum civitutem) pour ètre recensés. Le recensement avait un double but : connaitre l'état général de l'Empire, faciliter le recouvrement des impits.

En Italie, le Tributum ex censu avait été exigé de nouveau en 43 avant l'ère chrétienne. On n'a pu établir qüll ait été maintenu sous l'Empire. Il n’y arait pas dautre impoit direct ou foncier en ltalie. Dans les provinces la situation était inextricable. On y rencontrait : $1^{\circ}$ les Etats ou les villes, exemptés du tribut envers Rome; $2^{\circ}$ les domaines particuliers, également exempts; $3^{\circ}$ les domaines appartenant aux citoyens romains; $4^{\circ}$ les Etats ou provinces soumis à un tribut fixe, tels que les Gaules; $5^{\circ}$ les États ou provinces, comme la Sicile ou l'Éggpte, où le peuple romain avait complètement pris la place de l'ancien gouvernement; $6^{\circ}$ enfin les territoires, comme celui d'Attale, légrués au peuple romain. Pour surcroît de complication, il fut fait entre Auguste et le Sénat un partage des États ou provinces.

\section{\$ 4. Les impîts directs et le Cudastre.}

En principe, le gouvernement impérial essaya d'étendre aux provinces le tributum ex censu, l'impòt romain sur le capital. Il n'y est jamais parrenu dans les mèmes conditions qu'en Italie (1). 
Jusqu'à Dioclétien, les provinces payèrent deux impöts directs : $1^{\circ}$ le tritutum per capita, principe de la capitutio humana de Dioclétien. C'est le tribut de la conquète, de mème que le bjisyé des Ilusu'mans; c'est celui auquel Jésus-Christ fait allusion en montrant le denier du cens. Il était inconnu aux citoyens romains. Saint Paul ne l'a pas payé; $\mathbf{2}^{\circ}$ le stipendium ou tributum soli, principe de la cupitatio terrena de Dioclétien. Cet impòt variait d'après les provinces. Dans les unes, il était payable en blé pour l'umona, tel était le cas de l'Égypte et de la Sicile; dans les autres, telles que les Gaules, il était payable en argent. Enfin dans quelques-unes, comme encore en Turquie, on l'acquittait partie en nature, partie en argent.

En dehors du recensement général, Auguste fit dresser par l'ingénieur Ballus un plan géométrique re l'Empire dont l'original fut déposé au Tubulturium imperii: des copies de ce plan furent remises aux colonies et aux rilles. Nous avons déjà ru qu ïl existait un cadastre pour l'Italie sous la République; il en existait aussi dans plusieurs provinces de l'Empire, notamment en Orient (Egypte, Syrie), arec des cadastres parcellaires bien tenus. Dans la levée du tributum ex censu, comme pour le stipendium, ces cadastres jouaient un rôle important, parce que l'impòt sur la propriété foncière était l'élément fiscal principal. Cet état de choses s’est maitenu jusqu'à Dioclétien.

\section{\$3. Réorganisution des impóts indirects.}

Auguste et ses successeurs rétaljirent, réorganisèrent complètement et augmentèrent les impits indirects (1).

$1^{\circ}$ Portorium. Les taxes directes (portoria), comprises sous ce nom, s'étendirent partout. Ces taxes avaient les plus grands rap. ports arec celles levées par les contributions indirectes en France.

tionnaire Daremberg (census, ararium). - Mommsen. Histoirf des Romains, t. VI, chạ. XI. - Marquardt sur le tributum cicium fiomanorum, et les lmpôts dans les provinces, $230-270$.

(1) Plnsieurs monographies inportantes, notamment celles Ie II. Cagnat, Humbert, Xaluet, donnent des rensejgnements it preu pres complets, Dureau de

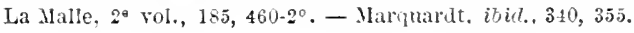


Les principales étaient surtout des droits de douane ou de péages aux frontieres de l'Empire et des grandes provinces, et d'octroi à l'entrée des villes principales. Il en était de mème en France en 1789. Pertinax les abolit; on les rétablit après sa mort. Des bureaux de perception, dont $M$. Cagrnat a dressé le tableau, étaient distribués par tout l'Empire; ils formaient un vaste réseau fiscal. Comme droits de douane, le Portorium variait d'après les objets qu'il frappait, $21 / 2$ p. 0 , 0 pour les marchandises d'usage ordinaire et $121: 2$ p. 0 (1) pour celles de luxe. Il rariait aussi selon les provinces (1), d'après la valeur déclarée et vérifiée à la perception. Il fut surélevé à l’époque de Justinien. Le droit n'était dù que sur les objets destinés au commerce lointain. On suppose que le blé, le vin, l'huile, le sel, objets de consommation ordinaire, de mème que l’or, l’argent, les armes étaient exempts. Le droit était dù à l'entrée et à la sortie. Le transit tet l’entrepòt étaient inconnus; toute marchandise, changeant de destination, se trourait exposée à acquitter des droits quadruples, septuples. Les soldats, les maitres pour leurs esclaves domestiques, certains hauts fonctionnaires, exempts. Les Pomains ont, de bonne heure, pratiqué l’immunité fiscale. La politique les y arait préparés dans la République; ils n'y ont pas renoncé sous l'Empire. Aussi l'Empereur arait-il le droit d'exempter du Portorium. Il était affermé aux publicains ce qui le rendait plus lourd.

Les péages étaient déjà des stations intérieures auxquelles certaines marchandises deraient acquitter, en outre du Portorium, un réritable droit de circulation. Il en a été de mème en Europe pendant le Moyen-àge. Le droit était dù à chaque bureau. Nul n’en était exempt. Le droit se payait sur les ponts, sur les routes, à l'entrée et à la sortie des villes.

Les octrois, qu'il ne faut pas confondre avec les póages, faisaient partie du Portorium. Ils étaient aussi affermés aux sociétés de publicains. L:Empereur les contrölait et vérifiait les tarifs. A la fin de l'Empire, les Empereurs s'attribuèren les

(1) Sicile, 5 p. 0 (1 - Gaules et Asie, 2 1/2 p. $0 / 11$ - Espagne. 2 1), 0/0. - Marquardt, ibirfm, 350 , releve six catégories de marchandises. 
deux tiers des octrois. Au surplus, il en est de mème pour l'État dans litalie actuelle.

2o Octroi de Rome. - Les changements furent si rapides pendant cette première période de l'Empire et la condition de Rome est déjà si abaissée, que dès le second siècle, Rome eut son octroi. Il fallut lui donner une organisation municipale, des finances, une caisse; cette caisse fut placée sous la surveillance du Sénat. On établit un portorium, sorte d'alcabala, sur les légumes du marché; quelques vieux romains s'indignèrent; les publicains durent se contenter de taxer, après les aroir jaugés, les rases ou corbeilles dans lesquels on les enfermait. Les publicains allèrent si loin que Narc-Aurèle lui-mème traça une ligne dans Rome en dehors de laquelle le citosen romain n'eut rien à craindre deux.

$3^{\circ}$ IIonopole du sel. - Dans les derniers temps de la République et sous l'Empire, le monopole du sel fut aggravé et le prix de rente porté si haut que Dion Cassius signale le fait comme une augmentation d'imprit. II. Cagnat a discuté l'interprétation de Dion Cassius en partant de l'idée que lorsque l'État exige un prix excessif d'une denrée de consommation nécessaire à la vie dont il s'est réservé la vente exclusive (il n'y avait de monopole de fabrication qu'en Italie), il ne faut roir dans ce fait que l'abus d'un droit domanial. Il est difficile de partager cette opinion. Le monopole du sel, comme bien dautres monopoles, notamment celui des allumettes en France, n'est qu'une forme de l'impòt, forme déguisée, afin d'en obtenir davantage (1).

\section{$\$ 6$. Impóts mixtes, de mutation et de succcssion.}

Parmi ces impôts, appelés à un si grand avenir, un seul est véritablement d'origine romaine : c'est la vicesima libertatis ou manumissionum. Nous arons indiqué plus baut la date de son établissement. Les trois autres ont été institués sous le principat d'Auguste $: 1^{\circ}$ La centesima rerum renalium; $2^{\circ}$ la quinta

(1) Marquarit, ibidem. 
et vicesima venalium mancipiorum; 3 " la cicesima herelitatium: Auguste parait avoir importé ces trois impoits d'Égypte.

I. Vicesima libertatis. - Il était supporté en grande partie par les esclaves. Caracalla le porta au touble. Macrin le remit à l'ancien taux. Il disparut avec Dioclélien, ce qui tend à prouver que le nombre des esclaves et celui des affranchissements avaient dès lors beaucoup diminué. En 209, a. J.-C., cet impôt avait produit 4.000 livres d'or, évaluées par Dureau de La Malle à $4,496,200 \mathrm{fr}$.

II. Centesima rerum venalium. - Véritable droit de mutation entre-vifs sur les objets vendus a l'encan (auctiones). Sur les instances de la population de Rome, encore rebelle a l'impót, Tibère le réduisit de moitié. Caligula le supprima. Le Sénat fit frapper une mérlaille pour perpétuer cet acte mémorable. Il ne tarda pas à ètre rétabli. D'après Serrignny et Dureau de La Malle, il aurait eu un carictère plus général; il aurait été levé sur tous les objets vendus dans les foires et marchés. Ce qui explique les réclamations des populations. En ce cas, il n’aurait été que l'impòt égrptien du mème ordre, origrine de l'Alcabala arabe et espagnol. Les Espagnols l'ont porté avec eux dans l'Amérique du Sud (1),

III. (uuinta et vicesima venalium mancipiorum. - Taxe de 4 p. $0 / 0$ sur la vente des esclaves : elle devait ètre acquittée par les acquéreurs. Néron la mit à la charge res marchands. Ce changement coustaté par Tacite $(\boldsymbol{2})$, nous a valu l'avantage de connaitre lopinion du grand historien romain en fait d'incidence d'impôt. "Vectigal quoque quintor et vicesimat venalium mancipiorum remissum specie magis quam vi, quum venditor pendere juberetur, in partem pretii emptoribus accrescebat ". M. Cagnat se range à l'opinion de Tacite. "La réforme de Néron, resta, dit-il, sans effet pour les acheteurs; ce furent eux qui continuèrent à payer un droit de '́ p. 0,0 à l'ĺtat ". Le cas est curieux, mais ce qui est le plus à noter dans l'histoire des théories sur

(1) Marquardt pense que le droit le $1 \mathrm{p}$. o/u citait dú sur tous les achats et qu'il domnait une forte somme, ibiitr $m, 351$.

(2) Ariculs, live XIII, chap. 31. 
l'impit, c'est l'opinion de Tacite, reflet de celle de son temps; on admettait à lépoque de Tacite que les droits de transmission restaient pour compte de l'acquéreur - système accepté par M. Cagnat - lorsqu'aujourd'hui prévaut partout lidée qu"ils demeurent au compte du vendeur. La théorie actuelle n'est plus la théorie romaine. Théorie pour théorie, il est souvent délicat, sourent difficile de prendre parti $(t)$.

IV. ricesimu herenlitutium. - c'est la grande réforme fiscale d'Auruste 2 . Elle arait un but financier et un but social; elle devait procurer les ressources pour l'entretien des armées; elle était une compensation aux arantages des citoyens romains, notamment aux cliarges de la loj Frumentaire; elle atteignait surtout la haute aristocratie romaine; elle l'obligreait à restituer peu à peu ce qu'elle arait pris; elle ne portait pas sur les patrimoines en ligne directe; elle épargnait les héritages paurres; elle réalisait ainsi plusieurs des progrès que les sociétés contemporaines n'ont ohtenus que tard ou qüincomplètement.

Quelques détails sur cette réforme sont donc nécessaires, car les taxes successorales occupent une place de plus en plus grande dans les budgets des Etats et paraissent appelées, pour bien des raisons, à en prendre une plus grande encore; plles possèdent pour nos sociétés si complètes ou tant d'intérêts opposés sont en présence, l'avantage de ne se prêter à aucune répercusion. Elles frapent le capital à un moment farorable. Leur perception peut ètre facilitée, comme en Angleterre, par une graduation préroyante et des facilités de paiement.

Octave et Antoine, au plus fort de la lutte contre les fils de Pompée (3 , avaient rendu un édit portant que les transmissions

(1) Cignat, Ibid., 1. 227-233.

(2) Cagnat. Ibid., 1) 175-217, tri-curienx travail. - Marquardt, 311.

(3) A-t-il existé un impôt sur les suecesions daus les deux derniers siécles de la litpub'ifue. en vertu de la loi Voconia, comme le dit Pline le Jeune? La fue-tion est tres-conturerse. Cicerm, dans le passage célabre de ses lettres, oủ il dit que depuis les réfurmes du tribun Métellus, il n'existe plus à Rome que la Vicesima Libertatis, sem!le formellement contredire Pline. M. Cagnat se prononce jour la negative. Dureau de La Malle jour l'affirmative, 2e vol. $471,1^{\text {er }}$ rol. 324. 
testamentaires donneraient lieu à une part au profit de l'ararium. Le peuple s'étant soulevé, l'édit fut rapporté. Mais en l'an 5 de l'ère chrétienne, Auguste ayant fondé l'xrrtrium militaire, chargé de servir une pension de retraite aux lécionnaires, il fallut réunir des ressources. Auguste promit une contribution personnelle et annuelle de 170 (1) millions de sesterces. Puis il engagea le Sénat à étudier le moyen de parfaire les fonds nécessaires; quant à lui, il proposa une taxe du $20^{\text {e }}$ sur les successions et les legs testamentaires. Les sénateurs et le peuple se montrèrent consternés. Auguste répondit qu il faurlrait alors soumettre les biens fonciers à un droit sur les maisons et fonds de terre. Le Sénat courba la tète; la loi Julia fut acceptée. Cette loi disposait: $1^{\circ}$ que les successions ou legs aux parents proches ou paurres ne devaient pas la taxe pourru que les ayants-droit ne fussent pas citoyens romains au jour de la promulgation de la loi; $2^{\circ}$ qu'elle serait due seulement par les citoyens romains pour leurs biens meubles et immeubles. Trajan admit tous les citoyens romains à invoquer la proche parenté ou la paureté; on estime que le minimum devait être 100,000 sesterces. La loi anglaise, plus large que la loi fravesaise, a admis aussi la limitation.

Cette loi importante reçut divers remaniements. Caracalla porta le taux au double et accorda le droit de cité à tous les habitants libres de l'Empire. Il atteignait ainsi toutes les successions. Cet excès produisit une réaction; Macrin rétablit l'ancien taux. Dès l'époque de Dioclétien, on ne rencontre plus de trace de cet impót. II fut d'abord affermé, puis recourré directement par des procurateurs spéciaux. Ml. Cagnat a dressé la statistique de l'organisation arministrative de cet impöt. Les Romains, à cet égrard, n'ont laissé que peu à inventer après eux.

L'impüt devait être payé à bref délai : on déduisait les frais funéraires et les legos qui payaient leur taxe spéciale; les legs d'aliments, de pension, d'usufruit étaient évalués d'après des tables de mortalité où la vie moyenne (des classes riches) était calculée à trente ans. Les dettes étaient défalquées.

(1) Dureau de La Malle, ibiam, ze vol.. page 132. Voir a lappentice la discussion de cette somme de $170 \mathrm{~m}$. sesterces $(42,500,000 \mathrm{fr}$.$) .$ 


\section{$\$$ T. Prestations.}

Les prestations (Functiones) remontaient fort loin; elles tenaient au mode de paiement de l’impùt, à celui de rétribuer les fonctionnaires, aux nécessités militaires, à la politique même de Rome. L'État, non seulement devait nourrir les soldats, mais il fournissait aux officiers et aux magistrats : blé, vin, huile, viande, bois, chevaux, mulels, tentes, vaisselle, sel et jusqu'à des cuisiniers. De là des réquisitions qui se régularisèrent et se convertirent en prestations. Leur importance fiscale, aux derniers jours de l'Empire, devint extraordinaire.

Les prestations ou corvées générales se rencontrent dans la plupart des cirilisations primitives, ainsi les Merina ou Hova les ont établies à Madagascar, et certainement elles ont beaucoup contribué à fonder leur domination et à améliorer la partie de l'iłe où ils se trouvent. Elles ont existé dans tous les anciens empires. L'usage de fournir des aliments, l'habitation, des chevaux ou des beeufs de marche aux voyageurs chez beaucoup de peuples n'est qu'une question de nécessité; c'est un degré, un pas assez avancé dans la civilisation.

Elles étaient d'après l'ordre de leur importance (1).

I. Annona species. - La plus lourde était celle qui résultait de la loi frumentaire et qui était dénommée Annona species. La loi frumentaire s'est prolongée bien au delà de la grandeur de Rome et de l'existence du véritable citoyen romain. Elle a été étendue à Constantinople; elle finit même par ètre appliquée dans toutes les villes et colonies, sans se confondre cependant avec les lois sur l'assistance privée, dues à l'initiative de Trajan. Les Édiles municipaux eurent le soin de l'Annona. L'extension de la loi correspondit naturellement à celle du droit de cité, au titre de citọen romain. Le temps vint où il fallut nourrir presque toute

(1) X. Serrigny est tres complet sur les 1nestations, 2e vol., page 200. Dictionnare Diremberg - article Anmona - Dureatu de La Malle, 2e vol., 487.- Humbert, ibidem. 1 vol., 159, 498. Joumal des sarauts, oet. 1882, article de M. Dareste et de. Cha-sipol, Finomers des Romuins, 1740, clat. 10 it 13. 
la population. On améliora en mème temps le régime. Le pain blanc fut substitué au blé. Le citoyen dut recevoir à peu prìs le mème congiarium que le soldat, c'est-à-dire une portion de lard, de rin, d'huile, parfois de viande.

On dut agrandir les magasins, ou élever partout areu frumentaria, area olearia, arca vinaria; on organisa des collèges de marins (naciculurii) pour porter les blés, des boulangers pintores) pour faire le pain.

Les Empereurs durent se préoccuper, arant tout, de cette immense administration. En mourant, Septime Sérère laissa un approvisionnement de $\mathrm{i}$ années. La crainte de la disette était redevenue générale. L'Ég̣pte, la Sicile, l’Afrique produisajent moins; elles araient recourré une sorte d'indépendance; Rome n'était plus dans Rome; les Empereurs durent recourir au maximum plus dune fois.

L'Italie avait écliappé, pendant quelque temps, aux prestations de l'Annona; tous les territoires en deçà de 100 milles autour de Rome y furent assujettis. C'était une véritable taxe des paurres en nature. Cette prestation derint ruineuse; Maximien la rendit plus accablante en la proportionnant au cens.

II. Comparatio publica. - Autre prestation extraordinaire destinée à pourvoir aux besoins des armées : les propriétaires devaient fournir le congiurium complet : pain, rin, riande, huile, vinaigre, ları, vètements, bois, fourrages. Certaines provinces donnaient le blé, d'autres le vin ou la viande, d'autres le vètement. C'était le cas de la Thrace. Cuelques-unes payaient en argent; cette prestation s'imputait sur le trilutum soli. C'est l'une de celles qui devaient prendre le plus de déreloppement à la fin de l'Empire et au Mogen ìge. En effet, les propriétaires furent bientòt tenus à fournir le logement, à cuire le pain et le biscuit, et mème à fabriquer le matériel de guerre.

III. Aurum Coronarium. - Couronne dor que les villes et les provinces devaient envoyer à l'Empereur à son a vènement (1). C'est le don de joveux avènement. Cette prestation doit tenir à

(1) Narcluarit, itirlom, 372. 
l'intluence orientale, très çrande à Rome dès l'Empire. Le don volontaire est une des plus antiques formes de l'impòt.

IV. Aurum ablutitium. - Impòt quinquennal à la charge des sénateurs et qui arait le même caractère que l'aurum coronarium.

V. Aurum Lustrale. - Taxe spéciale due, tous les cinq ans, par les marchands, destinée à devenir l'impüt des patentes. C'est le résultat de la transformation du tributum ex censu.

VI. Aurum negotiatorium. - Taxe établie par Caligula, abolie, rétablie. Elle portait sur les valeurs engagrées dans le commerce sur les navires. Elle provient du méme mouvement d'idées que la précédente.

VII. Aurun tironicum. - Quelle ironie rlans les événements, et combien les impòts sont leur exact retlet! c'est le prix d'exonération du service militaire pour les sénateurs, les fonctionnaires et les propriétaires! C'est le renversement de la constitution romaine. Mais il faut que le changement soit encore plus complet. Il faut que les classes supérieures qui formaient le fond des armées et payaient l'impôt. s'exemptent aussi de l'impôt.

\section{s. Le clomaine.}

Arec l'Empire s'opéra dans la composition et l'administration du domaine un changement complet. L'Empereur en fut d'abord le représentant, puis comme le propriétaire. Le domaine a été l'élément principal du Fiscus impérial. Il vint mème un moment où il fut nécessaire de distinguer entre les biens du domaine mème et ceux personnels à l'Empereur qui furent confiés à l'administration spéciale des Procuratores. Cette distinction derint fondamentale arec Dioclétien et Constantin. Quant à la consistance du domaine, elle tendit à s'amoindrir parce que les conquètes, le butin de guerre $y$ eurent une moindre part. Il fut suppléé à cet amoindrissement par la confiscation, les lois caducaires sur les hérédités, l'appropriation des mines; certains États tout entiers, tels que l'Egypte, furent compris dans le domaine pricé. Toutefois les rérolutions dynastiques ruinèrent peu à peu le domaine, de mème qu'elles compromirent la 
fortune personnelle des Einpereurs (1), soumise à toutes les oscillations politiques; le mourement elfroyable et normal d'accroissement du domaine par la guerre, la spoliation, la destruction ou l'esclavage des populations, la ruine et la désolation des familles fut arrètée. Il y eut un soulagement immense dans le monde de la Méditerranée. Au lieu d’ètre une ressource, la guerre devint une lourde charge, d'abord onéreuse, puis accablante, puis désastreuse; car les races du Nord, les races du Midi se levèrent ì leur tour. A la gruerre, aux spoliations, aux massacres, elles opposìrent à leur tour la guerre, les incursions par terre, par mer, les longues courses à travers l'Europe. Et bientòt s'annoncèrent des temps aussi terribles, mais moins dévastateurs que ceux auxquels ont présidé Scipion, Panl Émile et César.

\section{\$9. L'Empire et la Sorièté romaine d'Anguste a Lioclétion.}

Le contraste entre la période républicaine de Rome et la première période de l'Empire, celle pendant laquelie dominent encore les traditions romaines, est tel, qu'on ne jeut l'expliquer que par une transformation politique et sociale complète. Pour la Rome républicaine, un seul impòt, et encore un impòt temporaire, l'impòt sur le capital des cirium Rmanorum, puis le butin, élément principal du domaine, la guerce, l'exploitation et la spoliation du monde par une aristocratie implacable, ayant à ses ordres la plus formidable des armées. Pour la Rome impériale, une série d'impòts qui ne cesse de s'enrichir et qui revèt toutes les formes arec tous les titres, mélange singulier de taxations, venant surtout de l'Orient, antique foyer de la civilisation, ainsi le don volontaire, aurum tironicum, aurum iblatitium. Arec la variété, la diversité des formes, ce qui caractérise cette série, c'est le conccurs demandé au travail, centesima renalium, aurum lustrale, aurum negotintiorum, fait absolument nouveau dans le monde romain. Toutefois le fait dominant, quant à cette

(1) On peut se faire une idie le la fortune personmelle des Empereurs par les legs d'Auguste au peuple. $43,500,000$ sesterces. 
seconde période, c'est l'ensemble des charges imposées à la propriété foncière. L'Empire lui accorde, sauf les caprices de la volonté des empereurs, très-vacillants eux-mèmes, une sécurité nouvelle, elle doit la payer; d'où pour tous les propriétaires, romains ou autres, le terrible poids de prestations, correspondant elles-mèmes à une très-grande extension de terres mises en culture; pour les propriétaires, non romains, les exactions ruineuses de l'amnonu spexies; et enfin la taxe successorale.

Sans doute, on rencontre tout cela, sauf la taxe successorale, à Athènes, mais Athènes est un microcosme à cưtẻ de l'Empire romain, elle $y$ est elle-m户̀me comme perdue; le fait de l'Empire, c'est de développer la culture du sol et la sécurité au moyen des itinéraires militaires, des garnisons et de l'impòt; et comme le travail est encore à peu pris servile et, en tous cas, humble, apprécié à sa valeur future seulement par des génies supérieurs, comme Aristote et saint Paul, c’est à la propriété foncière de supporter le poids de cette série nouvelle de taxations.

De là les tentatives du fisc romain pour unifier l'impòt foncier, pour le propager partout, pour mettre quelque ordre, quelque uniformité dans tous les impòts qui portent sur la terre dans les diverses parties de l'Empire. Marquardt a consacré à ces impits un des chapitres les plus importants de son livre sur lorganisation financiere chez les Romains. La dime, le stipendium, sur les biens mobiliers ou immobiliers, la capitation, souvent arec une évaluation du travail de chaque famille et de ses profits, plus un grand nombre d'impòts locaux, étaient les formes les plus répandues; il faut ajouter le très-grandes variétés dans l'application, le taux, la perception de l'impout. Rome mit la main tantòt sur la totalité de ces impòts, tantòt sur une partie; parfois elle ne demanda rien, ce qui n était pas le cas le plus ordinaire. 11 y arait des traités pour chaque État, chaque province, chaque ville, et, par suite, une infinie quantité de conditions différentes pour les unes et pour les autres. Il en a été des impòts à payer comme des territoires. Lacte de Délitio originaire, pour les vaincus, l'acte darrangement pour les alliés, Socii, plus ou moins changés, remaniés par le Sénat, servaient de fondement aux obligations fiscales. 
On apporta peu ì peu, mais sans hésiter, ni reculer, de grandes modifications à cet état de choses, en vue de tout soumettre aux mèmes règles. Avec le temps, les ehangements d'Empereurs, les ehangements économiques, les nouvelles lois, l'uniformité fit place à la diversité et l'unité prévalut. On annula les traités loeaux; on profita des divisions intérieures pour inposer la seule autorité des agents de l'Empire, appuyés partout par les grands propriétaires; partout les défenseurs attardés des idées républicaines et des intluences démoeratiques, durent s'effacer, sauf à saffilier au grand mouvement religieux qui allait demander ses comptes à la société romaine et la renverser pour tout renouveler: "u: noxis ex rebus aucti tuta et presentia quam "retera et periculosa mallent; neque procincia illum rerum sta "tum abnuebant", paroles que Tacite applique au temps d'Auguste, mais qu'on peut appliquer is la période entière qui est close par Dioclétien.

Dans le cours de cette période les impòts prirent définitivement les formes sous lesquelles nous les avons résumés. Tout sourenir républicain, démocratique, tout pacte local, tout traité disparurent et l'on peut ajouter a vee Tacite : omnes exuta xqualitate jussa Principis aspecture (1). L'époque républicaine des cirilisations greeque et romaine qui s'est ouverte vers le septième siècle A.-C., et qui a fourni une si illustre earrière, est close pour de longs siècles; tout ce qui la constitue et la rappelle s'etfondre; Thucydide, Polybe, Cicéron, Taeite font la place aux ehroniqueurs de l'histoire augrustale; les citoyens romains paient une taxe pour ne pas faire leur service militaire, mais ils vivent aux dépens de l'État, c'est-à-dire des propriétaires.

(1) Annules, lir. 1, chap. II, 


\section{CHAPITRE IV.}

DES CHANGEMENTS DANS LA SOCIÉTÉ ROMAINE ET DANS LE GOUVERTEMENT DE L'EMPIRE A L'ÉPOQUE DE DIOCLÉTIEN.

Les institutions fiscales d'Auguste, légèrement modifiées, appropriées aux nécessités des érénements, se maintinrent dans leur ensemble jusqqu'à la fin du second siècle, mais elles subirent naturellement le contre-coup des révolutions diverses qui caractérisent le $111^{\mathrm{e}}$ siècle et particulièrement de la grande crise monétaire proroquée par la misère générale, par les altérations persistantes des monnaies d'or et d'argent et par la lutte mémorable du cuirre contre l'argent. En outre, il s'ètait accompli, dans la société romaine, au point de vue économique, comme au point de vue politique, des changements considérables qui préparaient la transformation de la plupart de ses éléments; c'est la coïncidence de ces changements, contemporains et parallèles, qui donne tant d'intérèt et d'importance à cette époque dans l'histoire de la civilisation : $1^{0}$ tous les peuples méditerranéens sont soumis à la mème règle; $2^{\circ}$ les institutions monarchiques remplacent les institutions républicaines dans toute l'Europe romaine; $3^{\circ}$ l'esclavage se désorganise ê diminue; $4^{\circ}$ naissance, prédication, lutte, établissement du christianisme, religion unitaire; $~^{\circ}$ déreloppement de la culture du sol et de la propriété foncière, mise en exploitation du sol européen; $6^{\circ}$ intervention des races du Nord dans le mouvement de la civilisation européenne, préludant à la réapparition des races du Midi asiatique et africain.

\section{$\$$ 1. Changements dans le gourernement et la societe politique.}

Les idées républicaines ont définitivement disparu. On en trouverait encore quelques vestiges dans certains municipes, certaines colonies romaines qui en conserveront la tradition et 
le dépòt pendant les longrs siècles du moyen ìre, comme l'a remarqué Augustin Thierry. Dautres courants l'emportent. En sénéral, linfluence des peuples dOrient prẻvaut sur celle des peuples d'Occident. Ce fait est indépendant de la propacation du christianisme. Il tient a la supériorité de richesse et de civilisation, sous beaucoup de rapports, des peuples dOrient. Il tient aussi à ce que les traditions, les mueurs, les lois des Orientaux sont étrangères aux idées républicaines et farorables aux idées monarchiques.

D'Auguste à Dioclétien la nature du fouvernement a été mixte. Le principe héréditaire n’a pu prévaloir encore sur le principe électif. Le Sénat a conservé une notable part dans le gouvernement. L'aristocratie sénatoriale reste en scène. A la fin do $111^{\text {e }}$ siècle tout change, l'hérédité s"infiltre partout. La noblesse titrée remplace l'aristocratie politique : le citoyen romain disparait. Lne nouvelle hiérarchie sociale, inconnue jusqu'alors aux peuples d'Europe, se prépare, se constitue et développe ses classifications (1). La cour est la tîte et le cesur de toute la machine. La faveur prend la place du mérite. Un sourire de l'Empereur fait un homme d'État. Le consul en est réduit à signer les baux de lagger publicus ou du Fiscus; tous les fonctionnaires de la cour sont investis de titres en rapport avec leurs fonctions. Pour la première fois, apparait l'almanach impérial, Notitix populi Romani. Après les hauts fonctionnaires, viennent les sénateurs, les grands propriétaires, ce sont les amis ou les compagnons de l'Empereur; on les intitule illustres, clurissimi, respertabiles. Prennent ensuite rang, les propriétaires ordinaires ayant plus de 23 arpens. C'est la bourgeoisie de l'époque - l'expression ne conrient pas à la condition

(I) Tous ees chingements ont ete exposes par M. Inuly dans de- lates remarquables (tome VIl. 1) 34 et 226). Inutile dinsi-ter str leurs consequences au point de vie fiseal et financier. "Parmi c* fometions, dit ll. llaruy, les unes

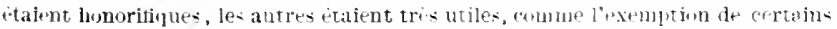

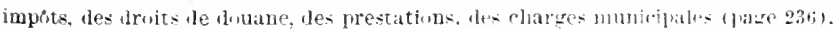

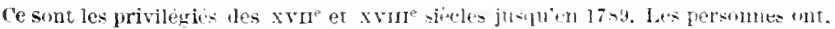

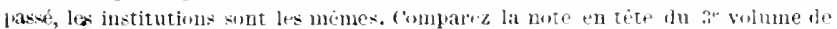

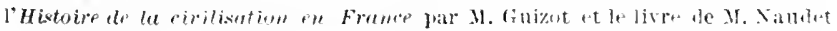

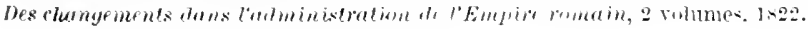


de ces propriétaires. Il vaut mieux les désigner par le nom de Curiales que l'histoire leur a donné (1). Ils représentent un élément nouveau dans le monde romain; cet élément qui s'est formé et s'est accru, sous l'empire, gràce au progrès de l'époque : fonctionnaires en retraite, officiers hors du serrice, négociants, moyens propriétaires, médecins, professeurs, artistes, affranchis enrichis, fils de famille appaurris, étrangers, en forment le fond principal. C'est une classe récente et comprenant des éléments disparates; elle est étroitement liée par ses derniers échelons avec les Humiliores. L'Humilior est l'homme déchu ou paurre qui n'avait pas 30 aurei (environ $900 \mathrm{fr}$.). MI. Duruy fait remarquer qu'avec ce tarif, près de 3 millions de Français seraient Humiliores $(\boldsymbol{2})$.

\section{\$2. Chungements duns lin condition du tracail.}

D'Auguste à Dioclétien la societé civile romaine s'est transformée. Le vieux monde gréco-latin s'est en quelıue sorte décomposé sous diverses influences; celle des civilisations plus anciennes, douées d'une forte vitalité, telles que l'Égrpte, la Perse, la Srrie, la Judée; celle des peuples plas jeunes devenus les soutiens de l'Empire, la Gaule, l'Espagne, la Thrace, l'lllyrie; celle de races plus éloignées encore qui menacent autant t’Empire par leurs incessantes infiltrations de travailleurs que par leurs guerriers, toute la Germanie, mais surtout celle d'idées nourelles et d'une nouvelle religion. A ces influences se joignent une longue paix, un gouvernement réparateur, une sorte de pacification générale. Le fait dominant est à la fois, comme tous les faits d'une haute importance, politique, social, économique; c'est la diminution de l'esclavage. L'esclavage tend à disparaitre; au ure siècle de l'ère clrétienne, il y a moins d'esclaves à Rome qu'il n'y en arait à Athènes du temps d'Aristote. Athìnes comp-

1) Burny. Ibihl., 220 et suiv., les articles ('upitutio du dietiomnaire Daremberg. - Eustel de Coulange-, Institutions pultiqus, tout le live 2 : Serrigny, 1 vol., 11. 1 : 11.245 et suivants.

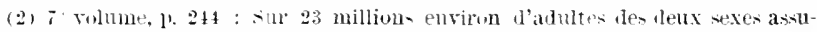

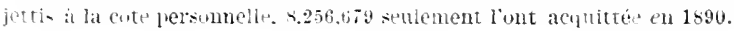




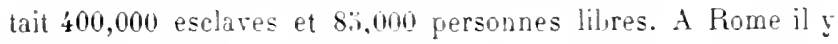
avait, arant l'Empire $\mathbf{1} 10,000$ esclares et 900,000 personnes libres. Au me siècle, l'esclavage avait encore diminué et la liberté perdu de sa valeur. Le jurisconsulte parquait avec indifférence dans la plèbe de Rome les hommes libres propter turpem quæstum ou propter paupertutem. La lilerté nétait plus rien. La fonction, la naissanc , le titre, la richesse avaient gagré tout ce quelle arait perdu. Lèpoque nouvelle est celle des affranchis. On peut dire que latfranchi caractérise l'Empire. Ce sont les affranchis qui administrent, qui gouvernent, qui font fortune; quand Dioclétien renonce à la ticesimu Libertati, c'est quelle nétait plus dans les muurs. Lopinion la condamnait comme un obstacle aux affranchissements. Les affranchis ont été l'élément principal des classes moypnnes qui se sont recrutées, dune part, au moyen des affranchis enrichis et, d'autre part, au moven des citoyens romains appauvris; appartiennent au mème mouvement les artisans réunis et surveillés dans de nombreuses corporations et associations dort tous les historiens et le Digeste indiquent lexistence au $\eta^{e}$ et au $n^{e}$ siècle, époque d'une sorte de mouvement corporatif. Les lesoins se sont étendus, diversifiés; les idées sur le travail se sont modifiees; on a été contraint à le diviser de plus en plus; on a reconnu combien le travail libre était supérieur et moins coùteux que le travail servile 1 .

Nous sommes ainsi arrivés à une des époques décisives de l'histoire de la cirilisation; la condition du travail change en Europe; alors commence la longue transformation destinée à tout modifier sur le globe et à exercer une influence si considérable sur l'organisation de limpòt. Notre époque actuelle n'est pas sans certaines ressemblances avec ce frand mourement. II s' prépare également dans le monde du travail des changements: nous n’en décourrons pas plus le fil, la suite et le terme qu’on ne les apercevait au we siècle; mais les causes se révélaient comme elles se manifestent aujourl'hui, changemen!s dun ca-

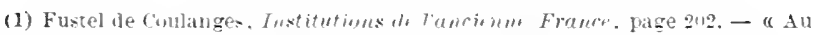

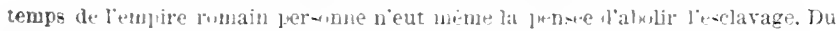

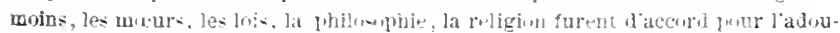
cir. $)$ 
ractère général, invisibles et irrésistibles. On en rencontre partout sans bien les comprendre et ils nous entraìnent on ne roit pas où. Il en a été de mème au $1 r^{\mathrm{e}}$ siècle.

M. Levasseur a nettement accusé le point de départ et le caractère de cette évolution du travail. "Au $1{ }^{\mathrm{e}}$ siècle, le nom" bre des esclaves avait considérahlement diminué, ils avaient " cessé d'ètre un danger. La guerre n'amenait plus chaque jour " sur le marché des captifs à vil prix. Les naissances étaient " derenues la principale source qui alimentait encore l'esclavage " et cette source mème avait été appaurrie par les affranchisse" ments que l'adoucissement des muurs, les progrès des idées "d'humanité, quelquefois l'intérèt bien entendu, avaient rendus "très fréquents; cet usage tournait au profit des classes libres. "Il fallut mème restreindre la faculté qu'araient les maitres de " disposer de leurs esclaves... L'équilibre finit cependant par être " rompu. La rareté et par suite la clserté des esclaves rendirent "leur travail plus couteux; la classe libre, dont les rangrs étaient "plus pressés à mesure que ceux de la classe servilé s'éclaircis"saient, put à son tour lui faire concurrence et l'on vit des in"génus et des affranchis se méler, se substituer aux esclaves " jusque dans la profession de gladiateur..., c'est surtout dans "le cours du second siècle que les classes ourrières reçoivent "la forme définitive qu'elles ont conservée jusqu'à l'époque des "invasions. Dès le me siècle on les trouve partout formées en " collèges et partagées en trois groupes, dont les membres jouis" sent d'autant moins de la liberté individuelle qu'ils ont avec "l'État des rapports plus intimes; ces trois groupes compren" nent les manufactures de l'État, les professions nécessaires à "la subsistance du peuple et les métiers libres (1)."

Un mourement analogue et parallèle se produisit pour les esclaves attachés à la culture du sol. "Ils étaient traités en hommes, " mais en hommes qui devaient rapporter beaucoup et coùter " peu, on les nourrissait en proportion du travail qu'on espérait "d'eux. La villa renfermait ordinairement une prison souterraine " où ils étaient enfermés en punition de leurs fautes. Les plus

(1) Des classes ouvritres en France, 1er vil.. 1). 28. 
" mauvais travaillaient avec des entraves aux pieds ,.... ce qu'on " a appelé depuis le servage de la glèbe n’existait pas encore. "Toutefois l'habitude s'établit natureliement de les considérer " comme attachés à la terre; on les inscrivait dans les registres " du cens comme faisant partie intégrante du domaine et, dès "lors, ils pouvaient difficilement ètre séparés du sol; on les " vendait avec lui et on ne les vendait guère sans lui. Les Juris"consultes du $\|^{\mathrm{e}}$ siècle professent que lorsqu'on a vendu " un domaine garni cette formule signifie que les esclaves sont « compris dans la vente. Ce qui n’était d’abord prescrit que par "la coutume le fut ensuite par la loi. A partir du $1 v^{\ominus}$ siècle, les " empereurs défendirent formellement de vendre les esclaves ru" raux sans la terre ou la terre sans eux. Il arriva ainsi peu à " peu que l'esclave appartint plus au sol qu’a la personne du "maitre... Fixé au sol, il eut une demeure assurée, une terre " à laquelle il s'accoutuma. Il eut surtout une famille et il connut " son père et ses fils : avec l"hérédité du sanor et des affections, " il fallut inseusiblement lui donner celle des biens. Toutes les " conditions matérielles et morales de son existence se trouvè"rent ainsi changées (1). " Pour apprécier l'importance de cette révolution, il suffit de rappeler que, jusque vers la fin du $\mathrm{x}_{1} \mathrm{x}^{\mathrm{e}}$ siècle, malgré tant de progrès dans les idées et les mueurs, les esclaves noirs, dans les colonies esclavagistes, sont demeurés meubles et ont pu être séparés, éclıangés, vendus sans égard ni au sol, ni à leurs parents, ni à leurs enfants.

\section{Changements dans la culture du sol et la propriéts foncière.}

Les causes de ce changement se rattachent à un fait plus général encore : la mise en culture des vastes provinces qui dépendaient de l'Empire. D'Auguste à Dioclétien l'agriculture s'étendit partout gràce à la sécurité, à la paix, aux progrès de la richesse. La civilisation tendit à s'éloigrner des rives mèmes de la Méditerranée pour s'enfoncer dans l'intérieur de l'Europe; les colo-

(1) Fustel de Coulanges, Institulions politiques de l'ancienne France, page 215, édition 1875. 
nies militaires des Romains favorisèrent ce mouvement; il en fut de même des routes qu'ils ouvrirent partout. "Les bras mana quèrent alors pour la culture..., on avait depuis deux siècles " défriché beaucoup de forêts, créé des routes, amélioré le sol, "la terre cultivable s'était fort étendue (1). "

Les colons libres ou attachés à la glèbe se répandent de tous còtés. Bientìt des monastères, qui seront à la fois des foyers de culture et des marchés, sont construits au fond des anciennes forêts ou sur les pentes des plus hautes montagnes. D'autres centres d'exploitation se constituent, ce sont ceux qui, avec les anciens domaines des sénateurs ou grands propriétaires sont destinés à devenir les seigneuries (2).

Avec l'extension de la mise en culture du sol, le nombre des propriètaires a augmenté; il s'est formé, à còté de l'aristocratie terrienne, une sorte de bourgeoisie foncière, dont fait partie tout propriétaire de vingt-cinq arpents. Les crises militaires et politiques du $11^{\mathrm{e}}$ siècle n'ont pas suffi pour détruire à cet égard les progrès qui ont eu lieu de Nerva à Septime Sévère. Ces progrès sont particulièrement importants en Gaule, en Espagne, en Afrique, en Syrie, en Asie mineure, en Macédoine et en Thrace. La décarlence de la Grèce et de l'Italie continue. Rome s'est dépeuplée; la campagne romaine est un désert ( 3 ).

Dans les villes, les marchands libres, les artisans, les ourriers classés en corporations, plus ou moins obligatoires, croissent également en nombre; mais, à raison mème de la nature du gouvernement, ils ne donnent plus aucune idée des citoyens des vieilles cités républicaines. Telles ces villes fonctionnent à la fin de l'empire, telles on les retrouve à peu près au milieu du $x \amalg^{e}$ siècle quand un nouveau changement s'opère dans les conditions de la société européenne.

(1) Institutions politiques de lancienne France, p. 215. Fustel de Coulanges. Du même, Le colomat mmain, premiers chapitres, lans Recherches sur quelques problemes allistoire (1885).

(2) Fustel de Coulanges, Colonat romain. - Guizot, Civilisatim en France, $3^{\mathrm{e}}$ et $4^{\mathrm{e}}$ volumes, $7^{\mathrm{e}}$ et se lecons. - DeMontalemhert, Lfs moines alocidfnt, $4^{\bullet}$ édition, $2^{e}$ volume, chapitre $u$. Nous donnons plus lle détails ci-contre à propos le l'établissement des scigneuries.

(3) Duruy, Histoire des Romains, 7e vol., 1'p. 197, 218. 
Dans les villes, le travail n'est pas entièrement libre, néanmoins l'esclave y est rarement devenu le serf. L'artisan dépend d'une corporation qui le protère tout en garantissant à l'ĺtat qu'il remplira ses oblications, consistant en de nombreuses prestations; ces prestations sont le résultat nécessaire de la fin rle l'esclavage urbain. Le travail est à la fois lilıre et obligatoire rlans les campagnes; il est libre en ce que la coutume en règle les conditions, il est obligatoire en ce que le colon est tenu de les remplir 1).

\section{S. x. Changement genéral thans la direction de la cirilisation.}

La civilisation change de caractère; elle cesse d'ètre urbaine; elle devient rurale, du moins en Europe: les villes, qui ont dominé pendant tout le cours de la civilisation grecque et re la civilisation romaine, perdent la direction de la civilisation; leur population, leur richesse, leur intiuence s'amoindrissent; les populations républicaines, les citoyens de Lacédémone, d'Athènes, de Rome, encore sur la scène dans les derniers temps de la République romaine, ont complètement disparu. Athènes est devenue une cité stipendiuire et annonaire. Elle paie le tribut: elle est soumise à l'annona civica avec un conseil municipal. Dioclétien interdit aux citoyens romains de porter les armes et aux sénateurs de faice partie de l'armée. Pome n'est plus qu'un municipe.

Ainsi se préparaient, dès cette époque, les élément sociaux qui devaient composer la société du moyen àge.

\section{§ั. Changements dans les effets de limpoit.}

Dans les anciennes sociétés de la Grèce et de Rome où l'es-. clavage tenait une si grande place, les reflets de l'incidence de l'impòt étaient, en quelque sorte, à courte distance. lls se produisaient néanmoins, plus limités, mieux suivis et on y remédiait par les législations fiscales de la Crète, de Lacédémone et

(1) Duruy, Ibidem, 250 . 
d'Athènes qui araient pour but de maintenir ou de rétablir l'égalité entre les citogens actifs.

Pendant la période royale, à Pome, à une époque où les esclaves sont peu nombreux, où prévaut la petite culture, où limput se paie en nature et en services perzonnels, où la guerre agrandit sans cesse le territoire national, époque prospère, lincidence de l'impoit ne soulevait pas de grandes difficultés. Il consistait en une taxe proportionnelle sur le capital. Dans un milieu agricole de petits propriétaires, cet imput était supporté a peu près dans les conditions de sa répartition, sauf les accidents et les inégalités inhérents à tout ce qui est humain.

Pendant la période républicaine, il faut marquer deux époques, celle de la conquète et celle des lois agraires. La première est encore prospère. Toutefois des changements considérables s'accomplissent; la guerre détruit la petite culture, le nombre des esclaves augmente; liimpòt est souvent surélevé; des taxes indirectes sont établies. Ces changements ont pour effets de modifier la composition de la société. Les petits propriétaires quittent la terre et la culture du sol: ils se rendent dans les villes, surtout à Rome; ils y forment les éléments de la plèbe. Cette plèbe ne peut plus supporter limpòt sur le capital; elle est trop paurre. Le Tributum ex censu pèse de tout son poids sur les classes supérieures. Paul Emile le supprime en 10\%. Restent les taxes indirectes qui, retombant en grande partie sur les mèmes classes, surtout après l'adoption des lois Frumentaires, sont abolies à leur tour. L’imput est uniquement payé par les vaincus. La conquète et la guerre doivent laire face à tout.

La seronde époque républicaine sourre alors. C'est celle des récolutions sociales et des gruerres ciriles. L'incidence de l'impùt y tient une grande place. Litalie se soulève contre le Tributum ex censu dont les citoyens romains ont seuls été exemptẻs. lls obtiennent également de ne pas le paỹer. La plèbe se soulève contre les classes supérieures qui possèdent le sol sans payer d'impòt; elles obtiennent les lois Frumentaires. Les citoyens romains sont nourris par l'État. Toutes ces charges rejaillissent sur les provinces dont le mécontentement est le principe des guerres civiles. L'anarchie derient telle, les res- 
sources de l'État sont tellement épuisées, que le Tributum ex censu et la plupart des taxes indirectes sont rétablies avant la formation de l'Empire.

Ainsi les classes supérieures romaines n'ont réussi à rejeter l'impôt ni sur les classes inférieures, hors d'état d'y faire face, ni sur les provinces qui ont résisté.

Sous l'Empire cette situation se j,rolonge, s'accentue, puis elle se modifie. Les iéformes d'Auguste et de ses successeurs immédiats ont pour but de régulariser les résultats des révolutions sociales et des guerres civiles.

Les provinces sont mises à l'alıri des déprédations des agrents romains. Leurs charges sont fixes. Le concours onéreux qu'elles doivent fournir est limité. Mème limité, ce concours, surtout dans les provinces orientales, les plus riches, les plus civilisées, a toujours été contesté; il donnera lieu pendant tout l'Empire, à d'incessantes difficultés. Les provinces n'avaient, en effet, aucun moyen de se récupérer des tributs qui leur avaient été imposés. Elles travaillaient pour le compte de Rome et de l'aristocratie romaine, elles s'épuisaient à les entretenir. L'incidence de l'impòt n'est pas moins curieuse à étudier entre les diverses parties d'un grand empire qu'entre les direrses classes de société. Aussi la tendance du nouveau gouvernement sera-t elle de soumettre aux mêmes règles fiscales toutes les parties de l'Empire afin de modifier cette incidence de l'impôt. Il serait facile de montrer que Paris joue, à cet égard, en France, le ròle que Rome a si longtemps rempli et que le produit des impôts de la France vient s'y engouffrer au profit d'un nombre très limité de personnes qui, par les résultats d'une centralisation portée au maximum d'intensité. peuvent non seulement réfléchir sur la France les charges leur incombant, mais encore s'approprier une bonne partie des taxes que les départements sont hors d'état de répercuter sur Paris.

Sur un théâtre bien plus vaste encore, nous aurons à mọntrer comment se répercutent dans les impùts de l'Inde les intérêts économiques de l'Angleterre.

Les réformes fiscales de Dioclétien et de Constantin au $\mathbb{1}^{\mathrm{C}}$ siècle ont eu pour objet de régler définitivement les rapports de l'Empire avec ses diverses parties. 
Le second but de la politique d'Auguste a été de faire supporter à l'aristocratie romaine et aux classes supérieures une plus large part d'impòt; ce résultat fut atteint par les taxes successorales, par celle sur la vente des esclaves, par les prestations; aucune de ces charges n'était répercutable, sauf la seconde, de beaucoup la moins importante et encore dans d'étroites limites - puisque Tacite pense que l'acquéreur la supportait. Si la taxe de transmission résulte d'un échange, il faut, en effet, tenir compte de divers éléments qui manquent quand elle résulte d'une libéralité; le besoin réciproque des parties et l’approvisionnement du marché en capitaux pour acheter, en marchandises pour vendre. Supportera le droit, celle des parties qui a le moins de ressources et le plus de besoins.

Quant aux Portoria, aux taxes indirectes et de consommation, si on tient compte du nombre des esclaves, des lois Frumentaires, des tarifs qui portaient principalement sur des objets de luxe, des caprices de classes riches, il faut reconnaitre qu'ils retombaient en très-grande partie sur ces dernières, sans répercussion possible sur les autres.

On trouve cependant dans les impöts de cette époque les traces des changements qui ont eu lieu dans la composition de la société; l'aurum lustrule el l'aurum neyotiatiorum annoncent et précèdent les réformes de Dioclétien et de Constantin. L'impòt égalitaire proportionnel sur le capital, d'après les déclarations des contribuables, plus on moins contròlées par les agents du fisc, semble ètre, à première vue, une taxation fort acceptable, surtout si elle est restreinte dans de sévères limites. Il répond, en effet, à certaines époques de l'histoire de l'humanité où le capital se forme, s'accroit, s'accumule avec rapidité; il en est ainsi, de nos jours aux États-Unis, en Australie et mème, il en a été ainsi en Angleterre et en France. Mais, dans une longue durée de siècles, les choses changent. Aux temps où le capital augmente succèdent ceux où il demeure stationdaire, ceux où il diminue. Dans ces époques, l'impôt sur le capital devient insupportable parce qu'il prive les nations de l'instrument qui leur est le plus nécessaire.

En outre, dans le mouvement économique des sociétés, il 
importe de ne pas se méprendre sur les formes diverses que revèt le capital et sur son degré d'utilité dans les différentes fonctions qu'il remplit. Le eapital circulant, nécessaire dans toutes les branches de la production, est cependant plus indispensable dans lindustrie et dans le commerce que dans l'agriculture; sa rémunération n'est par la mème dans celle-ci que dans celles-la. Chaque année, en moyenne, la terre récompense elle-même, plus ou moins, le labeur des grénérations; dans le commerce et l’industrie les profits résultent de la capacité et de l'intelligence arec lesquelles le capital est mis en ceuvre. Par suite l'impòt sur le capital est un instrument fort délicat. Dans les périodes de décadence il accable la production agricole, et prépare les disettes; dans toutes, il paralỵse le commerce et l’industrie. 


\section{CHAPITRE V.}

RÉFORMES FISCALES DE DIOCLÉTIEN ET DE CONSTANTIN.

Ces réformes ont pour but d'approprier les institutions fiscales de l'Empire aux changements sociaux et économiques qui s'y sont produits. La richesse a revètu d'autres formes; elle s'est répartie d’une autre manière. Les idées sur la nature de l'impôt se sont modifiées avec les transformations politiques et sociales. Déjà se dessine le courant d'opinion qui fera considérer l'impôt comme l'obligation naturelle des classes qui vivent du travail et qui en exemptera, en déclarera Immunes, les classes supérieures; l'impùt prendra peu à peu un caractère servile. Il deviendra comme la marque des personnes de rang inférieur; néanmoins ce courant d'opinion et ces réformes correspondent à une amélioration considérable dans la condition de l'homme et du travail, ainsi qu'à un progrès décisif de la production en Europe. Il est clair, au surplus, que sans cette amélioration et sans ce progrès les réformes de Dioclétien et Constantin n'auraient point eu l’importance et la durée qui les caractérisent. Nous appartenons à une époque où se manifeste, ainsi que le prévoyait Graslin, il y a plus d'un siècle, en répondant victorieusement à Turgot, un courant en sens inverse. Limpòt est aujourd'hui considéré comme l'affaire des classes riches seules, par des théoriciens ou des politiciens qui tendent, en effet, à ramener l'humanité aux organismes d'autrefois, mais le fond de la société européenne depuis le re siècle n'a cessé toutefois de se modifier dans le mème sens, la dissémination de plus en plus grande de la richesse, l'atténuation de la paurreté et l'égalisation des conditions.

\section{\$1. La Capitatio terRE.YA.}

Jusquà Dioclétien, la distinction entre le tributum ex censu et le tributum soli s'était maintenue avec la tendance accusée 
de substituer le premier au second tant que préralut, dans le gouvernement de l'Empire, l'intluence romaine. Avec les Sèvères, l'influence provinciale, surtout l'intluence orientale, l'emporte. Le mouvement inverse se produit (1) : le gouvernement s'efforce de substituer le tributum soli au tributum e.c censu, afin de soumettre l'Italie aux mèmes charges que les provinces. Dioclétien réalisa cette suhstitution. Ce fut, dit $\mathrm{M}$. Marquardt, l'introduction en "Italie de la forme du tribut provincial pour limpeit "foncier (grundstener). Le tributum soli remplace le tributum "civium romanorum."

Dioclétien fit précéder ce changement d'un recensement général, afin de connaitre les conditions économiıpues de l'Empire. L'impòt sur le capital fut conservé, mais son assiette fut modifiée, puisque le capital ne se trourait plus appartenir tout entier aux mèmes classes sociales.

Néanmoins, la capitatio terrenu ne correspondit pas complètement au tributum soli; elle n'eut pas un caractère exclusivement foncier. Elle comprit, en effet, les hiens-fonds, les maisons, les esclares, les valeurs mobilitres des propriétaires; les capitalistes ou rentiers retirés des alfaires y furent astreints. Son élément principal fut la propriété foncière. La valeur de chaque propriété était fixée sur la déclaration des contribuables, vérifiée par des agents spéciaux, censitores, et d’aprìs une unité imposable, variable par province et par genre de culture. Les $P e r^{2}-$ aquatores établissaient une sorte de péréquation dans la même province. L'unité imposable fut le jugum (2) ou caput; aussi l'impôt prit-il souvent le nom de jugatio terrena. Ordinairement le jugum était formé de 5 jugera de vignes - de 20 jugera de terre labourable supérieure, - ou de $\mathbf{4} 0$ de terre moyenne, - ou de 60 de terre inférieure, - de 220 oliviers de première qualité ou

(1) Documents : 1" articles de XI. Humbert, fupitutio of consus; ; Dict. Darem-

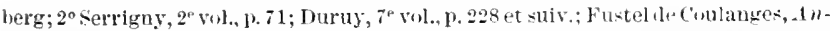

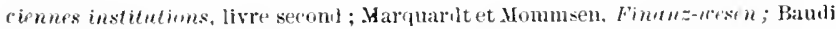

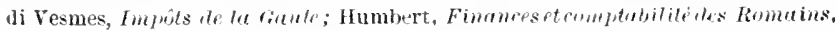

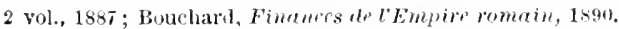

(2) Humbert, $2^{e}$ vol., [1. 343. - Serrigny, no 716 et suiv. Nul auteur n'est plus compétent, plus clair qu serrigny. - Bouchard, Ihutern, p. 827. 
de 400 de deuxième qualité. Les prairies étaient imposées d'apris leurs produits. Le jugum de bois était réparti en haute tutaie, taillis et piture.

La contenance moỵenne du jugum de terre était de 88 arpents romains, et sa valeur de 1,000 solidi. Le jugum n’était que l'unité moyenne, probablement des terres attribuées aux colons romains, aux vẻtérans, ou la quantité de terre qu'un attelage pouvait cultiver en un an 1. Les corps de domaine (villx) étaient arpentés, cadastrés et imposés à part, de mème que les centuries, ou lotissements de propriétaires colons. Les villa correspondaient aux Farms aux États-Lnis et en Australie. M. Fustel de Coulanges a établi qu'elles araient conservé leurs formes pendant des siècles. Il existe, en France. des métuiries qui n'ont pas changé depuis cette époque, quelque lointaine qu'elle soit.

Ln cadastre détaillé, mais non parcellaire, fut dressé par canton ou circonscription fiscale principale. Chaque jugum, villa ou centurie derait acruitter, selon les provinces, un nombre de solidi d’or déterminé tous les ans par l'Empereur selon son indirtio: dans les nécessités pressantes, l'Empereur pouvait exiger tout ou partre d'une nourelle cote : c'était la super indictio.

Le callastre devait ètre tenu à jour, contrilé chaque année et

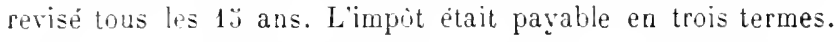
On ajoutait à chaque cute le montant des frais nécessaires pour le recourrement, en aryent ou en nature. Le recourrement était fait par des Décurions ou Curiales dans chaque circonscription ou municipe; is en itaient solidairement responsables. C’étaient eux qui devaient veiller à la bonne tenue du cadastre. Ils remettaient le montant de l’imput aux Procuratores, ou le tenaient à la disposition des gourerneurs des provinces, sur les ordres de l'Empereur. Les recourrements étaient laborieux. Il n'y eut pas dexercice sans reliquat. Les Curiales ne purent jamais $\mathbf{y}$ faire face. Leur condition saggrava avec les crises du rve siècle; il

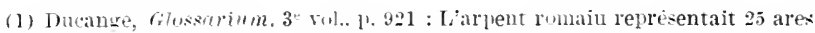

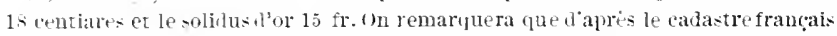

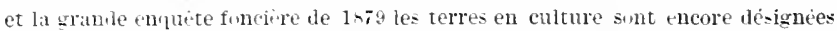

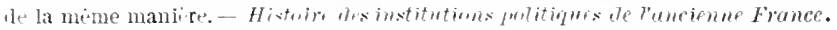

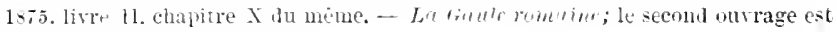
le deretmement du lintier. 
fallut la rendie herdituire. La taille a eu longtemps en France. les mèmes caractères. Leur ruine fut dès lors consommée; un nouveau mouvement de concentration de la propriété lóncière commença, analogue it celui qui avait eu lieu au $\mathrm{I}^{\mathrm{e}}$ siècle avant l’ère chrétienne, sous l'inlluence des causes différentes dans leurs origines, mais les mèmes dans leurs rèsultats, l'insécurité, l'impồ, la guerre.

La capitutio terrenu était établie à raison de tant par mille de la valeur en principal représentée par le cupul: cétait un impòt sur le capital comme le tributum e.r censu. On appelait simplum le tant par mille ordinaire. Le simplum de la crpitutio terrena parait a voir été de 1 1/2 par mille - soit 1 solidus et demi ou 22 fr. $30-$ par caput de 1,000 solidi ou $103,100 \mathrm{fr}$. Mais charque année le tant par mille réel variait.

Godefroy et Baudi di V'esmes ont admis que les Gaules, arant Julien, furent taxées à $2: 3$ p. 0/00 du capital et que Julien ramena la proportion à 7 p. $0 / 00(1)$. Ml. Serrigny en a conclu que l'imprit absorbait presque le revenu. Mais on ne connait pas le taux de capitalisation du capital. A cette époque il était bien supérieur à 3 p. $0 / 0$ et mème à ä p. $0 / 0$. Baudi di Vesmes, au moyen de supputations hypothétiques sans fondement, évalue qu'avant lit réforme de Julien la capitutio terrenı des Gaules avait été fixée à $348,794,000$ fr. La copitutio terrena était déjà un impòt de répartition, ce qui constituait un grand changrement dans les impôts romains, qui, juśqu'alors, paraissent avoir consisté en impôts de quotité. L'Empereur en conseil, arrètait lui-mème it signait en caractire de pourpre l'édit annuel d'impit. Cet édit en fixait le montant. Le prélet du Prétoire était tenu d'en

(1) Serrigny, 2 vol., 1. 86. On peut discuter sur les taux de $250 / 00$ on the $70 / 06$ : mais les craluations de Batuli di Vesmes lemeurent incomprenenibles et inacceptables. Pom justifier ce resultat, Hureau de La Malle attribme aux franles $10,617,000$ habitants, ju'elles ont ens á peine an $x \mathrm{I}^{\text {te }}$ siecle. T'ailleurs, dix millions de Ganlois at IV sicele n'amraient jamais payé $548,724,000 \mathrm{fr}$. que Baudi di Vesmes reduit, suls Julien, a $151,983,600 \mathrm{fr}$. Brockl ne se serat pas permis de telles hypothéses. M. Fustel de Conlanges a ramené ce bloc a 75 millions de fr. (La monarchie franque, 1). 273), et Gibbon it 185 m., sums Constance, puis a

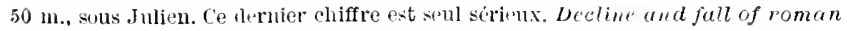
Empire, 3" vol., p. 39 1. Renooi à lappendice. 
faire, dans un certains délai, la répartition entre les diocèses. Dans les diocèses s'opérait une première sous-répartition entre les provinces. Puis venait une seconde sous-répartition, entre les diverses circonscriptions (cités, curies, pagi) par les Décurions. Savigny a émis l'opinion, qui semblait plausible, que cette sousrépartition avait lieu d'après la valeur réelle du Jugum, suirant la fertilité comparée des divers éléments qui le composaient. A cette théorie on en a opposé une autre yui convient mieux à un impôt de répartition et qui explique mieux la nature du Jugum, type d'une valeur de $13,100 \mathrm{fr}$. "Le domaine à imposer était frappé " de l'impot, d'après sa valeur comparée à celle du type, par " exemple, suivant qu'il représentait le 13 ou le $1 /$ '́ de la me"sure type (1). " Dans la théorie de Savigny i iéraluation préalable du Juyum reste inexpliquée. Toutefois le Jugum, dans une étendue telle que l'empire romain, variait lui-mème d'après les provinces, la nature du sol, celle des cultures, celle de l'exploitation du sous-sol. Les pays miniers (metalla) étajent soumis à un Jugum différent du Juyum des pays à céréales, à élevage ou viticoles.

Il I arait, dans ces dispositions, un bien grand progrès au point de vue fiscal, car des règ]es étaient fixées aux gouverneurs des prorinces qui, jusqu'alors, mème sous le contrile de maitres, tels que Tibère, n'en aeceptaient pas (2). On peut comparer ce progrès à celui dont la France a profité en 1789, quand l'impòt a été établi sur des hases stables, claires, permanentes.

Dans la super indictio étaient compris les fonds destinés aux dépenses provinciales et locales. M. Bouchard les compare à nos centimes additionnels.

En 383, une constitution de rratien, Valentinien et Théodose, rendit permanentes les évaluations (peraquationes) de la cupitatio terrena. C'était encore une aggravation; de mème que dans les temps prospères, la permanence des bases de l'impòt est un grand avantage, parfois excessif, pour le contribuable,

(1) Martuarit, ibiclem, p. 283. - Butchart, 306. - Humbert, 1 rol., 487, 2* vel., 343 .

(2) Itidem, 307 . 
de mème, dans les temps de décadence, elle peut derenir une cause de ruine.

\section{\$. LU C.APITATH H'YAVA.}

La marque de la conquete romaine avait été le Tritutum pro cupite, celui qui se payait ave le nummus ensi. celui qui irritait les Juifs en particulier. Par un juste retour des choses humaines, Dioclétien crut équitable de l'applipuer par tout l'Empire et par suite a ce qui pourait subsister de citogens romains atfranchis de la capitation.

La pensée d'égalisation fiscale ne fut point cependant le principe dominant de ce changement. La cupitutio humanu correspondit à un tout autre ordre de faits, à la diminution de lesclavage, aux progres accomplis par les classes laborieuses. Serrius Tullius ne leur demandait riea; Dioclétien leur demanda leaucoup. Il levança mes les temps, en exigeant d'elles ce qu'elles ne pouraient encore fournir.

Tous ceux qui n'étaient pas décurions, tous ceux qui ne payaient pas la capitatio terrena 1, meme les esclaves durent acquitter la taxe de capitation plebeiu apitutio d'un simplum. On ne connait pas le taux du simplum pour la cajitatio humana. La femme devait la moitié du simplum. Gratien réduisit le taux à deux cinquièmes pour les hommes et au quart pour les femmes.

Dioclétien, Constantin après lui, exempterent la plèbe des villes de la capitutio humana; elle fut par suite essentiellement rurale: ce qui indique combien avaient ite grands les changements de toute nature accomplis dans les campagnes. Elle s'appliquait presque exclusivement aux colons libres ou serfs; les esclaves y étaient assujettis. Elle n’était due qu’ì partir de l’àge de vingt-cinq ans. Elle ne se confondait pas avec la apitation terrena. Liune et laautre étaient exigibles séparément. Elle se payait souvent en nature (unnona), ce qui a eu pour conséquence de la faire placer dans les Coles Théorlosien et Justinien sous le titre de Annona.

(1) En tons cas, la cupitatio humana tenutit is derenir une elatge foncirere agricole, - Buchard, ibidem, 301 . 
Elle était graduée; elle équivalait donc à la capitation établie par Louis XIV et à la rlussensteuer prussienne. D’après Baudi di Vesmes, " elle ne consistait pas dans un imprit fixe et uni"forme dans chaque caput, mais en une somme variable par " chaque individu, et calculée sur la valeur de la personne et "des biens meubles du contribuable. Cette contribution devait " monter environ au dixième du revenu de la personne el des "biens meubles du contribuable, quoique le chiffre n'en soit pas "connu. "

Elle était un impòt de répartition, ce qui la rendait plus arbitraire 1 .

\section{S 3. GLEBALIS CONLATH'.}

Dans les deruiers temps de l'Empire les sénateurs furent soumis a une taxe personnelle qui était une réritable capitation; elle était assise sur leurs biens fonciers, dou le nom qu'elle portail. Faute de biens, le sénateur derait compter sept solidi. Les femmes de condition sénatoriale étaient astreintes aux mèmes charges. Le sénateur devait déclarer la nature et la valeur de ses biens. La taxe était probablement proportionnelle, on l'appelait aussi Follis, du sac d’or ou d’argent que les sénateurs étaient censés posséder ou apporter; nul sénateur ne pouvait s'y soustraire, si ce n’est en renonçant à la dignité sénatoriale.

Les sénateurs ne concouraient pas à l'aurum coronurium; mais ils devaient donner des étrennes (Stronæ) à l'Empereur.

\section{§. La LUstralis conLATJo.}

La Lustrulis conlatio a été un démembrement du Tributum ex rensu. Lorsque le commerce, l’industrie, la richesse mobilière

(1) Serritrny, 2 rol., 99. - Humbert, 2e vol., 350. - C"est une question très interesinte que celle de saruir si les esclares - compris, comme le betail dans la drerintion animalum pui faisait partie the la matiere imposable de la capitaico terrena - payaient eneore la capitatio humana. Tel est l'avis de $\mathbf{M}$. de savigny. M. Serrigng prense que l'esclare ne comptalt que pour établir le quantum de la capitation du proprietaire; cela ne parait pas ratisemblable, juis"lue le prontictaire ne layait las la eapitatio humana; meme réponse à ceux fui lépmlent que lecclave rarait pas de biens, mais il avait sa personne et la tenlance de léwnne etait de la degager eharue jour darantage. 
eurent fait de notables progrès, on reconnut la nécessité de les recenser et de les imposer à part; c'était une taxe sur les commeresants, en donnant a l'expression mercatm ou negraciator, la plus grande étendue. Elle sappelait le chrysurymrum; elle était exigible chaque année, puis à chaque lustre, soit tous les $\ddot{5}$ ans. Un ne peut mieux la comparer qu'à l’impòt des patentes. Elle remonte à Alexandre Sévère qui, sous le nom de Veptigul Artium, demanda une contribution particulière aux artisans : tailleurs, vitriers, pelletiers, selliers, orferres, tisserands. Cette taxation indique les progrès que ces industries avaient faits, par suite du changement dans la condition du travail. Les portefaits (saccurii), qui jouissaient d'un monopole, acquittaient un impùt spécial (1).

Dioclétien et Constantin revisèrent cette taxe. Elle ne fut exigible que tous les cinq ans. Anastase l'abolit en zol : rectigul miserabile, Deo incisum, barburis ipsis indiynum. Anastase n'était pas prophète.

Limpòt était de répartition et proportionnel. M. Serrigny pense qu'il portait sur le revenu et non sur le capital. C’était une exception aux traditions du fisc romain. Le taux parait avoir été de 2 p. 0 o. Les commeregants le répartissaient et le recouvraient eux-mèmes d'après une matrice $(2)$.

\section{$\S$ ö. Portoria et monopoles.}

Ils ont été maintenus jusqu'à la fin de l’Empire. Les Portoriu furent mème surélevés. Le droit fut porté au huitième de la raleur par Gratien, Valentinien et Théodose. Justinien confirma ce $\operatorname{taux}(3)$. On ignore si, à chaque station ou étape des Portiora et des péages, si, dans chaque port, la marchandise devait acquitter les droits, de mème quarant Dioclétien - c'est fort probable. M. Serrigny fait remarquer que les lérislations douanières des Etats actuels sont tout aussi excessives.

Au premier rang des monopoles venait celui du sel, falıriqué

(1) Dureau de La Malle, $2^{e}$ rol., 487.

(2) Serrigns, ibidem, ge rul., 130.

(3) Serrigny, ibidem, 205. 
dans les salines du domaine. Les particuliers étaient admis à en fabriquer moyennant permission et un impòt de 10 p. $0 / 0$ du produit, mais ils n'avaient pas le droit de vente. Le fisc le leur prenait à bas prix et le revendait avec bénéfice, exactement comme le tabac en France en 1893. Exploitation des salines et des monopoles était affermée aux publicains, de mème que, sous l'ancien régrime en France, plusieurs impòts.

Quant aux octrois, les empereurs s'étaient réservé de les autoriser et d'en reviser les tarifs; il en est toujours ainsi en Europe. Sur les produits, ils prélevaient les 23 ; mème prélèvement en Italie et en Espagne aujourd'hui. Du moins, en France, l'État ne prélève plus rien.

\section{s. Mutation et succession.}

I. - Vicesima libertutis. Quinta et vicesima mancipiorum. Ces deux taxes, caractéristiques de l'esclarage, furent abolies. C'est la preuve d'un grand changement dans les idées et dans la constitution de la société.

II. Vicesima herelltutium. - On n'en trouve plus trace au $\mathrm{w}^{\mathrm{e}}$ siècle. Ainsi cette réforme fiscale s'effondra. On peut en donner plusieurs raisons. A l'origine, elle avait été une charge particulière des citoyens romains. Le droit de cité ayant été accordé aux provinciaux, la taxe n'a plus eu de portée compensatoire. L'extension du tributum soli à toutes les provinces de l'Empire, sous une forme plus rigoureuse, avec un taux plus élevé que le stipendium, la dime en nature ou le tributum $c x$ censu, ont pu ètre considérées comme ne pouvant cadrer avec le maintien d'un autre impôt sur le capital. A ces raisons il faut ajouter la résistance des familles, encore solidement constituées, et la concentration de la propriété foncière dans les mains des grands propriétaires. Au surplus, Trajan avait déjà affaibli le rendement de limpôt en exemptant tous les collatéraux proches.

\section{§. Trestations.}

Il n'en est pas de même des prestations. Elles prennent un ruineux accroissement. Elles n'avaient été, en quelque sorte, 
qu’ébauchées pendant la période précédente, sauf en ce qui concerne l'Annona 1 ; elles se régularisent durant celle-ci; elles prennent la forme qu'elles conserveront jusqu’à Charlemaırne et mème beaucoup plus loin. Elles se divisent en $\langle\boldsymbol{z}\rangle$ :

$1^{\circ}$ Prestations militaires Innonx , fournitures de vives, de vêtements, de chevaux, de fuurrages et mème d'armes pour l’armée; prestation de moudre le bé, prestation de cuire le pain, de fournir le charbon;

20 Prestations administratives, rations des fonctionnaires, les chevaux et fourrages pour la poste, les réquisitions de meubles, de bètes de somme, l'entretien des mansiones hotelleries), du Cursus publicus (la poste), les lournitures à faire aux manufactures de l'Etat;

$3^{\circ}$ Le logement, qui deviendra le droit de gite et qui s'est perpétué au-deli du moyen àge; il faut loger et défrager l'Empereur, la Cour, les fonctionnaires, les soldats;

$4^{0}$ Les corrées : véritables impits que le contribuable payait sous forme de travail; il devait fournir un certain nombre de journées par an pour la construction et l'entretien des routes, des ponts, des édifices et magasins publics; il devait prêter ses chevaux et ses roitures pour les charrois de l'Etat, meme fournir de la chaux, du bois de charpente, du charbon, des cordages, etc. La plupart de ces prestations devaient ètre livrées

(1) Il existait les rappurts etroits entre les leux capitario et la jupart urs prestations. les prestations consistaient les unes en fournitures en nature yui

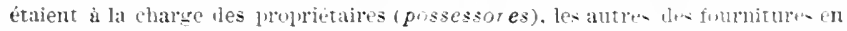
travall qui ctaltent a celle des corporations ouvrites dams les villes et des cohohs ou eselaves dans les camparmes, in cititatibus urbance ae ruspice pletis adunate.

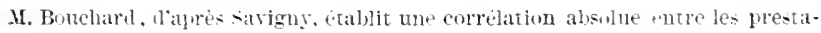
tionset la capitatio terrena, ibidem, p. 3iz. - H. Humbert th l'un aris diffi-

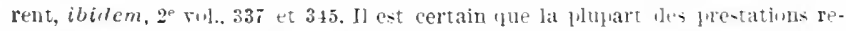
tombaient sur les memes personnes. Toutefois elles datent exclusivement rurales. Elles aldaraisilent ainsi comme les enmplements (cullationes) aux deux tapitations. Tel est aujourlhui l'impôt des prestations, en Franew, intimement lie à limpôt foncier rural, mais ne se confonlant bas avec lui. - llumbert, 2o pel., 345.

(2) Consulter l'artiel. An nona, Dieti, maire I)arembery et srrigny, 2e vol., nos 885 et suivant. - Buchard, ibidem, 347. 
en nature. Pour s'en acquitter en argent (adærare) il fallait ètre muni dun privilège impérial, ce qui s'explique fort bien au milieu des perturbations monétaires de l'Empire romain (1). L'udxratio était une faveur. En grénéral, le fisc impérial tenait la main à ce que les paiements stipulés en nature ne fussent pas convertis en argent, parce que ces conversions et les paiements donnaient lieu à beaucoup de fraudes.

;o L'unnona cirica (car on avait appliqué aux prestations mi- litaires le mème nom qu’à la prestation frumentaire), fut aggravée par la construction de Constantinople. Constantin accorda aux habitants de sa capitale les mèmes faveurs quä la vieille plèbe romaine. On y établit une caisse de la boulangerie arcafrumenturir - comme à Paris sous Napoléon III. Le congiurium de cette plèbe coùtait encore $2 \pi, 000,000 \mathrm{fr}$. Sous Septime Sévere, - celui d’Alexandrie en exigeait douze --il fallut, plus tard, pour Constantinople en dépenser 29. On accorda la Tesseru aux propriétaires et aux entrepreneurs qui élevaient des maisons; il en avait été de mème à Rome sous Auguste. Pour tenter les locataires, on suspendait la Tessera à la porte comme un écriteau $(2)$. Les théoriciens qui parlent de doubler, tripler, quadrupler la contribution foncière dans les rilles feront bien de prendre en note cet emploi de la Tessera. Le fardeau des lois frumentaires n'en devint que plus accablant. Toutes les provinces furent déclarées annonaires. Il fallut diriger sur Constantinople des flottes comme on en expédiait sur Rome. Les blés ćtaient réquisitionnés de tous còtés. Les corporations obligatoires durent être augmentées ainsi que leurs privilèges et leurs inmunités. La région suburbicaire de Constantinople fut peu à peu convertie en désert comme celle de Rome. Que deviendrait la prospérité de la France s'il fallait entretenir gratuitement les 2,300,000 Parisiens? Qui ne comprend maintenant l'arrangement que le patriarche d'Alexandrie fit avec Omar? Omar garantit à l'Égryte, chrétienne alors, la liberté religieuse et la délivra de la charge de nourrir Constantinople et Rome.

(1) Bonchard, ibidem, p. 310. Sur les corvées, voir page 23.

(2) Serrigny, 1 vol. 283. - Marquardt, Administrition de t'Annona, p. 139177, ibikem, chapitre einquieme, chapitres des plus curienx. 
S. Les corporations.

Il était pourvu à la plupart de ces corrées par de nombreuses et puissantes corporations qui ont rendu les plus grands services à l'Empire romain pendant cette époque. On peut les comparer aux principales artèles russes, parce qu'artèles russes et corporations romaines proviennent également de la décomposition de l'esclavage. Elles représentent la transition entre le travail servile et le travail libre (1). Labolition de la Lustralis conlutio fut décidée pour favoriser les corporations, lien autrement utiles à cette époque que le concours des activités personnelles. Les plus importantes étaient : $1^{\circ}$ les neygtiatorés commerçants); - 20 les naricularii (armateurs et marins); - 3" les Fubricenses (forgerons) marıués au bras; $-4^{\circ}$ les Pistores boulantrers ; $\ddot{0}^{\circ}$ le Corpus catubolensium charretiers ; - "o Corpus sumiorum, boarionum. Pecuariorum bouchers divers; - $7^{\circ}$ les Bastugirii (voituriers impériaux); - $8^{\circ}$ les Dendrophores charpentiers-poutriers). - Ces corporations se sont répandues de toutes parts pendant le moyen àge. Elles se sont dissoutes arec les progrès généraux du travail et de la richesse. Elles tendent à se reconstituer aujourd'hui sous la forme de syndicats, probablement à raison de linfluence de la diminution des profits, résultant de la concurrence du travail libre. Elles tiennent une grande place dans l'histoire des prestations, formes essentielles de limpot, et dans celles de la civilisation.

\section{\$9. Le service militaire.}

De tous ces changements, le plus significatif eut lieu dans le service militaire. Sous la République, le service militaire étant une obligation personnelle et dhonneur; le légionnaire et le citoyen ne faisaient qu'une seule et mème personne. Pendant la première partie de l'Empire, l'obligation se maintint encore,

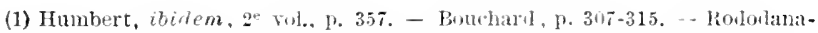
chir, Lrs corporations a Constantinople, 1493; -- Iournal des bébats. juill. 1895. An surplus on rencontre edralement des corporations importanters dans la Rome primitive, royale et républicaine. 
mais avec une tendance à se modifier, à raison de la durée du service militaire. On finit par donner la préférence à l'engagement volontaire que lon compléta au moven de réquisitions. La réquisition conduisit, d'abord, à la corvée militaire pour les soldats, puis d̀ la fourniture de soldats par les propriétaires fonciers. Aucun fait naccuse mieux l'étendue des changements qui ont eu lieu, les proerès de la culture du sol et des populations rurales, limportance des propriétaires fonciers ruraux. "La " propriété foncière devait fournir les hommes dont on avait "besoin pour remplir lez cadres de l"armée. Les pussessores "étaient tenus de céder, pour le serrice militaire, les colons "qui cultivaient leurs champs. Le plus ordinairement nejan"moins on admettait l'ararutio (c'est-à-dire l'exonération "pécuniaire, et le prix du rachat variait par homme de $\mathbf{2 0}$ à 36 " aurei '300 à ớto fr.'; c'était l'aurum tirmicum. Le proprié"taire qui ne possédait par le nombre de millenæ (contenance "variable d'après le nombre des juger"l suffisant pour ètre im"posé jusqu”a concurrence d"un soldat, parait sa part propor"tionnelle de l'adxratio. ou bien, si la prestation était exigée "en nature, on rúunissait sa possession à celle de ses roisins, "jusqu“à ce que l'on eìt obtenu une valeur totale de millenæ " (ou une contenance) égrale au nombre de millenx daprès "lequel on devait la fourniture d"un soldat. Lorsque la pres"tation était exigée en nature et que le propriètaire n"avait "pas sur sa terre d'hommes propres au serrice militaire, il "devait s"en procurer ailleurs (1). "Dans les villes cette corrée derint municipale.

Voilà bien déjà les institutions, les charges militaires et foncières du moyen àge. La terre doit le serrice militaire; l'homme n'est plus rien, la terre est tout.

\section{\$10. Impôts temporaires.}

Il faut ajouter à ces direrses taxations quelques impôts qui n’ont été que temporaires à cette époque, mais qui ont reparu 
sous l'action des mèmes nécessités que celles auxquelles avajent à faire face les Empereurs de la décadence de l'Empire :

$1^{\circ}$ L'impot sur les édifices (redificis intritutiones);

$2 \circ$ Limpit sur les portes (ostiurium);

3o L'impoit sur les fenétres (xricum):

$4^{\circ}$ Limpôt sur les colonnes (culommirriumi;

$\ddot{a}^{0}$ L̈impoit sur les courertures des maisons, sur les cheminées ou la fumée.

Limpot sur les portes et sur les colonnes remontait à l"époque républicaine, ainsi que celui sur les couvertures. Daprès Cicéron, on imposa chaque tuile à sir sesterces, ce qui parait exorbitant. Limpit aurait produit 60,000 sesterces $0 u 150,000 \mathrm{fr}$.; c'est une invention fiscale qui pourrait servir à remplacer les octrois, d'après certains réformateurs modernes, mais qui ruinerait les tuileries; on pourrait aussi imposer les briques.

On inventoriait colonnes, tuiles, portes, fenètres, tout comme depuis le Directoire 1 .

60 Les prétures que l'on peut comparer aux liturgies grecques (2). La préture était conférée par l'Empereur aux personnages en rue. Elle consistait à donner des jeux, à faire certains travaux; sous Théodose, il y arait huit prétures, chacune taxée :

$1^{\circ}$ Constantinienne et Constantienne, 1,000 livres $73,443 \mathrm{fr} .70 ;$

2 Théodosienne et Arcadienne, mème taux;

$3^{\circ}$ Triomphale et Augustale, 400 lirres $(32,338 \mathrm{fr}$.);

$4^{0}$ Romaine et Laureata, 230 livres $(18,110 \mathrm{fr}$. $)$.

Les prétures n’étaient pas recherchées, mais on poursuivait rigoureusement ceux qui, aỹant dù les subir, n’en remplissaient pas les obligrations.

Dans les provinces, la charge des prétures incombait aux duumirs, premiers magistrats locaux.

$7^{\circ}$ La Scriptura, taxe de passage, exigée sur les troupeaux nomades de passage.

(1) Bunchard, ibidem, 304 .

(2) Boucharil, ibideni, 354 . 


\section{Des immunités.}

Dès leur origine, les réformes de Dioclétien et de Constantin se heurtèrent à un grand obstacle qu'elles n'ont jamais pu surmonter. Cet obstacle, c'est l’immunité. L“immunité fiscale a diverses origines; nous l'avons rencontrée sous différentes formes dans notre royage à travers les civilisations anciennes. $1^{0}$ Les princes, hauts fonctionnaires de l'Empire de la Chine sastreicrnaient difficilement au paiement de l’impót; $2^{\circ}$ les Brahmanes en étaient expressément exempts; $3^{\circ}$ de mème les Perses, dorigine, dans l'Empire des Perses; $4^{\circ}$ En Israël, les Lévites en étaient affranchis. En Grèce, les Doriens, spécialement le Spartiate, ne paşaient pas d’impót à l'État; le Spartiate considérait l'acquittement de limpòt comme une sorte de servitude, du mème genre que celle du travail. Il n'en était pas, en principe, ainsi à Athènes. L'Athénien vọait surtout dans l'imprit son coité économique et sa nécessité; mais c’était un esclavagiste endurci. L'esclarage le condamnait fatalement à supporter l'impoit. Malgré ces tendances générales, on accordait, à Athènes, l’immunité fiscale à certains citoyens à raison de services particuliers. On cherchait à attirer les riches métèques par des exemptions diimpit, qui étaient de véritables immuntés. Ainsi, depuis longtemps, l’immunité d'impòt a été pratiquée à titre de privilège de rang, de fonction, de caste, de race, avec une tendance accusée à faire de l'impòt la part des classes inférieures ou des populations vaincues, ce qui, longtemps, a été le mème fait politique et écoromique.

A Rome, pendant la belle période de la République de ä10 jusqu’à la conquète (1) de la Macédoine, c'est-à-dire pendant 343 ans, l'impüt sur le capital, levé d'après le cens, a été accepté

(1) L'Immunité est l'un des sujets le's plus importants le l'histoire de l'impôt, consulter Durean de La Malle, $1^{\text {er }}$ vol., 169-181; 323-336: 2 vul., 347-375,447-451; Championnière, De la propriété des eaux courantes, 1442; de Vuitrỵ, Régime Anancier de la France, ler part.; Flach, Origines de l'amcienne France, 1er vol., 91-379 ; Bonchard, ibidem, 2e part., chap. 2 et 3 ; Bandi di Vesmes, ourrage déjì clté. 
par les classes supérieures, arec l. service militaire le plus rude. Elles ont eu pour compensation la formation du plus puissant empire qui ait été constitué et l'accaparement de la terre, la possession de magnifiques propriétés foncières.

A partir de la conquète de la Mlacédoine s'ourre une seconde période qui dure jusıu à Augruste et qui preut se résumer ainsi : le citoyen romain, comme l'ancien spartiate, ne paie pas d'impoit, ne travaille pas, est nourri par les peuples de toute l'Europe. Durant près de 130 ans, le citoyen romain sest fait traiter comme se traitait un rrai Spartiate; Africains, Siciliens, Eryptiens, Sardes, Italiotes remplissaient pour lui la fonction de Pénestes. Les guerres sociales ont mis un terme à cette exploitation quant aux Italiotes, et les guerres civiles quant aux autres peuples, sauf les effets des lois frumentaires; mais il nen est pas moins resté, dans le monde romain, un couraut contraire à toute égalisation en matière d’impùt. Cette égalisation, préparée entre Rome et les provinces par Auguste et Tibere, consommée par les empereurs du second siècle, a bientìt rencontré d'autres obstacles dans le caractère mème du gourernement, dans les changements économiques et sociaux.

Le gouvernement impérial tempéré, intelligent avec Auguste et Tibère est derenu, dès le premier siècle, capricieux, arbitraire. De même que l'Empereur sattribuait le droit, tantút avec le concours du Sénat, tantùt sans linroquer, de modifier les impits, d'en créer de nouveaux, d'interpréter les lois par une simple lettre, il s'arrogea celui d'exempter de l'impòt, et mème de déléguer l’impòt.

Cette exemption, appelée dès lors Immunitas, ne pouvait surprendre personne, car l'immunité avait été accordée, durant l'époque de la conquète, à des peuples, à des villes, à des particuliers, à des propriétés; ainsi il y avait en Sicile, dix-sept villes sujettes au tribut, huit en étaient exemptes. Athènes avait èté exemptée à lorigine. Il en était de mème des terres consacrées aux Dieux, à l'entretien des temples. Antoine concède au rhéteur Sextus Clodius, qui écrivait ses discours, 2,000 jugera du domaine public à Leontium, en Sicile, exempls d'impóts. Trajan accorde à Polémon et à tous les gens de sa maison 
l'exemption des Portoria. Il exempte de la vicesima hereditatium tous les membres de la gens unis par une communauté d'alliance, de culte et de sacrifices (1).

Jusqu’à la fin du second siècle de l'Empire, les distinctions de citosen romain, de municipe libre, de colonie romaine, de droit latin, de droit italique se maintinrent et dùrent créer bien des difficultés, bien des inégalités dans les charges fiscales. Hygrin parle d'un livre dans lequel on inscrivait les bénéfices et, selon Godefroy, Immunitas et Beneficium étaient synonymes $(\boldsymbol{2})$.

Les soldats, les officiers, certains fonctionnaires étaient exempts de tous les Portoria (3). Il en était de mème des marchands, des armateurs pour les denrées de l'unnona. Plus tard les exemptions devinrent plus nombreuses pour la capitatio terrena, pour la coppitutio humana, pour les prestations, pour la ylebalis conlutio, pour la lustrulis conlatio (4), les corporations. En 383, Gratien, Valentinien, et Théodose, abrogèrent toutes les immunités soit pour les biens, soit pour les personnes inscrites, sans titre valable, sur les regristres publics du cens, sur les cadastres des villes ou des provinces (艹̈).

Deux autres causes avaient, en effet, aggraré encore la situation, depuis Dioclétien et Constantin. $1^{\circ}$ Lorganisation nouvelle du gouvernement, cette création de hauts fonctionnaires qui tinrent bientòt à honneur, comme leur maitre, de ne point payer dimput. La fonction comporta peu à peu l'immunité; $2^{\circ}$ L'immunité fut accordée aux ecclésiastiques, aux communautés religieuses, aux biens de l'Église, comme en jouissaient les biens des temples.

L'exemption conduisit, dans les derniers temps, à la délégation. De nos jours, la Turquie a été obligée de déléguer une partie notable de ses impúts. C'était un moyen de récompenser

(1) Dureau de La Malle, 1er kul. $169,175,321,323$.

(2) Ioidem, 169.

(3) On les exempta mêne des impóts lirect. Cette exemption sétendit à leurs familles. Les auxiliailes jbarbares protitirent flus tard de cette exemption, lbidem, 457 .

(4) Bouchard, ibidem, 349, 361.

(5) Durtau de La Malle, 1er vol., 181. 
des services, de se procurer des ressources, d'accorder des faveurs (1). On cédait l'imput de tel villagre, le péage de tel pont. En Perse la Reine disposait de 40 villages pour sa ceinture

Mais la cause principale provint des changements sociaux, de la transformation de la société, de la diminution de l'esclavage, de l'extension de la culture, du colonat, de la place nouvelle que le travail prit rlans la société, et des profits qu il réalisa, révolution immense, quelque lentes qu'en aient été les étapes.

Au premier apercu, il peut paraitre singulier d'affirmer que la diminution de lesclavage, sa transformation en servage, le développement de la culture du sol, le changement dans la forme, les conditions du travail et dans lopinion quon pourait s’en farre, ont asgravé l’inégalité en matière d'impùt.

L'esclavage restreint les bénéfices de la production, parce qu'il en amoindrit la masse et en enchérit le prix; il les attribue a une infinie minorité qui vit dans l'oisiveté et dans le mépris du travail auquel elle doit ses jouissances. La force des choses impose à cette minorité toutes les charges sociales, puisque l'esclave ne fait pas partie de la société.

La condition du serl n'est pas la mème. Il compte dans la société. Il possède une famille, des intérèts particuliers. Lorsqu'il a rempli ses olıligations, il reste maitre de lui; il peut par son travail modifier sa situation; il a une part dans les bénéfices sociaux; il coopère à les augmenter précisément puisqu’il n'y est pas étranger.

ll en résulte : $1^{\circ}$ qu'll doit supporter une part des charges sociales; $2^{\circ}$ que son maitre ne doit ou ne peut continuer à $y$ faire seul face, pourvu qu'il trouve dans la société les garanties indispensables à la sécurité de sa personne et de son trarail.

Mêmes résultats quant à l'extension de la culture áu sol; elle se fit du $1 v^{\mathrm{e}}$ au $\mathrm{x}^{\mathrm{e}}$ siècle sur une échelle extraordinaire. L'homme s'enfonçe dans les forèts, les marais, les déserts; c’est là seulement qu'il rencontre la sécurité. Ce mouvement explique la rareté des bras, la dépopulation des villes et des campagnes. Aussi on trouve déjà dans les historiens, les publicistes de cette époque

(1) De Vuitry, 1er rol., 9 . 
des lamentations sur le dépeuplement des campagnes. M. Fustel de Coulanges les a reproduites, après A. Smith; cètait une illusion : elles se peuplaient, au contraire; mais comme les cultures s'étendaient de toutes parts les campagnes paraissaient devenir désertes. La production dut augmenter. Le serf qui en arait sa part, part garantie par la coutume, dut contribuer à son tour.

Dès que le serf payait l'impòt, l'impòt prenait un caractère servile. Paỵer impòt à Athènes, à Rome, attestait quon était libre, riche, porté dans les premières classes du cens, parce 'Iue l'esclavage était le fondement de la société. Réciproquement, lorsque le serf fut admis à payer l’impit, ne pas payer l'impòt dut devenir la preuve de la réritable supériorité sociale, d'une famille sans tache, d’un homme qui n'était pas condamné au travail. Dans les sociétés esclavagistes, il n'y a pas de confusion possible entre le maitre et l'esclave; il n'en est pas tout à fait de même entre le maitre et le serf; ce ıui différencie, dans le premier cas, ce n'est pas le travail, c’est la liberté; ce qui les différencie dans le second, e'est le travail.

Il y eut un autre motıf, non moins énergique, plus persistant que le premier, motif qui se rattache directement au problème de l'incidence de l'imput et qui exerce encore une grande inluence dans les sociétés contemporaines, le rejet des charges fiscales sur les classes les plus nombreuses.

Dans les sociétés anciennes, à base esclavagiste, ce rejet était impraticable, non seulement sur les esclaves, mais entre les classes lilıres. On en trouve la preuve dans l'institution de l'échangè à Athènes et dans l'histoire des impòts à Rome. L'aristocratie romaine parrint à accaparer les terres de l'ager publicus, mais il ne lui a pas été possible d'échapper à l'impòt; c'était l'effet de l'esclaragre.

L'esclarage, en partie, rompu, dissous, tout changeait. Le rejet de l'impùt pouvait ètre d'autant mieux essavé qu'il avait pour but de modérer la révolution en cours, en atténuant les pertes des maitres et en diminuant le moins possible le fardeau séculaire des esclares.

Enfin tout esclare ne devenait pas serf. Beaucoup d'esclaves étaient affranchis; au bout d'un certain temps, au milieu d'une 
société aussi troublée, aussi mouvante que la société romaine du $11^{e}$, du $w^{e}$ et $r^{e}$ siècle, il se formait dans la société res multiturles de conditions nouvelles, variées, différentes. Les premiers écheJons des classes moyennes apparaissaient, se consolidaient, s'étendaient; médecins, professeurs, marchands, artistes, banquiers, juristes, architectes, entrepreneurs, capitalistes, armateurs, propriétaices de tout ordre (1). Duelques-uns attrapaient, mème par l'utilité à laquelle ils répondaient, l'immunité. En France, les artistes en jouissent encore. Dans le dernier siècle de l'Empire romain l’immunité se développa, ainsi que la délégation, avec une extrème rapidité; ça été une des causes du détraquement de l'Empire.

Les progrès du christianisme, les infiltrations, puis les invasions de races germaniques accélérèrent beaucoup ce mouvement. L'Église, comme tous les sacerdoces (Inde, Éçpte, Isrä̈l), a prétendu de bonne heure ne pas payer dimpót, tout en devenant le plus grand propriétaire de l'Europe. En Grèce, les temples ne payaient pas d'impòt et recevaient certaines dimes. En Égypte, les grands propriétaires n’ont payé d’impòt que dans la seconde période.

Quant aux Germains, ils étaient réfractaires à l'impùt. Si leurs infiltrations ont eu plus d'importance que leurs invasions, ils n'en ont pas moins introduit dans le monde romain de nouvelles idées sur l'impôt, de nouvelles traditions, de nouveaux éléments. S’ils neétaient pas res maitres, encore moins pouvaient-ils ètre traités en vaincus. Acceptés à divers titres dans l'Empire, ils étaient avides d'immunités tont en se refusant à subir l'impùt.

Divers éléments vont aşir, avec une grande puissance, pendant les premiers siècles du moven àge, coopérer à la destruction de l'impôt. De ces éléments, l’immunité a été et restera le plus redoutable.

\section{S 12. Reflets et incidence les impôts.}

Quelle intluence de si grands chantrements dans les impits ont-ils eue sur leurs effets économiques et sociaux? Pendant la

(1) Duruy, ibidem, ie rol., 230. Fustel le f'sul, 'r... dneiennes institution.. liv. 2, chatp. 14, eilit. 1n.5. 
première époque de l'Empire, l'impùt réorganisé par Auguste et par Tibère demeure presque en entier à la charge des classes supérieures. Le citoyen romain perd à peu près la situation privilégiée qu'il avait obtenue, ses charges s'équilibrent avec ses arantages. L’impòt foncier et le tribut forment la part des prorinces, l'impôt sur le capital et la taxe successorale celle de l'Italie et des Romains. Les uns les autres acquittent les Portoria et les prestations. Quelques taxes spéciales sont appliquées aux classes moyennes qui, pendant les $1^{\mathrm{e}}$ et $u^{\mathrm{e}}$ siècles, ont fait de notables progrès. Les immunités commencent à poindre. Tout considéré le gouvernement impérial, le principat a été contraint pour subsister de maintenir sur les classes riches le fardeau de limpòt.

La situation est loin d'être la mème dans la seconde période de l’Empire; ce qui l'atteste, c'est l'accroissement de l'immunité. Cet accroissement a un double effet : $1^{\circ}$ de rejeter une notable partie des impöts sur les classes moyennes et inférieures; $2^{\circ}$ de préparer, dans les rangs mèmes des classes supérieures, une inégalité qui, tît ou tard, aura une grande influence sur la société.

Tels sont, en effet, les résultats de l'incidence de la cupitatio terrena, de la capitatio humana, de la Lustralis conlatio.

La Lustralis conlutio était un progrès, elle réalisait la spécialisation de l'impòt. Combien n'était-il pas préférable pour l'industriel, le marchand, l'entrepreneur d'avoir à payer un impôt sur les profits que sur le capital? Elle n’était due que tous les cinq ans; son taux était modéré. Seulement, elle était arbitraire et nouvelle. C'est ce qui explique les protestations contre le chrysargirum et les termes de l'édit d'Anastase. Telle quelle, elle devait encore être plus lourde que le tributum ex censu sur les capitaux commerciaux, parce que, à raison de son origrine même, le tributum ex censu portait surtout sur les capitaux immobiliers. Ces protestations semblent démontrer un autre fait, c'est que les personnes atteintes par la conlutio lustralis ne pouvaient pas facilement répercuter l'jmpòt sur autrui, et ajouter la taxe à leurs factures. Les impôts, qui s'acquittent à terme plus ou moins éloigné et qui ont le caractère de taxe directe, sont à tous égards moins susceptibles de répercussion que ceux payés à raison 
d'une marchandise déterminée. Les Portoria pouvaient ètre plus facilement répercutés que le chrysarg!rum. Il en est de mème aujourd'hui. Un négrociant est moins incertain de rentrer dans les droits de douane qüil avance que dans le coùt de sa patente, mème donnàt-elle lieu à un prélèvement proportionnel sur ses affaires.

A la charge de qui retombait la capitatio humana? La question est délicate, car les modifications survenues dans la composition de la société avaient nécessairement une certaine influence sur l'incidence de la taxe.

$1^{\circ}$ S'agit-il des esclaves? Le maitre la payait et la supportait.

20 S'agit-il des affranchis? Elle demeurait à leur charge, quelqu'étroits que puissent ètre les liens du patronage, puisque les affranchis opéraient pour leur compte, à leurs risques et périls.

$3^{\circ}$ S'agit-il des colons serfs? Le maitre en était responsable, il devait l'avance de l'impôt. En était-il remboursé? Il faut ici distinguer, entre les serfs domestiques et les serfs réellement colons. Pour ceux-là, le salaire n’était pas encore assez nettement dégragé pour que le serf fùt à mème de rembourser; quant au serf' colon, les opinions diffèrent sur sa condition. Moins on lui accordait de liberté, moins il pouvait rendre la taxe. Il devait exister des différences sensibles entre les serfs-colons, à raison de leur condition. selon les circonstances, la nature des cultures، la fertilité du sol, le climat, la proximité des marchés, la faculté de payer limpòt en nature; les plus favorisés pouvaient en garder une part, les moins favorisés aucune.

S'agit-il des colons libres, leur part dans la production étant garantie par la coutume, ils devaient ètre à mème de supporter l'impôt personnel (1).

Ces questions se reproduiront dans les siècles qui vont suivre; leur solution variera d'après la condition du colon et le milieu social. En principe, on est porté à admettre que le colon, même perpétuel, ne pouvait échapper à l'impôt. Faut-il encore que l'état de la société ne le réduise pas au strict nécessaire.

La capitatio terrena était l'impot foncier. Les propriétaires

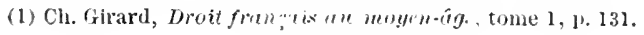


avaient-ils le moyen de le répercuter, en tout ou en partie, sur les autres classes? Comme toutes les taxes directes, l'incidence de l'impùt foncier est immédiate. Est-il assis sur le capital, comme la capitatio terrena? le propriétaire doit l'acquitter dans tous les cas, mème s'il n'a pas de revenu. Est-il assis sur le revenu? le propriétaire pourra en être déchargé faute de récolte. La capitatio terrena était assise sur le capital. Restait au propriétaire la chance de s'en récupérer sur les prix des récoltes.

Dans les sociétés esclavagistes, toute répercussion étant impossible en principe - elle peut avoir lieu néanmoins entre propriétaires producteurs de denrées différentes ou situés dans des conditions de production très opposées - nous avons vu que le Tributım ex censu ne pouvait donner lieu à des reflets; mais la capitatio terrena était appliquée dans un milieu différent où se rencontraient plusieurs classes de personnes de conditions très diverses. Les propriétaires fonciers n'avaient plus affaire seulement arec des masses d'esclaves réduits au strict nicessaire toujours guranti, mais à toute sorte de consommateurs, les uns ayant beaucoup plus, les axtres moins que le nécessaire; d'où résultait une variation dans les prix, selon les variations des besoins et des ressources; ce sont ces variations qui facilitent le mieux les propriétaires pour rejeter l'impôt, c'est-à-dire pour le comprendre dans les frais de production.

ris-à-vis des esclares, des colons serfs et mème des colons libres, tous pourvus par des prélèvements en nature, le rejet ne pouvait ètre efficace, - il n'en était pas de mème pour les populations urbaines, formées principalement d'anciens affranchis, à moins qu'elles ne fussent entretenues au moyen du congiarium. Mais, dans les derniers temps de l'Empire, le congiarium diminua beaucoup à Rome; il disparut peu à peu de l'Empire. Il n'en était pas de mème pour l'État qui avait de grandes armées à nourrir. De là l'édit de Dioclétien sur le maximum 301 (1). Cet

(1) Élit de Dioclétien, étublissant le maximum alans l'binpire romain, par MM. H. Wadilington, 1864 ; ee curieux travail se compose dn texte latin et a'm commentaire tris important. On tronve page 18 is propos des salaires (chapitre vil, de meredibus operariorum, un commentaire sur les salatres. Dans ce 
edit est du commencement de la seconde période de l'Empire romain. Il appartient aux belles années qui suivirent les mesures réparatrices de Dioclétien. Il dénote une crise économique prorenant de causes très diverses, notamment une cause monétaire. Toute."ois, on peut en induire l"jmportance des villes, pour lesquelles l'édit avait êté fait. "Chacun sait par sa propre expé"rience que les objets de commerce et les denrées qui sont "vendus journellement sur les marchés ont atteint des prix " exorbitants et que la passion effrénée du gain n’est plus modé"rée ni par la quantité des importations, ni par l'abondance des "récoltes..., quant aux négociants qui ont l'habitude de fré"quenter les ports de mer et de parcourir les provinces loin" taines, qüils se souviennent qüil est inutile d'accaparer les " denrées en temps de cherte் 1 ,. "Il y avait donc dans l'Empire un mourement commercial important, preure de l'existence de nombreuses populations, de nombreux consommateurs, en dehors des exploitations agricoles où tout dépendait encore des anciens liens de famille, de clientèle et de servitude.

Quelque part que les propriétaires fonciers puissent répercuter de la capitatio humana et de la capitatio terrena, ces deux impòts nen constituaient pas moins pour eux une charge très lourde, d'autant plus que les prestations, de plus en plus croissantes, venaient l'agraver encore. Quelques-unes de ces prestations, par exemple les corrées pour les chemins, les charrois, retombaient sur les colons; les plus onéreuses restaient au compte des propriétaires.

Ainsi s'expliquent les deux faits, contradictoires en apparence, de cette époque, en ce qui concerne la propriété foncière : $1^{\circ}$ les

commentaire, I. WVaddington admet que le salaire de l'ourrier des campagnes, sans nourriture, était fixé par le tarif au maximum de $1 \mathrm{fr} .55$, - d'après les prix de $21 \mathrm{fr} .55$ l'hectolitre de seigle. $0 \mathrm{fr} .92$ le litre de vin et $1 \mathrm{fr} .52$ le kilog. de mouton. A ces $1 \mathrm{fr} .55$ sajuutait la nourriture. Dajris Cicéron, l'ourrier des campagnes était payé $0 \mathrm{fr}$. 80, - plus la nourriture. Pour expliquer de tels prix, il faut toujours se rappeler qu'ils šappliquaient à les hrommes libres, payés à raison même de leur liberté et de la superiorité soit deleur jersonne, soit de leur travail. Quant au maximum de Dioclétien, il $y$ avait daus le tarif de $1 \mathrm{fr} .55$ une certaine déduction $\grave{u}$ opérer à rasson de la monnaie avec layuelle on payait. L'édit du maximum arait une cause monetairo.

(1) Traduction de .I. Waddington, page 3 . 
obligations de plus en plus rigoureuses qui lui sont imposées, telle que la responsabilité solidaire de l'impót; $2^{\circ}$ les immunités. Les unes et les autres préparent la transformation qui s'annonce déjà : la formation des grands domaines, élément primordial de Ja société féodale. La rigneur de la législation atteste la gène et les souffrances de la propriété foncière; l'immunitas n'est que le moyen d'y échapper par l'exemption de ses obligations.

La glebalis conlatio avait le même caractère. Le sénateur était toujours un propriétaire. La glebalis conlatio constituait un second impôt foncier qui ne rendait que plus précieuse l'immunitas.

L'extension de l'immunitas aux biens de l'Église ne pouvait qu'accroitre encore les souffrances des propriétaires, décourager ou ruiner les moins importants et précipiter le mouvement de concentration.

Il en était de mème des invasions des Barbares, des malheurs qui en résultaient de près, de l'inquiétude, de loin. Tout ce qui empirait la condition de tous retombait sur les propriétaires, car ils étaient encore l'élément social principal. Beaucoup désertaient, beaucoup disparaissaient dans les forêts, dans les déserts. Ils y trouvaient la sécurité ; ils défrichaient le sol, loin des routes que suivaient les Barbares comme les agents du fisc. Nous les retrouverons dans l'époque suivante, comme le squatter qui est resté un demi-siècle dans les savanes du Farwest.

La disparition de l'impôt successoral est provenue des mêmes causes. L'impôt successoral n'a de fondement durable qu'en ligne directe. Les mœurs romaines, la constitution de la famille étaient contraires à la taxe en ligne directe. Les charges des propriétaires étant ruineuses, au moment mème où ils étendent le plus la culture, il est naturel qu'un impôt qui restait entièrement à leur compte, sans répercussion possible, ait été impraticable, par suite aboli, afin deleur permettre de faire face à tous les autres.

\section{$\S 13$. Le domaine.}

La constitution du domaine se relie directement à celle de l'impôt. C'est ce qui résulte du tableau historique que nous avons 
dressé. Toujours, nous nous sommes attachés à donner quelques renseignements sur lo domaine des États, parce que les revenus du domaine peuvent préserver les peuples de trop lourdes charges fiscales. Les Romains, gui ont longtemps procédé avec une véritable intuition de leur prodigieuse destinée, dont peutètre Bossuet seul a compris et montré le plan, ont, de tout temps, formé, conservé, étendu un domaine important. Nous avons mème dù montrer la place de premier ordre que ce domaine, énormément accru par les guerres, tenait dans l'histoire intérieure du peuple romain.

Pendant la seconde période de l'Empire romain, le domaine, d'après les changements qui se sont produits dans la première période, a en partie changé de caractère. Il est devenu, tout comme en Égypte, à la fois territorial, fiscal et industripl. .1. Bouchard dırise ses revenus en 8 classes : $1^{0}$ terres, maisons, forèts; 20 vente des denrées provenant des imprits frumentaires; $3^{0}$ mines, carrières, salines; - $\dot{4}^{\circ}$ manufactures de l'État; $\breve{3}^{0}$ monnaies $;-6^{\circ}$ lois caducaires; $-7^{\circ}$ amendes $-8^{\circ}$ confiscations; $-9^{\circ}$ droits divers 1 .

$1^{\circ}$ Terres, maisons, for entretenue au moven des lois caducaires et des confiscations. Nous n'arons pas à revenir sur les explications déjà fournies à ce sujet. Les immeubles étaient affermés à temps ou à bail perpétuel, movenuant des rederances en or et en nature. Le taux des rederances est ordinairement de 10 p. 000 pour les terreslabourables et de 20 p. 00 pour les terres complantées. Les redevances étaient pareées en or ou en nature et vérifiées avec pesage par des fonctionnaires dits susceptores.

$2^{\circ}$ Lois frumentaires. - L'Etat trafiquait souvent des blés et autres denrées provenant des lois frumentaires; il agiotait sur les cours dans le sens de la baisse $(\boldsymbol{z})$.

$3^{0}$ Ventes publiques. - Faute de fermiers ou de locataires, en cas de grosses réparations urgentes, le fisc mettait en rente publique les immeubles qui l'embarrassaient; il en était de mème

(1) Bouchard, it, it, $m$, p. 379-4us.

(2) Bouchard, th, im, in, I. $3 \rightarrow 6$. 
d'objets mobiliers, tels que les défroques impériales, robes des impératrices, pierreries, armes; le fisc entassait moins d'oripeaux qu'aujourd'hui; on vidait plus souvent les grands meubles (1).

$4^{\circ}$ Mines. - Les mines appartenant aux particuliers devaient le dixième du produit, les mines d’or le septième. On accordait facilement le droit de rechercher de nouvelles mines, surtout de l'or, à la double condition de payer une redevance proportionnelle du septième pour l'or et de vendre à l'État les produits à un tarif ru'il fixait (2).

$5^{\circ}$ Monnaies. - L'Empereur seul pouvait battre monnaie. Les particuliers avaient la faculté d'apporter aux établissements monétaires le cuivre, l'argent et l'or pour les convertir en pièces. Il leur était retenu un seizième du poids pour frais de fabrication; quant à la valeur monétaire, elle était fixée par l'État qui se réservait la différence entre la valeur réelle et la valeur nominale. Les Romains n'ont jamais recınnu, jamais pratiqué les lois monétaires comme les Athéniens. Ils se sont toujours arrogé le droit de fixer la valeur des monnajes, quelle que fùt celle clu métal monnayé. Les Empereurs n'ont pas manqué de s'emparer de ce droit retrouvé par les Institutes dans les formules célèbres des jurisconsultes; quidquid exsari placuit legis debet habere vigorem. Aussi il n'y a jamais eu à Rome de véritable régime monétaire. Tant que la guerre et la conquète approvisionnèrent le Trésor romain des monnaies étrangères d'argent ou d'or, les choses s'y maintinrent tant bien que mal, mais lorsque l'afflux des monnaies étrangères cessa, les ateliers monétaires romains, conformément à la tradition romaine, fabriquèrent des monnaies de tout type.

Le premier effet de cette anarchie monètaire fut de raréfier l'or. C'est pourquoi, dans la seconde période de l'Empire, les impòts doivent ètre payés en $n r^{r}$ ou en nature. Les prélets du prétoire étaient tenus d'expédier l'or à Constantinople : quant aux produits en nature, ils s'en arrangeaient comme ils pouvaient; de cette situation est née la plus terrible crise monétaire connue. Elle a

(1) Bonchari, ibidem, 1. 387.

(2) Bouchard, ibidem, p. 388. 
eu une très grande influence sur les changements accomplis par Dioclétien, Constantin et sur la dislocation de l'Empire. Le moment arriva, en effet, où l'or étant devenu très rare, l'argent renchérit de valeur. Alor's l'ltat, les empereurs romains euxmèmes, avec l'aris des jurisconsultes, Paul et Iodestin notamment, entreprirent de faire passer le cuivre - l'ĺtat possédait de grandes mines de cuivre en Dalmatie - pour l'argent. On abaissa, d'un côté, le poids et le titre des pièces en argent et, d'un autre còté, on revêtit la pièce de cuirre d'une légère pellicule d'argent, mème de plomb. De là une anarchie monétaire aussi grande que l'anarchie des assignats, le maximum, et une perturbation économique inouie (1).

$6^{\circ}$ Lois calucaires, amendes, comfiscutions. - Inutile d"insister sur la corrélation intime des lois contre les célibatajres ou les testaments des grens riches, les enfants illégitimes, sur les confiscations, sur les amendes dans un temps aussi redoutable que celui de la fin de l'Empire romain. La sécurité disparut, c'est tout dire. La société seigneuriale, puis la société féodale sont nées du défaut de sécurité tout autant pour les biens que pour les personnes, M. Bouchard a énuméré 29 cas de confiscation (z); quant aux amendes elles n'étaient souvent que des confiscations déguisées.

7o Droits divers. - Ces droits produisaient certaines ressources au fisc, - la pèche, - les concessions d'eau, - l'entretien des égouts, - le monopole de certaines marchandises, le passage dans des propriétés de l'État (3).

(1) Mommsen, Histoire de la monna is monane, traluction de Blacas, 3 w wh., chap. 3 .

(2) Butharal. ibidim, 394-399. - - Thans ces cin'l bages, M. Boucharil domne de grands details sur les confiscations, inventaire, frise de possosion, aprel des com-

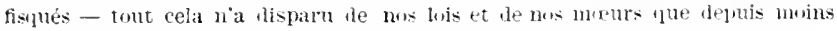
"l'um siècle.

Étaient callues :

1 Les leas aux ceelibataires on anx ipux sin: enfants.

20 Les legs aux enfants naturels sans heritjers jorpres.

$3^{\circ}$ Les fitticommis anx incapables.

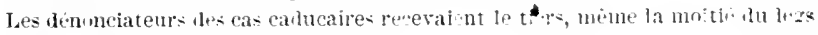
ou sucensioms, 392-393.

(3) Bouchard, bialem, 400 . 


\section{\$14. Le fisc imperial.}

Qu'est-ce qui sera chargé de la rentrée, de la surveillance, de la gestion, de la distribution de toutes ces ressources, ressources provenant des impóts, ressources provenant des domaines, ressources provenant des confiscations et des lois caducaires, qu'il ne faut pas confondre avec le véritable domaine? Ce sera le fisc. - Sous la République romaine, le fisc, institution des rois, avait disparu. L'ærarium l'avait remplacé mais, dès la constitution de l'Empire, il avait fallu faire la part au Prince, ou plutit Auguste et Tibère se l'étaient adjugée et ils avaient reconstitué le Fiscus. - Nous en avons déjà parlé plus haut. Jusqu'à Dioclétien, xrarium et Fiscus firent plus ou moins bon ménage ensemble, mais le Fiscus, c'est-à-dire d'abord le trésor personnel du Prince, puis son administration fiscale et financière propre, empiéta beaucoup sur l’ararium. Ainsi la division originaire en provinces du Sénat, reliées à l'æararium, puis en provinces du peuple ou du Prince, reliées au Fiscus, tendit à s'affaiblir et tomba en complète désuétude. Le Prince mit la main sur toutes pour la forme: il l'arait toujours mise en réalité. Le Fiscus derint ainsi le représentant de tous les intérèts fiscaux de l'Empire (1). Au contraire, les affaires personnelles de l'Empereur se détachent du Fiscus; elles deviennent celles de son domaine particulier (Patrimonium Principis).

A partir de Dioclétien et de Constantin une réforme financière jmportante correspond à la réforme fiscale. Elle sera traitée dans un autre livre de cet ourrage. Quant à présent, il nous suffit de dire que les anciennes attributions de l'ærarium furent données au comte, ministre du Trésor (comes Sacrarum largitionum), expressions qui nous rejettent bien loin du principat d'Auguste, de Tibère, et celles du Fiscus au comte, ministre du domaine impérial (comes privaturum largitionum). - Mais le nom de fisc resta attaché, dans la mémoire du peuple, au ministère du Trésor, chargé de l'encaissement des impòts et mème, en partie, 
des encaissements du domaine. Pline le Jeune arait trop bien, sous Trajan, caractérisé le fisc de cette époque, tout autrement modéré qu’au $1 \mathrm{l}^{\mathrm{e}}$ et au $\mathrm{w}^{\mathrm{e}}$ siecles, pour que le fisc perdit son nom, devenu universellement impopulaire.

Le fisc romain date réellement de ce temps. Ce n'est plus le procurator ou le prator faisant sa fortune personnelle par des exactions dont il est parfois tenu de rendre compte, tantôt devant les comices poptiaires, arec un accusateur ou un défenseur tel que Cicéron, tantüt devant le Sènat, tantrit devant un juge aussi sérieux que Tibère; c'est une armée de fonctionnaires obscurs, arisés, diligents, impitorables, disséminés de tous còtés, au courant de tout, multipliant les enquètes, les visites, les pesées, les procès, les paperasses, obéissant comme une machine aux ordres d'un Rulfin à court d'argent, entourés de registres où tout se troure écrit, résumé, examiné, compulsé, inventorié et dont le poids sur le contribuable est aussi redoutable que la pression dans la machine hydraulique de Pascal.

Ce fisc est armé afin d'attaquer, de se défendre, de lois dont les législations fiscales modernes nont eu garde de dédaigner l'héritage (1). $1^{\circ} \mathrm{Il}$ ne doit pas d'intérêt; $2^{\circ}$ il peut vendre l'objet indivis; $3^{\circ}$ pas de caution; $4^{\circ}$ pas de frais en justice; ${ }^{\circ}$ pas de vice rédhibitoire; $6^{\circ}$ il passe arant tout autre créancier; $7^{\circ}$ ses droits sont imprescriptibles; $8^{\circ}$ privilège génẻral sur les biens mobiliers et immobiliers du débiteur; $9^{\circ}$ hypothèque tacite ou légale; $10^{\circ}$ usage des délateurs. Les plus redoutables étaient les personnes de la Cour, attachées au service de la Chambre du prince. En $32 \%$, Constantin fit paraître l'édit ad unicersos procinciales proroquant les délations contre les juges, les comtes, les gens de le Cour, ses propres amis. Tous tombaient sous la coupe du fisc.

"C'était aux agents de l'officium, en Écrpte, qu'était confiée " la perception des taxes. On aurait rougi, rapporte Ammien "Marcellin, d'aroir satisfait aux collecteurs sans pouroir mon" trer son corps sillonné de coups... De nombreux témoignages " racontent "les épourantables moyans de contrainte du fisc.

(1) Serrigny, $2^{*}$ vol., p. 4, 26. 
"Des emprisonnements sans fin, des coups de fouet armés de " plomb, le supplice du froid (sorte d'estrapade, lente et hor" rible). Pour échapper à ces cruautés beaucoup rendaient et "prostituaient leurs enfants, ou furaient chez les Barbares. "On ne saura jamais ce que le fisc romain a coùté de larmes et "d'angoisses au genre humain. On prèta à un empereur ce mot (1) "terrible: "les débiteurs insolvables ne sont bons qu"à tuer."

Sous ce rapport, les progrès de la cirilisation ont amené des changements considérables dans les idées et dans les mours des grandes nations appartenant à la civilisation chrétienne; mais ces changements datent, quant à certaines l'entre elles, de moins d'un siècle, parfois ils sont mème incomplets et imparfaits. Les fiscs italien, prussien, russe, ottoman sont encore d'une sévérité rigoureuse; si le fisc anglais est modéré en Angleterre où des excès ne seraient pas tolérés. il est impitoyable en Irlande. Enfin, malgré l'extrème adoucissement des lois et des mours en France, toutes les branches du fisc ne sont pas animées des mèmes sentiments de bienveillance et de juste modération qui caractérisent celle (administration de contributions directes) chargée de lever précisément les impôts qui représentent la capitutio terrena et la capitatio humana. On a vu des agents, qui peut-être auraient employé la courbache au besoin, rendre les bancs des élères des écoles gratuites et jusiju'aux lits des religieuses, quand ils decidaient qu'il $y$ avait trop de lits; on a ru des magistrats interpréter ainsi le Code de procédure civile.

Le progrès n'en est pas moins réel, et comme les nations européennes, la France surtout, paient chaque année, sans résistance, ni murmure, ni plainte, des sommes colossales, comparées

(1) Journal officiel , no 355,1580 . - Commmication de M. Leblant à l'Académie des Inscriptions. Cette citatiun d'Ammien llarcellin est trés précieuse. Elle justiffe ce que M. Maspero nous a appris des procédes immémoriaux du fisc en Égspte et elle explique. contrairement à l'opinion du duc d'Hareourt (l'Égypte, 1593 l'nsage actnel, le print dronneur du fellah de ne payer qu'après quelques coups de courbache: cest la senl protestation que la dureté de sa condition lui permette. C'est une sorte d'appel í la justice. Celui qui se dégrade ainsi n'est pas le fellah accablé, mais le percepteur. 
à ce qu'elles payaient sous Dioclétien et Constantin, à coups de fouets plombés ou gràce à l'estrapade, il faut bien constater le progrès qui est bien grand, en effet, mais qui peut ètre et qui deviendra plus grand encore.

$\$ 1$ ö. Les imputs des provinees, des cicitates et des villes.

En principe, l'Empire romain se composait encore, au $\mathrm{IV}^{\mathrm{e}}$ et au ve siècles, des mêmes éléments politiques que vers la fin de la République et sous Auguste, d'une part l'Empire, d'autre part les villes ou municipes. La raison fondamentale de cet état de choses venait du caractère essentiellement urbain des civilisations grecque et romaine. Il n'y en a point de preuve plus péremptoire que l'histoire de Rome et de son Empire. Le citoven romain, nourri par l'Etat, a toujours été un citadin. Dans les derniers temps de l'Empire, il ne recevait le congiarium que dans les villes.

Les provinces, au nombre de 120 , partagées en 4 préfectures et 14 diocèses, ne formèrent jamais que des divisions administratives. Un grand nombre conservèrent ou furent invitées à constituer des assemblées provinciales, mais ces assemblées étaient, avant tout, religieuses. Les Romains les favorisèrent pour apporter quelque unité dans leur Empire. Ils leur reconnurent même la faculté d’avoir des monnaies locales (xorvx). Ces assemblées étaient composées des délégués des curies des villes ou municipes, élus d'après une certaine proportion. Ces délégués recevaient une indemnité de route. Elles étaient bien plus nombreuses en Orient qu'en Occident. La présidence appartenait à l'Asiarque, sorte de personnage mis au premier plan par sa fortune, sa famille, le sacerdoce qu'il exerçait. Mais qu'étaient ces assemblées? De simples réunions de tolérance, " des associations d'ordre privé, autorisées, protégées et surveillées par la puissance publique ", dit M. Guiraud (1). Elles servaient de moyen de communication entre l'Empereur et les populations. Elles interve-

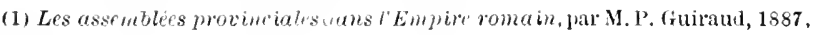
p. 114 . 
naient surtout pour maintenir les fêtes provinciales, auxquelles les Romains attachaient une grande importance. Il y avait cependant un budget provincial, mais il était tout religieux, par suite volontaire. Il y avait aussi le budget provincial du gouverneur; ce budget était réglé directement entre les gouverneurs et les préfets du Prétoire, dont ils dépendaient, probablement au moyen de ces fonds complémentaires (canonici tituli ad arcam Præfecti Prætorio pertinentes ou superindicta) indiqués par M. Bouchard (1). Ce n'est pas que les assemblées provinciales n'aient eu une importance politique indirecte, à còté de leur fonction religieuse, mais elles ne disposaient pas de droits fiscaux, de moyens financiers provenant d'impòts; elles devaient pourvoir à leurs dépenses au moyen de contributions toutes volontaires et personnelles. Il n'en fut pas différemment aux $1 \mathrm{v}^{\mathrm{e}}$ et $\mathrm{v}^{\mathrm{e}}$ siècles, quand les Empereurs essayèrent de leur demander un concours qu'elles n'étaient pas faites pour donner.

Tout autre était la condition des ivitates et des municipes. La civitus, en grénéral, consistait dans une ville avec un certain territoire plus ou moins étendu; le municipe proprement dit ne comprenait que le corps municipal d'une ville. Les Romains furent toujours favorables aux droits des civitates et surtout des municipes, soit par politique, soit par tradition latine, soit parce que beaucoup de citoyens romains habitaient les villes. Lors de la conquète, de la formation de leur Empire, les Romains consentirent un grand nombre de traités avec les villes, et, en général, respectèrent longtemps leurs institutions locales, comme nous l'avons vu à propos de la Grèce romaine; ce respect s'affaiblit arec le temps et tous ces traités disparurent peu à peu devant les règles communes, surtout à partir de Dioclétien. Les ciritates et les villes étaient représentées et administrées par les decurions et les curiales, c'est-à-dire les habitants et surtout les propriétaires les plus considérables, responsables de l'ordre génèral. Ils formaient la curie, qui se recrutait elle-même au fur et à mesure des extinctions. Ils recevaient parfois le nom de sénateurs. Leur condition continua à grandir avec la formation et la

(1) Bouchard, ibul, m, p. 3ui. 
durée de l'Empire. Ils jouissaient d'une considération et d'une autorité réelles : ils étaient, comme le dit Serrign! 1), le nerf et le soutien de l'État. Leur intervention, au profit de l'État, était double. D’un cuté ils ètaient charés, sinon de la perception, dn moins de lassiette et du recourrement des imputs principaux des deux capitations, et ils en répondaient personnellement et solidairement 2 ). Dun autre coté, ils arlministraient la ville ou les civitates et araient droit à certains honneurs et privilèges. Leurs fonctions étaient héréditaires et obligatoires; on ne pouvait renoncer à la condition de décurion ou de curiule: sur les derniers temps de l'Empire, il est facile de comprendre que les charges de leurs fonctions devinrent plus lourdes que nétaient grands les arantages.

De quelles ressources disposaient-ils pour faire face aux dépenses locales? Ces ressources consistaient : $1^{\circ}$ dans les revenus des biens de la cité; $2^{\circ}$ dans les octrois, autorisés par l’Empereur qui en approuvait les tarifs, mais dont un tiers seulement était attribué aux villes; $3^{\circ}$ probablement dans certaines taxes locales; mais cétait surtout la fortune personnelle des décurions et des curiales qui formait la ressource principale. Le décurionat n'était, en définitive, qu'un mode d'exiger limpit local. Il en a été de mème, dans une grande partie de la Grèce, pour les Liturgues. Les charges des décurions et des curiales, qui ont donné lieu à tant de récriminations de la part de Lactance et de Salsien, dont limpartialité mérite examen, étaient en rapport avec les traditions des anciennes civilisations. Elles ne devinrent excessives, intolérables qu'à l’époque de la dislocation de l’Empire, non pas à raison de leurs obligations locales, mais à raison de leurs obligations fiscales générales. Ces obligations, en outre, du recouvrement des impôts, consistaient $3_{/}: 1^{\circ}$ à faire la police

(1) Serrigny, 1 rol., 186. - Glasion, Histrive the drott th de institutiuns do the France, 1 vol. 245. M. Glasson pense que les villes joul rutu ctaient, en principe. exemptes des imjots romains directs ; c'est aller un peu luin. Leur cundition fiscale dépendait de leurs arrangement= primitifs et posterieurs; mais la tenlarep était $\dot{u}$ faire payer l'impot par les cicilutes. Voir De-jartins, La Guule romaine, III . rol. Sl. On en comptait bu sous Auguste.

(2) Ils nommaieut les susceptor, (reseveurs) et il, en ripondaient.

(3) Serrigny, 1 vol., 228, 31.-Consultez Guizut, Essui eur l'histwire de Fratue, premier essai. 
municipale; $2^{\circ}$ à assurer l'exécution des jugements; $3^{\circ}$ à entretenir les bàtiments locaux et les murailles de la cité, la poste aux cheraux; $4^{0}$ à surveiller les procurateurs des mines de l'État; $5^{\circ}$ à veiller au recrutement militaire (prototypies); $6^{\circ}$ à faire remettre à l'Empereur l'aurum coronarium, - don de joyeux avènement - et l'aurum tironicum (remplacement militaire). Ces charges, jointes à celles locales, accablèrent la propriété foncière et préparèrent la dislocation intérieure de l'Empire. Les Empereurs en vinrent mème, contrairement à toutes les traditions romaines, jusqu'à mottre la main sur la propriété foncière privée : $1^{\circ}$ lls obligèrent toute personne devenue propriétaire, à titre lucratif, de biens d'un décurion à parer annuellement à la curie une portion du revenu de ces biens, le sixième au moins, l'Etat devenait ainsi copropriétaire des biens des décurions; 2o lorsque les biens d'un rlécurion passaient à une personne étrangère à la curie, la curie asait droit au quart de l'hérédité (2). Toutes ces dispositions se retrourent dans le régime féodal; on l'a cru sorti des forêts de la Germanie; les empereurs et les jurisconsultes romains y ont eu aussi leur part.

$\mathrm{Au}$ fond, toutes ces dispositions ont leurs racines dans les progrès de la propriété foncière elle-mème, son importance nouvelle. chaque jour plus grande. Elles équiralent à des taxations arbitraires, mais qui ont grand rapport avec nos droits de mutation actuels, entre-rifs ou par décès.

Ces progrès de la propriété foncière sont attestés par l'apparition d'un nourel organisme politique, social, le municipe rural, appelé metrocomiu, réunion de plusieurs groupes ruraux, de villages, première forme de la communauté villageoise(1). Nous sommes sur le seuil du moven ìge. Élevez une maison fortifiée, mème en terre, au milieu de la metroemia, rous arez la seigneurie.

(1) Serrigny, 1 rol., 186, 11. Pour les villages, ils étaieut, selon leur plus ou noins d'importance, tantôt pıurus d'une municipalité particulière, tantôt groulés plusieurs ensemble sous l'auministration d'une municilalité nnique, siégeant au chef-lieu, appelé metrocomia, comme nos communes au-dessous de 5,000 hahitants sous la constitution de l'an III. 


\section{CHAPITRE VI.}

FORMES, IMPORTANCE, INFLUENCE DES CHAXGEMENTS OPÉRES PAR

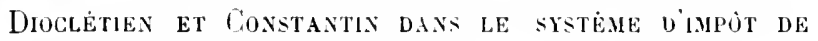
L'EMPIRE ROMAIN.

A raison de l'étendue et le la diversité des territoires auxquels ils s'appliquaient, de la masse d'hommes, différents euxmèmes de race, de climat, de traditions, de tendances qüil: concernaient 1), il n'y a jamais eu de changements aussi considérables dans le système d’impòt d'un litat que ceux lentement accomplis par Diocletien, Constantin et leurs successeurs. Les réformes de 1789 n'ont eu qu'une bien médiocre sphère d'action, comparée a la portée des modifications elfectuées alors dans le systeme d'imputs de l'Empire. Ni l'Augleterre, ni l'Allemagne, ni l'Autriche-Hongrie, ni la Russie n’ont tenu compte des rélormes françaises. En outre, ces changements eurent lieu à une époque de révolutions prolondes, révolution dans les institutions politiques et la lorme du gouvernement, révolution rans le développement économịue de l'Europe, rérolution dans l'organisation du travail, révolution dans la culture du sol qui prend une extension énorme, révolution dans la propriété foncière qui devient l'élément politique el social directeur, révolution dans les religions, révolution dans les races d'hommes appelées à peupler l'Europe. Aussi lintluence de ces changements, se prolongeant avec celle de ces diverses révolutions, dure-t-elle encore.

Pour se faire une certaine idée des transformations accomplies dans cette grande époque, il suffit d'ourrir et de comparer entre eux les monuments incomparables qu'elle nous a laissés, le Code Théodosien avec le Code de Justinien et les Norelles, et ces diversiurra-

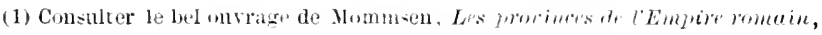
dont il a paru une traduction en angliti $<$ 1si6, Limdon. 
ges avec les Pandectes et les Codes Grégorien et Hermogénien.

Avec ceux-ci on demeure dans le véritable milieu romain; on s'entretient avec les jurisconsultes qui ont été la plus haute expression de la civilisation romaine, Ulpien, Papinien, Paul ont plus fait pour le progrès du genre humain, avec Cicéron, Sénèque, Pline l'ancien et Tacite, que Cincinnatus, Papirius Cursor, Fabius Maximus et Paul Émile. Aussi les Pandectes, publiées en 333 , ont le caractère purement romain.

Avec ceux-là, avec le Code de Théodose II, paru en 438, et celui de Justinien qui date de 534, la différence est saisissante. Le titre XVI du Code Théodosien nous transporte dans un monde étrange; la secte pestiférée de Tacite a eu la victoire; elle va assister à l'effondrement et à l'ensevelissement de ce peuple romain dont les destinées semblaient éternelles. Car Tite-Live a cru, et peut-être Tacite, à cette éternité. - Titre Ier, Le fide catholica; titre II, De Episcopis, de Ecclesia, de clericis; titre III, De monuchis; titre IV, Qui de religione contendunt; ce titre anrait stupéfait Cicéron et Sénèque; titre V, De Hereticis; titre VI, Ne sanctum baptisma iteretur; titre VII, De upostasis; titre IX, Ne elvistianum mancipium judxus habeat, et ainsi de suite. Justinien refait en partie le Code Théodosien. Il ne trouve plus suffisant de placer it la fin du Code les lois religieuses. Elles sont mises en tète, a vant les constitutions impériales, avant les dispositions sur l'autorité des lois.

Ces changements, en germe bien avant Dioclétien, reçoivent de sa main vigoureuse une impulsion puissante. Si ce soldat de fortune ( 1 a exercé sur tout l'avenir de notre civilisation une influence immense en séparant les éléments civils et militaires, en isolant l'empereur des soldats, en plaçant l'origine de son pouvoir dans la volonté divine et non dans la délégation du peuple, en constituant la cour avec ses fonctionnaires, ses gardes, ses silentiaires, ses écoliers, sortes de pages (scholures), sa police publique et privée (2) (ayentes in rebus), il n’a pas été

(1) Granle encychlidie, au mot Liochtien.

(2) Les écoles militair's contenaient 3.500 éléves, formaient la garde de l'Empereur. The section des seholares fommissait les ayente's in rebus avee 240 oftieiers, 250 sons-oflieiers, 750 agents. - Grande enejelopédie, au mot Empire. 
moins prévoyant en préparant, dans les impoits et les finances de l'Empire, des changements qui subsistent encore pour certaines parties de l'Empire où dont d'autres lonertemps profitent.

\section{$\$ 1$. Formes des thangements.}

Ces changements nont pas eu lieu subitement, à la suite de bouleversements intérietrs et d'une sorte de volte-face dans l'ensemble des institutions. Au contraire, ils se sont accomplis peu à peu. Dioclétien en a été le principal promoteur (1), de mème que c'est lui qui a commencé la série des modifications successives dans le crouvernement de l'Empire; mais plusieurs de ces changements lui sont fort antirrieurs; d'autres n'ont élé faits que du temps et sous l'impulsion de Justinien. on peut évaluer à au moins 300 ans $(2630363)$ la période pendant laquelle ils se préparent, apparaissent, s'exécutent et se complètent. Aussine consistent-ils pas dans des lois d'ensemlile, comme certaines lois mémorables de l'Assemblée constituante, du Directoire et de la Restauration, quant à la France de 1is9, mais en des constitutions, des édits, des rescrits innombrables des Empereurs depuis Dioclétien, et mème avant lui, jusqu’à Justinien, et mème après lui. Ces cunstitutions, édits, rescrits, décisions quelconques se trouventépars dans les divers monuments juridiques de cette période : $1^{\circ}$ le Code Théodosien (-2), de leaucoup le plus riche et le plus important en documents, arec les deux Codes ou plutót les débris des Codes Grégorien et IJermogénien, dont le texte précède celui du Code de Theodose II; $2^{\circ}$ le Digeste ou les Pandectes; $3^{\circ}$ le Code de Justinien $\left(3 / 4^{\circ}\right.$ les Novelles et les Authentiques de ce

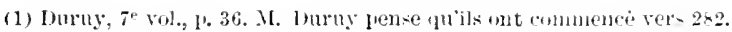

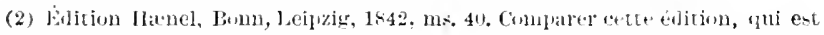

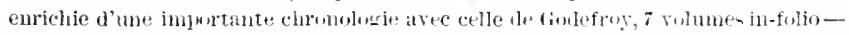

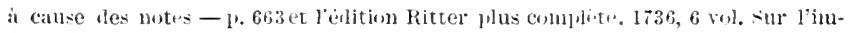

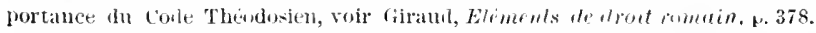

(3) Gurqute tri's inferieur an code Théentusien comme nummutent fiscal, le corle de Instinien loit etre consulte. Livre III, te ersligulia. livre $\mathrm{x}$, be jure fisei-

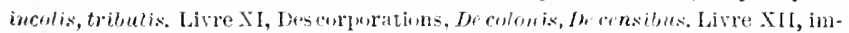

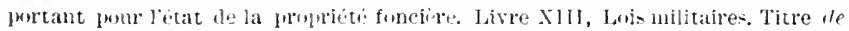

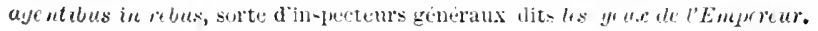


dernier. Les dispositions et lécisions contenues dans ces Lodes sont presque innombrables. On peut les partager en deux catégories. La premitre comprend celles qui s'appliquent exclusivement et directement aux réformes fiscales des Empereurs, ce sont de beaucoup les moins nombreuses. On peut ciler notanment : le titro ler, live V'l du Code Théodosien sur lı glebulis conlutio, linum oblutitium - plusieurs titres du lisre VII sur lamona. Le titre Ir du lirre X. Le jure fisci. Le titre fer du livre XI de cmnon et tributis. Le titre XII du mème livre sur l'Immunitas et plusieurs autres sur les prestations - plusieurs titres du livre XII sur les dicurian et les curales 1. Le titre ler du livre XIII, Lustralis comlatin, les titres X et XI de censu, de censoribus. peræunacoribusetiuspectoribus. Tout le livre XIY sur les corporations et l'administration des grandes villes de Rome, Constantinople, Alexandrie, Carthage. Guant aux deux capitutio et aux Portoria, on trouve très peu de textes directs. Vient ensuite la seconde catégorie, celle des textes indirects. Il a fallu des générations de travailleurs très laborieux et éminents, les Godefrog, Savigny, et arant eux Cujas, Juste Lipse, Casaubon, et leurs prédécesseurs depuis le $x^{\circ}$ siècle, pour les établir, les classeret les interpréter. A la fin de lédition Hanel du Code de Théodosien se trouve le classement des documents contenus dans ce code. On peut jugrer de ce qu'il a exigé d'ellorts séculaires pour opérer un classement sérieux 2 par le fait que lon possèrle 1,200 constitutions ou autres actes législatifs de Dioclétien. Le mème travail a dù ètre fait pour les Pandectes, le Code Justinien et les Kovelles, car les seules traces dechangements importants, notamment pour les deux capilutio, ne se rencontrent que dans des documents indirects. En voici un exemple : le titre XV du lirre Vंdu Digeste est intitulé De censibus, quion peut traduire par l'expression: Des recensements.

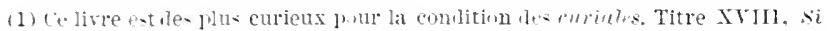

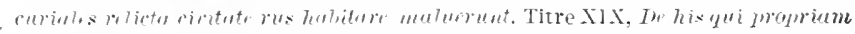
conulitionem in tipuerunt. Aujourd"luti on se precilite dans les villes.

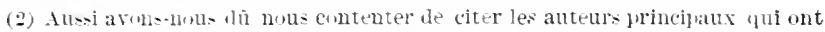

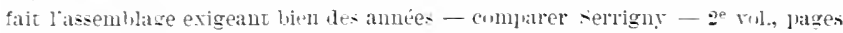

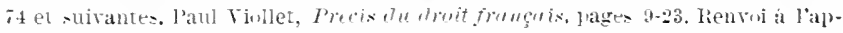
lendice wh hes textes le- plu- impromts sont releves pour les prineipax imints. 
Sous ce titre on a flacé les extraits des ourrages l'Clpien, de Papinien, de Celsus, de liäus, de Paul. Les extraits d Cipien touchent aux plus importantes matières fiscales : fo l'application du jus itulicum dans les villes de sırre, et Phénicie, notamment it Tỵr; 2 les conditions du tributum mar cupita, première forme de la crpiutio humana; 30 les effets à l'époque d’Clpien de l'Immunitas; $\dot{4}^{\circ}$ le mode dappliquer lo stipendium ou tributum suli. premiere forme de la cupitutin teriem. Des milliers de textes ont autant d'importance. Ces extraits d'Ulpien doivent itre classés au nombre des dispositions préparatoires des réformes postérieures.

Parmi ces reformes. la constitution de la mitutio terremuet de la cruitatio humanu a étí certainement la plus importante; elle ne résulte cependant que de textes indirects ou des inscriptions. On ne connait cette constitution, wurre du temps, que par des interprétations dautres textes, ou quelques prassages des écrivains de l'histoire Aurustale, en particulier d'Aurelius Victor(t). C'est dans les titres du Code Théodosien tels que de imblyentio debitorum. de itinere muniendo, de Annona, de colonis, de censu, que l'on a pris les éléments indiquant ces changrements, qui ont été plutìt des transformations successives que des actes législatifs; aussi cette constitution na-t-elle pas revètu un caractère d'ensemble; cet ensemble s'est accompli peu à peu, souvent avec des différences nombreuses, puisque Dioclétien porta le nombre des provinces à 96 , formant 37 grouvernementsel $1 \dot{x}$ diocèses.

Le courant réformateur s'est prolongé jusqu’à l’époquede Justinien qui l'a consolidé, déreloppé et régularisé; mais, en cr qui est du système fisial, la coutume, la tradition, si anciennes en Orient, ont fini par prévaloir entièrement sur la lŕgislation. Peu à peu l'activité légrislatrice impériale se calme. Liưre est accomplie. Le latin mème perd sa place éminente qüil avait conservée. Les dernières Novelles sont écrites en grec et ont dì être traduites en latin.

Ce sont par suite les compilateurs, les grossateurs, les critiques de ces grands monuments qui, pièce à pièce, ont réuni,

(1) Duruy, re vol.. page 50, nutes 1 et 5. 
comme dans une mosaïque, et ajusté les uns avec les autres, les divers éléments de ces réformes fiscales dont la tradition et la coutume sont derenues la forme réelle, de lreaucoup d'impoits, notamment la taille en France.

\section{S. Leur importunce.}

Pour apprécier toute la portée de ces changements, il faut laisser de còté, dans le système d'impôt du bas empire, tout ce qui est particulier au régime impérial mème - et porter seulement son attention sur les grrandes lignes du système d'impôt, spécialement limpöt foncier ou capitutin terrena, l’impùt personnel mobilier ou capitatio humuna, les douanes et les péages, les corvées, les octrois, les monopoles. Nous négligeons les confiscations, les lois caducaires, les délations, bien qu il n’y a guère plus de 100 ans, au plus 200, que les budgets royaux ou républicains n'y aient plus recours - mais il est évident qu'avec ces éléments noureaux le sýstème fiscal de l'Empire était complet et quon y a peu ajouté. La rapitatio terrenu portait sur le capital foncier, de mème que la taille réelle en France et que l'impoit foncier au Japron. En Prusse et mime dans toute l'Allemagne on a la tendance à substituer l'impôt foncier sur le capital à l'impòt foncier sur le revenu. Aux États-Lnis la réul property-trex porte surle capital. Quant à la cupitatio humuna, elle était comme le vestiluule à limpòt sur les revenus personnels et mobiliers. Elle avait une très grande importance, parce qu'elle correspondait, comme nous l'arons vu, à la désor ganisation de l'esclavage et à la première éclosion de classes moyennes et agricoles. De mème de nos jours les impits sur les valeurs mobilières et les objets de consommation correspondent à limmense diffusion de la richesse. Les péages étaient indispensables sous l'limpire romain parce qu'ils complétaient les douanes. Lempire était trop raste pour que les droits d'entrée ne fussent percus que sur les marchandises étrangères; quant aux corvées, si nombreuses, si lourdes, et auxquelles sont consacrés un très grand nombre de textes des Codes, elies résultaient à la fois de l'état de la civilisation et du caractère agricole quelle tendait de plus en plus à revètir. On 
retrouve les corvées dans la plupart hes litats contemporains; il en existe encore des débris en France; la Russie, la Perse, la Chine ont conservé la corsée. Xiulle part, elle n’est plus générale qu'à Madagascar. Sans la corvé, le fouvernement malgache ne pourrait subsister. Sous ce rapport, les textes romains, qui nous paraissent si étranges, parce que notre civilisation nous permet de nous passer des corvées, donnent peut-être un tableau plus sincère de la condition historique de l'humanité que ne le font les législations fiscales actuelles des principales nations de l'Europe.

\section{\$ 3. Leur influpner.}

Aussi l'influence du srstème d’impit qui a préralu dans les derniers temps de l’Empire romain a été immense l. Le systime a survicu il l'Empire, soit l'Empire d'Occident, soit l'Empire d'Orient. En Orient les Arabes, les Turcs et les Perses y ont apporté fort peu de modifications. Les impuits : ont clıange de nom, tout en restant les mèmes. On les y retroure encore. En Occident, où tant de rérolutions ont tout détruit et renourelé, le système fiscal romain a dominé chez tous les peuples d'origine latine, particulièrement en Italie et en France. Toutefois, c'est en France que la persistance a été le plus extraordinaice. Pendant l’époque gallo-franke et pendant l'eporque monarchique nul doute, tailles réelles, tailles personnelles, péages, douanes intérieures, corrées, octrois, la France a conservé tout le système romain jusqu'en 1789. Nous établicons que les fameux droits féodaux, qui ont soulevé tant de malédictions de la part de ceux qui ne roulaient plus les payer, tout en restant déliteurs, et parfois en les exigeant d'autrui, n’étaient, en grande partie, que les impòts romains ou des droits fonciers d'une parfaite légritimité.

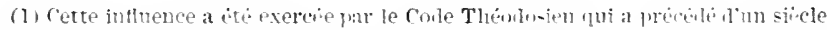

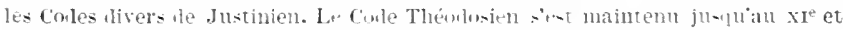

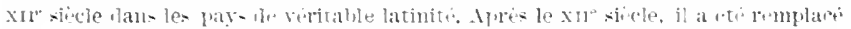

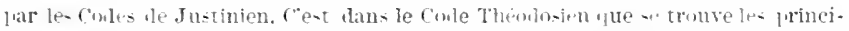

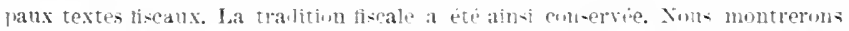

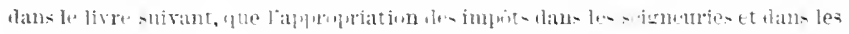

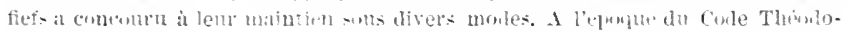


Tontelois, depuis la Révolution française et principalement depuis la seconde moitié du $\mathrm{x}_{\mathrm{x}} \mathrm{x}^{\mathrm{e}}$ siècle, la direction générale de la civilisation change; l'influence de la propriété foncière s'est amoindrie; la richesse, tout en augmentant beaucoup, s'est disséminée; le pouvoir personnel des monarchies a perdu de son lustre, mème en Orient, mème en Chine, mème au Japon; la séparation, établie par Dioclétien, à lïnstar des antiques monarchies orientales, n'a pu être maintenue. Il y a loin du président de la République Frangaise à Louis XII; le Tzar de toutes les Russies n'est pas relégué au fond d'un palais; aucun souverain n'est plus aecessible; le Fils du eiel a dù consentir ì reeevoir les ambassndeurs des Barbares lui-mème. Ouel homme rappelle mieux Antonin ou Marc-Aurèle que le président Cleveland? En même temps, les nécessités militaires ont reparu et la distinction fondamentale, absolument contraire aux trarlitions romaines et grecques, entre le citoyen et le soldat, distinetion qui a survécu à la Révolution française, distinction qui n'a pas empèché l'Angleterre de fonder le vaste empire de l'Inde, n'a pu être maintenue en Europe. Tout homme est militaire. 11 n'arrive à aueune fonetion s’il n’a pas été soldat.

Ces diflérenees servent à mienx faire comprendre limportanee historique de l'époque qui s’étend de Dioclétien à Justinien. Elle est de premier ordre dans l'histoire de la civilisation; aussi at-elle produit un tres grand nombre dhommes éminents et nous a-t-elle transmis dans les Codes romains les monuments quiprésentent le résumé général de l'histoire de la civilisation au moment où le ehristianisme en prend la direetion religieuse et morale et on se préparent, en Europe, la rencontre et la fusion des principales raees de l'humanité.

sien les rapports entre les deux jarties de l'empire romain étaient encore importants: ils dtatent trop affaiblis en 533 frour 'pue les Coles de Justinien y aient été aplliliués et mème connus. 


\section{CHAPITHE VII.}

COUP D'IEIL GEXXERAL SIR L'HI=TMIRE DE L'IMPIT DASS LE:

ANCIENES CLULATIONS.

Par suite, il est nécessaire de résumer les randes liunes de lhistoire de limpit, au inoment où trut va changer dans la direction de la civilisation, où l'humanité, sous l’impulsion d'une force qui n’est pas eucore fatiguée, va transporter son fočer principal hors de l'Europe, pour rayonner de là non seulenent sur le territoire des anciennes cirilisations de l'Asie, mais sur le globe entier.

Les premieres cirilisations, celles de la Mésopotamie. de l'Égrpte, de la Perse, de l'Inde et re la Chine nous ont présenté deux systimes d’impit, correspondant it deux civilisations différentes. Doun cité. le système de l’Inde, ayant pour seul fondement, la culture du sol et le morcellement de la souveraineté politique. Tous les autres systemes ont un autre caractire. Les éléments de la civilisation sont très variés en Chine, en Fryite, en Mésopotamie, en Perse, quoique reposant sur la propriété foncière et la culture du sol à titre principal, mais sans exclusion de lindustrie et du commerce. De là des imprits atteignant les branches diverses de la production et parvenant en Égrpte à une perfection extrème. Cependant pour tous ces șstèmes, limpòt agricole, qui est le principal, se perooit, en tout ou en partie, en nature, et parfois il ne consiste mème que dans une dime en nature. Malgré les guerres, les conquittes, les oppressions des races vaincues, maluré l'esclarage, ces traits marquent nettement les institutions fiscales de ces premières civilisations et caractérisent toujours celles d'entrelles qui durent encore. On les retrouve en Chine, duns l'Inde, en Perse, dans l'Empire turc et mème en Égrpte. A l’immutalilité fiscale correspond un état social et politique moins incertain, mais moins 
progressif qu'en Europe, la richesse y est moins grande, mais la misère moins excessive.

Ces civilisations subsistent encore. Au Japon règne une dynastie qui remonte ả plus de 2,500 ans. Cependant le Japon ne montre aucun signe de décarlence. Il est plus peuplé que la France et en voie d'accomplir un renourellement complet. La Chine compte 400 millions d'halitants, c'est-à-dire plus du quart du grenre humain. L'Inde est très peuplée et heureuse. L'iggpte n’a jamais été plus peuplée qu’aujourd’hui.

$A$ ces grands États constituant un seul groupe arec une population de 700 millions d'hommes — out fait longtemps face la Phénicie, la Judée, les Grecs et le peuple romain. Malgré l’originalité de leurs institutions, la Phénicie et la Judée n’ont pas conservé de ròle politique - mais la Judée a rempli un rôle religieux tellement extraordinaire quelle a eu une influence fiscale, ne serait-ce pue la dime ecclésiastique, que nous allons avoir ì étudier avec les impòts au moren ige. Cette dime subsiste encore en Angleterre, la nation qui est actuellement à la tète de la civilisation.

Cette intluence, la Frèce, conquise, dévastée, humiliée par les Romains, ne l'a exercée à aucun point de vue sur l'Europe; néanmoins elle a eu un développement politique, social, éconnmique, financier extremement brillant et plein aujourdhui pour l'Europe d'enseignements, puisque les idées démocratiques d'une partie de la Grèce tendent à y prévaloir. Dans ce développement, que nous a vons appelé un microcosme, les Grecs ont eu deux systèmes d'imprit; d'abord, celui des Athéniens ou des Ioniens, des plus variés et des plus complets a raison de la fécondité déployée par l'esprit fiscal démocratique. Néanmoins cette fécondité a fini par compromettre la vie sociale, la production et la conservation de la richesse en Grèce, et par provoquer une décadence effroyable qui ne s'est arrètée fuelque temps que sous l’influence de Rome et du christianisme. Bien que les institutions fiscales de la Grèce démocratique n’aient exercé aucune intluence sur l'Europe, elles nen sont pas moins intéressantes: il faut les étudier afin de se prémunir contre le virus démocratique. Juant au régime fiscal dorien, dont Lacédémone a été le ț̣pe, il a été encore plus 
funeste; il peut servir dantidote aux maladies socialistes.

Le système romain, dans ses trois grandes époques, est, au contraire, en rapports intimes et profonds arec les sociétés européennes contemporaines, mème avec leurs colonisations.

Dans la première époque, le trilnutum ex censu et les Portoria ont constitué un ensemble simple et puissant, offrant heaucoup' de rapprochements à faire avec les impits aux litats-Lnis. Cet ensemble a été altéré par la direction donnée à la politique de Rome, par la guerre, la conquète du monde méditerranéen et la formation d'une aristocratie foncière oppressive, qui a exploité tous les peuples méditerranéens.

Dans la seconde époque, transition entre la liépublique et l'Empire, les peuples conquis par fiome ont, peu à peu, arraché la concession d’un systeme d“imprit uniforme, dans la mesure du possible, pour toutes les parties de l'Empire. Le prix de cette uniformité a été les lois frumentaires. Le citoren romain paurre a été nourri par l'Europe, qui a pu respirer pendant quelque temps.

Dans la troisième, le peuple romain est définitivement sulımercé par les peuples conquis. L'Italie est soumiseà l'impòt. Les citoyens romains ne sont plus nourris que dans les grands centres turbulents. Les Empereurs cessent d'etre en rapports directs arec les citoyens, profondément dégradés; on leur refuse mème d’ètr soldats; l'armée derient celle de lEmpereur; il la tient au loin; il a ses gardes spéciaux; il est le maitre de l'impút; il en dispense ses amis, il le délègue à ses courtisans; l'impùt rerèt un caractère d'autant plus servile que les esclaves sont moins nombreux et qu'on peut l'exigrer des anciens esclaves, transformés en négociants, employés, propriétaires, colons. A eux de payer et faire payer l'impòt. Peu à peu les granrls fonctionnaires, les grands propriétaires en seront tous exempts. Cette exemption dite immunité diminue les ressources fiscales du gouvernement qui procède, avec Dioclétien et Constantin, à une modification profondo des impùts, principalement mis à la charge de la propriété foncière rurale par la capitatio terrena, la cupitutio humana, les prestations et les corrées. Tant que l'Empire est en mesure de résister aux causes de dislocation qui lui sont propres, ce sys- 
tème se maintient, parce qu'il correspond à deux révolutions économiques: $t^{\circ}$ la transformation de l'esclavage antique; $2^{\circ}$ l'extension du développement agricole et rural de l'Europe et de la propriété foncière. Il a le plus grand rapport avec les impits rui avaient prévalu dans les anciennes monarchies de l'Orient, notamment de la Mésopotamie, et il en provient en partie; aussi, en Orient, a-t-il résisté à tous les changements politiques qui s'y sont accomplis.

Il n'en a pas été longtemps de mème en Occident, parce que les conditions politiques et économiques de l'Europe ont eu pour résultat la ruine totale de l'Empire romain d'Occident. En réalité, l'état de cirilisation de l'Europe, très inférieur aux $v^{\mathrm{e}}$ et $\mathrm{rl}^{\mathrm{e}}$ siècles à celui de l'Orient (Asie mineure, Ancienne Mésopotamie, Palestine, Phénicie, Egypte) ne permettait pas à un système d’impit, tel que celui adopté par Dioclétien et ses successeurs, de subsister. Dans leurs vastes réformes, Dioclétien et Constantin ont été dominés par les influences orientales, bien autrement puissantes alors. Le christianisme et le mahométisme le prouvent asse\%; ces réformes convenaient fort bien à l'Orient; elles ont dù, en Occident, participer aux changements de toute sortequi allaient y aroir lieu sous l’influence des invasions, de la dissémination des populations, des progrìs extraordinaires de la culture, de la décarlence des villes et do la ruine du gouvernement central.

De toutes ces causes, cependant, la plus active a été la transformation de l'esclavage. L'esclavagre dans la Grèce ancienne et à Rome avait pris un développement inconnu toujours en Orient. La liquirlation de cet escla vage a duré longtemps; associée à d'autres éléments perturbateurs, elle a produit la société du moyen ìge et le fait décisif de l'appropriation de l'impoit.

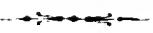




\section{LIVRE QUATHIEME.}

DE LIMPUT AL MOTEX AGE. 

CHAPITRE I.

WRSERVATIUXS PRÉLIMINARES.

Dans la course rapide que nous avons dủ faire à travers les siècles, depuis les premières civilisations écloses dans les deltas du Tigre et de l'Euphrate jusqu'aux réformes de Dioclétien et de Constantin, nous avons suivi une mème route qui, malgré bien des détours ou des précipices, nous a conduits à un ensemble de constructions, qu'on peut considérer comme présentant, dans leurs grandes lignes et leurs compartiments divers, l'abrégré de tous les elforts des peuples, de tous les progres du temps.

La dissolution de l'Empire romain d'Occident marque un retour en arriire extraordinaire; c'est le point de départ d'une époque pendant laquelle vont temporairement s'altérer tous les fruits du passé. En Europe, l'impìt subit une lente dégradation qui se termine par une sorte d'éclipse. Il faut retourner en Asie, soit dans les provinces dépendant encore de l'Empire romain d'Orient, soit dans celles composant l'empire des Arabes, pour retrouver une véritable organisation financière, des institutions fiscales, approprićes aux besoins généraux d'un lítat et dornant encore quelque idée de ce qu'ont fait la Chine, les ligyptiens, les Perses, les Grees et les Romains.

Et cependant, durant cette époque qui se prolonge pendant neuf cents ans, les peuples européens accomplissent d'assez notables progrès et se trouvent en mesure de soutenir, pendant deux cents ans, le mourement extraordinaire des croisades.

Il faut en conclure que, dans l'histoire de l'humanité, il importe de ne pas consacrer uniquement son attention aux faits réguliers et symétriques comme la marche de la civilisation en Égypte ou l'Empire romain. L'autres événements, d'un caractère différent, opposé, méritent de provorjuer l'attention et les études 
de tous ceux qui s'intéressent à bien saisir le sens des principaux érénements de l'histoire.

A cette organisation fiscale presque parfaite de l'Empire romain, succède en Occident une complète désorganisation. Lanarchie la plus profonde remplace l'ordre le plus savant. Tous les rouages, qui devaient garantir l'impìt et procurer à l'État les ressources nécessaires, s’approprient et accaparent limpòt. La notion elle-mème de l'impòt s'oblitère. Des générations ront se lever, pour lesquelles l'impòt sera encore moins compris qu'à Sparte. Des usages, des législations s'établiront, fonctionneront au hasard, sans aucune main directrice, un Solon, un Auguste, un Dioclétien, qu'on puisse reconnaitre.

Cette première époque, pendant laquelle la notion de limpôt s'obscurcit, soblitère complètement, dure cinq cents ans. Vient ensuite une autre époque, qui dure encore pendant trois cents ans : l'impoit refait son apparition, mais il n'a aucun caractère grénéral, permanent. Il est purement occasionnel, local. Dans la troisième, qui s'étend du $x \mathrm{r}^{\mathrm{e}}$ au $\mathrm{xr}^{\mathrm{e}} \mathrm{1}^{\mathrm{e}}$ siècle, l'impôt reprend son ancien caractère d'utilité générale. Toutefois il n'est encore que temporaire. Enfin, arec l'éporque monarchique, mais non sans de grandes difficultés, limprit redevient une institution stable. Entre l'ensemble des réformes de Louis Xill et la clute de l'Empire romain, il s'écoule 1200 ans. Et mème en 1789, l'organisation fiscale de l'Europe était-elle inférieure à lensemble des institutions fiscales de Dinclétien. 
CHAPITRE II.

Époque fraxco-romaine, appropratiox de l'impót.

\section{$\$ 1^{\mathrm{er}}$. Dislocation de l'Empire rmunin.}

S'il fallait préciser une date à la crise qui constate la dislocation de l'Empire romain, il semble que la moins inexacte serait celle où Théodose opère le partage entre ses deux fils de l'Empire d'Orient et de l'Empire d'Occident. L'èbranlement de la machine remonte beaucoup plus haut. On peut considerer qu'elle ne fonctionne plus que par intervalles et par saccades dès la mort de Marc-Aurèle. Ni Septime Sévère, ni Dioclétien, ni Constantin ne parriennent, au prix des plus grands efforts, à dominer la force séparatiste centrifuge. Les Gaules se séparent durant soixante ans. Dioclétien trace lui-mème, sur la carte de l'Empire, les lignes du démembrement. Constantin coupe l'Empire en deux en transportant sa capitale à Bỵzance.

C'est là le mourement de dislocation politique, national, ethnique. Les peuples et les races que Rome a vaincus, ruinés, gouvernés (1) pendant quelques siècles n'ont pas disparu. Ils ont repris de nouvelles forces en s'associant au foyer commun; ils tendent maintenant à le briser avec une force irrésistible. $\mathrm{Si}$, en Orient, la dislocation n’a pas la mème énergrie, c'est que déjà, à diverses reprises, bien arant l'Empire romain, les diverses parties de l'Empire y ont ėté grroupées par les Assyriens, les Égyptiens, les Perses, les Grecs, et qu'elles ont pris, durant de longs siècles, l'habitude de virre ensemble. De Sismondi a cependant émis l'opinion que puisque l'Empire d'Orient avait duré dix siècles de plus que l'Empire d'Occident, celui-ci, sans ses chefs, aurait pu prolonger son existence. Cette opinion est contraire aux faits

(1) De Sismondi, Histoire de le clute de l'Empire romain, p. 25u, 1 vol. 
historiques. I partir des Flaviens, c'est de l'Orient que l'Empire romain reçoit ses ressources, c'est de l'Occident que proviennent ses plus grands dangers. Les conditions des populations, létat de cirilisation auquel elles étaient parienues, différaient entièrement.

A cité de ce premier mouvement de dislocation, il s'en opère un second, à l'intérieur de chacun des groupes principaux de l'Empire; les intérèts, qui araient été si longtemps juxtaposés ou confondus, se dissocient, d'autres intérèts surgissent à còté d'eux. Tout change, se renourelle, se mêle dans les conditions sociales et dans l'état économique; une immense révolution religieuse, une véritable immigration à l'intérieur du continent européen, une décomposition complète dans l'état des personnes qui a sa répercussion dans l'état des biens, l'introduction dans la société d'un élément nouveau, l'homme du Nord, le Goth, le Franc, le Lombard, le Saxon, le Vandale, qui prend place au premier rane et dans les mains duquel tombe ce qui reste de gouvernement; le haut fonctionnaire romain, le grand propriétaire, l'évèiue, admis à prartager ce reste, admis à s'asseoir, non sans craintes parfois, au festin; les institutions romaines, avant tout les impuits, se perpétuant, mais dans un état de dégradation, devenant une proie, une marchandise, un objet de trafic; toute idée d'utilité générale, de direction commune s'affaiblissant pour disparaitre bientit; l'anarchie, linsécurité, la violence se glissant partout; l'homme et la propriété ne trourant plus de protection que dans la force personnelle et physique.

\section{\$. Dislocution des proxinces - les États modernes.}

Aussi dès que le partage de Théodose fut réalisé, il s'en produisit un second par la force mème des choses. Dans l'Empire dOccident chacun des principaux territoires géographiques recourra une sorte d'indépendance et, dans chacun d'eux, s'instalia, pour la préparer, un groupe germanique. C'est un des phénomènes les plus curieux de cetteépoque de rénovation. Les Ostrogaths et les Lombards en Italie, les Wisigoths au midi, les Burẹondes à l'est, les Francs au nord des Gaules, les Wisigoths 
en Espagne, les Vandales en Afrique, les Saxons en Angleterre $(t)$.

Le sort de ehaeune de ces prorinces est loin d'avoir été le mème. De là des lifférences fondamentales dont il faut tenir compte des l'oririne, pour apprécier les conditions actuelles de formation des États modernes, car leurs bases ont été projetées dès le $y^{\text {re }}$ siècle.

L'Italie est de toutes les parties de l'Empire celle qui a le moins souffert des invasions. Sa renaissance late de la fin de l'Empire. Elle se partage, dés lors, en trois groupes principaux qui se sont maintenus jusıue dans la seconde moitié du xixe siècle. Au midi domine l'intiuence greçue avecl'Empire d'urient, au centre celle des Papes, au nord celle des Lombards. Mais a cóté de cette première démarcation, il $y$ en a une seconde nulle part le nombre, la population, limportance des rilles ne sont aussi considérables qu'en Italie. Cela tient à l'ancienneté de la civilisation et aussi au climat. La campagne n'est habitable en Italie que dans le nord. Le climat a un autre arantage pour l'Italie. Le Goth, le Franc, le Hérule n’y peurent résister. Ils décrénèrent rapidement. Dès les inrasions, les villes se ferment, se courrent de murailles; les rues, les maisons zont fortifiées; les habitants des campagnes se transportent sur les sonmets des Apennins et $\mathrm{y}$ établissent ces villages que l'on $\mathrm{y}$ voit encore aujourd'luui. Dans les villes se réfugrient tous les débris de la civilisation romaine, ses lois, ses traditions, ses monuments, ses curres, ses arts, ses impits. Bientut les ports de l'Italie, rendus ì la liberté, émancipés des servitudes romaines, deviendront les premiers fovers des Républiques italiennes; c'est là que se préparent les éléments de la seconde cirilisation de l'Italie.

En Espagne, les Wisigoths organisent, arec le concours de l'Église, une monarchie régulière qui a son grouvernement, sa dynastie, ses lois, ses codes, ses assemblées politiıues, et qui

(1) Sur ce mouvement le dislocation, frlas-on, $H$ istoire du troit it des institutions de la France, 1 vol, page 5n5. - Les diverses parties de l'Empire sont demeurées systématiqueuent séfrares les unes des autres. 
prolonge son existence jusqu'à l'invasion des Arabes. L'élément germanique joue un rôle important dans l'histoire du peuple espagnol. Après l'Italie, l'Espagne a été la partie de l'Empire romain la plus profondément romanisée, surtout le long des côtes de la Méditerranée et dans les provinces méridionales. Mais le séjour des Wisigoths et la longue domination des Arabes, qui dure près de sept cents ans, ont beaucoup amoindri l'influence romaine, notamment l'organisation fiscale de Rome. Presque partout la rederance se substitue à l'impoit. Toutefois, comme en Italie, les villes conservent leur indépendance.

En Afrique, les invasions des Vandales et celles des Arabes n'ont pas eu le caractère destructif qu'on leur attribue généralement. Les provinces d'Afrique sont demeurées prospères jusqu'au xne siècle (1), mais leur organisation sociale et fiscale est devenue complètement arabe. Elles ont participé à la prospérité et à la décarence des Arabes.

A la fin du second siècle, les Gaules étaient déjà la province la plus importante de l'Empire romain. Pendant le $111^{\mathrm{e}}$ siècle, elles en sont demeurées longtemps séparées. Constantin et Julien ont dù l'Empire à l'influence des Gaules. Les Gaules ont essayé de soutenir l'Empire sans y parrenir : ce sont elles, en effet, qui ont supporté le poids principal des invasions. Tous les peuples du Nord s'y snnt donné rendez-rous; tous les ont traversées, plusieurs s'y sont établis. Par suite, les Gaules occupent, dés cette époque, une place de premier ordre dans l'histoire de l'Europe et dans celle de la civilisation. Elles sont le territoire où se sont juxtaposées et fusionnées les races du Nord et celles du Mlidi, les peuples germains et les peuples latins. Tout y convenait à cette ouvre, la nature de leur climat, leurs productions, la situation et l'importance du territoire. Au Midi, les races latines se sont conserrées avec les trarlitions romaines, dans le Nord ont incontestablement dominé les mours et les institutions germaniques. Il y a mème eu dans les Gaules certaines parties comme la Bretagne, le Poitou, l'Aurergne où ont survécu les

(1) Voir l'ouvage de M. de Max Latrie, Rflations et commene de l'Afrifue septentrionale ave les hations ehriticnnes au inoyen tuge, 1886. 
vieilles intluences celtiques ou kymriques, comme dans les Landes les débris de la race ibérique.

C'est par suite, dans les Gaules qu'il est le plus curieux d’étudier comment a eu lieu la dissolution des institutions fiscales de Rome, le sort qu'elles ont subi, leur transformation, enfin leur disparition, soit à raison de l'étenclue du théitre, soit à raison le l'opposition des éléments en présence.

D’ailleurs, de cette époque, s’accusait la prépondérance politique de ce territoire dont Strabon avait révélé et signalé les merveilleuses ressources. Cette prépondérance, ì travers bien des ricissitudes, s'est maintenue longtemps; malgré d’immenses changements en Europe et sur le globe, la France est encore, à 1400 ans d'interralle, un des facteurs principaux de lhistoire et de la civilisation; c'est dans les Gaules, en outre, que se rencontrent les documents les plus complets et les plus précieux sur toute cette période.

\section{\$3. Dislocation des villes et des campannes.}

"Après la chute de l'empire romain, dit Adam Smith, les ha"bitants des rilles ne furent pas mieux traités que ceux des " campagnes. Cles villes étaient, il est rrai, composées de gens "bien différents des premiers habitants des anciennes répu" bliques de Grice et d'Italie. Ce qui composait principalement " celles-ci, c’étaient les propriétaires des terres, entre lesquels le " territoire public avait été originairement divisé et qui avajent " trouvé plus commode de bàtir leurs maisons dans le voisinage "l'une de l'autre et de les environner d'une muraille pour la dé"fense commune. Au contraire, après la chute de l'empire ro" main, il parait qu’en général les propriétaires des terres ont " habité dans des chàteaux forts, sur leurs propres domaines et " au milieu de leurs tenanciers et de tous les zrens de leur dé"pendance. Les villes étaient particulierement habitées par des " artisans qui étaient alors, à ce qu'il semble, de condition ser"vile ou d'une condition qui en approchait beaucoup (1). "

(1) Richesse des nations, Livre III, chap. III. 
Adam Smith a relevé, avec sa capacité habituelle, dans ce passage, la seconde séparation qui eut lieu lors de la dislocation de l'empire romain, entre les villes et les campagnes. Mais les villes, à cette époque, avaient déjà pris et ont conservé plus d'importance qu'il ne l'a pensé. Toutes les rilles n'ont pas été soumises au régime féodal; le véritable régime féodal, au surplus, n'était pas contraire à l'indépendance des villes.

Pendant de longs siècles, à partir de la fin de l'empire romain d'Occident, cette séparation des rilles et des campagnes se maintient et mème s'aggrave. Les villes s'isolent et perdent l'influence politique. C'est un changement complet avec la civilisation grecque et romaine. Ce changement est dù aux causes que nous avons déjà indiquées, seulement elles agissent avec plus d'efficacité : $1^{\circ}$ les progrès de la culture du sol; $2^{\circ}$ les monastères et les abbares; $3^{\circ}$ l'immigration des populations i l'intérieur; $4^{\circ}$ la transformation de l'esclarage. Lne nouvelle impulsion est donnée à ce mourement par les populations germaniques qui, habituées à habiter les campagnes, conservent leurs préférences, et leurs mours.

\section{\$4. Importunce des campaynes.}

Jusqu'alors, à quelques exceptions près, l'histoire de la civilisation avait été l'histoire des villes. En Égypte, l'histoire de chacun de ses trois empires est associée à l'histoire d'une des capitales de l'Égrpte; il en est de mème pour la Chaldée, l'Assyrie, la Perse. Lacédémone et Athènes n'étaient guère que des villes. L'Empire romain est sorti d'une ville, entourée d'un fort médiocre territoire; la civilisation des Arabes a mème eu un caractère urbain. Cette race de nomades n'a grandi, n'a donné l'expression de sa puissance que dans les villes.

Il n'en a pas été de mème des races du nord, et, parmi ces races, il faut compter les Celtes, les Kỵmris, qui ont occupé le nord, l'ouest et le centre de la France, bien arant les tribus grermaniques. Lors de la conquète romaine, les Gaules étaient déjà habitées par des populations qui préléraient la vie rurale. Les villes n'étaient encore ni nombreuses, ni importantes. La 
ville gauloise, plus tard francaise, est surtout dorigine romaine.

Le changement qui transporta la vie et l'intluence politique dans les campagnes a quelque chose d'extraordinaire. Il faut, pour en bien saisir la portée, se rappeler la fonction des anciennes cités : Babyglone, Tỵr, Jérusalem, Carthage, Athènes, Rome. Tous ces organismes si puissants, tombent en ruine. La foule humaine qui les a si longtemps recherchés, les abandonne; les grands noms qu'on était habitué à vénérer, à redouter, sont oubliés. La vie est entièrement changée. Qui a conservé quelque souvenance des repas publics, du triobolon, des liturgies, des gladiateurs, du congriarium, du citoyen romain? Le consul devient un paure magistrat municipal qui s”inquiète plus des caprices du seigneur voisin que des annales de Tite-Live.

Et le fond de cette rérolution radicale (1), la raison de ce changement à rue de décor, c'est cependant encore de fermer les ergastula romains, de briser les fers de l'esclave grec, de transformer le colon latin en un métayer ou un bon vigneron qui pourra nourrir, vétir, élever, aimer sa famille, sans la permission de personne, et sans que personne lui arrache, sous forme d'impöt ou de redevance, le fruit de son labeur.

\section{\$5. De la condition des personnes.}

Dans la société grecque la composition mème de la société ne présentait pas d'embarras, les Grecs pratiquaient l'esclavage comme des pirates. Ils viraient de piraterie. Ils affranchissaient peu. A Athènes on ne trouve dans les documents historiques que des hommes libres et des esclares (2). A Lacédémone, à Thèbes, où la piraterie était plus rare, il y avait une classe intermédiaire qui se tenait plus près de la liberté que de l'esclarage. C'étaient les Pénestes, les Périèques, les Clarotes, cultivateurs du sol, dont la coutume fixait et garantissait la condition.

(1) Ingram, History of Stacery aut serfolom, 1895, 1.77. M. Ingram insiste sur les causes qui ont prépare dans la socite romaine la transformation de l'esclavage en servage.

(2) Wallon, Histotre de l'esclavage, livre I, chap. X. 
Dès l'origine, la composition de la société romaine a été plus complexe, parce que la serritude $₹$ arait une place moindre. La société était profondément aristocratique; les rangs sévèrement marqués et gardés. Patriciens, plébéiens, sénateurs, cheraliers, citoyens, il y arait entre eux, quoique libres, des démarcations perpétuelles, les démarcations s'augmentèrent encore arec la conquête : il y eut en Italie les personnes qui possédaient le Iroit de cité complet (ciritas), celles qui n'avaient que le droit latin, celles réduites au jus italicum, les Déditices, les colons des municipes; plus tard la confusion s'accrut encore: en Sicile seulement, il $y$ eut trois sortes de conditions, les tributaires, les decumani et les alliés (1). Toutes ces différences se retrouvaient, quelquefois plus nombreuses, plus variées dans les autres provinces. Il ne s'agissait dans ces distinctions que des droits politiques. Les mêmes existaient quant aux droits sociaux. Les Romains araient, toutes proportions gardées, beaucoup moins desclares que les Grecs; ils les affranchissaient plus volontiers, les affranchis entraient dans leur clientèle. Il $y$ avait bien des degrés dans la clientèle de mème que dans les affranchis. Dans les rilles les affranchis étaient plus nombreux que les esclares. Dans les campagnes on rencontre, dès les premiers temps de l'Empire, à cuté des esclares, des colons serfs ou anciens affranchis, des colons libres, sorte de métaỹers ou de fermiers. Parmi ces derniers, il faut comprendre les nombreux colons germains auxquels asile a été accordé $\{\mathbf{2}\rangle$.

Nous arons ru que peu à peu il s'était fait une sorte d'égalisation au point de rue des droits politiques, et que l'impôt avait joué un grand röle dans cette égralisation. Jusqu'à un certain point, il en a été de même quant aux conditions sociales, mais avec heaucoup plus de difficulté, de lenteur et précisément sous linfluence du mème mobile, l’impòt.

Tous les documents impériaux de la fin du $1 \mathrm{r}^{\mathrm{e}}$ et du $\mathrm{v}^{\mathrm{e}}$ siècle, résumés par II. Fustel de Coulanges dans son beau mémoire sur

(1) Vuir Fustel de Coulanges, Institutions politiques, ehap. Xr, et Dureau de La Malle, Économie politique des Romains, se vol., 336-375.

(2) Marcel Fournier, Des afjranchissements, 1582, 1. 27 et suiv. 
le colonat (1), indiquent les efforts des Empereurs pour fixer ì demeure et maintenir la condition des colons, les retenir, mème par la violence, sur les domaines qu'ils exploitent.

A cela plusieurs raisons : $1^{\circ}$ la rareté des bras eu égard an développement de la culture; $2^{\circ}$ les soustractions de colons entre propriétaires; $3^{\circ}$ les besoins croissants des prestations; les services personnels tendant à remplacer l'imprit en nature ou en argent; $4^{\circ}$ le goùt et lhabitude du vagabonlałre; $3^{\circ}$ le service militaire; $6^{\circ}$ enfin et surtout le paiement de l'imprit.

L’inscription du colon sur le livre du cens (adscriptio) était une première garantie qui répondait à toutes les nécessités. Mais la garantie pouvait ètre insuffisante. Comment réclamer, mème au propriétaire, les services de colons libres, mais qui ont disparu? De là, après bien des bésitations, la loi de Théodose portant que " dans toutes les provinces de l'Empire, c'est une règle " établie par les ancètres que les colons soient retenus par une " sorte de droit éternel; il ne leur est pas prermis ni de s'éloigner " des champs (lont ils ont la jouissance, ni d'abandonner la terre " qu'ils ont une fois mise en culture. Le colon ne peut pas aller où " il veut comme l'homme qui aurait son plein droit et qui serait "libre. S'il quitte la terre, le propriétaire a plein pouvoir pour "le ramener $(\boldsymbol{2})$. "

Plus tard Anastase et Justinien (3) adoucirent cette loi; ils décidèrent que si le colon était resté 30 ans sur la terre, par réciprocité il ne pouvait plus ètre évincé ni les conditions de l'exploitation modifiées. Il devient un tenancier à rente fixe; qui fixe cette rente? La coutume. C'est un point particulièrement élucidé par M. Fustel de Coulanges et qui est en parfait accord avec les traditions rurales, mème les traditions actuelles. La coutume est la

(1) Le colonat romain, premier mémoire contenu lins dés Richerches sur quilques problemes l'histoire, 1886 ; c'est l'ouvrage qui cclaire le mieux l'étude et la conmaissance le la louble révolution agitant l'empire romain et préparant la société féodale et la transformation de l'Eumepe; notamment les chapitres sur les colons partiaires, p. 21. - sur les saltus, 11. 25. - sur les colons germains, p. 43. - Tenurcs serviles, P. 55. - Colons eensitaircs, p. 57. - Colonat apres l'Empire, p. 145 .

(2) Fustel de Coulanges, Colonat, p. 93.

(3) Le même, I. 97. 
loi de la culture. Le contrat n'y intervient que très rarement, et seulement dans les temps dexploitation intensive, de cirilisation progressive. Le colon est héréditaire, mais il est maitre chez lui. Sa famille, son mobilier, son bétail lui appartiennent. Il peut acquérir, hériter, il est tenu seulement à la culture. Le colon suit le sort de la terre. Il est cédé avec elle, pas sans elle (1).

Telles étaient, à la fin du $v^{e}$ ou au $v^{*} 1^{c}$ siècle, les conditions des populations rurales, telles on les retrouve pendant toute la période franco-romaine. Leur état général aurait plutôt empiré, à raison du défaut de garantie, qu'il ne se serait amélioré. Néanmoins si au lieu de considérer les colons seuls on tient compte des esclaves, on constate un grand progrès. On trouve la preuve

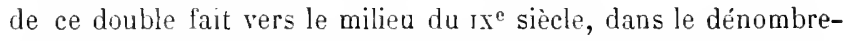
ment de la population rurale établie sur les domaines de la grande abbaye de Saint-Germain-des-Prés; cette population se décomposait ainsi $(2)$ :

10 Ménages de personnes libres............. 9

$2^{0}$ Ménağes de lèdes................. 4 ă

$3^{\circ}$ Mlénages de colons serfs............... 120

$4^{\circ}$.lénages de colons................. 2,090

$\because{ }^{\circ}$ Ménages de condition indéterminée........ 606

Ensemble........ $\overline{2,860}$

Ces ménages sont établis sur 221,187 hectares et forment un groupe de 10,282 personnes. Le groupe principal se compose de 2,080 colons, quelle est la condition de ces colons? Ce sont les colons attachés à la terre, mais l'exploitant pour leur compte. Voici ce qu'en dit M. de Vuitry. "Les colons et les lèdes for" maient plus des trois quarts des tenanciers de l'abbaye et, sans " en conclure qu“ils étaient partout ailleurs dans la même pro" portion, on peut tenir pour certain qu'ils occupaient ane place " considérable dans l'état social de cette époque, qu'ils avaient "le principal ròle dans l'exploitation du sol et que les anciens

(1) Le même, l. 117.

(2) Au. Tuitry, Études sur le régime fluancier de la France, $1^{\mathrm{er}}$ volume, p. 67. 
"imputs romains, s"il en restait, devaient surtout grever leurs "personnes et les terres qu'ils cultivaient (1)."

Les autres groupes ne sont pas moins intéressants à analyser. La liberté absolue est minime, mais elle n’a pas disparu; c'est la confirmation par la statistique des récits de Grégoire de Tours. Les esclaves n'ont 'ju un röle tout ì fait secondaire; sont-ils encore appelés colons-serfs. Les lèdes, colons-francs, montrent que l'élément germanique n’a pas d'importance. Le groupe des conditions diverses, achève le tableau, car l'anarchie profonde du $1 x^{2}$ siècle devait créer, dans les situations personnelles, bien des variations et des incertitudes (?).

Quant aux rangs supérieurs de la société, la composition en est trop connue pour qu'il y ait lieu d'insister; on y rencontrait les grands propriétaires gauleis, romains, francs, les descendants des hauts fonctionnaires romains, ducs, comtes, agents financiers, les érèques chefs d'abbayes, de monastères, tous devant leur rang et leur inlluence à l'importance de leurs possessions territoriales, virant au milieu des campagnes, dans des villæa, la plupart fortifiées; c'étaient les héritiers des hatites classes romaines, augmentées des représentants du clergé et des chefs de bandes germaniques.

Dans les villes, dominent les comtes, représentants de l'autorité centrale et les évèques; elles perdent une partie de leur population; elles souffrent plus encore que les campagnes des incursions des Sarrasins et des Northmans; elles s'entourent de murailles, elles restent pendant toute cette époque, sans influence.

\$6. De la survivance des impots romains.

La persistance des conditions sociales (3), sur lesquelles les documents contemporains ne laissent aujourd'hui aucun doute,

(1) Le mème, 1. 70.

(2) Comparez les chap. Ix it xu du lirre de M. Fustel de Cunlanges, Sur lalleu; 1892, ses conclusions sont les mêmes.

(3) Fustel de Coulanges, La wonarehie franque, 1. 219, 287, a indiqué les imphts qui avaient persisti et eenx yui avaient disparu. Parmi les premiers les 
a longtemps accrédité l'opinion que les invasions germaniques n'avaient point exercé d'influence dirimante dans les Gaules, que le gourernement romain s'était éclipsé plus de nom que de fait, que les Francs s'y étaient substitués dans le Nord, les Burgondes à l'Est, les Wisigoths au Midi, que toute l'administration romaine était restée debout et que les impòts, établis par Dioclétien et par Constantin, avaient continué d'ètre percus; c'est le système soutenu avec beaucoup de science, au siècle dernier, par l'abbé Dubos, condamné avec une certaine irritation par Boulainvilliers et Nontesquieu, relevé par un grand nombre de publicistes contemporains, MII. Pétigny, Lehuerou, Pastoret, Championnière, Guerard, Fustel de Coulangres, tandis que Baudi di Vesme, Montlosier, Pardessus adhéraient aux idées de Montesquieu. La question a été complètement élucidée par les travaux de II. Ad. Vuitry, de M. Flach et de M. Glasson. L'organisation et l'arlministration fiscales romaines ont survécu à l'empire romain dans les Gaules, pendant le vie et le vire siècles; à partir du vme siècle elles se sont peu à peu transformées pour disparaitre en partie à la fin du $x^{\mathrm{e}}$ siècle; en outre, elles se sont conservées plus intactes dans le midi que dans le nord de la France, dans les villes que dans les campagnes. Les leux capitations ont continué à ètre perçues, ainsi que les portrirt. Les prestations se sont aggrarées. Les autres taxes ont disparu. Il a été procédé sous les rois Mérovingriens à plusieurs opérations du cens, nécessaires pour l'application de la capitatio humana; ces opérations ont fini par rencontrer de grandes difficultés; elles ont mème provoqué en 613 une sorte de révolution fiscale à partir de laquelle la perception directe de l'impôt au profit du pouvoir central demeure restreinte et cesse bientòt. Nais, jusqu'à cette époque, l’impôt a été exigé de tous les contribuables, sans égard à leur origine ;

deux capitatio avec tendance à se confondre, les portoria, les corvées. Parmi les seconuls, le chrysargyum, 1. 260, 264. " Le mode de réjartition de l'impôt foncier, s'est continué de l'époque romaine à l'époque fran'jue. C'est lí un fait de la JIus grinde importance et nous aurons ì le rappeler plus tard pour rendre raison de la transformation qui se proluira dans l'impôt foncier au début de la période fíolale, p. 271. Voir également Glasson, Ibidem. 2e vol., 358, 381. 
et quand il seffondre dans l'anarchie du sme siècle, tous profitent, sans distinction de race, de sa disparition.

"On ne voit pas, dit II. Lehuerou, qüil soit question nulle "part, sous les Carlovingiens, de rien qui ressemble à l"impit "territorial et à la capitation tels qu"ils existaient sous l'Empire. "Les divers cens assis sur les biens ou sur les personnes dont "il est fait mention si sourent dans les capitulaires et ailleurs "ne sont que des rentes domaniales prayées à des propriétaires "par des censitaires et des colons. Le tribut public périt $(1$. "

\$. Les viri potentes. limmunitas et lhonor.

Cous avons vu comment les Empereurs romains, en vertu du droit qu'ils araient détablir et de modifier l'impit, en arrirèrent à l'exemption d'impòt, à l'immunité et comment cette immunité se développa progressivement, au profit des hauts fonctionnaires et des grands propriétaires au fur et à mesure que l'émancipation des classes serviles permit de les assujettir it liimpüt (2). Le caractère essentiel de la rérolution politique qui précéda et suivit la dissolution de l'Empire romain d'Occident a été de reconstituer une puissante aristocratie, formée de propriétaires, de fonctionnaires, des chefs de bande germains et des érèques. Les éléments de cette aristocratie, qui a gourerné l'Europe si longtemps et à laquelle la civilisation européenne est rederable de sa supériorité, était déjà réunis au 1 re siècle (2) . Elle a puisé ses forces dans la propriété foncière, parce qua partir du $1 \mathrm{r}^{\mathrm{e}}$ et mème du $11^{\mathrm{e}}$ siècle, la propriété fonciere prend en Europe une importance jusqu'alors relatirement moindre; le colonat a été la conséquence de ce grand mouvement territorial et agricole.

C'est alors qu'apparait dans les documents le vir potens: ce n'est plus le sénateur romain, un illustris, un clarissimus. C'est

(1) Ad. Tuitry, ibiden, 41.

(2) Fustel de Coulanges, Institutions politiquis, ch. xr. M. Fustel de Coulanges a repris cette 'puestion les immuntes dans son live sur les origines du sloteme feirlal, ch. xin, mais il he remonte yas aseez loin dans les origines de lexemption de l'imput. 
un homme puissant, un duc, un comte, un évèque, un gros propriétaire foncier. Sous les derniers empereurs, ces viri potentes avaient arraché beaucoup d'immunités particulières; quand le pouvoir central s'affaissa, ils se les attribuèrent euxmèmes. "Les fonctionnaires deviennent omnipotents : confis" cations, prestations arbitraires, exactions dans la levée des "impits deviennent l'exercice régulier de la fonction publique. "Les grands propriétaires gallo-romains se rendent plus indé"pendants encore que les fonctionnaires; ce sont eux qui, dans " chaque canton, répartissent l'impòt territorial, et ils font en " sorte d'en détourner tout le poids sur les petits cultivateurs. "Au besoin ils s'entendent arec les agents du fisc, ou bien ils "obtiennent de l'État lui-mème, soit par la collation de fonc" tions ou de titres honorifiques, soit par des privilèges, l'im"munité d'impóts. Ils se mettent en dehors et au-dessus des "lois; ils résistent par la force à la perception des impòts dont "ils n’ont pu se décharger (1). "

Le chef de bande franc, àjportionné d'un domaine, le reçut immunis, tel que le grallo-romain l'avait possédé. "Toutes les "grandes villæ gallo-romaines, dit .I. Flach, dont le proprié" taire autrefois avait su empècher l'inscription au registre ca"dastral, arrivèrent libres de toutes charges publiques aux "mains des chefs francs qui en prirent possession. Le mème " avantage fut assuré aux grandes fermes établies par les en"vahisseurs, soit sur des terres désertes, soit sur des terri" toires concédés par le roi. Les terres désertes, fort nombreuses " au $\mathrm{r}^{\mathrm{e}}$ siècle, n’étaient pas recensées. Quant aux terres du fisc, " elles passaient franches d'impòt foncier à tous ceux qui en "obtenaient la concession. Il en était ainsi du temps de l'Em"pire (2). "

D'autres, en entrant dans le mundium du roi, obtenaient l'immunitus. C'est par le mundium que l'Église parvint à protéger ses domaines et à se débarrasser de l'impòt. Le roi faisait don des charges publiques à son recommandé "ce qui équivalait à une " dispense de l'impòt foncier et à une transmission de droit aux

(1) Flach, Origines de lancienne Frunce, 1. 90. T. $1^{\text {pr }}$.

(2) Flach, Dito, p. 99. 
"imputs de capitation et de rederance. Il faisait don, en outre, "à son recommandé des amendes judiciaires Freda) qui au"raient dù tomber dans son trésor. Par cette double libéralité, "les fonctionnaires rosaux étaient écartés du territoire privilé"grié. L'accès leur en était riçoureusement interdit par la charte "rorale que nous pourons appeler maintenant de son vrai nom "charte d'immunité 1\%."

Fonctionnaires, propriétaires, chefs de bande, évèques, grands abbés étaient donc ainsi pourvus de l'immunitas.

Ils le furent aussi de l'honor 2 . On sait que les empereurs romains araient eu la faillesse de consentir quelrques déléçations dimprits. Cétait altérer la notion de l'impit; c'était en détruire la base. Ces déléçations prirent une grande extension sous les Mérovingriens. La déléfration étàit l'honor. Par l'immunitas, on était affranchi de ses propres imprits, par l'honor on acquérait les impùts dautrui. Yous y reviendrons sous le $\$ 10$ du présent chapitre où est élucidée la transformation de l'impit.

\section{S. La Dirne.}

Dès le m $^{\circ}$ siècle, oriæzène rappelait que la dime remontait à l'époque d'Abraham et qu'elle était due sur tous les produits de la terre en vertu d'un ordre direct de Dieu. Plus tard saint Augustin recommandait formellement l'établissement de la dime comme conforme ì la tradition immémoriale des peuples, comme nécessaire à l'entretien de l'Église. Les chrétiens l'acceptèrent dès lors d'une maniere générale (3. En 383 , le concile de Hâcon excommunie les personnes qui ne payent pas la dime. Les capitulaires de Charlemagne la considerent comme obligatoire. La dime variait, selon les localités, du 110 au 113 du produit brut; elle était réelle ou prédiale sur les fonds ruraux, personnelle sur les produits du travail.

Son introduction en Oceident est un fait nouveau. Les Romains l'avaient, en général, respectée, là où ils l'avaient rencontrée; ils la comprenaient dans le Tributum soli; mais ils ne l'a-

\footnotetext{
11) Flacl, Ditri, 1'. 109.

(2) Flach, Dilo, 1. 119.

(3) A1. Vuitry, 1er vol., p. 2it.
} 
vaient pas propagée. Il est intéressant, dans l'histoire de la cirilisation, de constater l'expansion des diverses formes de l'impòt. On sait combie! la dime a eu de partisans à la fin du xrri ${ }^{\circ}$ siècle. Beaucoup de personnes, même en dehors des idées de Vauban, appartenant aux divers partis révolutionnaires, admettaient que la dime pourait devenir la base de l'impòt foncier en France.

Il y eut dans l'attribution de la dime à l'Église un fait d'ordre supérieur. D'abord, au point de vue fiscal, ce fut un bien grand démembrement, un bien grand affaiblissement des ressources de l'État; ce fut une immense appropriation. Mais cette appropriation fut le résultat des changements très-considérables dans les éléments mèmes du pouvoir, du gouvernement et dans les facteurs de la cirilisation. L'F́nglise était devenue, sous l'influence d'une révolution religieuse extraordinaire, l'un des éléments du pouvoir, du gouvernement, de l'État mème, le fondement principal de la société; avec la charge de l'enseignement et de l'assistance, elle était le premier facteur de la civilisation du temps, exactement comme autrefois les Lèvites en Israël, comme les prêtres d'Egyte, comme les Brahmanes, non seulement exempts d’impòts, mais entretenus par l'impòt. La dime, dans toute l'Europe, au profit de l'Église n'a donc été nullement une usurpation, mais une modification dans la forme et l'attribution de l'impòt parallèle à un changement dans la constitution du pouvoir, de l'État, du grouvernement. Il faut voir aussi dans l'établissement de la dime, d'un cóté la marque de l'influence nouvelle en Europe des civilisations orientales, que nous arons dù mettre au premier plan, puisqu'elle ont été la force génératrice de la cirilisation, et, d'un autre còté, lintluence de la mise en culture d'une grande partie de l'Europe. I'rédominante durant lépoque franco-romaine, déjà très-importante dans la seconde période de l'empire romain, cette influence est le fait générateur de la société féodale. Développement de la culture du sol, importance des campagnes, société féodale, dime, sont concomitants, solidaires, caractéristiques des mèmes temps.

Il dut y avoir un grand accroissement de produits. Le prélèvement d'une dìme, qui variait du dixième au treizième sur les 
résultats bruts n'étaient pas une charge aussi lourde yu'on pourrait le croire. Bien autrement aléatoire est la conversion des récoltes en métaux précieux, conversion qui augmente les alirs des cultivateurs et qui a pour conditions une certaine abondance dans la masse des produits et une certain: stabilité dans leur valeur. C'est pour ces raisons, d'une part, que la Chine, l’Empire ottoman, l'Angleterre religieuse pratijuent encore la dime en nature; et, d'autre part, 'Tue l'abolition de la dime en France ne fut pas un aussi grand bienfait que l'Assemblée constituante le crut. Sur une production lrute de $2, \mathbf{1 0 0}$ à 2,800 millions de lranes les dimes représentaient en tisg environ 100 millions de franes, soit moins de 10 p. $0 / 0$ de la produetion nette 1 .

\section{S. De la rondition des terres.}

"Si nous réunissons tous les traits $(\boldsymbol{2})$ sous lesquels le do"maine du grand propriétaire vient de nous apparaitre, nou: " arons derant nous une Potestas, franche et libre, une terre " inaecessible aux arents de la foree publique et aux collecteurs "d’impits... Ouel agent du fisc oserait tenir tète au petit sou"verain 'jui § commande, pénétrer jusqu'i sa somptueuse le"meure que ne défendent pas seulement des murs et des en" ceintes (burgus, custella), mais dont l'approche est gardée par "la foule des elients? Les habitants du domaine sont les hommes "du propriétaire; il les juge, les punit, colons aussi bien qu'es" clares et affranehis. Il les assiste et les secourt. Il les encrile

(1) Nous aron rérluit le chiffre le 133 millions arance par Necker tr accelsit

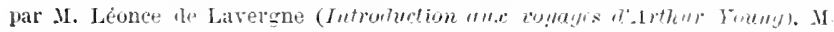

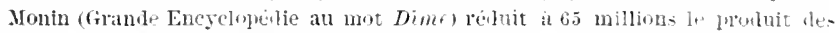

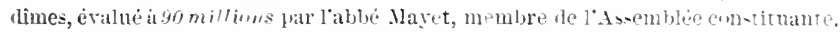
Il est certain ine diverses parties an territoire, nouvellement mises en culture, échappaient a la lime. Dautre prart, l’Église avait infénle un lartie le ses dime

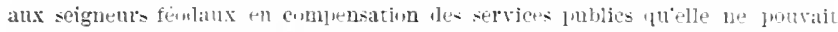
remplir ; en outre, toutus le- dimes jersmnelles affectant le travail tomberent th

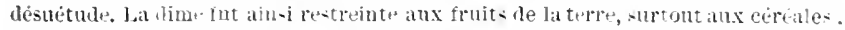

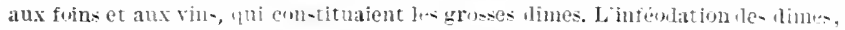

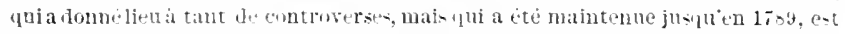

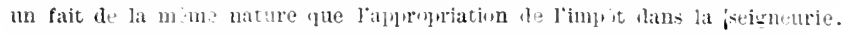

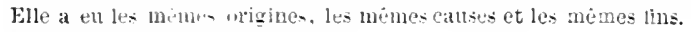

(2) Flach, wrigine, 1\% it, 99. 
" et parfois, arec leur aide, il repousse les Barbares... (1) " Ce portrait rlu grand propriétaire gallo-romain est resté exact $\mathrm{du} \mathrm{vi}^{\mathrm{e}}$ au $x l^{e}$, mème au $: 1^{e}$ siècle. Il s'applique à l'évèque et au noble franc. On dirait un riche mexicain, enfermé dans son Rancho, offrant à tout venant assistance et protection, movennant obéissance et travail $(2)$.

Les rois francs purent maintenir, à leur profit, pendant près de denx siècles, sous diverses formes, les principaux impôts romains, mais ils ne parrinrent jamais à maintenir l'ordre social, à rétablir la sécurité. Ils y furent plus impuissants que les autres gouvernements germaniques, parce que de nouvelles bandes, accourues d'au delà du Rhin, venaient sans cesse compromettre l'ordre et toute sécurité. Il en fut de mème plus tard pour les Northmans.

Confondant les époques franque et féodale, Montesquieu a soutenu, arec sa viracité habituelle, que les Francs n'avaient jamais consenti à subir les impòts romains. C'est un point que M. Ad. Vuitry a particulièrement traité (3). Les Francs ont résisté aux impôts personnels, mais ils ont partout dù se plier aux imputs provenant de la condition des terres. Cette obligation, comme il résulte de plusieurs texles célèbres de Grégoire de Tours et des traités si importants d'Andelot en 610 et de liersy-surOise en $8 \pi$, a été l'une des causes de la chute des Mérovingiens et des Carlovingiens. Elle a exercé une grande influence sur la constitution des fiefs; mais elle a subsisté rlu $v^{\circ} I^{e}$ au $v u^{e}$ siècle, et encore au $1 \mathrm{x}^{\mathrm{e}}$ siècle. Mième après l'édit de Kiersy en 877 , qui est considéré comme l'acte consacrant la dépossession fiscale des

(1) Comparer la descriftion de la vrande ferme on villit de Braine au vie siecle. Ricits dis trmps mirovingiens, tome 1.

(2) su les Haciendas lu Mexique et du Texas, For une mographie de M. Claulio Jannet, 1893.

(3) Lorsque Montesiuieu refusait aux mots census ft tributum la signification

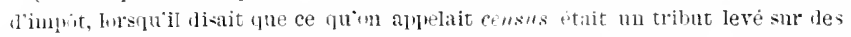
serfs, une relevince privee, nou une charge mblique, il avait en vue le dixime

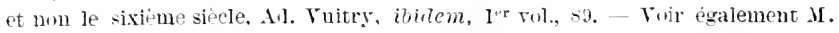

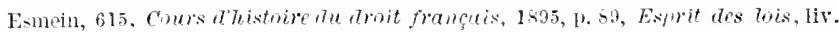

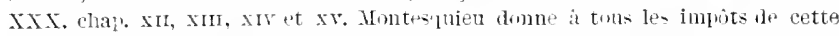

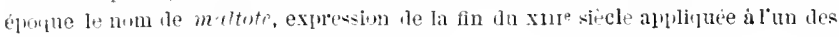
lremiels impots généraux en France. 
Carloringiens, Charles le Chaure en 879 et Raoul en 92', purent lever encore un tribut général. "Ce fut, dit M. Ad. Tuitry, le dernier subside imposé à la nation, à titre de tribut cénéral, et quatre siceles sécouleront arant que le pouvoir roval puisse seulement essager d'y aroir recours 1,."

La condition des terres se calqua, à partir du vı siècle, sur celle des personnes et suivit le sort de l'insécurité connune. D'une part il dut, jar suite du déreloppement de la culture, dans des parties éloignées, inconnues, inaccessibles du territoire sultus) se former des terres très nombreuses qui ne furent jamais soumises à limpit. D’autre part, dans les derniers temps de l'Empire, au milieu d'une anarchie croissante, l'opération du cens n'eut plus autant de régularité. Beaucoup de domaines échappèrent, mème avec la connivence des agents du fisc. Il yeut certainement, dès le ve et surtout au vie siècle, des domaines anciens ou noureaux qui ne furent pas compris daus le cens.

Pour se faire une idée assez exacte de l'état réel des Gaules à cette époque, qui s'étend du ru au $x$ é siècle, il faut ne jamais perdre de vue que la Gaule formait alors un territoire relativement très-considérable, courert de forèts, de marais et de landes, arec une population restreinte et disséminée. En 17s9, après plus de dix siecles de prosrès, il $y$ arait encore en France plus de $\mathbf{J}$ millions d'hectares en forèts, lun les et marais; c'est-à-dire le quart au moins du territoire. Les agents du fisc romain n'avaient pu exercer leur action que dans le raçon des groupes principaux, en pressurant les curiales ou propriétaires fui rivaient dans les villes. Les défrichements noureaux, les mises en culture, les plantations continuèrent, surtout par les monasteres, de toutes parts, mais à des distances relativement très-trandes.

On ne saurait trop insister sur ces défrichements, cest-à-dire sur la mise en culture du sol des Gaules. Au rne siẹcle, la forèt, la lande, le marais, devaient occuper plus des trois quarts de la superficie totale. Bénéfices, précaires, emphỵthéoses, fiefs, cen-

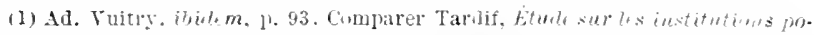

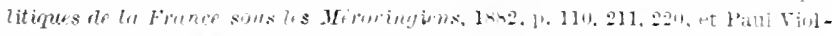

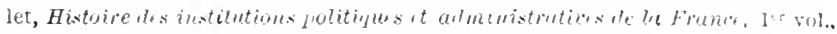
1890: 11. 319, 333, 391, 79. 
sives. toutes ces formes de la propriété araient pour fondement le défrichement, le faire-raloir. Dans la deuxième loi de la seigneurie de Coucr, revisant en 1563 celle de 1163 , le cultivateur censier a le droit de défricher telle partie qu il pourra de la forèt appartenant à la seigneurie; il derient propriétaire des lots défrichés qu’il peut vendre 1. Dapris ce fait, qui se reproduit dans des milliers de terriers, on peut juger de ce qu'étaient les Gaules du $v^{e}$ au $x_{1}^{e}$ siècle. M. Lamprecht en a dressé le tableau en marquant limportance des trois éléments de l'économie rurale de l'éporque, l'eau. la forèt, la lande. C'est de ces éléments qu'est sortie notre administration des Elux et forts 2, qui est d'origine seigneuriale 3 . Il y arait des étendues sans maitre, sans valeur aucune, des déserts, comme aux États-Lnis, qu'on nommait indominicuturu ‘. Ilỵa encore aux États-Lnis. en Argentine, au Brésil, en Australie et partoute l'Afrique, d“immenses etendues de terre sans maitre. non appropriérs. Tel était l'état des Gaules, et le résultat économique le plus considérable de la Rérolution a été de mettre en culture 7 millions d'hectares, sur les 1 :̈ millions de marais, landes et forèts en 1789. Le mourement de centralisation politique des xrn et xrmi siècles arrèta les défrichements. On en trouve une curieuse preure dans la rie de Montesquieu, auquel l'intendant de la Gusenne refusa l'autorisation de transplanter en rignes une lande près de Bordeaux 3 . En appréciant la fonction économique de l'époque féodale, nous montrerons combien elle a eu dimportance au point de vue de la mise en culture du territoire.

Aux domaines noureaux, à ceux qui échappèrent au fisc, il importe de ne pas les confondre -- sajouterent ceux qui obtin-

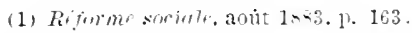

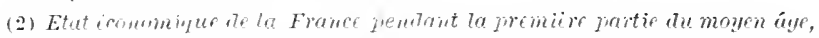
1890. livre II. chap. I ${ }^{\mathrm{er}}$. Tout lourrage est it consulter, 1. 108, 111, 140 spécialement. Comparer sur les forits en Frauce Le troit de tims itranger. Recherches sur dives stive jublics au xine siccle, par le colonel Borelli de Serres, 1896, mrrage des lihu curieux.

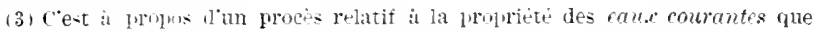

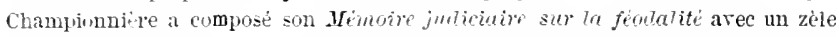
funeste is sat case.

(4) Par suite, le fief sera aplele Dominicatma, 1'. 172.

(5) Eurrs incinites de Montesquien, t. I. 
rent limmunité. Pendant l’Empire ronain, l’immunité avait été principalement personnelle; elle devint principalement réelle, foncière; elle fut accordée par les rois Francs à des personnes déterminées, mais sous une forme qui lui donnait le caractire d'une faveur, d'une exception fonciere. Les rois Francs avaient hérité de la pleine autorité impériale; ils en usaient comme les empereurs; ils alfectaient mème de se servir des mèmes procédés et des mimes expressions que les empereurs de Constantinople et de se montrer tout-puissants et capricieux comme eux. Ils avaient conservé le mème personnel fiscal et arlministratif, duces, comites, vicurii, judices, auxquels on appliquait les mèmes épithètes. Ce personnel était chargé comme, du temps de l'empire, de percevoir les imprits, de veiller à l'exécution des charges publiques. Il s'en tirait comme il pouvait, au milieu d'une anarchie effroyable, combattu entre deux tendances, celle de procurer quelques ressources au fisc royal et celle de s’en réserver davantage. Par suite, il nen était que plus ipre dans ses poursuites à l'égard soit des propriétaires, soit de tous fermiers, colons, serfs, hommes libres, réunis dans leurs villie. La forme nouvelle de l'immunitus consista à interdire aux agents du fisc, auxqueis on donna, d'après la tradition romaine, le nom générique de julices, toute entrée dans les domaines des Immunistes (1). L'Immunitus passa ainsi des persomnes aux domaines, du moins pour la partie des domaines demeurés sous la main de l'Immuniste. Mais les diverses personnes et les domaines dépendant de l'immuniste durent continuer à acquitter leurs impoits et charges. L'immuniste devait le faire lui-mème. L'Immunitus conserva ainsi, en partie, le caractère qu'elle avait à l'époque romaine. C'est un temps fort curieux de transition que Hontesquieu (2) a fort bien remarqué, qui a été quelquefois méconnu et sur lequel M. Fustel de Coulanges n’est pas lui-mème assez net. Ce qui reut dire qu'il $y$ eut diverses étapes dans les transforma-

(1) Fustel dr: Coulanges, origines du systime feodrel, chalp. xr. M. Fustel de Coulanges jusiste sur lte caractire peromel des actes dimmunite. ('t pui atait lien également sur le: regime romain.

(2) Esprit des Lots, liv. Xxx, chap. Xvi, xxi, xxir. 
tions et l'appropriation de l'impit (1). Les origines de ce mourement remontent aux derniers temps de l'Empire romain. Il a puisé de nouvelles forces dans les invasions germaniques; mais l'Immunitrs et l'Honor romains provenaient des mêmes influences que l'Immunitas et les Honsres de l'époque gallo-franke et les ont précédés; c'est le mème courant économique. Les rois mérovingiens ont procédé comme les empereurs romains, bien qu'arec des formes différentes et en attribuant plus d'importance aux terres qu'aux personnes. Au point de rue de l'impòt, il y eut agr̨ravation; mais le mourement était le mème : exemption des classes supérieures de l'impit et des cliarges publiques, parce que les progrès des classes inférieures leur permettaient d'y concourir pt que l'acquittement de l'impit et des charges publiques avait changé de caractère. Au-dessus des faits historiques, des actes, des formules, il faut reconnaitre et suivre les mouvements économiques et sociaux. La capitatio hememu n'arait jamais concerné les classes élevées, encore moins les hauts fonctionnaires, les sénateurs; 'qui aurait osé la réclamer des Potentes? Il en fut de mème pour la capitutio terrenu et toutes les autres charges romaines, les seules pratiquées du $v^{\mathrm{e}}$ au $r 1^{\mathrm{e}}$ siècle. On peut mème dire qu'elles disparurent ou se transformèrent d'ellesmèmes. Les formules des rois méronvingiens indiquent plutit leur impuissance que leur bonne volonté. Ce serait se méprendre completement sur l'époque que d'y attacher trop d'importance.

Mais tous les propriétaires n'obtenaient pas l'immunitas. On l'accordait à ceux qui étaient assez forts pour l'imposer. Dans les mouvements sociaux, surtout dans les mouvements aristocratiques, il faut compter déjà par soi-mème pour profiter du courant. Il y eut beaucoup de propriétaires, beaucoup de functionnaires qui demeurèrent, par l'infériorité de leur condition et de leurs intérèts, en dehors du courant. Ce sont ceux

1) Lan- sun traité, sur i'Immunité (Paris, 1882). U. A. Prost sembleconsidérer limmunitas comme un fait voureat qui aplarait tout ì coup et qui résulte des circon-tances. M. Fustel de Conlanges essaie de suntenir, arec plus de réserve, la méme "upinion (Origines du régime féodal, chap. xro, mais les faits et les rai-

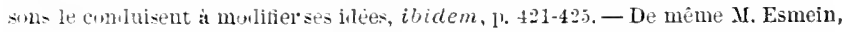
Cour's lhist. du droit, 1. 146, wégligeant l'origine romaine, ne peut donner zine raisun iconomique de l'Immuniras. 
qui èrent recours, au milieu de l'anarchie générale, à la recommandation. Les plus petits se placèrent, avec un juste instinct de leur surt, sous la protection de l'église et lui créerent son immense clientile; les autres sollicitèrent le patronage (putrocinium) des Putentes, en leur célant tout ou partie de leurs domaines.

Cette cssion était suivie d'une rétrocession, mais à titre nouveau et différent, à titre de beneficium ou bienfait. Le beneficium a eu, d'ailleurs, une autre source, la cession directe. La tenure ou propriété bénéficiaire prit, $d u v^{1} 1^{\circ}$ au $x x^{e}$ siècle, une énorme extession; elle ne prorint pas seulement de l'état anarchique de la société, du besoin d'ordre et de protection, mais du déreloprenent de la culture, de ses nécessités, de l'abondance des terrs, et de leur peu de valeur.

Les modes d'iccupation et d'exploitation spécialement romains tels que la locatire à divers termes, l'emphỵtéose ne disparurent pas ; elles e propagèrent', au contraire, au fur et à mesure de l'extension dis territoires défrichés.

Il y eut ainsiolusieurs catégories de terres : 10 les grands domaines, les vilie qui deriendront les seigneurips; $2^{\circ}$ les domaines tenus à ttre bénéficiaire provenant do la commendutio ou du beneficium; $3^{\circ}$ les domaines compris dans une locature ou une emphrtéose $; \mathfrak{t}^{\circ}$ les biens propres de l'Église; $\ddot{3}^{0}$ les domaines dits precuria, protégés par l'Ëglise.

Limmunitus cocernait essentiellement les grands domaines ou rilla. Les allex (1) qui ont tenu jusqu'en 1789. une si importante place dan l'histoire de la propriété foncière en France, faisaient partie de es grands domaines. Ils ont eu deux caractères : $1^{0}$ lexemptio dimpìts, de services, sauf le service mili-

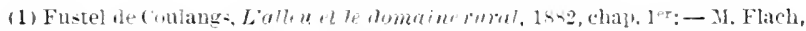

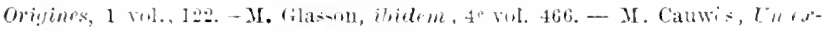

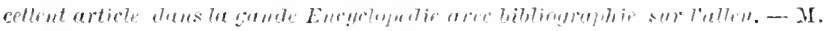

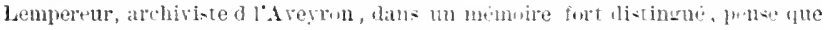

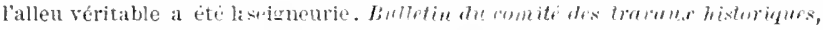

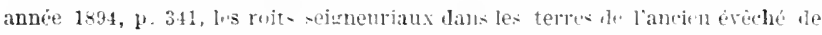

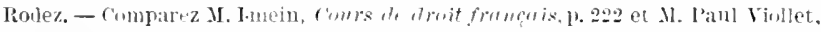

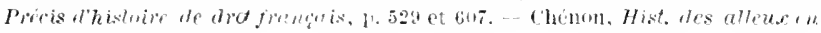
Frence, 1808 . 
taire, de charges et d'hommage pour leurs propriétaires, et $2^{\circ}$ l'héritage pour origine. C'étaient des domaines patrimoniaux et familiaux.

Mal_rú beaucoup de traraux, la discussion est encore ouverte sur la condition réelle des alleux. Les alleux ont été des domaines, de consistance très-rariable, libres d"impòts, de services et d'hommage. Par des circonstances diverses, les ures territoriales, les autres politiques, d’autres économiques, un certain nombre, surtout dans le midi de la Fiance, échapoèrent à la hiérarchie féodale. Aussi l'opinion s'est-elle fait jou'que le véritable alleu représente la véritable seignneurie, ou vlutiot la propriété foncière, le domaine acricole, sans appartznances politiques, sans liens de patronage, et, avant tou, le domaine possédé à titre d’héritagre, le domaine patrimonid; ce qui s’applique fort bien à une époque où la propriété porenait de tant d'autres causes, arec des caractères trè-lirers, wemporaire, viarer, par donation, par recommandation, par lication à temps ou perpétuelle, mème par emphytéose, par occuation, par conquite, par violence.

L'Immunitas est-elle la seule origine de l'exmption d"impòts et des charges publiques des alleux? Cela semle peu probable. Dautres causes ont dù y concourir, notammert la constitution de l'alleu sur des territoires nouveaux ou non jortés au cens.

Lalleu, tout en échappant à la hiérarchie férlale, et aux obligations qui en résultaient, profita, quant à si dépendances domaines ou personnes - de tous les arantaces de la féodalité. Il ne fut tenu à aucune obligation, sauf le serice militaire, mais il exerca tous les droits des autres seigneurio 1).

Aussi jusqu'en 1789, l'alleu n’a-t-il cessé d’ètre battu en brèches par les feudistes féodaux et surtoutpar les feudistes rọaux - mais il leur résista. Les juristes de 'Assemblée constituante, Merlin, lui-mème, tous pénétrés è lancien régime bien qu'en étant ses adversaires sourent injutes, toujours implacables, s`imaginèrent, peadant quelque tenps, que tous les

(1) In $y$ eut des anlenx froncs meme de la dime: robablement apres rachat . 
domaines rleviendraient des alleux, à la suite de l'abolition du rérrime féodal.

Tant que l'imput et les clrarges diverses purent ètre exigés, c'est-à-dire jusquà la fin du vate siècle, les domaines non garantis par limmunitus, de moins en moins nombreux, les domaines bénéficiaires spéciaux, les diverses locatures les acquittèrent selon la condition et les formes des temps. Les alleux ne le payèrent jamais. M. Flach a consacré un chapitre spécial à l’alleu. Il prouve par des documents qu il y a eu de tout temps des domaines, mème de petits domaines, entièrement libres, ne devant rien à personne - ni rederances, ni taxes - c'est un véritable phénomène fiscal, qui s'explique dès qu’on reconnait l“importance de ces deux faits principaux, pour cette époque : $1^{\circ}$ le développement de la culture; 2 o l'appropriation progressive de l'impoit.

Toutes les questions, si complexes, relatives ì la condition des terres ont été traitées, avec un talent particulier, par 11. Fustel de Coulanges dans son ourrage sur l'alleu et le tomaine rural. M. Fustel de Coulangres est certainement le publiciste français qui a eu le sentiment le plus exact de l'immense changement accompli dans la propriété foncière et la culture du sol depuis le $w^{\text {e }}$ siecle jusqu'à l'époque féorlale, qui n’a été que la consolidation de ce changement. Il a spécialement montré la constitution et la consistance des divers domaines romains, la villa qui sera la seigneurie, la manse qui sera le fief, la corrélation entre charque nature de tenure et la condition des cultivateurs; tenure servile pour le serf, tenure intermédiaire des affranchis, tenure du colon qui deviendra le censive. II y aura même plus tard plusieurs espèces de censives.

Car, dans le mouvement, si considérable, de la transformation lente de l'esclavage en servage, du servage en condition libre, il y a eu mille nuances, mille transitions dont on retrouve les traces jusqu'en 1789 et mème au delá. Ce qui est vrai de la condition les personnes est aussi vrai du la condition des terres sur laqualle la première avait et a longtemps conservé une inlluence directe. Ces distinctions fondamentales font comprendre l'état social au moyen ìge et les nombreuses appropriations et transiormations de limpit. 
Il ne faut pas juger les siècles qui nous ont précédés, surtout les époques qui ont formé le moỵen-àge, avec nos idées actuelles. La régularité, la publicité, la simplicité de toutes choses a ujourd'hui étaient remplacées par la confusion, l'obscurité et la complexité dans les conditions des biens et des personnes.

Il est certain que le fait du maintien du $v_{1}^{\mathrm{e}}$ au $x^{\mathrm{x}} \mathrm{m}^{\mathrm{e}}$ siècle de l'exemption d'impòt au profit d'un certain nombre de domaines spéciaux sur le sol français, exploité, ravagé à fond et de tout temps, de mème que l'Eggpte et l'Asie mineure, par des successions de fisc, a queliue chose de fort extraordinaire; mais, si on sort de France, et si on jette les yeux sur l'histoire de la propriété foncière et de l'impoit foncier en Europe seulement, on est beaucoup moins surpris, car on trouve plus d'un État où limpit foncier a été longtemps et est encore inconnu, notamment l'Allemagne, ou, dans certaines régions, les grandes terres en sont encore exemptes.

\section{s 10. De lappropriation de limpoit.}

Les éléments de l'appropriation de limput se trouvaient dans le double principe de l’immunité; l'exemption et la délégation de l'impist; l'Immunitas et l'Honor. Lun et l'autre prourent à quel point les notions fiscales s'étaient rapidement dégradées dans l'Empire romain. Lexemption d’impòt n’était pas entièrement étrangrère aux républiques grecque et romaine. Mais convertir l“impoit en une propriété cessible ou un don gracieux, leur a été inconnu. On rencontre toutefois des délégations d'impòt dans l’Éggple musulmane. L’impòt y derint aussi un objet de trafic. Peut-ètre en a-t-il été de mème dans lempire des Perses, puisque les satrapies étaient presque des délégations d'impót à titre onéreux.

L'Homor' a eu d'abord moins d'importance que l'Immunitas (1) dans la transformation de l'impùt. Ce fait seul suffit à démontrer que l'incidence de l'impit arait lieu sur les classes supérieures.

(i) Ad. Tuitro. Itr vil., 47. 
Il y avait, dans les premiers temps, plus d'avantages pour elles à ne pas payer l'imprit qu’à l'exiger d’autrui.

Lappropriation de l'impoit, commencée par l'Immunitas, s'est complétée par l'Homor et par la constitution de la seignemrie. Le propriétaire de la seigrneurie après avoir, pour lui, agi par exemption, s'est approprié, quant à toutes les personnes et quant à toutes les terres de la spigneurie, les impots et charges auxquels elles étaient tenues, au moyen de l'occupation et par la confusion, en sa personne, des droits de propriété et des droits de l'État.

On a longtemps affir que cette confusion arait été l'ourre et le caractère de la société féodale. Il ya, à cet égarr, une listinction importante à faire. Les seigneuries ont précédé la société féalale. Cest dans la seigneurie, cest-à-dire dans ces grandes villit, si souvent décrites par Grégoire de Tours, que la confusion a eu lieu. La société féollale a, au contraire, réglementé les seigneuries; elle leur a imposé une classification, des règles communes, des devoirs d'ordre supérieur d'où sont provenus, en partie, les droits du pouvoir roval, destiné à reconstituer l'impôt en France.

Ainsi, pour les mimes causes, sous des formes différentes, mais dans le même but que sous l'empire romain, l'Immuntus s'est développée du $v^{e}$ au $\mathrm{I}^{\mathrm{e}}$ siècle, sans abolir les impüts et les charges, autres que ceux des grands propriétaires, des Potentes, en interdisant aux judices ou au personnel fiscal de pénétrer sur les domaines, mais en réservant, au contraire, au fisc royal, dans la mesure du possible, les impóts et les charges des personnes, comme des terres sous la dépendance des Immunistes. "Voulons, " porte un acte de $70 \%$, qu'aucun fonctionnaire public n'entre dans " vos curtes pour y faire aucune perception; mais en renouve" lant cette faveur qu'aucun de rous ni de ros subordonnés ne se "permette de rien perceroir de ce qui est dù à notre fisc, mais "que les 12 solidi soient portés à notre træisor. "N. Fustel de Coulanges ajoute : "quand cette clause se tronve dans un diplóme, il " est visible que la terre privilégiée n’est pas expmpte de l'impoit; "l'impôt public subsiste (t). Sans doute, mais l"impót est déja

(1) Origims all s!lstime finderl, page 371. 
bien amoindri, puisque les plus riches personnnages en sont exempts. "Que l'érèque ou ses agents lèvent les 200 solidi "d'inferenda et $\mathbf{2 0 0}$ autres solidi d'aurum pregense qui revien"nent à notre fisc du fait de cette ville et de ses curtes (1)." Ce texte indique clairement que le potens lève déjà l'impòt, c'està-dire le fait payer par autrui.

C'est le premier degré de l'Immunitus. Restait à s'approprier les impòts payés par autrui. L’interliction faite aux judices de lever les impóts et les charges, de mème que celle de remplir leurs fonctions judiciaires. révète déjà un profond désordre, une anarchie presque absolue, en mine temps qu'une bien grande concentration de la propriété foncière. Peut-on s’imaginer dans quels dédales de détails fiscaux le trésor royal aurait été engragé šil avait eu affaire à quelques milliers de Potentes et d'érèques?

On franchit bientit le second degré, qui consista non pas dans l'abandon complet des impots, des charges, abandon qui résultait du retrait des pouvoirs des judices, mais dans la consécration rovale de cet abandon. Voici un texte donné par M. Fustel de Coulanges. "Tout ce que notre fisc avait coutume de "percevoir (sur leurs hommes, et sur ceux qui babitent leurs "terres), nous par notre bonté, nous le remettons et concédons " aux moines, afin que cela serve à l'entretien du saint lieu (2)." 11. Fustel de Coulantres cite d'autres diplomes; mais il y attache trop d'importance. On ne posséderait pas ces diplomes que l'on serait autorisé à conclure que l'appropriation rle l'imput et des charges publiques a eu lieu dans les seigneuries ou grands rlomaines, dès que les judices n'ont plus été autorisés à $y$ entrer. Pas de fisc, pas d’impot. Au surplus, les détails de toute nature que l'on possède sur les seigneuries ne permettent aucun doute sur l'appropriation de l’impit. Les diplomes n'ont que l'avantage d'en donner une preuve écrite et d’indiquer les étapes.

Il y a eu cependant un troisieme degré dans l'appropriation

(1) Dito, lage 394 .

(2) frigines du systime fédul, page 395. - Ce chapitre consacré par M. Fustel the coulanges est des plus remarquables bien que nous nen acceptions yals tutes les ikles. 
de limpit, une autre étape, peut-itre plus curieuse à étudier que les deux précédentes, plus pariculière il l’époque gallo-franke, plus caractéristique de la société féodale.

"Pour se faire obiir dans les provinces, la rovauté franke " arait à sa disposition tout un corps administratif quelle tenait " de lempire romain. Loin re le supprimer, elle le développa; " elle augmenta le nombre des agents du pouvoir; elle eut ses "Duces et ses comites, à yeu près comme lEmpire; elle eut de "plus des ricarii, des tribuni, des centenurii. Cela fit un réseau "qui courrit tout le rọ̧aume. Les dues et les contes étaient " nommis par le Roi et pouvaient ètre réroqués par lai. Les "vicaires, tribuns, centeniers paraissent aroir été nommés par " les comtes dont ils étaient les délégués. Le terme cénéral, dont " on désignait les membres de cette vaste hiérarchie adminis" trative, était celui de Julices. Ce terme renait de l'Empire ro" main. Ouand on rencontre le terme de Judex dans les lois ou " dans les textes historiques, il ne faut pas croire qu il sagisse " simplement d'un magistrat de l'ordre judiciaire. Le Julec est "un duc, un comte, un icurius, ou un centenier, c'est-à-dire " un agent de l'administration (1, ". Sous l'Empire romain, ils araient la main dans toutes les matières fiscales. II en fut de même pendant l'époque grallo-franke. C'est aux Judires que les diplómes d'Immunitus interdirent l'entrée des domaines immunistes, et par suite la perception de l'impüt et l'exécution des charges publiques, mais l'Immunitas ne fut pas accordée à tous les propriétaires; et il a dù arriver, plus d'une fois, que les Julices ont passé outre aux diplòmes. Il est certain qüils conservèrent, sous les deux premières dỵnasties, et quils eurent, sous la troisième, une très grande importance; notamment ils obtinrent en $8 \%$, par le traité de Kiersy, que lears fonctions devinssent des charges héréditaires. Ils ont rempli un ròle de premier ordre dans le régrime féodal, jusqu’en 1789. Il est résulté de l’inlluence,

(1) Fustel de Coulangrs, Origines du ststime fimlul. 1. 342. Il imprte de ne

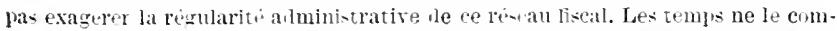
fortaient fas. En general, M. Fustel de Conlanges y attache trol d'importance.

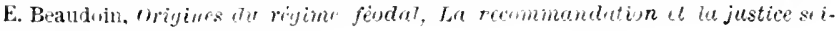
mimirale, 18 s. 
des extorsions et des droits héréditaires de ces divers personnages, une troisième et définitive appropriation de l’impót.

Championnière a jeté de vives lumières sur cette appropriation des impüts, sans en saisir complètement le caractère. Championnière n’a pas reconnu, en effet, les faits supérieurs, qui, mème en donnant aux invasions germaniques limportance la plus étendue (elle a été, en réalité, considérable), dominent toute l'histoire de la civilisation en Europe, depuis l'Empire romain jusqu'au xuse siècle : $1^{\circ}$ le développement de la culture du sol; $2^{\circ}$ l'abolition de l'esclavage $; 3^{\circ}$ la défense du territoire, et $4^{\circ}$ la formation des éléments de la nationalité. Il ne roit que violences et usurpations dans des changements dont il a perdu la clé et qu'il ne peut expliquer. Il est ainsi amené à admettre que les Judices, après ètre devenus propriétaires hèréditaires de leurs charges se seraient emparés d'une portion du revenu que l'État aurait encaissé des colons pour les propriétaires, les seniores, en mème temps que l'impit. Par suite, il introduit dans l'exploitation du sol sous l'empire, un élément, que les documents contemporains ne signalent jamais : c'est un propriétaire (possessor) dont l'État se chargerait de recevoir les revenus confondus avec l'impòt. Or, Caton l'ancien et Pline le jeune ont tracé le tableau de la condition du propriétaire à 300 ans d'intervalle. L'un et l'autre administrent directement, et à leurs risques et périls, jamais les agents de l'ararium n'ont encaissé les revenus des propriétaires(1).

Aux $\mathrm{v}^{\mathrm{e}}, \mathrm{r}^{\mathrm{e}}$ et $\mathrm{vi}^{\mathrm{e}}$ siècles, le propriétaire est à peu près le propriétaire romain. Il est plus indépendant et plus important. Il doit s'entendre arec les propriétaires d'origine germanique, dans les cantons où il s'en rencontre et, presıue partout, avec l'Église et les anciens fonctionnaires, ou leurs représentants, propriétaires eux-mèmes. Ces derniers sont les Julices ().

Le Judex, sous l'administration impériale, veillait à la perception de l'impùt et jugeait les difficultés aurquelles elle pouvait donner lieu. Il prélevait, pour sa rémunération et ses frais, une

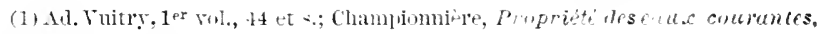
1. 181.

(2) Le mence, 1. 53 . 
part sur les receltes qui, au surplus, comprenaient une certaine somme supplémentaire pour $y$ faire face. Le Julex s’appropria cette part, probablement en l'augmentant, de mème que le $P_{0}$ tens, après s’ètre affranchi de tout impoit et de toutes charges, s'était approprié les impôts et les obligations diverses des personnes et des domaines sous sa dépendance.

Championnière ajoute que le Judex s’appropria également la portion de la rente du sol ou revenus (redilitus) qu'il encaissait autrefois pour le compte des propriétaires. Cette seconde appropriation est contradictoire avec les documents, avec l'organisation de la propriété et linfluence des Potentes ou Seniores. Elle n'aurait pu, en tout cas, aroir lieu quau détriment des petits et movens propriétaires (possessores) qui tris certainement surreillaient eux-mèmes leur exploitation; ce n'est pas à dire que quelques exemples de cette dépossession n'aient pu se produire; mais elle n’a point été ni pu ètre un fait général.

M. Ad. Vuitry a accepté le s:stème de Championnière, en s'appuyant sur un texte emprunté au Code de Justinien (1). Il admet que, dans les derniers temps de l'Empire romain, les Judices receraient des colons, d'une part, les imprits et charges diverses dits Functiones publice, et, d'autre part, les revenus des propriétaires, redditus. Ils auraient ainsi rempli le röle d'intermédiaires, de mème les Zémindars le sont devenus dans l'Inde, entre les cuitivateurs et l'État. Tout en citant le mème texte, II. Fustel de Coulanges s'est montré bien autrement réservé. Il fait payer par le colon les Functiones au Jude. et les Redditus au propriétaire. Il est inexplicable que Championnière ait pu, ainsi que M. Ad. Vuitry, se servir de textes d'un code, qui n’a été connu en Europe quau xı ${ }^{e}$ siècle, pour établir des faits fiscaux et économiques qui se seraient produits dans les Caules,

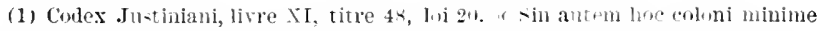
"facere voluerunt vel putuerunt, tune ilem, rellitus per witicium julicis annui "exigantur per sulita tempora et heponantur in rele sacra ". M. Al. Vuitry, tome 1 ,

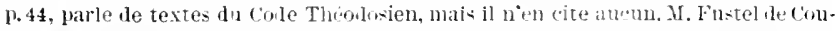

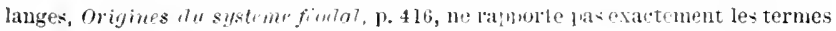

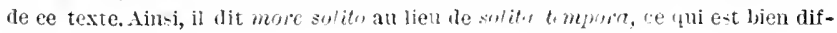
ferreut. 
du ${ }^{\prime} 1^{e}$ au $1 \mathrm{I}^{\mathrm{p}}$ siècles. Ces assertions se reliaient, dans l'esprit de Championnière, à de fausses notions sur la féodalité et à la théorie que les Judices, plus tard les seigneurs justiciers, qui ont tenu une si grande place dans la société féodale, non seulement avaient usurpé les impòts et les charges publiques, Functiones, mais encore les revenus, la rente du sol, Redditus, sur laquelle les idées de Ricardo et de Rossi avaient projeté les notions imparfaites, en complète fareur à l'époque ou Championniere écrivait. On saisit facilement limportance que certains publicistes, poursuirant longtemps après la Révolution de 1789 leurs polémiques de parti pris contre le régime féodal, pouvaient attacher à démontrer qu'une partie des propriétaires les plus anciens du sol en France avaient usurpé non seulement les impöts de l'État, mais les revenus des moṣens et petits propriétaires. C"était une thèse polilique, comme tant dautres, contre les classes supérieures qui avaient pu résister à la crise de 1789.

Le texte invoqué par Championnière et M. Ad. Vuitry, cité par M. Fustel de Coulanges, a une très grande importance économique et fiscale, mais il n’a pas le sens qu’on lui a prèté. Il signifie que lorsque le colon n’aura pu ou voulu payer, soit limpit, soit le revenu du propriétaire, celui-ci pourra faire exiger son R dilitus par le Judex, sans autoriser ce dernier à le receroir, puisque le Redditus derra ètre déposé dans une église. Rien d'extraordinaire à ce que le Judex, magistrat administratif et juliciaire, recoive ce mandat - , mais ce que le te:ite constate c'est le paiement de limpòt par le colon; c'est là le fait considérable, le fait que nous arons indiqué comme décisif dans la seconde période de l'Empire romain, le fait qui va prendre une place dominante pendant toute la période féodale et mème après elle. C'est à raison de la portée exceptionnelle de ce texte que nous avons dù entrer dans plus de détails.

L'impòt s'est trouvé ainsi complètement approprié soit par l'immunitas, soit par lhonor, soit par l'action du Judex. Cette appropriation a eu lieu aussi bien pour les impòts indirects que pour les imputs directs; chaque Potens ou chaque Judex avait la main sur les deux capitations, sur les prestations, sur les portoria, sur les péages. C'est ainsi que s'expliquent les droits, aussi 
multiples que variés, pxiggibles à tout instant, que révèlent lis documents de cette époque.

Pour achever cette dislocation de l'ktat, quelques-unes de ces appropriations tombèrent dans le commerce. Limpöt derint un droit de propricté pourles uns et une servitude pour les autres. "Les anciens impits romains, dit II. Ad. Vuitry, ainsi tombés " dans le domaine public, furent lolijet de toutes les transac"tions de la vie civile; ils se transmirent et se divisèrent par "toutes les voies du droit conventionnel. Plus tard, quand aux " onzième et douzième siècles, l'inféodation fut devenue le con"trat le plus usuel, les propriétaires de l'impoitl"inféodèrent (1 , " comme ils l'avaient partagé, donne, vendu, atfermé. Ces con"cessions furent variées. Elles comprirent tantiit le's produits de "tout un territoire, tantit ceux d'une localité déterminée. Quel"quefois elles se bornerent à tel ou tel droit, à telle ou telle "rederance : c'est ainsi que les cartulaires montrent tenus en "fiefs, des droits de péazes, de tonlieux, de foires et de marchés. "L'appropriation privée de l'impót fut complète 2 ."

Ainsi lappropriation de l’impot a eu un triple caractère. Dobord le propriétaire a cessé de payer les impots auxquels il était tenu en vertu des lois et des traditions romaines; puis il est devenu délégataire des impots dus sur sa terre par les personnes et les biens, en vertu de la charte d'Immunitas, réunissant les deux avantages de l'lmmunitas et de l'Honor des Romains de l'Empire et y correspondant entièrement. Ce propriétaire c’est le Senior (3).

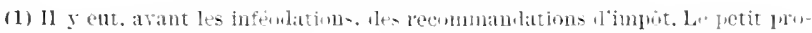

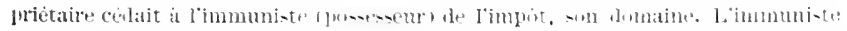

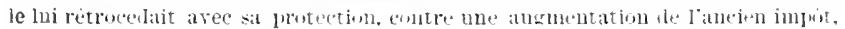

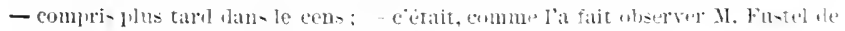

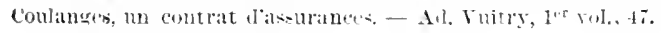

(2) AI. Vuitry, I'r vol., 53.

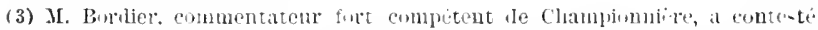

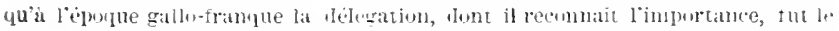

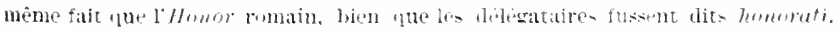

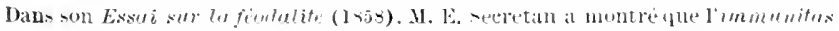

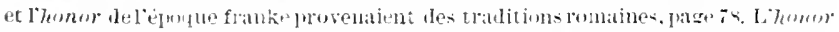

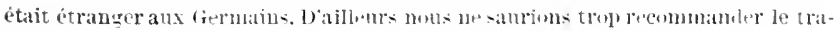

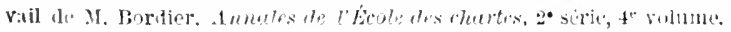


Enfin le Jude. approprié les lloits résultant de ses fonctions, consistant à rendre la justice et à percevoir les impoits, fonctions confondues plus tard dans sa Justitia (1).

De là, une situation complexe qui était parfaitement connue des feudistes, avant 1789 , mais qu'on avait perdue de vue dans la tempête de 1789; ça été le grand mérite de Championnière de la remettre en évidence $(\boldsymbol{2})$, car elle a une très-grande importance fiscale, juridique et politique.

On a vu plus haut qu'il $y$ avait plusieurs espèces de terres, d’après le régime de propriété auquel elles appartenaient (3). $1^{\circ}$ Les alleux; $2^{\circ}$ les biens de l’Église; $3^{\circ}$ les bénéfices derenus les fiefs; $4^{\circ}$ les terres pourvues de l'Immunitus. Sur lesquels de ces hiens les Judices pouvaient-ils avoir conservé le droit d'exercer leurs fonctions? Sur les bénéfices et les domaines non pourvus d'Immunitus; c'est de ce fait qu'est sortie la seigneurie justicire, celle qui avait le droit et le devoir de juger et de perceroir les impòts. C'est, dans l'ordre des pouroirs, la première seigneurie, la seigneurie qui avait le véritable commandement fiscal, administratif, juficiaire. C'est celle qui a caractérisé le seigneur haut justicier arec potence publique jusqu'en 1789. Elle représentait le magistratus romain. Surtout, c'est elle qui a eu la garde des impots, des charges publiques, de la voirie, de la police, des débris de l'administration. De là, les hauts pouvoirs des ducs, des comtes, des ricomtes, des viguiers, remontant aux fonctionnaires romains. Leur autorité s'exerçait sur tous les domaines qui n'étaient pas des alleux ou qui n'étaient pas immunistes. Cette autorité n'arait aucun fondement féodal, et cepen-

(1) Plusieurs des drotts du keirneur justicier avaient, ell effet, le earactere juliciaire: mais le mot institia provenait de la fonction th Judta it la fois ficale et judiciaire. - Ail. Vuitry, ibidem, 1. 54.

(2) Champiomiere, ibitem, 1. 275 et suiv.

(3) hes frersomes, habitues au caractere it lit foin simple et prussant de la profricte ronaine, sont lortées it etre surprises par les modalites du droit de propriété en Europe au moyel âtre, mais ees molitites existent encore, notamment dans rinle et pn Russie. Suns ce rapport voir une de nos études dans l'Économiste formenis. - bes fummens la promitite en Russit, 17 juin 1593. 
dant c est à raison delle quont eu lieu les principales attaques contre la févilalité ( 1 .

Passons à la situation du smior immuniste et de l'alleutier. Il ne paie plus d'imprits: la plupart des propriétaires les acruittaient sous l'Empire. Sil a l'mmunitus. il percoit les redevances et les impits des biens et des fersonnes compris dans son domaine; de grands changements se produiront lorsque les fiefs et les censives remplaceront les bénifices. Il rend également la justice. Il est derenu ipso farto seigneur justicier, puișue les fonctionnaires ne peuvent plus entrer sur sa terre ni pour juger, ni pour percevoir limput. Il est maitre chez lui :-

Toutefois les choses nélaient pas aussi simples qu’elles le paraissent.

1"Les Judiw's étaient sourent eux-mèmes grands propriétaires. En ce cas, ils réunissaient les avantages de la propriété à ceux de la justice; ils étaient entièrement maitres chez eux.

$2^{\circ}$ Les propriétaires ou seniores naraient pas souvent l'Immunitas; par suite sur leurs domaines il y arait deux seigneurs, le seigneur terrien. plus tarl féodal, puis le seigneur justicier. cas assez fréquent.

$3^{\circ}$ Les changements dans l'étendue des terres, changements multiples, avaient dautres consequences: tantrit la seigneurie terrienne avait un territoire plus vaste, tantit moindre que la seigneurie justicière ou réciproquement. De là bien des complications.

Létablissement du régrime féodal régularisa et ą̧rara cet état de choses; il $y$ apporta des morlifications notaliles, fui seront expliquées dans le paragraphe qui suit.

En général la proprictıs du senerr et la Justitin du Judecc. surtout dans les trìs-grands domaines, se trouvèrent réunies; mais souvent, dans les domaines de moindres dimensions, bien qüimportants encore, elles furent séparées, de telle sorte que sur un mème domaine, il se trouva reux potentes, par suite

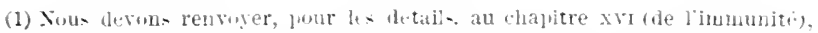

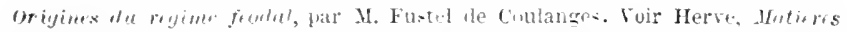

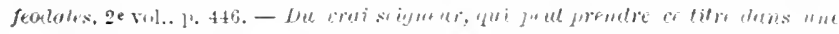

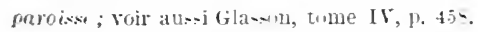

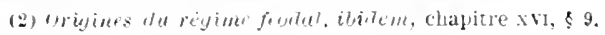


deux seirneurs. "En remontant vers la constitution originaire " de la Seigneurie et de la Justice, on trouve la puissance du "comle et celle du senior, opposées l'une à l'autre et commen"çant une lutte qui ne doit pas finir de sitòt (1) ". Le senior. est le grand propriétaire romain, qui, dans la hiérarchie féodale, va devenir le seigneur véritable, le scigneur féodal par excellence, qui vivra surtout du produit de sa terre et des redevances féodales et agricoles, quand il n'aura pas la justice. Le comes ou comte, c'est le fonctionnaire romain qui vivra, s'il est grand propriétaire, des mèmes revenus et des mèmes redevances, en mème temps que des produits exclusivement fiscaux de sa Iustitin et qui, s'il n'est pas grand propriétaire, ne vivra que de sa Justitia. Il la rendra par conséquent très-rigroureuse, trèsproductive; il aura des rapports pénibles avectous les seigneurs et toutes les populations; il sera pris en aversion; il aura des tribunaux, des greffes, des terriers, des prisons, des carcans, une multitude de petits officiers, greffiers, huissiers, voyers, cruyers et autres; il multipliera les aveux, enquètes, dénombrements et toutes sortes de procédures; et ce sera de ses exirences que proviendront les plaintes des populations et leur haine contre le régime féodal, bien que le seigneur justicier descende en droite ligne du fisc romain, tandis que la véritable féodalité, c’est-à-dire le lieu d'honneur (Fevum) reliant le rassal au seirneur raui lui a concédé un fief militaire ou une censive roturière, a eu un caractère essentiellement militaire ou agricole et jamais fiscal. M. Bordier a assez bien résumé cette situation si curieuse en disant: "La Justice est un pouroir, la seigneurie - est une propriété. La Jastice est le pouvoir tombé dans le do" maine privé; la seigneurie féodale est étrangère à l'autorité " publique, le seigneur justicier est étranger à la possession du " sol."

\section{\$11. La seignewrie.}

La seigneurie est l'un des faits les plus curieux de l'histoire de la civilisation en Europe, particulièrement en France. On ne

(1) Al Vuitry, ibintw, p. 55-58. M. Vuitry etablit que parfois le mot Justitics

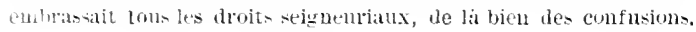


la rencontre ni en Grece, ni dans l'limpire romain, dout la cirilisation a revètu un caractère essentiellement urbain; mais elle a existé en ligrpte, dans l'Inde, en Chine, probablement dans l'empire des Perses, sans qu'on puisse dire qu'elle y ait alfecté les mèmes caracteres quen Europe. Ellw provient, avant tout, du progrès de la mise en culture du sol, de la constitution de la propriété foncière, des garanties dont la propriété foncière a été entourée, de son intluence, de ses services sociaux. C'est là son premier et fondamental élément, de mème que dans les grands Latifundia des sénateurs romains: quelques-uns de ces Latifundia existent encore aux environs de Liome, en Calabre, en Sicile; ce sont les Haciendas du Mexique, du Pérou, du Brésil, de la République . Irgentine; ce sont les grandes farms du FarWest américain, de l'Australasie, ou de l'Afrique australe; on rencontre quelques grands domaines dı mème ordre en Espagne, un grand nombre en Fussie, dans l'Nllemagne du Nord; ils se partagrent encore le sol de l'Angleterre (1. Par suite, il est tout naturel que du ler $^{\text {au }} v^{e}$ siècle, dans les Gaules qui s’étendaient jusquau Plin et dont la population ne dípassait pas 4 millions dhommes, il y eut res Haciendas; on les appelait des civitates.

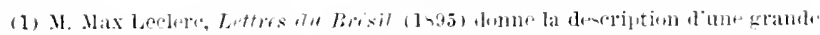

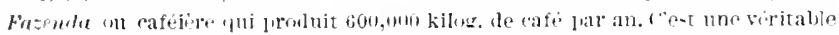

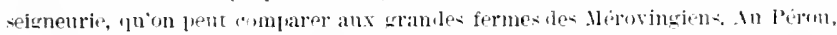

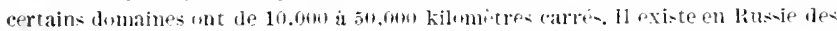

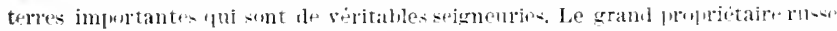

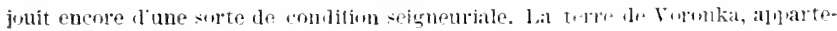

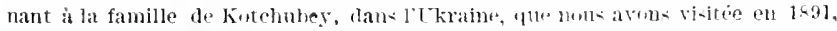

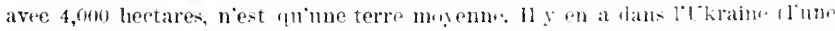

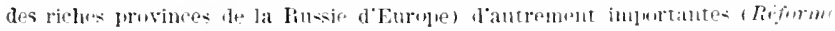

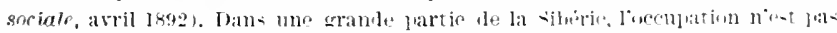

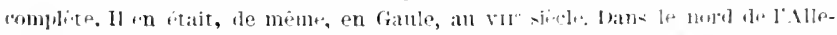
magne, talls le Mecklemlentrg notamment, il existe de framles terres on sei-

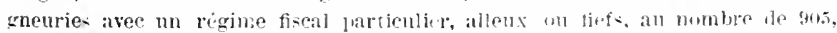

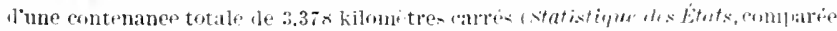

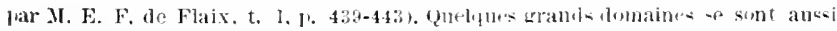

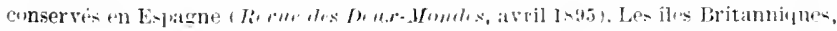

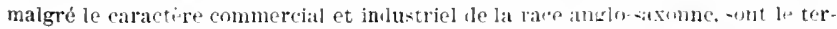

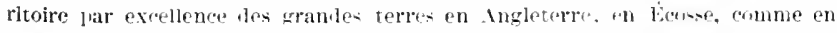

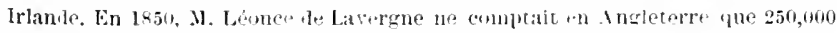
proprietaires ruranx et $\boldsymbol{i}, 600$ en Écosi. La terrede lord Lansiowne, en Irlande. contenait 10,000 hectares. 
Les civitates (1) formaient, en général, de grandes étendues qui se subdiviserent en payi, les prgi en metrocomia, celles-ci en rillix, en curta. César constatait, dès son époque, la tendance des Caubis à multiplier les pagi: mème aujourd'bui, cette tendance à linfiui morcellement en pays rlivers subsiste encore en France. Dès la chute de ladministration romaine, les cicitates se morcelèrent; d'ailleurs le développement de la mise en culture du sol favrrisa ce mouvement; il en fut de mème des incursions, occupations, colonisations des tribus germaniques, puis de l’établissement des évèchès, des archidiaconés et des doyennés, mème des abbayes ef des monastères, des châieaux forts ou castra, des villa fortifiées, des metrocomia ou réunions de villa. Tout castrum, toute metrocomia, toute grande villa, toute abbaye, tout monastère, tout évèché devint une seirrnenrie ou le centre d'une seigneurie sous divers noms : chàtellenie, haronnie, comté. M. Lon Ce serait une erreur de croire qu'il est entièrement dù aux institutions féodales. Ces institutions ont coïncidé avec l'occupation, le défrichement, l'ocupation des Gaules; mais, sans contester lintiuence que ees zrands faits économiques ont eue sur la féodalité et réciproquement, ils sont indépendants, en réalicé, les uns des autres. Demeurés romains, les civitates, les pagi, metrocomix, villat, se seraient étendus de tous côtés dans les Gaules, de mème que les fundi ou domaines. Si les lieux habités portent des noms celtiques, romains, féodaux ou des désinences germaniques, c'est que les populations s'y sont fixées aux époques celtique, romaine, germanique ou féodale. Il est facile par l'étude des noms de reconnaitre limportance supérieure des désinences romaines et féodales (3).

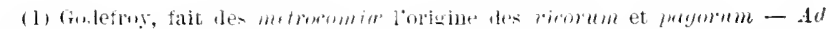

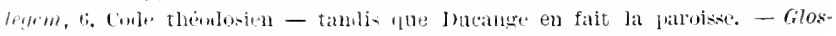
sarium, 4. vil., 291.

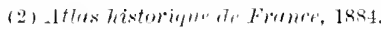

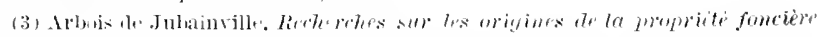

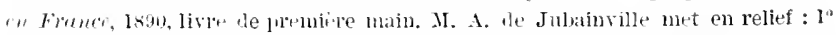
l'incertitule de la propricté tans nu milith on la population fait defaut; $2^{\circ}$ le ca-

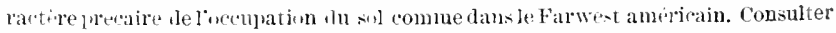
églement liourage cite plus haut de Ml. Lampecht, prineipalement le live seentrl, chaptre ill. 
Si on étudie, avec soin, les renseignements donnés par 11 . Arbois de dulainville et M. Longnon, on voit que les seigneuries ont correspondu aux centres hatités et fortifiés et qu'elles se sont morcelées en petites seigneuries on fiefs à mesure de l'accroissement des lieux habités, c’est-it-dire de la population. Le mème fait se passe aux États- $L^{-}$nis et en Australie, au milieu d'une sécurité qui, sans être entière, est tout antre. De sorte que l'histoire des seigneuries n'est autre que l'histoire de l'occupation et de la mise en culture du sol. On peut en trouver plusieurs exemples dans lourrage de X. Longrnon, tels que le comté de Vitry en Perthois, primitivement comté de Changr, le comté de Santerre, le vicomté de Thouars, les sept comtés formés du démembrement de la ciritas de Poitiers et le territoire inter duo Maria (entre deux mers en Guyenne 1).

En un mot, pour comprendre les origines, la fonction, l'histoire des seigneuries, il faut laire plus de géographie que de droit feudiste, plus d’économie politique et d'économie rurale que d’art héraldique ou de procédure. In ayprendra davantage en consultant MII. Arbois de Jubainville, Longron et les recueils darchives locales que Brussel, Henrion de Pansey et Merlin, lesquels, malgré une science juridique aiguisée, nont pas eu, pas plus que M. Guizot, et surtout qu'Auģustin Thierry, le sens économique et militaire des origines de la France féodale. La France féodale a été le produit de la mise en culture et des conditions politiques et militaires du territoire.

Nous pouvons en fournir la preuve imméliate grice à de nombreuses el récentes publications, parmi lesquelles nous arons dü faire un choix. Nous citerons ciny grandes seigneuries appartenant aux diverses parties de la Frunce: Est, Centre, Ouest, Midi. Un remarquable mémoire de M. Whenon, professeur à la Faculté de droit de Paris, inserié dans les Ḿmoires des Antiquaires du centre (2), contient l'histoire dun vaste domaine, devenu une seirneurie considérable, depuis les temps antérieurs à la conquète romaine jusqu'au plein moven ìge. Centre de population

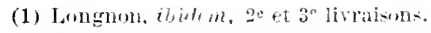

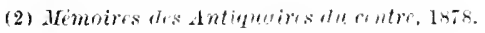


des Bituriges, en Berry, oppidum romain, pris en 583 par les Francs, depuis Castrum Melanum, chàteau .Jeillant était au commencement du sie siècle, une châtellenie, c'est-à-dire un fief noble militaire, une seigneurie, faisant partie de la grande seigneurie de Déols. La seigneurie de Déols, avec ses seirneurs, les Ebbe, a été une des principales seimneuries du centre de la France. C'est la seigneurie primordiale, dorigine tout à fait foncière, l’alleu antérieur à l'époque romaine.

Dans les mèmes conditions, la seigneurie de llontravel, en Guyenne, ne comprenait pas moins de dix-huit paroisses, ce qui correspondait à près rle 20,000 hectares. Elle appartenait au xlv siècle à l'archevèché de Bordẹux (1). En 1306, 47 tenanciers nobles, clacun avec fief militaire, prètaient à l'archevèque l'hommagre lige, tète nue, sans ceinturon ni épée. L'un de ces fiefs existe encore, avec chiteau et donjon. Le donjon est celui où Nichel Nlontaigne a récu et dans lequel il a écrit les Essais. Le fief de llontaigne avait été acquis en 1'ã par Ramon Eyquem, aïeul de Mlontaigne, marchand de sel et de pastel à Bordeaux, petit-fils d'un serf questal, entré par cet achat dans le milieu noble féodal. Le pire de Montaigne, Pierre Eyquem de Montaigne, dut faire, par suite, les camparnes d'Italie. Des parents de Montaigne possédèrent, jusque dans ces dernières années, la terre, ancien fief noble, de Cantemerle en Mlédoc. C'est ainsi que la terre et les familles sont inséparables dans les sociétés stables.

Il y a eu cependant des seigneuries plus importantes, tout en s'en tenant aux seigneuries exclusirement territoriales, sans parler des seigneuries politiques, telles que certains duchés, comtés, vicomtés qui correspondaient à des divisions territoriales ou administratıves ef qui, sauf sur les seigneuries véritablement allodiales, exercaient la fonction de seigneurie supérieure, ainsi le duché de France, le duché de Bourgogne, le duché d'Aquitaine. L'une de ces seigneuries les plus remarqua -

(1) Malvezin, Wichel Hontaifuf, sa famill, 1880, Bordeaux. Citon- encore cu Guyenue la seigneurie de Bénauge. qui comprenait 19 faroisses. Le corps prin. i hal subsiste tumjurs, de meme que le château de Michel Montaigne. sur le châtean de Benaugre, comsulter Lèn Dronyn, La fruyennf militaire. 
bles, donnant absolument liidée des Haciendas du Mexique, du Pérou ou des Faciendas du brésil a été la baromnie ou seigneurie Castelnau de Montratier-en-1) Juercy 1). Cette seigneurie avait une contenance de 30 lieues de circonférence et ne comprenait pas moins de so fiefs. C'était une terre allorliale, noble, militaire, le plus haut type de la seigneurie indépendante, remontant à l'époque romaine, probablement antérieure 2 . Son histoire est tout un drame. Elle a eu ses dynasties, ses guerres, ses malheurs, mais elle a duré jusquen lis9. Xous terminerons cette bien rapide excursion dans lihistoire des spigneuries, entreprise pour faire comprendre que la fonction politique, éronomique, militaire, sociale des seigneuries explique les changements lans les conditions de limput et des charges publiques, par le marquisat de Planey, dont thistoire est l'une des plus curieuses et des mieux faites (3). Le chiteau de Plancy. situé en pleine Champagne, a été d’abord, comme chiteau Meillant, une station romaine, dans un pays àpre et saurage. Peut-ètre saint Victor s'y est-il retiré $\left(\mathrm{rnt}^{\circ}\right.$ siècle. Au $\mathrm{x}^{\circ}$ siecle, Plancy est une seigneurie, relevant des ricomtes de Troyes et appartenant à filia, femme noble (1080). Depuis cette époque on a la liste des propriétaires ou seigneurs de Plancy, avec une importante collection de documents et de chartes, à laquelle nous reviendrons à propos des droits féodaux. Les seigneurs de Plancy nont pas joué les mèmes ròles politiques que les larons de Craon, de chiteau Meillant, de Montratier. Ce sont de réritables senion'es, propriétaires simplement. La seigneurie s’augmenta beaucoup prar la mise en culture de terres nouvelles. La famille de Guénéraud en devint propriétaire en 1667 ; elle fit procéder a un dénombrement régulier des fiefs, villes, villages et paroisses de la seigneurie, document du plus grand intérèt au point de vue des revenus de la terre, des imprits, des droits féodaux. Après plusieurs mutations, elle fut acquise par des financiers littérateurs, les d'Aucour

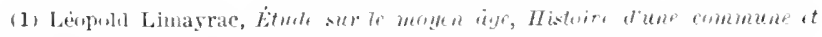

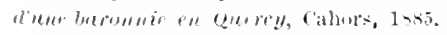

(2) Reforme sorialt, janvier lixhe.

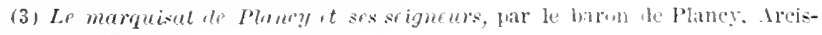
slir-Aube, 1895. 
qui n’émigrèrent pas et la préservèrent des V'andales de 1793. Un d'Aucour est devenu préfet sous Napoléon, qui redora les armoiries de la famille. Nais la terre est encore la mème. En 1815, on ne se rendait encore à Plancy quà cheval.

Nous citerons, comme autre type, la grande seigneurie de Clermont en Beauroisis sur laquelle $\mathrm{M}$. le vicomte de Luçay a publié un important mémoire. Peut-être moins considérable que celle de Montratier, elle contenait plus de fiefs et surtout des fiefs plus riches, ì raison de sa situation dans un territoire tout autrement fertile. Elle s'étendait sur 1,;00 fiefs et arrière-fiefs. C'est la seigneurie dont Philippe de Beaumanoir a écrit les coutumes (1).

A ces types, on pourrait en ajouter des milliers d'autres $(\boldsymbol{2})$. On se trouve alors transporté dans des milieux bien différents de ceux rlont les ouvragres des feudistes, des légistes rérolutionnaires et des historiens citadins donnent lidée.

L'occupation, la culture, le partage de la terre, tel est le premier élément de la seigneurie; c'est un élément économique, foncier, agricole. Il suffit d'ouvrir les documents relatifs à quelques-uns de ces grands domaines pour le reconnaitre. Pas besoin de eorles, de formules, de juristes, mais l'intelligence des

(1) Le comte de Clermont en Bunvisin. - Lf denombermont de 13\%3, Paris, 1878 .

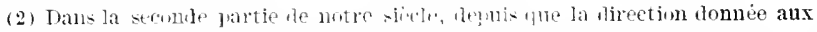

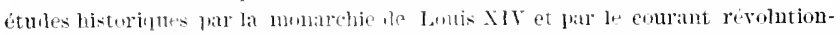

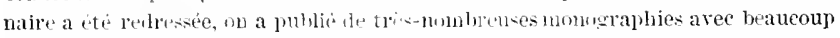

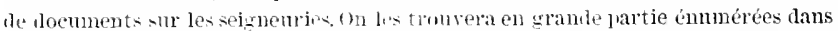

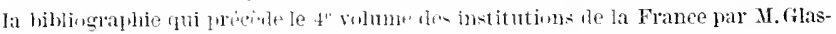

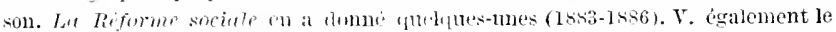

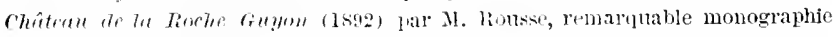
a'nne torre noh]e depuis lix siecles. - La Rorhe Tulbot, dans le Maine, par le

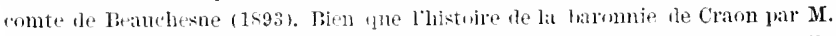

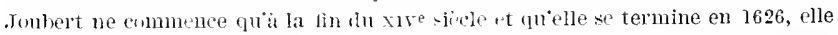
nen est fas muns interessante jom montrex la luntetion que les folulations onb lingtemps remamlée aux seigneurs. on troure meme dans l'histoire the cette srignenrit un traite formel de protertim. Le barm siblige, moyennant cspress

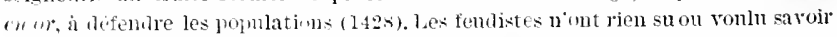
de tout cela, de mème ine les saluns, wir Vultaile lisait la Pucelle, n'ont rien comfris a la mission de Jeanne d'Are. Cotte harmmie, située aux confins de l'Anjou et de la Bretagne, setendait sur 68 fiłfis. Le grant chateau, bâti sur loudon, confrenait 27 tours, arec une muraille fle 2 à 3 mètres depaisseur. 
faits économiques. Ainsi pour la seigneurie de Montratier, en mème temps que l'on suit ses destinées historiques par la succession de ses familles seigneuriales, on assiste aux extensions des cultures, i la transformation les redevances el des droits, ainsi qu'aux changements dans la condition des populations. Il est clair que les publicistes qui se morfondent à s'imaginer que la petite propriété de 10 arés a 1 hectare est le nec plus ultia de lappropriation du sol -- nous avons mis en scène un centurion romain dont la famille risait sur un lot d'un hectare ne peuvent que difficilement comprendre pourquoi et comment il a existé en France des domaines de 30 lieues de circonférence. Ce sont leurs écrits rqui ont jeté tant l'obscurité sur l'époque dont nous nous occupons. C'est l'époque de la très-rrande propriété dans l'Europe accidentale, de l'occupation d'immenses étendues. Il en est de mime aujourd'bui aux États-Unis, dans l'Afrique australe, en Australasie, dans l'Amérique tu Sud, oì les domaines ont peut-ètre des formes moindres, mais encore colossales, comparées ì nutre conception démocratique le l'appropriation de la terre. La seigneurie a été la forme de loccupation et du défrichement du sol en Europe et en France, de mème que la Farm dans la colonisation anglo-saxonne (1) et l'Hacienda dans l'Amérique espagnole.

Sans une très-nette intelligence de ce premier élément, qui est tout économique, l'histoire fiscale de l'Europe occidentale, du $v^{e}$ au $x^{\prime} l_{1}{ }^{e}$ siècle, est incompréhensible et on s'expose aux erreurs profondes et aux actes révolutionnaires de l'Assemblée constituante, mème sous la direction de Merlin.

La seigneurie a été également un centre de production, production arricole, production industrielle; c'est dans les seirneuries que se sont formés, surtout dans les abbayes, les premiers ateliers industriels, cordonniers, taillandiers, fondeurs, forgerons, orlèrres, serruriers, charpentiers, tourneurs. Charlemagne recommandait que dans toutes ses fermes les ateliers fussent tenus

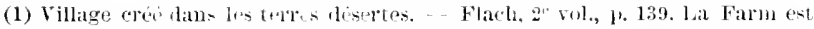

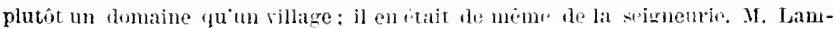

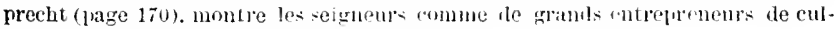
ture, des sortes de squuttris. 
en état, approvisionnés d'ourriers et surreillés, notamment pour le tissage de la laine et du lin (1).

A ces éléments économiques principaux il sest joint un autre élément de nature différente, un nouvel ordre politique et social, à la place de l’anarchie profonde qui est résultée de la dislocation de l’Empire romain, sous l’influence principales de causes intérieures et des invasions. La grande propriété, sur laquelle les empereurs romains seétaient exclusirement appurés depuis Dioclétien, est derenue l'héritière d’un pouroir qui sombrait. Ce prouroir est passé, en Gaules, dans les mains des Mérovingiens, puis dans celles des successeurs de Charlemagne, mais il n'a pu garantir l'ordre politique et social. Les grands propriétaires, les seniores, se sont trourés ipso facto investis de cette obligation, aussi bien pour eux-mèmes que pour les autres.

"Le rosaume, écrirait Noreau de Beaumont, l'un des pu"blicistes financiers les plus instruits du xrnte siècle, s'est trouvé "la proje d'une mulitude de seigneurs qui tous regardaient " comme faisant partie de leurs seigneuries des droits et des "rederances qui, autrefois, arajent appartenu à l'État ". Rousselot de Surgy ajoutait : "Ils s’approprièrent les tributs, les "amendes, les droits du roi dont ils n'ètaient auparavant que "les receveurs " $\in t$ Henrion du Pansey : "L Limpòt fut trans"formé en droit seigneurial; le cens levint l'un des attributs " du seigneur (2). ")

Ces publicistes, fort distingués, se trompent complètement quand ils parlent d'usurpation. Ils disent vrai quand ils parlent dappropriation, mais ils oublient d'ajouter qu'elle était nécessaire. Leurs idées ont été partagées par toutes les personnes instruites de la période monarchique; elles ont beaucoup contribué à répandre sur l'époque féodale en Europe les notions les plus fausses et parfois les plus extravagantes. L'impôt féodal s'est constitué dans la seigneurie; la seigneurie est le moule de la société féodale; elle en est aussi le pouvoir, le grouvernement; elle est la forme de l'Etat. Pendant plusieurs siècles, dans toute

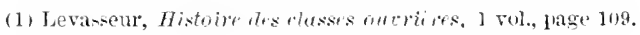

(2) Citations de M. 11. Fuitry, 20 ru., 1. 20 et 23. 
l'Europe occidentale, méridionale, centrale mème, il n'y eut plus de pouvoir, de gouvernement, d'Elat. A la suite de la dislocation et de la chute de l'Empire romain; en particulier, dans la Gaule franque, les Mérovingiens, puis les Carlovingrions, aprís Charlemagne, furent impuissants sinon à fonder, du moins à maintenir le pouvoir, un crouvernement durable et respecté. Ils ne purent sulfire à assurer l'ordre social. Aucun de leurs grands ofticiers ou feudataires, aucun exèque n'y parvint darantage. Moreau de Beaumont et tous les feudistes $d u x r 1^{e}$ siècle, mème le plus récent, Merlin, vivant au milieu de la sécurité profonde des derniers jours d'une puissante monarchie, nont pas été à mème de se faire une idre exacte de l'état politique et social des principales nations de l'Europe à la chute de l'Empire romain d'Occident.

La seigneurie a été une forme locale, mais réelle du pouroir, par suite le seimneur s’appropria l’impot. C'était sa mission, son droit, son devoir. M. Flach a très-bien marqué les diverses étapes ou trausformations de la propriété foncière qui ont abouti à la seigneurie. A travers toutes les ejoques se dessine et s'accentue la suprématie de la grande propriété foncière. Après la conquète romaine, indépendance du grand seigneur gallo-romain; au $v^{e}$ et au vile siècle, domination des propriétaires puissants, des riri potentes, sur des circonscriptions territoriales; an $1 x^{e}$ le domaine devient une potestrs; enfin au $x^{e}$ siècle le grand propriétaire terrien est investi d'une souveraineté de fait 1 .

La seigneurie est la grande propriété a laquelle se sont jointes l'immunitas et l'honor, ce qu'on appelle la potestus. A cet égard M. Flach insiste aver raison, sur le fait que, dans les anciennes civilisations le proprietaire a toujours joui de la potestas domestique, par une tradition immémoriale et incontestée. Le propriétaire français actuel ne donne pas l'idée de l'ancien propriétaire à Rome et en Grèce, ni mème dans plusieurs États de l'Europe, encore moins aux litats-Unis, en Australie et en Orient. La

(I) M. Flach a honnés au premier folume de son ourrage, origints do l'an-

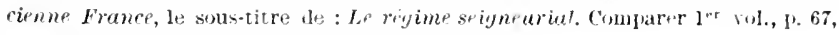

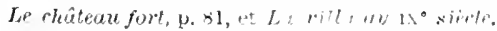


force des choses, au milieu de la dissolution et de l'anarchie des invasions, compléta cette potestus au profit de l'homme puissant "qui a de nombreux hommes darmes, des retraites assurées "Castella', qui a des soldats, des parsans, des villages entiers " dans sa clientèle ". Voilà le seigneur. Il ne doit l'impùt à personne; il lève sur ses terres les impòts accoutumés et il exerce la justice 1. Cest le résultat du temps. Il commande parce qu'il n'existe pas d'autre pouvoir que le sien et que la possession du sol a toujours été, sera toujours une force, plus ou moins grande selon les circonstances.

Les droits seigneuriaux sont les impits auxquels il a droit en rertu de la coutume (ils ne sont autres que lesimpôts romains). Ilais il est en mème temps propriétaire. Comment distinguer entre ses droits comme seigneur, dépositaire de la puissance, de la protection publique et partant de l'impòt, et ses droits comme propriétaire?

En ce qui est des imprits indirects, la distinction était possible. Aussi le seigneur a-t-il plus tard perdu une partie des taxes indirectes. Cela était moins facile en ce qui concerne les impoits et les revenus de la terre. De là une confusion qui s'est perpétuée jusquen 1789. La mème confusion a eu lieu en Ergypte.

En eflet, comme la mème personne réunissait sur sa tète la propritus et la jutestas, qu'est-il arrivé? c'est que les garanties indispensables a lexploitation du sol ont prévalu sur le caprice inhérent à la potestus. Les droits du seigneur sont devenus immuables et le colon a été considéré comme possesseur immuaLle de sa tenure. Voilà les éléments de la censive roturière qui a été pour les classes agricoles un immense progrès puisqu'elles sont devenues libres propriétaires d'une grande partie du territoire moyennant des rederances fixées par une coutume immémoriale. M. Ad. Vuitry a donné de nombreuses citations sur ce dernier point qui est conforme, au surplus, aux textes des lois romaines, réunis par II. Fustel de Cuulanges. L'édit de 61 ŏ portait textuellement que les impòts ne seront exigés que suivant 
la coutume. II. Borilier a étahli que la coutume antique de chaque localité a partout limité les droits seigneuriaux. "Outre "l'impit dù à l't́tat, a lit .1. Liuerard, les colons acquittaient "ordinairement au profit de leurs maitres une rellerance an"nuelle, suirant les conventions ou l'usaçe th qui ne pouctait "être aurgmentée 1."

M. Guérard continue:

"Si, d'un cité, la condition du colon, inclinait rers la serri" tude, de l'autre, la serritude s'élevait de plus en plus vers la " liberté. La possession se conrertit en propriéte entre les mains " des serfs cultivateurs, comme entre celles des bénéficiers; le "simple tenancier se rendit proprietaire de sa tenure en mème "temps que les offuciers du Roi s'uppropriérent leurs honneurs "et leurs bénéfices; les uns et les autres quittèrent leur condi"tion en mème temp's pour passer dans une toute autre, bien " différente et bien supérieure, ear de simples possesseurs qu'ils "étaient jadis, ils se trourèrent au $\mathrm{x}^{\mathrm{e}}$ siècle de réritables pro"priétaires. A partir de cette époque, les chartes et tous les "autres documents témoignent d'une srande rérolution dans "les plus basses comme dans les plus hautes spheres de la so" ciété. Ce sont d'autres institutions, d'autres droits, dautres " usages. Les colons et les hommes non libres sont confoudus " arec les serfs pour ne composer arec eux qu'une classe de "personnes. Les rederances et les services apparaissent sous "une forme nouvelle... La propriété de son champ n"est plus " contestee au rillain qui la définitivement conquise; s'il a dé" sormais à combattre, ce n'est plus pour la propriété, mais "pour la franchise et pour l’indépendance de sa terre 2. . "

Ainsi les droits seigneuriaux n’ont pas été une usurpation sur les cultivateurs, mais une appropriation nécessaire d'après la forme nourelle de l'État. Ils comprenaient une part d'impit, mais une part plus grande de rente et de revenus léritimes, fixées par la coutume. Tous ces résultats sont conformes à lérolutior de la propriété foncirre dans la plupart des États.

(1) Ad. Vuitry, 1er vil.. 62, 81.

(2) Ad. Tuitry, der vol., 72 . 
Trois sortes d'impit ont survécu : $1^{\circ}$ les impôts directs, ta capitation foncière et la capitation personnelle; $2^{\circ}$ les Portoria, devenus les droits de tonlieu et de péagre; $3^{\circ}$ les prestations qui se sont multipliées et dautant plus lourdes; $4^{\circ}$ il faut y ajouter la dime.

11. Ad. Vuitṛ̂ admet que tous ces impòts " restèrent à la charge "des personnes, presque toutes de condition servile, placées "ris-à-vis des propriétaires dans des liens de dépendance per"sonnelle, mais aỹant sur la terre un droit perpétuel et hérédi"taire 1). "

Peut-ètre en a-t-il été ainsi pour la seconde partie de cette période: quant à la première, il est difficile de partag̣er le sentiment de Il. Ad. Vuitry. Les documents contemporains représentent ces populations comme absolument hors d'état de supporter limprit. Les temps étaient trop difficiles; elles-mêmes étaient trop près de la serritude. "La capitation personnelle, dit M. Ad. "Vuitry, était si accablante pour les familles que beaucoup de "parents souhaitaient la mort de leurs enfants afin de ne pas "ètre contraints de la paỵer ". La reine Bathilde, veuve de Cloris 11 , en déchargea les enfants. Comment done auraient-ils pu faire face aux prestations, aux portorir, à la capitation foncière 2$)$ ?

En analysant les éléments de la population des terres de l’abbaỵe de Saint-Germain-des-Prés, nous arons reconnu que la masse était composée de colons à perpétuelle demeure et de personnes de condition indéterminée. Le nombre des ménages libres était sans importance. Sous l'Empire, le propriétaire derait parfois avancer l'imput pour ses colons et sadresser au Judex : combien tout était devenu plus difficile des $\gamma^{\mathrm{e}}$ au $v^{\mathrm{e}} \mathrm{u}^{\mathrm{e}}$ siècle! Les impits retombaient à la charge des propriétaires formant une aristocratie puissante, seule force sociale du temps. De là ses efforts, pendant deux siècles, pour se débarrasser des charges qu'elle ne pouvait répercuter; de là les érénements qui préparent l'édit de 61 ŏ; de là la transformation de l’impòt.

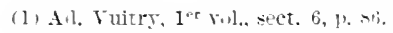

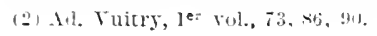


"Cette espèce de charte politique, dit M. Ad. V'uitry, à pro"pos du traité de 613 , est peut-être le monument législatif le "plus considérable de la dynastie mérovingienne. Il est un té"moignage irrécusable de limportance qu'avaient prise à cette "époque les questions fiscales. Sur les divers articles que com"prend l'édit de 613 , huit s'appliquent à des matières de finances " et d'impóts." "L'un garantit le droit de succession ab intestat "et défend aux agents de l'autorité publique, et spécialement a " ceux de l'administration fiscale dy mettre obstacle. D'autres "ordonnent la suppression des nouveaux cens qui ont provo"qué des réclamations, ou ils interdisent tont accroissement du " tarif des tonlieux, res péages, e’est-à-rlire des impòts indirects "Ils constatent done l'existence des anciens imprits; ils as" surent leur maintien; en mème temps, ils décrètent leur fixité " et font ainsi commencer en cette matière l'empire de lu cou"tume. En outre, ils ont implicitement pour effet de conserver, "en ce qui concerne le cens, les exemptions déjà obtenues et " conquises par l'Égrlise et par les Francs (1). " Liempire de la coutume n'est autre que la théorie des économistes sur la fixité de l'impùt, théorie entièrement opposée it la tradition de l'impüt romain.

A partir du xe siècle la situation change. La condition des seigneurs et des coluns s'améliore parallèlement; ceux-ci sont devenus propriétaires des impòts; ceux-là de leurs tenures. En outre, la coutume a été applípuée comme règle aux uns comme aux autres. Le jeu naturel des lois économiques a dès lors tendu à rejeter sur les colons l'efficacité de l'impüt, souvent confondu avec les direrses redevances agricoles et foncieres, puisquils pouvaient le supporter.

Il en a été de mème de la dime. Dans la première partie de cette période, elle a di rester au compte des propriétaires; dans la seconde, elle a été supportée par les colons.

C'est un moment important dans l'histoire de l'impuit et méme dans celle de la cirilisation. Il n'est pas possible de lui indiquer une date même approximative; mais il n’? a aucune témérité at

(1) 1 iol., 9u. 
penser que les classes rurales, dans toute l'Europe occidentale, ont largement profité du grand mouvement qui se manifeste dans le cours du $\mathrm{xl}^{\circ}$ siècle et qui prépare les Croisades. Les Croisades n'ont pu avoir lieu qu'à une époque prospère. L’émancipation de ces classes n'est pas encore achevée. Les Croisades vont leur fournir l'occasion de la poursuivre rapidement; mais elles prélèvent déjà une part plus grande dans la production; elles jouissent de plus de liberté; une part de l'impòt leur incombe nécessairement.

En outre, de ces deux premiers éléments, d'un còté, l'occupation, le défrichement et la mise en culture du sol, et d'un autre côté, le maintien d'un ordre régulier au milieu d'une anarchie complète, désespérée, pour employer les termes mèmes des chroniqueurs du temps, éléments dont les feudistes royaux, tels que Loysel et surtout Merlin, n'ont eu aucune idée, il y a lieu d'en étudier un troisième de première importance, l'élément militaire (1). C'est dans la seigneurie que se sont fixés et qu'ont pris corps les liens militaires du comitatus germanique, au moyen de la constitution des fiefs et de la transformation des bénéfices en fiefs, l'une et l'autre ayant pour fondement le service militaire. Agrandie avec les bénéfices, longtemps temporaires et viagers, la seigneurie s'est morcelée avec les fiefs héréditaires. C'est dans les fiefs que se sont formées les traditions, les mœurs, les idées, les familles militaires de la France. Acquérir un fief, c'était devenir militaire; le propriétaire d'un fief était dit miles. Pendant plusieurs siècles, les seigneurs ont été les défenseurs de l'ordre social et du territoire. C'est ce que M. Fustel de Coulanges a nettement établi en contradiction arec les attaques des feudistes aux ordres de la Royauté et avec les injustices et les passions, nées du mouvement réformateur du xvıl ${ }^{\mathrm{e}}$ siècle. Le seigneur, a démontré M. Fustel de Coulanges, a été un défenseur, un protecteur, celui danslequel

(1) Voir deux articles remariluables de M. Fustel de Coulanges dans la Revue des Deu.r.Mondes, 15 mai 1573 et ler aunt 1574 . Ces denx articles nont pas été reprodults dans les reurres de. M. Fustel de Coulanses: un doit le regretter. Jamais M. Fustel de Coulanges n'a été mieux inspiré. 
les populations tourmentées, pressurées, accablées par l'anarchie du $1 \mathrm{x}^{\mathrm{e}}$ siècle se sont mises à espérer in quem sperure). De là la popularité réelle dont la féodalité a été entourée pendant plusieurs siècles. "Les peuples se serrent autour de leurs défenseurs, "autour des seifneur's et des comtes. Rien de plus populaire que "la féodalité à sa naissance. Le sourenir confus de cette popu"larité est resté dans les romans où Géraril de Roussillon, où "Renaudiet les autres fils d'Aymon soutiennent une lutte hérö̈"que contre Charlemagne.... ilichelet continue. "La fusion des " races commence et la société cherche à šasseoir. La France "voudrait devenir un monde social, mais l'orranisation d'un " tel monde suppose l'ordre et la fixité. La fixité, l'attachement " au sol, à la propriẻté, cette condition impossible à remplir " tant que durent les immigrations des races nouvelles; elle ne le " sera complètement que par la féodalité... (1)."

Nème au point de vue fiscal, il y a liẹ d'insister sur le caractère militaire de la féodalité et sur les services militaires qu'elle a rendus, d'abord en fermant le territoire aux invasions, puis en faisant les Croisades, enfin en fournissant les cadres des familles à l'aide desquels la monarchie a constitué la France. Dans celte constitution, l'ceurre des classes féodales et des classes rurales a été énorme, celle des classes du tiers-ètat bien moindre (2). C'est avec la plus grande persistance que les classes moyennes sont devenues étrangères au service militaire. Hème quand elles acquéraient des fiefs nolıles militaires, elles araient la prétention de profiter des avantages, sans remplir les charges; ce qui a été le cas de Montaigne lui-mème; or, le service militaire a décimé les nobles et livré leurs fiefs aux classes moyennes. Les privilèges, les exemptions d'impöt, les immunités, les honores avaient une pesante compensation, la défense du territoire, l'éducation militaire, la vie militaire $(3.1$ cet étgard, il a

(1) Michelet, Hist. df. France, 1 vol., Jage 408.

(2) Aug. Thierry, sous l’influ-nce du frarti libéral de la Restauration, a san* doute retrace avec un grand talent l'histoire lu tier-ectat, mais il a mblie l'his-

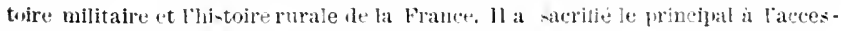
soire.

(3) La chesateris, far M. Lein fiantier. 
existé de curieux rapports entre la chevalerie militaire française, les familles nobles militaires françaises et les systimes militaires de l'Égyte, de lacédėmone et de Rome. Le réritable service militaire, accepté par tous, comme dans la Rome républicaine, ne date en France que de 18 : 2 (1).

Il est sorti des foyers militaires seigneuriaux, une race d'hommes extraordinaire. Cette race a fait les Croisades, qui ont été et qui Aemeureront l'époque héroïque de la France $(\cdot \overrightarrow{2})$. Les clientèles commerciales de la France par tout l'Orient s'y rattachent (3). Ces hommes ont porté le nom et les souvenirs de la France en Syrie, à Rhodes, à Chypre, en Crète, en Égypte, en Tunisie, à Constantinople, dans la Grèce entière. Ces sourenirs n’ont pas disparu. La France est populaire dans tout l'Orient. A aucun moment de son listoire, la France n’a été plus influente, plus cirilisatrice que du sue au xive siècle. La France de saint Louis a été moins pompeuse, mais plus grande que celle de Louis XIV. A ces mèmes foyers transformés, mais encore les mèmes, ont appartenu les familles militaires qui ont releré la France du xre et du xrne siècles. Les services des familles militaires de la France sont attestés par les plus illustres souvenirs de la patrie : Philippe-Anguste, saint Louis, Duguesclin, Jeanne d'Arc, Richemont, Bayard, Guise, Henri IV, Turenne, Condé. Plus d'un général de la Rérolution ou de l'Empire a eu les mèmes origines: Davout, Marmont, la Riboissière; le maréchal Bugeaud lui-mème est né dans un rieux nid seigneurial. La Piconnerie.

Nous n'entreprendrons pas de tracer le tableau d'une seigneurie. Nous renvoyons à l'excellent ouvrage de M. Dareste de la Chavanne dans lequel la formation, l'exploitation, les conditions des seigneuries ont été remarquablement étudiées. M. Dareste de la Chavanne n’a cependant pas insisté sur la fonction mi-

(1) Voir, di-apres nos réflexiu- à lropon du ervice militaire prour les tenures "n roture, les commumes et les villes.

(2) Comparer les reflexions de M. Finlay, History of Grofed, t. 4, p. 67, sur la standeur de lat France du xir siecle.

(3) La France entretient encure a rec l" Empire ut toman un commerce considérable : clle vitut au recond lang. alues l'Angletere, arec $\$ 02$ millions de francs en 1894. 
litaire, nationale, protectrice des seigneuries: c'est dans la seigneurie que s’est organisée la résistance, contre les Northmans, les Allemands au Tord, les Sarrasins au Midi, avant la véritable époque féodale. Ce point, si essentiel, si important, a été mis particulierement en relief par Nichelet, par X. Fustel de Coulanges et par M. Flach. On a dit que la royauté avait fait la France, cest une vérité incomplète. La royauté a réuni les éléments de la nationalité en un faisceau puissant; mais beaucoup de ces éléments ne proviennent pas d'elle; ils proviennent de la seigneurie; mieurs militaires, mours agricoles, hahitudes du travail ont été façonnées dans la seirnneurie. Il existe encore, en France, plusieurs anciennes seigneuries, celle de Meillant en Poitou, celle de Valencay dans le Berry et bien d'autres, car da propriété foncière possèrle une force de résistance correspondant à la vitalité de la nature elle-mème. On peut encore y étudier sur place les populations seirneuriales. Ces populations valent bien celles des rrands centres industriels modernes. Peut-ètre sont-elles moins actives; mais elles sont aussi plus saines, plus vigoureuses et plus heureuses (1). La seigneurie a survécu, en effet, à la société féodale dont elle a été l'élément constituant. mais par laquelle elle n`a pas été absorbèe. Des temps malheureux pourraient reconstituer la seigneurie, parce que la propriété foncière sera toujours la condition et la garantie d'une véritable civilisation.

\section{S12. Résumé ginérul de cette periode.}

Résumons à grands traits cette période si intéressante. Dès l'époque de Dioclétien l'impit avait pris un caractère rural; il portait, avant tout, sur la production agricole. Avec l'accroissement des cultures et l'importance des campagnes, cette tendance devint encore plus grande. La vie politique et sociale eut son foyer dans les campagnes, dans les trandes exploitations ou domaines qu'on peut comparer aux Hacienlıs du Mexique et de l'Amérique du Sud. C'est là que les Germains aimaient à habiter; les

(1) Point de vne develunte arec talent par Wichel Chevalier. 
Gallo-Romains firent de mème et le mouvement devint général. Les habitations furent fortifiées dans un but de sécurité publique, en rue de protéger les populations. Ainsi se créèrent les seigneuries par un mourement naturel, social, national. Lorsqu'un centre fut formé, beaucoup de propriétaires s'y rallièrent par la recommandation, et placèrent leurs personnes et leurs terres sous la dépendance du seigneur, moyennant sa protection; de mème le seigneur accorda la jouissance ou le bénéfice de diverses parties de la seigneurie aux familles qui venaient s'y établir; par suite, c’est dans la seigneurie que l'impòt s'est transformé. Le seigneur en ètait le propriétaire, le dispensateur, le maitre. Du $\mathrm{rx}^{\mathrm{e}}$ au $\mathrm{xu}^{\mathrm{e}}$ siècle cet état de choses s'est maintenu dans la plus grande partie de l'Europe. Les grands Capétiens, qui out préparé la formation de la France, n'ont levé des impits que sur les terres dont ils étaient les seigneurs. Le fait de l'État, et le fait de deroir et de payer l'impoit à l'État avaient été remplacés par le fait du seigneur, et par le fait de devoir et de payer l'impit au seigneur.

Dans beaucoup de seigneuries, les droits du propriétaire primordial, du senior, et les droits du fonctionnaire, du judex furent réunis. Dans quelques autres, ils demeurèrent séparés. Il y eut, parfois, deux seigneurs dans la mème seigneurie - le seigneur propriétaire et le seigrneur justicier. Ce second seigneur était investi des dronts de l'ancien jurlex. c'est-à-dire des droits de justice, dont l'impìt était l'élément principal. Cette distinction s'est maintenue, en France, jusqu'en 1789, arec de nombreuses difficultès tenant soit aux origines mêmes des deux espèces de seigneuries, soit à leur superposition dans bien des cas, soit à leur séparation dans beaucoup d’autres. En général, le seiEneur justicier a été le seigneur d'ordre supérieur. Il représentait, en effet, non pas l'influence de la terre et la richesse, mais l'autorité publique. Quant au baron féodal, le senior sans justice, il a tenu bon jusqu'en 1789 et mème au-delà. Le départ entre le pouvoir que donne la richesse et le pouvoir que donne la fonction publique est toujours difficile à faire. Qu'est un préfet républieain à còté d'un grand industriel, ou d'un grand propriétaire, ou d'un grand banquier? Il est moins important qu'un chef 
de rạon achalandé dans une coopérative importante, celui-ci peut compter sur sa place grâce à sa clientèle; mais que va devenir l'autre?

Ce qui veut dire que, dans les transformations socialès, les éléments économiques ont plus de résistance, de force et de durée, bien que moins d'éclat, que les éléments politiques.

Quel plus amusant type que celui de Godard d'Aucour, fermier général, littérateur, poète, vaudevilliste, qui remplace à Plancy les chevaliers des Croisades, fait gérer sa terre par un parent de Danton, n’émigre pas, la conserve intacte et se métamorphose en préfet de Napoléon!

Eh bien! la terre de Plancy a été transmise pendant plus de trois siècles dans la famille des d'Aucour et, en 18 1 , le baron d'Aucour, après s'ètre engagé, à l'igge de plus de ö0 ans, parmi les mobiles de l'Aube, et avoir combattu à Bagneux, à còté du comte de Dampierre, a été élu membre de l'Assemblée nationale.

Il y a donc des traditions d'honneur immuables, attachées i lin possession du sol. 


\section{CHAPITRE III.}

L'ÉPOQUE FÉOTALE EX FRANCE.

\section{\$1. Caractères généraux de la féodulité en France.}

La féodalité est tout à fait postérieure à la constitution de la seigneurie. La seigneurie en a été l'élément générateur. La féodalité est, avant tout, un organisme militaire; la seigneurie un organisme économique, politique, social.

On peut fort bien considérer la féodalité comme la confédération, l'association, le syndicat, la cristallisation des seigneuries. La féodalité ne s'est faite, comme une sorte de soudure des seignneuries, que lorsque la dỹnastie des Carlovingiens, c'est-à-dire la Royauté, eut reconnu son impuissance à garantir aux intérêts sociaux la protection dont ils ont toujours besoin (1). Le traité de Kiersy, en $8 \pi$, constata cette impuissance. Charles le Chauve accorda l'hérédité de leurs fonctions et de leurs bénéfices (Honores), aux Comtes, à tous les grands feudataires, c'est-à-dire aux seigneurs les plus considérables, aux propriétaires les plus importants, à ceux qui représentaient les principales parties du territoire. Ce traité n'ajouta rien, en fait, à leurs propriétés foncières, tout en sanctionnant, en droit, l'hérédité de celles qu'ils possédaient, à titre précaire, de la Royauté; mais il leur conféra la perpétuité, l'hérédité des fonctions politiques dont ils étaient revètus à titre temporaire $(2)$. En outre, il accorda aux vassaux les mèmes arantages qu'aux Comtes. Les Comtes représentent les seigneuries et les rassaux les fiefs. Et il prescrivit aux érèques, abbés, Comtes, d'en faire autant pour leurs propres vassaux. L'hérédité devint le fondement de tout, elle assit tout.

(1) Glasson, Institutions de la France, $4 \mathrm{e}$ rol., introduction. - Mortet, article Feolalite (grande Encyclopedie), travail important.

(2) H. Martin, Historie de France, 2e vol., $46 \pi$. 
En réalité, Charles le Chauve ne fit que sanctionner un état de choses préexistant, auquel le pouvoir royal ne pourait s'opposer et qui était l'expression d'une nécessité politique et sociale.

A l'anarchie intérieure se joignaient les incursions des Northmans, des Sarrasins, des IIongrois, qui la rendaient plus intolérable encore. Rien de surprenant si, de ce chaos, est sortiun frand mouvement militaire ayant pour fondements la propriété foncière, le salut public, la défense du territoire et des populations. C'est ce que Nichelet a si bien expliqué, il y a déjà 60 ans, et c'est ce qu'au milieu des splendeurs de Louis XIV, Loysel avait absolument oublié : "Ces libérateurs du pays occuperont les défilés " des montagnes, les passes des tleuves; ils y dresseront leurs " forts (castra); ils s'y maintiendront à la fois et contre les bar"bares et contre le prince. Les peuples se serreront autour de "leurs défenseurs, autour des seigneurs, des Comtes ". "Celui" ci perche arec l'aigle; l'autre se retranche derrière le torrent. "L'homme prend racine, il s"incorpore à la terre; naguère l'homme "était une personne, la loi était personnelle. Aujourd"hui, l'homme "s'est fait terre; la loi est territoriale (1)".

A cet égard, il est indispensable de ne pas oublier quelles étaient les conditions économiques et sociales de la Gaule franque après la dissolution de l'empire éphémère de Charlemagne. On en trouvera le tableau, tracé d'après les sources mêmes, dans les premiers chapitres du second volume de l'ourrage de M. Flach; les villages de la Gaule romaine et de la Gaule franque, les effets des invasions sarrasines, normandes et hongroises, le chàteau-fort remplaçant la villa, les débris des villie, les villæ transformées eu villages, les villages indépendants, les villages créés dans les forèts, les bourgs-neufs, les asiles et les sauvetés. Ces formes diverses de l'occupation du territoire correspondaient, d'une part, à l'anarchie générale de l'époque et au besoin de sécurité, d'autre part, aux proụrès des défrichements et des cultures (2). Les sametés étaient des centres de culture,

(1) Histoire de France, 1 rol., 1. 429.

(2) En somme, le grand proprietaire (le sfuior ou le jutr,r), rit sur sa terre comme dans un camp' retranché, aree une maraille et des forts, oi il échaple aux pouwirs publies et oil il leur soustrait tuus ceux qui se sont mis dans sa clientèle 
d'élevage de bétail, de foires, comme il s'en crée chaque année aux litats-Unis, qui se formaient sous la protection des abbayes; ainsi l'abbaye de la Sauve, Entre-deux-Mers, en Guyenne, devenue actuellement une école départementale (1).

Dès que ces foyers sont constitués, l'impòt $\mathrm{y}$ fait son apparition, comme le résultat naturel, et mème, comme la condition nécessaire, de toute aggrlomération. Prenons-le dans sa molécule génératrice. "Tous les habitants, qu'ils soient ou non tenanciers, " sont astreints au droit de gite, quand arrive dans le bourg " un personnage de marque. Tous aussi doivent, en pareille "accurrence, faire un crédit de 13 jours pour le paiement du " pain, de la viande et de toutes autres denrées marchandes. "Enfin un impòt est levé sur les bœufs, les porcs, le vin vendu, " un denier par porc, deux par bœuf $(2)$ ".

Le milieu est troublé, anarchique, mais plein de sève et de vie. Le régime féodal donnera à ce milieu, non pas une sécurité complète qu'il ne supporterait pas, mais une sécurité d'ordre supérieur, sans amoindrir ses forces vitales. Pendant toute l'époque féodale, à raison mème de l'intensité du développement agricole, il y a eu, en France, comme une surabondance de vie.

Les seigneuries, les abbayes, sortes de seigneuries monacales, étaient éparses de tous cìtés sur le territoire, séparées par de grandes distances; les chàteaux-forts, qui en étaient le centre, se rencontraient, au fond des forèts, comme Plancy ou Bénauge, Chateau Meillant; sur des plateaux éloignés, comme Montratier; au passage des fleuves et des rivières, comme Craon. La féodalité a consisté à souder les uns aux autres, par la force mème des choses, les éléments divers réunis dans les seigneuries, à demander à la terre, à la propriété foncière, les premières ressources

(E. Beauloin, onvrage dejjá cité, page 88). M. Beautoin oublie que ces pontoirs fublics ont disparu et rue les barons de Montratier, le Château Meillant, de Bénange, de Plancy, de Cran, étalent les véritables jouvoir's jublics; cétait à eux que les polulatious sidressaient.

(1) L'Église de cette saureté est encore un des beaus monumeuts du moyen âge cn Gruemue.

(2) Flach, Origines, 2 fol., 1'. 200. C'est l'impôt sur le butail, tradition des anciens temps, tratition des peuples nomades. 
pour reconstituer le territoire, puis le gourernement, puis la nation. C'est un premier mouvement d'une très grande intensité, parce qu'il est territorial, rers la formation de la nationalité. Son aurre principale a été le territoir

C'est bien ainsi que l'a compris Michelet lui-mème dans l'une de ses plus belles inspirations.

"La variété infinie du monde féodal, la multiplicité dobjets "par laquelle il fatigue d'abord la vue et l'attention, n'en est "pas moins la révélation de la France. Pour la première fois "elle se produit dans sa forme géographique. Lorsque le vent " emporte ce vain et uniforme brouillard, dont l'empire allemand " arait tout courert et tout obscurci, le pays apparait, dans ses "dirersités locales, resserré par ses montagnes, par ses rivières; "ses divisions politiques répondent ici aux dwisions phryiques. "Bien loin qu'il y ait, comme on l'a dit, confusion et chaos, e'est " un ordre, une régularité inéritable et fatale. Chose bizarre! Yos " 86 départements répondent, à peu de chose prés, aux 86 dis"tricts des capitulaires, d'où sont sorties la plupart des sourerai"netés féodales, et la Rérolution qui renait donner le dernier coup "à la féodalité. l'a imitée malı̌ré elle (1)."

Et cependant, malgré un brillant déreloppement de cinq siècles, du $\mathrm{s}^{\mathrm{e}}$ au $\mathrm{x}_{\mathrm{i}}^{\mathrm{e}}$, et une longue transformation, puis, décadence, de cinq siècles encore, du xive au xvile, e'est-à-dire après dix siècles d'existence, la forme particulière, à plusieurs égards supérieure, que la féodalité arait imprimée à la propriété foncière en France, Y a presque complètement disparu pour reprendre la forme de la propriété romaine quiritaire. La France présente mème ce singulier contraste quaprès aroir été la partie de l'Europe où la léodalité a eu son plus rif éclat, c'est aussi la partie de l'Europe où elle a laissé, dans les institutions le moins de traces, bien que les monuments, les sourenirs, les traditions y reportent sans cesse les générations. Ainsi l’Angleterre, toute l'Allemagne du Yord, l'ltalie, l'Espagne, quoique moins pénétrées par l'esprit féodal que la France, sont restées tout autrement sous l'intluence du mourement féodal. Nous n'hésitons pas

(1) Histoire de Frumer, 2" volume, page 2. 
à attribuer ces contrastes au caractère particulier de la race celtique ou gauloise, à sa nature, profondément individualiste, d'une part, et à la persistance de l'influence de la civilisation latine, d'autre part; à cet égard, le lisre de Pierre de Fontaines:1) est un monument historique de premier ordre. On ne saurait trop le relire. Pien d`intéressant comme de voir le vieux juriste féodal, après avoir disserté sur les coutumes qui n'ont aucun rapport arec le droit romain, s'occuper tout à coup d'L'lpian et de Paulus et crnduire son lecteur du milieu féodal dans le milieu romain. Cette conduite fut considérablement facilitée par la supériorité de civilisation de la France romaine du midi sur la civilisation de la France féodale du nord, par l'action de la papauté, par celle de l'Eglise romaine dominant en France aux $\mathrm{x}_{1} \mathrm{e}, \mathrm{x}_{1} \mathrm{e}^{\mathrm{e}}$ et $x_{1} \mathrm{v}^{\mathrm{e}}$ siècles. Le droit romain envahit alors la France, il y est enseigné de toutes parts; il $y$ a eu au xum siecle comme une première Renaissance. Les monuments juridiques romajns révèlent à tous les esprits perspicaces, tels que Pierre de Fontaines, un droit de propriété tout autre et, à beaucoup d'égards, supérieur à la propriété féodale, un droit in rem, absolu, primordial, qui ne connait pas de supérieur, qui n'est subordonné à aucune condition, qui résulte ou de l'occupation, comme la plupart des seigneuries, ou de la convention, du contrat.

Ce n'est pas que, sur tout le territoire des Gaules, on puisse dire que ce droit absolu de la propriété eùt complètement disparu. L’alleu héréditaire en portait la marque, en conservait la tradition; quoique l'alleu lui-mème, soit à raison du service militaire, soit à raison de la justice, eùt souvent subi l'intluence de l'association féodale; mais le mouvement général du développement de la mise en culture du territoire et de la propriété foncière, s'était opéré dans une autre direction, provenant et des nécessités économiques, et des lois de la décadence de l'empire romain, et des invasions du Nord comme du Midi. Cette direction avait pour fondement la concession du sol à temps au

(1) Ximprte l'auteur anonyme ou suppost du const il a un ami. Im sait qu'il al té composé rers le milieu du xur siecle, cela suffit pour lui dommer son véritable caractire. Farre, Intrulution au glossaire de Laurière. 
lieu de la vente, le bail emphytéotique ou perpétuel au lieu de la transmission complète. Deux causes historiques à cette direction: d'abord, linncertitude et l'imperfection du droit de propriété chez les Germains et ensuite les nécessités que les temps, la nature des choses imposèrent aux concessions du sol, aux exploitations des cultures dans les derniers sièeles le lempire romain. Dans leurs deux livres remarquables sur les locations perpétuelles. MM. Ciarsonnet et Lefort ont parfiatement indiqué ces origines, en suivant chez les divers peuples de l'kmpire et chez les direrses races les oscillations des formes différentes du droit de propriété sur le globe 1).

Lorsque commença et s'étendit ce grand mourement d'occupation et de défrichement du territoire européen. vers le ine et le we siècles. mouvement qu'il ne faut jamais perdre de rue dans l'histoire de la propriété foncière et des impûts en Europe, en mìne temps que s'accomplissaient de si grands changements dans la condition personnelle des hommes, la forme absolue de la propriété romaine quiritaire, adaptée parfaitement au territoire du Latium, très restreint et très peuplé, ne convenait plus à d'immenses solitudes, courertes de marécages et de forèts, oi l'homme avait plus de valeur que la terre (2. De là les locations perpétuelles où à long terme qui araient linexprimalde arantage de fixer l'homme à la terre. Telle a été et telle est encore la condition de la Russie, ou le Vir a retenu et retient l'homme. de mème que les diverses formes de locations perpétuelles du $1 x^{*}$ au $x{ }^{\mathrm{e}}$ siècle le retenaient en faisant de lui un propriétaire conditionnel (3).

Fief, bail à cens, bail à rente foncière, champart, bordelağe,

(f) E. Garsonnct, professeur a la Faculte de droit le l'ari-, Mistoir des loca-

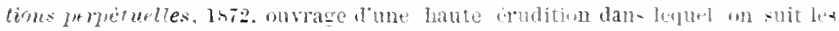
diverses etapes de la double trau formation le letat des teres. des personues

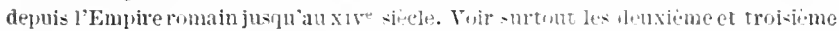

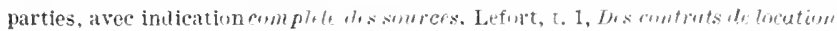

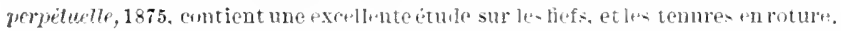

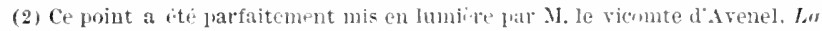

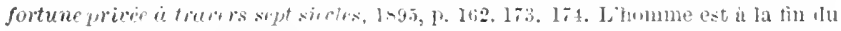
xue siecle le bien lo plue precienx. on st larrache. p. 175.

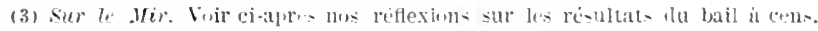
Mackenzie Wallace. Lat Retsole, chapitre 29 at 32. 
métairie, bail congéable, bail colonger, tenure en échevinage, emphytéose ont été des formes diverses d'occupation conditionnelle du sol présentant le double avantage, pour le seigneur ou propriétaire primordial de peupler, de défendre et de cultiver sa seigneurie et, pour le tenancier, de devenir propriétaire sans bourse délier, association plus farorable au tenancier que le Mir qui ne l'a jamais enrichi et qui a facilité son asservissement, ou que le prèt hypothécaire, surtout à une époque d'extrème rareté et cherté des capitaux.

Nalgré ces avantages, le moment dut venir cependant où bien des roturiers et mème des possesseurs de fiefs se laissèrent entrainer comme Pierre de Fontaines par le libre droit de propriété romaine. Hommage, fidélité, dénombrements coùteux, aides, quint ef requint, rachats, reliefs, amortissement pour les uns, cens, rente, partage des fruits, aveux, tailtes, gites, corvées, banalités, tonlieux, lods et ventes, pour les autres, parurent accablants et sans fondements; greffes, offices, terriers à entretenir; tout cela desint à la fois onéreux, humiliant, désagréable.

C'est que les formes de la propriété adaptées, du $\mathrm{I}^{\mathrm{e}}$ au xu $\mathrm{u}^{\mathrm{e}}$ siècle, à l'état économique et social en France, qui ont pu persister du xire au xrne siècle - sans dépasser le milieu du siècle - ne convenaient réellement plus à l'époque où ont brillé Descartes, Pascal, Corneille et Molière. On en a la preuve dans les ordonnances qui précédèrent et suivirent les grands jour's d'Aucergne. Ces ordonnances montrent à la fois combien il était déjà nécessaire et facile de modifier des institutions qui avaient fait leur temps. C'est ce dont Colbert était entièrement convaincu. Louis XIV préféra placer son petit-fils sur le trine de toutes les Espagnes, par des guerres qui ont ruiné la dynastie et compromis l'avenir de notre race, que de renouveler un matériel sans valeur; on ne saurait comparer ce matériel tel que l'ont connu Fénelon, Vauban et Nontesquieu qu'à ces vieilles machines qu'on montre, dans les écoles d'arts et métiers, comme les modèles primitifs de l'industrie (1).

(1) Telle est limpression qute latise un ourrage récent sur la fémlalité dans le

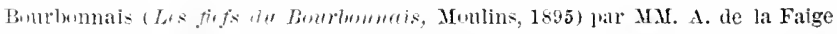

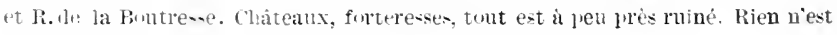

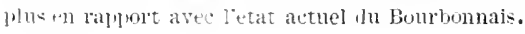


11 est vrai que sur dautres territoires d'autres races conservent encore des formes plus antiques de la propriété, notamment en Chine, dans l'Inde, en Perse, en Russie, dans l'Empire ottoman et que les formes féordales on seigneuriales de la propriété foncière tiennent encore une assez grande place chez diverses nations de l'Europe. Il est probable que c'est à la diversité des tendances des races qu'il faut faire remonter ces ditférences. Loin de nous de considérer comme tout à fait définitive pour l'avenir de l'humanité, à raison de sa supériorité, la forme de propriété qui a prévalu en France. Il est probable que des hommes d'État, comme Richelieu et Colbert, auraicnt pu suffisamment émonder l'arbre remarquable qui avair jeté de si profondes racines et qui s'était couvert d’une si brillante régétation sur le sol français, pour le raviver et l'adapter à des temps nouveaux. En tout cas, notre petite propriété parcellaire qui a provoqué tant de dithyrambes et de statistiques, n'est plus entourée d'aucun engouement. Elle ne retient plus personne aux champs. Elle n'apparait plus comme l'élément d'une démocratie satisfaite, mais elle a certainement amoindri le nombre et la consistance de nos familles, limité l'essort de notre race et contribué à lui prèparer un avenir qui n'est pas sans inspirer quelque perplexité.

\section{§ 2. Les fiefs ct le service milituire.}

Lorgane essentiel de la féodalité c'est le domaine militaire, le fief avec service militaire obligatoire (1). Le service militaire obligatoire, c'est le prix du fief. La seigneurie s'est démembrée en fiets afin de se procurer et de s'assurer les moyens de sa défense, défense du sol, défense des populations. Avant tout et partout, la féodalité a consisté à former une aristocratie militaire, qui n’était pas sans ressemblance avec les anciennes aristocraties d'Égypte, d'Assyrie, de Perse, de Grèce et de Rome, même avec celle des Arabes musulmans, au moyen de la terre, de la propriété foncière. Le service militaire obligatoire! II a fallu les plus grands

(1) Cujas le detinit. Feudum est jus in praln alieno, in perpetum utemil faciendi, quod pro beneficis dominus dat calege, ut gui aceipit, sibj filem et mllitie munu aliudre servitium exhibeat (Dueange, inforrum). 
malheurs, une nécessité impérieuse pour y rompre les familles, surtout les familles sortant des rangs du tiers-état; même lorsqu’à la suite de transformations économiques, ces familles ont pu acquérir des fiefs, elles ont sourent reculé derant le service militaire obligatoire pour emprunter, dès le xirr siècle, avec le concours du pouvoir roval, le remplacement militaire, aux lois de la seconde éporque de l'Empire romain. Tel a été le cas de Nontaigne, de Ilontesquieu et de combien dautres, de Mirabeau lui-mème, qui appartenait à une famille militaire très-honocable(1). "Le service militaire, dit M. Beugnot dans sa belle préface "aux coutumes de Philippe de Beaumanoir, était le fondement " de l'édifice féodal. Les concessions de terre, faites par les pro"priétaires à ceux qui ne l'étaient pas, avaient eu pour but de "rendre le service régulier et obligatoire afin que la seigneurie " et le seigneur ne manquassent pas de bras pour les défendre." Aussi le traité de Kiersy en 877 imposait-il à tous les fonctionnaires ou bénéficiers, auxquels il accordait l'hérédité, l'obligation du service militaire. Cette obligation a été la première page de la longue histoire du service militaire en France. Le fief a remplacé le bénéfice. Le fief est, à l'origine. essentiellement militaire et, comme tel, noble, avec dispense d'impaits.

La seigneurie a alors subi un premier démembrement, tel que celui constaté pour la seigneurie de Clermont - en fiefs militaires, qui, daprès leur importance, sont derenus les movennes et les petites seigneuries. La propriété foncière, d'abord via-

(1) Les ourrages sur les fiefs sont innumbrables. M. Mortet les a résumés dans

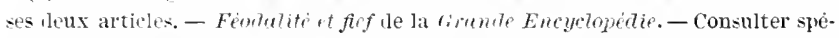
cialement Histoire du droit t tes Institutions de la France, par M. Glasson : La Fiontatie, tume IV, chap. 2 ; M. Léoluld Delisle sur la contition dés classes agricolfs an xile sieple, l'Histoire des claswes agricolfs par M. Dareste de la Charanne, le livre de M. Lamprecht cité plus haut. - Garsonnet et Lefort, Loeations perpétuelles. - Lavisse, Histoire yenerule, tome II. - Luchaire, Manuel des institutions do la Fronce ct lis institutions monarchiuws de la France sous les Capitiens, a volumes. - Gasquet, Les institutions potitiques de la France, 2 volumes, et,parmi les feulistes, les ourrages cités plus bas de Brussel, Renauldon, de Fréminville, laturière. Loysel, Herré, de Buttaric. Beaumanoir, P. de Fontaines (édition Ducange). - Les Assises de Jirusalem (Recueil des (roisades). - Ad. Vuitry, nurrage léja citt. - Dorlu, Institutions du rogume latin de Jirusalem, 1895, livre al courant, et Borelli te serres, Recherhes, indiefué plus haut. 
grère, puis híréditaire, a donc été le premier et le principal élément des fiefs, comme le pensait Guérard et comme les faits le disent. Mais il $\mathrm{y}$ en a eu un second; .1. Flach a eu raison de l'établir, c'est le comprasnonnage militaire 1 , le crmitatus germanique, plus rarement celtique, la muimir, la parenté, la famille, la rie commune ì une époque où la solitude ne pourait convenir à personne. Faut-il aller jusqu'à penser, a vee .I. Flach, que cet élément a été le clan? ceia parait insraisemblable. C"était la vie rurale commune, la rie familiale militaire. Le clan mème ne subsistait qu'en Bretagne, en Écosse et en Irlande. C'est ici qu’apparait l'importance du seigneur féodal à cîté du seigneur justicier - dans les cas où ils sont séparés. - C’est le seigneur féodal jui concède le fief, le domaine militaire, comprenant le service militaire et certaines rederances foncieres, qui n'ont jamais eu le caractère fiscal, mais le caractère foncier, vraiment féodal - féodal est le contraire de fiscal. La grande injustice de la Convention a été de ne pas le recomnaitre 9 ).

Le propriétaire de fief, le vassal n'a de rapports, sauf pour la justice, arec le seiønneur justicier que si ce dernier est son seigneur féodal, et ił ne lui doit que les services féodaux, résultant tous du contrat; il ne doit pas d'impöt. Le prix du Ferum, c'est le serrice militaire. Par la suite des temps, certains impôts se glisseront, comme dans toute société, entre le seigneur et son rassal, particulièrement les droits de mutation entre-vifs et par décès, mais lien rarement limpüt personnel. Le fief est libre d'impíts. Il est noble parce qu'il est militaire.

un comprend maintenant pourquoi les terres nobles sont restées exemptes d'impirt foncier ou de la taille rọale jusqu'en 1789.

Sous cette expression trénérale de fiefs ont été comprises diverses formes de concession de la propriété. Du Cangre n’a pas

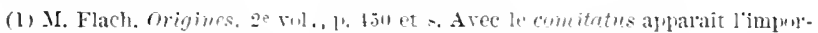

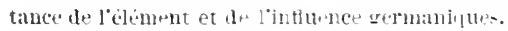

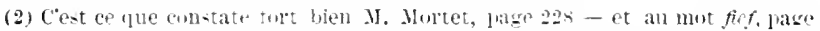

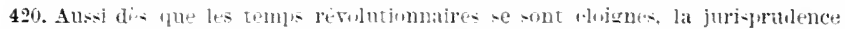

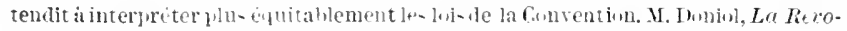

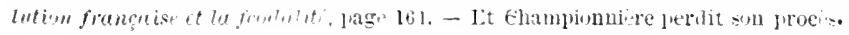


indiqué moins de 16 espèces de Feudum (fief), bien que Cujas ait donné pour toutes les espèces une formule générale acceptable. Il y a, toutefois, à faire une première distinction fondamentale. Le véritable fief a deux conditions essentielles : $1^{\circ}$ la transmission d'un fonds de terre, rural ou urbain; $2^{\circ}$ le service militaire. Ces deux conditions remplies, le fief s'appropriait à toute sorte de combinaisons; elles étaient, en fait, très variées, surtout en France, dont le territoire, selon la belle expression de M. Léonce de Lavergne, est le résumé de l'Europe. Des différences naturelles, irréductibles de ce territoire, différences qui persisteront toujours et qui ont résisté aux niveleurs de 1789, sont issues des formes multiples de propriété, de possession, de jouissance, d'exploitation, de droits, de redevances dont il est nécessaire de prendre connaissance dans les feudistes, notamment dans Boutaric et dans Renauldon; nous allons indiquer quelques-unes de ces formes pour les tenures roturières, qui étaient l'opposé des fiefs; mais elles étaient, quoique bien plus restreintes en réalité pour ces derniers, encore fort nombreuses. Par suite, il y a eu pour les fiefs certaines différences au point de vue des droits féodaux. L'extrìme variété et complication de droits féodaux n'est que l'expression de l'extrème variété des formes de l'occupation, de l'exploitation et de la propriété du sol.

A còté des véritables fiefs, avec propriété territoriale et service militaire, tels que le Feudum loricx ou de haubert, on rencontre d'autres fiefs qui prennent place dans le milieu féodal, qui lui donnent un autre caractère, mais qui ne sont pas de véritables fiefs, tels que le Fudum annum ou fief d'office et de dignité, Feudum bursa vel de Camera regis, Feudum in curiu, Feudum in curte, Feudum ministeriale.

Il y avait mème des tenures roturières ou serviles auxquelles on donnait le nom de fief, Feudum censuule, Feudum communule, Feudum corporale, Feudum de Haro, Fendum habitantis comportant une servitude d'habitation, Feudum talliatum; ces deux expressions sont coutradictoires, elles doivent appartenir à la décadence féodale; Feudum ad ritam; Feudum gentile, qui ne pouvait appartenir qu'à des ingénus, gens de naissance libre.

Le Feudo firma qui a eu une grande importance, comme l'in- 
diquent les comptes conservés des grands Capétiens, était-il un véritable fief: On doit en douter. Du Cange le définit, "Tenura "terrarum pro annuo redditu concessa, quir tertiam, vel ad " minus quartam rerce æstimationis iequat, absque aliis servitiis " in charta expressis. "D'après ces terme le Feudo firma ne pouvait ètre un fief.

Au contraire, le Feudum francum, franc fief, était un véritable fjef, bien que possédé par des hommes libres, non nobles, parce que, bien qu'exempt d'hommage, il était tenu au service militaire et soumis au cens: censui obnoxius (1).

Ces diverses formes de fief sont strictement réglées par le contrat. Il en résulta un très grand prog̣rès pour la constitution du droit de propriété. Al l'occupation, à la recommandation, à la concession bénéficiaire, succède une forme moins imparfaite, bien qu'encore incomplète; le serrice militaire et ses compléments, la fidélité, l'hommage, la justice, les aides, composent un véritable prix; cela est si vrai que, au bout d'un certain temps, ces services divers s'éranouiront, mais la propriété demeurera acquise; elle se transmettra légalement et cette transmission donnera lieu à des taxations nourelles.

A partir du $x u^{\mathrm{e}}$ et surtout du $\mathrm{x}^{\mathrm{e}} \mathrm{e}^{\mathrm{e}}$ siècle, il se produisit dans cet organisme des changements qui s'aggeravèrent avec le temps, et qui, en 1789 , justifierent, en partie, les critiques des feudistes et des économistes.

Nous arons ru que, dès les derniers temps de l'Empire romain, les véritables cultivateurs, les colons avaient beaucoup amélioré leur condition et quaprès la crise du $\mathrm{v}^{\mathrm{e}}$ et du $\mathrm{rn}^{\circ}$ siècle, cette amélioration arait repris son cours au $\mathrm{ix}^{\circ}$; elle ne s'est ralentie depuis qu'au $x w^{\mathrm{e}}$ et $\mathrm{x} \mathrm{r}^{\mathrm{e}}$ siecles; mais elle a été très grande au $x u^{e}$ et au $x m^{e}$. Yous allons en demander la preuve à une autorité compétente, II. Léopold Delisle. Ces colons, qu'on rencontre à toute époque dans les Gaules romaines et autres, premier élément de la propriété roturière, n’ont cessé de croitre en nombre et en importauce; surtout après les pertes terribles que les Croisades infligèrent aux seigneurs féodaux, ils

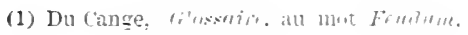


devincent acquéreurs de fiefs nobles, militaires. Tantôt favorisés, tantit interdits, ces achats ont persisté jusqu'en 1789. C'est ainsi que les Ramon Eyquem et autres marchands bordelais acquirent des fiefs nobles, militaires, et entrèrent dans la société féodale. Mais ils naraient pas l'entrainement militaire, ni la tradition, ni l'élucation, ni le goùt; ce n'étaient pas de rrais compagnons ces trafiquants en sel, en toile, en pastel? Rarement pouvaient-ils monter à cheval, porter le haubert et manier la lance, trop lourde pour eux. Le service militaire leur derint à charģe; y a-t-il ja mais eu un plus piètre chevalier que Michel Montaigne, fils d'une juive et pelit-fils d'un marchand de sel (1)? Les honneurs du fief leur allaient fort bien, mais point les charges. Il arriva ainsi, comme l'a expliqué de Tocquerille, que les seigneurs de fiefs, acquis par des mains point militaires, cessèrent de remplir la fonction à raison de laquelle ils étaient exempts d'impòts (2). Ils propagèrent, mème parmi les fiefs, le remplacement militaire, de mème que dans la seconde époque de l'Empire romain. L'Église arait nécessairement conservé la tradition du remplacement militaire qui derint une nécessité lorsque les femmes purent posséder des fiefs. Puis tout se morlifia dans les armées. Le seigneur f́edal et ses rassaux étaient des cheraliers excellents, mais les archers réguliers, les arquebusiers, l'artillerie les décimèrent à Crécy, à Poitiers, à Azincourt. Il fallut leur substituer l'infanterie et l'artillerie elle-mème. Néanmoins, cette organisation militaire des fiefs a eu son époque, ses beaux jours. Elle a donné à la race francaise des chevaliers admirables; cent chevaliers conqquirent le Péloponèse au xm siècle. Leurs exploits ralent bien ceux des caraliers de Fernand Cortez (3).

(1) Sur on tumbau (chapelle de li Faculti des seienees it Borleax) Michel Mnntaigne et lepre-ente comme un lueux chevalier alu xue siecle; on dirait d'un crobe. Malvezin. Wirhel Montrigne it sa fomille, 1880.

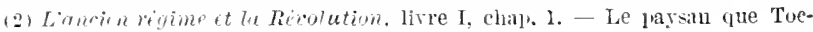
ųuril], met toujouls en serne est lancien eolon, devenu proprietaire roturier. Ce n'e-t ni le fermier, ni le métayer, ni le valet labolreur, ni le prixfaiteur, ni le mulier, undi. lour Tocinerille et bien d'antres, sont censes ne pas exister. C'est "elenlant anx 'ple Lafayette a lit en juin 1815 'pu'ils avaient couvert l'Eulolu le lenls omements. Ja Réwhution française a éte jom enx un eimetiere.

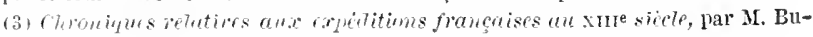
chon, introluction VI-VII. 


\section{$\$ 3$. Les tenures roturiries.}

Le chevalier n'était pas un cultivateur; on ne lélevait pas i semer, labourer, battre le grain, engranger, soigner le bétail, planter la rigne. La chevalerie est la tleur d'une grande aristocratie militaire, tout comme les Spartiates de Lacédémone, servie de mème qu'eux par d'autres classes, qui cultivent le sol et qui, dans les ateliers, se livrent aux travaux industriels de plus en plus variés; ce sont les diverses espèces de personnes que le polyptique d'Trminon nous a fait connaitre, devenues au xil $1^{\mathrm{e}}$ siècle plus nombreuses et plus importantes. De mème que la seigneurie s'est démembrée en fiefs, de mème le fief se démembre à son tour en ce quion nomme des tenures, c'est-à-dire des domaines de formes, de rlimensions et de noms différents : bail à cens, champart, bail à rente foncière, bordelage, borde, vicairie, albergement, pagesia, métairie, parcières, les premières comprises sous l'appellation générale de censives, toutes dites tenures en roture, soit parce que ceux auxruels elles appartenaient cultivaient, rompaient eux-mèmes la terre, ou provenaient de ceux qui l'araient rompue, soit parce qu'elles étaient, en fait et en droit, soumises à diverses charges, notamment it des prélèrements en nature sur les récoltes, à des redevances en argent ou en nature, à diverses taxes résultant des conventions ou de la coutume. "Roture, enseignait Loysel (1), héritage " tenu en villenage, héritage tenu à cens, rente, en serciers "vilains, à la différence du fief qui est tenu par services no"bles. " Le sens des mots villenage, vilains, n'etait pas exactement le mème que celui qu'on y attacherait aujourd'hui. Le vilain n'était autre que l'habitant de la villa, le colon devenu locataire à titre perpétuel d'une partie de la villa, parfois mème propriétaire au moyen de la rente foncière. Sa condition sociale restait très inférieure à celle du seigneur noble, mais elle n’avait rien de servile. Bon nombre de tenures roturières appar-

(1) Instituts coutumains, idition Laboulaye, an not Roturior. Apres awor dit : et sont nobles ou roturiers; Loysel ajoule: vilain we sça it que culeqt iperons. Il naurait pas ju rire la meme chose dos bourgeois. 
tenaient mème à des hommes dits francs-homme et considérés comme d'origine libre (1), tandis que d'autres, en plus grand nombre, étaient possédées par des colons, devenus libres, mais d'orimine servile.

A côté de ces tenures qui araient un caractère essentiellement seigneurial ou féodal, il s'en trourait d'autres qui, sans avoir ce caractère, n'en étaient pas moins des tenures en roture, telles que les domaines tenus à bail ordinaire, ou par rente foncière non féodale. En général, le criterium pour distinguer les tenures roturières féodales de celles qui ne l'étaient pas, se trourait dans le droit fiscal des lods et ventes, droit très important. Étaient féodales celles qui le devaient, étaient libres celles qui ne le devaient pas.

Malgré toute l'extension de l'organisation féodale et seigneuriale du $1 \mathrm{x}^{\mathrm{e}}$ au $\mathrm{x} 1 \mathrm{v}^{\mathrm{e}}$ siècle, elle ne parvint jamais, sauf pour le service militaire et l'administration de la justice, à s'imposer à toutes les personnes et à toutes les propriétés foncières rurales ou urbaines. C'est un des faits les plus curieux du moven àge et l'un de ceux dont on s'aperçoit le plus rapidement, quand de la lecture des ourrages de doctrine sur les temps de la féodalité on passe aux documents contemporains. Dans ces documents, tout revêt un autre aspect. Tout est extrêmement varié, pour les personnes comme pour les biens, tout donne nettement l'idée et le tableau de l'immense transformation (2) qui s'accomplit pendantle moyen àge par le concours de ces deux faits de premier ordre, d'une part la mise en culture et l'occupation du sol de l'Europe; d'autre part, la lente évolution qui substitue le servage à l'esclarage, et la liberté au serrage.

Par le bail à cens et la rente foncière, les propriétés urbaines eurent le mème caractère, elles devinrent aussi, surtout dans le Nord et l'Est de la France, des tenures en roture. Il y avait encore eu 1789 des maisons tenues à cens dans toutes les villes. Mais les bénéfices du commerce, de l'industrie, de la banque, les traditions romaines dans le Midi modifièrent promptement la

(1) D'Arenel, tbit., p. 164.

(2) D'Atrenel, ibia., 1. 166. 
condition des roturiers dans les villes. Ils devinrent des bourgeois. L'importance de ce changement est attestée par les assises de Jérusalem. La cour du ricomte ou des Burghéois est placée à côté de celle des barons, dés le xu siècle.

\section{$\$$ ł. Eléments divers de lu propriaté foncière en France.}

Seigneuries, alleux, fiefs, tenures en roture, féodales ou libres, tels sont les éléments divers de la propriété foncière en France. De ces divers éléments, l'alleu est le plus ancien, puisquil remonte au moins à l'époque romaine, probablement à des temps antérieurs, et la tenure en roture, libre ou féodale, le plus important, non pas du $1 x^{e}$ au $x u^{e}$ siècle, ni même au $x v^{e}$, mais à partir du $\mathrm{xr}^{*} \mathrm{1}^{\mathrm{e}}$ et du xrm1 esiecle, époque où un grand élan a été imprimé aux défrichements et où la population a sensiblement augmenté -6 millions au $\times \mathrm{xrut}^{\mathrm{e}}$ siècle, 9 millions au $\mathrm{x}^{\mathrm{r}} \mathrm{H}^{\mathrm{e}}$; mais toutes ces distinctions, seigneuries, fiefs, rotures, ont disparu. Les domaines, les terres et autres formes de la propriété foncière de la France actuelle ont tous revètu le caractère de la propriété romaine, depuis moins d'un siècle. Cette transformation dans la possession et la propriété de la terre sera-t-elle définitive?

\section{§ä. Reconstitution de l'impót.}

Dans les premiers temps de l'époque féodale le développement des fiefs a été très considérable; mais les conditions économiques du fief et les obligations militaires limitèrent peu à peu ce développement, bien avant mème l'intervention directe de lit royauté. Au contraire, les tenures roturières, malgré les charges qu'elles avaient à supporter, ne cessèrent d'aurmenter; elles devinrent la véritable forme de l'accroissement du territoire cultivé. Il arriva un moment où l'établissement des fiefs fut de plus en plus restreint; il n'en pouvait ètre de mème pour les rotures, appelées à ètre le moule principal de la propriété foncière en France. C'est surtout dans la tenure en roture, quel que fủt le modé de propriété à laquelle elle correspondit, que le régime féodal a rétabli l'impùt, ensuite dans le fief, mais incomplettement pour celui-ci. 
"L'impoit changeant de destination, dit Championnière (1), " devait ètre modifié dans sa nature : le nouveau possesseur " n'avait plus besoin des armes et des fournitures exigées pré" cédemment, cependant il dut se garder de laisser périr les "ollimations dont le profit lui était attribué et chercher à les "approprier à son usage. Les polyptiques des églises immunes " sont expliqués par cette observation et en mème temps la "confirment. On y trouvera, en effet, tous les impöts romains " convertis en redevances privées; prar exemple, les obligations " de transporter, de faire des charrois, de fournir des chevaux, " de recevoir les officiers publics, de les héberger, de fabri"quer des armes, des rêtements, des instruments de labou"rage, enfin le service militaire, s'y rencontrent très exacte"ment, mais appliques uux besoins du monastire; ainsi le "colon, au lieu de loger les fonctionnaires du roi, logera les "moines en rovage, au lieu de fabriquer des tuniques mili"taires, les femmes confectionneront des chemises ou des "robes pour les religieux; au lieu de marcher personnelle" ment au service du roi, l'homme de potestuti paiera une rede"vance en argent; toutes ces obligations conservent le mème " nom et constatent leur cause primitive. La corvée des char"rois se nommera unguria, comme dans les textes du Code; le "deroir dérivant des fournitures de chevaux s'appelle parave"redum : celui qui remplace le service militaire est désigné "sous la dénomination al hostem. Le census persiste partout "sans changer ni de nom, ni d'ètendue, ni d'objet et lorsque "les polyptiques deviennent les terriers féodaux, la redevance "conserve encore le nom de censive."

Parmi ces charges, la plus grande partie de celles ayant un caractère fiscal appartenaient au seigneur justicier, quand les deux seigneuries étaient séparées, et celles ayant un caractère foncier au seigneur féodal. Les charges fiscales provenaient

(1) Proprite dts Eau, courantes, p. 184-185. Tuns les détails si curieux de ce texte saphliquent anx fiefs et anx tenures roturieres; senlement pour les fiefs le service militaire était fersomnel et oblig:ttoire. Pour les romaines eeclésiastiques, le remplacement militaire avait presalu, comme il pẻvalut plus tard pour les te. nures roturieres. 
presque toutes des impots romains, appropriés par le seigneur justicier. Elles etaien: exigrées d'autorité, mais toujours avec un traditionnel respect de la coutume.

M. Ad. Vuitry a soutenu lopinion que limpit etait sorti de l'aide féodale, impoit extraordinaire que le vassal derait au suzerain dans certaines circonstances. II y a lieu de faire à ce sujet une distinction importante. Si l'on considere l'impoit, au point de vue de sa destination, au point de vue de son emploi, cette opinion peut aroir quelıup fondement quant à l'imprit puur les fiefs. C'est l'aide féodale, surtout à l'occasion du grand mouvement des Croisades, qui serait, en partie, l'origine de limprit moderne, la molécule génératrice; mais si, au contraire, lon considere limpoit au point de rue de lohligation, au point de rue de la nécessité, au point de rue du concours à la chose publique, c'est aux droits ordinaires du seigneur féodal ou justicier que limpôt remonte. Il ne semble pas qưa cet égard il puisse $y$ avoir de difficulté. Il suffit de parcourir, dans le livre de II. Ad. Vuitry, les chapitres $\dot{x}$ et $\ddot{z}$, où il traite, avec compétence, des revenus du Roi, sous les premiers Capétiens, pour reconnaitre que l'aide féodale n'a eu d'importance qu'en ce qui concerne la destination; or, l'élément principal de l'impuit est-il l'emploi ou la nécessite? Enfin, on pourrait mème discuter sur l’emploi, car bien que d'un caractère moins général, la défense de la seigneurie, l'exercice de la justice dans la seigneurie étaient tout autrement le concours à la chose pullique que la Croisade. A l'appui de son opinion, II. Ad. Vuitry insiste sul' le fait que l’aide féodale extraordinaire a dù ètre consentie et qu'ainsi le consentement à l'impòt est entré dans le droit public de la France, comme dans celui d'autres peuples européens. Mais le consentement à l'aide féodàle n'a été que partiel et que temporaire. Louis XIV et Louis XV ont profondément modifié le système fiscal de la France avec le simple enregistrement des Parlements. Les premiers Capétiens eux-mèmes ont pris, dès le $x_{1}{ }^{\mathrm{e}}$ siècle, des mesures fiscales d’une portée générale, de leur seule autorité. La Rosauté francaise, du xwe au xrne siècle, a subi, plutut que reconnu, le libre consentement de limput. 
Si de ces questions théoriques on passe à l'examen du mécanisme de l'impàt, des procédés d'application, on est obligé de reconnaitre combien l'impòt féodal a laissé une marque profonde dans les institutions de la France et de l'Europe. La taille est féodale, les droits de mutation entre-vifs sont féodaux, féodaux ceux de mutation par décès, féodaux ceux de mainmorte.

La Royauté n’a fourni que la gabelle - qui ne lui a fait jamais honneur - la capitation et les vingtièmes ou liimpòt général du revenu; ces deux derniers ont à peine duré cent ans. Les imprits féodaux remontent à 7 à 800 ans et durent encore. Enfin, la taille réelle a beaucoup servi à l'établissement de l'impit foncier et la taille personnelle à celui de l'impôt mobilier.

Dans l'Europe moderne, la seigneurie a été la molécule reconstitutive de la société. Jusqu'en 1789, la Royauté française est restée une grande seigneurie; lorsque les Parlements haranguaient le Roi ils lui donnaient toujours son titre seigneurial et féodal : seigneur roi. Le chapitre 3 du livre de II. Ad. Vuitry est tout entier consacré à montrer comment, pendant trois siècles, s'est agrandie la seigneurie capétienne; une famille de paysans qui, durant le mème temps, aurait ajouté lopins à lopins, n'aurait pas procédé dilféremment. Il en a été de mème pour les autres seigneuries. C'est ainsi que se sont resoudés les divers troncons de la France. Le territoire national s'est formé par les évolutions de la propriété foncière.

L’impòt féodal, bien que restreint, à l’origine, à la seigneurie, était aussi légitime que tous les autres impòts. La seigneurie était un pouroir, un ètat; aussi 11 . Dareste de la Chavanne, at-il dit à propos de l'impit féodal : "Telle était l'incontestable "légitimité des droits pécuniaires que les seigneurs levaient "à titre de puissance publique et quils pouvaient en con"séquence augmenter dans les circonstances extraordinai"res (1). "

Dans son rapport du 3 novembre 1789 à l'Assemblée constituante sur les droits féodaux, Merlin a fait la triple distinction des droits afférents : $1^{\circ}$ à la justice seigneuriale; $2^{\circ}$ aux servitu- 
des personnelles; $3^{\circ}$ aux baux ì cens, mais il a méconnu la fonction politique qui a incombè à la l'éodalité et amoindri sa fonction économique.

En réalité, l’impit romain a été approprié par les seigneuries et l'impòt reconstitué par la léodalité. Ce doulle fait a été et est encore l'objet de thèses qui ne sont pas près d'ètre épuisées. Lappropriation et la reconstitution ont pu le mème caractère. Elles ont été le résultat des nécessités publiques. C'est ce que M. Flach a établi, avec une grande ahondance de textes, dans divers chapitres du premier volume de son ouvrage. "Sous "la monarchie carloringienne, le grand alleutier imposa déjà " ses hommes, tenanciers ou simples habitants de ses terres, "par voie d'analogie avec les procédés en usage en dehors de " son domaine. Il exigea d'eux des redevances ou des corvées. "L’immuniste fit de même... De leur cùté, les officiers royaux, "ducs, comtes, vicaires ne se firent pas scrupule de modifier " la nature et l'assiette de l'imput. Ces taxes, une fois consa"crées par l'usage, alleutiers, judices, immunistes, officiers "durent les défendre contre les noureaux venus, contre les "barons (1). "

Ces quelques lignes résument, assez heureusement, les conditions de la réapparition de l'impôt dans la société fẻodale. La convention, l'usage, la violence y eurent part, la violence moins qu'on ne l'a dit. M. Flach a trop insisté sur la violence et la surprise. On remarquera aussi la complesité et la diversité des droits. Elles disparurent lentement avec la création du droit féodal. Les durs et les comtes devinrent les suzerains; les barons, les rassaux. Le grand propriétaire fut suzerain ou rassal; plus tard, il put être l'un et l'autre.

\section{$\$ 6$. Les droits fiodaux.}

L'expression générique Droits fiolaux a été presque une arme de guerre contre la féodalité, contre les modes de pro-

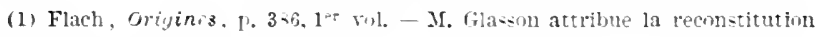

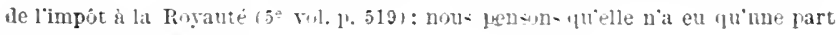
dans cette reconsitution. 
priété parfaitement légitimes, particuliers au régime féodal, contre les contrats qui en résultaient et contre les revenus des propriétaires. On a compris, sous le nom de droits féodaux, des droits différents d'origine et de nature parce qu'ils appartenaient le plus souvent aux mèmes personnes sur les mèmes biens. De tout ce qui a été établi plus haut, il résulte qu'il y a eu, sur ces mots, Droits fíodaux, une double confusion et qu'il y a lieu d'y opposer une double distinction :

to Il faut distinguer les droits féadaux qui étaient dus par les fiefs, tenures nobles - et par les tenures roturières;

20 Il faut distinguer ceux qui, dans les unes et dans les autres, redevances, taxes, impöts, obligations, étaient de nature économique de ceux de nature politique ou fiscale.

Le fardeau fiscal était considérable pour les tenures roturières; permanent, régulier, judiciaire, il s'étendait, quant aux roturiers et à leurs biens, de mème que quant aux serfs, à tous les détails de leur activité économique. Il n'en était pas de mème pour les fiefs, les seigneurs ou les nobles qui les possédaient. Le fardeau militaire était régulier, mais non permanent; toutes les autres charges, parfois onéreuses, araient un caractère occasionnel. Longtemps le service militaire lui-mème ne fut que temporaire. Dans la seigneurie mème, il fut d'abord fixé à 40 jours.

Ciest, par suite, dans la seigneurie, à l'époque féodale, qu'est arrivé à son apogée le mouvement fiscal, commencé sous l'empire romain, mouvement qui avait pour but de décharger des impôts les classes supérieures, mais ne travaillant pas, et de les mettre exclusivement à la charge des classes laborieuses, mais en partie émancipées, admises à la propriété du sol, maitresses exclusives de l'agriculture, du commerce et de lindustrie qui les enrichissent. C'est mème dans la seigneurie que ce mouvement a commencé son oscillation en sens contraire, puisque le service militaire est devenu la part des classes supérieures, ce qui avait cessé pendant les derniers temps de l'empire romain, et qu'au service militaire ont été peu à peu ajoutées des charges fiscales assez lourdes, mais occasionnelles. 


\section{$\$ 6$. Des droits fiodun sur les fiefs.}

En principe, le propriétaire de fief, le noble militaire est exempt d'impôts directs ou indirects, de mème que le spartiate. Le légionnaire romain n'a joui de ce privilize que sous l'Empire; il a aussi appartenu au musulman militaire. Le nollo militaire ne doit que le serrice militaire, la foi, l'hommage et diverses rentes féodales foncières, conformes à son contrat avec son seinneur. C'est lit le droit originaire mais, avec le temps, de numbreuses modifieations y ont été apportées (1).

Il $y$ a lieu, par suite, d'indiquer, d'abord, les oblirations militaires et foncières des fiefs, les devoirs et les charçes qui en résultaient.

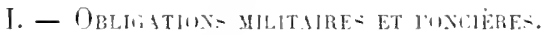

$1^{\circ}$ Le possesseur de fief ou rassal arait, avant tout, à prêter le serment de foi et it faire l'hommage (2) au jour consenu, afin de recevoir l'investiture régulière, sauf délai, sous peine de confiscation ou plutit de rérocation, au moyen dela saisie féodale. - S’il manquait à son serment, le fief lui était retiré au moyen de la commise.

$2^{\circ} \mathrm{Il}$ devait faire l'aveu et le dénombrement aux époques et flans les délais fixés, à peu près tous les 30 ans.

Car il n'était que possesseur eonditionnel; le seigneur avait un intérèt érident à s'assurer que le fief était maintenu en bon état et que toutes les conditions du contrat ftaient remplies $i 3 \%$.

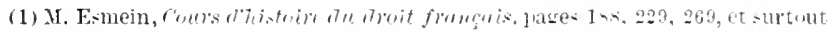

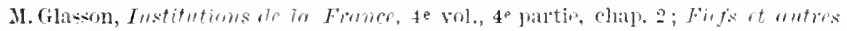

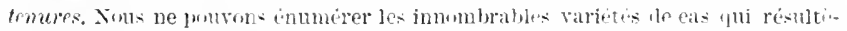

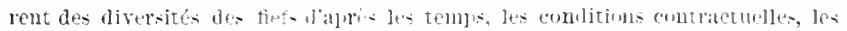

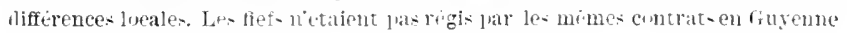
fue daus lilie le France.

(2) M. Ad. Vuitry, ombrage cité, 1 vol. 1). 117, sontient que l'hommage simple Ctait la rigle et l'hommage-lige lexcelition. - cette exception ent contrairu it

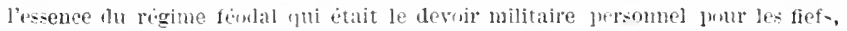

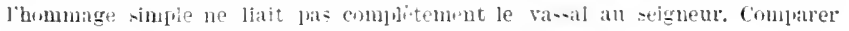

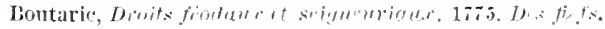

(3) Glasion, ibiden, 4 soi., 3i2. 
Cette charge périodique rappelait au vassal sa condition subordonnée et représentait certaines dépenses.

30 La principale obligation du vassal était le service militaire personnel, à raison de 40 jours par an et encore pendant toute la guerre, s’il était tenu par hommage-lige, notamment si la guerre avait lieu dans la seigneurie; il devait ètre accompagné de sou écuyer et d'un certain nombre d'hommes d'armes; il devait la garde du chàteau-fort de la seigneurie. Il ne pouvait se dispenser du service personnel qu'en cas de maladie, à condition d'envoyer une autre personne de sa condition en son lieu et place.

Toutefois, le principe du remplacement qui, de très bonne heure, fut accepté pour les tenures roturières et pour les vilains serfs ou d'origine servile, s’introduisit peu à peu parmi les fiefs. La Royauté favorisa ce mouvement, surtout après les désastres du xrye siècle; mais il n'eut jamais l'opinion publique favorable. Tous les Etats généraux du $x^{\circ} l^{\circ}$ siècle sont remplis par les plaintes du tiers état à ce sujet, aussi le père de Montaigne crut-il devoir faire les campagnes d'Italie. Michel Montaigne, son fils, n'en fit aucune.

$4^{\circ}$ En cas de minorité du vassal, la puissance du fief passait à un plus proche parent, avec les obligations à remplir. La tutelle féodale donnait lieu à de grands abus. Le Roi et les hauts seigneurs s'attribuèrent le droit de garde de mineur; souvent ils mirent la main sur ses revenus et ses biens, et, lorsque le mineur était une fille, s'emparèrent du droit de la marier. La protection due par le seigneur supérieur devint souvent une oppression. Parfois mème elle dégénéra en une sorte de taxation au profit du seigneur (1).

¿o Au décès du rassal, l'ainé des fils le représentait sans exclure les droits des frères et scurs; il prêtait l'hommage pour eux et les garantissait. C'était le droit de pariage qui modifiait le droit d'ainesse. Les ascendants ne pouvaient hériter du fief; propre héritage ne remonte pas, et ce, à raison du service militaire. A lorigine des temps féodaux, il en était de mème des

(1) tilasson, ilivem, 4e ol. $3 \pi 2$ 6e vol., 1. 19. 
femmes; mais dés le $x u^{\circ}$ siẹcle, le droit des lemmes à l'héritage soit à défaut de màtes, soit en concours arec eux, devint général.

Le principe du partage des fiefs a éte l'une des causes les plus efficaces pour empècher la nollesse féodale de devenir une véritable aristocratie territoriale.

Le principe anglais de l'indirisibilité de l'Estate et du droit de l'ainé à en ètre le seul maitre, n’a pas préralu en France. Aussi en Normandie (1), le fief était indivisible.

$6^{\circ}$ En outre de l'ost ou service militaire, le vassal est tenu d'assister au plaid du seigneur, de le seconder dans l’administration de la justice civile ou criminelle; il fournit aussi le service de cour.

7o 11 doit encore, dans certaines circonstances, pledyer son seigneur, c'est-à-dire le garantir, le cautionner, mẻme venir à son aide, lui faire crédit.

$8^{\circ}$ Enfin, dans la seconde époque de la féodalité, et surtout dans les prorinces du midi de la France, le seirneur arait droit à certaines redevances foncieres en nature, toujours spécifiées dans les actes. Ces rederances correspondaient à une certaine part du revenu (2). Les fiefs araient pris une grande importance. Leur valeur, leurs produits avaient augmenté. Si. à partir du xire siècle, le röle militaire du fief alla toujours s'amoindrissant, sa fonction économique, au contraire, ne cessa de s'accroitre.

\section{II. - Obligations fieciles.}

Les obligations fiscales du vassal, de ses héritiers, représentants ou ayant-cause ont une grande importance, parce qu il ell est résulté des changements profonds dans les impots. Yous avons rencontré certains droits de mutations entre-vifs à Athènes, en Égypte et à Rome; quant aux droits de mutation par décès, après un loner séjour en Eg̣pte, les Romains les lui ont

(1) Glasson, ilidem, 4e volume, page 334 .

(2) Dans quelques contres, le vissal devait, ontre les ahits aux quatre cas, des aides annuelles dont le montant rariait suivant les actis de conce-sion ws

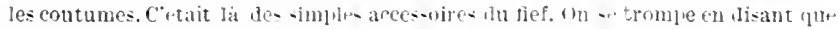
la taille relle, même permanente, n" pouvait jamais greser l'heritage noble. -

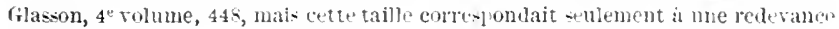
foncitre. 
empruntés, sans parvenir ì les conserver pendant au delà de trois siècles. Ils ne figurent plus dans les ressources fiscales de Dioclétien.

La féodalité les a retrourés, sous l'influence du caractère conditionnel de la propriété des fiefs. Dès que cette propriété n'était que conditionnelle, les changements, que la transmission familiale ou volontaire pouvait y apporter, domnaient au seigneur $1^{\rho}$ droit d’intervenir. Cette intervention a été basée, en droit féodal, sur le principe du maintien de l'intégralité du fief. Les changements pouraient en diminuer la valeur, l'abreger, selon le terme féodal mème; de lì nécessité de demander et d'obtenir le consentement du seigrneur (1). Il y a mème eu une période, du $1 \mathrm{x}^{\mathrm{e}}$ au $\mathrm{x}^{\mathrm{e}}$ siècle, pendant laquelle le fief ne pouvait ètre vendu; une secondle époque suivit, nécessité du consentement; puis, arec le temps, la substitution à ce consentement d'un droit de mutation, pour toutes transmissions entre-rifs ou par décès. Ce droit paraît avoir surtout fonctionné en France, parce que, du $x^{\mathrm{e}}$ au $x \mathrm{r}^{\mathrm{e}}$ siècle, la France a été certainement la partie de l'Europe la plus riche et celle ou la terre a eu le plus de valeur. - Iussi est-ce en France que les mèmes droits de mutation ont été le plus anciennement établis au profit de l'État et qu'ils ont produit les sommes les plus considérables. Les droits de mutation de toute nature ont versé au budget de 1893 la somme énorme de 416 millions. Pareil rersement n'existe chez aucun autre peuple, mème en Angleterre, mème aux États-Ĺnis, les seuls dont la richesse puisse ètre comparée à celle de la France. Ce sont les foyers féodaux qui ont habitué les Français à supporter, avec une certaine facilité, des droits fiscaux souvent exorbitants. C'est un point de vue auquel les pamphlétaires anti-féodaux ne se sont guère placés. Peut-ètre seraient-ils encore plus surpris si on établissait, ce qui ne nous serait pas difficile, que la grande administration de l'enregistrement et des domaines est féodale; les principes de ses perceptions et ses moyens dactions sont féodaux.

A. Droits de mutution, rachat, relief, mariage.

$1^{\circ}$ En cas d'aliénation du fief, l’acquéreur ou le vassal ven-

(1) Giklown. ilielem, te rol., 314. 
deur - ce qui est encore le principe français de l'Enregistrement - devait payer un véritable droit de mutation dit quint. Ce droit était fort élevé puisqu'il représentait le cinquième du prix. Dans plusieurs provinces on $y$ ajoutait le requint ou le cinquième du quint. Peut-être est-ce le requint qui a donné lidée du dixième. Dans quelques provinces, le requint était remplacé par le treizième du prix. Les nèmes droits étaient dus en cas de licitation, d'échange, de dation en paiement, d'aliénation quelconque. La plupart des questions agitées, depuis un siècle, entre les particuliers et l'Enregistrement, ont été soulevées par les feudistes seigneuriaux, notamment dans les circonstances diverses que présente la licitation, pour les charges à ajouter au prix, pour les fruits, pour les loyaut couts, expression encore fort bien portée (1).

Le seigneur avait le droit de refuser son consentement et de reprendre ou racheter le fief, en remboursant tout ce que l'acquéreur avait payé : droit de rachat ou racat $(2)$. Lorsque l'usage eût fait prévaloir, en France, le droit absolu de vendre par le vassal, sauf à payer le quint et le requint, le rachat, réchat, racat changea pour ainsi dire de caractère. Il ne signifia plus la faculté de raclıat pour le seigneur, mais le droit fiscal remplaçant cette faculté.

On trouve dans les comptes des baillis royaux, des prérits, ou du Temple, qui ont été conservés, non seulement des mentions très nombreuses de racats, mais des chiffres relatifs à leur quantum. Ces racats étaient fréquents et leur produit formait un élément considérable du budget roval au xm siècle (3).

Il devait en être de mème pour les seigneuries importantes.

$2^{\circ} \mathrm{A}$ la mort du vassal, il était dì au seigneur un véritable droit de succession ou mutation, dit de relief. De mème en cas de donation. Ce droit était égal, d'ordinaire, à une année de

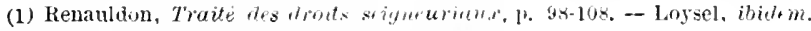
5.17, 565, 572. - Glasson, ibitem, 4" vol., 369-350.

(2) C'était le retrait féorlal.

(3) Consulter: Historipns des diuztes, t. XXII; Comiotus ballivorum, p. 623, 455, 746, 752. - Leopold Deli-le. Opretatins financiors des Templiers; les

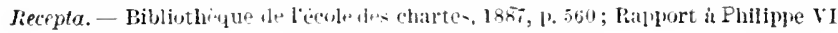
sir ses flnances. 
revenu du fief, à moins d'arrangements particuliers à forfait. En général, cependant, les héritiers en ligne directe étaient exempts de cet impôt (1).

Le droit de mutation par décès féodal doit être considéré comme une plus grande nouveauté que le droit de mutation entre-vifs. Il devait être fondé sur le fait que les bénéfices, qui ont précédé les fiefs, étaient, à l'origine, temporaires et tout au plus viagers. Le droit de mutation a été, en quelque sorte, le prix de l'hérédité, qui, par essence, n'appartenait pas à une tenure conditionnelle, bien que noble, surtout pour la ligne collatérale. Faut-il rappeler avec quelle lenteur et quelles difficultés cet impôt s'est propagé en Europe? En 1789 on ne le rencontrait que dans les États du pape, en Hollande, en Autriche, dans les États Scandinaves, en France.

Dans beaucoup de documents rachat et relief sont confondus. Le rachat finit par prédominer. Dans les comptes du roi de France au $\times 111^{\circ}$ siècle, on rencontre très rarement le relief, de relievo; tandis que le raccato ou rachato, méme racheto se trouve à toutes les pages des recepta des baillis ou des prévôts.

Le taux du relief variait, comme la plupart des impòts, d'après les provinces; en général, le seigneur avait le choix entre trois partis : 10 les revenus d'une année, à son choix, sur les trois années précédant le décès, payables en nature ou en argent; $2^{\circ}$ la jouissance d'une année par lui-mème; $3^{\circ}$ l'estimation du vassal, et même l'estimation d'expertise de bonnes gens (2).

Si plusieurs mutations par décès avaient lieu dans l'année, il n'était dù qu'un seul droit de relief. Il n'en est pas de mème aujourd'hui.

Si plusieurs mutations entre-vifs se produisaient, autant de mutations, autant de droits de rachat.

Les communautés religieuses devaient le relief en cas de décès $(3)$.

En cas de minorité du possesseur du fief, le garde noble ou

(1) Les théries fiscales aut xvir it xvm siectes, par E. F. de Flaix, livre 1, chap. 3,4 et 5 .

(2) Ronauldon, ibidem. - Glassun, t* vol., 371.

(3) Renauldon, ibidem, 1'. 107. 
bailliste, jouissant du fief, arait à sa charge le droit de relief. Dans quelques cas de tutelle, il pourait ètre dù deux reliets, lorsque la garde et la tutelle nappartenaient pas aux memes mains (1).

Les transmissions gratuites entre-vifs donnaient lieu au relief; mais l'usufruitier n'en devait pas. le relief restait au compte du nu-propriétaire.

$3^{\circ}$ Le relief était encore dú : $1^{\circ}$ lors du mariage de la demriselle, propriétaire du fief, à moins dindivision ares, un frère; $2^{\circ}$ lorsque la reuve se remariait - et à chaque convol 2 .

$\dot{t}^{\circ}$ Jl a longtemps existé des restrictions au mariage des enfants du vassal, surtout des filles. Le seigneur arait un druit dintervention et de conseil, qui s'est traduit par une sorte de tutelle supérieure, dont l'exercice dégénéra en droits fiscaux. "Le seigneur était directement intéressé à ce que la vassale ne "restìt pas fille et à ce qu'elle épousit un bon chevalier; la " conséquence fut, qu’il eut, à ce point de vue, voix au chapitre. "Nous constatons, dans divers documents anciens, que la "femme féodale ne peut se marier sans le consentement du "seigneur, et parfois celui-ci peut la forcer à se marier en lui "présentant plusieurs prétendants à choisir. Bien entendu, la "femme restait libre dans le premier cas de contracter un ma"riage valable et, dans le second cas, de ne point se marier; " mais la sanction était alors la commise du fief au profit du " seigneur. "De là bien des transactions et des exactions. $(3$, .

B. Amortissement. - Jo Si le fief était vendu ou donné à l'Eglise, il était dû au suzerain un droit d'amortissement, payable dans l'année, et variant, quant au taux, de 3 à 6 ans de revenu. L'entrée du fief dans le giron ecclésiastique constituait, en effet, pour le suzerain une perte sérieuse et irréparable. Il n'y a pas de matière féodale que les feudistes aient traitée avec plus de soin et de détail que l'amortissement qui était destiné à prévenir

(1) Glasson, te rol., 1'.373.

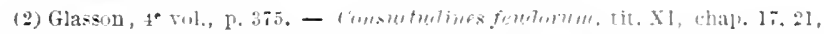

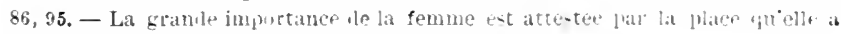
dans le lirre de la Hauto-four le Jirusalem.

(3) Esmein, nuvaru cite. p. 21:. 
ou à compenser l'une des causes les plus fréquentes de l'abrégement du fief. Comme il existait les liens les plus intimes entre la société ecclésiastique, fort antérieure en France, et à la société féodale, et que la première se composait principalement de femmes et de filles appartenant à la seconde, l'Église favorisait le plus possible les donations de tout genre, ce qui eut de bonne heure pour résultat de nombreuses restrictions à ces donations. Les biens ecclésiastiques n'étant jamais aliénés, les seigneurs se trouvaient frustrés, à leur égard, des droits de rachat et de relief. Ces biens étaient morts, ou improductifs, comme l'enseigrnaient les feudistes. Par suite, les biens ecclésiastiques étaient lits, de même que ceux des serfs, mais à des points de vue diflérents, biens de mainmorte. Fiefs et tenures roturières durent réparer le préjudice fiscal subi par les seigneurs. C'est le principe du droit d'amortissement féodal ; c'est également le principe des taxes actuelles qui frappent en France les biens de mainmorte, au double point de vue des mutations entre-vifs et par décès. Ce droit n'était prescriptible que par 30 ou 40 ans. Faute de paiement dans l'année de la sommation, le seigneur se mettait en possession du fief et en jouissait jusqu'à final paiement.

Il y a eu trois étapes, fort intéressantes à suivre, dans la constitution du droit d'amortissement. Pendant la première, qui aboutit à un règlement du parlement en $127 \%$, le seigneur immédiat eut seul droit à l'amortissement fixé, en cas de mutation gratuite, à $\dot{4}$ ans de revenus pour les fiefs ou terres roturières du Roi et à 3 ans pour les autres, et, en cas de mutation à titre onéreux, à 6 et à $\dot{4}$ ans. En 1320, les droits furent augmentés et les alleux furent soumis au droit d'amortissement; c'est la seconde étape. Mais au $\mathrm{xr}^{\mathrm{e}}$ siècle, l'amortissement cessa d'ètre considéré comme un droit féodal, il devint un droit roval. Les rois en fixèrent le montant par des ordonnances. C'est une des pertes sensibles de la société féodale comme l'une des premières étapes fiscales du pouvoir royal: ordonnance de Charles V du 8 mai 1372 (1).

(1) M. Grasson a traité la matiore de lamortissenent dans tous ses détails $4^{\circ}$ volnme, 312). - Comparez Lauriere, Origimes du droit a amortissement. 
C. Liten. - o Le rassal était tenu aux aides coutumières dites mxilia et connues sous le nom des quatre cas : $1^{\circ}$ quand le seigneur armait son fils chevalier; $2^{\circ}$ quand il mariait sa fille; $3^{\circ}$ quand il partait pour la croisarle: $4^{\circ}$ quand il arait à payer sa rançon.

Ces diverses aides disparurent peu ì peu. au fur et ḋ mesure que la société fédale se transforma. Le rassal ne pourait s soustraire sous aucun prétexte.

Ces diverses obligations se modifierent arec le temps, principalement celles ayant un caractère fẻodal, tandis que celles essentiellement fiscales, comme le quint, le relief, le rachat ont persisté jusqu'en 1:89.

Les rederances foncieres furent toujours très undérées; elles ne représentaient qu'une part modique d'un revenu, le plus souvent médiocre. Les charges militaires, judiciaires et politiques formaient le veritable prix du fief, dont le seigneur conservait, au surplus, la propriété éminente en vertu de la directe, droit féodal du propriétaire et du seigneur (1.

7o Ces diverses obligations avaient un caractere strict et rigoureux. Elles étaient garanties par des droits divers que le seigneur exerçait lui-mème, d'abord, et ensuite par le recours en justice. Les obligations les plus importantes étaient ramenées à exécution par le seigneur mème.

D. Confiscations, commise et saisie féalale. - 11 y avait lieu à confiscation, au moyen de la commise, pour plusieurs causes (2): le désaveu, la félonie et le défaut de foi et hommage, l"indignité, la déshérence. Parmi ces causes le défzut de foi et hommage dans l'an et jour ou le délai convenu, était la moins grave; on $\mathrm{y}$ substitua à la confiscation la saisie féodale, au moren de laquelle le seigneur s'emparait et jouissait du fief jusyu à lin restiture du vassal; mais, dans les autres cas, il y arait confiscation complète,

(1) Lamprecht, itidem, p. 172. - Parl Viollet, Histoin dis inotatutiuns, p. \$31. 448.

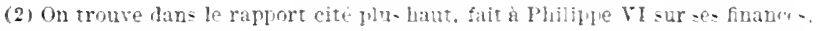

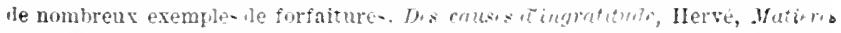
feodales, 3 vol, P. 425. 
en France, du moins; faute d'aveu et dénombrement, il y avait encore lieu ì saisie.

$11 \mathrm{y}$ arait beaucoup d'autres causes de confiscation d'après les provinces et les coutumes, telles que la violence, la menace, la corruption de la femme ou de la fille, le déni de la justice du seigneur, mais ce n'étaient pas des causes générales, absolues.

Quant aux obligations spéciales du vassal qui ne touchaient pas à l'honneur du seigneur, service militaire, redevances, droits de mutation, tutelle, ils ne donnaient pas droit à la confiscation, mais seulement à la saisie féodale, avec ou sans les fruits au profit du seigneur.

Le seigneur avait des obligations réciproques à remplir. S'il ミmanquait, il était exposé à perdre ses droits sur le fief.

\section{HI. - Le MILIEU FÉODAL NOBLE.}

Nalgré l'importance des obligations fiscales qui reliaient les rassaux aux seigneurs, ces obligations, n'ètaient, à l'origine, que l'accessoire de l'association féodale. L'objet principal de cette association était plus élevé. Il consistait à former, comme à Sparte, comme en Crète, etc., sur une grande échelle, comme à Rome, un noyau aristocratique, militaire, ayant pour fondement la propriété foncière, investi du gouvernement, et à l'abri de tout travail. Dès le $1 \mathrm{I}^{\mathrm{e}}$ siècle de notre ère cette association jette ses premiers soubassements; lédifice est acheré au $\times 11^{\mathrm{e}}$ siècle; puis il se dégrade arec le temps; mais, détruit en France, il est encore représenté, dans plusieurs parties de l'Europe, par des monuments, des idées, des préférences, des mœurs qui résisteront probablement à l'action du $\mathrm{xx}^{\mathrm{e}}$ siècle; c'est donc une ceuvre plus considérable que ne l'ont supposé les publicistes libéraux du $x x^{e}$ siècle. Et il est certain que la fréquentation de nos antiques ouvrages de jurisprudence du $x 11^{\mathrm{e}}$ et du $\times 11^{\mathrm{e}}$ siècle, ainsi que la. lecture des feudistes les plus éclairés, tels que Brussel et Renauldon, exercent sur l'esprit une impression profonde, en contradiction arec les enseignements de nos classiques contemporains. Dans les rapports du suzerain et du vassal, il y avait quelque chose de plus noble, de plus haut que ceux du propriétaire actuel 
arec son fermier ou son métayer. Il y a eu là, non seulement une conception, mais une vie d'ordre supérieur dont on retrouve l"int]uence partout, dans les obligations du vassal, dans la fidélité, dans l'hommage, dans le respect, dans le concours, dans la défense du seigneur. De mème le seigneur devait protection à la famille, aux enfants, à la personne du rassal. Le dévouement, le sacrifice mème tenaient une place dans les liens sociaux. Il en résultait une solidarité extraordinaire. A la lyałaille de Monsen-Puelle, les deux frères rentien, bourgeois de Paris, se firent tuer à còté de Philippe le Bel, en le défendant. Nous n'en sommes guère là aujourd'hui (t).

Le còté fiscal de la féodalité ne doit donc pas faire tort à son còté social; sur beaucoup de leurs terres, les seigneurs élevèrent de bonne heure des refuges, des hópitaux, des asiles, qu'on retrouve au $x v^{e}$, même au $x_{v} 1^{e}$ siècle.

Les divers droits féodaux n'étaient pas aussi onéreux qu’on pouvait le supposer, parce que beaucoup se compiensaient. La hiérarchie féodale étant essentiellement territoriale, il arrivait sans cesse que la mème personne, pour des domaines différents, était seigneur d'un còté, vassal d'un autre, arrière-vassal d'un troisième. Le roi lui-mème, jusqu'en 1789 , s'est trouvé propriétaire de domaines pour lesquels il était vassal. Il recevait d'un fait et payait de l'autre.

On ne saurait contester, eu égard à la stricte rigueur des coutumes sur les fiefs, que les droits de mutation entre-rifs et par décès ne soient réellement sortis du milieu fèodal. Mais ce serait commettre une grave erreur que de leur attribuer pour origrine exclusive le régime féodal; ils ont une autre origine, l'importance, les progrès, les revenus, la valeur de la propriété foncière en France au mojen àge (2). C'est pour n'aroir pas tenu compte de

(1) Borelli de Serres, Recherches : tes cientien. On peut lle dans le juemier volume de M. Ad. Vuitry. p. 176, le dramatique rélt du duel par lequel l'hon. neur de la comtesse du Gátinais est vengé par le chevaller Ingelger, l'un des fonlateurs do la maison d'Anjoll; ricit tont à fait féolal.

12) Consulter sur ce sujut les étwles de M. le vicomte d'Arenel, la fortune pricée a tracers sent siecles. Paris, 1894. Blen qu'il $\mathrm{y}$ ait lien de faire res réserves sur les resultats monetaires des étules ale $\mathbf{~ l l}$. le vicomte d'Arenol, son 
ce grand fait économique que des historiens de talent n'ont ru, dans le moyen àge, que l'influence du tiers-état et des villes; ils ont oublié la terre et les propriétaires. Dans les barons féodaux, ils n'ont pas vu les grands propriétaires, les terriens, selon l'expression de Ph. de Beaumanoir, non seulement les terriens, mais aussi une forme dorganisation sociale qui a produit des tỵpes, et réalisé des idées qui tiendront une grande place dans les progrès de la civilisation et les beaux jours de l'humanité; car la brillante société du $\mathrm{Xr}^{\mathrm{D}}{ }^{\mathrm{B}}$ siècle, si remarquable en France, celle plus près de nous, plus savante mais moins naturelle du $x_{r} \mu^{e}$, et mème celle du $\lambda r^{e}{ }^{e}$ siècle quand on les étudie complètement et qu'on est juste à leur égard, proviennent de l'époque féodale; elles en sont tout imprégnées; ce sont bien souvent les mèmes familles, propriétaires des mèmes domaines, qui les composent.

Il est vrai que la société féodale a été infectée, quoique séparée par plusieurs siècles et de grands événements, du mème vice que les sociétés grecque et romaine, l'abstention, l'aversion, l'oppression, le mépris du travail. C'est la cause principale de sa décomposition et de sa ruine. La réhabilitation du travail est, au contraire, l'œurre mémorable du $\mathrm{x}^{\mathrm{e}}{ }^{\mathrm{e}}$ siècle. Ce n'est pas que la société féodale n'ait fait une place au travail, mais elle n'en a pas compris le caractère; et le sens de la grande parole d'Aristote : il raut mieux trarailler que commander, lui a échappé. Aussi lui est-il arricé d'en venir à renoncer à la foi, à l'hommage, à la fidélité, au dévouement, à l'esprit de sacrifice, à la défense de l'ordre et du territoire, à ce fier sentiment chevaleresque de l'honneur qu'elle arait porté si haut, à la protection des mineurs, au culte respectueux de la femme, pour se consacrer presque exclusivement à la culture savante des avantages fiscaux que le temps lui arait conserrés. Le seigneur n'a plus considéré le rassal que comme un prébendier chargé de l'entretenir. Il s'est totalement consacré au quint, au requint, au

livre est rempli dobservations julieielises et bourelles quant à ha fonction économípue et sociale de la proprièté foncirre an moyen âge et quant aux oscllations de sa valeur. Consulter aussi lfeux articles de גi. le vicomte d'Arenel. Rerue des Denc. Mondes, 15 férr. et 15 anit 1893. 
relief, aux rederances diverses, à l'amortissement. Réciproquement, le vassal n’a plus songé qu’à payer le moins possible. Tout ce qu'il y avait de fraternel, de social, d'amical, dans le milieu féodal a été peu ì peu remplacé par l'appétit fiscal, l'activité des greffes et le nombre des terriers. Aussi M. Beugnot a-t-il pu dire :

"Le service militaire et le service de cour étant réduits à de "vaines formalités, l'esprit féodal s'éteignit dans le cour res " seigneurs; il y fut remplacé par un sentiment jarlis inconnu " à la noblesse. Les droits utiles des fiefs, c'est-à-dire les pro" duits réels, pécuniaires de ce grenre de propriété, devinrent le "fondement de la féodalité (t)."

La féodalité, perdant son caractère militaire, son caractère social, revètit sa dernière forme, la forme fiscale. Comme l'imprit avait été très certainement l'une de ses principales origines, comme la reconstitution de l'impôt, sa propagation, sa diversification ont eu lieu dans les seigneuries, l'impist devint l'objet à peu près exclusif de la noblesse, car il n'est pas possible de confondre la société élégante et fort aimable, que Louis XIV pnferme et corrompt dans les entresols et les greniers du chìteau de Versailles, avec les chevaliers qui ont soutenu la Croisade pendant trois cents ans et qui ont défendu les colonisations françaises d'Orient jusqu'au xvı siècle. La noblesse devient alors fiscale; elle vit de fiscalité; elle concourt, il est rai, mais saris entrevoir les suites de ce concours, à répandre les idées fiscales, les moyens fiscaux en France. Jes feudistes se multiplient et composent les ouvrages que nous possidons encore: les uns, les moins nombreux, mais peut-ètre les plus intéressants, défendant les droits féorlaux d'une noblesse qui n'est plus féodale; les autres les attaquant, presque toujours arec injustice, souvent avec ignorance, au nom du pouroir supérieur du Roi.

C'est dans ces controverses, c'est dans les tribunaux, greffes, perceptions de la noblesse au $\mathrm{xrmi}^{\mathbf{e}}$ sibcle que se sont formés

(1) Beugnot, préface aux Coutumes de Peamuanur, fage 64. Aussi dans le live: de la Haute-Cour de Jernsaleni on ne trutre ancune mention de relievances; la fief est tout militaire. 
les plus redoutables juristes de la Révolution, Merlin, de Malleville, Treilhard, et les rédacteurs des lois fiscales du Directoire. La grande administration de l'enregistrement et des domaines est de provenance féodale. Elle relève de la féodalité par tous les còtés. Elle personnifie, au milieu d'une société nouvelle, la dernière forme de la société féodale; ses lois, sa rigueur, son rocabulaire, ses amendes, ses doubles, ses triples droits, tout son génie est féodal; aussi a-t-elle rendu à la France les plus grands services, parce qu'elle correspond exactement, comme la féodalité, à la prodigieuse fortune de la propriété foncière en France.

Et si on peut reprocher à la rovauté de Louis XIV et de Louis XV, comme à la noblesse humanitaire, libérile et sceptique du $x^{\prime} u^{e}$ siècle (c'est elle qui a volé au secours de Washington et qui s'est laissé duper par Franklin), de n'avoir pas remplacé à temps un édifice vermoulu, elles ont bien quelques droits à revendiquer l'honneur d'avoir légué, au moins, à la France les plus puissants instruments fiscaux que l'humanité ait jamais tolérés.

\$7. Des droits féodulu sur les temures roturieres.

Au contraire, avec la roture qu'il ne faut, à aucun prix, assimiler à la servitude, on pénètre dans le milieu du travail, dans le milieu, déjà puissant, de ceux que les assises de Jérusalem appellent les Borgheois. Dès le $\mathrm{x}_{1}{ }^{\mathrm{e}}$ siècle, les bourgeois ont à Jérusalem leur cour qui est présidée par le vicomte. De mème, à Lacédémone, à còté des Spartiates, se trouvaient les Périèques, propriétaires, commerçants, militaires, qui ont plus tard formé la redoutable ligue des Achéens, derniers défenseurs de la Grèce contre les Romains. Polybe, l'un des plus grands esprits de la civilisation grecque, l'ami de Paul-Émile et de Scipion l'Émilien, était achéen.

Pendant tout le moyen àge, et surtout à partir du $x_{1}{ }^{\mathrm{e}}$ siècle, le roturier est l'homme libre qui travaille de ses mains ou s'occupe d'affaires, dans les seigneuries ou dans les villes. Beaucoup de roturiers sont incénus, c'est-à-dire d'origine tout à fait 
libre, du moins depuis de longues générations; les autres proviennent des divers rangs de la servitude : servitude domeztique, servitude ecclésiastique principalement, servitude urbaine, servitude rurale, car les degrés de la servitude sont infinis. Dans l'esclavage, il n'y a pas de degrés; il n'en est pas de mème de la serritude. Aussi faut-il, dans ce paragraphe, détacher tout ce qui concerne les droits féodaux ou autres concernant les divers degrés de la servitude et les réserver pour un paragraphe spécial, afin de mettre la roture en relief et de la montrer telle qu'elle était.

Ses éléments principaux consistaient dans : $1^{\circ}$ les personnes libres des rilles; 20 les anciens colons qui n’étaient pas tombés eu servitude; $3^{\circ}$ les propriétaires des campagnes non nobles; $4^{\circ}$ les serfs antérieurement affranchis; $\partial^{\circ}$ et les nouveaux arrivants. Pendant tout le moven âre, du $\mathrm{rl}^{e}$ au $\mathrm{x}^{\mathrm{e}}$ siècle, il $\mathrm{y}$ a eu sur le territoire gaulois ou franęais un mouvement d'immigration important. Ce mouvement existe encore aujourd'hui. Il est dans la nature des choses; il tient à la situation du territoire, à l'extrémité de l'Europe et de l'Asie.

La plupart de ces éléments se trouvaient répandus dans les seigneuries; les autres dans les rilles, arec un mouvement perpétuel de va et vient qu'on constate dès qu'on ourre les documents du temps. Néanmoins, la situation des roturiers dans les villes se différencia de bonne heure de celle qu'ils asaient dans les campagnes, et ces différences ont modifié les droits féodaux, parce que certaines villes conserrèrent quelque indépendance vis-à-vis des seigneurs et que, dans le milieu féodal, une situation à part fut faite, surtout à partir du $x 11^{\mathrm{e}}$ siècle, soit aux villes, soit aux communes, et par suite aux populations comme aux biens, meubles et immeubles, leur appartenant. Nous traiterons donc à part des droits féodaux dans les villes et les communes, affectant exclusivement ce paragraphe aux tenures roturières rurales, de beaucoup les plus nombreuses et les plus importantes jusqu'en 1789 (1).

Nous arons indiqué plus haut la diversité des formes des te-

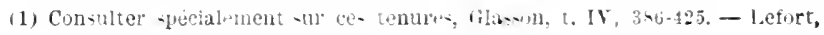


nures roturières. Les unes, le plus grand nombre, étaient féodales. Les autres, baux à ferme, métayagres perpétuels ou à temps, baux héréditaires, n`araient pas le mène caractère. Néanmoins, les unes et les autres supportaient égralement les charges qui, nétant pas des redevances foncières ou des droits purement féodaux. provenaient surtout du pouvoir seigneurial et de la justice.

\section{I. - TENLRE- RITLRIIRE- FÉDDALE:}

Ces tenures étaient les domaines ou les terres cultirès par les propriétaires non nobles, les colons, les serfs entièrement affranchis et les immigrants (Hospites. A l'époque féodale, ils étaient les vilains vilani), tous dits d'abord hommes de preste; cétaient les habitants des rillages, situés au pied ou autour des chàteaux et plus tard les roturiers, c'est-à-dire les cultivateurs. Avec le temps, les vilains sont devenus les propriétaires roturiers, ceux yui ont fait, en partie, la Rírolution de 1789, et les serfs de tout fenre sont devenus les paysans : ralets, laboureurs, domestiques, prixfaiteurs, métayers. Les domaines qu'exploitaient les vilains restèrent leur propriété héréditaire, movennant des conditions réglées, tantit par par le contrat, tantòt, et le plus souvent, par la coutume (1. Diailleurs, le déreloppement du sol exploité ne cessa de multiplier les exploitations rurales sous toutes espèces de formes, de noms et de conditions. C'est un point essentiel. Le fief fut, à partir du $x r^{\mathrm{e}}$ siècle, tout à fait l'exception.

Les différences principales entre les tenures roturières et les fiefs étaient : 10 que le vilain ne derait pas, en principe, le service militaire personnel comme condition de sa tenure; $2 \circ$ qu'il était tenu à donner au seigneur féodal ou censier une

Locations perpetuelles, 204-250. - Garsonnet, ibitrin. livre 2, troisi-me partie. chapitre 1er. - Renauldon, Troite des doits seigneuriauc, Hèitages en roture, T. 152.

(1) C'est l'une des différences essentielles entre les fiefs - règlés par le contrat - Les Assises de Jerusalem ont le sens de convention habituelles - et le- prupriétés ruturiéres réglees, ordinairement par la coutume antique, dont la bastert la culture. Pour le fief, la culture du sol etalt un accesonire. 
part plus ou moins grande de revenu; $3^{\circ}$ que le seigneur avait le droit d'augmenter cette part, d'après la coutume; $4^{\circ}$ que le vilain avait à faire face à d'autres obligations à l'égard du seigrneur justicier; ces obligations représentaient la plupart les anciens impùts romains. - Le vilain ou propriétaire roturier arait donc toujours affaire au seigneur à double titre, titre féorlal, titre justicier, ou à denx seinneurs, le féodal et le justicier; $3^{\circ}$ qu'il n’était appelé a aucun service de cour, non plus, sauf des exceptions, au plail ou it ladministration de la justice.

Ces différences ont été résumées par. I. Cilasson, auquel nous empruntons le paragraphe gui suit à raison de limportance du sujet :

"La censive (1) était, comme le fief, une terre qui dépendait "d'un seigneur. Mais le fief avait le caractère d'une tenure " noble, aussi bien vis-d̀-vis du vassal qu'à l'égard du seigneur, "tandis que la censive était un bien roturier vis-à-vis du te"nancier. Dans les deux cas, la terre était concédée à perpé"tuité, arec réserve toutefois d'un droit supérieur et de cer"tains services. Ces services étaient nobles et personnels pour "les fiefs, dune nature roturière (2) pour les censives. Le "vassal reconnaissait sa dépendance (3) par la foi et l'hom" mage et si le vassal de petite noblesse payait, lui aussi, des * redevances en argent ou en nature, ce nétuit puurtant pus lu " un èlement essentiel de sa tenure. Le censitaire ne derait ni "la foi, ni l'hommage, et il payait nécessairement un cens, " c'est-à-dire une certaine redevance en argent ou en nature "dont la quotité variait à l’infini suivant les contrées, mais était "toujours en général très modique. Le censitaire, à la diffé"rence de certains vassaux, ne détenait pas et n'exerçait pas " une partie du pouvoir souverain : c'était une sorte de proprié"taire d'une nature inférieure; il n'était pas noble conme le "rassal, ni libre comme l'alleutier. car il reconnaissait un sei-

(1) La censive st une exprosin noin extensive plue tenure roturiere.

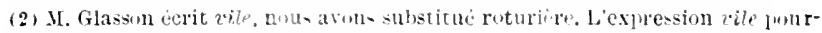
rait induire eu tremr.

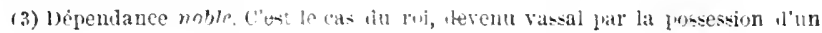
nes. 
"gneur. Aussi la censive n'impliquait aucune participation à la "justice pour le tenancier, lequel était soumis à la cour $d n$ "seigneur (1)."

On n'a rien écrit de plus clair et de plus exact sur la condition mog̣enne de la propriété foncière au moyen âge dans l'Europe occidentale, particulièrement en France. Il est cependant nécessaire d'ajouter que la possession d'une censive comportait le service militaire obligatoire, mais non personnel. C'est un point très-important qui n'a pas toujours été assez catégoriquement indiqué; mèwe le serf devait le service militaire.

Il n'est pas possible de ne pas relever les analogies frappantes entre les conditions des possesseurs de censires roturières dans l'Europe occidentale au moyen igre et celles de la seconde catégorie de propriétaires fonciers de la Grèce: Périèques, Pénestes, Clarotes, astreints également à des redevances d'un caractère mixte et au serrice militaire.

Seigneurs, vassaux, propriétaires nobles, pouvaient devenir possesseurs par achat, héritage, droit de retour, saisie, de tenures roturières; ils en devaient alors les services, de mème que le Roi devait le service des fiefs, dont il devenait le maitre. Ces services conservaient le mème caractère roturier - sans amoindrir la conditioñ personnelle de celui qui les rendait. De même le roturier parrint de bonne heure à devenir propriétaire de fiefs et même de seigneuries, mais il fallut beaucoup de temps pour que la condition de la terre noble qu“il détenait influât sur sa condition personnelle. Ce n'est qu'à la troisième génération que Michel Montaigne, petit-fils de Ramon Eyquem, l'acquéreur du fief noble de Montaigne, encore était-il conseiller au parlement de Bordeaux, jurat, maire et fort riche, fut admis dans la noblesse de Guyenne, vers la seconde partie du xve siècle. Combien cette admission eût-elle été plus difficile, quoique non impossible au $\times \mathrm{xII}^{\mathrm{e}}$ siècle?

Enfin, le seigneur suzerain, rentré en possession d'un fief, pouvait en faire une tenure roturière et, réciproquement, il avait la faculté d'élever une tenure de roture au rang de fief.

(1) Glasum, ibrilem, 4e rol., $356-357$. 
Ces divers changements, modifiant le caractère de la tenure, modifiaient rgalement la nature des rederances, des obligations, charges dimpôts.

Elles étaient loin d'ètre les mèmes pour des rotures que pour des fiefs; neanmoins certains impits, particulierement ceux de mutation (entre-vifs, par décès, amortissement), araient la plus grande analog̣ie; le service militaire était un impôt pour les roturiers puisqu'en général ils pouraient s'en acquitter en argent, mais les redprances et les charges différaient profondément.

Pour le fipf, en grénéral modique eu égard à l'importance du fief, la redevance était toujours foncière, tout ì fait agricole; elle correspondait à une véritable rente foncière non rachetable, sans aucun caractere fiscal: c'était un accessoire aux services nobles (guerre, garde, justice) du vassal. En outre, le vassal ne devait, d'ordinaire, aucunes tailles autres que les aides ni aucune des charges et rederances indirectes, si nombreuses au moyen ìge.

La situation économique et fiscale de la tenure roturière était, au contraire, très-complexe; si le fief représentait la partie du territoire, spécialement affectée au service militaire, la tenure en roture représentait celle beancoup plus importante, affectée it la production agricole comme à l'entretien grénéral des ressources et dépenses publiques; elle devait, tout en parant à ces dépenses, et en suffisant à celles du possesseur roturier, concourir à celles du seigneur, non seulement comme dépositaire, en tout ou en partie, de la puissance, mais comme véritable propriétaire primitif du fonds. De lá une confusion incontestable dans les obligations, rederances, charges et impits. Cette confusion s'est maintenue jusqu'en 1789, quant à la partie du territoire, où s'étaient conservées les institutions et coutumes rurales de l'époque féodale. Nais du xn siècle au xrinle, les conditions de propriété, d'exploitation, de rederances, charges et impüts du territoire ont bien changé. Les fiefs et les tenures roturières, avec les charges à elles propres, ne formaient plus la partie la plus importante du territoire. Aussi le xnne siècle est-il le plus convenable pour étudier les droits féodaux. C'est le moment de leur plein épanouissement; l'un crité, ils se sont définitivement 
formulés; d'un autre cìté, ils n'ont pas encore étẻ altérés par le nouveau pouroir qui doit tout approprier à un état politique et social différent.

De l'extrème complicité des droits féodaux résulte la nécessité de les diviser en direrses catégories. En étudiant avec soin res catégories, on assiste, en quelque sorte, à la confection de nos budgets modernes. Ce ne sont pas les mèmes chiffres, mais re sont les mèmes éléments fiscaux. On peut établir quatorze catégories : rederances foncières; droits de mutation; taxes directes; impôts de consommation; douanes et péages; servitudes et corvées; taxes de travail et d'industrie; domaine; confiscations; ḋroits judiciaires; monnaie; dimes inféodées; service militaire.

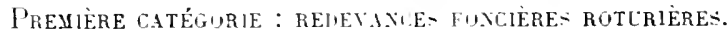

Cette première catégorie a une grande importance parce 'ju'elle comprend les revenus agricoles, la plupart en nature, qui constituaient le produit principal de la tenure aussi bien pour le seigneur que pour le possesseur roturier. La part du seigneur et, par suite, les obligations du tenancier variaient d'après la nature des tenures roturières. 11 est donc indispensable de passer en revue les principales tenures: c'étaient le bail à cens, le champart, le bail à rente foncière, le bordelage, le bail à locatairie perpétuel. Le caractère essentiel de ces cinq tenures roturières était de transférer au tenancier la propriété conditionnelle, mais perpétuelle des fonds. D'où, l'obligation d'en acquitter les lods et rentes, ou droits de mutation des tenures roturières. Le paiement de lods et rentes, comme l'indique Loỵsel (1), était, mème au xirıe siècle, le critérium d'après lequel on pourait apprécier le caractère juridique et fiscal d'une tenure. Etait féodale toute tenure soumise aux lods et rentes.

A. Le bail a cens. - Du $\mathrm{Ix}^{\mathrm{e}}$ au $\mathrm{x}^{\mathrm{e}} \mathrm{j}^{\mathrm{e}}$ siècle, le bail à cens a ité la tenure principale 2 . Elle était essentiellement féodale et

\footnotetext{
(1) Institutes coutumisres, ibistem, 544. 545, 546.

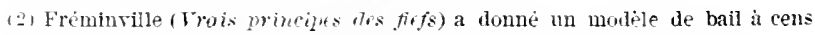
arec le commentaire les articles: cest un doeument important.
} 
roturière. D'oú les expressions aceenser un domaine, une maison, c'est-à-dire les donner à bail à cens, par lequel la propriété utile était trarsférée à perpétuité, mais conditionnellement. Doù également le terme de censice pour tout domaine soumis au cens. Il est nécessaire de connaitre la fonction économique du bail à cens pour avoir une idée exacte de la féodalité et se rendre compte des arantages que longtemps elle a eus, soit pour l'amélioration de la condition des tenanciers, soit pour les progrès de la culture du sol, soit pour constituer et transférer la propriété. En outre, le bail à cens a été un mode de lever et dacquittèr limpòt foncier.

En principe, pour les biens ruraux et urbains, le cens correspcndait à la fois au droit seigneurial, manifestant le caractère roturier de la tenure, et à une part quelconque dans le revenu, à la rente du sol. Aussi un fief n’était jamais accensé. Il acquittait parfois une certaine rente foncière; il devait les aides, mème la taille, dans certaines parties du midi; mais il n'était jamais tenu à cens, parce que la tenure du fief était noble, la tenure de la censive roturière. Le fief arait pour fondement le service de l'armée, et là censice, non pas la servitude, comme on l'a dit, mais la culture du sol. C'est une méprise complète, dès la fin de l'Empire romain, que de confondre la culture du sol avec la servitude.

Par suite, le cens, au milieu de variétés infinies, était double. II se subdivisait en chef cens, capittlis rensus (1), et en gros cens. Le chef cens, comme charge fiscale, était quérable; le gros cens était, au contraire, portable; il représentait la rente du sol, mais nullement un prix de fermage; le clef cens était coutumier, invariable, imprescriptible; le gros cens résultait du titre ou de l'aveu; à défaut de récolte il pouvait ètre réduit; réciproquement, dans certains cas, il pouvait ètre augmenté, d'oì la croix du

(1) Serrigny, Revue critique de legistution ot jurisprudenre, 1573 , 2 serle, page 417. - Ducange, Glossarium an mot census. Le cens etait it la fois un impot, tributum et une redevance Pensitatio. - Laturite, Gossair de Rigean, au mot cens. M. All. Vuitry, en citant ( $1^{\text {er }}$ vol, 205 ) lopinion de Pardessus que le cens dénote seignfur de fiefs, semble ne voir dans le cens qu'nn impôt, un débris des impôts romains; ètait aussi une redevance fonciere, la rente du sol. Ce 'lui était l'opinlon de Guérard, rapportée frur 11 . All. Vuitry, itielcm, pages 78 et $8 \mathbf{1}$. 
cens, census incrementum (1); mais, d'une manière générale, il était ordinairement très modique. Dans la seconde loi de la seigneurie de Coucy (en 1563) (2), des concessions de terres sont faites aux serfs, qui sont affranchis, moyennant un cens de donze deniers par an (3), le treizième du revenu, et la douzième gerbe, plus les droits ordinaires de mutation. La modicité habituelle du cens est un fait reconnu; aussi, le plus sourent, il y avait dans le bail a cens. un contrat de champart, en vertu duquel le seigneur arait droit à une certaine part, presque toujours le tiers du revenu brut. Ces conditions ont été considérées comme très favorables. Le bail à cens a été l'instrument principal des défrichements (c'est le cas pour la forèt de Vervins), et de la culture du sol ainsi que pour la concession de la terre aux roturiers.

La civilisation ne disposait pas, au moyen àge, des ressources qui lui permettent de faire aujourd'hui, à d'autres conditions, le défrichement et la mise en culture du Farwest américain, des Pampas argentins, des plaines de l'Australie et de l'Afrique australe. Nlais les faits sont de mème nature.

On a longtemps discuté sur l'origine et la réritable signification du cens. Les uns ont admis, c'est l'opinion développée avec talent par M. Glasson et par Serrigny (4), qu'il devait provenir des anciens impòts et redevances romains; d'autres, notamment .1. Fustel de Coulanges, n'y ont reconnu qu'une redevance foncière (3). Guérard (6) roit, dans le chef cens, la manifestation de la directe du seigneur, et, dans le gros cens, la rente seigneuriale ou foncière, se rangeant à peu près à la première opinion, qui nous parait tout à fait conforme à l'influence considérable de la tradition dans l'impùt. Coutumier, invariable, imprescriptible, indivisible, solide ou solidaire, le capitalis census devait représenter la capitatio terrena en partie. Il y arait, d'ailleurs, bien des variétés de cens. Ducange en fait connaître

(1) Ducange, au mot census : Gilossarium. - Brussel, itidem, p. 475.

(2) Réforme sociale, 1883 .

(3) Sous saint Louis le denier touruois valait 0,084 , et à peine 0,015 au xrre siècle.

(4) Glasson, t. IV, 392, Rerue critique de légistation et jurisprudence, 1873, p. 417.

(5) Revue ales Deuc-Hondes, ferrier 1878 .

(6) Polsptique de saint-Pire de Chartre. 
soixante-dix, mais il le définit à la fois tributum et pensitatio in agris et prædiis (1).

Le cens était un droit réel; en cas de non-paiement, le seigneur exerçait non pas la commise, mais la saisine censuelle. S'il rentrait dans la propriété de la tenure (2), tous les droits concédés par le tenancier devenaient caducs.

On reconnait toutefois dans le cens le double caractère des droits féodaux, la part due au propriétaire du sol - part foncière - et la part due au seigneur, part fiscale. Au contraire, comme l'a fort bien remarqué $\mathrm{M}$. Glasson, le sureens ou cens costier était purement foncier. "II représentait, dit M. Glasson, "le fermage qu'acquittent aujourd"hui les tenanciers (3)". Aussi, ajoute-t-il, " la condition des tenanciers eût été des meilleures " si leurs terres n'avaient pas été grevées d'une foule d'autres "charges".

Dans le relevé des comptes royaux, à la fin du xul1 ${ }^{\mathrm{e}}$ sièclé, les cens forment un revenu important (4).

B. Le champart. - "Il y avait trois sortes de champart : cen" suel, seigneurial et simple rente foncière. Le champart censuel " était celui qui tenait lieu de cens; il formait le véritable cens " de la seigneurie lorsqu'il était dû au seigneur de l'héritage " grevé et quand il en était la première ou unique charge. Au " contraire, il était seigneurial, quand il était établi par le sei" gneur et par le bail à cens, et quand l'héritage (la tenure), "était grevé d'un cens indépendant de cette redevance. Le " champart n’était tout simplement qu'une rente ou prestation " foncière quand ce n'était pas entre les mains du seigneur de "l'héritage qu'il devait ètre acquitté (艹) ". Dans ce dernier cas, le champart n'avait rien de féodal et ne pourait contenir aucune part d'impót. Il n'en était pas de mème dans les deux autres, surtout dans le premier. Aussi Loysel enseigne-t-il formellement que les terres tenues à champart devaient les lods et ventes
(1) Ducange, Glossarium, au mot Census.
(2) Qui negliget censum, perdat agrum. Ducange, inilom.
(3) Ibilem, yol, p. 394.
(4) Historiens des Gaules, tome XXII.
(5) Lefort, ibidem, 2I8. - Ad. Vuitrs, ibitem, 266. 
au chief seigneur foncier seulement (1). Certains champarts étaient perpétuels et transféraient un droit d'exploitation qui ne cessait que faute de culture. Il consistait dans un prélèvement en nature (blé ou vin) qui s'exerçait, après celui de la dime, ecclésiastique ou inféodée, et qui variait, d'après les prorinces et les coutumes, depuis la vingtième gerbe jusquà la quatrième, du cinquième au quart des fruits $(2)$.

On peut dire, d'une manière générale. qu'il y avait deux champarts, le champart censuel ou féodal, pouvant représenter une part d'impòt foncier, et le champart foncier, qui n'en représentait aucune. Le paiement des lods et ventes marquait la différence.

Le champart, ou agrier, ou terrage, portait dans les contrées viticoles d'autres noms, tels que ceux de bail à comptant, parcière, baillette. C'est l'une des formes de l'exploitation agricole qui ont le plus contribué à l'extension des vignes, aux progrès de l'agriculture et à l'amélioration de la condition des populations rurales $(3 j$.

C. Le Bordelage. - La tenure en bordelage ou bourdelage (4), spéciale au Bourbonnais et au Nirernais, mais plus répandue dans le centre de la France qu'on ne l'a cru, était cependant moins générale que le champart, moins libérale envers le tenancier et strictement féodale. Les besoins de la culture et son caractère rigoureux l'araient fait étendre aux fiefs; elle donnait lieu au profit du seigneur à deux redevances, en argent et en nature, comme le cens, beaucoup plus élevées, tantôt portables, tantôt quérables, prescriptibles seulement par trente ans; mais elle transférait la propriété conditionnellement. Le tenancier a vait le droit de vente, sauf le retrait féodal que le seigneur pouvait exercer en remboursant le prix et les loyaux coûts. S'il n'usait pas du retrait, il percevait, au lieu des lods et rentes, le tiers du prix ou le tiers denier. La tenure était donc féodale. Elle

(1) Instiutes coutumieres, 544, 545, 546 .

(2) Renanldon, ibidem, page 181.

(3) Nous arons connu, 60 ans après la Rérolution, daus un rignoble, un cas le champart simple. fonlé sur titre. Il fut maintenu et le champart racheté.

(4) Lefort, itirlem, 22 $;$ : Renaulton, page 181. 
équivalait à la tenure à cens champartier. Dans le Bourbonnais on donnait aux redevances borlelieres le nom de tuilles relles. C'est un renseignement précieux pour lorigine de la taille. Autre caractere de cette tenure, elle était garantie par la commise fíodale (1).

1). Le bail a rente foncisu. - Bien que le bail à rente foncière n'eut pas le mème caractère que le lail it cens, Loysel l'a compris parmi les tenures féodales: " on met sa terre en gagnage "par baux à rente, cens ou fief 2 ". Aussi la plupart des coutumes décidaient que lorsque le bail a rente fonciere portait que le rachat pouvait aroir lieu, le seigneur du fonds avait droit aux lods et ventes, afin de prévenir des rentes fictives $(3)$. En outre la rente était due par le fonds et non par la rersonne, it moins de la stipulation de faire culoi,; le preneur sen débarrassait par le déguerpissement. La faculté de déguerpir, "jui se pratique sur une vaste échelle dans les Etats lu Farwest américain, ou dabandonner le fonds, a un caractere qui le rapproche du fief. Le possesseur du fief pouvait aussi déuerpir. Le déguerpissement est toujours lindice d'une condition difficile pour la terre et la propriété foncière.

E. Le bail à locatairie perpétuelle. - Un peut comprendre, sous cette formule, direrses sortes de locatures arant le carac. tère de perpétuité et par suite morlifiant la propriété : $1^{0}$ la locatairie perpétuelle, 20 l'albergement, $3^{\circ}$ mème l’emuhrtéose. Lorsquelles étaient consenties par le seigneur et que soit les actes, soit les coutumes, accordaient au seigneur les lods et ventes, elles avaient le caractère féodal; mais si ces deux faits ou l'un d'eux manquaient, elles araient le caractire foncier. C'est le principe que la jurisprudence adopta apris la crise révolutionnaire. Pour donner un exemple de la coutume, il suffit de rappeler qu'en Provence le bail a locatairie perpétuel était tenu pour féodal et pour foncier en Languedoc.

(1) Pour les maisons le lroit fut abaisse an $\mathrm{xrl}^{\mathrm{e}}$ sirele, an sixime lenier, 3 sols et 4 deniers stur 20 sils. - Lefort, iluilt in. 228.

(2) Institutes, 505 .

(3) Lefort, ibilem, 237. En baux is rente rachetable ont this his et ventes. Loysel, Institutes, 536. 
Régle générale : les lods et ventes, contractuels ou coutumiers, révèlent le caractère de la tenure; seul le seigneur a droit d'en jouir, parce que seul il a droit à l'impôt; et chaque fois qu'il avait droit aux lods et ventes, les redevances qu'il percevait pouvaient comprendre une part d'impôt (1).

Aussi la main ferme dans le nord de la France était-elle une tenure féodale parce qu'elle était grevée des lods et ventes (2).

F. L'emphytéose. - Faut-il comprendre l'emphytéose parmi les tenures roturières? Le régime féodal avait modifié les idées et les pratiques romaines relativement à l'emphytéose. " Si " je compare, dit M. Garsonnet, l'emphytéose consentie par un "possesseur d'alleu noble au bail à cens ou à rente seigneuriale, " j'ai encore plus de peine à les distinguer l'un de l'autre». El le savant juriste ajoute: "la retenue des droits honorifiques si le " fonds était noble, les louls et ventes s'ils avaient été expressé" ment stipulés, le droit de retrait ou de prélation, s'il était ad" mis par la coutume, l'obligation d'améliorer même en l'absence "d'une convention formelle, tels étaient les caractères distinctifs "de l'emphytéose ». Enfin Merlin reconnaissait que les lods et ventes étaient dus en principe, mème sans stipulation, bien qu'il y eût désuétude à cet égard (3).

Il faut conclure de l'ensemble de ces faits, qu'au moyen âge, l'emphytéose était devenue une tenure féodale roturière de la même nature que le bail à rente foncière; elle s'était modifiée; elle s'était appropriée aux temps. Il est, au surplus, très difficile de définir le véritable caractère de l'emphytéose. Il semble que ce soit une forme variable, incertaine, transitoire de la propriété, convenant aux époques de disproportion entre la terre à cultiver et les capitaux nécessaires à la culture.

L'emphytéose a conservé une grande importance, surtout au milieu de la race anglo-saxonne; une partie du sol des villes anglaises, de Londres en particulier, et des villes américaines

(1) En rentes a'héritage, tenus à cens, soit pour cas simple, solt à faculté do rachat et en baux à rente rachetable, sont dus lods et ventes. - Loysel, Institutes, 536. - Volr en ce sens Garsonnet, Loeations perpétuelles, pages 409-427.

(2) Ducange, Firma : Glossarium.

(3) Garsonnet, ibidem, p. 418. 
de la Nouvelle-Angleterre, telles que Boston, a été cédée par bail emphytéotique, mais de 99 ans seulement. Au moyen ìgre, l'emphytéose était un bail perpétuel, ayant les mèmes caractères que le bail à cens ou à rente foncière. Il transférait, en réalité, le domaine utile. D'où les lods et rentes.

\section{Seconde catéliorie. - Droito he altation.}

Les droits de mutation sur les tenures roturières étaient au nombre de cinq, en laissant à part divers droits qu'on pourrait relever soit dans les feudistes, soit dans les coutumes; ces droits avaient beaucoup d'importance. D'abord, ils indiquaient nettement les conditions de la tenure, puis ils constituaient pour les seigneurs une partie notable de leur revenu, de mème qu'une charge assez lourde pour les tenanciers. C'étaient les lods et ventes, le relief, l'amortissement, le marciage et le franc fief.

A. Lods et rentes. - Ils étaient stipulés par les actes ou dus en vertu de la coutume. Ils formaient un droit de mutation entre-vifs sur les tenures roturières correspondant au quint et au requint sur les fiefs; ils devaient ètre acquittés dans les 40 jours de la mutation et à Paris, d'abord dans la huitaine, puis dans les 20 jours. Actuellement le délai est de 3 mois pour les actes sous seings privés, mais il n'est que de 10 jours pour les actes notariés ou de 15 jours pour les actes judiciaires qui contiennent les mutations les plus importantes. Ils variaient du sixième au douzième du prix selon les coutumes. Ils étaient ainsi un peu moins élevés que pour les fiefs (1). Le seigneur avait le droit de saisir le revenu en cas de retard et mème d'exiger le double droit. C'est un emprunt que la loi de frimaire an VII n'a

(1) Ducange clte des cas oủ les lods et ventes représentaient le tiers du prix et dautres le vingtième. - Renaulion (Dietionnaire des fiufs au mut lods et rentes), admet qu'ils variaient du sixieme au vingtième du prix. - laurière indique 2 sols par livre, e'est-à-dire pour le xın siècle $2 \mathrm{fr} .97$ sur $17 \mathrm{fr} .84$. - Guérard (Cartulaive de Saint-Pire de Chartres) eite une vente de 12,000 livres tournols donnant lieu à un lod de 1,000 livres, redult à 500 par Charles VI. Jans les comptes des ballls royaux (compotus bultivorum), Historicns de France, $22^{\mathrm{e}}$ vol., les lods et ventes ont beaucoup moins d'loportance que les raehats et les rellefs. 
pas manqué de faire aux lods et ventes. Les lods et ventes étaient dus dans les mèmes cas que le quint ou le requint : échange, vente, transaction, donation en paiement, partage, louage perpétuel, donation. Ducange explique fort bien que les mots lods et rentes proviennent du verbe lauclare approuver, renda les ventes (1), approbation que donnait le seigneur, car il avait le droit de retrait. L’impót remplaca le retrait, de mème que l'impòt finit par remplacer le service militaire.

Ainsi que frour le quint, les lods et rentes donnèrent lieu ¿i une multitude de questions et de difficultés. On les trouvera résumées pour la Saroie seulement dans un curieux ouvrage de Bailly 2 . On croirait, en le parcourant, feuilleter un dictionnaire d'enregistrement contemporain, car l'impit, et ceux qui en ont la responsabilité, sont immuables, ou à peu près.

B. Relicf. - Les terres roturieres acquittaient aussi un droit en cas de mutation par décès, d’ahord sur lhabitation et ensuite sur les terres, par arpent. Ce droit était moindre que pour les fiefs, parce que, dans les idées du temps, le fief noble, militaire, arait une toute autre importance que la censive roturière.

Daprès Loysel, il équiralait, selon les coutumes, soit au double du cens ou de la rente, soit à une année de revenu $(3)$. Dans d’autres, selon Renaulion, le droit de relief était de :0 deniers par live du prix de i’héritage ('s .

C. Amortissement. - Les terres roturières, particulièrement les censives, qui entraient dans le domaine de l'Eglise, devaient également le droit d’amortissement, de mème que pour les fiefs dans les mèmes conditions.

D. Marciage. - Dans certaines provinces, les tenanciers de rotures, non sujettes au cens, deraient payer à la mort du seigneur un droit dit de marciage. Renauldon le fixe au double du cens ou à un an de fruits (ว).

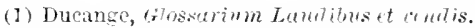

(2) Traité des lods, 1770, en Savoie, tris curieux liwre. Les lods ne sont pas dus sur les meubles, mais ils sont dus sur les immeubles par destination et sur les fruits pendants par racines.

(3) Insticutes coutumieres, 547, 567 .

(4) Dictionnaire des flefs, au mot Relirf.

(5) Dictionnaire des fiefs, al mot Marciage. 
E. Fram fef- - Droit de mutation que tout roturier devait acquitter quand il achetait un fief; on considérait que, par cet achat, la raleur de la seigneurie était amoindrie (1).

L'histoire du droit du franc fief est fort curieuse. En principe féodal, le roturier ou vilain ne pouvait acquérir un fief, parce que, bien que tenu lui-mème au serrice militaire, il n’était pas dans les conditions requises pour remplir en personne les divers services du fief $(2$. . l l'époque des Croisades, les pertes de la noblesse firent changer le droit, dans un intérit commun. Dés la fin du $\times 11^{\mathrm{e}}$ siècle, les roturiers purent actuerir lus fiefs a condition de payer, du moins dans le dumaine roval, une indemnité ercale à 2 aus de revenu. Le roturier pourait s'en dispenser en faisant le serrice militaire du fief. En 1321 une ordonnance rogale décila que lindemnité serait due, mime au cas où le roturier ferait le serrice; elie fut fixie it 3 ans de revenu, pour le cas ou le roturier lerait le serrice t í $\dot{x}$ ans sil ne le faisait pas. Plus tard le Roi sappropria le droit de frane fief, comme il s'était emparé du droit d'amortissement.

Il était écalement dì un droit de $\dot{x}$ ans de revenu lorsqu'un fief etait converti en censive ou tenure roturiere.

Le droit de mutation acquittr, le roturier arait-il, comme possesseur de fief, les mèmes arantares qu'un possesseur noble, qu'un réritable seigneur? La qualité de la terre changreait-elle la condition du possesseur:) en un mot, se métamorphosait-il en gentilhomme? Cest une des questions les plus intéressantes du moyen ìge. On peut répondre quen général la qualité de la tenure ne l'emportait pas sur l'oricine sociale du possesseur, lorsquil était dextraction servile, surtout dans le Nord. Ainsi, la succession du ruturier possesseur de fief se partageait roturièrement pendant trois générations. On extait moins rigoureux dans le Midi. On admettait qu'aprés trois générations, ou quartiers, le possesseur de fief devenait gentilhomme et pro-

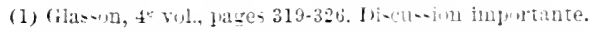

12) De lu le texte de Beauman,il : r solon l'e-tablisement le Roy, li home "de prette ne jueunt devenir tenir fle, ne ens atruitre en fiè et ne pour ruant " no i verus aucun remele coment ils lueunt abuir tié, et si n'est pas l'establis" sement brisits v (édition Beugnot). 
fitait des avantages de son fief. Le cas s'est réalisé pour Michel Montaigne. A la troisième génération, l'arrière-petit-fils d'un serf questal, a épousé une demoiselle noble (la mère de Montaigne était juive) et a marié sa fille unique dans l'une des premières familles nobles militaires de Guyenne, la famille de Lur) ( 1 ).

Mais, à la fin du xvi siècle les tendances devinrent plus sévères et il fut plus difficile à un bourgeois de devenir noble en acquérant un fief; en effet, il abrégeait ainsi les revenus royaux. La terre n'annoblit plus. Le Roi seul put annoblir.

Ces divers droits de mutation étaient essentiellement féodaux; seul, à l'origine, le seigneur féodal, ancien propriétaire de la tenure, pouvait les exiger. Cependant les droits de lods et ventes, de relief, d'amortissement et de franc fief formaient de véritables impôts; c'étaient des impòts de mutation; c'est dans la seigneurie que ces impôts, appelés à un si grand avenir, se sont, en réalité, constitués.

M. Ad. Vuitry fait remonter ces droits (2) aux impôts romains. A son avis, les droits de mutation par décès proviendraient de la ricesima hxreditatium et les droits de mutation entre-vifs de la centesima rerum renalium. On peut en douter : d'un côté la vicesima hxreditatium a disparu au $\mathrm{IV}^{\mathrm{e}}$ siècle; d'un autre côté la centesima rerum venalium ne portait que sur les marchandises vendues à l'encan. Il est plus naturel de reconnaitre dans l'in. vention de ces divers droits, la double influence de l'importance de la propriété foncière et du caractère même du régime féodal. Championnière a considéré ces taxes comme des appropriations privées; c'est qu'il jugeait le régime féodal avec les idées du $\mathrm{x}_{1 x^{\mathrm{e}}}$ siècle et non point d'après les nécessités du $\mathrm{x}_{1}^{\mathrm{e}}$ siècle.

\section{TroisièMe Catégorie. - TASEs directes.}

Les taxes directes se composaient des aides extraordinaires et des tailles.

(1) Malvezin, Mfichel Montaigne et sa famille. Cet ourrage, do à l'initlativo de M. Magne, ancien ministre, est rempli de documents authentiques qui lui don nent une grande valeur.

(2) Ad. Vuitry, ibidem, p. 278. 
A. Les aides. - Elles étaient dues par les tenures roturières dans les mêmes conditions que les fiefs; mais elles étaient moins rigoureusement exigées, parce qu'elles reposaient sur le principe $d u$ don volontuire au lieu du principe de lobligation. Au milieu de tout l'appareil fiscal du moyen àge, le don rolontaire ne disparut pas. Il resta la forme de l'impòt la plus antique et la plus respectable.

B. La taille. - Il importe de faire immśdiatement, quant à la taille, deux remarques préliminaires $: 1^{c}$ Il ne faut jamais confondre les tailles que payaient certains fiefs, la plupart des tenures roturières et les roturiers arec les tailles diverses qui portaient sur les biens serriles et sur les différentes personnes serviles. C'est faute de faire cette distinction essentielle entre personnes et biens des roturiers, personnes et biens des serfs et nous verrons combien d'autres distinctions il y a lieu d'établir entre les gens et les biens entachés de servitude - qu'il a été mis en circulation tant de faits et d'idées contradictoires sur les divers genres de taille.

$2^{\circ}$ Le principe de l'abonnement se généralisa pour les tailles, mème pour les tailles serviles. L'abonnement n'est autre que l'impôt de répartition. La répartition limite les inégalités et les excès. Il y a contradiction entre l'idée de l'abonnement et lidée de la taille al misericordiam. Celui qui peut tout prendre ne donne pas d'abonnement. L'abonnement a pour raison la fixité aussi bien pour le contribuable que pour le maitre.

Il ne saurait y avoir de doute sur l'origine de la taille roturière, pas plus qu'il n'y en a sur son caractère. Elle correspondait certainement à la capitatio terrena et à la cupitatio humana réunies (1); elle provenait des traditions romaines qui n'ont jamais disparu dans le midi, pas plus que dans le centre des Gaules, surtout dans les villes où plusieurs documents, notamment pour Paris, ont conservé les cotes de la taille roturière. Elle consistait dans un impout global sur le capital et sur le revenu, telle que la monarchie l'a pratiquée pendant 400 ans. Si

(1) Les Iférovingiens avaient conservé les deux grandes sources du revenu pu* blic impérial, la jugatis terrena et la capitatio humana. - Ad. Vuitry, ibidem, p. 34. 
on réunissait aux États- Cnis les deux taxes sur la real property et la personul property, on reconstituerait la taille. Aussi Rageau la définissait-il comme d'origine grecque et germaine (1), même comme une sorte d'offrande volontaire. Telle était également l'cyinion formelle d'un des plus grands feudistes, cle Brussel $\{2\rangle$. En tout cas, les feudistes autorisés ne la présentent jamais sous les formes odieuses qui l'aurajent rendue inapplicable et improductive.

Daprès Ducange, Brussel, Penauldon, Freminville, Hervé, Fagreau (3), on peut ramener aux termes suirants les règles de a taille sur les roturiers : 10 elle consistait en une taxe sur les facultés (fonds, meubles, revenus) des censitaires; $2^{\circ}$ elle était due sourent par les fonds immeubles seuls : c'était la taille réelle: $3^{\circ}$ elle était en général anquelle, paşable en aoùt, à Noël

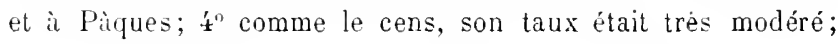
5 ") les seigneurs l'abonnaient souvent afin d'avoir un revenu fixe; $6^{\circ}$ les officiers confectionnaient les ròles dans chaque seigneurie; $7^{\circ}$ elle était payable en nature et en argent $(4) ; 8^{\circ}$ elle arait partout pour fondement la coutume et non le caprice arbitraire du seigneur; $9^{\circ}$ elle ne parait pas avoir furmé un revenu important pour les seigneuries; $10^{\circ}$ dans les recettes des comptes royaux que l'on possède pour la fin du xnle siècle, les produits de la taille ne tiennent qu une place tout à fait secondaire (i).

La taille n'est devenue un imprit proluctif que dans les mains du pouroir rog̣al.

(1) Est canon inlatio, pensio, collatio oblatio, inlietio, pensitatio, guse libet publica sı - Lauriere, Glessaire. - Brusiel, Ecumen drs fufs, $1^{\text {er }}$ vol., 411.

(2) Do la les talles dites grorieusfs, 'pui ćtaient demandées de temps en temps et accoriées. C"est un les plus grands arguments contre les exagerations de certains écrivaius à l'endroit des violeuces dont les tailles auraient été l'occnsion.

(3) Encyclopédie méthodique, au mot Tuille. - Ducange, Glossarium, au mot Tallia. - Laurière, Glossaire. - Pagean. an mème mot. - Hervé. Matièrcs féorlales, 1.r rol., p. 161. - Brussel, $1^{\text {คr }}$ vol., p. 411, 416. - Fréminville, Vrais principes des flefs. - Renauldon, Traité des droits seigneuriaur, p. 225.

(4) Surtout en nature, spécialement eu grains. - Historiens des Gaules, 22 rol., compotus ballivorum.

(5) Hisloriens des Gaules, 22e rol., comyotus ballivorum. 
Il ỹ arait cependant des exceptions qui tenaient à la violence des murs au moven irre et à la nature desinstitutions. Ainsi la présence sur une seigrneurie de deux seigneurs qui, chacun, avaient le droit de lever la taille, aggravait beaucoup la condition des tenanciers. C'est ce qui explique pourquoi toute taille seirneuriale a dù ètre interdite ruand la rovauté a été autorisée it lever une taille annuelle pour entretenir une armée permanente.

La taille ne parait pas aroir eu dans le Midi de la France. bien plus arancé en civilisation au moven itreque le Nord, les mêmes caractères. Elle a tendu de honne heure à derenir un impôt foncier, ce qu'était la capitutio terrena. Ainsi. dès le milieu du xue siècle, dans toute la zòne oì se répandirent les doctrines des Albigeois, précurseurs des Calvinistes Cuercy, Velay, Vivarais, Rouergue, bas Languedoc la taille consistait daus une taxe foncière. calculée d'après les instruments de trarail. les rîles étaient dressés par les curés, sous le contrile des évèques: mais les tenures roturières ou serviles la supportaient seules. Il en fut ainsi jusqu'en 1;89 1 .

$$
\text { GLATRIEHE CATÉ,ORIE. - TAXE- DE CONGOMUTIOX. }
$$

Ces taxes ne pouraient atteindre que les roturiers et les serfi. Elles consistaient principalement dans :

A. Les banalités, moulins, fours, pressoirs, boucheries, taureaux, moulins à drap seigneuriaux dont les roturiers ou les serfs devaient se servir à des conditions que le seigneur fixait seul. A cet égard, on a singulièrement exacéré les choses; car il est bien certain que moulins, fours, pressoirs seicneuriaux ont dù être, pendant bien du temps, un très grand avantage et un grand progrès.

B. Des droits sur les marchandises dans les foires, à l'entrée

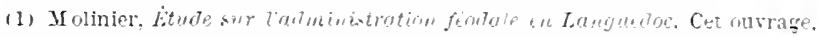
fait dapres los sources mimes, est important comme donnant la fhysionomic féodale et fiscale du mià le la France au xir ficle. Il contient une wre de

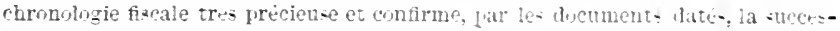
-ion des diver-étapos le léprque fédale. 
des villes et dans les villes mèmes, tels que le droit d'étalage, celui des poids et mesures ou de leyde, dans les marchés.

Ainsi dans les principales villes du domaine royal, Paris, Bourges, Orléans, le roi levait, tous les trois ans, une taille sur le pain et une autre taille sur le vin (1).

C'étaient les anciens portoria que chaque seigneur appliqua, dans sa seigneurie, sous toute espèce de formes et de noms. Seulement les taxes furent étendues à tous les objets de consommation, blé, pain, viandes, boissons, fruits, sel, métaux, produits fabriqués, cuirs, bois, meubles, métiers; le vin notamment était déjà traqué sans pitié et sans merci. "Le vin était " surtout imposé, tantòt au moment de la récolte, soit à la mise " en cuve, soit à la mise en cellier, tantòt au moment du trans" port ou de la vente. Le mode d'imposition variait dans chaque "localité : le nombre de ces perceptions, leur variété ne per"mettent pas d'en donner une idée générale (2)".

Après le rin, renait le sel, que la royauté ne s'est réservé qu'au xive siècle.

Les droits se levaient surtout dans les foires et dans les marchés. Les grandes foires sont dorigine féodale; elles ont rendu d'immenses services; elles donnaient lieu à la perception de nombreux droits de transport. De là les péages sur les routes, les ponts, les rivières, les ports, à l'entrée et à la sortie des villes, le long des rivières et des cours d'eau.

\section{Criquiène chtégorie. - Dolhanes et péages.}

Le transit de seigneurie à seigneurie donnait lieu à de réritables droits de douane qu'il fallut restreindre. Dans les ports, les seigneurs levaient des droits à l'entrée et à la sortie des marchandises. Ces droits se réglementèrent peu à peu, lors de la formation des grands fiefs. Les grandes divisions douanières de la France el des principaux États de l'Europe se formèrent.

En dehors des taxes dans les ports, les droits principaux

(1) Historiens des Gaules, 22e volune, compotus ballivorum, 1295.

(2) Ad. Vuitry, ibiden, 1*r vol., page 341. 
étaient ceux de tonlieu (Theloneum) perçus, de mème que dans l'Empire romain et qu'en Chine encore aujourd'hni à des endroits déterminés, ceux de travers qu'il fallait acquitter pour traversel la seigneurie, ceux de parcour's. Le tonlieu était tantòt un droit sur la circulation (1), tantôt sur l'entrée ou la sortie des márchandises. On le confondit d'abord avec le droit d'octroi et d'entrée des villes, puis on l'en distingua. Dès la fin du xum siècle, le pouvoir royal tendit à accaparer tous les droits de tonlieu et à partager, tout au moins, ceux d'octroi.

Quant aux péages, ils étaient différents; ils se prélevaient surtout sur les ponts, les rivières, les bacs. Dès le $\mathrm{xr}^{\theta}$ siècle tous ces péages furent réglés par le pouvoir royal qui ne reconnut que ceux établis par des titres, surtout les droits de bac. Ils avaient un caractère domanial.

\section{Sixième catégorie. - taxe de traysh et d'industrie.}

Les empereurs romains intervenaient dans la production; ils réglaient, par leurs édits, les conditions des ouyriers, des associations, du travail; ils avaient établi la conlatio lustralis. Les seigneurs firent aussi des règlements pour l'agriculture, le commerce, l'industrie, les métiers, les salaires, le pesage et le mesurage des marchandises, l'arpentagre des terres; ils prélevajent des taxes à cet effet; ils intervenaient particulièrement dans la production agricole pour régler l'époque des moissons, des fauchaisons, des vendanges, de la vente, du transport des vins.

Pendant longtemps cette intervention et ces règlements ont été indispensables. Abolis par la Révolution française, les règlements ont survécu. Mème aujourd'hui, les maires, dans une certaine partie du nord de la France, prennent encore des arrètés concernant les récoltes, spécialement les venrlanges. Il faut reconnaitre toutefois qu'en 1789 , cette intervention et ces règlements étaient devenus un grand obstacle aux progrès de l'agriculture et de l'industrie. Le pouvoir royal s'était, en partie, emparé du droit de les faire; ce qui, bien souvent, avait aggravé les entraves

(1) Thelonea circulorum, Hist. des Gaules, $22^{\circ}$ vol., compotus ballivorum. 
à la production, notamment pour le commerce de laines, considérable dès le $\mathrm{xul}^{\mathrm{e}}$ siècle. L'un des plus grands bienfaits de la révolution de 1789 , l'un des moins contestables, a été la liberté rendue au travail. N. Léonce de Lavergne, agronome si éclairé, n'était pas éloigné d'admettre que tous les progrès de la Rérolution se ramenaient à la liberté du travail (t), surtout pour la production agricole.

\section{Septièye catégorie. - Córtées.}

Limportance des corvées était très grande. Elles constituaient une charge bien plus iourde que les tailles. Elles provenaient, arec aggravation, des traditions romaines. Certaines d'entre elles étaient aussi bien à la charge des fiefs que des autres tenures, notamment la plus redoutahle, le gite ou le droit de procuration. Yous avons montré la nécessité et Yorganisation de cette corvée lans les derniers temps de l'Empire romain. Elle était devenue plus nécessaire et plus lourde au mộen ị̀e arec laugmentation de la population, des territoires cultivés, et des personnes qui les réclamaient: le roi, les officiers, les seigneurs et leur suite, les érèques, les abbés mitrés, les préròts, les baillis. Brussel a donné la statistique de gites (gistaj dans le domaine royal, a vec le tableau des distances et des gites par villes, pour le roi, les évèques, les seigneurs, ainsi que l'évaluation en argent des dépenses. Il existait un ròle de gites sous Louis VII. Plus tard, le gite fut converti en un impòt en argent et en nature. Le gite ne comfrenait pas seulement le logement et la nourriture pendant un certain temps et à certains moments; mais, selon la tradition romaine, la fourniture, soit gratuitement, soit à des tarifs fixés par les seigneurs, de prorisions, de moyens de transports. Cette corrée était donc fort lourde (2). Les corrées, proprement dites, étaient surtout appliquées aux domaines seigneuriaux et aux fiefs

(1) Introluction aux royages d'Arthur Foung: comparer : $1^{\circ}$ notre étnde sur les mures indites de Uontesimieu. Juhrnal des Economistcs, 1894. -- 2o, Seignouns. Le rifime fiodal en Bomryogne, la seignemrie de Vergs.

(2) Bru-sel, ibthem', tome F, p. 536. -- Historiens des Gaules. XXII rolumes,

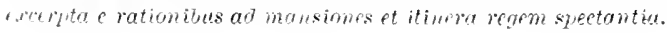


nobles, de mème qu'aux biens de l'ĺglise. Elles consistaient dans l'entretien des chemins, le transport des récoltes et des provisions, dansles réquisitions pour les récoltes, dans la confection de vètements et d'armes, dans l'entretien des bois, des eaux. - Renauldon leur a consacré un chapitre très curieux (1) dans lequel il pose quelques règles générales: $1^{\circ}$ quiconque doit la taille réelle, doit les corvées d'après la coutume ou le titre; $\mathbf{2}^{\circ}$ quiconque est taillable est corvéable; $3^{\circ}$ qui n'est pas taillable n'est pas corvéable. De là bien des difficultés et des complications qui entretenaient de procès sans fin toutes les justices seigneuriales, notamment pour saroir si la corvée affectait d'un caractère spécial l'héritage (fief ou tenure roturière) ou la personne.

Les corvées n'avaient aucun caractère servile. Les vassaux les devaient fournir en partie. Elles résultaient de la force même des choses. Elles araient autant le caractère réel que personnel. Seuls les serfs, ou anciens serfs devaient, en général, des corvées dites de corps; nous ne mentionnerons pas l'obligation que. certains roturiers auraient subie de battre les eaux de l'étang, près du château, pour faire taire les grenouilles.

Toutefois le guet a été une rude corrée, ainsi que le rabattagre pour la chasse.

Hutiène catégurie. - Domaine.

Chaque seigneurie arait également ses produits domaniaux, provenant des fournitures en nature et de la culture de la partie réservée de la seigneurie. Certains domaines royaux étaient également cultivés directement.

Cette catégorie de droits était certainement très productive pour la plupart des seigneurs, en particulier pour le premier seigneur, pour le Roi. On ne peut avoir une idée de l'importance des domaines, mème pour le Roi, qu'en recourant aux documents originaux. Par cette expression domaine nous entendons seulement les droits ou les produits domaniaux, el nullement l'ensemble des possessions rovales.

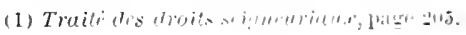


A. Produits domaniaux. - Les produits domaniaux étaient les blés, avoines, orges, vins, poirés, cidres, bestiaux divers, poissons, qui, chaque année, étaient livrés au Roi, soit à raison des terres qu'il faisait cultiver, soit à raison de cens, bien plus considérables, qui lui étaient remis à titre de paiement de toute sorte (1), redevances, fermies, gites, impôts. Ces remises n'étaient, en partie, que le paiement de l'impôt acquitté principalement en nature. Nous allons parler des forêts, le produit domanial par excellence.

B. Droits domaniaux. - Quant aux droits domaniaux, ils étaient très multiples et très variés : nous ne pouvons énumérer que les plus importants (2):

$1^{\circ}$ Le droit de deshérence, sur les biens vacants, abandonnés et sur les liéritages sans héritiers;

$2^{\circ}$ Le droit d'épaves, le droit de bris;

$3^{\circ}$ Le droit de découverte de trésors;

$4^{\circ}$ Le droit sur les biens des baitards et des aubains (étranger) d’après la coutume;

$3^{\circ}$ Les amendes;

Les amendes étaient très nombreuses; elles appartenaient au seigneur, qui avait le droit de les prononcer. Nous reviendrons sur ce point essentiel ì propos des droits judiciaires;

$6^{\circ}$ Les droits de chasse, de pêche, de garenne, de colombier. Ces droits relevaient surtout du seigneur féodal. Ils paraissent s'ètre beaucoup agggravés du $x^{\mathbb{e}}$ au xvil ${ }^{e}$ siècle. Ils comptent parmi ceux qui pesaient le plus sur les tenures roturières, parce qu'ils en diminuaient l'indépendance et la jouissance;

To Les droits sur les cours d'eau et rivières navigables et llottables. En général, ces droits appartenaient au seigneur justicier. Ils donnèrent lieu à beaucoup de vexations. C'est à propos l'un procès sur un cours d'eau que Championnière a composé son livre fort intéressant, mais qui n'a que la valeur d'un pamphlet judiciaire. Le pouroir royal parvint, assez rapidement, à

(1) Census vinearum, census dumorum, census terae in frischia. - Hist. res ranles, 22 vol., compotus ballicorum.

(2) Brussel, itidem, tome I, Revenus des spimpurs et du Roi. 
faire prévaloir ses droits sur les ricières navigables et thot tables, en abandonnant les autres aux seigneurs, qui lerèrent des taxes sur les moulins, les passages;

$8^{\circ}$ Les droits de bac, très importants au moven àge et assez. lucratifs. La léşislation des cours deau leur fut appliquée;

$9^{\circ}$ Les droits d'etangs, d'égouts, de pluip, de puits (1), qui demeurèrent longtemps seigneuriaux et qui avaient de l'importance dans les villes;

$10^{\circ}$ Le droit de blairie ou de péage sur les terres ragues;

$11^{\circ}$ Le droit de banvin, qui autorisait le seigneur a rendre ses vins avant ceux des vassaux ou des tenanciers. De mème, les coutumes de Bordeaux, mème au xm1 e siècle, nautorisaient l'entrée des vins du Haut-Pays (Haute-Gurenne) qu'ì un certain délai des rendanges.

C. Fortts. - Les revenus forestiers tenaient la première place parmi les ressources du Foi et des seigneurs. Brussel a donné beaucoup de renseignements à ce sujet, mais les comptes des baillis pour 129.5 en contiennent bien davantage. IIM. Lamprecht et Borelli de Serres ont mis en évidence yue le territoire de la France a été couvert de forèts pendant le moyen àge et que leurs produits ont eu une grande importance aussi bien pour le Roi que pour les seigneurs. Aussi, dès 1302, le personnel des eaux et forèts était organisé. De là les droits de gruerie, de graierie, de tiers et danger. Les forits donnaient lieu à un grand nombre de droits et de procès. Les forèts formaient le véritable domaine, la réserve du Roi et des riches seigneurs. On trourera à cet égard les détails les plus curieux et les plus précis dans le remarquable mémoire de M. Borelli de Serres (2) sur l'origrine du droit de tiers et danger, droit caractéristique des faits domaniaux it cette époque.

D. Exploitations diverses. - Bien que les produits des exploitations agricoles ou industrielles ne fussent pas des irn-

(1) Renauldon, ibintem, livre $\vee$, chapitre $\forall$

(2) Recherehs su divers strices publis, Pais, 1s95, 1' 293 . Lamprectb. La France au $\mathrm{xi}^{\mathrm{e}}$ suide, shapire premier. 
pôts, il est nécessaire d’en tenir compte parce qu'ils constituaient une des plus grandes ressources des seigneuries, comme l'indiquent les liecepta ballicorum du domaine royal pour 1293 (1). La Royauté arait des terres, des vignes, des prairies sous sa main directe, les unes affermées, les autres exploitées. Elle avait des abeilles, des ruches, de la cire. Elle récoltait des blés et des avoines; elle exploitait des étangs; elle en affermait la pèche ou faisait pêcher elle-même. Dès Philippe le Bel on s'occupait de repeupler les étangs.

Le Rưi avait également des mines; la propriété des mines était seigneuriale. Ce n'est qu'en 1413 que le Roi s'attribua un droit supérieur de propriété sur les mines (2).

\section{Yer vieje catégurie. - Drolts jedichalres et le sceau.}

Les droits judiciaires étaient très multipliés. Ils alimentaient les innombrables greffes des justices seigneuriales et royales. II serait tout à fait fastidieux de les rappeler. Au surplus, on peut les trouver, en partie, énumérés dans la loi de frimaire an VII, et dans le Code de procédure civile de $1800^{\circ}$, qui, l'un et lautre, sont une sorte de miroir des justices seigneuriales. Les saisies de nos Codes, saisie-arrêt, saisie-exécution, saisiegagerie, saisie-brandon, proviennent de la saisie féodale. Les tenures roturières étaient sans cesse menacées par la saisie féodale, de mème que les fiefs par la commise. En parcourant les cent un droits divers, mentionnés par Boutaric, il serait facile de relever beaucoup de droits judiciaires. Le mot exploit, dont Racine s'est tant serri dans Les Plaideurs est féodal : expleta.

Les seigneurs avaient, de mème que le Roi, des greffes, des huissiers, des notaires ou tabellions. Les jugements, les actes donnaient lieu à des droits, notamment à l'apposition du sceau. Il faut y reconnaitre la première apparition, lointaine encore,

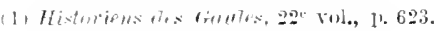

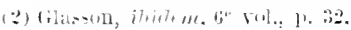


des produits dune mine qui derait ètre si fèconde, en France du moins, le timbre et l'enregistrement. Le sceau donnait une sorte d'authenticité aux actes. Dans les comptes royaux, les produits du sceau (sigillum tiennent une certaine place (1).

Les amendes étaient plus productives encore. Elles étaient en rapport direct avec la société féodale, fondée essentiellement sur le contrat. Les chartes des villes et des communes araient surtout pour objet de les diminuer ou d'en exempter les bourgeois ou autres membres de l'association. Après les tailles, les corvées, les banalités, les amendes étaient les impositions qui pesaient le plus lourdement sur les habitants des villes et des campagnes. Leur tarif était minutieux; on l'exigeait avec rigueur. M. Luchaire les divise en trois catégories: $f^{\circ}$ redevances prélevées pour exemption des devoirs judiciaires ou services de cour (placitum); $2^{\circ}$ les amendes payées pour crimes et délits (infractura, amendæ); une des sources les plus importantes du revenu seigneurial; $3^{\circ}$ les amendes prélevées par le justicier à l'occasion des frais de procédure (2).

Le milieu féodal a été, à la fois, militaire, arricole et procédurier, fiscal, inquisiteur. Sous ces trois rapports, il a exercé une influence immense sur la France, mème celle d'aujourd'hui. Nos codes foisonnent damendes, surtout nos lois fiscales en sont émaillées au delà de tout ce que l’on peut imaginer. Les uns et les autres tiennent de fort près au .milieu féodal, malgré 1789 et 1793.

\section{Dixiėae catéliorie. - Police.}

La police appartenait au seigneur justicier, mème dans le cas où la justice et la seigneurie n'étaient pas dans les mèmes mains. Elle faisait partie de la justitia. Comme la plupart des institutions

(1) Glasson, ibidem, 6 6 vol., lage 7 .

(2) Luchaire, Hotruel, 1. 343, 388, 542, 594. - Flaszm, ibirlom, 1) 23. L. amendes sont multipliées dans les Établissements de Saint-Louis. - Élition Ducange, p. 379. - Seignobos, Le rigime feodal en Buurgognt', l'. 399, nute desamendes: do la prévòté tlo Noyer. 
féodales, elle aboutissait le plus souvent à des affaires d'argent, a des amendes qui formaient un revenu et un véritable impôt. Si on ouvre nos budgets actuels, on trouvera, tout de suite, la place qu'y occupent les amendes de toute sorte provenant de la police. Ainsi pour les foires et marchés, il faut distinguer les taxes policières qui relevaient du seigneur justicier et les taxes féodales dues à raison des locaux appartenant au propriétaire du fonds. Cette police était assez fort active, car il $\mathrm{y}$ avait beaucoup à faire au milieu de la complexité qui régnait dans la condition des personnes et des biens. Le déguerpissement, qui a caractérisé toute l'époque féodale, parce que la population n'était pas tout à fait stable, les changements de seigneurs, les soustractions entre seigneurs de tenanciers et de serfs, l'exécution des saisies, les allees et venues des gens flottants ou vagabonds, les guerres privées, les mouvements des foires et marchés, la surveillance des droits si multipliés des seigneurs, sur les personnes, les terres, les bois, les cours d'eau, les récoltes, les marchandises, les bandes d'aventuriers et de bandits parcourant la France de part en part et trouvant dans les forèts des abris infranchissables, mais surtout les procès de toute espèce qui encombraient les tribunaux, les rapports encore violents des hommes entre eux, les duels privés et judiciaires, les tournois, la multiplicité des contraventions, des délits et des crimes, les règlements économiques et administratifs, la levée des taxes, tout l'ensemble social et fiscal donnait une grande importance à la police.

La police se traduisait surtout par les amendes; amendes seigrneuriales, amendes royales, destinées à grossir le trésor seigneurial ou royal et aussi à faire vivre les agents de tout genre qu'ils tenaient sur pied (1).

\section{Oxziène catégorie. - Les confiscations.}

La confiscation est à peu près de tous les temps. La démocratie athénienne en avait fait, malgré le type supérieur de gouver-

(1) A. Monteil, Hist. des divers États, surtout le volume consacré au xxme et xIVe siècles. L'ceurre de M. Monteil, eritiquée doctoralement par M. Guizot, donne une idée plus vivante du moyen âge que les leçns du granı professeur. 
nement qu'elle a réalisé, une des ressources régulières de ses budgets. Rien de plus réel et de plus amusant que le personnaçe d'Aristophane se demandant le matin quelles propriétés devront ètre confisquées le soir. La confiscation n'a pas chomé à Rome; il suffit d'ouvrir Tacite et les codes inspirés par le christianisme. Les rois Francs et Carolingriens ne confisquèrent pas moins. Faut-il parler des confiscations sous Louis XIV mème et de la répartition des biens confisqués? Mais nul régime n'a cependant pratiqué la confiscation avec autant de persévérance que le régime féodal; la confiscation n'y était pas seulement une ressource fiscale et domaniaie, mais elle résultait de la nature des institutions, surtout pour les fiefs. La commise n'était, en réalité, que l'application du droit de se faire justice soi-méme, reconnu au seigneur. Les alleux mèmes pouvaient ètre confisqués, en certains cas, parce que la confiscation dominait le droit de propriété qui n'était encore que conditionnel. Il suffit d'ourrir les comptes des recettes royales au $x \| I^{e}$ siècle pour reconnaitre l'importance de forfaitures ou confiscations (1).

Ainsi, on peut comprendre parmi les confiscations le droit, que les seigneurs ont exercé, de spolier (jus spolii) le mobilier de l'érèché à la mort de l'érèque (2). Quant à la regule les seigneurs mèmes ne l'ont pas eue. Les grands feudataires seuls Normandie, Bretagne, Aquitaine, Toulouse) en ont joui quelque temps.

\section{Dolzièye catégorie. - Dìnes cafégnées.}

L'inféodation des dimes est antérieure au $\mathrm{x}^{\prime} 1^{\mathrm{e}}$ siècle. Elle fut sévèrement interdite par le concile de Latran en 1179 ; mais les rois capétiens se sont toujours refusés ì admettre à cet égard les plaintes de l'Église. L'inféodation donnait lieu à de réritables fiefs de dimes avec aveu, démembrement, partage. On ne possède aucun renseignement sur leur importance; mais elle était sérieuse. Cette inféodation fut maintenue jusqu'en 1789. L'abo-

(1) Luchaire, Manuel, 149,578. - M. Iuchaire comprend avec raison la confis(ation parmi les revenu= du seigneur, page 212. - Historiens de France, lome 22,

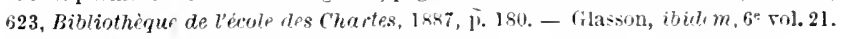

(2) Glasson, 6 vol. 53 . 
lition des dimes en priva seule les seigneurs et les fieffés qui les représentaient. Pour eux la perte fut totale; ces inféodations n'ont pas été étrangères à la Révolution, qui ne put réussir qu'arec le concours des religieux et du bas clergé. Elles formaient un véritable impòt au profit de ceux qui en profitaient. Les unes pouvaient avoir l'usurpation et la violence pour origine; les antres représentaient le coùt des services que l'Église n’avait pu rendre ou payer (1).

\section{Treiziène Catégorie. - Lis yoxxale.}

Jusquà la fin du siı siècle, la royauté et les grandes séignneuries ont possédé des ateliers monétaires et ont battu monnaje (2). A l'époque de saint Louis, 80 seigneurs frappaient de la monnaie; un siècle plus tard on en comptait encore 3ă. Jusqu'en 1337, la Foyauté n'émit pas de fausse monnaie, soit en altérant le poids, soit en altérant le titre, mais elle s'attribua. de tout temps, de mème que les seigneurs, le droit de fixer la raleur de la monnaie et, par suite, de faire varier les prix. Sous le roi Jean, de 1330 à 1360 , la livre tournoi changea 70 fois de valeur. Les mèmes changements, bien qu'avec plus de modération, avaient lieu dans les seigneuries. Ces changements procuraient des bénéfices qui constituaient un véritable impòt monétaire. Cet impôt monétaire a été maintenu jusque sous Louis $\mathrm{XV}$, quant au pouroir royal; mais il $\mathrm{y}$ a eu, jusqu'au xve siècle, un autre impòt monétaire. Les villes, les communes, les ccrporations de marchands traitaient tantôt avec le roi, tantùt avec les seigneurs, soit moyennant une redevance, soit comptant, pour être garanties pendant un certain temps, contre les variations dans les monnaies; c'étaient des contrats d'assurance ou de garantie monétaire. On ne niait pas le droit royal ou seigneurial, mais on voulait s'en préserver. Dès 1120 des traités intervinrent avec le Roi, en 1133, 1183, 1193 et ainsi de suite. En 1282 le duc de Bourgogne s'engage pour 2 ans moyennant

(1) Renaulan, Traité drs droits scigmuriaur, page 188 .

(2) Nuus renvoyons à l'exposé de M. Glasson, ibidem, 6e volume, pages 28 et suis. Consulter également Engel et serrure, Hist, numismatique du moyen âge, $1+94,2$ vil. 
z̈ sols par feu et un dixieme de revenu; c'est bien l'impòt 1 . On peut rattacher it la monnaie une autre pratique dont on retrouve les traces dans les comptes des rois au $x_{11}{ }^{e}$ siècle; cette pratique était féolale et seigneuriale; elle consistait à s'approprier à crédit des marchandises, des provisions chez les vassaux, tenanciers et marchands. Cétaient de véritables emprunts forcés; aussi dans les comptes des baillis on trouve des quantités de mutua contractés et remloursés; ces mutuu ont dì correspondre à un assez grand mourement de capitaux 3$\}$.

\section{Q̨iatorzièné catégorie. - Le -errvice Militaire.}

Les récents travaux de .III. Langlois, Luchaire, Borelli de Serres, et les derniers volumes (XXII et XXIII) des Historiens des Gaules ont renouveié en quelque sorte l'histoire des origines du service militaire en France $(\boldsymbol{2})$. Le service militaire parait y aroir toujours présenté de grandes difficultés. Bien que la race celtique ait déployé des qualités gruerrières remarquables, puisqu'elle a lait le fond des armées I'Annibal, de César et de Constantin, elle se pliait difficilement aux habitudes militaires; aussi, dès que les armées romaines eurent quitté les Gaules, les Gaules restìrent désarmées ou à peu près; Germains, Sarrasins, Northmans, Hongrois purent les parcourir tout à leur aise; une anarchie générale, que Charlemagne ne parvint qu’à peine it dominer de son vivant, envahit tout le territoire; il fallut procéder à une organisation militaire sérieuse pour la combattre. Cette organisation a été l'élément principal du régime féodal qui représente une véritable révolution militaire. La terre, le fief, n'est que le prix du service militaire, le moyen de fixer l'homme à la terre et de l'intéresser à la défendre. C'est une prime payable en terre. Ce qui a pu se faire sans dilficulté eu

(1) Glasson, itidem, 132, 5e rol.

(2) Langlois, Philippe le Hardi, .Hongroph is marrouble, 1855, pages 348,365 : les faits réunis sur larmée rovale au xine siecle sont des plus curieux. Borelll de Serres, Rechrches, 467. Historiens de France, 22e vol., scriptu dr

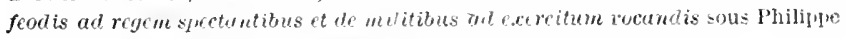
Auguste; Document des phe imorintersts. 
égard à l'étendue relative du territoire et à l'exiguité de la population.

C'est ce dont les historiens, imbus des idées de 1789, n'ont pas tenu compte. Ils n'ont vu que les derniers temps féodaux. Peut-être moins partial, Tocqueville, aussi moins instruit, n'a pount dégagé la face militaire de la féodalité ni compris la rérolution dont elle est née. Il a fallu donner la terre à l'homme pour + n faire un militaire, un soldat voué à défendre le territoire. La plupart de nos familles militaires sont d'origine féodale et enrore territoriales.

Le mème service a été imposé aux tenures roturières et mème aux tenures serviles, mais dans d'autres conditions. Le seigneur avait le droit de requérir pour les affaires de la seigneurie les roturiers et les serfs, à la charge de les payer ou de les entretenir. Les roturiers accompagnaient les chevaliers et combattaient à pied; les serfs remplissaient les rôles subalternes (1).

Le Roi possédait les mêmes droits pour les intérèts généraux lu royaume; le fait était accepté dès la fin du xı siècle dans les mèmes conditions $(2$.

Au $x_{111^{\mathrm{e}}}$ siècle on constate deux changements considérables; les roturiers obtiennent de substituer au service un subside en argent; quant aux seigneurs ils obtiennent une solde (stipendium) et enfin ils finissent également par être admis au remplacement militaire contre argent. Ces changements s'expliquent par diverses causes : $1^{\circ}$ la longueur des guerres nouvelles, contraires

(1) sur tons ces faits, le livre de M. Langlois est des plus int éressants. Pour le service uilitaire de's villes, voir Luchaire, Manu, 389 et le compotus ballivom, tome $22^{2}$, 1. 623 ; Historiens des Ganles; on y trouve la distinction et le detail des servientes rruite - serientes pedite. Seul le smripres rquite est appelé miles. Aussi Ducange lit les loturiers: dieuntur non esse nobites; non habent equm seu equos nec whin arma in domibus eorum (au mot nobilitas). Comparer (H. des Gaules, XXIII") la convocation de l'ost de France, 1303-1304, l'enroi des lettres et le r'levé des subsilles par sénéchanssée.

(2) Colınel Borelli de Serres, Recherches, Les frentien, tués à Mons-en-Puplle, motice fles flus intéressantes sur le scrvice militaire. Les Gentien étaient des bourgeois taillables. Ils se firent tuer pour sanver la vie à Philippe le Bel; leur fantille resta roturière. Toir également le mémoire : Les prisées du service roturier "1/ $\mathrm{xm}^{\mathrm{e}}$ sitcle. La prisée était l'estimation, l'éraluation des charges militaires (llummes, voitures, subsiles). 
aux termes féodaux; $2^{\circ}$ la préférence que les rois et les hauts seigneurs donnent à des soudovers, aventuriers, bandits, militaires de profession, tels que les bandes de Duguesclin; $3^{\circ}$ les progrès dans la composition des armées, qui, dès Philippe le Hardi, ont une artillerie, un corps de génie, des remontes, des magasins, un corps du train, un corps de grendarmerie de lorteresse.

Les chevaliers des fiefs, formant la cavalerie, tenaient encore la première place, mais les vilains des rotures et les bourgeois des villes, qui avaient fait bonne contenance à Bouvines, ne convenaient plus pour aller en Sicile et en Aragon. Les rois leur préféraient de l'argent; le service militaire se changea en une taxe. Cette taxe devint l'une des plus grandes ressources du Roi et des hauts seigneurs. Elle a préparé l'établissement de l'impôt roval, de la taille, qui avait un fondement militaire. On en retrouve la preuve dans les documents contemporains. Il y eut certainement parmi les riches bourgeois des villes des hommes fort braves, comme les Gentien, mais les familles bourgeoises derenaient difficilement militaires. Il en a été ainsi de la famille de Michel Montaigne.

Le service était très lourd; nombre de familles, possédant des fiefs acceptèrent le remplacement, mème après que la rèrgle générale de la solde eut prévalu pour toute l'armée; néanmoins, au point de rue militaire, les fiefs ont eu une influence décisive sur la formation des familles rurales qui ont constitué pour la France une inappréciable réserve militaire, fondement de son indépendance, garantie de son territoire, encore aujourd'hui (1).

\section{II. - Les texures roturières yox féodales.}

Nous n'avons à dire que quelques mots de ces tenures, puis qu'elles ne donnaient lieu à aucune redevance spéciale dans laquelle fut comprise une taxation à raison des fonds ou des personnes. Elles ne transféraient pas le domaine utile quelle que fut leur durée (2) : c'étaient le bail à métairie perpétuel et le bail héréditaire à terme. Le bail à métairie perpétuel, contrat prati-

\footnotetext{
(1) Opinion développée avec éloquenceet autorité par le géuéral Trochu en $\mathbf{1 8 7 4 .}$

(2) Garsonnet, Locations perpetuelles, pages 392-102. - Lefort. Même ourraye, lages 248-254.
} 
qué surtout dans le centre de la France, Limousin, Bourbonnais. Le métayage n’est plus perpétuel; il est, au contraire, devenu annuel, mais à raison des avantages qu'il présente pour lagriculture dans les terres pauvres, il est en progrès en France, à laquelle il a rendu de très grands services; c'est, au fond, une forme de l'association, mème de la coopération. On la rencontre en Tunisie, mais moins avantageuse pour les travailleurs. Le partage à moitié sera toujours une bonne condition pour le cultivateur. En tout cas, c'est un mode de culture qui permet de lutter, bien mieux que le fermage, dans les terres médiocres, contre la mise en culture des territoires nouveaux. Le fermier court à peu près seul les risques. Le métayer les partage.

Le bail héréditaire n'était qu'un fermage sans aliénation du fonds; mème situation pour les baux avec droit de marché dans le nord de la France; pour les baux à vie, pour le bail à domaine congéable, pour le bail colonger en Alsace (1). Le caractère féodal, c'est-à-dire la transmission perpétuelle du fonds, mais conditionnelle, manquait. Le preneur ne devenait pas propriétaire, il ne pouvait transmettre la propriété, hypothéquer, etc. Il était tenu vis-à-vis du propriétaire aux obligations du bail et non aux obligations féodales.

Ces différences ne l'exonéraient pas des obligations générales de la seigneurie dont dépendaient les fonds donnés à bail. La seigneurie représentait pour le preneur l'État. Par suite les obligations qui avaient un caractère strictement féodal ne lui incombaient pas, mais il devait remplir les autres, comme les possesseurs de tenures roturières. Les redevances et les droits de mutation, compris dans les deux premières catégories, étaient étrangers aux possesseurs de ces tenures; toutefois, ces derniers demeuraient obligés de faire face aux charges de toutes les autres catégories et de subir : aides et tailles à titre d'impôt direct, taxes de consommation, douanes et péages, taxes et règlements de travail et d'industrie, corvées, justices et droits judiciaires, dimes, impôts monétaires indirects, service militaire, police, ils ne pouvaient échapper à ce qui constituait la puissance publique du temps.

(1) Lefort, ibielcm, page 273 . 
\$ 8. Des taxes ct des droits féorlaux sur les serfis et les tenures semiles.

Quoiqu'il y eùt un assez grand nombre de serfs dans les rilles et dans les communes, les serls dépendaient beaucoup plus des campagnes que des villes et communes. Quels ont été les effets sur leur condition de l'établissement progressif du régrime féodal:? Au $x \times 1^{e}$ siècle, les esprits éclairés, les feutistes autorisés, tels qu'Hervé, savaient fort bien que la servitude ne provenait nullement du régime féodal, qu'elle était fort antérieure et qu'elle u'avait pas de rapports directs avec lui. II y a deux doctrines sur la nature de ces effets. Ainsi, Hervé admettait qu'avec le régime féodal, la servitude s'était développée. "La servitude qui courrait les campagnes (1), dit-il, avait aussi gagné les villes n. M. Esmein, qui a donné un paragraphe remarquabl. sur les serfs et les tenures serviles $(2)$, incline vers cette opinion, qui peut invoquer pour elle l'autorité de .11. Lamprecht. l'un des publicistes qui connaissent le mieux les premiers temps du moyen ìge. Mais Guérard, le sarant le plus compétent sur ce sujet, est contraire à cette opinion (3, ainsi que $\mathrm{II}$. Luchaire, avec quelques réserves (4 4 . Nous déférons à l'opinion de Guérard, parce qu'elle est à la fois conforme à un trés grand nombre de textes et à la direction économique des faits. Gette direction, nous en suivons les étapes depuis le $r^{e}$ siècle; il aurait été fort rigoureux de reconnaitre que le régime féodal qui, en réalité, a été, pour l'époque où il est sorti de la forcr mème des choses $\left(\ddot{j}_{i}\right.$, un yrand progrès, eat comprimé et fait

(1) Matiense findules, $1^{\text {es }}$ vil., list.

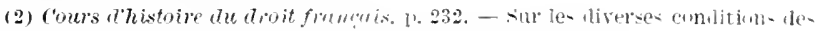

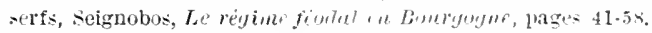

(3) Cartulaire de saint-Pire le chartres, [nolugomenes. - complarer un une-

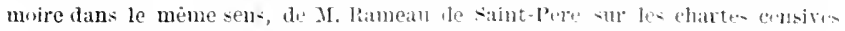

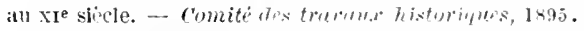

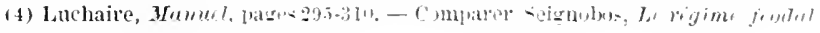
In Bouryogree, yages $\$ 1-54$.

(i) Guiraril, ibill $m$. 
rétrograder le mourement de transformation dans la condition du travail.

Il se peut qu'en resserrant les liens hiérarchiques et sociaux, la féodalité ait soumis temporairement les serfs à des obligations plus strictes, par exemple en limitant le vagabondage ainsi que le déguerpissement, et en réglant plus sérèrement les conditions du mariage; mais ces restrictions eurent pour les serfs un avantage inappréciable, celui de les fixer de plus en plus sur le sol.

Il est nécessaire de faire une triple distinction dans la condition des serfs, afin d'indiquer les taxes et les droits féodaux qui pesaient sur eux et sur leurs tenures. Ces tenures étaient serviles. Elles ne pouvaient être habitées et cultivées que par des serfs. Tout homme libre, qui y résidait plus d'un an et un jour, devenait serf lui-mème. Elles ne pouvaient être acquises que par des serfs. Cet état de choses s'est prolongé aussi longtemps que les serfs ont occupé une certaine place dans la société. Mais, dès la fin du xın ${ }^{\mathrm{e}}$ siècle, les serfs étaient, pour la plupart, devenus des roturiers (1). Les tenures serviles se transformèrent en tenures roturières. D'ailleurs le serf arait pu, depuis longtemps, acquérir des tenures roturières. Il y en a qui sont parvenus à acquérir des fiefs. En ce cas, la tenure conservait son caractère et le serf sa condition.

Il y avait trois sortes de serfs ou trois catégories de serfs : 10 les colliberts, qui formaient la transition entre le roturier et le serf 2$) ; 2^{\circ}$ le serf de servitude réelle; $3^{\circ}$ le serf de servitude personnelle, ou serf questal (homo de corpore). Les taxes et les Iroits féodaux rariaient par chaque catégorie de serfs, sinon dans les termes, du moins dans leur application.

1. La capitatio. - La première preuve de servitude était le paiement annuel de la taxe servile de quatre deniers par tète pour le serf, et de deux par serve (3). Cette taxe n'était nulle-

(1) Sur ce fait, le mémriłe de Y. Rameau de Sitint-Père est décisif. Il s'occupe le yuatre chatellenies ou seigneuries dans l'Oise, le Cher, l'Aube et l'Orne.

(2) Guerard et Luchaire, ibilem.

(3) Crlasson, ibilem, 5 vol., page 3. - Etablissenonts de suint Louis, mène eilition, page 303. 
ment féodale. Elle tenait à la servitude mème. C'était le chrvage (capitulicium, chevagium, capitulis census). Aussi la reconnaissance du servagre, le paiement pour la servitude ou lacceptation se faisaient-ils en placant quatre deniers sur la tète du serf. Tous les serfs payaient la capitation. Laffranchi complet seul ne la payait pas.

Le chexagium pouvait se rattacher, quant au mot pour l'èxprimer, à la cupitatio humanu, mais il en différait. La capitati" humanı n'avait aucun caractère servile spécial, tandis que 1. chevagium était le cens des serfs.

II. La taille. - La taille exigée des serfs, de mème que des roturiers, et, en certains cas, des possesseurs de fiefs, ne provenait pas de la servitude, comme le checagium; c’était une contribution sur les ressources et les bénéfices des serfs, arbitraire pour le serf questal, extorquée ad volontatem et al misericordiam, plusieurs lois par an, peut-être trois fois (t) sur tous ses biens, le plus souvent abonnée ou réglée par la coutume pour le serf prédial, toujours pour le collibert. Mais il ne faut, pis plus pour les serfs que pour les roturiers, pousser les choses aux extrèmes. Après aroir cité un texte de labhé suger, dans lequel Suger déplore les excès dont sont parfois rictimes les serfs de corps, Ducange fait de la coutume du Bourbonnais l'extrait suivant $(2)$ : "Quiconque doit taille personnelle et sur lo " clıef, soit taille franche, soit taille serve, ladite taille est à ro"lonté raisonnable, et la peut le seigneur croitre et diminuer " selon la faculté des biens de celui qui la doit 3 )". Ce texto donne un commentaire sérieux de l'application de la taille ser-

(1) Dheange, Glesorium, all mot Trille.

(2) Peut-etre a-t-on pris les trois termes ustuels at Sinil, Paidues et aont jour

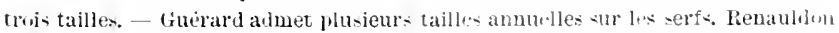
divait : La taille servile est une imposition dute le veigneur a droit de lever tous l.s a as sur les serfs qui demeurent sur sa terre.

(3) Rageau cite et texte de Beaumanoir : "Tant comme ils vivent, li signemr n. lew (les serfs) purent rien demander se il we muffont, lurs lems cens, et leurs rudevanes que ils sont acostumè à payer jor lems servitudes n. - M. Flach (Xom-

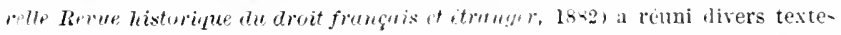
indiphant une "lpression sauvage. Ces texte- null, paralsent de exception-

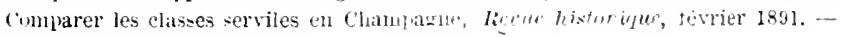
seignobos, ibiriem, liagr 222. 
vile ou roturière. C'était un impôt global sur toutes les facultés du contribuable, arbitraire pour les hommes de corps, réglée, modérée, mème souvent rachetée pour les autres serfs.

Si la taille avait eu le caractère de servitude et d'oppression que quelques publicistes lui attribuent, le pouvoir royal n'aurait pu en faire le premier impòt permanent.

IJJ. Le Formariage. - Taxe due au seigneur au moment du mariage du serf questal et du serf prédial (1). Il est probable que le collibert ne la devait pas. C'était une sorte de droit de mutation spécial aux serfs. La légitimité du mariage du serf a été le plus grand concours que le christianisme ait donné à son émancipation. Par la force même des choses, quelles que fussent les difficultés économiques, l'égalité dans le sacrement du mariage devait les amoindrir. Mariage légitime, enfants légitimes, la liberté devait suivre. Le mariage affectait donc beaucoup la seigneurie. A l'origine, le consentement du seigneur fut nécessaire. Son serf pouvait quitter la seigneurie pour se marier. C'était l'appauvrir et enrichir le seigneur voisin. C'était faciliter le désaveu : car le serf pouvait désavouer le seigneur et déguerpir. Les seigneurs firent des traités de parcours, c'est-à-dire réglèrent les limites des mariages, des désaveux, des déguerpissements. Hais leur intérèt réel était de retenir le serf sur sa tenure et de faciliter son mariage; on substitua par suite un impòt, une taxe, au consentement. Le taux de cet impót fut d'ahord arbitraire, puis établi d'après la faculté des biens, puis réglé par la coutume (2).

IV. La mainmorte. - En ce qui concerne les serfs, la mainmorte n`a aucun rapport arec la mainmorte ecclésiastique. II s'agit de l'héritage du serf (3). A qui appartiendra-t-il? L'histoire de l'héritage du serf résume celle de sa condition. Pendant de longs siècles, l'héritagre du serf appartint au seigneur, à moins que le serf ne vécut dans une communauté. La communauté, véritable mir, donnait au seigneur une incontestable

(1) Esmein, ibitrm. - Luchaire, Manuel.

(2) A. liéville, Le paysan au moyrn ây, 1896, montre le caractere nomal. l'une partie des populations.

(3) bismein et Luchaire, ibidem. 
garantie ou plus-value (1). Plus tard, sous le régime féodal, on admit que l'héritage du serf, vivant en communauté, passerait à ses enfants; le seigneur n’était préléré qu'aux collatéraux; quant à aliéner sa tenure de son vivant, le serf n'en avait pas le droit. Par suite, il achetait, mème affranchi, ce droit fort clıer : nouveau droit réel de mutation. M. Luchaire pense que le collibert était exempt de la mainmorte.

V. Les affranchissements (2). - Les affranchissements les plus nombreux eurent lieu à prix d’argent et moyennant des rederances à vie, elles-mèmes rachetables.

VI. Les corvées. - Les serfs étaient assujettis à des corvées plus nombreuses et plus onéreuses que les roturiers. Toutefois, les mêmes distinctions que pour la taille étaient appliquées. Partout la coutume se substitua à l'arbitraire seigneurial.

VII. Service militaire. - Les serfs devaient le service militaire plus rigoureusement que les roturiers. Leurs services étaient indispensables. Divers documents constatent des plaintes de leur part à cet égard.

VIII. Autres taxes et droits. - Ils étaient, en outre, assujettis à tous les droits et à tous les impôts qui affectaient les tenures et les persannes: dimes, police, justice, taxes de consommation, domaniales, d'industrie.

\section{\$9. Taxes et droits feolaux dans les villes et les communes.}

Ils étaient à peu près les mêmes que dans les seigneuries, pour les diverses classes de personnes et les divers biens. Hais. au fond, leur poids était plus lourd. Ceci demande quelques explications (3).

(1) Sur les communautés serviles au moyen âge et leur róle économlıue, consulter diverses communications faltes par $\mathrm{M}$. Tranchant, Comite des trataux h1.storiques, 1895 , pages $\mathbf{2 4}, \mathbf{2 8}, 30$. Peu de sujets ont donné lieu it autant d'exagérations et de pamphlets que la condition les muinmortables jusqu'en 1789 . En général, cette condition était meilleure que ne lont prétendu les lanphlets r.volutiounaires, mais elle variait beaucoup d'apres les provinces. - P. Allard, Serfs mainmortables, pages 235, 362. - Lecuy de La Marche, 1 tracers l'histoire de: France, 1896, fuges 1 à 16 .

(2) Sur le cens des affranchis, Glasson, $6^{2}$ vol., ibillem, p. 3.

(3) Nous renvoyons pour tout ce paragraphe : $1^{\circ}$ au tome cinquiène, pages 1 
I. Dans les rilles. - Les origines, les conditions, les institutions des rilles différaient beaucoup, surtout jusqu'au $\mathrm{xr}^{\mathrm{e}}$ siècle. Il y arait d'abord les anciennes villes où arait brillé la cirilisation romaine, plus nombreuses et plus importantes dans le midi et le centre des Gaules, sauf les colonies du Rhin, que dans le nord : Marseille, Lyon, Aix, Bordeaux, Toulouse, Autun, Poitiers, Orléans, Tours, Paris; puis les rilles nourelles ou rilles franches. Ces dernières appartenaient à l'époque seizneuriale. Elles ne remontaient pas au delà du $x^{\mathrm{e}}$ siècle. Elles représentaient entièrement le mourement féodal puisqu'elles en provenaient.

Fort antérieures, les rilles gallo-romaines dépérirent, se dépeuplèrent. Leurs institutions, leurs privilèges subirent une éclipse totale, à lexception cependant des institutions religieuses, érèques et grandes abbaries. Ce fut le résultat de l'anarchie profonde qui s'étendit partout (1). La servitude, dit Herré, s'étendit jusqu'aux rilles (2). C'était une métaphore, beaucoup plus réelle qu'il ne le supposait lui-mème et que ne l'ont enseigné Raynouard, Guizot et Augustin Thierry (3). Ces historiens du Tiers-élat se sont mépris sur ses oricines. Dans son remarquable ourrage sur l'Histoire de Bordeaux (4), la ville romaine peut ètre la plus prospère au $v^{\text {re }}$ siècle, déjà port de commerce, centre rinicole, foyer religieux et littéraire, M. Jullian montre les terribles effets des invasions des Germains et des Arabes. La ville parut se relever sous Charlemagne, mais elle fut à peu près détruite de fond en comble par les Northmans. Elle derint moins importante que le camp militaire de Cassevil;

: 64 de l'Histoire au droit th de institutions de la France, par M. Glasson ; $2^{\circ}$ au iivre seconl du Mrnuel les institutions françaises (priole des Capétiens directs), frar Af. A. Luchaire, 1592. - Cet ouvrage, composi daplès les plus récents travaux et les suurces mêmes, a completement modifie la direction donnée par liagnouard, Guizot et Aug. Thierry a l'Histoine des cilles t du Tiers-itat; $3^{\circ}$ Revelue historitue, janrier 1895.

(1) Des associations de pair. Luchaire, Manuel, $3 \mathbf{i} 4$.

(2) Motieres feodates, 1er vol., 164.

(3) Luchaire, Manuel, page: 370 et suiv., 373, 453.

(4) Borileaux, 1895, Periule gasconne. - Cet ouvrage a cité publié par la ville 1, Barileanx. 
par suite, elle tomba complètement dans les mains du comte que Charlemagne lui assigna ; elle ne fut plus qu'un foyer seigneurial et militaire. Marseille, Lyon et Toulouse, et toutes les villes dépendirent d'une seigneurie au moins jusqu'au . ^e siècle (1). Elles participèrent nécessairement de l'état général d'anarchie qui a produit la féodalité; elles ne conservèrent que leurs institutions religieuses, englobées elles-mêmes dans le mouvement féodal. Aussi bien au midi qu'au centre et qu’au nord, les anciennes villes prirent le caractère seigneurial; elles eurent un seigneur qui les représentail, les armin strait comme une partie de sa seigneurie. C'est ainsi qu'après bien des péripéties et d's luttes, Bordeaux ne fut plus qu'une sorte de succursale de Poitiers (2), capitale des ducs d'Aquitaine.

Les conditions des biens et des personnes étaipnt, au moins jusqu'au $x n^{\mathrm{e}}$ siècle, les mèmes que dans les campagnes et les seigneuries. Tenures nobles ou fiefs, tenures roturieres, tenures serviles se partageaient le sol urbain et les constructions : nobles, vilains, roturiers, colliberts, serfs prérliaux, serfs questaux ou de corps composaient la population. Redevances, imputs, taxes, droits, notamment les aides aux quatre cas, services divers, étaient les mèmes avec les différences résultant de la nature des choses. Ainsi les taxes de consommation, de tonlieu, de plasage, les banalités, les taxes d'industrie et de travail, avaient tout autrement d'importance que les dimes; les corvées, les baux à cens ou à rente foncière étaient plus nombreıx que les locatures perpétuelles, les emphỵtéoses que les champarts; mème droits de mutation, amortissement, formariage, enfin mèmes tailles.

Les bourgeois des villes étaient tenus au service militaire de même que les vilains ou roturiers des campagnes. Ils l'accomplissaient sous des chefs spéciaux.

A partir du $x 1^{e}$ siècle, les conditions de ces villes tendirent it s'améliorer par diverses causes : l'accroissement de la sécurité générale, les progrès de la production agrricole, le développe-

(1) Luchaire, Mamel, Les villes comsulaires, page 430.

(2) Jullian, H. de Borteaur, chapitre VIII. 
ment du commerce intérieur et maritime, l'augmentation de la population. Les différences de la situation économique et sociale du territoire entre les diverses parties du territoire, du ${ }^{\mathrm{e}}$ au $\mathrm{XII}^{\mathrm{e}}$ siècle, ont été très considérables. Les villes reprirent de l'importance, les éléments divers de leur population eurent plus de fixité. D'abord l'élément religieux, le premier de tous. L'église de la paroisse avait résisté à tout. Démolie, reconstruite en bois, brûlée, on la reconstruit en pierres au $\mathrm{x}^{\mathrm{e}}{ }^{\mathrm{e}}$ siècle. Bientôt la plupart des villes eurent plusieurs églises; chaque église forma une paroisse, chaque paroisse un quartier avec ses corporations, ses confréries (1). Après l'élément religieux, l'élément seigneurial, le seigneur, sa cour, ses vassaux, ses officiers, ses agents. De très bonne heure, jusqu'en 1789 et mème au delà, il y a eu dans toutes les villes le quartier de la noblesse. Après l'élément noble, l'élément (2) marchand, auquel appartiennent les vrais bourgeois; puis les métiers; enfin l'élément populaire, mélange de serfs, de colliberts, d'affranchis, de transfuges, d'étrangers; c'est de l'entente des deux éléments, noble et bourgeois, que naquirent les institutions municipales. De ces deux éléments, l'élément bourgeois avait pris le premier rang dès le $\mathrm{x} 1^{\circ}$ siècle; néanmoins les relations étaient, en général, excellentes entre les riches seigneurs et les gros marchands (3). La séparation qui s'accusera au xvil ${ }^{\mathrm{e}}$ siècle, n'existait pas au $x n^{e}$, ni mème au xve siècle. Il en a été ainsi dans la plupart des villes consulaires ou de bourgecisie, à l'exception des villes de l'extrême midi dans lesquelles prévalut l'influence italienne ('́). Cette influence facilita la formation d'une tourbe démocratique dont la répression exigea, de même qu'en

(1) Luchaire, Mamufl, 355. - Telle a été l'organisation de Paris jusqu'au $\mathbf{x v I}^{\mathrm{e}}$ wirele; sur les divers éléments urbains, voir P. 390 ; ( bourgeois royaux », 992.

(2) l'élement marchand est presque aussi important au moyen âge que l'élément religieux. - Luchaire, ibidem, 356, - Les métiers, 360. - Consulter à cet chard le livre les tailles de la ville de Paris publié en 1839 dans les Documents historinues. Ce livre donne l'organisation les marehauds et métiers par paroisse et 'Luartier en 1292. 15,200 contribu sbles, composant 61,028 feux à raison de 5,73 personnes par feu, daus 35 paroisses, étaient taxés à 12,213 livres 3 sols falsant en franes, 220,394 environ.

(3) Malvezin, Histoire de Montaigne et de sa famille.

(1) Luehaire, Manuel, 415. - Glasson, ibiutem, 50 vol., page 21. 
Italie, l'établissement des Podestats, uniquement chargés du maintien de l'ordre et de la paix publique (1).

Mais ces modifications politiques n'eurent pas pour conséquence de changer les institutions municipales. Elles subsistèrent telles quelles; or leur conséfuence inmédiate a été l'établissement de nouveaux impóts auxiquels l'élément noble n'était pas assujetti. Ces impòts consisłaient surtout dans de nouvelles tailles, des droits d'entrée ou d'octroi, des taxes sur les foires et marchés (2), notamment dans le Hauban des métiers (3). La coneurrence de la double taxation seigneuriale et municipale amena tantôt le rachat par la ville rles taxes seigneuriales, tantôt leur restriction, tantòt des luttes qui compromirent l'existence mème des institutions municipales.

Cet état de lutte s'accentua principalement dans le domaine royal; et le pouvoir royal s'habitua, de bonne heure, à régler, avec. sévérité, les franchises municipales et à en tirer le plus d'argent possible. Il en a été ainsi jusqu'en 1789, surtout aux $x$ viı et xvme siècles. L'incertitude, l'incohérence, l'exploitation des institutions municipales, comptent parmi les plus graves causes de la Révolution ('́t). Le pouvoir royal s'habitua ainsi à redouter l'importance et l'indépendance des villes de bourgeoisie, Paris, Orléans, Lyon, Marseille, Bordeaux. Il ne parvint que difficilement à y être populaire, et il y subsista toujours contre lui un levain qui a contribué beaucoup à sa ruine. A partir de Charles VII, les rois n'ont habité Paris que par intervalles. Louis XIV, Louis XV et Louis XVI jamais.

Si telle a été la condition des anciennes villes romaines, des

(1) Luchaire, Manuel, 443.

(2) Luchaire, Mfanuel, 387. - Glasson, ibiulm, 5" vol.. 1'. 101, Iroit de cauchiage, sur les charrettes, d'issue sur les sucessions attribues aux étrangers, de minage su. les farines, d'assise sur la vente des marchandises. M. Des Cilleuls, Bulletin des tracaur historiqu's, 1895, page l65, a donnequelques indications sur les droits d'octroi au xive slicele, en particulier à Angouleme.

(3) Luchaire, Manupl, 387. Le Ilimban est mue redevance que les gens de métier des princlpales villes du royaume palent pour les réliuer des corvétes, droits et coutumes que le prevot eat pu exiger deux, ì titre de services publics. Brussel, 1er vol., p. 53, ibial m.

(4) Toequeville, Anciun rigime, eh. III et IV. - Glasson, ibidem, tome 5e, page 19. 
cités consulaires, comme on les désigne, quoique consuls, jurats, jurades, maires, n'aient jamais eu qu'une autorité mal définie et précaire (1), on peut ètre assuré que les villes neuves, ou franches, malgré des chartes, plus ou moins consenties librement ou à prix d'argent, ne jouissaient pas de plus grands avantages (2).

II. Les communes. - Il en a été de même des communes. Sans nier l'intensité du mouvement communal au $x_{11}{ }^{\mathrm{e}}$ siècle, il est bien certain qu'il n'a pas eu, en général, le caractère insurrectionnel qu'Augustin Thierry lui a attribue et que ses tendances anarchiques expliquent sa complète décadence à la fin du xıu siècle (3). Toutefois, il parrint à tempérer, dans les petits centres urbains, dans les bourgs, les droits féodaux devenus excessifs puisqu'ils doublaient en quelque sorte, notamment quand la seigneurie était ecclésiastique; sous le rapport des personnes, le seigneur ecclésiastique était moins oppressif que le seigneur laïc, mais il l'était darantage sous le rapport fiscal (4). Les communes différaient entre elles d'après les diverses parties de la France. La plupart obtinrent une condition plus indépen-

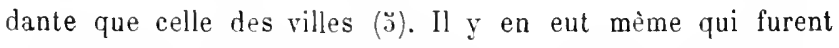
constituées en seigneuries, en fiefs et par suite exemptes des droits féodaux roturiers. Elles avaient, dès lors, à acquitter les droits féodaux des fiefs, ainsi que les taxes communales. Elles faisaient partie du milieu féodal (6); elles devaient foi et hommage, l'ost et le plaid; elles pouvaient appeler du seigneur suzerain au seigneur dominant; elles étaient plus haut placées que les villes de bourgeois; elles étaient tenues au service militaire noble; c’était là le principe. En fait, elles stipulaient des abonnements et des privilèges accordés à prix d’argent (7); un moment plus éleveees, dans l'échelle sociale, que les villes bour-

(1) Luchaire, Manuel, jage 387 .

(2) Luchaire, Manuel, $378,396$.

(3) Luchaire, Manme. 425.

(4) Tocqueville, Ancien regime, page 361 .

(5) Luchaile, Munuel, 415.

(6) Luchaire, Martuel, 413-420. -.. Glasson, ibithm. 5e rol., p. I3.

(7) Luchaire, Manuel, lage 422. 
geoises, elles disparurent rapidement, dès que commença la lente décadence de la société féodale; elles contenaient beaucoup plus de rassaux, de petits seigneurs que ne l'ont enseigné leurs premiers historiens. Leur chute a eu pour cause principale la discorde entre leurs divers éléments sociaux, tandis que dans les villes, l'élément bourgeois a complètement prévalu.

C'est un fait économique curieux que les communes qui eurent des charges moindres que les villes, aient disparu, et que les villes soumises, à deux séries de redevances, taxes, droits, non seulement aient subsisté, mais quielles aient repris leur antique influence politique et sociaie; c'est que les cominunes, ayant presque loutes pour origine des assuciations locales et rurales, appartenaient en réalité à la société féodale et que les villes leur étaient étrangères. Nous retrourons ici les lignes principales du mouvement mème de la cirilisation en Europe. Urbain arant l'ère chrétienne, rural dès les derniers siècles de l'Empire romain, ce mouvement devait lentement reprendre sa première direction. Les communes ont été des manifestations en grande partie rurales, locales, féodales. Elles s'éteiłnent précisément au moment où commence la décadenee de la féodalité.

\section{$\$$ 10. Tailles spéciales sur les Juifs et les Lomburds.}

En outre des impôts, taxes et charges qu'ils devaient acquitter comme tous les roturiers, les Juifs et les Lombards araient à supporter des tailles spéciales. On en trouse la preuve dans les comptes du Temple comme dans ceux des baillis. Ces mentions de recettes sont très fréquentes. Les tailles devaient ètre onéreuses. II ne faut pas confondre ces tailles arec les expulsions et les confiscations que les Juifs et les Lombards eurent également à subir.

Sans ètre tenus pour serfs, les Juil's étaient considérés comme inférieurs aux vilains, aux hommes de poeste, et comme essentiellement taillables et corríables à merci. On estétonné de l'insistance avec laquelle les jurisconsultes féodaux s'en occupent (1).

(1) Brussel, iliulem, $2^{e}$ vol., 562. 


\section{§11. Du Franc-alleu.}

Jusqu'à la fin du xil1 ${ }^{e}$ siècle, mème après Philippe-le-Bel, la Royauté est demeurée une seigneurie, la seigneurie supérieure, mais une seigneurie acquérant d'autres seigneuries par tous les moyens : mariages, achats, testaments, guerre, conquète, ce que devait faire, sur son modele, la terrible maison de Bourgogne, entièrement comprise dans la société féolale, c'est-à-dire levant ou acquittant la plupart des taxes ci-dessus cataloguées.

Il a cependant existé en France, depuis la chute de lEmpire romain, jusqu'en 1789 , des domaines, des seigneuries, que nous arons dù déjà signaler; les Alleux, dits domaines tenus en Franc-alleu durant l'époque féodale, lesquels recevaient taxes fiscales et rederances rurales, sans en acquitter généralement aucune, et sans autre obligation que le service militaire, auquel ils finirent par échapper mème avec le temps. On rencontre souvent dans les mémoires de Saint-Simon des propriétaires de ces domaines indépendants, pour lesquels il professe une complète admiration, et, envers lesquels, Louis XIV lui-mème ne manquait jamais de déférence. L'existence de ces domaines est une des plus curieuses anomalies de l'histoire fiscale de la France. Les propriétaires de ces alleux (grands alleux, alleux nobles, alleux roturiers) n'étaient nullement exempts dimpôts à titre de nobles, mais à titre de propriétaires de seigneuries ou de domaines; quelques-uns mèmes possédèrent et conservèrent la justice jusqu'en 1789. Il faut se figurer des propriétaires qui reçoivent des impòts, mais qui n'en paient pas; c'était le cas de la grande baronnie de Castelnau de Montratier en Quercy, dont le propriétaire émigra en 1790, au contraire le comté de Clermonten-Beauvoisis était un fief. En cherchant bien on retrouverait le mème phénomène parmi les grands propriétaires du Mexique et de l'Amérique du Sud, recerant des impòts et n'en payant jamais. Au Mexique et au Pérou, cela s'explique fort bien par les distances. En France, aujourd'hui, il n'y a plus de distances. Mais elles étaient bien grandes au $x n^{e}$ siècle, aussi M. Chenon a-t-jl pu dire " les propriétaires d'alleux sont les anciens pro- 
"priétaires romains, placés dans un milieu dilférent, auquel ils "échappent en partie (1) ". Ils garderent les impôts sans en rien rendre à personne. La féodalité et la royauté leur firent une guerre acharnée; les petits alleux lurent devenir des fiefs, les grands tinrent bon comme le chène de La Fontaine; il fallut un cyclone effrayant pour les déraciner; au surplus, ce qui est extraordinaire dans la France du moyen itge et de tous les temps, ce n'est pas que les alleux aient échappé à l'impôt, mais c'est que, depuis les Romains jusqu’à aujourd huui, la terre francaise, sanscependant accepter les chilfres de Baudi di Vesmo au $\mathbf{T}^{\mathrm{e}}$ siècle, ait pu devenir si féconde el sibelle en payant si cher le droit de la cultiver.

\section{\$12. Des exemptions d'impüts et des choblissements.}

Nous abordons ici, de nouveau, le plus grave des problemes fiscaux et sociaux que soulève l'histoire de l'impùt à travers les diverses civilisations. L'organisation des impôts chez les diverses races et les divers peuples est un très grand fait, présentant beaucoup d'intérêt; ce n'est pas cependant le fait principal, le fait directeur. Il y en a un autre, plus important, cest la charge de l'impôt, non pas la charge indirecte seulement, résultant de l'incidence, phénomène d’ordre économique très complexe, mais la charge directe, la charge immédiate qui a bien souvent une influence décisive.

Quant aux civilisations anciennes, antérieures à la civilisation grecque et à l'Empire romain, nous arons établi que si, dans l'empire de la Chine et er. Égypte, la charge directe de l'impôt élait répartie en diverses proportions sur les divers éléments sociaux, dans l'Inde, en Perse, en Israel, certaines classes de la société avaient été exemptées d'impôts.

Parmi les divers États helléniques, à base esclavagiste, l'impòt n'a pas reçu la même organisation dans les États doriens, agricoles, militaires, aristocratiques que dans les Etats ioniens, commerçants, maritimes et démocratiques. Chez ceux-ci la tendance

(1) Étude sur les Alleux. 
a été d'accabler les classes riches et chez ceux-là de faire supporter l'impüt par les classes vivant du travail.

Dans Rome républicaine et militaire, les classes riches supportaient une grande partie de l'impùt, mais s'en récupéraient par la guerre. Dans Rome impériale, moins militaire, plus pacifique, mais dominée par deux faits économiques d'ordre supérieur, la transformation de la civilisation qui d'urbaine devient rurale et la transformation de l'esclavage qui devient le servage : cette récupération cessant, les classes riches rejettent l'impit sur les classes serviles.

L'Empire romain se partage et se dissout au milieu de ces transformations qui aboutissent, l'une et l'autre, après quatre. siècles d'anarchie, à la société léodale. La société léodale substitue la règle, le contrat, la procédure à cette anarchie; elle jette la base dune cirilisation durable, dont les deux éléments sont le serrice militaire et la propriété foncière conditionnelle.

La propriété ioncière, énormément agrandie, se fractionne en centres militaires et économiques, les seigueuries, et celles-ci se morcèlent en fiefs, tenures nobles, puis en tenures roturières et serviles. Les charges fiscales sont mises au compte des tenures roturières et serviles.

Conséquence: les possesseurs de tenures nobles ont des avantages considérables aux dépens des autres. Sera-t-il libre à tous, roturiers et serfs, d'acquérir ces tenures nobles, et, en les acquérant, d'entrer dans la classe sociale qui jouit de l'exemption d'impòts (1)?

En traitant des droits de franc fief, nous avons montré dans quelles limites cette acquisition procurait l'exemptior ; l'acquisition d'un fief n’a pas été, dans la société féodale, le seul moyen de deveris gentilhomme. C'śtait le moyen le plus libre et le plus sùr, puisqu'il dépendait de la richesse, mais tout seigneur pouvait faire un roturier, mème un serf, chevalier. Tout chevalier derenait gentilhomme, par suite profitait de l'exemption. Toutefois l'attribution de la chevalerie à des roturiers, surtout à des

(1) Luchaire, Manuet, page 18:. - Glasson, ibidem, 4e vol., 314 et suivantes. La discussion de M. Glasson est des plus complètes. 
serfs, était un fait rare; elle abreigeait, en effet, le fief en le privant des droits payés par le roturier ou le serf anobli.

C'est en vertu de ce principe qu'à la fin du xille siècle (vers 1290) le pouvoir royal s'attribua le droit d'anoblir sans conférer la chevalerie. Il $y$ vit d'abord divers avantages : diminuer la puissance des seigneurs, récompenser des services et faire une certaine finance; mais les seigneurs ne furent pas privés du droit de conférer la chevalerie.

Ils ne perdirent ce droit - François I ${ }^{\text {er }}$ se fit armer chevalier - que plus tard, postérieurement à l'époque où le pouvoir royal aceapara l'impôt de frans fief.

Mais lorsque le pouvoir royal, par ses usurpations et par les mœurs, fut investi du droit d'anoblir, c'est-ì-dlire de la faculté d'exempter de beaucoup d'impòts ses privilégiés, il se trouva placé entre deux tendances; multiplier les anoblis afin d'en obtenir des services ou de l'argent, les restreindre afin de ne pas amoindrir le nombre des contribuables.

La contradiction de ces deux tendances eut pour résultat les revisions périodiques des titres de noblesse, résultant des anoblissements et de l'achat des tenures nobles; c'était reviser le droit de ne pas payer ou l'obligation de payer les impôts. Ces revisions ont été l'un des thèmes favoris des plaintes des États-généraux ou particuliers, intéressés à ce que les charges fiscales fussent réparties sur le plus d'épaules possibles.

De ces deux tendances, celle favorable aux anoblissements finit par prévaloir, malgrẻ l'édil de 1379 , parce que les Rois mirent au-dessus de tout l'avantage de faire finance immédiate avec les anoblissements; mais si les anoblissements procuraient l'exemption d'impôts, ils n'ouvraient plus les rangrs de la véritable noblesse; c'est alors que s'établit la distribution de noblesse d'épée et noblesse de robe; un conseiller à mortier, même Montesquieu qui était président, n'était jamais pris pour un gentilhomme. Au surplus, ces anoblissements n'avaient eux-mèmes qu'une valeur temporaire. Après les avoir vendus contre finances, les Rois les révoquaient, sauf à les restituer contre une nouvelle finance.

La véritable noblesse, qui remonte en France, souvent au 
$\mathrm{x}^{\mathrm{e}}$ siècle, et même bien au delà, a résisté à ces extorsions, mais l'inégalité fiscale a disparu.

Il en a été de même de l'Église catholique, élément bien antérieur au régime féodal dans la civilisation française. Elle a profité jusqu'en 1789 d'une exemption d'impôts, encore plus générale et plus étendue que la seigneurie dans la société féodale; elle a été dépossédée de cette exemption; mais elle a conservé dans la société née de la Révolution une importance religieuse et sociale relativement plus grande qu'en 1789. L'entrée dans l'Église a toujours été plus ouverte que l'entrée dans la noblesse. La tonsure était aussi efficace au point de rue fiscal que la chevalerie ou l'anoblissement, mème bien davantage.

Non seulement l'Église était exempte de tous les impôts, mais elle exerçait, en outre des droits de casuel, des prélèvements considérables au moyen des dimes. Si, en pénétrant dans la classe noble, un certain nombre de roturiers et de serfs participaient à l'exemption fiscale, la tonsure procurait des avantages bien plus grands à beaucoup plus d'entr'eux. Quoiqu'à partir du $x v^{e}$ siècle principalement, le haut clergé catholique se soit recruté parmi les familles nobles, la grande masse du clergé séculier et régulier sortait des rangs de la roture ou de la servitude. A ce point de rue l'Église a été, en France, un puissant moyen d'égalisation, en dehors de l'égalisation lente, mais profonde, opérée par ses dogmes et par ses sacrements. Gentilshommes, roturiers et serfs recevaient le même baptême, le mème mariage, la mème communion.

Ces faits, arec des différences tenant aux diversités des temps, des races, des territoires, ont eu, au moyen âge, et mème après, un caractère général. Ils appartiennent à toutes les parties de l'Europe.

\section{\$13. Uniformité des droits féodaux.}

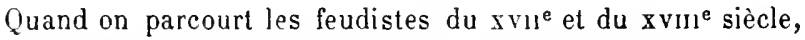
particulièrement Brussel, Renauldon, Loysel, Hervé, de Boutáric, qui comptent parmi les plus distingués, et qu'on compare leurs ouvrages aux livres que l'on possède sur la véritable féo- 
dalité, Pierre de Fontaines, Philippe de Beaumanoir, les Établissements de Saint-Louis (1), les Assises de Jérusalem, et les Consuetudines feudorum, les comptes royaux, on se trouve comme transporté dans des milieux différents. Plus forte est encore l'impression, si l'on rapproche les historiens politiques, encore en renom, du xise siècle, des publicistes teclıniques de ces derniers temps, par exemple les leçons de M. Guizot (2), de la monographie de la baronnie de Montratier; quant au réquisitoire de Championnière, il n'y a aucun livre avec lequel on puisse le confronter, du moins dans les anciens temps; certains chapitres de Boutaric seuls donnent une vargue idée des faits et notes amassés par Championnière. Dans le livre sur la IIaute-Cour des Assises de Jérusalem, on trouve beaucoup de détails sur les fiefs et sur les obligations qui en dérivent, jreşąuancun sur les taxes, redevances, impôts. Il en est de mème, quant à la cour du vicomte ou des borgeois (3).

On rencontre plus de détails sur les impîts divers, sur les racats ou rachats, sur les retrets, sur les censives dans Pierre de Fontaines ( $\mathbf{t}$ ), sur les cens, héritages, chemins et corvées dans Philippe de Beaumanoir; mais tout est uniforme; les droits qui concernent, surtout les fiefs, sont les mèmes; quant aux Consuetudines feudorum, elles ne mentionnent qu'accidentellement les droits fiscaux et féodaux sur les routes et les cours d'eau, et qu'à la fin du livre cinquième (: $:$ ).

(1) Les Etablissoments do Srant-Louis, edition avec comuentaire perpetuel de: M. Paul Viollet, lon des principaux ourrages sur, le moyen age fédal. Ihans ba table des matieres, M. paul Viollet mentiome la justice 97 fois - la cort le juntice 100 - les flefs 80 - le cens 13 fuis - censires 17 - banalités 6 - banvin 5 - relief 17 - retrait $3 \mathrm{~s}$ - taille 12 - suceessions 70 - champart 3 - prarage

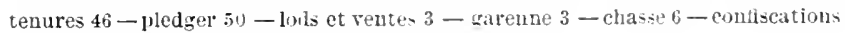
23 - amortissement $\boldsymbol{\imath}$ - aides $1 \tilde{i}$ fois.

(2) Hist. de la civilisation on France, tomes lit ot 11.

(3) Édition Beugnot, Recueit des cruisades.

(4) Édition Ducange à la suite de fa vie de Joincille 166.s. lac livre de Pierre de Fontaines est des plus curieux, larce gu'il commence ave la coutume frangaise pour finir avec les dicts dés grauds jurisconsultes romain. Il marque le moment oú, après une éclipse de 700 ans, la loi romalne reparait; nous solumes aussi prís de Pierre de Fontaines qu'il l'était du Coule Theodosien.

(5) Corpus juris, Editlon Galiost, 1362, liber quintus, tit. 8, de jure fioct. 
Dans les Etablissements de Saint-Louis, tous les impôts ou droits indiqués plus haut sont dénommés, mais pas d'autres. Aussi Brussel n'en indique pas lui-mème, si ce n'est des taxes sur les Juif's.

De Boutaric a dressé toute une série de droits au nombre de cent un; mais il n'y attache pas d'importance; au contraire, il développe, avec de grands détails, les droits compris dans la justice, qui sont la plupart des droits domaniaux, comme nous l'avons indiqué, y compris la confiscation sur laquelle il insiste longuement; ce sont ces détails qui ont inspiré Championnière (1). En réalité, ces droits étaient étrangers au régime féodal; ils provenaient du régime romain. Au fur et à mesure que se sont altérées les mœurs, les idées des temps féodaux, les habitudes fiscales en ont pris la place et, avec l'extension du droit romain, considérable, dès le $x u^{\mathrm{e}}$ siècle, le seigneur justicier est devenu plus rigoureux et le véritable représentant de la féodalité. Il est certain quentre le livre de Jean de Ibelin et le réquisitoire de Championnière bien des générations ont dù se succéder.

Cette uniformité des droits féodaux principaux dans toute la France féodale, depuis le comté de Flandres, aujourd'hui composant une partie de la Belgique, jusqu’à Lyon et Bordeaux de l'est à l'ouest et jusqu’à Marseille au midi, est particulièrement saisissante dans l'étude que $\mathrm{M}$. le professeur Molinier a consacrée à la féodalité en Langıedoc (2). Le liwre s'occupe presque exclusivement de la période féodale du $x^{\mathrm{e}}$ au $x_{u^{\mathrm{e}}}$ siècle, la moins connue, malgré l'intérèt qu'elle présente. Tous les faits et droits féodaux qui marquent la physionomie de la France féodale en plein $x^{e}$ siècle se manifestent en Languedoc au $\mathrm{xI}^{\mathbf{e}}$ et au xıe siècle : seigneuries, fiefs, alleux, censives, tenures serviles, hommage et fidélité, service militaire, aides pour les quatre cas, droits de mutation ou acaptes pour les fiefs, tailles, lods et ventes, corrées, serrice miitaire, taxes de commerce et d'industrie, péages, droits de leyde, foires et marchés, droits de bac, de

(1) De Boutaric, Des droits seignemiaux et des matieres féolales, Toulouse, 1775 , l'un iles mellieurs fendistes, onvrage impartial.

(2) Ourrage cité plus haut; cette étude fait partie de la nourelle édition de l'Histoive du Languedoe, 1ar. Dom Vaissette. 
chasse, de pèche, droits monétaires, droits de sceau, banalités, confiscations, pour les roturiers. C'est bien le mème ensemble que dans le surplus de la France : dimes et obligations réciproques, garde, tutelle, mariage, assistance. La différence principale tient à la servitude moins générale, moins dure déjà dans le midi que dans le nord. Le paysan a remplacé le serf. La taille tend à desenir un impót reposant plutôt sur le fonds territorial que sur la personne (1); le service militaire parait moins rigoureux; roturiers et paysans paient seuls les impóts; on constate une avance générale dans la civilisation; les villes ont plus d'importance; néanmoins le caractère général de l'époque est le mème, elle n'affecte nullement d'ètre un temps d'oppression, de malheur.

\$14. De la condition des populations sous le régime féodul. $d u x I^{e}$ au $x \mathrm{III}^{\circ}$ siécle.

Les grands ourrages, cités plus haut, n'en disent rien. Ils ne font allusion à aucune difficulté sociale. Le milieu aựuel s'appliquent les lois, assises, coutumes, aris dont ils s'occupent. parait ètre stable et remonter loin. Voici ce qu'en pensait .I. Léopold Delisle, il $y$ a bientòt un demi-siècle, dans un livre où rien n'est laissé au hasard; sorte de préface aux travaux qui vont suivre. On s'étonne même que M. Léopold Delisle ait pu trouver tant d'autorités à citer pour des temps si éloignés. "Les "rapports des seigneurs avec leurs hommes n'y sunt point " entachès de ce caractère de violence et darbitraire avec "lequel on se plait trop souvent à les décrire. De bonne heure "les paysans sont rendus à la liberté. Dès le $x 1^{e}$ siècle, l'es" clavage a disparu de nos campagnes. A partir de cette épo"que, il subsiste bien encore queliques rederances el quelques " services personnels, mais le plus grand nombre est attaché à "la jouissance de la terre. Dans tous les cas, les obligations, "tant réelles que personnelles, sont nettement définies par les

(1) La taille se convertit eu une tase sur les feux, c'est déju le funcaticu italien. 
"chartes et les coutumes. Le paysan les acquitte sans répu"gnance; en un mot, la féodalité du moyen âge (que nous "distinguons bien de la féodalité des temps modernes) n'a "point, au moins en Normandie, produit sur les paysans les "effets désastreux qui lui sont imputés avec plus de passion "que de justice (1). "

Ces réflexions sur l'état des classes agricoles en Normandie sont les mèmes que celles qui viennent à l'esprit quand on consulte les monographies concernant d'autres parties de la France : la baronnie de Montratier dans le Quercy, celle de Meillant dans le Berry, celle de Clermont en Beauvoisis, la chàtellenie de la Roque dans le Cantal, la seigneurie de la Roche Talbot dans le Maine, la seigneurie de la Roche Guyon près Gisors; réflexions entièrement confirmées par les lirres, non des feudistes monarchiques des $\mathrm{xv}^{\mathrm{e}} \mathrm{e}^{\mathrm{e}}$ et $\mathrm{x} \mathrm{vul}^{\mathrm{e}}$ siècles, bien autrement tempérés toutefois que les publicistes tels que Championnière, mais des jurisconsultes des $x 1^{\mathrm{e}}$ et $\mathrm{x}_{\mathrm{m}}^{\mathrm{e}}$ siècles, des monuments juridiques du moyen àge lui-mème.

Après avoir montré, dans le chapitre premier de son livre, qu'il y avait, au moyen àge, en Normandie (c'était à peu près la mème chose par toute la France) deux tenures, la tenure noble, le fief avec service militaire et redevances fixes, y compris les vavassories ou arrière-fiefs (démembrements du fief) et les tenures roturières avec cens, redevances et corvées, M. Léopold Delisle, explique les divers modes de possession et d'exploitation; les censives, emphytéoses, métairies, champarts; redevances; services. Les services consistaient en corvées rachetables; les redevances en rentes en argent ou en grains. Enfin il indique quels étaient les impôts, le cens, forme nouvelle d'anciens impôts - le surcens - les droits de mutation. Les transports, les gardes, l'entretien des chemins, les rentes des moulins ou banalités étaient les charges les plus lourdes. Ces charges se trouvaient, en partie, compensées par les obligations que la coutume imposait au seigneur, pour les pauvres, les infirmes,

(1) Les classes agricoles et l'agriculture en Normandie au moyen âge, 1851, preface. Comparer Marion (Bulletin des trarau.c historiques, 1894, page 99). 
les malades. Dans les derniers chapitres, MI. Léopold Delisle donne la description de la production agricole et de la vie rurale à cette époque : culture des céréales, culture de la rigne, engrais, marnage, forèts, moulins, prommiers et cidre, prairies et paccages, bétail. On se croit transporté dans la Normandie actuelle.

Grice aux nombreux documents que l'on posside sur Jeanne d'Arc et sa famille, M. Siméon Luce a pu reconstituer leur intérieur et retracer, à 2ä0 ans environ de l'époque décrite par. .I. Léopold Delisle, le tableau de la vie l'une famille de roturiers, propriétaires campagnards, dans la seigneurie ou chàtellenie de Vaucouleurs, dont dépendait Domrémy, oì Jeanne d'Arc a récu de 1412 à 1 ' 28 . Domrémy était un rillage entièrement féodal où les Bourlemont, seigneurs de Vaucouleurs, araient la morte main avec haute, moyenne et basse justice, rederances, corrées ordinaires, four banal, le tout énuméré daus un dénombrement de 1398. "On roit par le testament de Jean de Bourlemont "que les membres de cette noble famille entretenaient arec les "hommes de leurs villages des relations d'une familiarité toute "patriarchale... Tous les ans, le dimanche de Lxtare, appelé "par les habitants du Bassigny dimanche des Fontaines, fète "populaire dans tout le Barrois, Béatrix, femme de Pierre de "Bourlemont, allait sous un hètre magrnifique, dit larbre des "fées ou des dames, faire des repas champètres, des dinettes en "plein air; chacun apportait ses provisions, du vin et des petits "pains, et les jeunes filles de la seigneurie, mèlées aux demoi" selles de la chàtelaine, lui faisaient escorte... Les biens immeu" bles appartenaient à Jacques d'Are et à Isabelle Romée, père " et mère de Jeanne d'Are, représentaient environ 20 hectares " dont 12 en terres, 4 en prés et $x$ en bois, ils avaient de plus "leur maison, leur mobilier et une réserre de 2 à 300 fr. qu'ils "entretenaient arec soin en prérision d'une fuite derant quelque " invasion. En mettant eux-mêmes en valeur ce qu ils possé"daient, ils en pouraient tirer un revenu anuuel équiralent a " 4 à 2.000 fr. de notre monnaie, ce qui leur permettait de dis" tribuer des aumònes aux paurres et de donner l'hospitalité " aux moines mendiants et aux royageur's qui passaient sourent 
"dans ce pays. L'avoir de ces braves gens constituait ce que "l'on appelait dès lors dans le Barrois un yagnage ou petite "ferme (1). Ce qui distinguait le gagnage de simple conduit, "c'est qu'on employait toujours pour le premier un certain " nombre de cheraux... Le père de Jeanne d'Ire était qualifié " de dogen de village; il venait immédiatement après le maire "et l'échevin... Dans chaque village, le doyen convorquait les " bourgeois aux assemblées électorales et aux plaids..., il était "également chargé de la collecte des tailles, rentes et rede"vances; il était aussi préposé à la surveillance du pain, du "vin et des autres denrées ainsi qu'i la rérification des poids " el mesures... Les hauteurs couronnées de hìtres et de chènes "fournissaient en abondance le bois de chauffage; le gland des " ehenes permettait d'engraisser des troupeaux de porcs; le "vignoble de Greux, grimpant dès le xrve siècle sur ces hau"teurs, proluisait un petit vin acidulé... mais la principale ri" chesse des habitants de Domrémy, c'était le bétail qu'ils met" taient à paitre dans les prairies des bords de la Meuse. Cha"cun, après la récolte, avait le droit de faire pitturer un nombre "de tètes de bétail proportionnel à celui "des fauchces de pré" "qu'il possédait en propre. C'est ce qu'on appelait le bin de "Domrémy dont la garde était confiée tour à tour à une personne prise dans chaque comtuit ou ménagre. On voit, par certaines " réponses de leanne à ses jugres de Rouen, qu'elle avait été plus "d'une fois préposée à cette garde, lorsque renait le tour de ses "parents... ". La maison de la famille de Jeanne d'Are était presqu'adossée à l'église de Domrémy. C'est ce qui explique comment, en dehors de ses travaux, elle pourait aller si souvent it l'église. La chaumière paternelle n'était séparée de l'église que par un jardinet attenant au cimetière, c'est dans cette chaumière que les amies de Jeanne venaient "de jour comme de " nuit, filer, tricoter et coudre ". Les amies de Jeanne se marièrent et comparurent au procès de sa réhabilitation $(2)$.

(1) Le grunnue n'est autre lne ha Farm du Nebraska ou du Kansas, avee li difference des temps et des territuires.

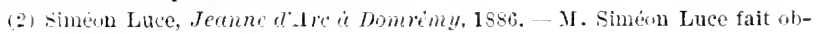


\$13̈. Fonetion da régime frodal dens la vicilisation de l'Euripe.

Voilà certes des milieux tout autres fur ceux dont Guizot, Augustin Thierry et Championniere (nous laissons de cité les paunphlétaires) ont tracé le tableau, sous linlluence, non pas de ce qui existait au $x \|^{e}$ et a $x r^{\circ}$ siecle, mais les luttes de la Revolution française et de la Restauration. L'époque de Philippe-Auguste et de saint Louis n'a pu ètre qu'une grante epoque. M. Guizot n’a pu comparer saint Louis gu’a Marc-turèle. Toutefois le trait principal de ces temps n'est pas la grandeur; cest l'apogie d'un mouvement très important, re ce mourement rural que nous avons suivi depuis le $m^{\text {e }}$ et le $w^{\text {e }}$ siècle pentant linpir romain et auquel ont correspondu les reformes fiscales, considérables mais prématurées, de Dioclétien et le Constantin; ce mourement a duré douze siècles. Il va se prolongrer jusifu à la

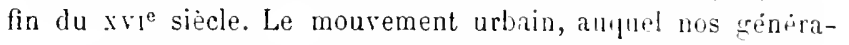
tions appartiennent, a eu ses débuts vers le xll siecle. II est aujourdhui à son apogée, à son tour: c'est le mourement qui farorisera l'ceurre nécessaire et unitaire de la Royauté et qui la détruira ainsi que la féodalité. Mais il restera, en France. de la féodalité d'immenses résultats; la mise en culture dı territoire, la distribution des populations sur plus de 30 millions d'hectares, la vie rurale, une richesse agricole qui soutiendra tout pendant des siècles, une race d'hommes incomparahle, cultivatcurs et soldats comme les Romains, race dont le maréchal Buscaud a été le type accompli. Sur ce territoire, particulierement lavorisé, les institutions fiscales de l'époque féodale trouveront les íéments, jetteront les bases d'un systeme fiscal puissant : mutations entre-rifs, mutations par décès, accroissenent, douanes,

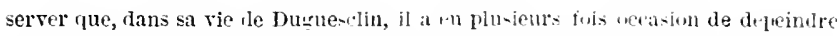

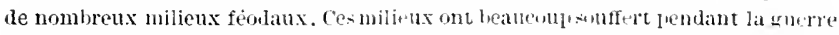

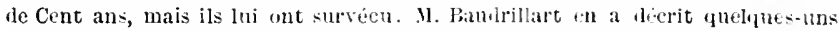

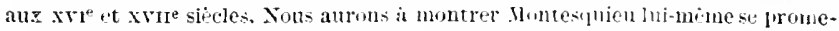
nant au unilieu de ses passans, eneme roturiers, sumis anx charges fiodales, vers 1740. - Chapitres principanx u confulter lu live le It. Simén lace, La fumille de Jeanne dire, Domerimy te lineroulows, n. 3 et 6 . 
contributions indirertes, droits domaniaux, prestations, taxes sur le travail, taxes sur les vins, bière, hydromel, greffes; la féodalité n’a rien négligẻ; elle n’a pas connu, il est rrai, le tabac, le sucre, le thé, le café, ni le timbre.

En somme, si l'on reconstitue le budget d'un véritable seigneur, féodal ou justicier, on se rapproche singulièrement des budgets de la France républicaine. La taille correspond à l'impìt foncier et mobilier; elle correspondrait exactement à un impòt arbitraire sur le capital et sur le revenu. Les droits de mutation, amortissemert, franc-fief subsistent encore. Il en est de mème des droits domaniaux et taxes judiciaires. Les cens et champarts se retrourent dans le domaine de lEtat. Les taxes de consommation, sel, vin, viande, huile, fruits, légumes, farines, y surabondent - celles de douanes y surabondent encore plus. En cherchant bien on y rencontrerait le cadenas luimême. - Les patentes équivalent aux taxes d'industrie et de travail. Les droits de navigation, pèche, chasse, bacs, péages, foisonnent partout. Les droits sur les chemins de fer sont moins incommodes, mais beaucoup plus onéreux que les péages.

Bref, l'époque féodale a été, au point de rue fiscal, complètement créatrice; elle a laissé peu de chose à faire à la royauté et beaucoup moins qu'on ne le pense aux temps modernes. Le budget de 1789 ressemble de fort près à celui du seigneur Roi du xure siècle, établi avec autant de science que d'intelligence par M. Ad. Vuitry et celui de 1789 est le cadre du budget de 1896. Elargissez la seigneurie, vous rencontrez la France; au delà de la France, l'Europe.

Tout, au surplus, dans l'eeurre de la civilisation, se prépare dans de petits foyers où la force se concentre et agit. Il en est de mème dans les productions des autres règnes de la nature. Athènes a fait la civilisation grecque, Rome l'Empire romain, la seigneurie capétienne a fait la France; la France féodale a exercé sur l'Europe, sur le monde entier, dès le $\mathrm{xi}^{\mathrm{e}}$ siècle, une influence prépondérante; c'est dans la molécule seigneuriale que se sont préparés, disposés, agglomérés les éléments de la civilisation française, éléments non pas uniques, mais principaux. "Alors 
"le monde féodal contiendra, a écrit Michelet, sous l'apparence "du chaos, une harmonie réelle et forte (1). "

Lowurre essentielle de la sociét félolale a consisté à fixer les populations, eneore ragabondes et presque nomades, sur le sol et à les y retenir par les liers de la proprieté foncière et de la solidaritŕ sociale, bien autrement étroite quaujourl'hui. La société féodale a, par suite, réveloppi, on toutes choses. le principe de l'hérédité, fondement de la propriétín de la stabilité. La forme conditionnelle de la proprietí fonciere arait pour objet principal de retenir l'homme qui était la principale valeur de l'éproque. Les droits de mutation, rolief, quint. l'equint, lods et ventes, amortissement, tendaient au me lut. Il en est de mème de toutes les rècles, coutumes, le tous les contrats qui caractérisent cette forme; l'homme sera attachi de frorce au sol. à la terre, mais il pourra en devenir propriétaire. Loricrine des familles de propriétaires camparnards, si nombreuses en France, est là. Cette rurre a complété les deux grands faits sncianx et économiques dont nous poursuirons leétude lepuis l'Empire romain : $1^{0}$ le défrichement, l'occupation, la mise en culture de l'Europe; 20 la transformation de l'esclavace en serrage. Ces deux faits dorule supérieur n'ont recu nulle part une aussi grande extension qu'en France: aussi la France a été le foger principal de la société féolale et la nation la plus importante de l'Europe au mogen ìge.

Nous avons trouré dans le polyptyque de la grande abbaye de Saint-Germain-des-Prés au commencement du $1 x^{\text {r }}$ sirele une sorte d'inventaire de l'état social du temps. Deux documents du mème ordre du commencement et du milieu lu $\times 1^{\circ}$ siècle, relatifs à l'abbaye de Narmoutiers en Alsace, ront nous permettre le constater los changrements qui araient ju sopérer du we au $\mathbf{x} u^{\prime \prime}$ siècle, cest-à-dire pendant la prériolle réllement fündale $(\boldsymbol{2})$.

(1) Histoire de France, 1, rol., llatge 133 .

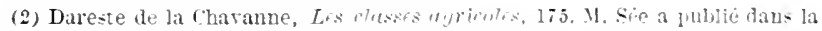
Revue historifue, janvier 1495, une etude interesante sur la conlition des classes serviles en Champagne. Il montio lp rapile muwpment de transformation dans la contition de ces classes. Lis serfo, quti etaitnt rives a lit terre au $x^{e}$ sibele (ce qui n'ètait même pas san- excention), ont preaque trus obtenu laffranchissement au xinc. Ils échiluent is la talle arhitraire: il forment des grumpe 
Les sujets de l'abbaye étaient divisés en quatre classes: $1^{\circ}$ Jes barons, au nombre de 30 , pourvus de fiefs de chevalier, et ne derant que le service militaire; ce sont les vassaux de l'abbaye; 20 les censitaires libres, au nombre de 80, devant un cens territorial annuel peu considérable, à raison de chaque manse leur appartenant. lls forment le conseil de chaque village et rendent la justice sous la présidence de l'intendant de l'abbaye; $3^{\circ}$ les détenteurs de manses serriles qui, outre les cens et contributions, doirent trois jours de trarail par semaine; $4^{\circ}$ les hommes narant pas de manses, serrant comme domestiques, nourris et entretenus, mais ne recevant aucun salaire; ce sont de véritables serfs.

On remarque tout de suite combien le progrès a été sensible en trois siècles. Les hommes libres (barons et propriétaires) ont une toute autre importance qu'au $\mathrm{x}^{\mathrm{e}}$ siècle; la servitude n'a pas disparu, mais la condition des colons serviles est nettement définie. Les barons, les censitaires libres représentent les hommes libres et les colons libres du $\mathrm{x}^{\mathrm{e}}$ siècle; le colon libre est encore sur l'abbaye; il ne l'a pas encore quittée, mais il ! est devenu propriétaire. Le colon serrile possède à peu près la situation du colon libre au $x^{e}$ siècle. Guant aux domestiques serviles, ils sont les derniers débris de la servitude.

Dans le langage du xile siècle les colons serviles de la troisième classe représentent les main-mortables, les serfs questaux, ceux que leur condition attachait encore à la terre et que le seigneur pouvait faire quérir partout. Les hommes libres de la seconde classe deriennent les rilains, les roturiers, les hommes de pooste; leurs domaines, les censives ou biens roturiers; milieu de la famille de Jeanne d'Arc.

Les Croisades ont amélioré la condition de ces deux classes d'hommes, celle des serfs questaux en les affranclissant et en les transformant en hommes de pooste, celle des lommes de pooste en leur fournissant l'occasion d'acquérir des fiefs de chevalier, ceux des barons, et de se glisser lentement dans la société

compacts; ils se precipitent vers les villes, les communes: ils collaborent à la eréation de la classe bumrenive... a ils peuvent devenir nobles " 
féodale qu'ils ont ainsi renouvclée aux $x 1^{\circ}$ et $x \times 1^{\circ}$ sipeles.

Le mourement daffranchissement, d'un caractire particulier au $x \|^{\mathrm{e}}$ sièele, a pris un caractère crénéral au $x \|^{\circ}$ et au $x \|^{\mathrm{e}}$. II a eu lieu en masse, prar des élits du suzerain (1). 11 rst devenu politique. Il n'en arait jamais été de mème auparavant, soit pour la transformation de l'esclavage en servage, soit pour le passage du servage à la libertí. Ces affranchissements en masse attestent limportance des progrès accomplis au $x$ I $^{\circ}$ siècle par la cirilisation.

Les hommes de pooste forment la souche des propriétaires bourgreois, quelques-uns même ennobllis, jusqqu en 1789. Lẹ serfs questaux correspondent, en grande partie, à celle de nos parsans, petits propriétaires, fermiers, métạers, bordiers, prixfaiteurs, à toute la classe proprement rurale et par snite ourriire, sauf les mouvements qui ont farorisé les uns en leur permetlant le monter plus haut ou contrarié les autres; car, à partir de rette éporque, la fixité qui, depuis tant de siècles, earactérisait la condition des elasses inférieures et qui rejetait, par suite, la presque totaliti des charges soeiales sur les classes supérieures, disparait. La société n'est plus qu'une échelle de Jacob : les uns crimprent, les autres descendent. Bien des barons deviennent ourriers; bien des serîs questaux deviennent barons. L'édifice féndal se maintient, mais it se change en une sorte de bazar. Combien les Croisades, les guerres privées, les guerres anglaises ont détruit de vieilles familles féodales qui ont été remplacées par des familles serviles? Quel exemple plus catégorique que celui de la famille de Michel Montaigne, des Eyquem qui, en un siècle, de la condition de serf questal, entre dans la noblesse terriloriale, puis de robe, puis d'épée?

Dans l'Europe oceidentale, en Ingleterre, en Allemagne, surtout l'Ailemagne du midi, en Italie et dans l'Espagne septentrionale, la féodalité a rempli la mème fonction et obtenu les mèmes résultats, quoique moins complètement qu'en France.

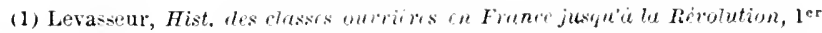

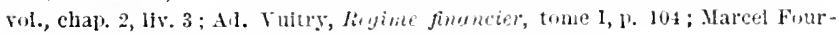
nier, Des affranchissements the ve un xne sivelf, 1853. 
Le mourement vers la liberté et la propriété ne s'est jamais arrèté en France. Il n'en a pas été de mème dans l'Europe orientale; aussi la condition de la civilisation de l'Europe orientale fut-elle longtemps inférieure à celle de l'Europe occidentale, spécialement de la France, la propriété l'oncière moins bien assise, moins bien répartie, les populations plus arriérées et plus pauvres.

Si on compare les conditions du développement de la propriété foncière et de la personnalité de l'homme, en France et en Russie, on reconnait, tout de suite, quel immense bienfait la propriété couditionnelle a été pour la France et pour l'Europe occidentale. On peut la considérer comme l’instrument économique et social qui a serri à conduire les populations, du milieu de la servitude et du vagabondage, à la situation de paysans propriétaires, fermiers, métaỵers, bordiers ; plus tard et peu à peu la perpétuité de la condition personnelle a disparu; mais deux choses sont restées pour les uns, les plus heureux, la propriété du sol, pour les autres l'entière liberté personnelle.

En Russie, mème au $x^{\mathrm{e}}$ siècle, il a fallu rétrograder vers la servitude, puis river les populations au sol, avec le . $\mathbf{W}$ comme compensation et comme garantie. La censive et la tenure servile ont formé de meilleures populations rurales que le Mir. Elles les ont faconnées lentement, ear il faut beaucoup de temps pour passer de l'esclarage à la servitude et de la servitude à la propriété libre (t).

Toutes ces réglementations, taxes, tarifs, impòts, tribunaux, greffes féodaux ont élevé les populations à un niveau supérieur et, avec le temps, ont permis à la race celtique, presque sauvage, de former une race mixte, d'occuper et de mettre en valeur un territoire de la plus grande valeur, de réunir les éléments de la civilisation française aux $\mathrm{x} \mathrm{u}^{\mathrm{e}}, \mathrm{x}^{\mathrm{e}} \mathrm{e}, \mathrm{x} \mathrm{ul}^{\mathrm{e}}$ et au xixe siècles 2 ). Sans la féodalité, telle qu'elle a été dans l'Europe occidentale, la race celtique de Gaule, aurait eu la destinée des

(1) Mackenzie, La Russio, chap. 29 et 30. La Reforme sociule, mars 1896, contient uno écule importante sur les difficultés auxquelles l'umanciłation des serfs donne actuellement lieu.

(2) Les feutistes des $x I^{*}$ et $x m^{e}$ siècles ont eu une grande part dans la rupture qui s'est faite a fartlr de Fenri IY, mais surtout sous Louis XIV, dans les 
Irlandais, qui ont conservé, au moins, la liberté personnelle; tandis que les paysans russes nont trouve de protection que dans l'association obligatoire du Mir. Combien était supérieure, en 1789 , la conlition des pupulations agricoles de la France, combien elle l'est encore aujourdhui!

L’époque léodale a été ceptendant longtemps méeonnue et les populations, en général, en ont conservi. sauf de très honorables exreptions, un souvenir rélaste. Si beaucoup de prijugés contre la féodalité ont disparu, il an subsiste encore. (1uelques écrivains, quelques politiciens ne peuvent on parter de sangfroid. Quand ils veulent combattre, devant la democratio contemporaine, linfluence des propriétaires, ils les taxent de vouloir rétablir les droits féodaux. Its šimagrinent compromettre aussi certaines formes nouvelles de la richesse, industriels, lanjuiers. gros marchands, sans lesquels l'ceuvre du travail irait fort mal, en les traitant de barons fëodaux, ignorant qu il y it une rare dose dextravarance a comparer une banque a une haronuie et beaucoup de mauvaise foi.

Il y a mieux. Aux $x^{\circ} m^{e}$ et xvm siecles la France arait perilu le sens de ses origrines et mème leur souvenir. Chute de l'Empire romain, occupation des Franks et autres tribus frermaniques, Croisarles, crise des xive et des xr" siecles, Jeanne l'Are, les grandes luttes du srie siècle, tout cela a été plongé tans les mèmes ténèbres. Leur souvenir mème déplaisait à Rich»lieu et surtout à Louis XIV. Boulainviliers, Fréret et Montesquieu, les premiers, osèrent effleurer ces sujets, alors sealreux, auxquels le courant du temps ne s'arrèta pas. 11 a fallı Clıateaubriand, Michelet, Victor Iugo ainsi que nos publicistes contemporains MII. Léopold Deliste, 1. Monteil, Beugnot, Eustel de Coulanores, Siméon Luce, Glasson, Flach, Vuitry, Paul Viollet, Esmein, Luchaire, Langlois et bien d'autres, pour replacer, sous les yeux des Français, les grandes époques, les grlorieuses figures

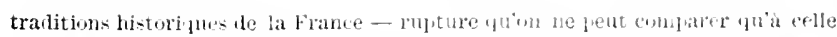

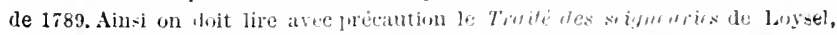

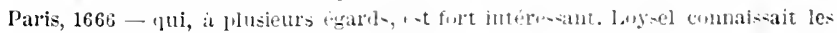

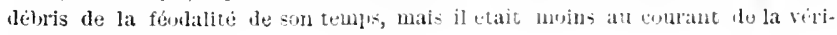
table époque fécudale. 
et les terribles épreuves de la vie historique de leur territoire et de leur race.

Sur la politique de Louis XIV à l'égard des bistoriens de son temps, on peut consulter les explications données par Ausustin Thierry (1) sans oublier la discrice de Mézeray et la mise a la Bastille de Fréret. Augustin Thierry est bien loin d'aroir apprécié, sans complaisance pour les passions de son époque, l'œurre de la féodalité. Pas mème de Tocqueville qui, dans la Récolution et lancien rigime, attribue au mouvement si complexe de 1789, l'abolition de la féodalité pour principal mobile $(\mathbf{2}$. Ce qui subsistait en 1 is9 du régime féodal, bien que rexatoire, n'était que d'une importance fiscale relativement secondaire. Louis XIV aurait très certainement pu procéder à cette abolition, conme le lui ont conseillé Pussort et Colbert; mais elle n'aurait pas empèché le mouvement du xrmi ${ }^{\mathrm{e}}$ siècle, ni réfréné les vices, ni prérenu les fautes et les malheurs d'une monarchie qui ałait renoncé à ses traditions nationales poury substituer la politique selon l'Ecriture sainte de Bossuet (3). Voici sur la société féodale le jugrement calme et impartial de II. Glasson. "La société féodale est née des besoins l"une épo"que et leur a, en grande partie, donné satisfaction.... On a "beaucoup décrié ses abus, ses inégalités sociales, mais au"jourd'hui des appréciations plus justes tendent à prendre la "place de ces récriminations. Pendant les siècles de sa pleine "vitalité, le régime féodal a, lui aussi, à son heure, été le re"présentant du progrès et de la civilisation ('́) ". Nous voilà lien loin des accusations passionnées que MI. Guizot formulait en 1828 et quili a renourelées trente ans plus tard en racontant à ses petits-enfants : "de tout temps la masse de la population " a considéré le régime féolal comme un ennemi à abattre ".

(1) Fonstivations sur Thistoire dis Fruce.

(2) Ancien regime, chap. x11.

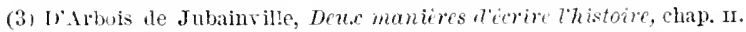

(4) Institutions de la France, 1er volume. Introduction. M. Mnortet l'a également jugte arec calne, bien quen sacrifiant trop à la sociologie et las assez à la terre, il sa cultur*, it sa mise en valem : cultiver et défenure le sul, robla les lettres do noblesse de la féolalité française. 
De nos jours, il y a un autre ennemi it abattre, cest la proprictés foncière elle-mème. Les révolutionnaires de la fin de notre siécle emploient exactement la mème formule que l'éminent professeur.

Aujourdhui on sait que la fëolalité a été, pendant phusieurs

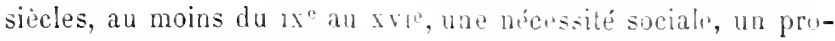
grès économique, un or ranisme puissant de protection et de défense du territoire, des personnes, des linens ut les lroits de tous, ainsi qu'un régime social approprié à la mise n'n culture de l'Europe et à la transformation de la servitude; n a retrouré les textes qui attestent la fonction de salut pubic ot dr développrement agricule, économique, politique, remplie pr le régime féodal.

Tocqueville a attribué, en partie, cette antipathie, profuis cette ingratitude des populations, au maintien des droits févlaux jusqu'en 1789. Les droits féodaux, dit-il, lérritimes lu $x^{\circ}$ an xure siècle, ne l'étaient plus, quand le rérim féorlal ne fut plus en rapport arec les conditions politiques et sociales de li france. Acceptés comme droits publics, ils devinrent les hroits privés. Il n'y a qu'une part de vérité rlans l'observation de Tucqueville. Les propriétaires des domaines, grevés de troits féorlitux, ont toujours aimé à confondre les droits fonciers, prarfaitempnt lécritimes, avec les droits fiscaux. Dailleurs leur importance a été exagérée. Ils ne représentaient guére, les uns et les autres, pour la France que 100 millions de franes en 1789 et 123 millions avec ceux du domaine roral. Les droits de transmission seuls étaiert onéreux. Les droits féodaux étaient, en outre, tres inçalement repartis. Mais ces divers droits donnaient lieu à de nomlreuses compensations et confusions, qui en diminuaient leaucoup le total, soumis à des prélèvements fort sensibles de la part l'une multitude dagents fiscaux tres retors et très couteux. Dhuis, les droits féodaux sont devenus un thème inépuisabte pour les politiciens, les feuilletornistes et les feudistes les boulevards.

Tout en faisant une certaine part aux observations de Tocqueville, en accordant, qu'au xrme siecle, ce qui demeurait alors debout de l'édifice féudal n'était plus, à peu près, 'ju'une ruine sans valeur, de mème que les vieux castels qui avaient si longtemps protégé les populations, il faut attribuer, ce semble, leur 
antipathie séculaire, sous certaines réserves très remarquables, à l'action du pouvoir royal et à ses agents d'une part, et, d'autre part, au caractère particulariste de la race, qui a fini par s'insurger contre les moyens nécessaires, mais trop longtemps conservés et appliqués, pour la civiliser et mettre en valeur son territoire.

Nèanmoins la France et, en Europe, aucun peuple ne comptent le générations plus illustres que celles qui l'ont constituée du $x^{e}$ au $\times 111^{c}$ siècle et saurée du $\times r^{e}$ au $x v^{e}$ siècle. Nais ce qu'il $y$ a peut-ìtre de plus digne d'éloges dans nos anciennes familles seigneuriales, c'est de durer encore et d'avoir résisté à l'action du temps (1). Nous en connaissons une très honorable dont les parchemins authentiques remontent au $x^{e}$ siècle. Fort peu de familles sénatoriales romaines ont eu la mème fortune. C'est qu'en même temps qu'elles ont possédé, défriché, cultivé la terre de France, plusieurs de ces familles y ont maintenu des traditions d'honneur, d'éducation, de résignation, de sacrifice, de devoir social et de civilisation chrétienne qui, seules, permettent aux générations de résister aux lois destructives de la vie (2).

\section{\$16. Les Croisades et l'Eylise.}

Commencées à la fin du $\mathrm{x}^{\circ}$ siècle, les Croisades se sont prolongées jusquau xive. Elles ont exercé, sur toute l'Europe, une très grande influence à divers points de vue $: 1^{\circ}$ elles ont manifesté combien avaient ité considérables les progrès accomplis depuis la fin du $x^{e}$ siècle; cette période, encore imparfaitement connue, a dù ètre une des plus prospères de l'Europe; $2^{\circ}$ elles ont ouvert la société féodale aux riches possesseurs de tenures

(1) Ineien régime, ehaj» xit. - Licet usus gentium nobilitatem in divitiis açuisitis intruxuerit dominari, ratime tamen sacios disponenti placuit ut mores et actus demonstrent nubilitatem hominum et exinde mereantur vere nobiles reputari (Ducance, ylossarium - an mot mobitutio), - de lat linue ajoute : Sponte assentior eos tantum inter nobiles cooptatos qui honeste et libero loco nati erant.

(2) Nous eiterons comme exemple la famille seigneuriale de La Roche-Guyon dont U. Roukr a éerit l'intéressante histoire: mais la famille à laquelle uous faisons allusion n'a pas éprouré les mêmes changements que eelle de La Roche. Elle est la mème depuis 900 ans. La famille de confucins possède eneore en Chine le lomalne sur lequel son illustre fondateur a recu (500 ans arant notre ère). 
yui avaient passé successivement de la condition de colon i celle de censitaire, de vilain, de roturjer et de lourgevis. Xous arons déja relevé dans la famille dr Michel Nontairne un cas très curieux de cette transformation. Cette admission a été, de la part des seigneurs, le résultat de la nécessité et, de la part des vilains, la preuve de l'anélioration de leur condition; $3^{\circ}$ elles ont rapproché les divers groupes sociaux les uns des autres, constaté entre eux des liens communs: elles les unt associés à des événements nouveaux, lointains, qui ont modifié les horizons de chacun d'eux; elles ont iti une manifestatinn, en partie, nationale; $\dot{t}^{c}$ elles ont mis li France on raplort arec d'autres nations, d'autres races, d'autres religions, l'autres climats. Il y a eu une sorte de renouvellement, diautant plus profond, que toutes les classes de la nation y out pris part; วo elles ont surexcite le sentiment religrieux et contribué ainsi à adoucir les mours, à tempérer ce que le régine féulal arait d'excessif; $6^{\circ}$ elles ont été l'occasion de la levée, à diverses reprises, pendant près de deux siècles, d'aides extraordinaires, sur lesqueltes il y a lieu d'insister.

La première a été levée en 11 t' du vingtième, parce que le taux de l'aide fut fixé par le lioi au ringtième des revenus. La levée de cette aide lut précédée d'un recensement général. Toutes les classes des deux sexes durent l'acquitter. M. Glasson a admis qu'elle fut exigée dans toute lu Guule. Il nous parait difficile de partager cette opinion.

La seconde, la dime saladine, fut demandée en 11 ss par Philippe-Auguste; cétait une taxe sur le capital quant aux hiens mobiliers el sur le revenu quant aux biens fonciers. La valeur des biens était déclarée sous serment par le contribualile. L“impòt était du dixième. Il portait sur tous les biens, sans exception, de tous les non-croisés. Le seigneur croisé recevait la dime do ses rassaux el de tous ses hommes. Ln an apres lhilippeAuguste rapportait son ordonnance qu il considérait comme une faute et une témérité. On a attribué cet acte, si curieux, à linHuence du clergé, qui préludait, dès lors, à la politique fiscale qu'il a suivie, sans jamais la modifier, jusqu'en 17s9. En partant pour la croisade, en 1190, l'hilippe-Ausruste défendit aux pré- 
lats et barons du royaume de donner taille dare tallium tant qu'il serait au service de Dieu). Cette aide ne fut demandée que dans les domaines royaux; ce qui rend fort improbable qu'en 11 'i, celle demandée par Louis VII, ait pu ètre exigée dans la Gaule entière; elle fut partagée entre le Roi et les croisés. Les lijens ecclésiastiques y furent soumis; elle fut levée par le Roi sur ses sujets immédiats, par les seigneurs dans les seigneuries, ei les communes, par les érèques et chapitres sur les biens du clergé. C'était donc une aide toute spéciale, n'ayant encore aucun caractère général. Ainsi l'irurre si considérable des Croisades n'a pas suffi pour généraliser la notion de l'impòt en France.

Longtemps, le caractère et limportance pour la race française, des Croisades ont été méconnus, de parti pris; mais aujourd'hui la lumière se fait peu à peu; les voyageurs et les savants du xix siècle ont replacé, sous les yeux des générations actuelles, ce qu’ont été les croisés, les luttes héroïques qu’ils ont soutenues, les institutions gu'ils ont pratiquées, les clientèles quüils ont établies, les impérissables traditions de Jérusalem, de Chypre, de Rhodes, de Candie et de Malte, les temoignages d’admiration des peuples qüils ont combattus. La France est toujours vivante en Syrie et les chrétiens de la Palestine et du Liban comptent toujours sur elle: les monuments que les croisés ont élerés n’ont pas tous péri; dans quelques-uns sont encore installées les écoles où nos sieurs, populaires dans tout l'Orient et respectées par toutes les races, professent la vieille langue et propragent la cirilisation de France.

Nous arons mème dù consulter les Codes ou Assises de Jérusalem, conservés en partie, pour donner une idée de l'époque féodale; car c'est en Sirrie, de mème qu'en Angleterre, que les institutions, les mours, le régime de la féodalité ont eu Jeur plus complet épanouissement. En France, ils ont toujours dù compter avec les débris de la civilisation romaine.

\section{S17. La Royauté féodale en France.}

A aucune époque l'idée et la tradition d'une force centrale, protectrice des intérèts communs, conservatrice de l'ensemble 
du corps social, peut-itre meme dune sorte de nationalite, plus ou moins indéterminé, n’a entiépement disparu, dans les tiaules, au milieu de l’anarchie profonde de la société gallo-romain et du mourement de reconstitution locals to la leodalité. Mais les peuples ne vivent ni par les souvenirs, ni prar l’imagination, ni sous l'empire de leurs preférences. Its sont dominés, avant tout, par les eireonstanees au milieu desquelles its sont placis et par les besoins présents. Wu r." au $x^{\prime \prime}$ siecle, sauf sous Charlemagne, le prouroir eentral, la Rnyanti, a iti impuissante ì maintenir lordre et la sécurite sur le territoire hes taules qui, avant, comme après la conquite romain, n’avit pas constitué un ensemble national. Charlemasne, lui-mime, uy est pas prarrenu.

La société féodale s'est formé ou agrtumée, en France. précisément pour procurer, far dautres moynons, lorilie et la sécurité, réunir sous un lien félératif les divers éléments appelés à constituer le territoire, la société, la nation. Le pouroir royal n'a point disparu au milieu de cette transformation, mais, en fait, il s'est trouvé considérablement rèluit. Nous verrons qu’il n’en a pas été de mème en Angleterre ni en Alemagne, dilférence qui a eu des conséfuences trèsétenlues. M. Lurlaire nous parait aroir saisi, mieux que II. Guizot, le double caractere de la royauté féodale, celle dont les grands feulataires, les éreques, les barons investirent Hugues Capet, comme duc de France, en 987. "La Foỵanté capétienne offre le double carac"tère: $1^{\circ}$ d'une monarchie traditionnelle de drot dirin: : d'une "suzerainete gineral" dorle? fiodul, mais ce dernier aspect "de linstitution ne se dessina pas, lès l'origine, aussi nutte«ment que le premier. I.es rois n ont jamais cessi de parler et " dagir au nom du droit monarchique fui rtait leur "lroit propre " et essentiel, tandis que leur action, comme chefs de l'édifice "féodal, appelés à bénéficier de leur haute suzeraineté, en vertu "des principes purement féodaux, ne s'est guere manifestée "dans les faits arant le commencement lu xu" sipcle 1)".

De ces deux caractères, le premier, malgré le sacre, malgré l'unité du titre, malgré le concours de l'Ĺglise, malgré

1) Luch ire, Hawn? liate 15:. 
la foi, plus vague et plus incertaine qu'on ne l'a pensé, du peuple en un pouroir supérieur de justice, malgré les aspirations longtemps confuses et fort obcures, si elles existaient, vers la communauté destinée du regnum ou de la patria Francorum, selon les expressions acceptées par M. Luchaire, mais sujettes à bien des interprétations, il était, quant au $\mathrm{x}^{e}$ siècle, un pur idéal (1). Les seuls fondements réels de cet idéal se résumaient dans le concours de l'Église, concours qui arait encore ses incertitudes et ses variations, et dans ce qui pouvait aroir surrécu des débris des traditions romaines. La Royauté n’a retiré de son caractère de droit divin aucune autre force qu'un certain prestige, jusqu'à ce que sa suzeraineté féodale ait définitivement prévalu, en s'étendant, arec des degrés et des conditions fort divers, sur les différentes parties du territoire. M. Guizot a tout à fait exagéré la portée de ce prestige et de ce pouroir idéal (2), qui ne se sont réalisés qu'au xrill siècle, dans la personne de Louis XIV, et qui n'ont guère duré plus que lui. L'histoire de toute la monarchie francaise atteste, particulièrement l'histoire de l'impôt, que son caractère de droit divin ne lui a pas servi à grand chose et qu'il l'a, a contraire, compromise et perdue. Dépourvu de tout pouroir, Louis XVI s'imaginait ètre encore roi par la gràce de Dieu.

Il est vrai que le principe d'hérédité dans le pouroir royal n'a amais été sérieusement contesté à la maison capétienne, depuis Hugues Capet, mais cette hérédité provenait-elle de l'origine divine ou de l'origine féodale? La féodalité avait tout autrement l'hérédité et la propriété pour fondements essentiels que la délégation populaire ou la désignation divine, auxquelles l'élection peut parfaitement s'appliquer. Enfin, Hugues Capet avait été choisi ou s'était imposé, avant tout comme maitre de la plus importante des grandes seigneuries. C'est à son duché de France qu'il dut la couronne, tout autant qu'aux suffrages des ducs, érêques et barons (3).

(1) II en est de méme de Ia therro le M. B sutaric sur le droit du Roi a la pro. bricté lu sol : pare excentricité d'archiviste.

(2) Histoire re la cirilisatim en France, tom. 4, legons XII à XY.

(3) Yichelet, ititem, 1 rol., 427, 431. 
I.a Royauté capétienne est lone sortie du mitieu féodial; "lle" a dì son plus grand lustre a son earactire léodal : Philippe-. Inguste, saint Louis, Louis Xll, Frameois ler, llenri II, mem. Henri IV ont été des rois feolaux. Lis qui Louis XIV a enfermé ses descendants dans le hartm de lirsailles, la décépitude s'est emparée de sa race (1). Li populariti de la liogaute est provenue de son caractère léodal. A peine sa missinn divine eut-elle pris corps avec le droit romain et les lévistes du xa siecle, que, des Philippe le Bel, la violence et la trreur, ha fraurle, les ronfiscations, la fausse monnaie, deviennent ses agents indispensables.

L’histoire de la rioyauté capétienne se partangen trois périones. La première finit avec Plıilippe le Jlardi en t2xä. C"est la réritable période féodale. La seconde finit avec Herri IV, f’est la peiriode de la monarehie contrilée; la troisiène arec Louis $\mathrm{XVI}$; c'est la seule période du droit divin on de la monarchie ahsolue; elle abontit à un désastre effrorahle. Nímmoins la Royauté capétienne, mème absolue, n'est jamais parvenue à se soustraire completement à l'intluence de ses origines. Née fürdale, elle est demeurée féodale en fait, sinon en troit.

Durant la première période, illustrée par les rois les plus remarquables, les Capétiens ont emplogé trois siteles a agrandir, par tous les moyens, la seigneurie splendide à laquelle ils levaient la Foyauté et à faire de cette seimneurie, le modile de toutes les autres. Nalgré les extorsions de Philipue le Bel, l"imput demeura purement féodal. Les premiers Capétiuns n'ont pas entrepris de changer la société féodale, mais de l'amétiorer. Les actes en matière d’impòt de Plilippe-Aucruste et le saint Louis, les plus éminents d'entre eux et de tous los rois de Frauce, ont nettement indiqué leur politique.

Durant la seconde période, qui a aussi une durée de près de 300 ans, surtout arec Philippe le Bel, Cluarles V, Charles Vll et Louis XI, la Royauté a essayé de modifier les conditions politiques et sociales de la France; elle n'y est parvenue qu'imparfaitement. Après la mort d'llenri $\mathbb{N}$, il a fallu avoir encore re-

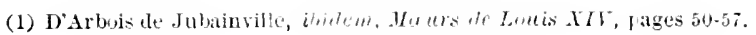


cours aux États généraux. Richelieu et Mazarin ont eu à soutenir des luttes violentes, renouvelées quelquefois même sous Louis XIV. Il y a peu de différence, au point de vue économique et social, entre la société française du $x \mathrm{v}^{\mathrm{e}}$ siècle et celle du commencement du xrif - mèmes institutions politiques, mêmes conditions économiques, mèmes classes sociales. - Aussi il a été difficile à la Royauté de modifier l'impòt pendant ces trois siècles.

De sérieux changements s'effectuent pendant la troisième période. Le droit divin, attribué au pouvoir royal, l'emporte sur son droit féodal. Le Roi devient à peu près seul maître de l'imprit, au point de vue politique, mais nullement au point de vue économique et social. La Royauté française, qui a pu se dégaser du moule féodal, comme pouvoir politique, n'y est pas parvenue comme pouroir social. Par suite, elle n'a pas accompli, dans l'organisation sociale et fiscale de la France, les réformes nécessaires. En 1789, il y avait encore en France des seigneuries pt des fiefs, tels qu'ils existaient au xme siècle, non pas en ce qui était de la condition des personnes, mais quant à la condition les terres et des impits. Le seigneur devait encore menu cens, gros cens, relief, quint, requint, lods et ventes. Le Roi se considérait comme le premier ćes seigneurs. Les édits royaux n'avaient pas changé de forme; on les écrivait en français au lieu demployer le látin. Il en est résulté, - nous le prouverons en examinant les projets de budgets royaux, - que jusqu'en 1789, il y a eu en France deux sortes d'imputs, l’impól féodal, le plus ancien, et l'impit royal. La Royauté levait le second sur l'ensemble du royaume et le premier dans son domaine particulier.

Ainsi s'expliquent les scrupules de Philippe-Auguste et de saint Louis (1), à l'égard des impòts, d’un caractère général, qu'ils se crurent autorisés à demander, à raison des Croisades, le plus grand événement politique de leur temps. Ils n'étaient nullement convaincus que leur prérogative divine leur permit d'exifrer des taxes en dehors de leur seigneurie royale. Et cependant leurs règnes (un siècle entier à peu près) forment la grande 
epoque de la rogaute fopulaire, religionse, lienfaisante. Its se contentent de leurs revenus féodanx. Rien ne montre mieux comment les orcanismes s'adaptent aux temps; rien nindique mieux la prudence que des hmmes ditat sont imus dappor-

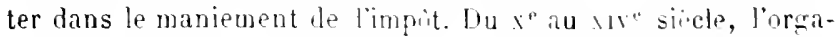
nisation féodale a correspondu aux besoins du pouvoir roval, c'est ce que Philippe-Auguste et saint touis ont reconnu. Leurs actes en justifient. C'est un arzument hécisil contre la thérie qui considère l'aide léodale extraorlimaire commo lorisrine de limput royal en France.

I. Lu fonctionnement du puatoir ingal pendunt liponue findule. - Malgré la violeuce des murs sous les dỹnasties Mérovingienne et Carolingienne, le pouroir des rois avait étri jusqu’i un certain point, contrilé ou assisté jar des assemblées temporaires. Luin de disparaitre arec l'époque fóodale, ce controle s'étendit et s'universalisa. Charque haron avait son plair?, chaque seirneur suzerain sa cour. Le jouroir roval eut d'ahord sa cour seigneuriale - la Curia regis. Les démembrements successifs de la curiu ont constitué les conseils du Hoi, la cour des Comptes et les Parlements - qui nont d’abord été créés jue pour la seigneurie rovale. Mais à coté de la curiu se maintinrent, à titre temporaire, les assembées traditionnelles des suzerains, evèques, grands abbés, barons, parmi lesquels les plus importants araient le titre de pairs de France, et des bourgeois des rilles (1). Ces assemblées furenl principalement composées. jusqu’au xw" siécle. des seigneurs divers appartenant à la seigneurie. au domaine du Roi. Les „grands Capétiens les ont convoruées et consultées, pendant les trois siècles de cette première période, sur tous les actes importants soit du domaine royal, soit du ponvoir roval. C'est de ces assemblées que sont provenus, an sur siecle, les lats générax qui ont joué un rile de premier ordre jusqu'en $116 \mathbf{k}$

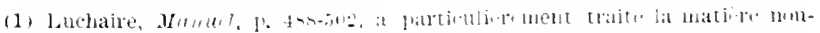

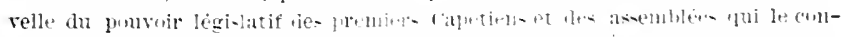

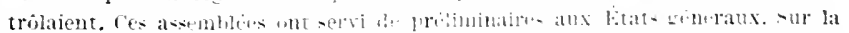

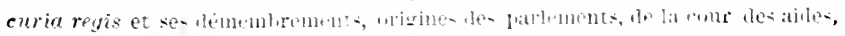

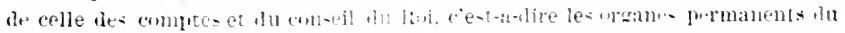

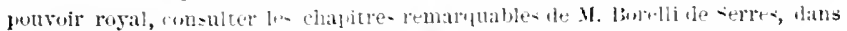

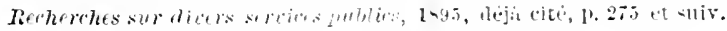


Lexercice flu pouvoir roval avait donc lieu en quelque sorte en participation; c'est bien le caractère de la véritable époque féodale en France et dans toute l'Europe 1).

Il. Des droits ferglaux et dos impits de lu Royaute fédule. - Il faut, dès à présent, établir une distinction fondamentale, qui se maintiendra jusqu'en 1789 , entre les finances et les impìts de la Royauté en France. Les imprits n'ont pas eu la mème destinée que les finances. Rarement excessifs en eux-mèmes, ils ne le sont devenus que par leur inégale répartition; quant aux finances, excellentes, jusqu'à Philippe le Hardi, elles nont cessé d'ütre en proie, à quelques exceptions près, arec Sully, Colbert, Orrỵ, de Nachault, Turgot, à un désordre perpétuel et incurable. Cie désordre a été l'occasion immédiate de la Rérolulion française.

Pendant les trois siècles de la période féodale les ressources orlinaires du Trésor roval sont provenues des droits féodaux et lu produit des domaines, tels que ces droits et produits viennent d'itre énumérés plus haut, levés dans la seigneurie ou dans le territoire du Pioj seulement. I'our assurer au pouvoir royal d'autres ressources permanentes, il a fallu la terrible crise du $x w^{\circ}$ et du $x r^{\circ}$ siècle dans laquelle la nationalité française a failli succomber, et, jusqu'en 161', le pouroir roval est demeuré indirectement limite, au point de rue fiscal, par lintervention des litats génèraux, remplacée, après 161 t, par celle des Parlements.

A raison de son étendue et de ses accroissements, qui ont été tris considérables et très rapides au xu comme au xw siècle, Ja Rogauté disposa hientit de ressources ordinuires importantes bien quelles fussent exclusirement réolales ou domaniales. Ainsi, elle parrint à lever les reliefs et autres droits de mutation sur les grands feudataires, tandis que, $d u x^{e}$ au $x n^{e}$ siècle, elle n’arait pu les demander qu’a la petite féorlalité. On peut éraluer l'ensemble aes ressources brutes du budget de saint Louis à une moyenne de 207,000 lirres tournois, avec un reliquat annuel net de 63,600 lirres $(2)$, fournies par les fo-

1) Eu meconnasisant la fonction historijue des Ltats generanx en France, en esłuivane leur contrile, Richelien, Lotis XW et leurs suceeseurs, ont vigle le Iroit nat iomal. C"est la cause réelle de la ruine de la Ruyate en France.

(2) La lispe tommols valait $17 \mathrm{fr} .90,-$ pomroir the largent reservé. 
rèts, les exploitations rurales directes, les droits de mutation tels que rachat, relief, louls et ventes, franc-fief, amortissement, cens, champarts, tailles, hanalités, peages, tonlieux, taxes d'indistries, corvees, droit de gite, Jroils domaniaux et de justice, sceau, police, confiscations saisie et commise féolale, dimes inféodées, monnaie, prisies et taxes militaires, taxes sur los biens et les personnes des serfs 1 , tiilles sur los Juils, sur les Lombards, droit de régale.

Aux ressources ordinaires qui étajent prrmanentes, se joignaient les ressources extraordinaires qui etaient temporaires. Elles consistaient dans $1^{\circ}$ les dons: $2^{\circ}$ les decimes ecclésiastiques; 3 "les aides aux quatre cas; $4^{\circ}$ les taxes militaires.

$1^{\circ}$ Les dons volontairés étaient demandés surtout aux villes et au clergé, toujours dans le ressort du domaine rosal seulement. Ces dons perdirent en partie leur caractere primitil volontaire pour devenir souvent obligatoires. Niantnoins le don volontaire n’a jamais entièrement disparu parmi les ressources des Fiois $(\boldsymbol{2})$.

$2^{\circ}$ Les decimes ecclisiastiques etaient accordés par les papes sur les biens de l’Égrlise. La croisade les Mlbrgreois à été l’origine de ces décimes, que les papes consentirent et que l’igrlise acquitta pour les croisades en Terre-sainte. Il est souvent arrivé que les papes sen sont attribué une part pour d'autres fins que la croisade. Ils en firent mème un instrument de rigne. En 12s', Martin IV accorda 3 décimes à Philipe le llarli, pour

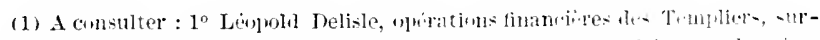

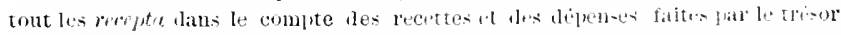

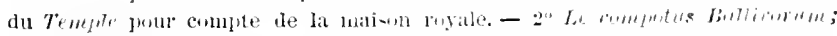

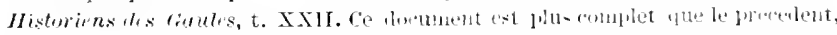
On y trouve la mention des bles, cires, aboiles, fours, monlin- pryax, - 3" Latn-

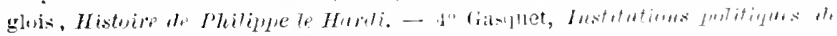

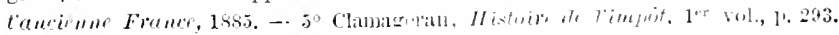

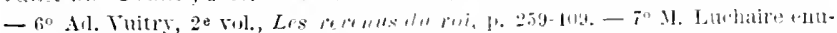

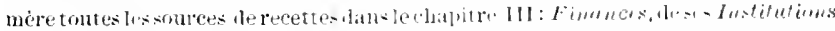

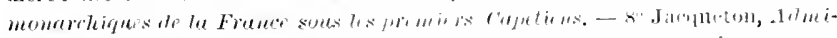

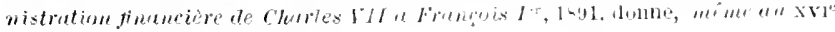
siecle, les méhes inmucrations.

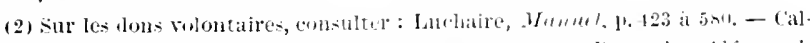

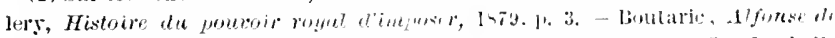

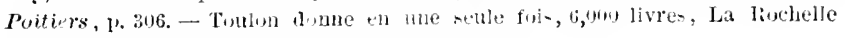
6,000, Reims 4,000. - A.l. Vuitry, 1 vol., 1. 400. 
la guerre d'Aragon. Les Croisades ont ainsi exercé non seulement une influence économique, mais une influence fiscale considérable. Les décimes se sont convertis, arec le temps, en une sorte de contribution permanente, sous le nom de don gratuit, tantùt générale, tantôt particulière à raison des impûts nouveaux. Les décimes ecclésiastiques furent accordés, pour la première fois, par Honorius III en 1226 à Louis VIII, à propos de son expédition dans le midi de la France (1).

Les décimes ecclésiastiques, ayant un caractère général, se levaient dans toutes les seigneuries du royaume au profit du Roi; elles ont donc formé un premier impit général au point de vue de la perception et de l'emploi. Nais les papes parvinrent bientît à en lever d'autres sur les diocèses particuliers, pourvu que ces diocèses eussent quelque importance, moyennant partage arec les seigneurs. En 1240, le concile de Senlis accorde au pape le treizième des revenus de la prosince de Reims. En 126:3, Clément IV accorde aussi des décimes à Charles d'Anjou pour la guerre en Sicile. Il se produisit bientòt de plus grands abus qui provoquèrent en 1268 la publication de la Prugmatique sanction de saint Louis $(\mathbf{2})$.

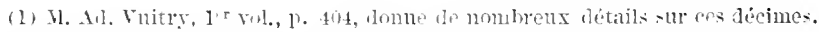

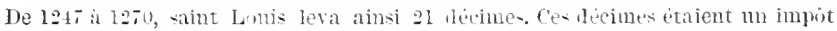

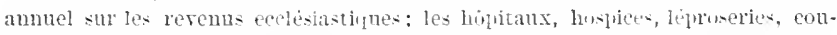

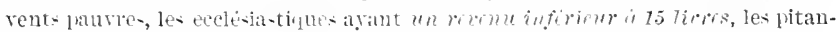
ces nunacales en itaient +xempts. On killue que le- 21 décimes de saint Louis proului-irent 5,250,000 lines. - Philiple le Harli leva 7 decimes qui rendirent $1,750,000$ litres.

(2) \& la perceptin arait pour sanction lexemmunicatiu : m retacd, après

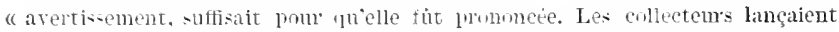
" enx-mens la censure et lenonçaient les exeommunies (les luêtres, munes et

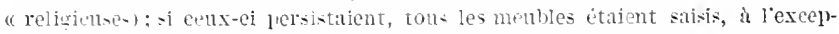
a tim les croix, calices, ormements; cu can de rebellion, ils étaient fivr's au bras

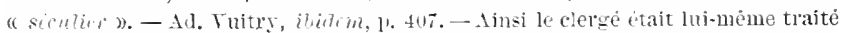
eomme les Albigeois. Pappelons a ce propus rue lime des eauses de la croisade albigenive et ghe l'un des buts de l'In puisition ont été une raste spoliation du milli de la France, alor's fort riche, an profit de la papante italieme. Ces déeimes itaient heves lapres un cadastre des revenus du elerge. Ou trouve daus le $21^{\mathrm{e}}$ rol. des Mistorians des Gaules, un document str la valeur des déeimes par dioeèse. On woit par la combien le fisc franȩis remonte loin. Historitns des Gaules, $21^{\mathrm{e}}$ vol. Tacatio Atcimurum pro negotio Arauone, 1. 33. - Talor aecimarum, 1. 540-562. - Ces doeuments se ralportent aux annees $1247,1252,1313,1330$. 
3u Les aides aux quitie cas. La levée de ces ailes se généralisa et s'étendit pendant le xur sièce. Saint Louis les leva en 1248 el 126 i pour ses deux croisades, en 1230 pour le mariage de sa fille ainee et en 1267 pour l'armement de son fils ainé comme chevalier. Il en fut de mime en 12s's pour Philippe le IJardi.

Mais la mesure la plus importante de la Rovanté pendant cette première période fut d'ouvrir l'ère de la transformation en aile extraordinaire du service militaire (ost et chermulve). Cette transformation fut préparée par une ordonnanes de PlilippeAuguste en 1213, relativement ì un projet le croisade. Dajua les villes araient fait des abonnements avec le roi pour le service miiitaire. Cette transformation a exigi plus de 200 ans. Elle ne s'est réalisée qu'après de grands désastres militaires prarce qu'elle avait pour condition première lis transformation lit limpơt. Mème pendant le xn siècle (1), laiłe roṣle conserra un caractère seigneurial, féodal, local. Le selrneur, comme le lioj, tendil à convertir en une taxe le serrice militaire des vassaux, des roturiers, des serfs. Le tarif des rachats de remplacement variait par province, mème par fief; chacun lemeurait libre de faire son service ou de payer la taxe de rachat; te Poi ne recevait le montant du rachat ou de l'aide, concernant son service personnel, que par l'intermédiaire des seigneurs.

Il importe de rappeler, en effet, que si, surtout a la fin du $x \|^{\circ}$ siècle et pendant le $\mathrm{x}_{1} \mathrm{H}^{\mathrm{C}}$ siècle, le droit féodal reconnut au lioi le devoir, comme le dit expressément Beaumanuir, de pourvoir ì toutes les nécessités générales du rọaume, ce qui teurlit à trénéraliser le service militaire et la taxe de rachat, - service et taxe n'en demeurèrent pas moins, dordinaire, localisés et féodaux; le service royal direct fut l'exception.

En quoi consistait l'airle féorlale, mìme celle qui ne se résumait pas dans un service personnel? C'était la taille, c’est-à-dire une taxe globale sur les facultés des contribuables, capital et

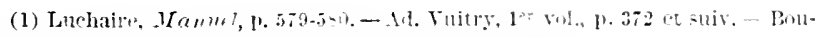

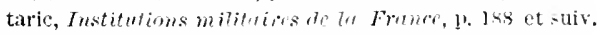


revenu(1). Essentiellement variable d'après les provinces(2), elle était limitée par la coutume. Telle fut l'aide royale militaire, elle ne se confondait pas avec l'aide seigneuriale; elle s'y superposait. "La quotité de l'aide que le seirneur avait le " droit de percevoir sur les habitants de sa terre, dit II. Ad. Vui"try, etait quelquefois indéterminée; il en fixait arbitrairement "le montant, l'assiette et la répartition; c'était la taille féodale "imposée sur les personnes ou sur les biens, et percue le plus " souvent sous une forme de capitation proportionnelle au re" venu de chacun, mais dans beaucoup de localités la quotité et "l'assiette de l'aide étaient fixées par la coutume. Le roi levait " aussi l'aide féodale, mais son droit n'était que l'exercice du "pouvoir seigneurial; il n'était pas plus étendu, il était soumis "aux mèmes limites, aux mêmes restrictions (3)."

En général, l'aide féodale dans son taux, correspondait à une partie du cens (4), parce que le bail à cens était la tenure roturière par excellence, soit seule, soit associée au champart. Le fief noble ne pouvait payer de cens pas plus que le gentilhomme. Dans beaucoup de cas, l'aide doublait le cens qui n'était jamais éleré. Il en fut de mème pour l'aide de l'ost roral. Les roturiers et les serfs étaient naturellement tenus de laille royale comme de l'aide seigneuriale, mais ils ne pouvaient ètre taillés sans le consentement des seigneurs, de leurs vassaux et de leurs varassaux. Que se passait-il alors! Le roi consultait les grands feudataires et les seigneurs ou barons les plus considérables. Il s'entendait avec eux, il leur cédait une part dans le produit de l'aide. C'était ensuite à eux à se mettre d'accord avec les autres seigneurs, les propriétaires de fiefs qui autorisaient seuls la levée de l'aide sur leurs tenanciers; cette aide asgravait en effet la condition des tenanciers; elle diminuait leurs ressources pour remplir leurs obligations ordinaires.

(1) M. A.l. Vuitry dit sur le capital on le revenn. - La tajlle ordinaire atteignait lés dirersés facultés du entribuable. - Il en a été de mème de la taille royale jusinuen 1789 .

(2) Variations inui existent eneore dans l'impût foneier actmel.

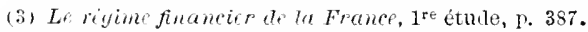

(4) Al. Vaitry, ibiden, lage 40z. - M. Ad. Tuitry a traité le sujet de laire fevelale et royale aree beancoup de soin. 
LA TAILLE SEIGNELRIALE ET LA TAILLE PUIAL, i:,

II. Ad. Vuitry, après aroir établi arec des documents relatits à une aide levée en 126s, dans le Lameruedoc, par Aphonse de Poitiers sur les feux, ou aide de fouage, le réritable caractire de l'aide royale, ajoute : "Cette situation respective du suzerain, "de ses rassaux, des tenanciers, qui se manifeste en Lanłue" doc, dans la seconde moitie du $x 1^{e}$ sirele, priprare é éclaire "l'avenir. Elle sera celle de la royaute, des nobles, du clergé, "du tiers-état, quand au commencement du siocle sllivant. "Philipne le Bel entreprendra de transformer liaile fuodale "(du roi) en un impit onénéral etalil et perou par ia Cou"ronne 1)".

Tels étaient les droits féorlaux et les imprits de la rovautr féodale à lavènement de Philippe le Bel. Is no surisaient dija plus à la mission de la Poyaute, non, à raison les depenses ordinaires, - pendant tout le xume siecle, le lioi fit lonneur à ses alfaires et conserva un crédit inaltéralite. i! avait mine des excédents et un riche trésor, - mais tout clanzeait. tnut se modifait en Europe; bien des dépenses extraor linaires stai nt ouvertes arec les Croisades, croisades en Terr-sainte, en trient, en Grèce, en Égpte, à Tunis, en France mima. Hautres néces sités allaient naitre des rapports de la France avec les nations roisines. L’expédition d'Aragon par Philipre te Harti fut un premier arertissement, pour ceux du moins qui ne tenaient fras compte des revers de larmée en Palestine, en lirypte et it Tunis. Les vices de l'organisation fómlale, vices irrémpliables au point re vue extérieur, militaire, national, allaient se manifester tout à coup; le pouroir roval allait aroir la terriliet tiche, tìche dans laquelle il a failli échouer, re modifier limprit afin le donner au rovaume arec une armée, la securité que l'orranisation féorlale arait procurée an $x^{\circ}$ siecle et quelle eitait dirit impuissante à garantir a la fin du s.1. . Nous devons diautant mieux saisir limportance de ces questions decisives dans la vie des peuples, quil y a à peine un quart de siecle que la France, cédant encore aux principes humnitaires d'un des principaux courants de la Révolution de 17o9, s’est laissée surprendre en

(1) Trielem, P. 40 : 
18:0, en pleine prospérité économique, de même que la France du $x w^{\circ}$ siècle, par l'insuffisance et l'imperfection de ses institutions militaires et qu'elle a dù subir un douloureux démembrement dù, avant tout, à son imprévoyance financière et militaire.

Il a suffi, en 1870 , de quelques mois de ravages et de quelques jours d'humiliations, pour obtenir de la France d'énormes sarrifices - mais elle était une nation; elle arait un puissant sustème d'impits, qui a montré son élasticité et ses ressources. An хाт siècle, tout cela n'existait encore qu'en préparation. Il a fallu faire le territoire, l'armée, l'impìt. Crécy, Poitiers, Azincourt, lo démembrement, le pillagre de la France, pendant cent ans, n’auraient peut-ètre pas suffi, si une jeune fille, dont la destinée est inexplicable, n’arait relevé la France aux Français mêmes.

III. Lis Finanres de la Royauté fégdule. - Pendant cette première périnde, les Pois ont eu de lonnes finances, bien que déjà ils aient dù souvent recourir au crédit. Iusquà la fin du xume siècle, malgré ses agrandissements, le domaine royal est resté divisé en prévités. bailliages et sénéchaussées, et administré par les prérits. les haillis et les sénéchaux. En général les prévôts levaient les droits et impìts, perceraient les rederances, céraient les fonds et valeurs, affermaient les biens sous le contröle des baillis dans lo nord et des sénéchaux dans le midi de la France, qui en versaient le montant au Temple, chargé de l'arlministration du Trésor roval, recettas et paiements. Le Temple était luimirne controjé par la Curiu regis. Plus tard, des receveurs, des contrileurs, des trésoriers et divers autres officiers ont été établis pour assister les prévìts, baillis, sénéchaux, pour les recettes. Quant aux détails des dépenses, ils étaient confiés à d'autres fonctionnaires, les chambellans, et à leurs cleres, chargés de gérer la caisse de l'Hotel royal et la Chambre anx deniers. Cette organisation suffit jusqu'à la fin du xire siècle. Il était dressé par la Crứn des états budgétaires ou plutôt des bilans de prévisions de recettes (magna recepta) et de dépenses (magna expensia à peu près tous les quatre mois par année. Dès le milieu du $\times 111^{\circ}$ siècle (12:j6), la Curiu regis déléguait à des commissions ambulantes la mission de surveiller l'ensemble des finances du 
Poi. Ces délégations devinrent successivement sédentaires et permanentes. Elles sont l'origrine des Parlements, de la Chambre et de la Cour des comptes (1).

A la fin du xme siècle la finance est mieux constituée que l'impôt pour la royauté féodale. Néanmoins, la finance deviendra le cancer destructeur de la Rovauté, quand, avec Louis XIV, I.ouis XV et Louis XVI, le caprice remplacera le devoir et que les recus au comptant lu Roi deriendront la piece comptable la plus sacrée.

$\$$ 18. Reflets et incidence des droits et impits fioduur. en Frence au xilo siecle.

Du xe au xile siècle, les éléments sociaux en présence sont : 11) les habitants des seigneuries dans lordre indiqué frar le cartulaire de Marmoutiers; 2 " les habitants des rilles, qui reprennent de l'importance surtout à la fin de l'époque fépdale; $3^{\circ}$ les habitants des localités, dejà nombreuses, formant des bourgs, eentres du mouvement communal. Il faut consilerer que, durant cette époijue, l'impòt, représenté par les lroits frodaux, a un caractère essentiellement local; il est seigneurial, arant tout, puis urbain en partie. Pas encore de véritables impits rrinéraux, levés et perçus sur l'ensemble du territoire, à l'exception des dìmes, dont quelques-unes étajent inféodées; pas mème encore de territoire nettement délimité et constitué.

Un publiciste distingué, M. Callery, dans un ouvrage intéressant (2), a conclu du caractère local des droits l'éodaux, qüils ne formaient pas des impoits réellement, mais do simples reulevances foncières ou personnelles. A notre aris, M. Ciallery a méconnu le caractère politique et social de la seirnfourie. Dans les longues énumérations qui précèdent, certaios droits sont des redevances, certains autres des impits. Le cens était à la fois une rederance et un impit. Comment contester le caractère

(1) Nous ronvogons aux tétails nombreux et nouveaux en partie des Iurberches de $\mathrm{X}$. le culonel Borchi de surres.

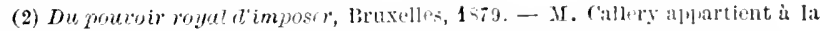
Belgique, territoire demeuré prestue étranger a la trabition fiscale ronaine. 


\section{4:8 CUMHENT LE PROGRÉS SOLIAL MODIFIE L'INCIDENCE.}

fiscal du quint, du requint, des lods et ventes, du relief, des péages, des tonlieux, des taxes sur le travail, de la taille des roturiers?

Dans lintérieur de la seigneurie, type Narmoutiers, qui compte 30 barons, do propriétaires libres et un plus grand nombre de serfs questaux, comment devait se faire lincidence de limpit? Il faut dabord retrancher, comme nous l'avons fait dès le $\mathrm{w}^{\mathrm{e}}$ siècle, les serfs domestiques qui ne reçoivent pas encore de salaires. Il faut ensuite, parmi les impòts féodaux, distinguer ceux susceptibles de répercussion et ceux qui ne le sont pas.

Ne sont pas répercutables les droits de succession et de donation, d'amortissement, de franc-fief, de justice, de gite et de prises. Ces droits retombaient exclusirement sur les 30 barons et les 80 hommes de pooste, mais ils étaient plus élevés pour les premiers que pour les seconds. Il en était de mème des droits domaniaux. Ils deraient peser bien plus sur ces deux classes que sur !es questaux.

Les cens, champarts, la taille, ne concernaient que les hommes de pooste et les questaux; cens et champarts étaient fixes; restait la taille, certainement plus forte pour les hommes de pooste que pour les questaux. Pouraient-ils s'en récupérer sur les 30 barons ou sur les autres seigneuries? C'est bien douteux.

Guant aux droits de vente, aux taxes de consommation, aux péares. tonlieux, ils concernaient en partie les trois classes. Ces divers droits ne pouraient être rejetés sur les questaux, trop paurres encore, cultirant eux-mèmes, rirant de leurs propres produits, achetant peu; ils retombaient sur les deux premières classes, et principalement sur la seconde, plus importante. Au contraire les corrées, les taxes dindustrie et de travail portaient presque exclusivement sur eux, par la nature mème des choses.

Pour les dimes, leur répartition s'opérait proportionnellement à la part de chaque classe dans le produit brut; elles étaient donc plus lourdes pour les hommes de pooste que pour les barons et que pour les serfs questaux.

Enfin les aides extraordinaires retombaient au compte des barons et des roturiers, selon leur nature. En réalité, la masse des impits demeurait pour le compte des deux classes supérieu- 
res sans réperussion possitie. C"est ce qui explique la folitique prudente des Capétions en matiere fiscale.

La charge principale ne était plus comme dans la fériode précédente, pour les seirneurs mais pour les anciens colons hihres, devenus les maitres des censires; cetaient les ruturiers gui supportaient la plus forte part : mais le roturier nest plus le serf; il était le principal profucteur.

Dans les villes, la situation était plus accentuée. les laxes dr consommation plus générales et riluśleres; les classesinlfurieures receraient des salaires; elles devaient donc antuder, dans la répartition de limpirt, une participation plus forte que dans les campagnes. Réciproquement leur cundition était déja préfécabte par la somme de liberté dont elles disposaient, frar la garantie et par la rémunération de leur trarail.

dinsi ce n'est que très lentement que peurent se molifier les conditions d'incidence de limprit, parce que limpit ne peut compromettre le strict nécessaire de l'homme et que pendant de longrs siècles, lesclarag̣e le démontre, linmme a été réduit au nécessaire le plus strict! 1 .

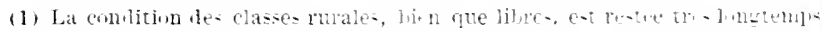

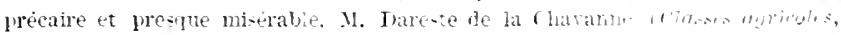

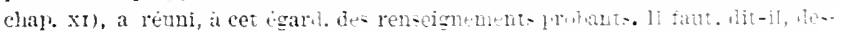

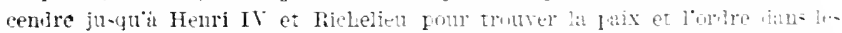

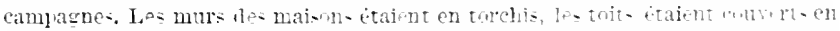

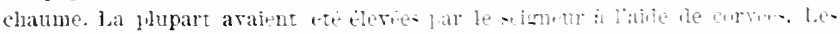

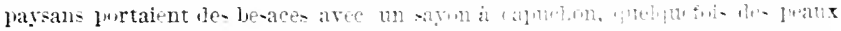

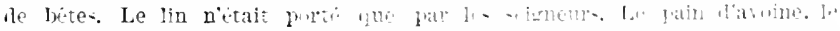

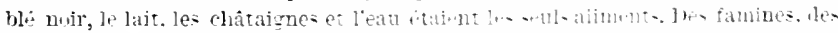

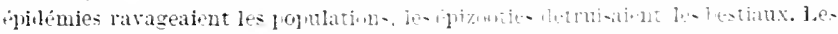

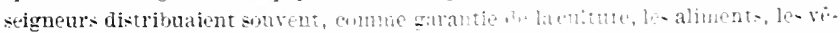

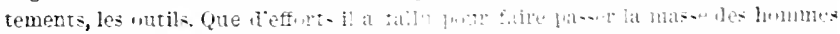

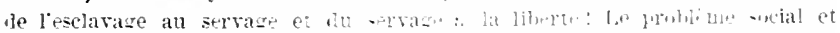

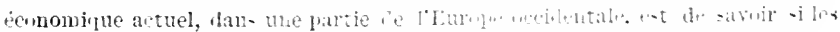

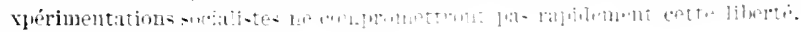














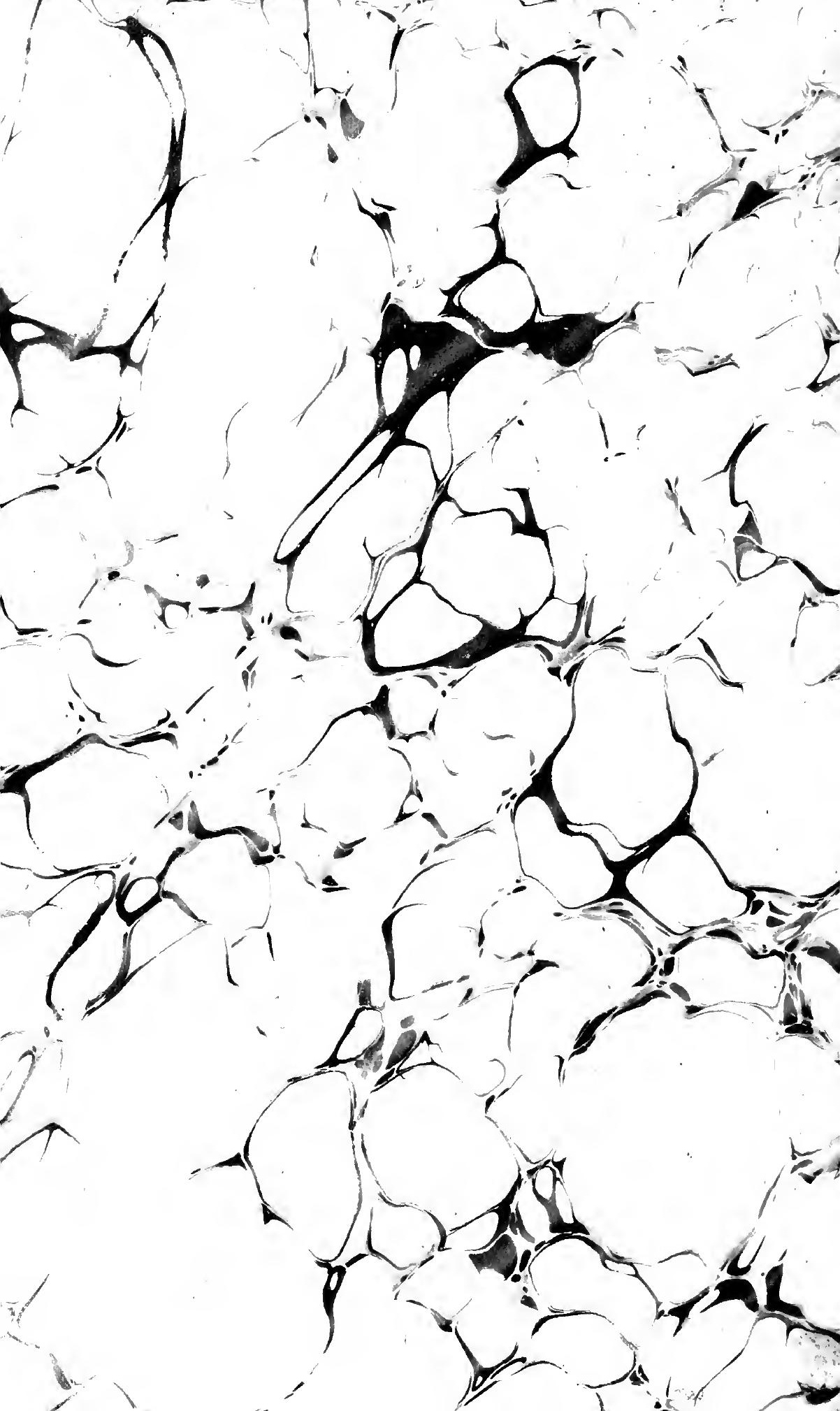




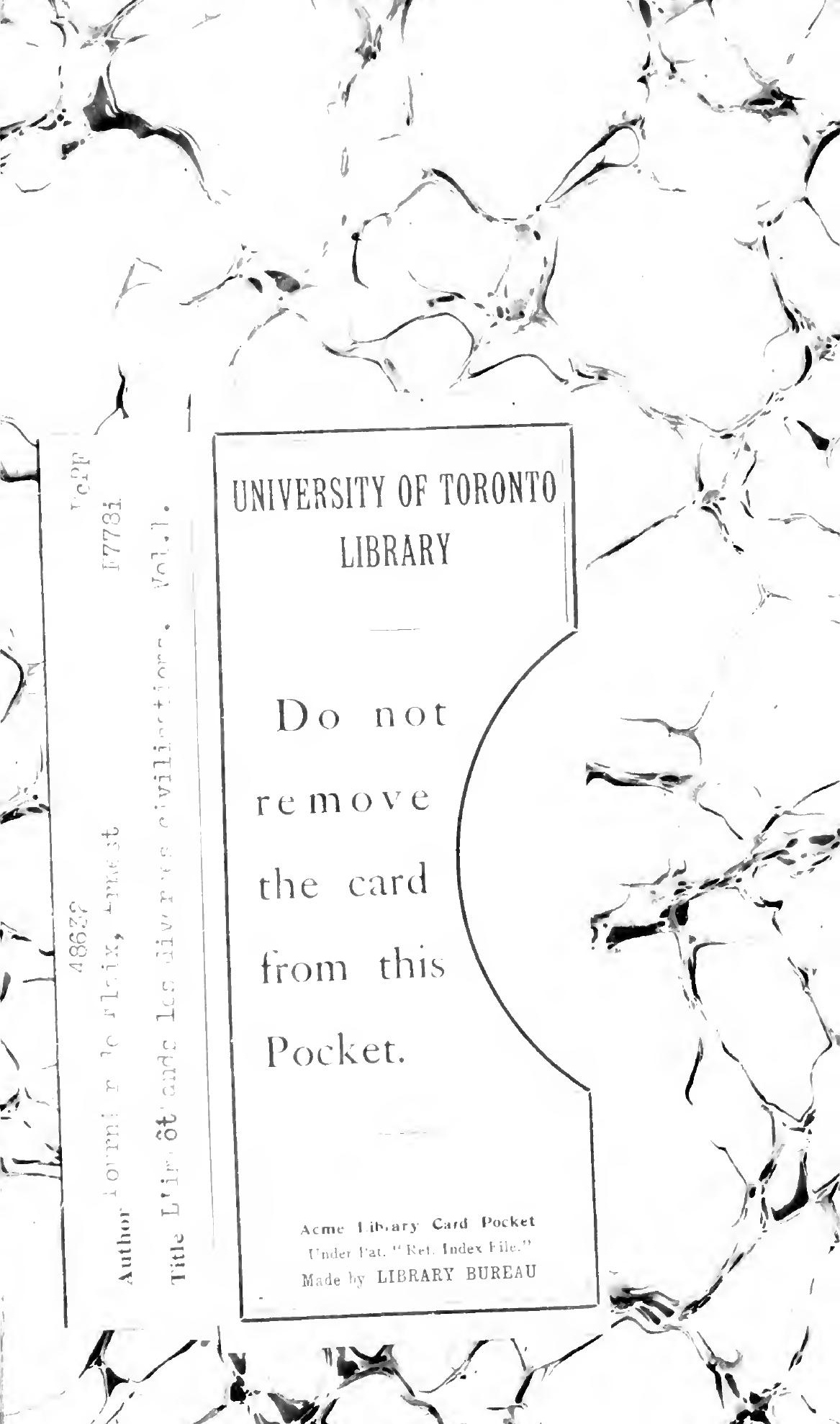


2.

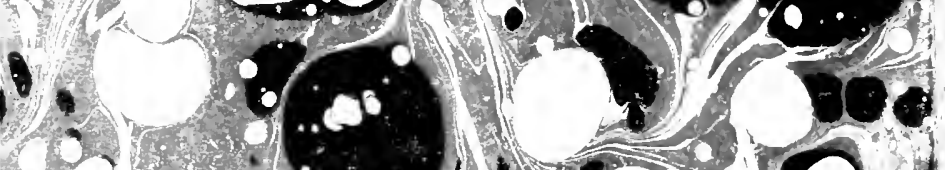

6. $\because 00 \% 101$

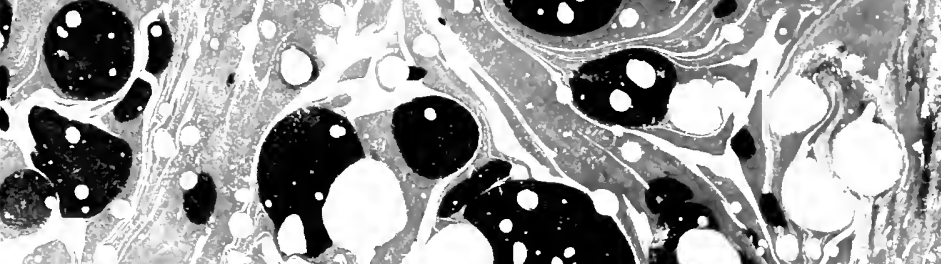

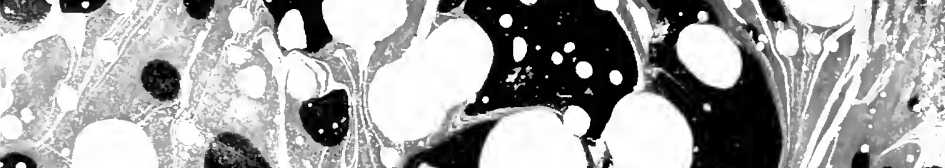

- $20 \mathrm{C}$ - 4 - 4001

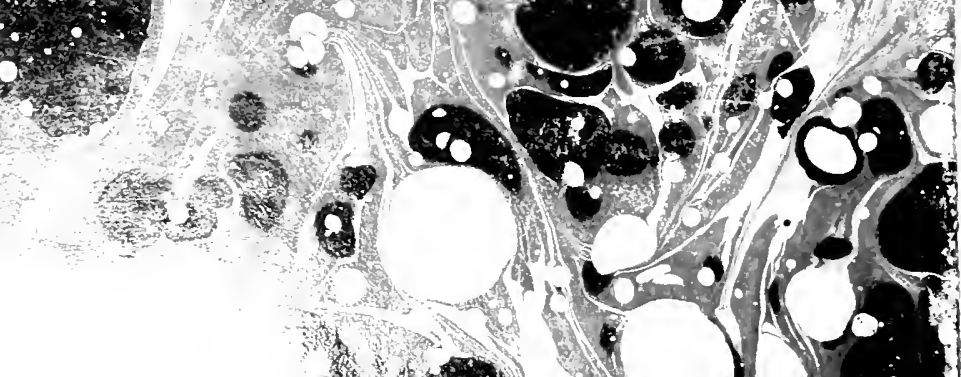

